\title{
Räumliches Einkaufsverhalten und Standortpolitik im Einzelhandel unter Berücksichtigung von Agglomerationseffekten
}

Theoretische Erklärungsansätze, modellanalytische Zugänge und eine empirisch-ökonometrische Marktgebietsanalyse anhand eines Fallbeispiels aus dem ländlichen Raum Ostwestfalens/Südniedersachsens

\section{Dissertation}

zur Erlangung des mathematisch-naturwissenschaftlichen Doktorgrades

"Doctor rerum naturalium"

der Georg-August-Universität Göttingen

im Promotionsprogramm Geowissenschaften / Geographie der Georg-August University School of Science (GAUSS)

vorgelegt von

Thomas Wieland

aus Holzminden

Göttingen 2014 


\section{Betreuungsausschuss:}

Prof. Dr. Heiko Faust

Georg-August-Universität Göttingen, Fakultät für Geowissenschaften und Geographie, Geographisches Institut, Abt. Humangeographie

Prof. Dr. Waldemar Toporowski

Georg-August-Universität Göttingen, Wirtschaftswissenschaftliche Fakultät, Department für Betriebswirtschaftslehre, Professur für Handelsbetriebslehre

\section{Mitglieder der Prüfungskommission:}

Referent: Prof. Dr. Heiko Faust, Georg-August-Universität Göttingen, Fakultät für Geowissenschaften und Geographie, Geographisches Institut, Abt. Humangeographie

Korreferent: Prof. Dr. Waldemar Toporowski, Georg-August-Universität Göttingen, Wirtschaftswissenschaftliche Fakultät, Department für Betriebswirtschaftslehre, Professur für Handelsbetriebslehre

2. Korreferent: Prof. Dr. Ralf Klein, Julius-Maximilians-Universität Würzburg, Philosophische Fakultät I, Institut für Geographie und Geologie, Lehrstuhl für Geographie und Regionalforschung

weitere Mitglieder der Prüfungskommission:

Prof. Dr. Joachim Vossen, Georg-August-Universität Göttingen, Fakultät für Geowissenschaften und Geographie, Geographisches Institut, Abt. Humangeographie

Prof. Dr. Wolfgang Krumbein, Georg-August-Universität Göttingen, Sozialwissenschaftliche Fakultät, Institut für Politikwissenschaft

Dr. Hans-Dieter von Frieling, Fakultät für Geowissenschaften und Geographie, Geographisches Institut, Abt. Humangeographie

Tag der mündlichen Prüfung: 15.10.2014 


\section{Danksagung}

Jetzt, wo das Buch fertig ist, bleibt als finale Aufgabe das Verfassen einer Danksagung. Diese Aufgabe fällt grundsätzlich nicht schwer, denn es gibt viele Personen, bei denen ich mich bedanken möchte und die ihren Beitrag dazu geleistet haben, dass diese Dissertation erfolgreich beendet werden konnte; ungleich schwerer ist es allerdings, hierbei auch wirklich niemanden zu vergessen... Ich hoffe sehr, dass das nicht passiert.

Zunächst erstmal möchte ich mich bei Prof. Dr. Heiko Faust für die Übernahme der Betreuung bedanken. Herrn Prof. Dr. Waldemar Toporowski danke ich dafür, dass er aus der Perspektive der betriebswirtschaftlichen Handelsforschung meine Arbeit als Korreferent betreut hat. Dank gilt ebenso Herrn Prof. Dr. Ralf Klein dafür, dass er bereit war, als zusätzlicher Experte aus der Wirtschaftsgeographie die Position des zweiten Korreferenten zu übernehmen. Allen dreien danke ich für ihre Motivation und ihren Zuspruch sowie für hilfreiche Anregungen und konstruktive Kritik.

Für Informationen und Hinweise im Rahmen meiner Datenerhebungen und/oder die Beteiligung an den im Vorfeld geführten Expertengesprächen danke ich den von mir kontaktierten Vertreterinnen und Vertretern der Untersuchungsgemeinden.

Für die unersetzbare Hilfe bei der Haushaltsbefragung danke ich (alphabetisch): Tim Brödje, Tanja Fritz (geb. Polupanow), Nils Lindenberg, Johannes Melcher, Sarah Landmann und Philipp Tusk.

Für die kritische Durchsicht meines Manuskriptes und die damit verbundene Auseinandersetzung mit meinen inhaltlichen Gedanken (und mit meinem Hang zu Schachtelsätzen) danke ich Michael Fink, Sarah Landmann sowie Martina und Ernst Wieland. Eure Kommentare haben mir wirklich geholfen!

Ganz allgemein möchte ich mich bei meinen Freunden bedanken, ohne die die schöne "Göttinger Zeit“" im Studium und der Promotion nicht dieselbe gewesen wäre.

Auch danke ich meinen Kolleginnen und Kollegen am Geographischen Institut bzw. meinen Mitdoktorandinnen und -doktoranden für eine spannende und abwechslungsreiche Zusammenarbeit und viele interessante Gespräche.

Abseits von ihrer "technischen“ Unterstützung möchte ich mich bei meiner Lebensgefährtin Sarah Landmann und meinen Eltern Martina und Ernst Wieland für den Beistand und die Motivation bedanken, die sie mir unaufhörlich gegeben haben. Eine Promotion ist wahrlich keine leichte Aufgabe, und es sind eben gerade die Menschen, die einem am nahesten stehen, die zugleich die notwendigerweise auftretenden "Hochs" und "Tiefs" am deutlichsten miterleben - und einem aus letzteren dann auch wieder heraushelfen. In diesem Sinne bedanke ich mich - neben der moralischen Stütze - auch für die damit verbundene Toleranz und Geduld mit mir! 



\section{Inhaltsverzeichnis}

I Inhaltsverzeichnis ...................................................................................

II Abbildungsverzeichnis .......................................................................... vi

III Kartenverzeichnis ............................................................................... vii

IV Tabellenverzeichnis ........................................................................... viii

V Abkürzungsverzeichnis .......................................................................... ix

$1 \quad$ Einführung ............................................................................................ 1

1.1 Gegenstand und Einordnung der Arbeit ................................................................... 1

1.2 Grundlagen und Begrifflichkeiten der Einzelhandelsforschung ........................... 3

1.2.1 Der Einzelhandel in funktioneller, institutioneller und warenorientierter Sicht ........ 3

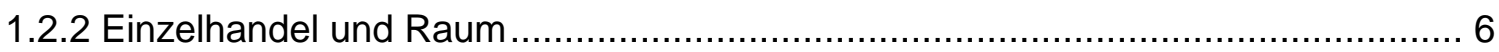

1.3 Ausgangssituation im deutschen Einzelhandel .............................................. 9

1.3.1 Der Strukturwandel im Einzelhandel: Angebots- und Nachfrageseite.................... 9

1.3.2 Steuerung des Einzelhandels durch räumliche Planung ....................................11

1.3.3 Räumliche Ausprägungen des Strukturwandels ..............................................14

1.4 Problemstellung und Zielsetzung der Arbeit .......................................................16

1.4.1 Einzelhandelsagglomerationen und Polarisierung der Angebotsstandorte ...........16

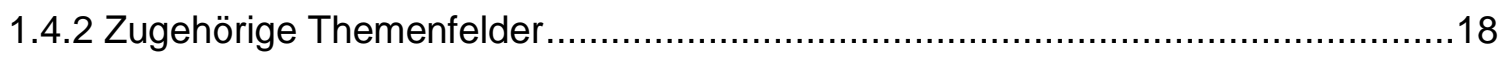

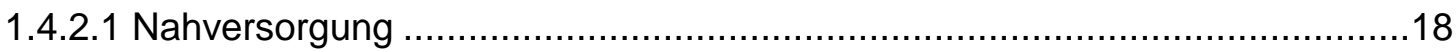

1.4.2.2 Innerstädtische Einkaufszentren .......................................................... 19

1.4.2.3 Einzelhandelsagglomerationen in der räumlichen Planung .........................20

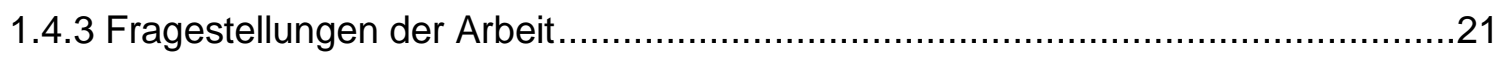

1.5 Aufbau der Arbeit .........................................................................................22

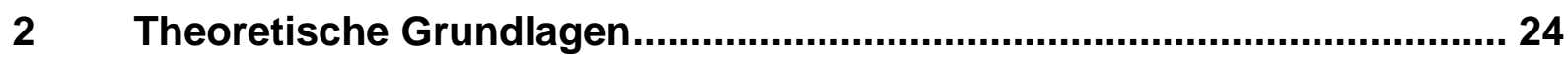

2.1 Grundsätzliche Anmerkungen ........................................................................24

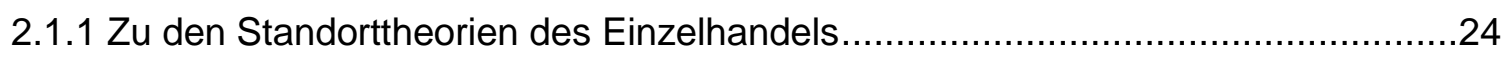

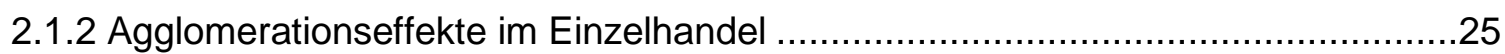

2.2 Mikroökonomische Ansätze mit Raumbezug ....................................................27

2.2.1 Die Theorie des monopolistischen Wettbewerbs von CHAMBERLIN......................27

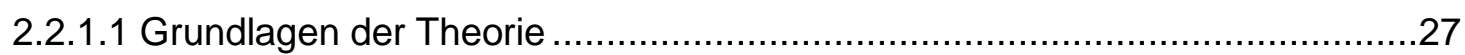

2.2.1.2 Monopolistischer Wettbewerb in einem räumlichen Markt ...........................30

2.2.2 Unvollständige Information und räumliches Einkaufsverhalten............................31

2.2.3 Das Konzentrationsmodell von HOTELLING.......................................................33

2.3 Die Raumwirtschaftstheorien von CHRISTALLER, LöSCH und LANGE ......................35

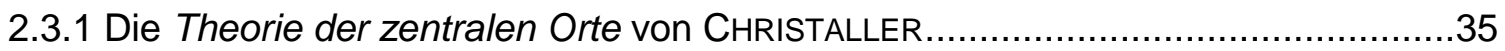

2.3.1.1 Grundlagen und elementare Begrifflichkeiten..............................................35

2.3.1.2 Annahmen und Funktionsweisen des räumlichen Marktes ...........................36

2.3.1.3 Marktgebiete einzelner Güter und Zentrenhierarchie..................................39

2.3.1.4 Zur Berücksichtigung von Agglomerationseffekten...................................42 
2.3.1.5 Dynamik im Zentrale-Orte-System .....................................................44

2.3.1.6 Agglomerationen und räumliche Disparitäten der Ausstattung .....................45

2.3.2 Die Theorie der Wirtschaftsgebiete von LösCH ...............................................48

2.3.2.1 Grundlagen und Beziehungen zur Zentrale-Orte-Theorie.............................48

2.3.2.2 Agglomerationseffekte und die Bildung von Angebotsstandorten ...................49

2.3.2.3 Wirtschaftsgebiete unter „einfachen“ und „schwierigen“ Verhältnissen...........51

2.3.3 Die Wachstumstheorie zentralörtlicher Systeme von LANGE .............................53

2.3.3.1 Grundlagen und Analyserahmen ........................................................53

2.3.3.2 Determinanten und Ausprägungen des (räumlichen) Einkaufsverhaltens......54

2.3.3.3 Betriebsformen- und Standortpolitik der Anbieter .......................................58

2.3.3.4 Marktinteraktionen und Dynamik der Angebotsstandorte ............................60

2.4 Der empirisch-induktive Standortansatz von NELSON...........................................62

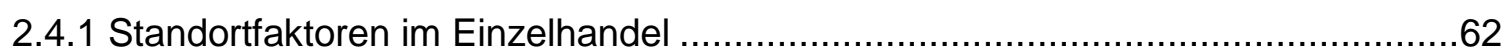

2.4.2 Das Prinzip der Konkurrenzanziehung (Kumulationsvorteile) .............................64

2.4.3 Das Prinzip der Kompatibilität (Kompatibilitätsvorteile) .......................................65

2.5 Räumliches Einkaufsverhalten aus der Marketing-Perspektive............................67

2.5.1 Mehrfachorientierung, Anbieterloyalität und räumliches Einkaufsverhalten .........67

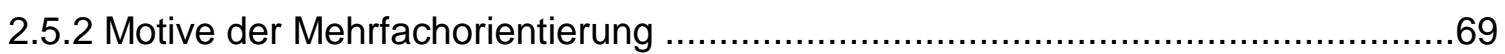

2.5.2.1 Angebotsgesteuerte Einkaufsstättenwahl...............................................69

2.5.2.2 Komplementarität kompetitiver Anbieter ..................................................70

2.6 Die Ansätze der New Economic Geography (NEG) ........................................71

$3 \quad$ Modellierung von Marktgebieten im Einzelhandel ................................... 74

3.1 Modelle des räumlichen Einkaufsverhaltens.....................................................74

3.1.1 Grundprinzip und Charakter der Modelle ......................................................... 74

3.1.2 Theoretische Grundlagen der Modelle ......................................................... 76

3.2 Theoretisch-deduktive Marktgebietsmodelle ....................................................78

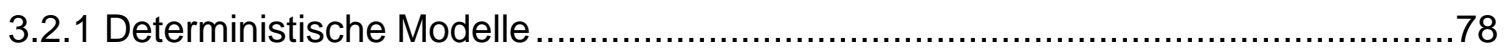

3.2.1.1 Das Gesetz der Einzelhandelsgravitation von REILLY..................................78

3.2.1.2 Die Breaking-Point-Formel von CONVERSE..............................................79

3.2.2 Das probabilistische Marktgebietsmodell von HUFF ..................................... 80

3.2.2.1 Herleitung und theoretische Fundierung................................................. 80

3.2.2.2 Mathematische Formalisierung …......................................................... 82

3.2.2.3 Bestimmung der Gewichtungsparameter .................................................. 84

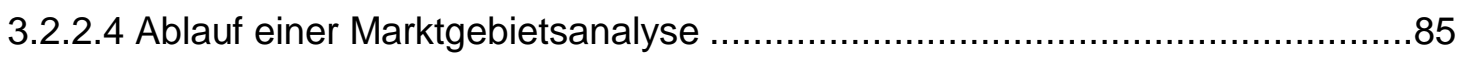

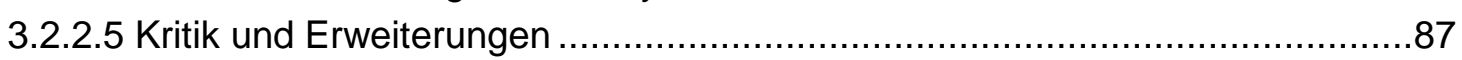

3.2.3 Das Competing Destinations Model von FotheRINGHAM...................................8

3.3 Ökonometrische Marktgebietsmodelle ............................................................90

3.3.1 Das Multiplicative Competitive Interaction Model von NAKANISHI/COOPER............90

3.3.1.1 Grundprinzip und Herleitung des Modells................................................90

3.3.1.2 Möglichkeiten und Probleme der Anwendung ..........................................92

3.3.2 Das diskrete Entscheidungsmodell nach MCFADDEN ........................................94

3.3.2.1 Grundprinzip und Herleitung des Modells..................................................94

3.3.2.2 Möglichkeiten und Probleme der Anwendung .............................................95

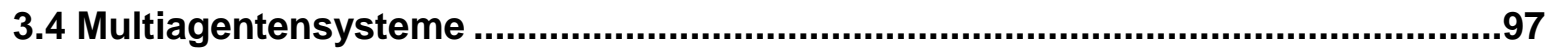


$4 \quad$ Agglomerationsvorteile im Einzelhandel - Stand der Forschung ........... 99

4.1 Angebotsorientierte Studien................................................................................99

4.1.1 Branchenspezifische Agglomerations- und Dispersionsmuster ..........................99

4.1.2 Bildung und Ausgestaltung von Standortkooperationen kompetitiver Anbieter ...101

4.1.3 Operationalisierung von (positiven) Agglomerationseffekten ..............................102

4.1.4 Auswirkungen von (innerstädtischen) Einkaufszentren ...................................105

4.2 Konsumentenseitige Studien .....................................................................107

4.2.1 Einkaufsverhalten am Angebotsstandort...................................................107

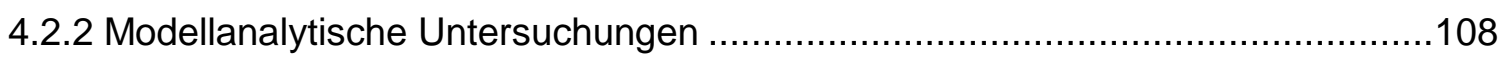

4.2.2.1 Überblick zum bisherigen Stand ..........................................................108

4.2.2.2 Bewertung der bisherigen Ansätze und weiterer Forschungsbedarf............111

$5 \quad$ Untersuchungsgegenstand und Methodik ........................................... 114

5.1 Aufbau der Untersuchung.............................................................................114

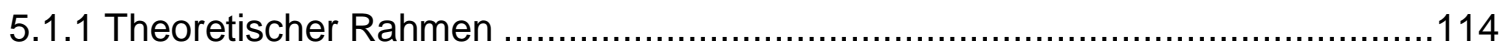

5.1.2 Ableitung von Untersuchungshypothesen .................................................118

5.1.3 Umsetzung in ein Marktgebietsmodell und Operationalisierung ........................121

5.1.4 Benötigte Daten, Form der Datenerhebung und Weiterverarbeitung ..................123

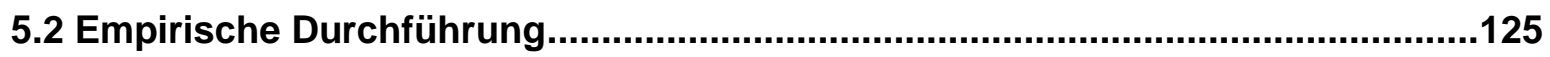

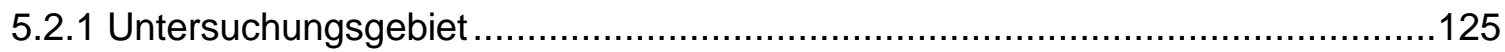

5.2.2 Erfassung des Einzelhandelsangebotes ..................................................128

5.2.2.1 Materialsammlung und Expertengespräche .........................................128

5.2.2.2 Vollerhebung und Kartierung der Einzelhandelsanbieter ............................129

5.2.2.3 Identifikation der untersuchungsrelevanten Anbieter ..................................131

5.2.3 Erfassung der räumlichen Einkaufsorientierung ……………..........................132

5.2.3.1 Auswahl der Befragungsmethode ....................................................132

5.2.3.2 Aufbau und Inhalt des Fragebogens ..................................................134

5.2.3.3 Durchführung der Haushaltsbefragung.................................................136

5.3 Ökonometrische Analyse mittels MCl-Modell...................................................138

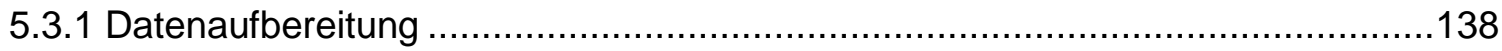

5.3.1.1 Neusegmentierung und Georeferenzierung der Nachfrageorte ..................138

5.3.1.2 Berechnung der lokalen Marktanteile ......................................................139

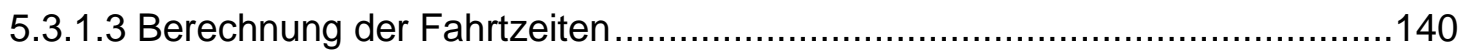

5.3.1.4 Berechnung der Konzentrationsvariablen............................................142

5.3.1.5 Erstellung der Interaktionsmatrix und Transformation ................................143

5.3.2 Modellschätzung und Modellüberprüfung......................................................145

5.3.2.1 Schätzung und Interpretation des Modells ............................................145

5.3.2.2 Überprüfung und Sicherstellung der Modellgüte.....................................147

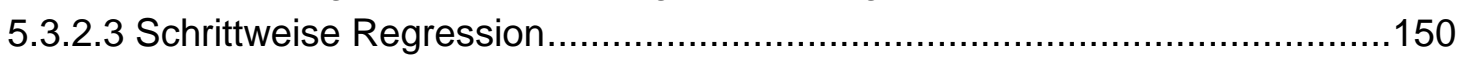

5.3.2.4 Berücksichtigung räumlicher Nicht-Stationarität .....................................152

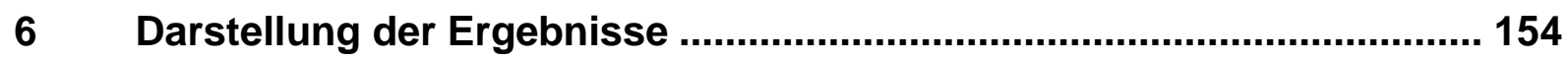

6.1 Einzelhandelsangebot und Standortstruktur....................................................154

6.1.1 Bestand des Einzelhandelsangebotes ........................................................154 
6.1.1.1 Einzelhandelsangebot im Untersuchungsgebiet .....................................154

6.1.1.2 Untersuchungsrelevantes Einzelhandelsangebot...................................155

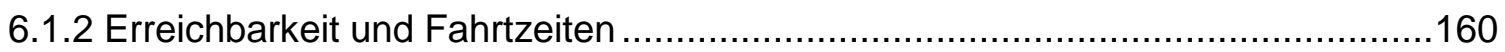

6.1.3 Ausprägung der räumlichen Konzentration von Anbietern ..............................161

6.2 Ergebnisse der Haushaltsbefragung.................................................................164

6.2.1 Eigenschaften der Stichprobe und erfasste Einkäufe .....................................164

6.2.2 Empirische Marktgebiete der untersuchungsrelevanten Anbieter .......................165

6.2.2.1 Lebensmittelmärkte.................................................................... 165

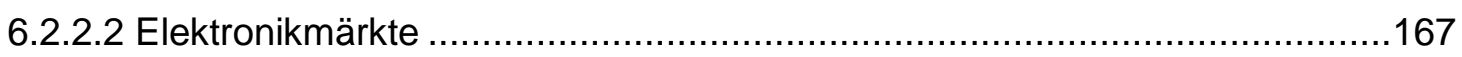

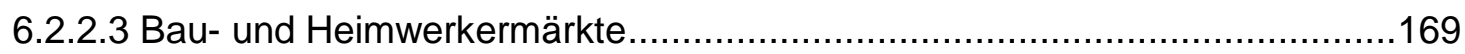

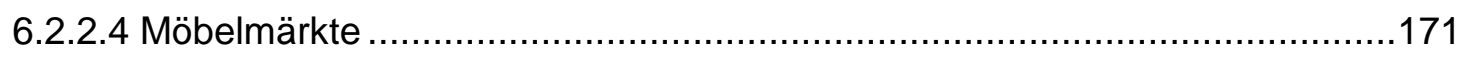

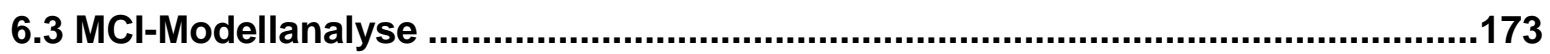

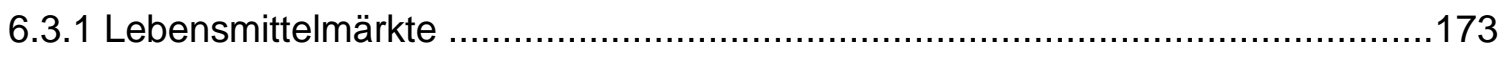

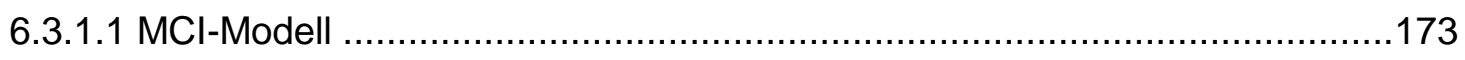

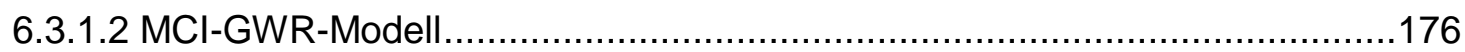

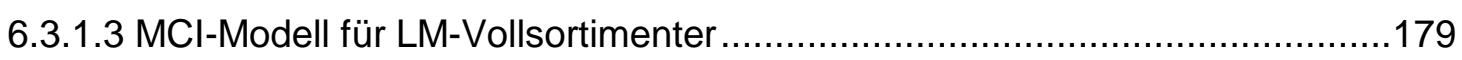

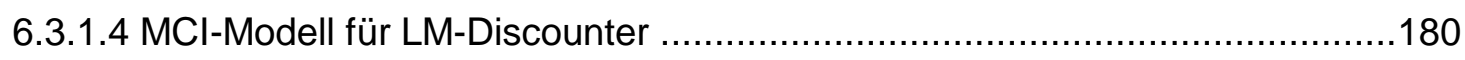

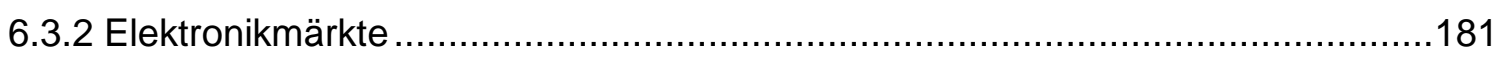

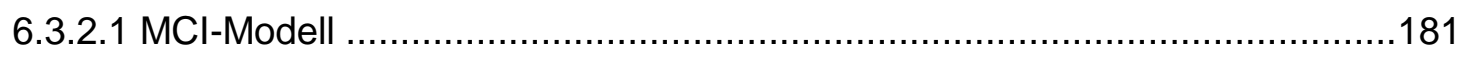

6.3.2.2 MCl-GWR-Modell......................................................................... 183

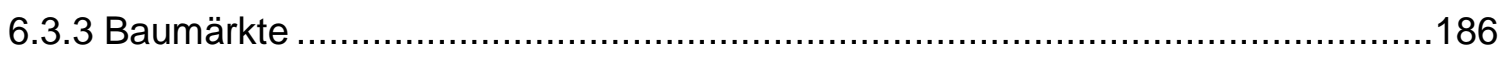

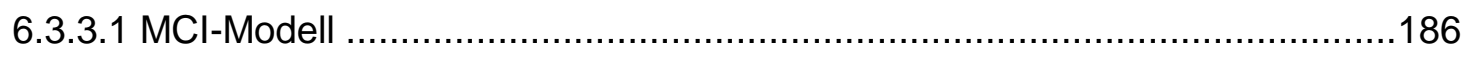

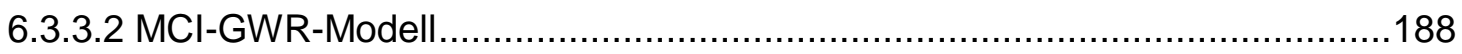

6.3.4 Zusammenfassende Betrachtung der Modelle ............................................190

$7 \quad$ Interpretation und Diskussion der Ergebnisse ..................................... 191

7.1 Inhaltliche Interpretation der Modellergebnisse.............................................191

7.1.1 Überprüfung der Hypothesen ................................................................. 191

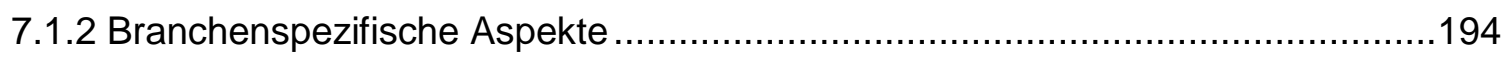

7.1.2.1 Lebensmittelmärkte...................................................................... 194

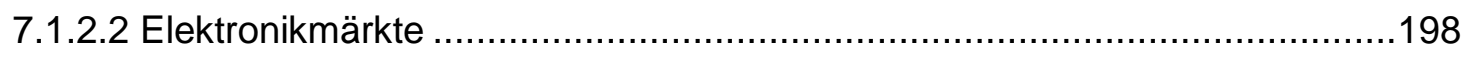

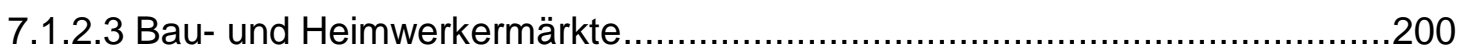

7.1.3 Zwischenfazit: Marktgebiete im Einzelhandel unter Berücksichtigung von

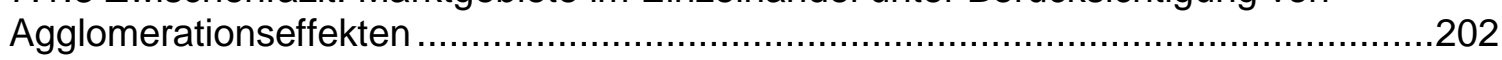

7.2 Optimierung, Erweiterung und Anwendung der eigenen Modelle .......................204

7.2.1 Zur Berücksichtigung räumlicher Nicht-Stationarität....................................204

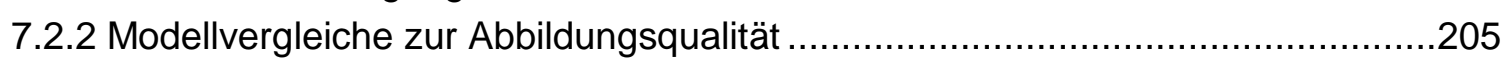

7.2.3 Modellerweiterungen am Beispiel der Lebensmittelmärkte ..............................210

7.2.4 Marktsimulation am Beispiel der Lebensmittelmärkte.....................................215

7.2.4.1 Das Simulationsmodell..................................................................215

7.2.4.2 Szenario 1: Ansiedlung Kaufland (Höxter) und Rewe (Holzminden) ............217

7.2.4.3 Szenario 2: Verlagerung Rewe und Aldi (Beverungen) ..............................219

7.3 Implikationen der Ergebnisse für die Praxis...................................................221

7.3.1 Sachrelevante Fragestellungen im Spiegel der Ergebnisse ..............................221

7.3.1.1 Nahversorgung contra Einzelhandelsagglomerationen? ..........................221 
7.3.1.2 Auswirkungen geplanter innerstädtischer Einkaufszentren.

7.3.1.3 Zentrenhierarchie in der Landes-, Regional- und Stadtplanung..................225

7.3.2 Durchführung von Standortanalysen und Verträglichkeitsbeurteilungen ...........227

7.4 Einschränkungen und Fehlerquellen der Untersuchung .................................229

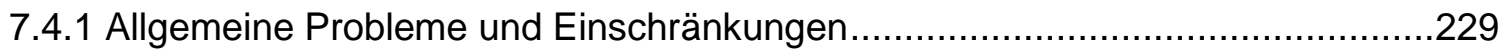

7.4.1.1 Zur Erhebung und Recherche der notwendigen Daten.............................229

7.4.1.2 Aussagekraft und Beschränkungen des MCI-Modells .............................231

7.4.2 Untersuchungsspezifische Einschränkungen und potenzielle Fehlerquellen ......233

7.4.2.1 Abgrenzung des Untersuchungsgebietes und Nachbearbeitung der

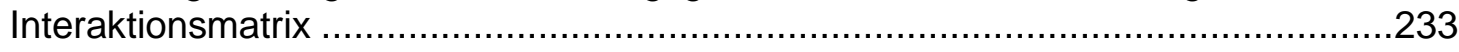

7.4.2.2 Datenerhebung mittels telefonischer Haushaltsbefragung........................234

7.4.2.3 Inhaltliche Einschränkungen allgemeiner Art...........................................235

7.4.2.4 Inhaltliche Einschränkungen im Hinblick auf die Fragestellung ..................237

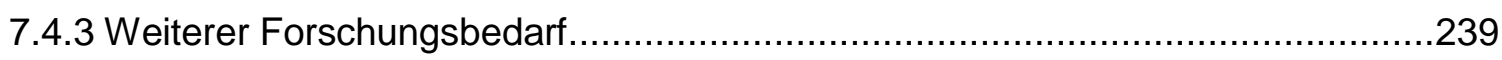

7.4.3.1 Differenziertere Modellabbildung räumlicher Konzentration.......................239

7.4.3.2 Empirische Fundierung der Konzentrationsvariablen .............................241

7.4.3.3 Übertragung auf andere Branchen und räumliche Kontexte .......................242

7.4.3.4 Untersuchung der Anbieterstrategien ................................................243

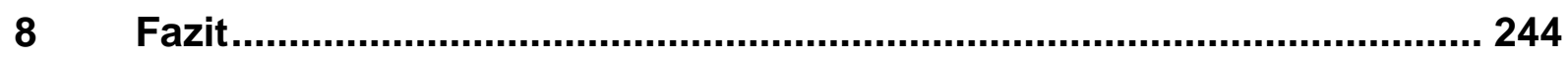

V Literatur- und Quellenverzeichnis ................................................... 251

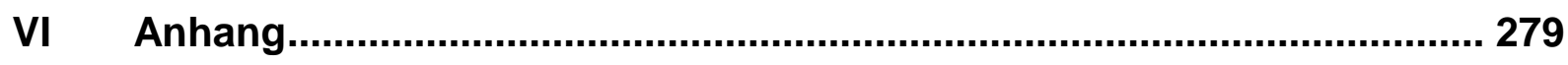




\section{Abbildungsverzeichnis}

Abbildung 1: HOTELLING - Ein Linienmarkt mit zwei Anbietern .........................................34

Abbildung 2: Zentrale Orte - Transportkosten und Preis zentraler Güter.............................37

Abbildung 3: Zentrale Orte - Transportkosten und maximal mögliches Marktgebiet .............38

Abbildung 4: Zentrale Orte - Minimal nötiges und maximal mögliches Marktgebiet..............38

Abbildung 5: Zentrale Orte - Ableitung hexagonaler Marktgebiete für einzelne Güter ..........40

Abbildung 6: Zentrale Orte - Zentrenhierarchie mit hexagonalen Marktgebieten .................42

Abbildung 7: Der Handlungsspielraum der Konsumenten in der Theorie von LANGE ............56

Abbildung 8: Wahrgenommener Konsumentennutzen der Angebotsgröße.........................82

Abbildung 9: Wahrgenommener negativer Konsumentennutzen der Distanz .....................82

Abbildung 10: HuFF-Modell - Marktgebiet mit Isowahrscheinlichkeitslinien (schematisch) ...86

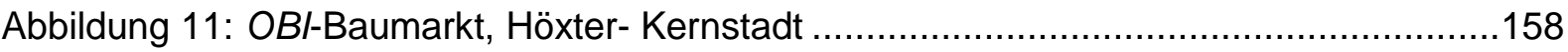

Abbildung 12: Standortkooperation Lebensmittelmärkte, Holzminden-Kernstadt ................158

Abbildung 13: Einkaufszentrum Minipreis Center An der Weser, Beverungen-Kernstadt....158

Abbildung 14: Leerstände Ortszentrum, Lauenförde .................................................158

Abbildung 15: Zusammenhang zwischen PKW- und ÖPNV-Fahrtzeit ............................160

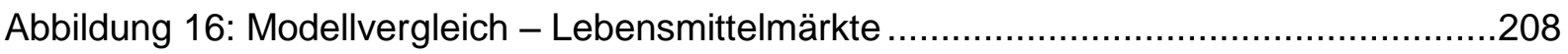

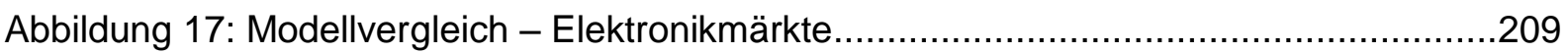

Abbildung 18: Modellvergleich - Bau- und Heimwerkermärkte ......................................209

Abbildung 19: Marktsimulation Lebensmittelmärkte - Szenario 1 (Ergebnisse) .................218

Abbildung 20: Marktsimulation Lebensmittelmärkte - Szenario 2 (Ergebnisse) ..................221 


\section{Kartenverzeichnis}

Karte 1: Lage und räumliche Struktur des Untersuchungsgebietes 127

Karte 2: Untersuchungsrelevante Anbieter im Untersuchungsgebiet ...............................157

Karte 3: Berechnung von Fahrtzeiten - Beispiel Baumärkte .......................................161

Karte 4: Konzentrationsvariable für gleichartige Anbieter - Beispiel Elektronikmärkte ........162

Karte 5: Konzentrationsvariable allgemein - Beispiel Elektronikmärkte ............................163

Karte 6: Lebensmittelmärkte - Lokale Marktanteile und erfasste Einkäufe .........................166

Karte 7: Elektronikmärkte - Lokale Marktanteile und erfasste Einkäufe.............................168

Karte 8: Baumärkte - Lokale Marktanteile und erfasste Einkäufe ....................................170

Karte 9: Möbelanbieter - Lokale Marktanteile und erfasste Einkäufe.................................172

Karte 10: GWR-Modell für die Marktgebiete der Lebensmittelmärkte ...............................178

Karte 11: GWR-Modell für die Marktgebiete der Elektronikmärkte ....................................185

Karte 12: GWR-Modell für die Marktgebiete der Baumärkte ............................................189

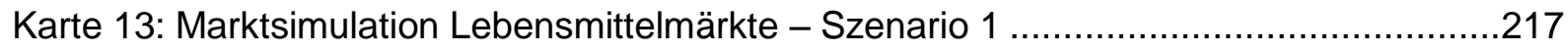

Karte 14: Marktsimulation Lebensmittelmärkte - Szenario 2 .......................................220 


\section{Tabellenverzeichnis}

Tabelle 1: NELSON - Kompatibilitätstabelle für verschiedene Angebotsformen (Auszüge) ....67

Tabelle 2: HUFF-Modell - Interaktionsmatrix (schematisch) ..........................................

Tabelle 3: MCI-Modellvariablen - Konstrukte, Indikatoren, Operationalisierung .................123

Tabelle 4: MCI-Modellvariablen - Datenerhebung und -verarbeitung ...............................125

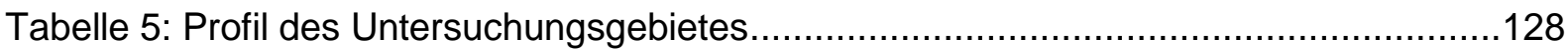

Tabelle 6: Methodisches Vorgehen in ausgewählten Marktgebietsanalysen......................133

Tabelle 7: MCI-Modell - Empirisch ermittelte Einkäufe (schematisch) ...............................139

Tabelle 8: MCl-Modell - Lokale Marktanteile (schematisch) ...........................................140

Tabelle 9: MCl-Modell - Interaktionsmatrix (schematisch) .........................................143

Tabelle 10: MCl-Modell - Transformierte Interaktionsmatrix (schematisch) ........................144

Tabelle 11: Einzelhandelsangebot im Untersuchungsgebiet nach Gemeinden ....................154

Tabelle 12: Einzelhandelsangebot im Untersuchungsgebiet nach Leitbranchen .................155

Tabelle 13: Untersuchungsrelevante Anbieter nach Gemeinden .....................................156

Tabelle 14: Untersuchungsrelevante Anbieter nach Lagetypen .....................................156

Tabelle 15: Jüngere Entwicklungen und Planungen im Untersuchungsgebiet ...................159

Tabelle 16: Haushaltsbefragung - Befragte Haushalte nach Gemeinden und Uhrzeiten ....164

Tabelle 17: Haushaltsbefragung - Sozio-demographische Eigenschaften der befragten

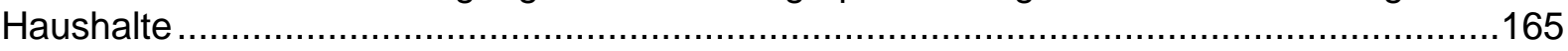

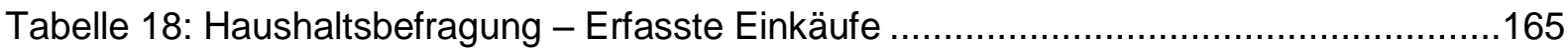

Tabelle 19: MCI-Modell für die Marktgebiete der Lebensmittelmärkte ..............................173

Tabelle 20: MCl-Modell für die Marktgebiete der Lebensmittelmärkte - Schrittweise

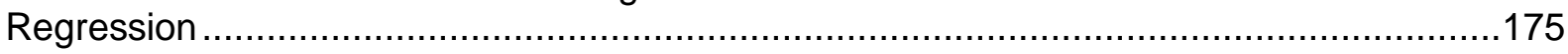

Tabelle 21: GWR-Modell für die Marktgebiete der Lebensmittelmärkte (Zusammenfassung)

Tabelle 22: MCI-Modell für die Marktgebiete der LM-Vollsortimenter................................179

Tabelle 23: MCI-Modell für die Marktgebiete der LM-Discounter .....................................180

Tabelle 24: MCI-Modell für die Marktgebiete der Elektronikmärkte...................................181

Tabelle 25: MCI-Modell für die Marktgebiete der Elektronikmärkte - Schrittweise Regression

Tabelle 26: GWR-Modell für die Marktgebiete der Elektronikmärkte (Zusammenfassung) .184

Tabelle 27: MCI-Modell für die Marktgebiete der Baumärkte ........................................186

Tabelle 28: MCI-Modell für die Marktgebiete der Baumärkte - Schrittweise Regression ....187

Tabelle 29: GWR-Modell für die Marktgebiete der Baumärkte (Zusammenfassung) ...........188

Tabelle 30: Überprüfung der Hypothesen ..............................................................192

Tabelle 31: Modellvergleich - Verwendete Nutzenfunktionen............................................206

Tabelle 32: Modellvergleich - Summe der quadrierten Abweichungen ................................207

Tabelle 33: MCI-Modell Lebensmittelmärkte - Alternative Spezifikationen .........................213

Tabelle 34: Zentrenhierarchie im Zentrale-Orte-System von Niedersachsen .....................225 


\section{Abkürzungsverzeichnis}

AGS Amtlicher Gemeindeschlüssel

BauGB Baugesetzbuch

BauNVO Baunutzungsverordnung

BBE BBE Handelsberatung (früher: Betriebliche Beratungsstelle des Einzelhandels)

BVerwG Bundesverwaltungsgericht

EHI EuroHandelsInstitut

EKZ Einkaufszentrum

GHF Geographische Handelsforschung

GPS Global Positioning System

HDE Handelsverband Deutschland (früher: Hauptverband des deutschen Einzelhandels)

HGZ Handels- und Gaststättenzählung

LEH Lebensmitteleinzelhandel

LEP Landesentwicklungsplan

LEPro Landesentwicklungsprogramm

LM Lebensmittel

LROP Landesraumordnungsprogramm

$\mathrm{MCl} \quad$ Multiplicative Competitive Interaction (Model)

NEG New Economic Geography

OSM OpenStreetMap

PoS Point of Sale

qm Quadratmeter

ROG Raumordnungsgesetz

RROP Regionales Raumordnungsprogramm

VG Verwaltungsgericht

$\mathrm{VGH} \quad$ Verwaltungsgerichtshof

VKF Verkaufsfläche

WZ Wirtschaftszweig

ZO Zentrale Orte 



\section{Einführung}

In diesem ersten Kapitel erfolgt die Einführung in die Fragestellung der vorliegenden Arbeit anhand des übergeordneten Kontextes und eine Skizzierung ihres wissenschaftlichen und praktischen Aktualitätsbezugs; abschließend wird der Aufbau der Arbeit vorgestellt. Zudem werden einige sachrelevante Begriffe und Zusammenhänge vorgestellt, die für das weitere Verständnis notwendig sind und zugleich zu den wesentlichen Grundlagen des Fachgebietes der (geographischen) Handelsforschung gehören.

\subsection{Gegenstand und Einordnung der Arbeit}

Der Einzelhandel ist ein dynamischer Wirtschaftszweig von großer ökonomischer Relevanz: Weltweit betrachtet ist das - bezogen auf den Umsatz - größte Unternehmen im aktuellen Global-500-Ranking der Zeitschrift Fortune ein Einzelhandelsunternehmen (Wal-Mart) - vor allen weltweit agierenden Automobil-, Software- und Mineralölkonzernen (FORTUNE 2014). Auch unter den 20 umsatzstärksten deutschen Unternehmen finden sich mit der SchwarzGruppe (Lidl, Kaufland), der Metro AG (u.a. Real, Media Markt, Saturn), der Aldi-Gruppe (Aldi Nord/Süd), der Rewe Group (u.a. Rewe, Penny, Toom) und dem Edeka-Verbund (inkl. Netto) fünf aus dem Bereich des Einzelhandels (FAZ 2013). Insgesamt generierten die 325.245 Unternehmen des deutschen Einzelhandels (ohne Kfz-Handel, inkl. Tankstellen und Apotheken) im Jahr 2012 einen (Netto-)Umsatz von ca. 498 Mrd. $€$ und beschäftigten rd. 3,1 Mio. Arbeitnehmer (StATISTISCHES BundeSAMT 2014).

Für seine Kunden bildet der Einzelhandel eine der Stützen der lebensnotwendigen Versorgung (Einkauf von Grundbedarfsgütern wie z.B. Nahrungsmittel), ist aber auch mit Aspekten der Freizeitgestaltung verbunden („Shopping“). Trotz sinkender Tendenz fließen in Deutschland (Stand: 2012) immer noch $28,1 \%$ der Konsumausgaben privater Haushalte in den Einzelhandel (HDE 2013). Die Bedeutung dieses Wirtschaftszweiges im Leben der Verbraucher schlägt sich aber nicht nur in volkswirtschaftlichen Größen nieder, sondern auch in der hierfür investierten Zeit: Beispielsweise unternehmen die deutschen Haushalte im Jahresdurchschnitt 222 Einkäufe von Gütern des täglichen Bedarfs (Stand: 2013); im Mittel werden also rein rechnerisch betrachtet - trotz ebenso rückläufiger Tendenz - an mehr als der Hälfte der Tage im Jahr Einkäufe getätigt (GFK 2012 u. 2014).

Der Einzelhandel ist ein Wirtschaftszweig von großer Raumrelevanz: Abgesehen von einem nicht unerheblichen Flächenverbrauch der Einzelhandelsstandorte sind die Einkaufswege der Bevölkerung ein wesentlicher Baustein ihrer Mobilität; Einkäufe induzieren Ströme im fließenden Verkehr und wirken sich - sofern individuelle Verkehrsmittel benutzt werden auch auf den ruhenden Verkehr (Parkplatzauslastung) aus (HEINRITZ et al. 2003, S. 183ff.). Unabhängig davon ist die räumliche Verortung von Einzelhandelsangebot eng mit der Erfüllung von menschlichen Grundbedürfnissen verbunden; insbesondere der Einzelhandel mit Lebensmitteln und anderen Gütern des täglichen Bedarfs ist der wichtigste Pfeiler der wohnortnahen Grundversorgung (Nahversorgung), die als wesentliches Merkmal der Lebens- und Wohnqualität angesehen wird (KÜHN 2011, S. 5ff.). Einzelhandelsnutzungen gehören zudem traditionell zu den Kernfunktionen der Citybereiche von (v.a. europäischen) Städten (HEINEBERG 2006, S. 169f.). 
Der deutsche Einzelhandel ist seit den 1960er Jahren einem tiefgreifenden Strukturwandel unterworfen, der sich u.a. am sog. „Wandel der Betriebsformen“ des Einzelhandels, dem stetigen Wachstum an Verkaufsfläche und der Ausdünnung des Verkaufsstellennetzes zeigt. Auch auf der Verbraucherseite haben sich u.a. aufgrund der Einkommensentwicklung und der Etablierung des PKW als Massenverkehrsmittel vielzählige Entwicklungen ergeben. Beide sind interdependent und schlagen sich in der Einkaufsstättenwahl der Verbraucher und der Standortpolitik der Unternehmen und somit in sich stetig verändernden Mustern der räumlichen Ausprägung des Einzelhandels nieder (KULKE 2010, S. 219ff.). Auf die einzelnen Entwicklungen wird in den späteren Kapiteln noch eingegangen.

Die vorliegende Forschungsarbeit beschäftigt sich mit den Standortkonfigurationen von Einzelhandelsbetrieben im Lichte des damit verknüpften (räumlichen) Einkaufsverhaltens. Im Fokus steht hierbei ein Aspekt des Struktur- bzw. Standortwandels im Einzelhandel, der, wie in den folgenden Kapiteln herausgestellt wird, die hervorstechendste räumliche Entwicklung in diesem Wirtschaftszweig darstellt: Die räumliche Ballung von Einzelhandelsangebot auf mehreren Maßstabsebenen bzw. die steigende Relevanz von Einzelhandelsagglomerationen sowohl unterschiedlicher als auch branchengleicher bzw. konkurrierender Anbieter. Hierbei wird der Frage nachgegangen, welche konsumentenseitigen Gründe die Bildung von Agglomerationen erklären, d.h. welche (positiven) Agglomerationseffekte im Einzelhandel präsent sind, die mit dem Kundenverhalten verbunden sind. Konkret wird aus theoretischer, modellanalytischer und empirischer Perspektive untersucht, inwieweit die Möglichkeit von Kopplungs- und Vergleichskäufen die Einkaufsstättenwahl der Konsumenten und somit die Kundenzuflüsse der Anbieter aus ihren Marktgebieten beeinflusst. Die Tendenz zur Agglomeration von Einzelhandelsangebot ist keinesfalls eine allein betriebswirtschaftliche Frage, sondern ist z.B. eng mit Fragen der Nahversorgung oder den viel diskutierten Auswirkungen von geplanten (innerstädtischen) Einkaufszentren verbunden.

Wie in dieser Arbeit aufgezeigt wird, ist die Agglomerationsthematik im Rahmen diverser sehr heterogener Theoriewerke aufgearbeitet worden, die einer Zusammenführung bedürfen. Auch existieren einzelne Ansätze zur Analyse des räumlichen Einkaufsverhaltens im Kontext von Einzelhandelsagglomerationen, jedoch weisen diese in entscheidenden Punkten (z.B. in der Berücksichtigung mehrerer Formen von Agglomerationseffekten oder in einer adäquaten Abbildung räumlicher Konzentrationen) maßgebliche Schwachstellen auf. Beide Aspekte werden in dieser Arbeit aufgegriffen und diesbezügliche Lösungsansätze erarbeitet.

Die Forschungsarbeit ist dem Fachgebiet der Geographischen Handelsforschung (auch: Einzelhandelsgeographie) zuzuordnen; diese Disziplin behandelt den Wirtschaftszweig des Einzelhandels und fokussiert dabei die raumwirksamen Verhaltensweisen der Angebots- und Nachfrageseite (Einzelhandelsunternehmen und Konsumenten). Im Fokus stehen hierbei angebotsseitig v.a. betriebliche Standortentscheidungen vor dem Hintergrund räumlicher Absatz- und Beschaffungspotenziale und nachfrageseitig die räumliche Einkaufsorientierung und die Konsumgewohnheiten der Verbraucher. Disziplingeschichtlich bildet die in den 1990er Jahren als eigene Forschungsrichtung etablierte Geographische Handelsforschung eine Ablösung der Zentralitätsforschung, deren theoretische/inhaltliche Grundlagen als nicht (mehr) kompatibel mit der empirischen Gegenwart des Einzelhandelssektors und v.a. des Konsumentenverhaltens angesehen werden (DEITERS 2006, S. 295ff.; HEINRITZ/POPP 2011, S. 1002ff.). Die Geographische Handelsforschung wird zumeist als sektoraler Bestandteil der Wirtschaftsgeographie begriffen (z.B. HEINEBERG 2006, KULKE 2009, SCHENK/SCHLIEPHAKE 
2005). Hierbei ergeben sich häufig Überschneidungen mit anderen Disziplinen, v.a. mit der Betriebswirtschaftslehre (Handelsbetriebslehre, Marketing), der Volkswirtschaftslehre (Stadtund Regionalökonomie) und mit der Raum-, Regional- und Stadtplanung.

\subsection{Grundlagen und Begrifflichkeiten der Einzelhandelsforschung}

\subsubsection{Der Einzelhandel in funktioneller, institutioneller und warenorientierter Sicht}

In der wissenschaftlichen Forschung wird der Einzelhandel aus verschiedenen Perspektiven betrachtet, die sich zwischen der betriebswirtschaftlichen (z.B. SCHRÖDER 2012, S. 30ff.) und der geographischen Handelsforschung (z.B. HEINRITZ et al. 2003, S. 20ff.) unterscheiden. Im Folgenden werden die funktionelle, institutionelle und warenorientierte Sichtweise auf den Einzelhandel grob skizziert, was zugleich die Vorstellung einiger zentraler Grundbegriffe und -zusammenhänge mit sich bringt, die für das weitere Verständnis notwendig sind.

Der Wirtschaftszweig des Einzelhandels ist in funktioneller Hinsicht, d.h. nach seiner Stellung im Wirtschaftsgefüge, als letzter Distributionskanal zwischen Erzeugern und Konsumenten für den Absatz bzw. die Verteilung von Gütern an Endverbraucher (d.h. private Haushalte) zuständig. Die Güter werden dabei von den Einzelhandelsunternehmen bei den Herstellern oder im Großhandel beschafft und i.d.R. ohne weitere Be- oder Verarbeitung direkt an die privaten Nachfrager verkauft. Der Einzelhandel erfüllt also die Funktion eines Intermediärs zwischen den Herstellern und den Verbrauchern; hierbei überbrückt er die (zeitliche und räumliche) Trennung von Produktion und Konsum, wirkt maßgeblich bei der Preis- und Mengenanpassung bei Konsumgütern mit, aggregiert diese zu einem Sortiment und sorgt für ihre Bekanntmachung und die Darbietung zugehöriger Informationen (HEINRITZ et al. 2003, S. 20ff.; SCHRÖDER 2012, S. 38f.). Aufgrund seiner Zielgruppe ist der Einzelhandel eine konsumentenorientierte Dienstleistung und gehört somit dem tertiären Wirtschaftssektor an (KULKE 2009, S. 142).

In der amtlichen Wirtschaftszweigklassifikation des Statistischen Bundesamtes (WZ 2008) wird der Einzelhandel mit der Wirtschaftsabteilung 47 erfasst, die sämtlichen Einzelhandel in sowie außerhalb von Verkaufsstellen einschließt; hierzu zählen z.B. auch Apotheken, Tankstellen und der Gebrauchtwarenhandel, nicht jedoch der Kfz-Handel (WZ2008-Abteilung 45). Nach dieser wirtschaftsstatistischen Definition gehört das Lebensmittelhandwerk (d.h. Bäcker und Metzger) nicht zum Einzelhandel, da die vertriebenen Produkte durch die Anbieter selbst hergestellt werden und diese daher dem Handwerk (WZ2008-Abteilung 10) zugeordnet sind. Aus der Perspektive der geographischen Handelsforschung ist es jedoch aufgrund der vergleichbaren Kundenbeziehungen und der räumlichen Nähe zu Einzelhandelsanbietern angebracht, sie ebenfalls als solche zu berücksichtigen (HEINRITZ et al. 2003, S. 24). Daher werden sie im Folgenden dem Einzelhandel zugerechnet.

Nach KULKE (2009, S. 142) zählen alle Dienstleistungen, deren Zielgruppe die Haushalte bzw. Endverbraucher sind, zu den konsumentenorientierten Dienstleistungen (z.B. auch Frisörsalons, Reinigungen, Reisebüros oder gastronomische Einrichtungen). Viele dieser Dienstleistungsformen sind häufig in räumlicher Nähe zu Einzelhandelsangebot angesiedelt (z.B. in Innenstädten oder geplanten Einkaufszentren) und werden kundenseitig auch in Verbindung mit Einzelhandelsanbietern frequentiert; diese werden daher auch als einzelhandelsnahe Dienstleistungen bezeichnet (GIF 2000, S. 22). 
Der Einzelhandel wird institutionell hinsichtlich seiner Erscheinungsformen differenziert; hierzu gehören u.a. die Vertriebskanäle, die Betriebsformen sowie die Systemtypen des Einzelhandels (HEINRITZ et al. 2003, S. 23ff.; SCHRÖDER 2012, S. 32ff.).

Die Vertriebskanäle definieren die Art und Weise des Kundenkontaktes bzw. des Warenabsatzes (HEINEMANN 2008, S. 14ff.):

- Im stationären Einzelhandel befindet sich der Einzelhandelsanbieter an einem festen Ort, den der Kunde zwecks Erwerb der nachgefragten Güter aufsucht

- Sucht der Anbieter an einem bestimmten Platz (Markt) oder durch direkten Kontakt (Haustürverkauf) die Nähe zum Kunden, liegt ambulanter Einzelhande/ vor

- Im Distanzhandel werden Produkte über Medien (z.B. Katalog, Internet) beworben, angeboten und verkauft, ohne dass ein persönlicher Kontakt zwischen Verkäufer und Kunde stattfindet; zum Distanzhandel gehört also auch der Onlinehandel

Die konsumentenseitig direkt wahrnehmbare Erscheinung eines Einzelhandelsanbieters ist durch seine Betriebsform bestimmt; diese stellt eine definitorische Zusammenfassung der Kombination verschiedener absatzpolitischer Instrumente von Einzelhandelsbetrieben in Gruppen von Anbietern mit ähnlichen Ausprägungen dar. Absatzpolitische Instrumente sind alle anbieterseitigen Handlungsparameter, die einen Einfluss auf das nachfrageseitige Einkaufsverhalten haben und auf diese Weise den Anbieter charakterisieren; anhand ihrer Ausprägungen lassen sich die Betriebsformen des Einzelhandels abgrenzen (HEINRITZ et al. 2003, S. 26ff. u. 68f.; MÜLLER-HAGEDORN et al. 2012, S. 50ff.; SCHRÖDER 2012, S. 32f.):

- Die Bedienungsform bezieht sich auf die Ausprägung des Kundenkontaktes im Geschäft (Fremd- oder Selbstbedienung, Vorwahlsystem)

- Die Sortimentsgestaltung drückt sich in der Sortimentsbreite (Zahl verschiedener Warengruppen), der Sortimentstiefe (Zahl von Artikeln innerhalb der Warengruppen, d.h. Auswahl bzgl. verschiedener Varianten eines Gutes) und der Sortimentshöhe (vorrätig gehaltene Anzahl der Stücke pro geführtem Artikel) aus

- Die Preisgestaltung lässt sich in vielerlei Hinsicht differenzieren; sehr häufig werden zwei preispolitische Konzepte unterschieden: Sonderangebotspolitik (auch: High-Low Promotion Strategy, HILO) ist gekennzeichnet durch regelmäßige, aber zeitlich eng befristete preisbezogene Aktionen (z.B. Sonderangebote für sonst teurere Waren, Rabatte). Eine Dauerniedrigpreispolitik (auch: Every Day Low Price Strategy, EDLP) bezeichnet das Angebot der Waren zu konstant niedrigen Preisen über lange Zeiträume bei gleichzeitig weitgehendem Verzicht auf Sonderangebote

- Mit der Sortimentsgestaltung ist die Größe der Verkaufsfläche (zum Verkauf dienender und den Kunden zugänglicher Teil der Geschäftsfläche, v.a. Fläche für Warenpräsentation) verbunden. Ein darauf aufbauendes Differenzierungsmerkmal zwischen Branchen als auch zwischen Betriebsformen derselben Branche stell die Flächenproduktivität (Umsatz pro qm Verkaufsfläche und Jahr) dar

- Der Standort eines Einzelhandelsanbieters (siehe Kap. 1.2.2) ist ebenso ein absatzpolitisches Instrument und eng mit allen genannten Komponenten verbunden 
Die Systemtypen des (Einzel-)Handels beziehen sich auf den organisatorischen Aufbau von Einzelhandelsunternehmen im Hinblick auf die Warenbeschaffung und - im Fall von Mehrbetriebsunternehmen - den gemeinsamen Marktauftritt (SCHRÖDER 2012, S. 37f.):

- In Filialsystemen (auch: vertikal integrierte Systeme) sind die Groß- und die Einzelhandelsebene unmittelbar miteinander verknüpft, da sie zum selben Unternehmen gehören. Die Filialen (Einzelhandelsebene) beziehen hierbei ihre Waren (fast) ausschließlich aus einer gemeinsamen Zentrale (Großhandelsebene). In Filialsystemen ist der Marktauftritt (z.B. Logo, Sortiment etc.) zumeist einheitlich, wobei die absatzpolitischen Instrumente in jeder Verkaufsstelle identisch oder nahezu identisch eingesetzt werden (Beispiele: Aldi, Lidl)

- Handelskooperationen bestehen aus rechtlich und wirtschaftlich überwiegend selbständigen Einzelbetrieben, die sich vertraglich an eine übergeordnete Zentrale gebunden haben. Betriebe, die Kooperationen angeschlossen sind, können ihre absatzpolitischen Instrumente aufeinander abstimmen, müssen es aber nicht, sondern haben auch die Möglichkeit, diese den lokalen Gegebenheiten anzupassen. $\mathrm{Zu}$ den Kooperationen gehören z.B. Verbundgruppen, Konsumgenossenschaften und Einkaufsgenossenschaften, in denen selbständige Kaufleute ihren Einkauf über eine Zentrale abwickeln (Beispiele: Euronics, Electronic Partner/EP)

- In vielen Einzelhandelsunternehmen herrscht eine Hybridform beider Systeme vor, d.h. die Kombination von weisungsgebundenen Filialen und kooperativ organisierten selbständigen Kaufleuten unter dem Dach einer Zentrale (Beispiele: Edeka, Rewe)

- Einzelbetriebe ohne jede Zugehörigkeit zu einem Filial- oder Kooperationssystem werden auch als freie, vertikal nicht-organisierte Unternehmen bezeichnet

Eine weitere Differenzierung des Einzelhandels erfolgt warenorientiert, d.h. anhand der Eigenschaften der angebotenen Ware (SCHRÖDER 2012, S. 39f.); hierbei sind vielfältige Differenzierungen möglich, von denen an dieser Stelle zwei Varianten vorgestellt werden. Aus einer Generalisierung der angebotenen Produkte oder Produktgruppen werden Branchen abgeleitet; diese lassen sich wiederum grob anhand von konsumentenseitigen Bedarfsstufen kategorisieren, die sowohl Verwendungszweck und -dauer der angebotenen Güter (Fristigkeit) als auch die Häufigkeit ihres Einkaufs widerspiegeln (HEINEBERG 2006, S. 181; HEINRITZ et al. 2003, S. 32f.):

- Zu den Gütern des kurzfristigen Bedarfs (auch: täglicher Bedarf) zählen vor allem Nahrungs- und Genussmittel sowie Drogerie- und Pharmazieprodukte

- Der mittelfristige Bedarf (auch: periodischer Bedarf) beinhaltet unter anderem Bekleidung, Schuhe oder Spielwaren

- Zu den Gütern des langfristigen Bedarfs (auch: episodischer Bedarf) werden unter anderem Möbel und Einrichtungsgegenstände, elektronische Haushaltsgeräte und Unterhaltungselektronik sowie Bau- und Heimwerkerbedarf gezählt

- Besonders selten erworbene und/oder nur für bestimmte Kundengruppen relevante Güter werden als Sonder- bzw. Spezialbedarf benannt (z.B. Musikinstrumente) 
Die Segmentierung nach Bedarfsgruppen ist insbesondere in Deutschland populär. Im angloamerikanischen Sprachraum ist die Einteilung der Branchen nach Aspekten des Käuferverhaltens weit verbreitet (HEINRITZ et al. 2003, S. 33; SCHRÖDER 2012, S. 39f.):

- Convenience goods sind vergleichsweise günstige, standardisierte Waren, die häufig benötigt werden, woraus abgeleitet wird, dass Konsumenten hierbei einen möglichst wenig aufwendigen Einkauf anstreben; diese Güterklasse deckt sich weitestgehend mit den Gütern das täglichen Bedarfs

- Shopping goods umfassen einen Großteil der mittel- und langfristigen Güter und werden anhand des Preises und des Kaufentscheidungsprozesses von den anderen abgegrenzt; sie sind teurer als convenience goods und werden seltener gekauft, wobei die Kaufentscheidung komplexer ist, da sie eine größere Planung voraussetzt und im Regelfall durch Preis- und Qualitätsvergleiche unterstützt wird

- Güter mit hohem Einzelwert, die nur sehr selten erworben werden und deren Kaufentscheidung intensiv vorbereitet wird, werden als Specialty goods bezeichnet

\subsubsection{Einzelhandel und Raum}

Der Standort eines Anbieters ist der geographische Ort, an dem der (Einzelhandels-)Betrieb seine Produktionsfaktoren kombiniert; er bildet in zweierlei Hinsicht ein absatzpolitisches Instrument, da über die unternehmensseitige Wahl des Standortes einerseits die Distanz zu den Kunden, andererseits die Distanz zu den Konkurrenten festgelegt wird. Der Standort eines einzelnen Anbieters des stationären Einzelhandels wird z.B. als Verkaufsstelle oder Einkaufsstätte bezeichnet (HEINRITZ et al. 2003, S. 67; MüLLER-HAGEDORN/NATTER 2011, S. 161; SCHRÖDER 2012, S. 57). Dieser Standortbegriff bezieht sich in seiner gängigen Gebrauchsform zumeist auf einen einzelnen Anbieter und wird häufig genutzt, um die angebotsseitige Perspektive zu beschreiben („Das Unternehmen $X$ wählt seinen Standort in Stadtteil Y"). Zur unternehmerischen Standortpolitik gehören v.a. die Wahl des Standortes sowie Entscheidungen zu Anpassungen an den Standort und seiner Gestaltung sowie - bei Misserfolg - die Aufgabe oder der Wechsel des Standortes (SCHRÖDER 2012, S. 59ff.).

Die Theorien und Modelle der Handelsforschung beziehen sich häufig nicht (nur) auf die Standorte von Einzelbetrieben, sondern (auch) auf Standorte, an denen mehrere Betriebe angesiedelt sind oder sein können; im Folgenden soll daher für die räumliche Verortung von Einzelhandelsangebot der Begriff Angebotsstandort im Sinne von LöFFLER (1999, S. 45) verwendet werden, der sich auf beide Fälle bezieht und die nachfrageseitige Perspektive zum Gegenstand hat (Die Konsumenten aus dem Stadtteil $Y$ kaufen bevorzugt am Angebotsstandort $Z$ ein"). Ein Angebotsstandort kann demnach aus einer einzigen Verkaufsstelle bestehen, aber auch eine Einzelhandelsagglomeration sein, d.h. eine räumliche Konzentration von mehreren Einzelhandelsbetrieben gleicher und/oder ungleicher Branchen auf engem Raum, die von den Kunden als zusammengehörig empfunden wird. Von einer Einzelhandelsagglomeration wird zumeist ab einer Menge von drei Betrieben gesprochen (HEINRITZ et al. 2003, S. 31; SCHNEDLITZ/TELLER 2008, S. 7f.).

Anhand ihrer Entstehung und der Existenz einer zentralen Steuerung lassen sich drei Typen von Einzelhandelsagglomerationen unterscheiden (TELLER 2008, S. 381f.): 
- Entstandene Einzelhandelsagglomerationen sind in einem längeren Zeitraum ohne zentrale Planung „natürlich gewachsen“, wobei sich die Geschäfte und die zugehörigen Immobilien in der Hand vieler einzelner Inhaber befinden und mögliche Maßnahmen eines gemeinsamen Außenauftritts rein freiwillig sind. Wesentliche Eigenschaften sind das Fehlen einer systematischen Angebotsplanung und eines zentral gesteuerten Managements; diese Agglomerationen können daher auch als ungeplante Agglomerationen bezeichnet werden. Zu diesem Agglomerationstyp gehören insbesondere innerstädtische Geschäftszentren oder Angebotsballungen an hoch frequentierten Verkehrsstraßen innerhalb und außerhalb der Innenstadt

- Dagegen zeichnen sich künstlich geschaffene Einzelhandelsagglomerationen durch eine bewusste Planung, eine zentrale Steuerung und einen gemeinsamen, für alle Anbieter verbindlichen Außenauftritt aus. Zu diesen geplanten Agglomerationen zählen die verschiedenen Formen von Einkaufszentren (auch: Shopping-Center) sowie deren (z.T. sehr spezifischen) Weiterentwicklungen (z.B. Factory-OutletCenter, Urban Entertainment Center)

- Es existieren ferner Agglomerationen, die eine Hybridform beider Typen darstellen: Einkaufsparks sind agglomerierte Angebotsstandorte, die als solche zweckgerichtet aufgebaut werden, jedoch aus freistehenden, unabhängigen Anbietern bestehen und auch nicht zentral gesteuert oder nach außen vermarktet werden ${ }^{1}$; sie sind häufig das Ergebnis planerischer Ausweisungen von Einzelhandelsflächen in Gewerbe- oder Sondergebieten. Ein weiterer Hybridfall sind zumeist kleinere Agglomerationen voneinander unabhängiger Betriebe, die ebenso kein Einkaufszentrum im o.G. Sinne bilden, jedoch gezielt von Einzelhandels- und/oder Immobilienunternehmen als Funktionseinheit mit komplementärem und/oder kompetitivem Angebot errichtet werden. Für diesen Agglomerationstyp wird auf der Grundlage von SCHRAMM-KLEIN (2012, S. 504) der Begriff Standortkooperation verwendet

Unabhängig vom Agglomerationstyp sind in aller Regel ein oder mehrere Magnetbetriebe dort lokalisiert; dies sind Einzelhandelsanbieter, die von besonderer Relevanz für den Angebotsstandort sind, da sie aufgrund ihrer eigenen Anziehungskraft maßgeblich für die Kundenfrequenz sorgen und somit den anderen Anbietern entscheidend zugutekommen. Bei Magnetanbietern handelt es sich zudem meistens um den oder die (flächenmäßig) größten Betriebe (GeRmeLMANN/NEDER 2012, S. 331; KULKE 2009, S. 158).

Bezogen auf die Kontaktaufnahme zwischen Anbietern und Nachfragern ist der stationäre Einzelhandel, genau wie viele andere konsumentenorientierte Dienstleistungen, eine anbieterbasierte Dienstleistung bzw. eine Angebotsform nach dem Residenzprinzip, d.h. die Nachfrager (Private Haushalte) suchen den Angebotsstandort auf, was notwendigerweise deren räumliche Mobilität voraussetzt (KULKE 2009, S. 140; SCHRÖDER 2012, S. 57). Die tatsächliche oder potenzielle Kundschaft (d.h. das Kundenpotenzial) solcher Anbieter lässt sich geographisch abgrenzen und segmentieren. Im Folgenden soll hierfür der Begriff Marktgebiet im Sinne von LÖFFLER (1999, S. 45) verwendet werden; dieses ist ein Ausschnitt der Erdoberfläche, also ein geographischer Raum, in dem die (tatsächlichen oder potenziellen) Nachfrager von Gütern (Waren, Dienstleistungen) eines Angebotsstandortes

\footnotetext{
${ }^{1}$ Dieser Begriff wird v.a. in Österreich verwendet und ist dort auch planungsrechtlich definiert.
} 
ihren Wohnsitz haben (auch: Absatz- oder Einzugsgebiet). Die äußere Grenze des Marktgebietes lässt sich interpretieren als die maximale Entfernung, die Konsumenten bereit sind, auf sich zu nehmen, um bestimmte Güter zu erwerben. Es handelt sich hierbei um ein Konstrukt, da sich Marktgebiete nur theoretisch oder modellanalytisch exakt abgrenzen lassen und ihre Außengrenze in der Realität schwer fassbar ist bzw. Schwankungen unterliegt (HEINRITZ et al. 2003, S. 29; VOGEL 2006, S. 160).

Überschneiden sich die Marktgebiete von Anbietern bzw. Angebotsstandorten der gleichen Branche bzw. mit Gemeinsamkeiten im Angebot, resultiert dies in räumlichem Wettbewerb (SCHÖLER 2005, S. 4); im Einzelhandelskontext lässt sich dieser hinsichtlich der beteiligten Betriebsformen in zwei Ausprägungen unterscheiden (HEINRITZ et al. 2003, S. 29f.):

- Intraformaler Wettbewerb besteht zwischen branchengleichen oder sich überschneidenden Anbietern, die der gleichen Betriebsform angehören

- Interformaler Wettbewerb bezeichnet das Konkurrenzverhältnis zwischen Anbietern, die verschiedenen Betriebsformen angehören

Marktgebiete sind das Ergebnis der räumlichen Interaktionen von Konsumenten mit Angebotsstandorten des Einzelhandels, d.h. Einkäufen bzw. Einkaufsfahrten. Diese Einkaufsinteraktionen sind Ausdruck des räumlichen Einkaufsverhaltens, also der Orientierung in Richtung der Angebotsstandorte (Einkaufsstättenwahl) sowie der Intensität und Reichweite dieser Beziehungen (KULKE 2005, S. 9f.; LÖFFLER 1999, S. 45). Im weiteren Sinne ist auch das Verhalten am Angebotsstandort Teil des räumlichen Einkaufsverhaltens. Einkäufe lassen sich nach ihren zu Grunde gelegten Motiven und Strategien bzw. ihrer daraus resultierenden räumlich-zeitlichen Organisation differenzieren.

Die Einkaufsmotive beziehen sich auf den konsumentenseitig bestimmten Hintergrund des Einkaufs (KULKE 2005, S. 16f.):

- Bei Bequemlichkeitskäufen suchen die Kunden Anbieter auf, die sie einfach erreichen können und deren Zugang zeitlich nicht oder nur wenig beschränkt ist (z.B. Tankstellenshops)

- Preiskäufe bezeichnen ein Einkaufsmotiv, bei dem sich die Nachfrager hin zu Anbietern mit einem besonders günstigen Angebot orientieren (z.B. Food- oder NonFood-Discounter)

- Bei Erlebniskäufen steht nicht der Versorgungsgedanke im Vordergrund, sondern Aspekte der Freizeitgestaltung; der Einkauf wird häufig mit freizeitbezogenen Aktivitäten verbunden

Die konsumentenseitige Einkaufsstrategie lässt sich anhand der Menge der eingekauften Güter unterscheiden (POPKOWSKI LESZCZYC et al. 2004, S. 86):

- Im Fall von Einzweckeinkäufen wird während eines Einkaufs nur ein Gut erworben

- Bei Mehrzweckeinkäufen werden mehrere Güter im Zuge eines Einkaufs erworben

Diese Einkaufsstrategien finden sich in der räumlich-zeitlichen Organisation des Einkaufs wieder, denn Mehrzweckeinkäufe resultieren in multifinalen Einkäufen, wobei zwischen sachlicher und räumlicher Multifinalität unterschieden wird (HEINRITZ/THEIS 1997, S. 222): 
- Werden alle gewünschten Güter bei einem Anbieter erworben, liegt ein sachlich multifinaler, jedoch räumlich monofinaler Einkauf vor

- Werden nicht nur mehrere Güter erworben, sondern auch mehrere Anbieter in einer Wegekette frequentiert, liegt räumliche und sachliche Multifinalität vor

Werden mehrere unterschiedliche Güter bzw. Zwecke in einem Einkauf miteinander kombiniert, wird auch von Kopplungskäufen gesprochen, die im Hinblick auf die miteinander gekoppelten Tätigkeiten differenziert werden (KÖHLER 2012, S. 36f.; KULKE 2005, S. 20f.):

- Bei der Kopplung mehrerer Einkäufe liegt eine Besorgungskopplung vor

- Eine Aktivitätenkopplung bezeichnet die Verbindung des Einkaufs mit anderen nichteinkaufsbezogenen Aktivitäten (z.B. Freizeit, Arbeit)

Besuchen Kunden mehrere Anbieter der gleichen Branche (Konkurrenten) an einem oder mehreren Angebotsstandorten zum Zweck des Preis- und/oder Qualitätsvergleichs innerhalb einer Produktgruppe, liegen Vergleichskäufe vor (HEINRITZ/THEIS 1997, S. 219; POPKOWSKI LESZCZYC et al. 2004, S. 86); sofern bei diesen nur ein Gut gesucht wird, handelt es sich um sachlich monofinale, jedoch räumliche multifinale Einkäufe, da notwendigerweise mehrere Anbieter aufgesucht werden. Kopplungs- und Vergleichskäufe können kombiniert werden (d.h. räumlich und sachlich multifinale Einkäufe).

\subsection{Ausgangssituation im deutschen Einzelhandel}

\subsubsection{Der Strukturwandel im Einzelhandel: Angebots- und Nachfrageseite}

Der deutsche Einzelhandel unterliegt einem kontinuierlichen und facettenreichen Strukturwandel, der an dieser Stelle nur kurz skizziert werden kann. In der einschlägigen Literatur wird diesbezüglich häufig zwischen angebots- und nachfrageseitigen Entwicklungen getrennt (z.B. JENNE 2006, KULKE 2010); diese Aufteilung wird beibehalten, wobei klar sein muss, dass beide Seiten in marktwirtschaftlich organisierten Systemen selbstverständlich ineinandergreifen. Die dargestellten Entwicklungen beziehen sich dabei auf den Zeitraum von ca. 1950 bis heute; konkrete Zahlenangaben zu Bestand und Entwicklung können an dieser Stelle nur exemplarisch erfolgen².

Auf der Angebotsseite - also hinsichtlich der Erscheinungs- und Organisationsformen der Einzelhandelsunternehmen - sind eine Reihe wesentlicher Entwicklungen zu nennen (KULKE 2010, S. 219ff.; LADEMANN 2013, S. 7ff.; SPERLE 2012, S. 41ff.):

- Konsumentenseitig sichtbar ist vor allem das kontinuierliche Aufkommen neuer und das Verschwinden alter Betriebsformen (Wandel der Betriebsformen). Im Lebensmitteleinzelhandel (LEH) ist dies vor allem an der Verdrängung kleiner inhabergeführter Fremdbedienungsgeschäfte („Tante-Emma-Läden“) durch Selbstbedienungsmärkte mit weit größerer Sortimentsbreite und Sortimentstiefe

\footnotetext{
${ }^{2}$ Ausführliche aktuelle Branchendaten sowie Zeitreihen bieten z.B. die Publikationen des Handelsverbandes Deutschland (HDE, z.B. Zahlenspiegel), des EuroHandelsInstituts (EHI) und seinen Vorläufern (z.B. Handel aktuell), der Metro Group (z.B. Metro-Handelslexikon) oder der statistischen Ämter. Hierbei gilt zu bedenken, dass die sich wandelnden Definitionen (z.B. der Betriebsformen oder der Verkaufsfläche) die Nachvollziehbarkeit und Vergleichbarkeit von Angaben im Zeitverlauf erschweren.
} 
(Verbrauchermärkte, SB-Warenhäuser) oder, ab den 1970er Jahren, von Lebensmittel-Discountern mit einer Dauerniedrigpreispolitik bei zugleich geringer Sortimentstiefe zu erkennen. Im Non-Food-Einzelhandel sind insbesondere die Entstehung von Fachmärkten (z.B. Bau-, Elektro- oder Möbelmärkte) und die Verdrängung von Fachgeschäften und Kauf- bzw. Warenhäusern spürbare Elemente des Strukturwandels

- Eng mit dem Betriebsformenwandel verknüpft ist die kontinuierliche Zunahme der Gesamtverkaufsfläche ${ }^{3}$. Gleichzeitig geht die absolute Zahl der Verkaufsstellen zurück; auf diesem Wege nimmt die durchschnittliche Größe der Verkaufsstellen zu (Maßstabsvergrößerung). In Kombination mit der seit der Jahrtausendwende feststellbaren Tendenz zur Stagnation der im Einzelhandel getätigten Umsätze bedeutet dies zugleich einen Rückgang der durchschnittlichen Flächenproduktivität

- Auf der Seite der betrieblichen Organisationsformen sind ferner massive Expansionsund Internationalisierungsprozesse der Einzelhandelsunternehmen sowie eine Unternehmenskonzentration sichtbar, die v.a. durch Übernahmen und Fusionen bedingt ist. So konzentriert sich z.B. der Umsatz im deutschen LEH faktisch auf fünf landesweit und zumeist auch international agierende Konzerne (Edeka Gruppe, Rewe Group, Metro Group, Schwarz-Gruppe, Aldi Nord/Süd), die über ihre Vertriebslinien unterschiedlicher Betriebsformen (Verbrauchermärkte, LebensmittelDiscounter, SB-Warenhäuser etc.) ein breites Angebotsspektrum abdecken

- Das Aufkommen des Onlinehandels in den 1990er Jahren stellt eine Veränderung zu Lasten des stationären und des sonstigen Distanzhandels dar. Dieser Vertriebskanal ist mittlerweile fest etabliert, wobei seine Bedeutung tendenziell steigt ${ }^{4}$

Als endogene Einflüsse auf den Strukturwandel im Einzelhandel werden die Umsetzung von (vor allem technischen) Innovationen (z.B. Modernisierung der Warenbestandserfassung und der Kassenvorgänge mittels elektronischer Warenwirtschaftssysteme), ein sich verschärfender Wettbewerb aufgrund einer stärker werdenden Kapitalkonzentration sowie der Anreiz einer günstigen Machtposition (Nachfragemacht) von großen Unternehmen gegenüber den Herstellern und dem Großhandel angeführt (HEINRITZ et al. 2003, S. 42f.;

\footnotetext{
${ }^{3}$ Laut den Statistiken des HDE hat sich die Verkaufsfläche des westdeutschen Einzelhandels im Zeitraum von 1950 bis 1970 von ca. 9,0 auf ca. 35,0 Millionen qm vergrößert (TIETZ/ROTHHAAR 1991, S. 125), was beinahe eine Vervierfachung im Zeitraum von 20 Jahren bedeutet. Der gesamte deutsche Einzelhandel (inkl. neue Bundesländer bzw. frühere DDR) umfasste im Jahr 1980 ca. 63,0 Millionen qm, was sich bis 2011 auf ca. 122,4 Millionen qm nahezu verdoppelt hat (HDE 2012, S. 24). Im Jahr 2012 ist die Gesamtverkaufsfläche erstmals leicht gesunken, was aber v.a. auf den Verlust von rd. 1,8 Mio. qm Verkaufsfläche in rd. 8.000 Verkaufsstellen durch die Insolvenz des Schlecker-Konzerns zurückzuführen ist (GFK GEOMARKETING GMBH 2012).

${ }^{4}$ Der Onlinehandel erreicht offensichtlich nicht den Einfluss, dass er den stationären Einzelhandel ersetzen würde; er ist vor allem auf standardisierte und leicht lieferbare Güter beschränkt (KULKE 2010, S. 223). Die größte Relevanz hat der Onlinehandel im Bereich der Unterhaltungselektronik, wo sein Marktanteil vom Branchenverband BITKOM (2012, S. 21f.) bei knapp einem Fünftel (19,2\%) angesetzt wird. Demgegenüber spielen Onlinekäufe z.B. im Lebensmittelbereich keine nennenswerte Rolle: Die BBE HANDELSBERATUNG (2011, S. 16) schätzt hier den Marktanteil des gesamten Distanzhandels auf ca. 0,5\%. Vielmehr ist eine Zunahme von Multi- oder Cross-Channeling-Strategien zu verzeichnen, in denen der Onlinehandel als weiterer Vertriebskanal eröffnet oder, wie am Beispiel von Media Markt, mit dem stationären Vertriebsweg verbunden wird (DER HANDEL 2012); umgekehrt steigen mitunter sogar ursprünglich reine Onlinehändler in den stationären Vertrieb ein, wie etwa die Eröffnung eines Zalando Outlet Store im Jahr 2012 zeigt (DER HANDEL 2013). Zudem wird aus der vertriebskanalspezifischen Umsatzentwicklung ersichtlich, dass der Onlinehandel vorrangig zu Lasten des sonstigen Distanzhandels (traditioneller Versandhandel) geht (DEUTSCHE HYPO 2013, S. 13f.).
} 
KULKE 2010, S. 221f.). Den wesentlichsten handelsexogenen Einfluss stellt das (räumliche) Einkaufsverhalten der privaten Haushalte dar, das nach KULKE (2005, S. 10) insbesondere durch das Einkommen, individuelle Einkaufsmotive, die Möglichkeiten räumlicher Mobilität sowie das konsumentenseitige Zeitbudget beeinflusst wird. Auf der Nachfrageseite sind folgende Basisentwicklungen festzustellen (HEINRITZ/POPP 2011, S. 1004ff.; JENNE 2006, S. $1 \mathrm{ff} . ;$ KULKE 2005, S. 10ff. u. 2010, S. 223ff.; SPERLE 2012, S. 46ff.):

- Zumindest bis zur Jahrtausendwende ist eine kontinuierliche Zunahme der Realeinkommen privater Haushalte zu verzeichnen gewesen; dies hat den Fokus auf den Erwerb von Gütern des mittel- und langfristigen Bedarfs gelenkt (z.B. Geräte der Unterhaltungselektronik, Fahrzeuge), deren Anteil am privaten Konsum im Fall eines Einkommensanstiegs in der Bevölkerung stark zunimmt (Einkommenselastizität). Demgegenüber sind Grundbedarfsgüter (v.a. Nahrungsmittel) kaum elastisch, d.h. ihr Nachfragevolumen erhöht sich mit dem Einkommenszuwachs nur unterproportional

- Parallel haben sich die gesamten privaten Konsumausgaben verschoben, da einerseits eine Reihe weiterer Konsummöglichkeiten hinzugekommen sind (z.B. hinsichtlich der Freizeitgestaltung), andererseits bisherige Ausgaben in vielen Fällen real gestiegen sind (z.B. Miet- und Heizungskosten, Treibstoff). Der Anteil der privaten Konsumausgaben, der dem Einzelhandel zufließt, sinkt in der Folge kontinuierlich. Seit Beginn der 2000er Jahre sind die Realeinkommen zudem kaum gestiegen, was diesen Trend noch verstärkt

- Im Hinblick auf die Einkaufsmotive sind zwei ineinander greifende Umstände festzustellen: Aufgrund einer steigenden Zahl konkurrierender Möglichkeiten zur Investition der eigenen Lebenszeit wird das für den Einkauf vorgehaltene Zeitbudget der Konsumenten immer knapper. Gleichzeitig erhöht sich der konsumentenseitige Anspruch im Hinblick auf die Sortimentstiefe (Auswahl) und die Sortimentsbreite der Einzelhandelsanbieter. In räumlicher Hinsicht schlägt sich dies in einer steigenden Relevanz von Kopplungskäufen und einer Mehrfachorientierung der Kunden nieder

- Die Etablierung des PKW als Massenverkehrsmittel („Motorisierung“ der privaten Haushalte) eröffnete den Konsumenten neue Möglichkeiten der Organisation ihrer Einkäufe: Einerseits war es nun für die Nachfrager problemlos möglich, weitere Einkaufswege zurückzulegen, andererseits wurde hierdurch ihre Transportkapazität für die erworbenen Güter massiv erweitert

\subsubsection{Steuerung des Einzelhandels durch räumliche Planung}

Die Standortwahl und -gestaltung von Einzelhandelsunternehmen und, damit verbunden, die gesamte räumliche Einzelhandelsentwicklung werden in Deutschland maßgeblich durch rechtliche Vorgaben beeinflusst, deren Umsetzung verschiedenrangigen Planungsbehörden obliegt (KULKE 2010, S. 226f.; MICHALLIK 2010, S. 41ff.):

- Im Raumordnungsgesetz (ROG) des Bundes sind die Grundzüge der erwünschten räumlichen Entwicklung festgelegt ${ }^{5}$. In den „Grundsätzen der Raumordnung“ ( $§ 2$

\footnotetext{
${ }^{5}$ Für die räumliche Entwicklung in Deutschland ist in den 1960er Jahren das Leitbild der dezentralen Konzentration aufgesetzt worden, das eine dezentrale Siedlungsstruktur mit einer großen Zahl an Zentren
} 
ROG) ist das Zentrale-Orte-Konzept als Leitlinie der räumlichen Versorgungsstruktur verankert. Hierbei erfolgt eine Klassifikation der Gemeinden nach ihrer Ausstattung mit versorgungsrelevanten Dienstleistungseinrichtungen in Ober-, Mittel- und Grundbzw. Unterzentren, wobei die Zuordnung auf nachgelagerten Ebenen erfolgt (siehe unten). Für die Zentren der jeweiligen Hierarchiestufe werden entsprechende Ausstattungsmerkmale vorgesehen, die auf das Angebot an konsumentenorientierten Dienstleistungen (z.B. Einzelhandel) sowie öffentlichen Einrichtungen (z.B. Schulen) abzielen und sich an den Bedarfsstufen der Waren und Dienstleistungen orientieren. Die Ausstattungshierarchie der Zentren ist additiv, d.h. höherrangige zentrale Orte übernehmen zugleich auch die Versorgungsaufgaben niederrangiger Orte

- Das Baugesetzbuch (BauGB) beinhaltet u.a. bundeseinheitliche Regelungen zum Ablauf von Bebauungsplanverfahren

- In der Baunutzungsverordnung (BauNVO) werden u.a. die Zulässigkeit von Einzelhandelsbetrieben in den jeweiligen Baugebietstypen geregelt (§§ 2-11 BauNVO $)^{6}$ und der Begriff des großflächigen Einzelhandels ${ }^{7}$ definiert (§ 11 Abs. 3), der einer besonderen raumordnerischen und baurechtlichen Regulierung unterliegt

- Auf der Ebene der Bundesländer erfolgt die Konkretisierung der erwünschten räumlichen Entwicklung in Landesraumordnungsprogrammen (LROP) (auch: Landesentwicklungspläne - LEP, Landesentwicklungsprogramme - LEPro); u.a. erfolgt darin die Ausweisung von Ober- und Mittelzentren im jeweiligen Bundesland

- Die Träger der Regionalplanung ${ }^{8}$ stellen Regionalpläne (auch: Regionale Raumordnungsprogramme - RROP) auf, die u.a. das Zentrale-Orte-Konzept auf der untersten Ebene konkretisieren, indem sie die unterste Hierarchiestufe (Grund- bzw. Unterzentren) in der jeweiligen Planungsregion festlegen

- Die Planungshoheit im Bereich der Bodennutzung liegt bei den Kommunen, die so auch die Ansiedlung von (großflächigen) Einzelhandelsbetrieben auf der Grundlage des BauGB und der BauNVO steuern. Im Zuge der kommunalen Bauleitplanung wird ein vorbereitender Flächennutzungsplan erstellt, in dem für das gesamte Gemeindegebiet Flächennutzungen festgelegt werden. Der verbindliche Bebauungsplan bezieht sich auf ein konkretes Baugebiet und legt die dortige Nutzung fest (z.B. Sondergebiet für großflächigen Einzelhandel)

Die zentralörtliche Funktion der Gemeinde und die Festlegungen des Bebauungsplanes haben unmittelbaren Einfluss auf die Standortwahl und -ausgestaltung von

\footnotetext{
unterschiedlicher Funktionsgrade postuliert. Ziele des Leitbildes sind v.a. eine flächendeckende Grundversorgung und eine räumlich ausgeglichene Wirtschaftsstruktur (ZECK 2003, S. 725).

${ }^{6}$ Nach der BauNVO sind Einzelhandelsnutzungen nur in bestimmten Baugebietstypen erlaubt; besonders eingeschränkt bzw. gar nicht zulässig sind sie in den verschiedenen Wohngebietstypen (§ 2-4a BauNVO). Großflächiger Einzelhandel und geplante Einkaufszentren sind nur in Kerngebieten ( 7 BauNVO) und bestimmten Sondergebieten ( $\$ 11$ BauNVO) zulässig.

${ }^{7}$ Nach aktueller Rechtsprechung ist großflächiger Einzelhandel ab einer Geschossfläche von 1.200 qm bzw. einer Verkaufsfläche von 800 qm (früher: 700 qm) definiert; im Gegensatz zur Geschossfläche ist der Begriff der Verkaufsfläche jedoch selbst nicht baurechtlich definiert, sondern erst durch verschiedene Gerichtsurteile operationalisiert worden (MüLLER-HAGEDORN 2009, S. 370f.).

${ }^{8}$ Welche administrative Instanz für die Regionalplanung zuständig ist, unterscheidet sich zwischen den Ländern (z.B. Niedersachsen: kreisfreie Städte und Landkreise, Nordrhein-Westfalen: Bezirksregierungen).
} 
Handelsunternehmen. Für die Neuansiedlung von großflächigen Einzelhandelsbetrieben gilt, dass das neue Angebot dem zentralörtlichen Rang der Ansiedlungsgemeinde entsprechen muss (Kongruenzgebot), d.h. nicht über die zugewiesene Versorgungsfunktion hinausgehen darf, und es der Versorgungsstruktur innerhalb der Standortgemeinde und/oder in anderen Gemeinden nicht wesentlich schaden darf (Beeinträchtigungsverbot). Die Ansiedlung eines Betriebs, der diese Voraussetzungen nicht erfüllt, kann vor diesem Hintergrund untersagt werden (WEERS-HERMANNS 2007, S. 113ff.). Den konkretesten Einfluss auf die Ansiedlung von (großflächigen) Einzelhandelsbetrieben hat der Bebauungsplan. Abgesehen davon, dass Einzelhandel generell nur in bestimmten Baugebietstypen zulässig ist, macht der Bebauungsplan nicht nur Vorgaben zum allgemeinen Nutzungstyp oder gestalterischen bzw. bautechnischen Elementen, sondern kann auch auf Branchen bzw. Sortimente angewandt werden; es können hierbei ganze Branchen untersagt oder Maximalwerte für die Verkaufsfläche bestimmter Sortimentsbereiche definiert werden (CALLIES 2004, S. 270ff.).

Im Jahr 1977 wurde in die BauNVO (§ 11) ein Passus eingefügt, in dem bei der Ansiedlung großflächiger Einzelhandelsbetriebe und Einkaufszentren grundsätzlich raumordnerische und städtebauliche Auswirkungen vermutet werden; dies sind negative Effekte von Kaufkraftumlenkungen, die so gravierend sind, dass sie zu weiträumigen Geschäftsaufgaben an existierenden, zu schützenden Angebotsstandorten führen. Es wird bei dieser Vermutungsrege/ jedoch nicht ausgeschlossen, dass diese Effekte auch schon bei Betrieben unterhalb der Großflächigkeit möglich sind; umgekehrt ist möglich, diese Vermutung bei großflächigen Ansiedlungen durch eine vorherige Prüfung der Auswirkungen des Vorhabens zu widerlegen (JENNE 2006, S. 14; MiCHALLIK 2010, S. 93f.). Als Obergrenze für die vorhabeninduzierten Kaufkraftumlenkungen haben sich in der Rechtsprechung bestimmte maximale Abflussquoten etabliert, die nicht gesetzlich festgelegt, sondern auf der Grundlage von Langzeitstudien in Gerichtsurteile eingeflossen sind; oberhalb dieser Grenzen ist demnach von schädlichen Auswirkungen für die Standortgemeinde (städtebauliche Auswirkungen) bzw. für andere Zentren (raumordnerische Auswirkungen) auszugehen. Die am häufigsten angesetzte Obergrenze für Umsatzabflüsse liegt bei zehn Prozent („ZehnProzent-Regel") (WOLF 2012, S. 124).

Ab den 1990er Jahren haben sich im Zusammenhang mit der planerischen Steuerung der räumlichen Einzelhandelsentwicklung noch weitere Veränderungen ergeben:

- Den zentralen Versorgungsbereichen kommt ein besonderer raumordnerischer und städtebaulicher Schutz zu, der mittlerweile als Aufgabe der Bauleitplanung ( $\$ 1$ Abs. $6 \mathrm{Nr} .4$ BauGB) und der Raumordnung ( $\S 2 \mathrm{Nr} .3 \mathrm{~S} .3 \mathrm{ROG}$ ) explizit definiert ist. Zentrale Versorgungsbereiche sind faktisch zumeist die Geschäftsbereiche gewachsener Innenstädte und bilden somit eine Art juristische Begriffsbestimmung dieser Angebotsstandorte (KOCH 2010, S. 233ff.; SCHULTE 2007, S. 135f.)

- Der Schutz des innerstädtischen Einzelhandels ist ferner durch die Formulierung und planerische Berücksichtigung zentren- bzw. innenstadtrelevanter Sortimente ausgeweitet worden, deren Ansiedlung außerhalb der Innenstädte z.B. durch Verkaufsflächenbegrenzungen in Bebauungsplänen verhindert bzw. eingeschränkt werden kann (WEERS-HERMANNS 2007, S. 273ff.)

- Mittlerweile werden auch in einigen Fällen Einzelhandelsagglomerationen in der Landesraumordnung und der Regionalplanung explizit berücksichtigt. Während 
geplante Einkaufszentren bereits in $\S 11$ BauNVO genannt werden, sind die nicht zentral gesteuerten Agglomerationsformen bisher jedoch nicht Gegenstand bundesweiter Regelungen (JANNING 2012, S. 95ff.; UECHTRITZ 2010, S. 17ff.)

- Ferner haben auch Gutachten zumeist privatwirtschaftlicher Beratungsunternehmen an Relevanz gewonnen, deren fachliche Aussagen planungsrechtlich umgesetzt werden: In regionalen oder kommunalen Einzelhandels- und Zentrenkonzepten werden u.a. der aktuelle Einzelhandelsbestand analysiert, der zentrale Versorgungsbereich abgegrenzt sowie Empfehlungen für einen möglichen Ausbau des Angebots vor dem Hintergrund planungsrechtlicher Rahmenbedingungen formuliert. Verträglichkeitsgutachten dienen der Analyse und Bewertung absatzwirtschaftlicher Folgen von Einzelhandelsansiedlungen und die dadurch induzierten möglichen raumordnerischen und städtebaulichen Auswirkungen im Sinne der o.g. Vermutungsregel (OSTERHAGE 2009, S. 42f.; WOLF 2012, S. 116f.)

\subsubsection{Räumliche Ausprägungen des Strukturwandels}

Die verschiedenen Aspekte des Strukturwandels im Einzelhandel schlagen sich unmittelbar räumlich nieder, wobei sich diese ab den 1960er Jahren einsetzenden Entwicklungen erheblich von den in den Jahrzehnten bzw. Jahrhunderten davor unterscheiden: Waren vorher der Einzelhandel und der urbane Raum - insbesondere der zentrale Geschäftsbereich der Innenstädte - untrennbar miteinander verknüpft, bedeuten die ab diesem Zeitraum aufkommenden Prozesse faktisch eine Entkoppelung des Einzelhandels von den (Innen-)Städten (HEINRITZ et al. 2003, S. 218f.; SPERLE 2012, S. 41). Diese „Suburbanisierung des Einzelhandels“ (KULKE 2010, S. 220) ist die Konsequenz der sich verändernden Standortansprüche und der daraus resultierenden Standortpolitik, die sich wiederum auf die räumliche Verteilung von Einzelhandelsbetrieben auswirken.

Das kundenseitig erhöhte Anspruchsniveau im Hinblick auf die Sortimentsbreite und -tiefe resultiert in einem gestiegenen Verkaufsflächenbedarf der Handelsunternehmen, der nicht an jedem Angebotsstandort befriedigt werden kann bzw. aus Kostengründen aufgrund hoher Bodenpreise und/oder Baukosten nicht betriebswirtschaftlich tragfähig ist. Die PKW-Mobilität der Konsumenten hat den Einzelhandelsanbietern zudem eine freiere Standortwahl ermöglicht, da die unmittelbare räumliche Nähe zu den Nachfragern - in gewachsenen Innenstadtbereichen oder in Wohngebieten - nicht mehr zwingend notwendig ist. Beides resultierte ab den 1970er Jahren in einer unternehmensseitigen Bevorzugung dezentraler Lagen bei der Standortwahl („Grüne Wiese“). Diese Lagen bieten einerseits große Flächenspielräume zu vergleichsweise günstigen Grunderwerbs- und Baukosten und gleichzeitig eine optimale Verkehrserreichbarkeit für die vorzugsweise PKW-nutzende Kundschaft (JENNE 2006, S. 7f.; SPERLE 2012, S. 49f.). Resultat dieser Entwicklungen war die Etablierung verschiedener neuer Betriebsformen mit ihren jeweiligen Standortansprüchen: Im Lebensmitteleinzelhandel sind dies vor allem Verbrauchermärkte und SB-Warenhäuser, im Non-Food-Bereich insbesondere Fachmärkte, die beide aufgrund ihrer flächen- und verkehrsbezogenen Ansprüche fast ausschließlich außerhalb der geschlossenen Bebauung angesiedelt werden mussten (KULKE 2010, S. 220f.).

Weiterhin steht die Ausweitung der Sortimentsbreite und -tiefe in einem wechselseitigen Zusammenhang mit dem Kaufkraftzufluss: Während im Allgemeinen der Größe der 
Verkaufsfläche eine positive Wirkung auf den Kundenzufluss beigemessen wird, ist umgekehrt auch zur betriebswirtschaftlich tragfähigen Erhaltung einer Verkaufsstelle ein bestimmtes Kundenpotenzial notwendig, das mit der Größe steigt (HEINRITZ 1999, S. 33f.; KULKE 2010, S. 219f.). Am Beispiel des Lebensmitteleinzelhandels lässt sich aufzeigen, dass heutige Neuansiedlungen aufgrund der hohen Standortanforderungen hinsichtlich z.B. der Flächengröße und der Mindestgröße des Marktgebietes an vielen Angebotsstandorten nicht mehr in Frage kommen (siehe Anhang, Tabelle A 1).

Der zweite wesentliche Aspekt des Standortwandels im Einzelhandel ist die wachsende Bevorzugung von agglomerierten Standorten bei der Standortwahl, die - im Gegensatz zu den gewachsenen Innenstadtbereichen - zugleich alle flächen- und verkehrsbezogenen Vorteile aufweisen, die vor dem Hintergrund der erweiterten Anforderungen für eine Ansiedlung maßgeblich sind. Einerseits ist dieses Prinzip insofern nicht neu, da bereits in den 1960er Jahren geplante Einkaufszentren (EKZ) nach US-amerikanischem Vorbild als neue Form von Angebotsstandorten in den deutschen Markt eintraten; die Gesamtzahl und -verkaufsfläche von EKZ in Deutschland ist seitdem ungebrochen gestiegen ${ }^{9}$ (JUNKER/KÜHN 2009, S. 54f.). Im Hinblick auf die bauliche Struktur, die Größe und die Standortwahl lassen sich mehrere Generationen von Einkaufszentren typisieren: Die ersten Einkaufszentren in Westdeutschland entstanden in eingeschossiger Bauweise und - hinsichtlich ihrer Verkaufsfläche praktisch unbegrenzt - in "Grüne Wiese“-Lagen, während ab den 1970er Jahren auch kleinere mehrgeschossige Zentren in stadtintegrierter Lage hinzukamen (z.B. Einkaufspassagen, City-Galerien). Ab 1990 erfolgte in den neuen Bundesländern eine rasche Ausbreitung von Einkaufszentren in dezentraler Lage, wobei ab Mitte der 1990er Jahre in beiden Landesteilen vermehrt innerstädtische Zentren neu errichtet wurden (KULKE 2010, S. 222f.; PITTROFF 2009, S. 18f.).

Die neuerliche Standortwahl von Einkaufszentren in Innenstädten ist hierbei maßgeblich auf die planerische Steuerung der Einzelhandelsentwicklung zurückzuführen. Die restriktivere behördliche Genehmigungspraxis hat tendenziell zu einer Abnahme der Relevanz von „Grüne Wiese“-Standorten geführt (JENNE 2006, S. 7). Dieser leichte Gegentrend zur "Suburbanisierung des Einzelhandels“ ist insbesondere anhand der Neuerrichtung von geplanten Einkaufszentren festzustellen; diese werden nämlich - genehmigungsrechtlich bedingt - tendenziell wieder eher in Innenstadtbereichen angesiedelt (BORCHARD 2012, S. 18; JUNKER/KÜHN 2009, S. 53f.). Insbesondere im Bereich des Lebensmitteleinzelhandels ist jedoch ein stetiger Bedeutungsverlust innerstädtischer Zentrenlagen festzustellen, der durch planerische Eingriffe nicht kompensiert wird (JENNE 2006, S. 8; KÜHN 2011, S. 8); neuere stationäre LEH-Vertriebskonzepte für den Innenstadtbereich werden von den Einzelhandelsunternehmen nur in hoch frequentierten großstädtischen Zentrenlagen realisiert (z.B. Rewe City, siehe Anhang, Tabelle A 1).

Andererseits ist als vergleichsweise neues Phänomen die Bildung von strategischen Standortkooperationen festzustellen; diese sind nicht, wie ein Einkaufszentrum, über ein gemeinsames Management miteinander verbunden, jedoch von Einzelhandelsunternehmen

\footnotetext{
${ }^{9}$ Die Zahl (bzw. Verkaufsfläche) von Einkaufszentren nach EHI-Definition hat sich von 363 (bzw. 11,4 Mio. qm) im Jahr 2005 auf 444 (bzw. 13,9 Mio. qm) im Jahr 2012 erhöht (HDE 2012, S. 20). Es werden weiterhin neue innerstädtische Einkaufszentren geplant und eröffnet; ihre Ansiedlung erfolgt vermehrt in Mittelzentren (z.B. DIE WELT 2013).
} 
bzw. Immobilienentwicklern als Funktionseinheit komplementärer und/oder konkurrierender Angebote vorgesehen. Standortkooperationen gewinnen sowohl im Food- als auch im NonFood-Bereich und in Verbindung beider an Bedeutung (SCHRAMM-KLEIN 2012, S. 504f.). Beispielhaft hierfür steht die gezielte gemeinsame Ansiedlung von verschiedenen, eigentlich in interformalem Wettbewerb stehenden, Anbietern des Lebensmitteleinzelhandels (Kombinationen von Verbrauchermärkten und Discountern sowie häufig ergänzenden Anbietern des Lebensmittelhandwerks) (JÜRGENS 2012a, S. 39f. u. 2013, S. 53; KÜHN 2011, S. 8); einige Filialisten beziehen die räumliche Nähe zu Konkurrenten sogar explizit in ihre Standortanforderungen ein (z.B. Kaiser's Tengelmann; siehe Anhang, Tabelle A 1).

Die aus den o.g. Umständen resultierende Standortverteilung von Einzelhandelsbetrieben und ihre Präsenz an Angebotsstandorten verschiedenen Typs bzw. innergemeindlichen Lagen lässt sich wie folgt grob skizzieren (KULKE 2010, S. 227ff.; SPERLE 2012, S. 50f.):

- Der Flächenausbau geht einher mit dem massiven Rückgang der absoluten Zahl an Verkaufsstellen (siehe Kap. 1.3.1), was sich räumlich in einer Ausdünnung des Verkaufsstellennetzes ausdrückt; eine neue Verkaufsstelle ersetzt mehrere alte

- Da nicht überall gleiche Standortbedingungen vorherrschen, werden bei Neuansiedlungen tendenziell große, bereits gut ausgebaute Standortgemeinden bzw. Angebotsstandorte aufgrund ihrer besser ausgeprägten Standortfaktoren bevorzugt. Hier kommen u.a. die gestiegenen Anforderungen an die Größe der Marktgebiete, die PKW-Zugänglichkeit sowie mögliche positive Agglomerationseffekte zum Tragen

- Dies führt(e) zu einer Stärkung von geplanten Einkaufszentren, hoch frequentierten Innenstadtbereichen in Großstädten sowie dezentralen Agglomerationen „auf der Grünen Wiese“. Verlierer dieses Standortwandels sind insbesondere gewachsene Innenstadtbereiche in kleineren Städten, was sich anhand verschiedener zirkulärkumulativ wirkender negativer Erscheinungen des relativen Bedeutungsverlustes zeigt („Trading down“, z.B. Leerstände, sinkende Angebotsvielfalt, „Textilisierung“)

- Als zweiter Lagetyp, der in diesem Zusammenhang negativ beeinträchtigt wurde (und immer noch wird), sind die Streulagen (v.a. in oder nahe Wohngebieten) zu nennen, in denen das Einzelhandelsangebot massiv abgebaut wurde. Besonders deutlich ist dieser Abbau im Bereich des Lebensmitteleinzelhandels zu spüren, der bis in die 1960er Jahre hinein in diesem Lagetyp dominierte

\subsection{Problemstellung und Zielsetzung der Arbeit}

\subsubsection{Einzelhandelsagglomerationen und Polarisierung der Angebotsstandorte}

In den vorherigen Kapiteln wurden die verschiedenen Aspekte des Strukturwandels im Einzelhandel unter besonderer Berücksichtigung der räumlichen Auswirkungen skizziert. Neben anderen (interdependenten) Makrotrends (z.B. Flächenwachstum, Rückgang der Zahl der Verkaufsstellen, steigende Relevanz des Online-Handels) stellt sich die räumliche Konzentration des Einzelhandelsangebotes als zentraler, wenn nicht gar wichtigster Aspekt der Standortentwicklung im Einzelhandel heraus. Diese Angebotskonzentration zeigt sich unmissverständlich in der steigenden Relevanz verschiedener Formen von Einzelhandelsagglomerationen; hierzu zählen einerseits die seit den 1960er Jahren 
bestehenden dezentralen "Grüne Wiese“-Standorte von großflächigen Lebensmittel- und Fachmärkten sowie Einkaufszentren der ersten Generation, seit den 1990er Jahren aber auch innerstädtische Einkaufszentren und neuerdings kleinere Agglomerationen von komplementären und/oder eigentlich kompetitiven Anbietern (Standortkooperationen).

Notwendigerweise ist im Kontext gesättigter Märkte mit der steigenden Relevanz von Einzelhandelsagglomerationen auch der Bedeutungsverlust von Angebotsstandorten in Streulagen bzw. weniger agglomerierten Angebotsstandorten verbunden; diese parallel stattfindenden Wachstums-, Stagnations- und Schrumpfungsprozesse lassen sich als Polarisierung der Angebotsstandorte beschreiben, die auf mehreren Maßstabsebenen zu beobachten ist (SPERLE 2012, S. 51):

- Großräumig betrachtet, also zwischen den Gemeinden (bzw. Zentren im Sinne des Zentrale-Orte-Konzeptes), begünstigt der Standortwandel die Angebotsentwicklung in ranghöheren Gemeinden, d.h. Ober- gegenüber Mittelzentren und Mittel- gegenüber Grundzentren $^{10}$

- Innerhalb der Gemeinden zeigt sich die räumliche Angebotskonzentration in der Stärkung bestimmter bereits gut ausgebauter Einzelhandelsagglomerationen (z.B. oberzentrale Innenstädte, dezentrale Agglomerationen, Standortkooperationen und Einkaufszentren) gegenüber kleineren Angebotsstandorten (z.B. Innenstädte in rangniedrigen Gemeinden, Streulagen in Wohngebieten, kleine Subzentren)

Ausgehend von der in der Raumordnungspolitik postulierten Vorstellung einer räumlich ausgeglichenen Wirtschaftsstruktur sowie einer flächendeckenden Grundversorgung (siehe Kap. 1.3.2) sind diese Entwicklungen natürlich als problematisch zu erachten. Aus einer eher ökonomischen oder, genauer gesagt, betriebswirtschaftlichen Perspektive stellt sich andererseits die Frage, welche einzelwirtschaftlichen Faktoren die skizzierte Standortpolitik als besonders günstig erscheinen lassen. Einzelhandelsagglomerationen rücken daher immer mehr in den Fokus handels- und planungswissenschaftlicher Forschungsarbeiten.

Insgesamt zeigt sich ein wachsendes Interesse an Einzelhandelsagglomerationen, wie etwa - auf nationaler Ebene - die themenbezogene Ausrichtung der Jahrestagung 2013 des Arbeitskreises Geographische Handelsforschung („Geplante Betriebstypenagglomerationen“) zeigt (AK GEOGRAPHISCHE HANDELSFORSCHUNG 2013). Auch auf der internationalen Ebene offenbart sich ein Zuwachs an Untersuchungen zu diesem Themenfeld, die jedoch in ihrem Untersuchungsgegenstand und ihrer empirischen Vorgehensweise sehr heterogen sind; hierzu zählen Analysen räumlicher Branchenkonzentrationen (z.B. ECKERT et al. 2013, KRIDER/PUTLER 2013), Untersuchungen zur Funktionsweise von geplanten Einkaufszentren (z.B. Damian et al. 2011, Des Rosiers et al. 2009, TelleR/Elms 2010, TelLeR/ReutTereR 2008, TELLER/SCHNEDLITZ 2012) und Standortkooperationen (z.B. ESTEBAN-BRAVO et al. 2012, REN et al. 2011, ZHU et al. 2011) bis hin zu Studien, die - vorrangig oder

\footnotetext{
10 Diese räumlich ungleiche Entwicklung lässt sich unter anderem in den regionalisierten Einzelhandelsumsätzen ablesen, die durch das GfK-Institut jährlich ermittelt werden; hier zeigt sich, dass sowohl branchenspezifische (z.B. Bekleidung) als auch die branchenübergreifenden Gesamtumsätze in den größten Zentren kontinuierlich steigen, während kleinere Zentren an Bedeutung verlieren (z.B. GFK GEOMARKETING GMBH 2009, GFK SE 2012). Eine ähnliche Entwicklung lässt sich in der divergierenden Entwicklung von Mietpreisen für Geschäftsflächen zwischen großen und kleinen Zentren bzw. innerstädtischen A-, B- und C-Lagen feststellen (z.B. DEUTSCHE HYPO 2013, JONES LANG LASALLE 2011).
} 
nebensächlich - das damit verbundene Konsumentenverhalten fokussieren (z.B. LI/LIU 2012, POPKOWSKI LESZCZYC et al. 2004, VROEGRIJK et al. 2013).

Die Aktualität und Relevanz der Thematik wird noch dadurch unterstrichen, dass sich die Problematik der Einzelhandelsagglomerationen zudem indirekt in anderen (handels-) wissenschaftlichen Problemstellungen und Diskussionen widerspiegelt.

\subsubsection{Zugehörige Themenfelder}

\subsubsection{Nahversorgung}

In Bezug auf den Lebensmitteleinzelhandel wird der skizzierte Standortwandel insbesondere unter dem Aspekt der Nahversorgung diskutiert. Unter Nahversorgung wird die wohnortnahe Grundversorgung der Bevölkerung mit Gütern des kurzfristigen bzw. täglichen Bedarfs (insb. Nahrungsmittel) verstanden (KüHN 2011, S. 5). Die Konkretisierungen dessen sind vielseitig; häufig werden in Bezug auf eine „ausreichende“ Nahversorgung (d.h. aus einer normativen Perspektive) zwei unterschiedlich benannte, jedoch inhaltlich deckungsgleiche Dimensionen unterschieden (z.B. KRÜGER et al. 2013, S. 8; KÜHN 2011, S. 5f.):

- Quantitative bzw. räumliche Dimension: Das nahversorgungsrelevante Angebot muss in einer räumlichen Nähe zu den Verbrauchern verfügbar sein, die - zumindest theoretisch - einen fußläufigen Einkauf innerhalb einer kurzen Distanz bzw. Zeitspanne ermöglicht. Die Obergrenze fußläufiger Nahversorgung wird hierbei meist zwischen 500 und 1.000 Metern bzw. fünf bis zehn Gehminuten angesetzt

- Qualitative bzw. inhaltliche Dimension: Im Allgemeinen wird von einer qualitativ ausreichenden Nahversorgung gesprochen, wenn mehrere Betriebsformen des Lebensmitteleinzelhandels (z.B. Verbrauchermarkt, Discounter, Verkaufsstellen des Lebensmittelhandwerks) sowie weitere Einzelhandelsangebote (z.B. Drogeriemarkt) und Dienstleistungen (z.B. Bank, Post) für die Nachfrager verfügbar sind

Im deutschen Raumordnungsgesetz ist Nahversorgung als „Erreichbarkeit von Einrichtungen und Angeboten der Grundversorgung für alle Bevölkerungsgruppen“ in den Grundsätzen der Raumordnung verankert ( $\S 2$, Abs. 2, Satz 3 ROG). Auch wird Nahversorgung mittlerweile in der Landesraumordnung ausdrücklich genannt und einem verschieden definierten Schutz (insb. Lockerungen bei der Ansiedlung von nahversorgungsrelevanten Betrieben oberhalb der Großflächigkeit) unterstellt, z.B. in den Landesentwicklungsprogrammen Bayerns (LEP Bayern vom 01.09.2013, Abschnitte 5.3.1 u. 5.3.3), das zusätzlich nahversorgungsrelevante Sortimente (Nahrungs- und Genussmittel, Getränke) definiert, und Niedersachsens (LROP Niedersachsen vom 08.05.2008, Abschnitt 2.2) sowie im Einzelhandelserlass des Landes Nordrhein-Westfalen vom 22.09.2008 (Abschnitt 2.8).

Die Zielvorstellung einer wohnortnahen Grundversorgung wird vor dem Hintergrund der genannten Entwicklungen im Einzelhandel notwendigerweise tangiert bzw. in Frage gestellt; die räumliche Konzentration von Anbietern des Lebensmitteleinzelhandels ist hierbei von besonderer Bedeutung, da diese Branche den Kern des als "Nahversorgung“ definierten Angebotes ausmacht. Die Nahversorgungsproblematik betrifft insbesondere ältere kleine Einzelhandelsagglomerationen (z.B. Nachbarschaftszentren) und Angebotsstandorte in wohngebietsnahen Streulagen bzw. in ländlichen Ortschaften unterhalb einer bestimmten Grenze des lokalen Marktpotenzials (siehe Kap. 1.3.3). Es überrascht daher nicht, dass 
dieses Themenfeld in Deutschland Gegenstand handelswissenschaftlicher Untersuchungen unterschiedlicher Prägung ist (z.B. BAASER/ZEHNER 2014, BAUMGARTEN/ZEHNER 2007, BMVBS 2011, JÜRGENS 2012a,b u. 2013, KLEIN 2014, KÜHN 2011, KRÜGER et al. 2013, SCHENKHOFF/POHLE 2010; zu den „Forschungsfragen der Nahversorgung" siehe JÜRGENS 2014), bisweilen unter Fokus auf die ländlichen Räume (z.B. BMVBS 2013, IÖW 2005, STEINRÖX 2013, TREBBIN et al. 2013) und/oder im Hinblick auf die Bevölkerungsentwicklung im Kontext des demographischen Wandels (z.B. PREISSNER/KNOB 2006).

\subsubsection{Innerstädtische Einkaufszentren}

Von großer Relevanz ist die räumliche Angebotskonzentration ferner im Hinblick auf geplante Einkaufszentren. Die erste Generation dieser nach US-amerikanischem Vorbild künstlich geschaffenen Agglomerationen ist in Deutschland seit mehreren Jahrzehnten vor allem in dezentralen Lagen präsent; aufgrund restriktiverer Genehmigungspolitik verlagerte sich der Schwerpunkt von EKZ-Ansiedlungen ab den 1990er Jahren auf Innenstadtbereiche von Mittel- und vor allem Oberzentren (siehe Kap. 1.3.2 und 1.3.3). Vor diesem Hintergrund werden die Auswirkungen innerstädtischer oder innenstadtnaher Einkaufszentren untersucht und kontrovers diskutiert (z.B. BECKMANN et al. 2012, BRUNE et al. 2006, EPPLE/PETER 2010, HOPFINGER/SCHMIDT 2010, JUNKER/KÜHN 2009, KRÜGER/WALTHER 2007, LADEMANN 2011, MOSSIG/DORENKAMP 2008, STADERMANN/STOLZ 2012). Die empirischen Analysen bestehen sowohl in detailorientierten Fallstudien zu den Auswirkungen einzelner Einkaufszentren (z.B. MOSSIG/DORENKAMP 2008) über die Betrachtung mehrerer ausgewählter, ,repräsentativer“ Beispiele (z.B. JUNKER/KÜHN 2009) bis zu dem Versuch einer allgemeingültigen Betrachtung (LADEMANN 2011).

In der Debatte bestehen die Meinungsverschiedenheiten im Wesentlichen darüber, ob die geplanten Einkaufszentren den „gewachsenen“ innerstädtischen Angebotsstandorten nützen (in Form einer positiven Magnetfunktion) oder innen im Zusammenhang eines ruinösen, ungleichen Wettbewerbs mit den etablierten Anbietern schaden. Die diesbezüglichen Positionen polarisieren zwischen der Sichtweise eines „Angriff[s] auf die City“ (BRUNE et al. 2006) und einer tendenziell positiven Betonung der Agglomerationswirkung und einer damit verbundenen Aufwertung des gewachsenen Angebotsstandortes Innenstadt (z.B. LADEMANN 2011). Die Standpunkte werden hierbei vielfältig begründet und empirisch belegt (Eine Gegenüberstellung von Ergebnissen und Positionen geben z.B. BECKMANN et al. 2012 sowie StADERMANN/STOLZ 2012). Ausgehend von der Differenzierung verschiedener Typen von Angebotsstandorten (siehe Kap. 1.2.2) lässt sich der Kern der Debatte also dahingehend einordnen, dass sie auf die Fragestellung abzielt, ob geplante Einkaufszentren einen der Innenstadt gegenüber konkurrierenden Angebotsstandort darstellen oder ob sie sich derart in die Innenstadt einfügen, dass sie selbst Teil des Angebotsstandortes Innenstadt - und idealerweise dessen Magnetbetrieb - werden.

Parallel dazu wird die Beeinträchtigung der Attraktivität vieler Innenstädte durch den Verlust ihrer früheren Magnetbetriebe, der Warenhäuser, diskutiert. Die bereits seit den 1980er Jahren diskutierte „Krise der Warenhäuser“ (z.B. KLEIN 1997) gipfelte Ende der 2000er Jahre durch die Insolvenz mehrerer Warenhausfilialisten und stellt insbesondere viele klein- und mittelzentrale Innenstädte vor große Probleme (z.B. HANGEBRUCH 2012). 


\subsubsection{Einzelhandelsagglomerationen in der räumlichen Planung}

In der räumlichen Planung werden geplante Einkaufszentren seit den 1970er Jahren durch ihre ausdrückliche Nennung in $\S 11$ BauNVO berücksichtigt; jedoch werden in der planerischjuristischen Diskussion zur Steuerung des Einzelhandels durch die Raumordnung und die Bauleitplanung seit einigen Jahren verstärkt auch nicht zentral gelenkte Agglomerationen thematisiert. Dies ist eine Reaktion auf die steigende Zahl von Standortkooperationen, insbesondere wenn es sich um eine Ballung von mehreren Betrieben handelt, die - einzeln betrachtet - keinen großflächigen Einzelhandel darstellen und dementsprechend nicht der Vermutungsregel (siehe Kap. 1.3.2) unterliegen, jedoch faktisch als Funktionseinheit auftreten (zur rechtswissenschaftlichen Diskussion siehe z.B. HARTMANN 2013, JANNING 2012, UECHTRITZ 2010). Die Frage, ob und wenn ja in welcher Weise benachbarte Einzelhandelsbetriebe als Agglomeration anzusehen sind, ist Gegenstand juristischer Auseinandersetzungen und daraus resultierender teilweise gegensätzlicher Gerichtsurteile.

Nach gültiger Rechtsprechung stellt eine reine räumliche Ballung von mehreren voneinander unabhängigen Einzelhandelsbetrieben kein Einkaufszentrum im Sinne von BauNVO §11 dar, da für diese Definition ein Mindestmaß an abgestimmter Planung und gemeinsamem Auftreten erforderlich ist (BVerwG Az. 4 C 16.87, 27.04.1990). Im Jahr 2005 urteilte zudem das Bundesverwaltungsgericht, dass benachbarte Einzelhandelsbetriebe nicht als eine funktionale Einheit zu einem großflächigen Betrieb im Sinne der Vermutungsregel „addiert“ werden können (BVerwG Az. 4 C 8.05, 24.11.2005). Zu einer gegenteiligen Auffassung kam der Verwaltungsgerichtshof Baden-Württemberg im Jahr 2007 (VGH Baden-Württemberg Az. 3 S 2875/06, 27.09.2007), der in einem späteren Urteil eine Agglomerationsregelung in Regionalplänen als rechtens anerkannte (VGH Baden-Württemberg Az. 3 S 324/08, 21.09.2010). Dieser Rechtsspruch wurde, anders als im früheren Urteil, durch das Bundesverwaltungsgericht später bestätigt (BVerwG Az. 4 CN 9.10, 10.11.2011).

Der in diesem Sinne auf ungeplante Ballungen selbständiger Anbieter bezogene Begriff der Einzelhandelsagglomerationen und damit verbundene Regelungen haben mittlerweile vereinzelt Einzug in die Landesraumordnung gefunden: Erstmalig wurde eine diesbezügliche Formulierung im Einzelhandelserlass des Landes Nordrhein-Westfalen vom 22.09.2008, der das Landesraumordnungsprogramm (LEPro NRW) ergänzt, eingeführt; die Vorschriften beziehen sich allerdings nur auf die Möglichkeit einer Beschränkung der Ansiedlung mehrerer agglomerierter Betriebe im Rahmen der Bauleitplanung (Abschnitt 2.7.3 bzw. 3.1.3). Wesentlich konkreter geht mittlerweile die bayerische Landesraumordnung vor: Seit der letzten Novellierung des Landesentwicklungsprogramms (LEP Bayern vom 01.09.2013) werden neben einzelnen großflächigen Einzelhandelsbetrieben (im Sinne von § 11 BauNVO) auch Agglomerationen zu den landesplanerisch regulierten „Einzelhandelsgroßprojekten“ gezählt, die in der Folge denselben Vorschriften unterliegen; das LEP Bayern definiert für derartige Ansiedlungen bzw. Erweiterungen ein eigenes Maß zur Verträglichkeitsbeurteilung in Form von maximal zulässigen Kaufkraftabschöpfungsquoten (Abschnitt 5.3 bzw. 5.3.3). Derartige Regelungen existieren z.B. in der Landesraumordnung Niedersachsens noch nicht.

Die Überführung in Bundesrecht im Sinne einer Ausweitung der Vermutungsregel auf Einzelhandelsagglomerationen dieses Typs wurde im Zuge der Novelle der BauNVO im Jahr 2013 durch den Bundesrat gefordert (BR-Drucksache 474/12 B, 21.09.2012, Nr. 23), jedoch nicht umgesetzt. Es lässt sich aus diesen Entwicklungen der letzten Jahre allerdings der Schluss ziehen, dass die kleinräumliche Ballung von Einzelhandelsangebot zukünftig in der 
Planung einen höheren Stellenwert bekommt und perspektivisch auch standardmäßig in Verträglichkeitsgutachten einfließen könnte.

\subsubsection{Fragestellungen der Arbeit}

Offensichtlich bilden Einzelhandelsagglomerationen nicht nur einen zentralen Aspekt der räumlichen Einzelhandelsentwicklung, sondern sie sind auch Gegenstand der Diskussion verschiedener aktueller Problemfelder in der Einzelhandelsforschung und der räumlichen Planung. Es stellt sich vor diesem Hintergrund die Frage, ob räumlich geballtes Angebot für Konsumenten überhaupt attraktiv ist; schließlich geht die räumliche Konzentration von Betrieben notwendigerweise mit einem dünneren Verkaufsstellennetz und somit längeren Wegstrecken einher, die bei Einkäufen zurückgelegt werden müssen, als dies bei gleichmäßig(er) verteilten, ggf. nicht agglomerierten Anbietern der Fall ist. Diese Frage stellt sich vor allem im Hinblick auf das Kundenverhalten beim Einkauf von Lebensmitteln und anderen Gütern des täglichen bzw. kurzfristigen Bedarfs, da in der Steuerung der räumlichen Einzelhandelsentwicklung normative Zielvorstellungen von Nahversorgung postuliert werden (siehe Kap. 1.4.2.1).

Im ersten Schritt zur Beantwortung dieser Frage muss das räumliche Einkaufsverhalten der Haushalte betrachtet werden: Es wird häufig ausgesagt, dass das Kundenverhalten verstärkt durch ein knapperes Zeitbudget für Einkäufe und einen gleichzeitig steigenden Anspruch geprägt ist (siehe Kap. 1.3.1), woraus sich schließen lässt, dass sich dies (auch) in der räumlichen Einkaufsorientierung niederschlägt. Diese Überlegung führt unweigerlich zu den Einkaufsstrategien der Kopplungs- und Vergleichskäufe bzw. deren räumliche Ausprägung in Form von räumlich und/oder sachlich multifinalen Einkäufen (siehe Kap. 1.2.2). Wenn jene Einkaufsstrategien relevant sind, dann spricht dies für die Wahl eines Angebotsstandortes, der möglichst viel Potenzial für Kopplungs- und Vergleichskäufe bietet, was die kundenseitige Bevorzugung von Einzelhandelsagglomerationen erklären würde; Einzelhandelsbetriebe, die sich an Angebotsstandorten mit anderen Anbietern befinden, müssten demnach höhere Kundenzuflüsse aus ihrem Marktgebiet generieren können als andere Anbieter außerhalb von Agglomerationen (Streulagen) oder mit geringerem Potenzial für Kopplungs- und Vergleichskäufe. Dieser Fragestellung kann nur anhand einer empirischen Untersuchung auf der Basis theoretischer Fundamente nachgegangen werden.

Weiterhin wirft dieses Problem die Frage auf, wie ein solches (mögliches) Verhalten überhaupt empirisch zugänglich ist bzw. dessen Auswirkungen „messbar“ gemacht werden können; die oben skizzierte Diskussion zur Berücksichtigung von Agglomerationen bei raumordnerischen und städtebaulichen Belangen lässt den Schluss zu, dass eine solche Methode zur Prognose von Kaufkraft-/Umsatzumlenkungen zukünftig im Kontext von Einzelhandelskonzepten und vor allem Verträglichkeitsgutachten notwendig werden könnte. Fragen der Zulässigkeit von Ansiedlungen ergeben sich einerseits vor dem Hintergrund der Nahversorgung, andererseits im Hinblick auf die immer zahlreicher werdenden (innerstädtischen bzw. innenstadtnahen) Einkaufszentren.

Die vorliegende Forschungsarbeit hat auf Grundlage dieser Überlegungen also zwei Fragestellungen, wobei die erste inhaltlicher und die zweite methodologischer Natur sind:

1. Haben Einzelhandelsagglomerationen eine positive Wirkung auf den Kundenzufluss? D.h. können Anbieter, die sich an Angebotsstandorten 


\section{gemeinsam mit anderen (branchengleichen und/oder -ungleichen) Anbietern befinden, größere Zuflüsse aus ihrem Marktgebiet generieren als ihre Konkurrenten, die sich in Streulagen oder weniger agglomerierten Lagen befinden? (Inhaltliches Ziel)}

2. Wie sind ein solches Einkaufsverhalten bzw. die daraus resultierenden Kundenflüsse aus den Marktgebieten empirisch fassbar und im Kontext der Standortanalyse methodisch umsetzbar? (Methodologisches Ziel)

\subsection{Aufbau der Arbeit}

Die Beantwortung der aufgestellten Fragen erfolgt in mehreren Schritten und leitet hierbei von einer theoretischen in eine empirische Perspektive über, woran sich der Aufbau der Arbeit orientiert. Die vorliegende Forschungsarbeit gliedert sich grob in einen theoretischen Teil (Kapitel 2, 3 und 4), der die theorie- und modellbezogenen Ansätze zu Marktgebieten im Einzelhandel unter Berücksichtigung von Agglomerationseffekten sowie themenrelevante empirische Arbeiten darstellt und diskutiert, und einen praktischen Teil (Kapitel 5, 6 und 7), in dem die Konzeption der eigenen empirischen Primärstudie diskutiert und ihre Durchführung und Ergebnisse dokumentiert und interpretiert werden.

Im folgenden Kapitel (Kapitel 2) werden die ökonomischen und wirtschaftsgeographischen Theorien dargestellt und diskutiert, die für die vorliegende Forschungsfrage relevant sind; es handelt sich hierbei um verschiedene Ansätze aus den Bereichen der „klassischen“ Raumwirtschafts- und Standorttheorien des tertiären Sektors (u.a. CHRISTALLER 1933), der Mikroökonomie, der empirisch-induktiven Standortforschung und des betriebswirtschaftlichen Marketings. Ziel des Kapitels ist es, die Aussagen dieser sehr heterogenen Ansätze zur Existenz und Bildung von Einzelhandelsagglomerationen und dem damit verknüpften räumlichen Kundenverhalten herauszuarbeiten.

Kapitel 3 beschäftigt sich mit verschiedenen Formen der Modellierung von Marktgebieten im Einzelhandel. Da diese Modelle sowohl inhaltlich-theoretisch formuliert als auch konkret methodisch anwendbar sind, bildet dieses Kapitel eine Schnittstelle zwischen den theoretischen Grundlagen und dem empirischen Vorgehen der eigenen Forschungsarbeit; im Vordergrund stehen dabei die Fragen, welche Modelle sich für eine empirische Analyse des räumlichen Einkaufsverhaltens eignen und inwieweit es möglich ist, Kopplungs- und Vergleichskäufe bzw. Agglomerationseffekte in diese Ansätze zu integrieren. Das Ziel des Kapitels ist die Identifikation eines Modellansatzes, der im Rahmen des eigenen empirischen Vorgehens die Verbindung beider Aufgaben ermöglicht.

Kapitel 4 stellt verschiedene nachfrage- und angebotsbezogene empirische Arbeiten vor und gibt in Bezug auf die Fragestellungen dieser Arbeit einen Überblick über den aktuellen Stand der Forschung zu (positiven) Agglomerationseffekten im Einzelhandel. Ziel der Diskussion der empirischen Befunde ist es aufzuzeigen, welche Aspekte des hier untersuchten Zusammenhangs bereits bearbeitet wurden, wie dies geschehen ist und in welcher Hinsicht noch Forschungsbedarf besteht. Ferner sollen die Arbeiten zum Aufbau des eigenen Untersuchungsdesigns beitragen.

Im ersten Kapitel des praktischen Teils (Kapitel 5) wird auf der Grundlage der Theorien, der Marktgebietsmodelle und der Empirie zu Agglomerationseffekten im Einzelhandel der 
Untersuchungsgegenstand dieser Arbeit genauer dargestellt und das methodische Vorgehen erläutert. In diesem Kapitel werden zunächst der theoretische Rahmen zusammengefasst und darauf aufbauend die Untersuchungshypothesen abgeleitet. Im Anschluss wird schrittweise die empirisch-analytische Umsetzung der eigenen Untersuchung besprochen (Untersuchungsgebiet, Datenerhebung und -weiterverarbeitung, Formen der Auswertung, Schema der Interpretation).

Kapitel 6 beinhaltet zunächst die Darstellung der Ergebnisse der eigenen empirischen Arbeit, wobei dies schrittweise entlang der tatsächlichen Bearbeitungsreihenfolge geschieht; dies ist notwendig, um die verschiedenen Arbeitsschritte des empirischen Teils nachzuvollziehen. Einzelne Schritte werden hierbei anhand von Beispielen illustriert, die Kernergebnisse daraufhin vollständig dargestellt. Die Interpretation und Diskussion der Ergebnisse ist strikt von der Darstellung getrennt und erfolgt erst im darauf folgenden Kapitel. Es ist an dieser Stelle darauf hinzuweisen, dass Zwischen- und Teilergebnisse dieser Untersuchung bereits im Rahmen zweier Aufsätze veröffentlicht wurden (WIELAND 2012 u. 2013).

In Kapitel 7 werden die Ergebnisse unter Rückgriff auf die theoretischen Grundlagen inhaltlich diskutiert und bewertet, wobei zunächst die Untersuchungshypothesen überprüft und dann einzelne, branchenspezifische Aspekte beleuchtet werden; daran schließt sich eine kurze Besprechung zu den praktischen Implikationen der Ergebnisse an. Im zweiten Abschnitt des Kapitels erfolgen verschiedene Verfahren zur weiteren Plausibilisierung der Ergebnisse sowie eine konkrete Anwendung. Im letzten Abschnitt dieses Kapitels wird eine kritische Reflexion der eigenen Arbeit im Hinblick auf theoretische und methodische Einschränkungen und Fehlerquellen vorgenommen sowie kurz der diesbezügliche weitere Forschungsbedarf besprochen.

Die Arbeit schließt mit einem Fazit (Kapitel 8) ab. Verschiedene ergänzende Informationen (z.B. Ergebnistabellen der eigenen Analysen, Daten zum Untersuchungsgebiet) sind aus Gründen der Übersichtlichkeit des Haupttextes im Anhang abgelegt. 


\section{Theoretische Grundlagen}

In diesem Kapitel werden verschiedene Ansätze der (wirtschaftsgeographischen und regionalökonomischen) Standorttheorie, der Mikroökonomie und des Marketings besprochen, die aus sehr unterschiedlichen Blickpunkten das Konsumenten- und Anbieterverhalten im Einzelhandel behandeln. Ziel des Kapitels ist es, die Aussagen dieser sehr heterogenen Ansätze zur Existenz und Bildung von Einzelhandelsagglomerationen und dem damit verknüpften räumlichen Konsumentenverhalten herauszuarbeiten.

\subsection{Grundsätzliche Anmerkungen}

\subsubsection{Zu den Standorttheorien des Einzelhandels}

Eine Reihe von sehr unterschiedlichen theoretischen Ansätzen behandeln das räumliche Einkaufsverhalten und die Standortpolitik im (stationären) Einzelhandel; abstrahiert gesagt treffen sie Aussagen zu nachfrage- und angebotsseitigen Aspekten im Markt dieses Wirtschaftszweigs unter ausdrücklicher Berücksichtigung einer räumlichen Perspektive. Ein Markt besteht aus (potenziellen) Verkäufern (Anbieter) und Käufern (Nachfrager) eines Gutes; ihr Zusammenspiel macht den Markt i.e.S. aus und bestimmt unter Berücksichtigung weiterer Aspekte die Preise (MANKIW 2004, S. 67f.). Diese Vorstellung eines Marktes berücksichtigt zunächst keine räumlichen (oder zeitlichen) Komponenten. Da im (stationären) Einzelhandel eine Markttransaktion jedoch die räumliche Mobilität der Nachfrager zum Erreichen der Anbieter voraussetzt, liegt ein räumlicher Markt vor (SCHÖLER 2005, S. 59f.). Dieser erweitert die o.g. Marktvorstellung um eine oder mehrere räumliche Komponenten, z.B. Faktormobilität, differenzierte Bodenpreise, die Ballung von Wirtschaftsaktivitäten etc.; in jedem Fall wird aber der Tatsache Rechnung getragen, dass der Austausch von Gütern notwendigerweise über eine (räumliche) Distanz erfolgt und dass diese Raumüberwindung Kosten (Transportkosten) verursacht (DICKEN/LLOYD 1999, S. 23ff.; SCHÖLER 2005, S. 2ff.).

Der Begriff Kosten umfasst hier nicht (nur) geldliche Ausgaben (z.B. Preis einer Tüte Milch oder einer ÖPNV-Fahrkarte), sondern ist am ehesten mit „Gesamtaufwand“ zu übersetzen bzw. wie in den „Zehn volkswirtschaftlichen Regeln“ nach MANKIW (2004, S. 6) definiert wird: „Die Kosten eines Gutes bestehen aus dem, was man für den Erwerb eines Gutes aufgibt". Hierzu zählt beispielsweise auch der Zeitaufwand im Hinblick auf andere mögliche Aktivitäten, der sich in den Opportunitätskosten niederschlägt; diese bestehen in all dem, was ein Marktteilnehmer aufgibt (entgangener Nutzen), wenn er eine Aktivität (z.B. Einkauf) anstatt von anderen (z.B. Kinobesuch) ausführt (RoGALL 2013, S. 44f.). Transportkosten bestehen demnach aus der Summe aller Teilaufwände (z.B. Geldausgabe, Zeitverlust), die für den Transport eines Gutes von einem Ort zu einem anderen Ort notwendig sind (SCHÖLER 2005, S. 49). Einige Ansätze berücksichtigen zudem weitere mit Einkäufen verbundene Formen von Transaktionskosten ${ }^{11}$, darunter z.B. Suchkosten; diese resultieren

\footnotetext{
${ }^{11}$ Nach RoGaLl (2013, S. 45) zählen Transport- und Übergabekosten sowie Kosten der Informationsbeschaffung zu den Transaktionskosten; dieser Begriff umfasst alle bei Marktaustauschprozessen anfallenden Kosten. Zu den Transaktionskosten bei Einkäufen zählt BECK (2004, S. 91ff.) u.a. Transport-, Opportunitäts- und Informationskosten (im Sinne der Transaktionskostentheorie Anbahnungskosten), Informationsbeschaffung am Angebotsstandort und Wartezeit (Vereinbarungskosten) sowie die (mangelnde) Verfügbarkeit von Produkten und das (möglicherweise notwendige) Aufsuchen einer anderen Einkaufsstätte (Kontroll-/Anpassungskosten).
} 
aus Informationsmängeln der Nachfrager und umfassen den Aufwand, der betrieben werden muss, um ein gewünschtes Gut bzw. einen gewünschten Anbieter zu finden (WIEDNEBBELING/SCHOTT 2005, S. 300ff.). Dieser Kostenbegriff ist also sehr weitreichend.

Von Relevanz für diese Arbeit und daher in diesem Kapitel besprochen werden die Theorie der zentralen Orte von CHRISTALLER (1933) und die Theorie der Wirtschaftsgebiete von LÖSCH (1944) ${ }^{12}$ sowie mit der Wachstumstheorie zentralörtlicher Systeme von LANGE (1973) eine dynamische Weiterentwicklung der Zentralitätstheorien. Zudem werden zwei klassische Ansätze zur räumlichen Ballung im Einzelhandel besprochen (HOTELLING 1929, NELSON 1958). Die genannten Werke werden in den meisten sachrelevanten Publikationen (z.B. BROWN 1993, S. 186ff.; DAMIAN et al. 2011, S. 458ff.; EPPLI/BENJAMIN 1994, S. 6ff.; KULKE 2009, S. 157ff.) zum Kern der Standorttheorie des Einzelhandels gezählt.

Ergänzend werden noch Arbeiten aus der Mikroökonomie behandelt: Die Theorie des monopolistischen Wettbewerbs (CHAMBERLIN 1933) bildet eine wichtige Basis für viele der o.g. Standorttheorien (KLEIN 2005, S. 340f.), andererseits beinhaltet sie selbst räumliche Aspekte; einige ihrer Erweiterungen stellen zudem räumliches Einkaufsverhalten sowie die Standortwahl von Anbietern in den Mittelpunkt (z.B. WOLINSKY 1983). Der monopolistische Wettbewerb ist ferner eine der Grundlagen der New Economic Geography (NEG) (z.B. FUJITA/THISSE 2002, TABUCHI/THISSE 2011), in deren Rahmen ebenso Modelle zu den hier im Fokus stehenden Inhalten entwickelt wurden, weshalb deren Ansatz ebenso behandelt wird. Wie in diesem Kapitel aufgezeigt wird, stellen diese Arbeiten jedoch keine inhaltlichen Neuerungen für die vorliegende Forschungsfrage dar; die „alten“ Theorien erweisen sich hingegen als inhaltlich höchst relevant und aktuell. Wirkliche inhaltliche Weiterentwicklungen stellen demgegenüber verschiedene Arbeiten aus der verhaltenswissenschaftlichen Marketing-Forschung dar, die daher ebenso berücksichtigt werden (z.B. POPKOWSKI LESZCZYC et al. 2004, VROEGRIJK et al. 2013). Die Theorien werden im Hinblick auf ihre Aussagen zur Existenz und Entwicklung von Einzelhandelsagglomerationen im Kontext des Konsumentenverhaltens besprochen. Zunächst wird aber das theoretische Konzept der Agglomerationseffekte im Allgemeinen und bezogen auf den Einzelhandel vorgestellt.

\subsubsection{Agglomerationseffekte im Einzelhandel}

Das Konzept der Agglomerationseffekte (Agglomeration economies) wurde erstmals in den Theorien der neoklassischen Ökonomie ${ }^{13}$ zur Standortwahl von Industriebetrieben formuliert. Agglomerationseffekte sind (unternehmens-)interne und (unternehmens-)externe Effekte, die aufgrund räumlicher Ballung auftreten und sich positiv (Agglomerationsvorteile) oder negativ (Agglomerationsnachteile) auf den betriebswirtschaftlichen Erfolg von Unternehmen auswirken. Sie sind als wesentlicher Grundgedanke der Wirtschaftsgeographie und der Regionalökonomie eine maßgebliche Erklärung für die räumliche Organisation ökonomischer

\footnotetext{
${ }^{12}$ In der Sekundärliteratur wird teilweise vermerkt bzw. kritisiert, dass die Theorien von CHRISTALLER und LÖSCH keine Agglomerationseffekte berücksichtigen würden (z.B. BATHELT/GLÜCKLER 2012, S. 137; LIEFNER/SCHÄTZL 2012, S. 53f.; MAIER/TÖDTLING 2006, S. 147f.); demnach müssten sie keine Relevanz für die Forschungsfrage dieser Arbeit besitzen. Wie jedoch in diesem Kapitel aufgezeigt wird, ist dies unzutreffend.

${ }^{13}$ Die Denkschule der Neoklassik, die in der Mikroökonomie dominiert, zeichnet sich durch ein angenommenes Optimierungsverhalten der wirtschaftlichen Akteure bei vollständiger Marktübersicht („rationales“ Verhalten) sowie vollkommenen Wettbewerb und eine Nichtberücksichtigung kultureller/politischer Einflüsse aus (MAIER/TÖDTLING 2006, S. 24f.; SöLLNER 2012, S. 43f.; Kritischer Überblick siehe vON FRIELING 2008).
} 
Betätigung (PARR 2002b, S. 151f.). Diejenigen (ökonomischen) „Kräfte“, die eine Ballung wirtschaftlicher Aktivitäten begünstigen, werden als zentripetale Kräfte bezeichnet; ihr Gegenstück sind die zentrifugalen Kräfte, die für eine Dispersion wirtschaftlicher Aktivitäten sorgen. Erstere begründen die räumlich ungleiche Verteilung von Wirtschaftsaktivitäten bzw. die damit zusammenhängenden unterschiedlichen Entwicklungsmöglichkeiten (Räumliche Disparitäten) auf verschiedenen regionalen Maßstabsebenen (FUJITA/THISSE 2000, S. 3f.). Der räumliche Aggregationsgrad kann hierbei sehr unterschiedlich sein, je nachdem welches Verständnis von (geographischer) „Nähe“ zu Grunde gelegt wird (PARR 2002a, S. 727ff.).

Im Allgemeinen werden (mindestens) drei verschiedene Typen von Agglomerationsvorteilen identifiziert (MULLIGAN et al. 2012, S. 411f.; PARR 2002b, S. 153ff.):

- Steigende Skalenerträge (Economies of scale) als unternehmensinterner Effekt: Senkung der Produktionskosten je Produktionseinheit durch Ausweitung der Produktion (Fixkostendegression). Diese Kostensenkung kann durch eine räumliche Konzentration der Produktion an einem oder wenigen Orten realisiert werden

und als unternehmensexterne Effekte:

- Lokalisierungseffekte (Localization economies): Betriebswirtschaftliche Vorteile durch die räumliche Ballung gleichartiger Betriebe. Der Anreiz zur Bildung von Agglomerationen gleichartiger bzw. konkurrierender Betriebe hat seinen Hintergrund u.a. in der Verfügbarkeit eines spezialisierten Arbeitskräftereservoirs (Labor pooling), eines abgestimmten lokalen Angebotes an unternehmensorientierten (z.B. Wartung, Reparatur) und anderen Dienstleistungen (z.B. Banken) sowie der Möglichkeit zum Wissensaustausch über Produkt- und Prozessinnovationen (Knowledge spillovers)

- Urbanisierungseffekte (Urbanization economies): Betriebswirtschaftliche Vorteile aufgrund der räumlichen Ballung verschiedenartiger Betriebe, die nicht zwingend miteinander in Verbindung stehen. Diese Effekte werden häufig als Erklärung für die räumliche Konzentration von Wirtschaftsaktivitäten in Städten herangezogen; sie beziehen sich auf die Verfügbarkeit von einer breiten Auswahl allgemeiner öffentlicher (z.B. Verwaltung, Verkehr) und privatwirtschaftlicher Dienstleistungen (z.B. Einzelhandel), die als positive Standortfaktoren fungieren

Agglomerationsnachteile interner Art liegen demnach z.B. vor, wenn die durchschnittlichen Produktionskosten bei einer Produktionsausweitung steigen (sinkende Skalenerträge). Ein populäres Beispiel für unternehmensexterne Agglomerationsnachteile sind insbesondere steigende Bodenpreise in Agglomerationen verschiedenen Maßstabs (PARR 2002a, S. 728). $\mathrm{Da}$ im vorliegenden Fall die Agglomerationsvorteile im Vordergrund stehen, werden bezüglich des Einzelhandels im Folgenden nur diese behandelt.

Im Einzelhandel „wirken“ verschiedene Formen interner und externer Agglomerationsvorteile, welche die unternehmerische Standortpolitik beeinflussen (können); die externen Agglomerationsvorteile lassen sich in konsumenten- und unternehmensseitige Faktoren untergliedern (DES Rosiers et al. 2009, S. 166ff.; KRIDER/PUTLER 2013, S. 125ff.):

- Konsumentenseitige Faktoren beziehen sich v.a. auf eine Erhöhung des Nutzens der Konsumenten im Hinblick auf deren Ansprüche hinsichtlich Auswahl, Preisen usw.

- Unternehmensseitige Faktoren können beispielsweise in einer Risikominderung in der Standortentscheidung oder der gemeinsamen Nutzung von Infrastruktur liegen 
Neben einer Reihe von Faktoren, die auch gänzlich andere Branchen betreffen (können), werden vor allem zwei nachfrageseitige externe Effekte für die Agglomeration von Einzelhandelsanbietern als besonders relevant identifiziert (MULLIGAN et al. 2012, S. 412; POPKOWSKI LESZCZYC et al. 2004, S. 86f.):

- Die Ermöglichung von Kopplungskäufen (Multi-purpose shopping): Die Konsumenten haben an Angebotsstandorten mit mehreren branchenungleichen Anbietern die Möglichkeit, den Einkauf verschiedener Güter miteinander zu verbinden (sachlich und räumlich multifinale Einkäufe); sie senken dadurch ihren Aufwand (z.B. Fahrtkosten, Fahrtzeit), da sie mehrere Besorgungen im Rahmen eines Einkaufs erledigen können (Reduzierung der Transportkosten). Die betriebswirtschaftlichen Vorteile durch die Möglichkeit von Kopplungskäufen lassen sich als Urbanisierungseffekte interpretieren

- Die Ermöglichung von Vergleichskäufen (Comparison shopping): Die Konsumenten haben an Angebotsstandorten mit mehreren gleichartigen bzw. konkurrierenden Anbietern die Möglichkeit, Preis- und Qualitätsvergleiche durchzuführen; hierdurch ist es möglich, den Suchaufwand zu senken (Reduzierung der Suchkosten) und einen besseren Überblick über das Angebot zu bekommen (Reduzierung der Informationsbeschaffungskosten). Der betriebswirtschaftliche Anreiz zur Ballung kompetitiver Anbieter lässt sich dementsprechend als Lokalisierungseffekt deuten

Beide konsumentenseitigen externen Agglomerationseffekte ${ }^{14}$ wirken sich dahingehend auf die Einkaufsstättenwahl aus, dass agglomerierte Standorte gegenüber solitär gelegenen Einkaufsstätten von Konsumenten bevorzugt werden, auch wenn sie deutlich weiter entfernt liegen. Demnach ist es für Einzelhandelsanbieter tendenziell vorteilhaft, sich in unmittelbarer räumlicher Nähe zu gleichartigen bzw. konkurrierenden und ungleichartigen Anbietern anzusiedeln, um auf der Basis einer gemeinsamen Anziehungskraft das eigene Marktgebiet zu erweitern (POPKOWSKI LESZCZYC et al. 2004, S. 87; TELLER/ELMS 2010, S. 25f.). Diese Agglomerationsvorteile liegen also vorrangig in der Reduktion verschiedener Arten von Transaktionskosten der Konsumenten (insb. Transport- und Suchkosten) begründet. Die hier vorgestellten theoretischen Grundlagen behandeln diesen Aspekt allesamt, jedoch mit z.T. völlig anderer Begründung bzw. Herleitung. Die o.g. Abgrenzung von Kopplungs- und Vergleichskäufen wird in den folgenden Kapiteln noch erweitert.

\subsection{Mikroökonomische Ansätze mit Raumbezug}

\subsubsection{Die Theorie des monopolistischen Wettbewerbs von CHAMBERLIN}

\subsubsection{Grundlagen der Theorie}

Ideengeschichtlich entstammt die Theorie des monopolistischen Wettbewerbs (auch: Theorie der monopolistischen Konkurrenz) von CHAMBERLIN (1933) einer grundsätzlichen Kritik an den neoklassischen Marktmodellen mit ihrer inhärenten Annahme eines vollkommenen

\footnotetext{
${ }^{14}$ Unternehmensinterne Effekte in Form von steigenden Skalenerträgen können ebenso konsumentenseitig sein, z.B. wenn einzelne Anbieter Sortiments- bzw. Verkaufsflächenerweiterungen vornehmen und so ihre internen Kopplungs- und Vergleichsmöglichkeiten ausbauen. Weitere einzelhandelsbezogene Beispiele hierfür sind Kosteneinsparungen wegen größerer Abnahmemengen bei den Lieferanten, die wiederum in Form geringerer Preise an die Kunden weiter gegeben werden (können), und geringere Personalkosten (GuY et al. 2005, S. 73ff.).
} 
Wettbewerbs, in dem monopolistische Strukturen durch die anbieterseitige Einflussnahme auf Produktionsmenge und Preis nur als außerökonomische Verzerrung betrachtet werden; sie bildete den Ausgangspunkt einer der wesentlichen Gegenströmungen zur traditionellen Mikroökonomie (ROTHSCHILD 1981, S. 17ff.). Der Theorie liegen die Überlegungen zugrunde, dass einerseits das traditionelle Marktmodell des vollkommenen Marktes unrealistisch ist und andererseits reine Monopolstellungen von Anbietern sehr selten sind; demnach müsse ein realistischeres Marktmodell beide Aspekte berücksichtigen (CHAMBERLIN 1933, S. vii u. 3ff.).

Ein vollkommener Markt, der das vereinfachende Grundmodell der Mikroökonomie bildet, ist wie folgt charakterisiert (MANKIW 2004, S. 70ff.; KLEIN 2005, S. 337f.):

- Es stehen sich zahlreiche Anbieter und Nachfrager gegenüber (Polypo/). Alle Marktteilnehmer verhalten sich ökonomisch „optimal“, was ein vollständig rationales Verhalten bedeutet, d.h. das zu Grunde gelegte Menschenbild ist der homo oeconomicus. Dieses Verhalten ist gekennzeichnet durch Nutzenmaximierung, was im Fall der Anbieter von Gütern Gewinnmaximierung bedeutet, und vollständige Information, d.h. uneingeschränkte Markttransparenz. Jeder Marktteilnehmer ist also über alle inm offenstehenden Alternativen informiert und kann den Erfolg jeder Entscheidung voraussehen; er ist also in der Lage, diejenige Alternative auszuwählen, die den größten Nutzen stiftet und entscheidet sich auch stets für diese

- Die Bedürfnisse und Präferenzen der Nachfrager sind identisch, ebenso gibt es keinerlei Unterschiede in den angebotenen Gütern (Homogene Güter). Auch räumliche und zeitliche Faktoren werden ausgeblendet, d.h. es herrscht ein Punktmarkt ohne Transportkosten oder zeitliche Verzögerungen der Marktreaktionen

- Gemäß dem Verhaltenspostulat der Nutzenmaximierung möchten die Nachfrager möglichst viele Güter zu einem niedrigen Preis erwerben, die Anbieter möglichst viele Güter zu einem hohen Preis absetzen. Anbieter und Nachfrager treffen aufeinander, wobei sich durch Anpassungsprozesse der Angebots- und Nachfragemenge ein Gleichgewicht ${ }^{15}$ zwischen Angebot und Nachfrage einstellt, d.h. die nachgefragte Menge entspricht der angebotenen Menge (Marktgleichgewicht); hierbei bildet sich ein einziger, für den betrachteten Markt allgemeingültiger Verkaufspreis heraus (Gleichgewichtspreis). Einzelne Anbieter haben keinen Einfluss auf diesen Preis, da er ein reines Wettbewerbsergebnis darstellt; fordert ein Anbieter einen höheren Preis, kann er seine Güter nicht mehr absetzen, da die Nachfrager keinerlei Preiserhöhung akzeptieren (die Nachfrage ist also vollkommen elastisch) und aufgrund ihrer völligen Markttransparenz und der Homogenität der Güter einfach einen anderen Anbieter aufsuchen können. Die Anbieter erwirtschaften im Gleichgewicht keine Gewinne

\footnotetext{
${ }^{15}$ Beim ökonomischen Begriff des Gleichgewichts handelt es sich um eine Situation, in der sich - unter Berücksichtigung der jeweiligen Grundannahmen des Marktmodells (z.B. Informationsgrad der Marktteilnehmer, Budgetbeschränkung, anfallende Kosten etc.) - alle beteiligten Einflussfaktoren gegenseitig ausgleichen und kein Marktteilnehmer mehr einen Anlass hat, sein Verhalten zu ändern (VARIAN 2007, S. 3f. u. 9). Im Fall des Marktgleichgewichts bedeutet dies, dass sich eine Situation verfestigt, in der die Angebotsmenge der Nachfrage entspricht, d.h. alle Nachfrager ihr gewünschtes Gut beziehen und alle Anbieter alle ihre produzierten Güter verkaufen. Ein Gleichgewicht ist in ökonomischen Modellen zumeist ein mathematisches Ergebnis, das nur vor dem Hintergrund der getätigten (Verhaltens-)Annahmen bzw. der im Modell berücksichtigten Faktoren einen „optimalen" Charakter aufweist; es handelt sich dabei um einen wertneutralen Begriff und ist nicht in moralischer bzw. sozialer Hinsicht als „Ausgleich“ oder gar „Gleichverteilung“ zu interpretieren (ROTHSCHILD 1981, S. 4f.).
} 
Wenn mindestens eine der Annahmen des vollkommenen Marktes (z.B. vollständige Information, homogene Güter) nicht erfüllt ist, handelt es sich um einen unvollkommenen Markt (ENGELKAMP/SELL 2013, S. 116f.); ein solcher wird durch das Marktmodell der monopolistischen Konkurrenz dargestellt. Die Ausgangsidee von CHAMBERLIN (1933, S. 56ff.) ist, dass, entgegen der Annahmen zum vollkommenen Wettbewerb, ökonomische Güter nicht homogen sind, sondern sich hinsichtlich bestimmter Eigenschaften unterscheiden (Produktdifferenzierung). Diese Unterschiede müssen nicht zwangsweise objektiv vorhanden sein; entscheidend ist, dass sie aus dem Blickwinkel der Nachfrager existieren, die darauf aufbauend für bestimmte Güter Präferenzen ausbilden, die dann den Austausch zwischen Anbietern und Nachfragern maßgeblich steuern. Das Produkt selbst kann differenziert sein, z.B. aufgrund der individuellen Präferenz für eine bestimmte Marke oder anhand einzelner sachlicher Produkteigenschaften (Farbe, Verpackung, Qualität etc.); gleichermaßen bilden auch die Umstände des Kaufs eine Differenzierung, z.B. durch das Image des Verkäufers, die (empfundene) Freundlichkeit des Personals oder den Standort der Verkaufsstelle.

Daraus folgt, dass ein Anbieter in einem Markt, da er als einziger eine bestimmte differenzierte, d.h. mit Präferenzen behaftete, Produktvariante anbietet, immer bis zu einem gewissen Grad als Monopolist auftritt. Das Verhältnis zwischen den Anbietern hat also stets einen monopolistischen und einen kompetitiven Aspekt (ebd., S. 62f.); die Bildung des Marktpreises erfolgt demnach weder als Monopolpreis noch in vollständigem Wettbewerb (ebd., S. 64). Die relative Monopolstellung erlaubt es einem Anbieter, einen höheren Preis zu verlangen, als dies bei vollkommenem Wettbewerb möglich wäre, da eine Preiserhöhung in einem bestimmten Toleranzbereich nicht zu einem Ausbleiben der Nachfrage führt. Die Möglichkeiten der Preissetzung werden jedoch dadurch begrenzt, dass die Konkurrenten Produktvarianten anbieten, die je nach Standardisierung der jeweiligen Produktklasse mehr oder weniger imperfekte Substitute (d.h. bedingt austauschbar) sind. Einschränkend wirkt ferner, dass für den Anbieter die Kontrolle über das Gesamtangebot nicht gegeben ist und die Preisgestaltung durch die Nachfrageelastizität begrenzt wird (ebd., S. 65f.). Der monopolistische Wettbewerb ist also eine Mischform aus Monopol und vollständiger Konkurrenz; wie stark der Monopol- bzw. der Konkurrenzeffekt im jeweiligen Markt ist, hängt davon ab wie ähnlich sich die angebotenen Produkte sind. Kein Produkt ist mit einem anderen vollkommen identisch, jedoch ist der Wettbewerb (bzw. die Monopolstellung) umso stärker, je ähnlicher (bzw. unähnlicher) sich die Produkte sind.

Auch bei monopolistischer Konkurrenz gibt es ein Marktgleichgewicht (CHAMBERLIN 1933, S. 81ff.; Zusammenfassung z.B. bei DEITERS 1978, S. 9f.; FITTKAU 2004, S. 15ff.):

- Es stehen sich so viele Anbieter und Nachfrager gegenüber, dass das Verhalten eines einzelnen Marktteilnehmers keinen Einfluss auf das Verhalten der anderen hat. Für die Marktteilnehmer gelten dieselben Verhaltensannahmen wie im vollkommenen Wettbewerb (Nutzen-/Gewinnmaximierung, gleiche Bedürfnisse, Markttransparenz). Die Güter sind aber nicht homogen, sondern sich nur ähnlich, wobei die Nachfrager Präferenzen für die jeweiligen Gütervarianten haben. Jeder Anbieter produziert eine Gütervariante, wobei die Stückkosten zwar für alle Anbieter gleich sind, jedoch mit steigenden Skalenerträgen produziert wird

- Da die Nachfrager Präferenzen für bestimmte Gütervarianten ausgebildet haben, wechseln sie nicht sofort bei einer Preiserhöhung den Anbieter; die Nachfrager sind bis zu einem gewissen Grad bereit, einen höheren Preis zu bezahlen. Die Anbieter 
haben daher einen Spielraum bei der Preissetzung, da der Wettbewerb zwischen innen nicht alleine durch die Preise bestimmt wird. Es entsteht daher zwischenzeitlich ein Ungleichgewicht, da die Anbieter aufgrund ihrer relativen Monopolstellung Sondergewinne realisieren können

- Die Sondergewinne motivieren weitere Anbieter, in den Markt einzutreten, was wiederum den Konkurrenzdruck erhöht, da sich die Nachfrage nun auf mehr Anbieter aufteilt. Der einzelne Anbieter produziert deshalb geringere Mengen, womit die Stückkosten seiner Produktion steigen. Ab einer bestimmten Menge sind die Sondergewinne verschwunden, da die Verkaufserlöse den Produktionskosten entsprechen. Der Gleichgewichtspreis ist im monopolistischen Wettbewerb höher als im vollkommenen Wettbewerb und die produzierte Menge niedriger

\subsubsection{Monopolistischer Wettbewerb in einem räumlichen Markt}

Der Einzelhandel dient CHAMBERLIN häufig als Beispiel zur Illustration seiner theoretischen Ausführungen; zu den produkt- bzw. anbieterbezogenen Möglichkeiten der Differenzierung zählt er explizit auch den Standort von Anbietern (CHAMBERLIN 1933, S. 56 u. 62f.). Die Theorie hat auch darüber hinaus räumliche Aspekte; im Anhang seines Originalwerks diskutiert CHAMBERLIN die räumlichen Ausprägungen monopolistischer Konkurrenz anhand der Standortwahl und -verteilung im Einzelhandel. Welche raumwirksamen Einflüsse diese Marktform hat, hängt dabei entscheidend vom Angebot bzw. Sortiment der betrachteten Anbieter ab, genauer gesagt: davon wie ähnlich sie sich sind.

Für einen (stationären) Einzelhandelsanbieter bildet sein Standort, den er selbst bestimmen kann, einen Handlungsparameter, der im Sinne der angestrebten Gewinnmaximierung im Wettbewerb eingesetzt werden kann; der Anbieter ist allein aufgrund seiner Standortwahl immer bis zu einem gewissen Grad ein Monopolist (auch wenn er sich ansonsten überhaupt nicht von seinen Konkurrenten unterscheidet), da er gegenüber jedem seiner Mitbewerber räumlich differenziert ist. Diese Stellung ermöglicht ihm einen gewissen, begrenzten Einfluss auf den Preis (ChAMBERLIN 1933, S. 62f. u. 194; HOLDREN 1965, S. 1323; LÖSCH 1944, S. 74f.). Dieses „Monopol der Lage“ (DEITERS 1978, S. 10) lässt sich an einem simplen Beispiel (angelehnt an CHAMBERLIN 1933, S. 62f.) erläutern: Ein Bäcker an einem peripher gelegenen Angebotsstandort (z.B. abgelegenes Bergdorf) kann durchaus höhere Preise verlangen als ein Bäcker in einem dicht besetzten Innenstadtbereich, wo er von konkurrierenden Anbietern umringt ist. Dies ermöglicht ihm die Tatsache, dass seine Kunden aus Gründen der Bequemlichkeit lieber den höheren Preis bezahlen als den Aufwand in Kauf zu nehmen, einen langen Anfahrtsweg zum nächsten (günstigeren) Anbieter zurücklegen zu müssen.

Die räumliche Konkurrenzmeidung ist jedoch nur relevant für jene Anbieter, deren Produkte perfekte Substitute (d.h. uneingeschränkt austauschbar und nicht durch unterschiedliche Kundenpräferenzen besetzt) sind, also die einzige Differenzierung der Anbieter gegenüber ihren Konkurrenten anhand des Standortes erfolgt. Für das Angebot von Produkten, die unterschiedlichen Produktgruppen (z.B. Brot und Butter) angehören oder zur selben Produktgruppe zählen, jedoch imperfekte Substitute (z.B. verschiedene Schuhmarken) sind, gilt etwas anderes; diese werden, um den Konsumenten Kopplungs- und Vergleichskäufe zu ermöglichen, in räumlicher Nähe zueinander angeboten. Die für die Kunden vorteilhafte räumliche Ballung des Angebots unterschiedlicher Produkte schlägt sich einerseits im breiten Sortiment einzelner Anbieter nieder, andererseits in der Agglomeration mehrerer Anbieter. 
Komplementäre Anbieter bieten den Nachfragern eine Einsparung ihrer Transportkosten (Zeit, Aufwand) durch die Ermöglichung von Mehrzweckeinkäufen; die Ballung kompetitiver Betriebe gewährt erst das "Shopping“ im eigentlichen Sinne, d.h. Vergleichskäufe im Hinblick auf z.B. Preis und Qualität (CHAMBERLIN 1933, S. 196f.). Agglomeriertes Angebot sorgt daher für einen größeren Kundenzufluss aus dem Marktgebiet, was sich in überproportional erhöhten Umsätzen am Angebotsstandort ausdrückt (ebd., S. 197ff.).

In einem unvollkommenen Markt mit monopolistischer Konkurrenz betreiben Anbieter also dann räumliche Konkurrenzmeidung, wenn sie ansonsten identisch sind bzw. sich zumindest so ähneln, dass sich die Ausprägungen ihres Marktauftritts nicht in differierenden Kundenpräferenzen niederschlagen; in diesem Fall überwiegt also der Wettbewerbseffekt vor allen anderen möglichen Vorteilen und das "Monopol der Lage“ erweist sich als beste Strategie in der Standortpolitik. Sobald die angebotenen Güter nicht perfekt substituierbar sind, können Lokalisierungsvorteile den Wettbewerbseffekt überlagern (WOLINSKY 1983, S. 275); diese entstehen auf der Basis von Vergleichskäufen bei vergleichbaren, jedoch eben nicht identischen Angeboten. Hinzu kommen Urbanisierungsvorteile durch die räumliche Ballung komplementärer Angebote, die den Konsumenten Kopplungskäufe ermöglichen; während diese plausibel durch eine Ersparnis an Transportkosten erklärt werden, spezifiziert CHAMBERLIN jedoch nicht näher, bei welchen Gütern und unter welchen Umständen Lokalisierungsvorteile wirksam werden und wie ausgeprägt diese sind.

\subsubsection{Unvollständige Information und räumliches Einkaufsverhalten}

Ein wichtiger Aspekt, der von CHAMBERLIN nicht explizit angesprochen wird, ist, dass das Vorkommen von Vergleichskäufen im Einzelhandel nicht konsistent ist mit der Annahme einer vollkommenen Marktübersicht der Konsumenten; denn die Notwendigkeit eines Preisbzw. Warenvergleichs setzt voraus, dass die Konsumenten nicht vollständig über die Angebote informiert sein können. Es ist also eine weitere Annahme des vollkommenen Marktes zu revidieren, nämlich die vollständige Information und somit auch die Vorstellung eines „rationalen“ Verhaltens, da dieses Menschenbild neben Nutzenmaximierung auch zwingend vollständige Information voraussetzt (siehe Kap. 2.2.1.1). Einige Erweiterungen der Theorie des monopolistischen Wettbewerbs im Einzelhandelsfokus befassen sich mit diesem Zusammenhang, wovon zwei Ansätze an dieser Stelle vorgestellt werden sollen.

Die theoretische Arbeit von NELSON (1970) behandelt die Fragestellung, bei welchen Gütern eine räumliche Ballung kompetitiver Anbieter aufgrund von Lokalisierungsvorteilen besonders günstig ist. Hierzu wird vorausgesetzt, dass Konsumenten keine vollkommene Markttransparenz besitzen und daher das ihren Präferenzen entsprechende Produkt nicht automatisch bekommen, sondern erst suchen müssen; hierbei wird das Einkaufsverhalten mit der informationsökonomischen Suchtheorie verknüpft. Die angebotenen Güter werden auf dieser Grundlage zweifach unterteilt (NELSON 1970, S. 312f.):

- Suchgüter können allein in Suchprozessen am Angebotsstandort gefunden werden, da die (subjektive) Beurteilung von Preis und Qualität bereits vor dem Kauf, d.h. durch den Besuch mehrerer Anbieter, möglich ist (z.B. Bekleidung)

- Demgegenüber sind Erfahrungsgüter dadurch charakterisiert, dass sie zwangsweise erst gekauft werden müssen, um zumindest ihre Qualität beurteilen zu können (z.B. Lebensmittel); erst durch mehrmaliges Kaufen verschiedener Produktvarianten 
gewinnen die Konsumenten die Erfahrung, welche Variante sie bevorzugen

Der Vergleichskauf bei Suchgütern erfolgt also unmittelbar am Angebotsstandort. Bei Erfahrungsgütern findet er hingegen in einer schrittweisen Prozedur statt, in der nacheinander verschiedene Produktvarianten erworben (bzw. ausprobiert) und implizit einer Prüfung unterzogen werden; kann der Preisvergleich zwar durchaus am Angebotsstandort stattfinden, so erfolgt der Vergleich mit den eigenen Präferenzen erst nach dem Kauf. Für die Standortpolitik der Anbieter von Such- bzw. Erfahrungsgütern und ihre wettbewerbliche Stellung zueinander ergeben sich daraus folgende Konsequenzen (ebd., S. 323f. u. 327f.):

- Da Suchgüter unmittelbar für Vergleichskäufe am Angebotsstandort relevant sind, wohingegen Erfahrungsgüter zumeist erst zu Hause nach dem Kauf von den Konsumenten evaluiert werden (können), ist es für Anbieter von Suchgütern sehr vorteilhaft, sich mit ihren Konkurrenten, die andere Produktvarianten anbieten, räumlich zu ballen (z.B. Möbelgeschäfte)

- Anbieter von Erfahrungsgütern können eine (relative) Monopolstellung weit besser ausbauen als Anbieter von Suchgütern, da die Aneignung von Erfahrung tendenziell aufwendiger ist als die Suche. Somit können sie sich im monopolistischen Wettbewerb eher behaupten, wenn sie räumliche Konkurrenzmeidung betreiben

Das Modell zur monopolistischen Konkurrenz in einem räumlichen Markt von WOLINSKY (1983) basiert auf den Überlegungen von CHAMBERLIN und NELSON, wobei es im Unterschied zu den vorherigen Ansätzen ein vollständig formalisiertes räumliches Gleichgewichtsmodell ${ }^{16}$ darstellt, das folgende Grundbedingungen hat (WOLINSKY 1983, S. 275f. u. 277f.):

- Es besteht eine große Anzahl an Anbietern einer Produktgruppe, die jeweils eine Produktvariante verkaufen. Das Verhalten der Anbieter erfolgt auf der Grundlage von Gewinnmaximierung; auch der Standort kann verlagert werden

- Die Konsumenten haben uneinheitliche Präferenzen und ihnen fehlt die vollkommene Markttransparenz, was die Suche nach den ihren Präferenzen entsprechenden Produkten notwendig macht; hierdurch entstehen Suchkosten

- Die Konsumenten haben zugleich die Transportkosten durch ihren Einkaufsweg zum Anbieter zu tragen, die sich aus der zurück zu legenden Entfernung und anderen distanzunabhängigen Komponenten (z.B. Zeit für Parkplatzsuche) zusammensetzen

Die Marktinteraktionen können in unterschiedlichen Ergebnissen resultieren (ebd., S. 277ff.):

- Um ihren Aufwand möglichst klein zu halten, steuern die Konsumenten statt eines isolierten Anbieters eine Agglomeration kompetitiver Anbieter an, wo die Suche nach dem idealen Produkt am vielversprechendsten ist. Die Suche nach dem passenden Produkt bzw. der damit einhergehende Aufwand für die Konsumenten ist demnach ein wichtiger Grund für die räumliche Ballung konkurrierender Anbieter. Die Anbieter passen ihre Standortwahl entsprechend ihres Ziels der Gewinnmaximierung an, d.h.

\footnotetext{
${ }^{16}$ Ein räumliches Gleichgewicht ist ebenso wie das Marktgleichgewicht (siehe Kap. 2.2.1.1) eine theoretische und berechenbare Zielsituation, in der kein Marktteilnehmer mehr einen Anreiz hat, sein Verhalten zu ändern; dies bedeutet, dass unter Berücksichtigung der jeweiligen Grund- bzw. „Optimal“bedingungen keine Veränderung mehr notwendig ist, z.B. dass keine Produktionsfaktoren mehr dauerhaft wandern müssen oder kein Unternehmer mehr seinen Standort verlagern muss (BRÖCKER/FRITSCH 2012, S. 90; LAMMERS/STILLER 2000, S. 14).
} 
sie verlagern ihn an einen Ort, an dem höhere Gewinne zu erwarten sind

- Es sind mehrere räumliche Gleichgewichte möglich. Im Ergebnis ist auch die Konzentration aller Wettbewerber an einem Angebotsstandort möglich, was zwar dem ökonomisch definierten Gleichgewicht gerecht wird, jedoch in Hinblick auf die Transportkosten nicht "sozial optimal“ ist. Die Agglomerationsbildung, die das Ergebnis von Marktvorgängen ist und ein ökonomisches Optimum darstellt, ist also unter anderen Aspekten durchaus problematisch

Diese Ansätze der monopolistischen Konkurrenz erklären also die Ballung kompetitiver Anbieter von Suchgütern und von komplementären Betrieben; Anbieter von standardisierten Erfahrungsgütern müssten demnach eine Konkurrenzmeidung betreiben, was allerdings in Anbetracht der empirisch feststellbaren Agglomerationsbildung von Lebensmittelmärkten (siehe Kap. 1.3.3) fragwürdig ist. Die Ballung kompetitiver Anbieter ist auch Gegenstand des Modells von HOTELLING, jedoch unter völlig anderen Voraussetzungen (siehe Kap. 2.2.3).

\subsubsection{Das Konzentrationsmodell von HoTELLING}

Einen frühen Ansatz zur Erklärung von Agglomerationen liefert der Ökonom HOTELLING in seinem Aufsatz Stability in Competition (1929). Die Grundidee seines Modells ist, dass privatwirtschaftliche Anbieter dazu tendieren, sich im Wettbewerb dem Konkurrenten gegenüber möglichst ähnlich zu positionieren, d.h. inn so gut wie möglich hinsichtlich der Produktqualität, des Standortes sowie weiterer für den wirtschaftlichen Erfolg wesentlichen Aspekte zu imitieren, ohne sich inm jedoch exakt anzugleichen (HOTELLING 1929, S. $41 \mathrm{u}$. 53f.). Das Theorem wurde später als Prinzip der minimalen Differenzierung benannt und auf unterschiedliche ökonomische und soziale Zusammenhänge übertragen, in denen eine Angleichung der Positionierung bzw. des Angebots im Wettbewerb stehender Akteure zu beobachten ist (EATON/LIPSEY 1975, S. 27). Die Motivation des Theoretikers ist es gewesen, aufzuzeigen, wie gewinnmaximierendes Verhalten unter marktwirtschaftlichen Bedingungen in gesellschaftlich unerwünschten Zuständen resultiert (HOTELLING 1929, S. 41 u. 52f.); es handelt sich hierbei also nicht um die modellhafte Umsetzung einer Idealvorstellung, sondern im Gegenteil um eine kritische Sichtweise auf problematische Wettbewerbsentwicklungen.

Das Modell beinhaltet einen stark vereinfachten räumlichen Markt und ist weiträumig als das Zwei-Eisverkäufer-am-Strand-Problem populär geworden (BRowN 1989b, S. 471f.). Die modellhafte Marktsituation hat folgende Ausgangsbedingungen (HOTELLING 1929, S. 45f.):

- Es besteht ein linienförmiger Markt (z.B. Strandpromenade), auf dem die Nachfrager gleichmäßig verteilt sind

- Für die Nachfrager gilt Nutzenmaximierung und für die Anbieter Gewinnmaximierung

- Zwei Anbieter (z.B. Eisverkäufer), die weit voneinander entfernt liegen, verkaufen ein identisches Gut (Duopol)

- Die Konsumenten haben identische Präferenzen und ihre Nachfrage ist vollkommen unelastisch, d.h. Preisänderungen haben keinen Einfluss auf die nachgefragte Menge. Um das Gut zu erwerben, müssen die Nachfrager den Anbieter aufsuchen, wodurch aber entfernungsabhängige Transportkosten anfallen, die den Güterpreis erhöhen. Da Nutzenmaximierung angenommen wird, bedeutet dies, dass die Konsumenten immer den näher gelegenen Anbieter aufsuchen 
- Beide Anbieter haben ein eigenes Marktgebiet, das einerseits durch das linke bzw. rechte Ende des Marktes und andererseits durch einen Indifferenzpunkt begrenzt wird, an dem die transportkostenabhängigen Güterpreise beider Anbieter gleich sind. Die Anbieter können demnach mit der Setzung ihres Abholpreises (d.h. Preis am Angebotsstandort ohne Transportkosten) die Größe ihres Marktgebietes bzw. mit ihrer Standortwahl den Gesamtpreis beeinflussen

Abbildung 1 zeigt schematisch die Ausgangssituation des linienförmigen Marktes mit zwei Anbietern. Das Marktgebiet des Anbieters $A_{1}$ umfasst die Strecken a (links von inm) und $x$ (rechts von ihm), das Marktgebiet von $A_{2}$ die Strecken $b$ (rechts von inm) und $y$ (links von inm). Am Indifferenzpunkt $M$ sind die transportkostenabhängigen Preise der beiden Anbieter gleich; damit $M$ wie in diesem Fall exakt in der Mitte des Marktes liegt, muss der Abholpreis von $A_{2}$ etwas geringer sein als der von $A_{1}$, da $A_{2}$ weiter von der Marktmitte entfernt liegt. Wenn der Abholpreis von $A_{1}$ und $A_{2}$ gleich wäre, wäre die Strecke $x$ länger (d.h. das Marktgebiet von $A_{1}$ wäre größer), die Strecke $y$ kürzer (d.h. das Marktgebiet von $A_{2}$ wäre kleiner) und der Indifferenzpunkt $M$ läge weiter rechts.

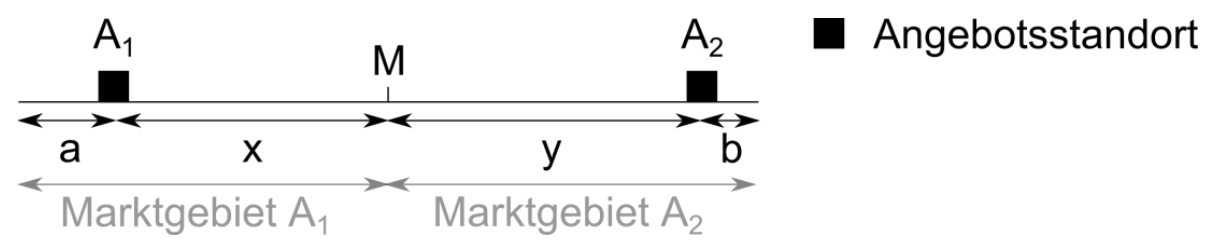

Abbildung 1: HOTELLING - Ein Linienmarkt mit zwei Anbietern

Quelle: Eigene Darstellung nach HOTELLING (1929, S. 45), verändert

Die Wettbewerbsinteraktionen zwischen den Anbietern können nun einerseits über Preisanpassungen erfolgen (ebd., S. 47ff.). Unter der Bedingung gegebener Standorte sind andererseits aber auch räumliche Strategien möglich, um Wettbewerbsvorteile zu generieren bzw. eine räumlich bedingte Monopolstellung zu erreichen, z.B. durch eine Behinderung der Transportwege (ebd., S. 50f.). Wenn einer der Anbieter oder beide Anbieter die Möglichkeit haben, ihren Standort zu verlagern, wirkt sich dies auf ihre Erreichbarkeit, d.h. auf die konsumentenseitig aufzubringenden Transportkosten aus. Die Anbieter beeinflussen so durch ihre Standortwahl den Gesamtpreis; dieser wirkt sich jedoch aufgrund der vollkommen unelastischen Nachfrage nicht auf die Nachfragemenge aus, so dass die Anbieter bei ihrer Lokalisierung nicht mit distanzabhängiger Senkung der Nachfrage rechnen müssen. So ergeben sich mehrere Möglichkeit der Standortstruktur (ebd., S. 51 u. 53f.):

- Wenn der Standort von $A_{1}$ gegeben ist, wird $A_{2}$ seinen Standort so verlegen, dass die Strecke $b$ maximiert wird. Ist $A_{1}$ nicht exakt in der Mitte des Marktes lokalisiert, wird sich $A_{2}$ auf der Seite von $A_{1}$ positionieren, die die größere Abschöpfung des Marktgebietes ermöglich. Befindet sich $A_{1}$ links von der Marktmitte, wird sich $A_{2}$ auf die rechte Seite verlagern

Können beide Anbieter ihre Standorte verlagern, sind zwei „optimale“ Konfigurationen möglich, wovon eine transportkostenminimierend und die andere gewinnmaximierend ist:

- Die gesellschaftlich wünschenswerte Variante wird als Minimierung der Summe der Transportkosten aller Nachfrager begriffen, d.h. eine Anordnung der Anbieter, bei der insgesamt so geringe Strecken wie möglich zurückgelegt werden müssen. Dies 
würde bedeuten, dass sich die Anbieter jeweils auf den vom linken bzw. rechten Rand ausgehenden Quartil des linearen Marktes lokalisieren; die Strecken $a, b, x$ und $y$ wären dann exakt gleich lang. Jedoch könnten die Anbieter in dieser Konfiguration über Preiskämpfe den Indifferenzpunkt nach links bzw. rechts verlagern

- Die in betriebswirtschaftlicher Hinsicht günstigste Lösung besteht allerdings darin, dass sich die Anbieter in der Mitte des Marktes direkt nebeneinander lokalisieren. So haben sie die größtmöglichen Marktgebiete und sind keinem Preiswettbewerb mehr ausgesetzt, da sie jeweils die linke bzw. rechte Hälfte des Marktes vollständig bedienen. Die gleichmäßig verteilten Nachfrager müssen hingegen in der Summe die größtmöglichen Transportkosten aufwenden; da diese sich aber nicht auf die Nachfragemenge auswirken, ist diese Standortkonfiguration für die Anbieter optimal. Es handelt sich hierbei um eine relative Monopolstellung, die aufgrund der Agglomeration konkurrierender Anbieter zustande kommt.

Das Modell von HoteLLING ist vielfach rezipiert und kritisiert worden (z.B. CHAMBERLIN 1933, S. 195f.; LÖSCH 1940, S. 12ff.; Überblick z.B. BROWN 1989a, S. 455ff.); im Zuge dessen wurden aber auch viele Modifikationen des Modells vorgenommen (z.B. EATON/LIPSEY 1975 u. 1979, THILL 1992). Als Bestandteil der Spieltheorie angesehen, wird HoTELLINGs Ansatz auch weiterhin als Basis für komplexere raumökonomische Modelle genutzt, die vorrangig den Einzelhandel betreffen (z.B. AGo 2008, EATON/TWEEDLE 2012, HINLOOPEN/MARTIN 2013). In jedem Fall handelt es sich um einen „Klassiker" der Standorttheorie, auch wenn die räumlichen Aspekte eigentlich nur zur Illustration eines allgemeinen mikroökonomischen Prinzips gedacht waren (HOTELLING 1929, S. 45 u. 53f.). Im Lichte der Forschungsfrage dieser Arbeit ist aber anzumerken, dass die Aussagen zum Konsumentenverhalten sehr vereinfacht und inhaltlich nahezu unbrauchbar sind: Es existieren keine Kopplungs- oder Vergleichskäufe; da nur ein Gut und zwei Anbieter existieren, von denen immer nur einer aufgesucht wird, sind erstere nicht möglich und letztere nicht nötig.

\subsection{Die Raumwirtschaftstheorien von CHRISTALLER, LöSCH und LANGE}

\subsubsection{Die Theorie der zentralen Orte von ChRISTALLER}

\subsubsection{Grundlagen und elementare Begrifflichkeiten}

Der Ausgangspunkt der Theorie ist es, ein räumliches Ordnungsmuster von Siedlungen unterschiedlicher Rangstufe nachzuweisen bzw. dieses zu erklären (CHRISTALLER 1933, S. 13ff.), allerdings verweist der Urheber selbst darauf, dass seine Theorie zugleich auch eine Standorttheorie des tertiären Sektors darstellt, die die Standorttheorien des primären Sektors (VON THÜNEN 1826) und des sekundären Sektors (WEBER 1909) ergänzt (CHRISTALLER 1933, S. 20). Der theoretische Teil in CHRISTALLERs Arbeit gliedert sich in einen statischen Teil, der sich mit der Erklärung der Ist-Situation beschäftigt („Vorgänge der Statik“, S. 33-85) und einen dynamischen Teil, der sich mit der (Weiter-)Entwicklung des Zentrale-Orte-Systems unter einer Reihe bestimmter Bedingungen befasst („Vorgänge der Dynamik“, S. 86-136); der statische Teil wird im Folgenden synonym als Grundmodell der zentralen Orte bezeichnet. Viele Verhaltensannahmen und deren Resultate werden in der ZO-Theorie nicht explizit genannt, sondern nur impliziert, so dass es notwendig ist, diese mitunter als „verwirrend“ (JENKIS 1996, S. 70) wahrgenommenen Inhalte systematisch zu ordnen 
(Ausführliche Besprechung der Theorie inklusive Begründungen bzw. Interpretationen siehe z.B. BEGUIN 1992, DeITERS 1978, GÜSSEFELDT 2005, HEINRITZ 1979).

Für das Verständnis der Theorie sind einige Begriffe notwendig, die weitgehend über die ZOTheorie etabliert wurden (CHRISTALLER 1933, S. 25ff.):

- Die Rangstufe eines Ortes wird als Zentralität bezeichnet, was ein Oberbegriff für den sich aus verschiedenen Faktoren zusammensetzenden Bedeutungsüberschuss eines Ortes gegenüber seinem Umland ist

- Jeder wie auch immer geartete Ort, der einen solchen Bedeutungsüberschuss verzeichnet, ist ein zentraler Ort. Der Begriff "Ort“ wird gewählt, um nicht den Anschein zu erwecken, dass hiermit politisch-administrative Gebietskörperschaften (Städte, Gemeinden) gemeint sind; ein zentraler Ort kann jedwede Lokalisation von Angebot sein und entspricht damit im Wesentlichen der Definition eines Angebotsstandortes (siehe Kap. 1.2.2)

- Der Bedeutungsüberschuss eines Ortes besteht im Vorhandensein verschiedener Angebote (Waren und Dienstleistungen) des tertiären Wirtschaftssektors (öffentlich wie privat); je vielfältiger das Angebot, desto zentraler der Ort. Hierbei offerieren die zentralen Orte auch grundsätzlich alle Güter (zentrale Güter bzw. zentrale Dienste) der rangniedrigeren Orte. Zentrale Güter und Dienste sind vor allem der Einzelhandel, sowie Banken, Handwerksbetriebe, die öffentliche Verwaltung, Kulturangebote und Gesundheitsdienstleistungen etc. Die so genannten dispersen Güter werden hingegen quasi ubiquitär produziert (z.B. in Subsistenzwirtschaft bei Landwirten) bzw. an dispersen Orten, d.h. Orte ohne zentrale Funktion, angeboten

- Die Orte werden nach ihren zentralen Funktionen in zentrale Orte höherer, niederer und niederster Ordnung klassifiziert. Je zentraler ein Ort ist, desto größer erstreckt sich auch seine überregionale Anziehungskraft auf die Orte in seiner Umgebung, die ein Bedeutungsdefizit vorweisen und für die der zentrale Ort der (Versorgungs-) Mittelpunkt ist. Das Gebiet, in dem sich diese Orte befinden, wird als Ergänzungsgebiet bezeichnet; dieser Begriff entspricht also dem, was für gewöhnlich als Marktgebiet eines Angebotsstandortes bezeichnet wird (siehe Kap. 1.2.2)

\subsubsection{Annahmen und Funktionsweisen des räumlichen Marktes}

Die Theorie der zentralen Orte ist eine deduktive Theorie, die aus den zeitgenössischen neoklassischen Wirtschaftstheorien hergeleitet wurde und eine Übertragung von deren Prinzipien auf den Raum bzw. die räumliche Verteilung von Angebotsstandorten darstellt (CHRISTALLER 1933, S. 14f. u. 17); jedoch wird (bewusst) auf wiederkehrende Verweise oder Zitate verzichtet, was die Nachvollziehbarkeit der Argumentation mitunter erschwert. Deutlich wird die inhaltliche Ausrichtung aber, wenn CHRISTALLER in Bezug auf seine Theorie von einem „[...] rationalen Schema der allgemeinen ökonomischen Theorie [...]" spricht, das sich im „günstigsten" Zustand befindet, „[...] wobei ,günstigst' nicht im Sinne einer Bewertung zu meinen ist, sondern als Zustand höchster Rationalität mit geringstem Wertverlust" (ebd., S. 74). Die Theorie ist somit als Übertragung der mikroökonomischen Optimierungs- und Gleichgewichtsannahmen auf einen räumlichen Markt anzusehen (DEITERS 1978, S. 5).

Damit verbunden sind bestimmte Annahmen zum menschlichen Verhalten, die CHRISTALLER weitgehend nicht explizit formuliert, sondern nur impliziert. Im Allgemeinen werden die 
Verhaltensweisen von Konsumenten (d.h. private Haushalte) und Unternehmern (d.h. Anbieter von konsumentenorientierten Dienstleistungen) in der Theorie als vollständig rationales Verhalten angesehen, wobei diese Grundannahme nicht ausdrücklich formuliert wird, sondern sich aus den in der Theorie angenommenen Handlungsweisen ergibt. Das vorausgesetzte Menschenbild ist demnach das eines homo oeconomicus (BEGUIN 1992, S. 218; HEINRITZ 1979, S. 23f.). Alle Marktteilnehmer verhalten sich also nutzenmaximierend, was für die Anbieter zentraler Güter Gewinnmaximierung bedeutet. Die Nutzenmaximierung der Konsumenten erfolgt unter der Einschränkung ihres Einkommens (Budgetbeschränkung) in Verbindung mit dem Preis der zentralen Güter (BEGUIN 1992, S. 218f.; DEITERS 1978, S. 6f.); letzteres wird in der Theorie auch explizit formuliert (CHRISTALLER 1933, S. 40). Die Übersetzung dieser Annahmen in einen räumlichen Markt erfolgt anhand der Berücksichtigung der von den Konsumenten getragenen Transportkosten bei räumlicher Trennung der Angebots- von den Nachfragestandorten (DEITERS 1978, S. 9).

Der Preis von zentralen Gütern wird unmittelbar durch die Transportkosten beeinflusst, wobei der Preis wiederum die Nachfrage vor dem Hintergrund der Haushaltseinkommen determiniert. CHRISTALLER (1933, S. 31f. u. 34f.) geht von der Gesetzmäßigkeit aus, dass die Nachfrage nach Gütern aus dem Ergänzungsgebiet mit steigender Entfernung zum zentralen Ort abnimmt, da sich der Transportaufwand der Konsumenten umso mehr erhöht, je weiter der Weg ist, den sie zum zentralen Ort zurücklegen müssen; die Transportkosten sind also entfernungsabhängig. Der Gesamtpreis eines zentralen Gutes besteht demnach aus dem (anbieterabhängigen) Preis des Gutes am Angebotsstandort (Abholpreis) und den (von den Konsumenten zu tragenden) Transportkosten. Die Transportkosten setzen sich aus den Transporttarifen selbst sowie dem sonstigen Aufwand der Raumüberwindung (z.B. Zeitverlust) zusammen ${ }^{17}$; sie müssen vom zur Verfügung stehenden Einkommen der Konsumenten abgerechnet werden, wenn die Nachfrage bestimmt werden soll.

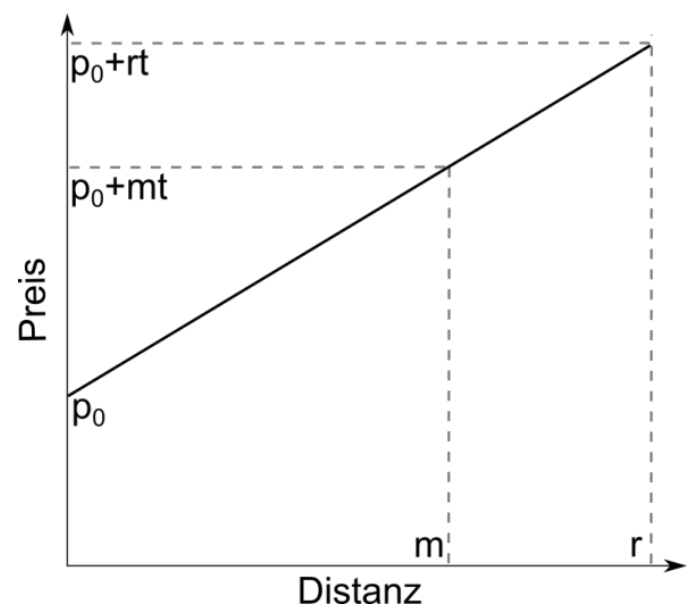

Abbildung 2: Zentrale Orte - Transportkosten und Preis zentraler Güter Quelle: Eigene Darstellung nach HuFF (1981, S. 110), verändert

\footnotetext{
${ }^{17}$ Hierfür wird der Begriff der „,wirtschaftlichen Entfernung“ eingeführt, die eine Übersetzung der geographischen Entfernung in ökonomische „Kosten“ darstellt; Einflussfaktoren sind u.a. die Reisekosten im engeren Sinne (z.B. ÖPNV-Preise), die Reisedauer bzw. der Zeitverlust und die Bequemlichkeit der Reise (CHRISTALLER 1933, S. 31f.). Während diese die „objektive wirtschaftliche Entfernung“ ausmachen, ergibt sich unter der Berücksichtigung individueller und/oder gruppenspezifischer Bewertungen und Einstellungen die „subjektive wirtschaftliche Entfernung“ im Sinne einer subjektiv bewerteten Entfernung, die der Theorie zugrunde gelegt wird (ebd., S. 56f.).
} 
Abbildung 2 zeigt die Preisbildung unter Berücksichtigung der Transportkosten; diese sind eine Funktion aus der Distanz zum Angebotsstandort (d) und den Kosten pro Entfernungseinheit $(t)$. Der Gesamtpreis des Gutes $(p)$ errechnet sich aus dem Abholpreis $\left(p_{0}\right)$ und den Transportkosten $(d t)$. Bei einer Distanz $m$ ergibt sich demnach der Preis $p_{0}+m t$, bei einer Entfernung $r$ der Preis $p_{0}+r t$.

Aus dem eigentlichen Preis des zentralen Gutes leitet sich die Begrifflichkeit der Reichweite eines zentralen Gutes ab (CHRISTALLER 1933, S. 32 u. 59):

- Die untere Grenze der Reichweite umfasst die Mindestnachfrage im Umfeld des zentralen Angebots, die für eine betriebswirtschaftlich tragfähige Aufrechterhaltung dieses Angebots notwendig ist. Nach der in Kap. 1.1.2.2 eingeführten Terminologie stellt die untere Grenze der Reichweite ein minimal nötiges Marktgebiet dar

- Die obere Grenze der Reichweite ist die weiteste Entfernung, bis zu welcher die Nachfrager ein in einem zentralen Ort angebotenes Gut gerade noch erwerben; ist diese überschritten, wird das Gut aufgrund zu hoher Transportkosten nicht mehr in diesem zentralen Ort (oder überhaupt nicht mehr) erworben. Sie ist also das maximal mögliche Marktgebiet eines Gutes, Anbieters oder zentralen Ortes

Abbildung 3 zeigt diesen Zusammenhang: Am Angebotsstandort selbst fallen keine Transportkosten an, d.h. hier wird zum Preis $p_{0}$ die Menge $q_{0}$ nachgefragt. Bei einer Distanz von $m$ steigt der Güterpreis auf $p_{0}+m t$, wobei sich die nachgefragte Menge auf $q_{1}$ verringert. Die Distanz $r$ bildet die obere Grenze der Reichweite mit dem Vorbehaltspreis $p_{0}+r t$; über sie hinaus wird das betreffende Gut aufgrund zu hoher Transportkosten nicht mehr nachgefragt, d.h. dort liegt die Außengrenze des (hier kreisförmig dargestellten) Marktgebietes.

Angebotsstandort

Marktgebiet

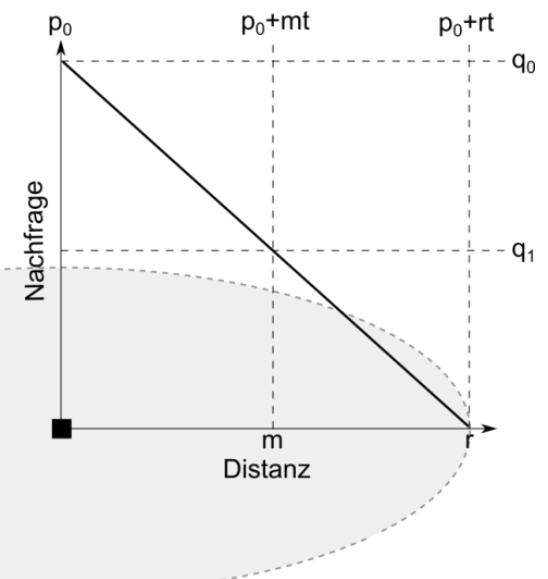

Abbildung 3: Zentrale Orte - Transportkosten und maximal mögliches Marktgebiet Quelle: Eigene Darstellung nach HUFF (1981, S. 111), verändert

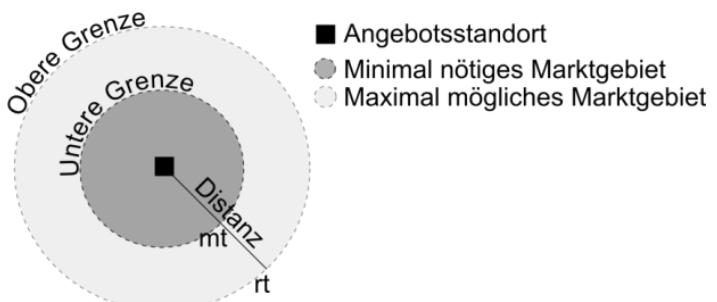

Abbildung 4: Zentrale Orte - Minimal nötiges und maximal mögliches Marktgebiet Quelle: Eigene Darstellung nach MAIER/TöDTLING (2006, S. 140), verändert 
Abbildung 4 zeigt die untere und die obere Grenze vom Angebotsstandort aus. Wie oben beschrieben, bildet die Distanz $r$ die obere Grenze der Reichweite. Die Distanz $m$ macht die untere Grenze der Reichweite aus; bis hierhin muss das Marktgebiet eines Anbieters mindestens reichen, damit das Angebot betriebswirtschaftlich tragfähig ist.

Beide Formen der Reichweite sind für jedes zentrale Gut verschieden und können auch raum-zeitlich differieren. Je größer die für ein betriebswirtschaftlich tragfähiges Angebot notwendige Mindestnachfrage (untere Grenze der Reichweite) und die Bereitschaft der Konsumenten zur Raumüberwindung zwecks Erwerbs dieses Gutes (obere Grenze der Reichweite) sind, desto ranghöher ist dieses Gut (CHRISTALLER 1933, S. 61):

- Bei zentralen Gütern höherer Ordnung ist sowohl die obere als auch die untere Grenze der Reichweite hoch, d.h. sie müssen innerhalb eines größeren Marktgebietes abgesetzt werden um rentabel zu sein und werden daher nur an vergleichsweise wenigen Orten, d.h. zentralen Orten höherer Ordnung, angeboten

- Wenn sowohl die obere als auch die untere Grenze der Reichweite niedrig ist, handelt es sich um zentrale Güter niederer Ordnung, die demnach an sehr vielen zentralen Orten angeboten werden müssen (und können)

- Sofern die obere Grenze hoch, die untere niedrig ist, kann das Gut an vielen zentralen Orten angeboten werden, was jedoch in einem starken räumlichen Wettbewerb resultieren würde; da jene Güter an Orten niedrigen Ranges angeboten werden können, zählen auch sie zu den zentralen Gütern niederer Ordnung. Ist die untere Grenze hoch, die obere niedrig, so beschränkt sich das Angebot dieser Güter auf zentrale Orte höheren Ranges mit einem großen Ergänzungsgebiet

\subsubsection{Marktgebiete einzelner Güter und Zentrenhierarchie}

Die Zielgrößen des statischen Teils der ZO-Theorie bestehen aus Marktgebieten für einzelne Güter und einer Hierarchie von Angebotsstandorten in einem funktional verknüpften System zentraler Orte. Diesem Grundmodell liegt die Vorstellung eines räumlichen Gleichgewichts zu Grunde, in dem weder eine völlige Konzentration (wegen zu hoher Transportkosten) noch eine gleichmäßige Verteilung unzähliger kleiner und gleich ausgestatteter Angebotsstandorte (aufgrund der nötigen Mindestnachfrage) vorherrschen, sondern eine Standortkonfiguration, „[...] wo möglichst viele Bedürfnisse befriedigt werden und wo für die die zentralen Güter Anbietenden ein möglichst hoher Ertrag resultiert" (CHRISTALLER 1933, S. 37). Zudem soll das gesamte Gebiet durch ein gleichmäßiges Netz von Angebotsstandorten verschiedenen Ranges abgedeckt sein, so dass keine unversorgten Teilräume existieren (ebd., S. 69).

Der statische Teil der Theorie setzt eine Reihe von restriktiven Ausgangsbedingungen voraus. Abgesehen von den genannten Verhaltensannahmen (siehe Kap. 2.3.1.2) betreffen diese insbesondere die Homogenität des Raumes (DEITERS 1978, S. 12):

- Die Bevölkerung ist gleichmäßig im Raum verteilt

- Das Pro-Kopf-Einkommen der Bevölkerung ist überall gleich

- Das Verkehrssystem ist einheitlich, d.h. ein Transport ist in alle Richtungen zu identischen Bedingungen (Transporttarifen) möglich

- Die Ausstattung mit natürlichen Ressourcen ist überall gleich 
- Zur Produktion notwendige Rohmaterialien sind überall in gleichem Maße vorhanden

Aufgrund des Anspruchs, dass es in diesem in alle Richtungen die gleichen Eigenschaften aufweisenden Raum einerseits keine unversorgten Gebiete geben soll und andererseits sich Marktgebiete nicht überschneiden sollen, müssen die zentralen Orte räumlich in einer bestimmten Weise angeordnet sein; „[...] so müssen benachbarte zentrale Orte gleichen Abstand von einander haben. Das ist aber nur dann gegeben, wenn sie auf den Ecken gleichseitiger Dreiecke liegen, die sich [...] zu Sechsecken gruppieren“ (CHRISTALLER 1933, S. 69). Die Marktgebiete einzelner zentraler Güter müssen unter diesen Bedingungen eine geometrische Form haben, die es ermöglicht, dass weder unterversorgte Zwischenbereiche zurück bleiben (siehe Abb. 5a) noch sich Marktgebiete überschneiden (siehe Abb. 5b). Dieser Anspruch wird in Kombination mit den anderen Ausgangsbedingungen nur dann erreicht, wenn die Marktgebiete der einzelnen zentralen Güter nicht kreisförmig sind, sondern eine sechseckige (hexagonale) Form haben (siehe Abb. 5c). Diese Ableitung wird von CHRISTALLER rein geometrisch begründet; eine mikroökonomisch fundierte Ableitung der Marktgebiete als "räumliche Entsprechung monopolistischen Wettbewerbs" (DEITERS 1978, S. 13) hat LöscH (1944) vorgenommen (siehe Kap. 2.3.2.3).
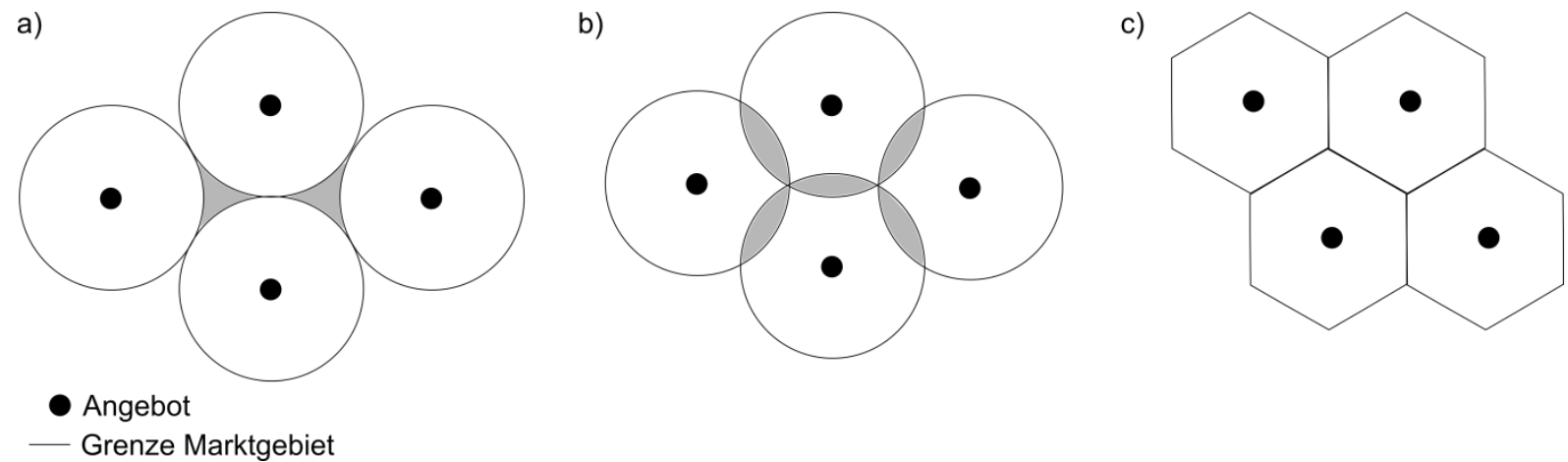

Abbildung 5: Zentrale Orte - Ableitung hexagonaler Marktgebiete für einzelne Güter Quelle: Eigene Darstellung nach HuFF (1981, S. 113), verändert

Hieraus leiten sich die raumwirksamen Verhaltensweisen von Konsumenten und Anbietern ab, die jedoch ebenso nicht explizit formuliert werden, sondern die logische Konsequenz der o.g. Rationalitätsannahmen und (zumindest für den statischen Teil der Theorie) notwendige Verhaltenselemente darstellen (BEGUIN 1992, S. 218f.; HEINRITZ 1979, S. 24f.):

- Die Nutzenmaximierung der Konsumenten wird als Transportkostenminimierung beim Einkauf übersetzt. Da im ZO-Grundmodell nur die Besorgung eines zentralen Gutes beim Einkauf angenommen wird (Einzweckeinkauf), bedeutet die Minimierung der Transportkosten in diesem Fall das Aufsuchen des nächstliegenden zentralen Ortes, an dem das gewünschte Gut angeboten wird (Nearest-Center-Annahme)

- Die Nutzenmaximierung bzw. Gewinnmaximierung der Anbieter drückt sich dadurch aus, dass sie versuchen, die Größe ihrer Marktgebiete zu maximieren. Anbieter gleicher zentraler Güter suchen den größtmöglichen Abstand zu ihren Konkurrenten; sie verfolgen in ihrer Standortpolitik also das Ziel der Konkurrenzmeidung

Die hexagonalen Marktgebiete für einzelne Güter bilden den Ursprung für ein hierarchisches System zentraler Orte, das folgende Eigenschaften hat (CHRISTALLER 1933, S. 65ff.): 
- In jedem Ort werden mehrere zentrale Güter angeboten

- Diese Güter haben aufgrund ihrer Eigenschaften unterschiedliche Reichweiten (sowohl hinsichtlich der oberen als auch der unteren Grenze)

- Das Angebot höherrangiger Orte umfasst stets auch alle Güter, die in den rangniedrigeren Orten offeriert werden

- Jeder zentrale Ort hat ein Ergänzungsgebiet, dessen räumliche Ausdehnung der oberen Reichweite des ranghöchsten angebotenen Gutes entspricht

Der Ablauf der Bildung eines solchen Systems lässt sich wie folgt grob skizzieren (ebd.):

- Mehrere gleichmäßig verteilte zentrale Orte vom Typ B versorgen zunächst das gesamte Gebiet mit einem Gut höchsten Ranges bzw. höchster Reichweite

- An diesen B-Orten wird noch eine Reihe weiterer rangniedrigerer Güter angeboten, die eine geringere Reichweite aufweisen; somit bleiben Teile des Gesamtgebietes im Hinblick auf diese Güter unversorgt bzw. gibt es Teilgebiete, an denen ein betriebswirtschaftlich tragfähiges Angebot dieser Güter noch möglich ist. Diese „Versorgungslücke“ wird kompensiert durch die Errichtung neuer rangniedrigerer Angebotsstandorte (Typ K) im Mittelpunkt eines Dreiecks, das sich aus drei B-Orten ergibt; diese beliefern nun den unversorgten Teil des Gebietes zwischen den B-Orten mit diesen Gütern

- Für noch rangniedrigere Güter, die dementsprechend eine noch geringere Reichweite haben, entstehen genau nach demselben Prinzip zwischen den K-Orten weitere Angebotsstandorte zur vollständigen Abdeckung der räumlichen Versorgung; diese Orte vom Typ A versorgen die bisher nicht abgedeckten Gebiete zwischen den KOrten mit den Gütern. Analog entstehen auf einer Hierarchiestufe darunter noch Orte vom Typ M, wobei sich diese Ausdifferenzierung noch weiter fortsetzen ließe

- In umgekehrter Weise ist die Hierarchie der Angebotsstandorte auch nach oben erweiterbar: Einzelne Güter verfügen über eine so hohe Reichweite, dass sie nicht an jedem B-Ort vorgehalten werden müssen (bzw. können), um das gesamte Gebiet (also auch die B-Orte) zu versorgen. Diese werden nun zwecks lückenloser räumlicher Abdeckung nur in dem in der Mitte liegenden B-Ort angeboten, der hierdurch noch eine weitere Aufwertung erfährt und daher als G-Ort klassifiziert wird

Abbildung 6 zeigt schematisch ein System der zentralen Orte mit vier Hierarchiestufen. Da es unter den o.g. strengen Prämissen die effizienteste funktionale Struktur zur Versorgung des Gesamtgebietes mit einer möglichst geringen Anzahl zentraler Orte darstellt, nennt CHRISTALLER (1933, S. 77) es das ZO-System nach dem Versorgungs- oder Marktprinzip ${ }^{18}$.

Dieses Grundmodell ist vielfach im Hinblick auf die als realitätsfern angesehenen Annahmen und Aussagen kritisiert worden (Überblick z.B. DEITERS 2006, S. 298ff.; LIEFNER/SCHÄTZL 2012, S. 53ff.); unabhängig von dieser Kritik ist es jedoch als theoretische Grundlage in das deutsche sowie in andere europäische Raumplanungssysteme eingeflossen (BLOTEVOGEL

\footnotetext{
${ }^{18}$ Nach derselben Logik entwickelt CHRISTALLER (1933, S. 77ff.) noch zwei weitere ZO-Systeme nach dem Verkehrs- bzw. Verwaltungsprinzip; je nach Strukturprinzip versorgt ein zentraler Ort eine bestimmte Anzahl mehrerer rangniedrigerer Orte bzw. eine bestimmte Anzahl von Ergänzungsgebieten.
} 
1996, S. 14ff.). Kaum Berücksichtigung gefunden haben hingegen die Aussagen der Theorie zu Agglomerationseffekten und - damit verbunden - die dynamischen Aspekte, die ohne die nachfolgenden Ausführungen mitunter nicht nachvollziehbar sind.

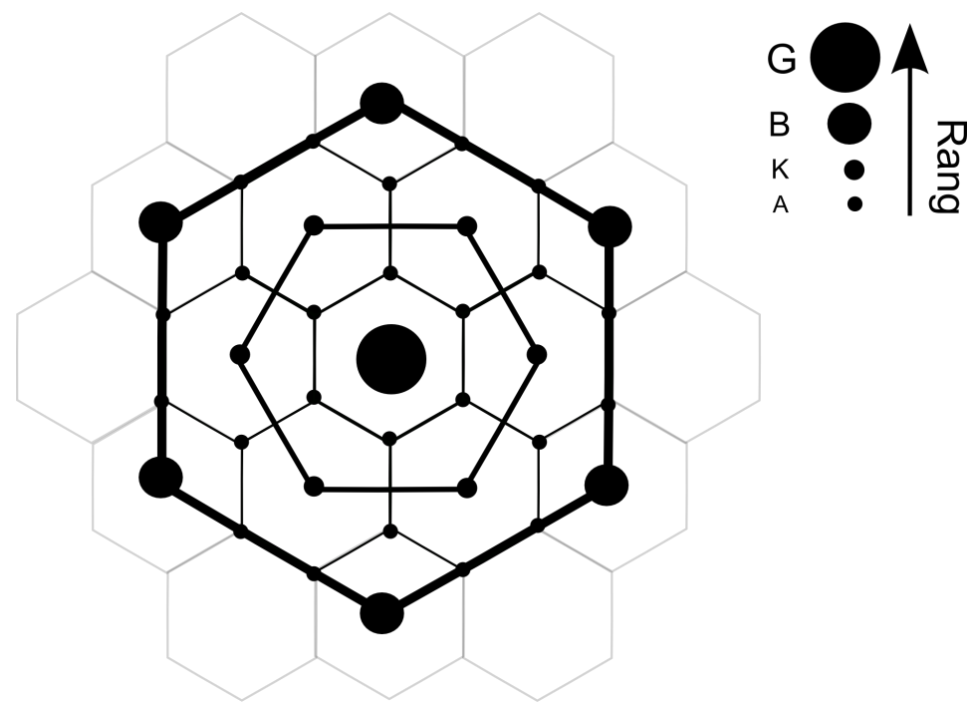

\section{Abbildung 6: Zentrale Orte - Zentrenhierarchie mit hexagonalen Marktgebieten} Quelle: Eigene Darstellung nach CHRISTALLER (1933, S. 71), verändert

\subsubsection{Zur Berücksichtigung von Agglomerationseffekten}

Es ist zunächst festzustellen, dass CHRISTALLER jederzeit von der Existenz agglomerierter Angebotsstandorte ausgeht, denn die zentralen Orte umfassen bereits per Definition das Angebot mehrerer zentraler Güter (siehe Kap. 2.3.1.1); die Zahl der Güterarten macht zudem die „Bedeutung“ des jeweiligen zentralen Ortes aus (CHRISTALLER 1933, S. 70). Da es also Agglomerationen gibt, lässt sich die implizite Grundvoraussetzung ableiten, dass sich die Anbieter an bereits existierenden Angebotsstandorten ansiedeln bzw. in der Vergangenheit angesiedelt haben; demnach muss es eine Interdependenz von Standortentscheidungen geben (DEITERS 1978, S. 10; Mulligan 1984, S. 9f.; VANDENBROUCKE 1995, S. 75). Diese Tatsache hat jedoch keinen Einfluss auf die hexagonalen Marktgebiete einzelner Güter und die Zentrenhierarchie im Grundmodell; es existieren darin faktisch zwar Agglomerationen, jedoch keine (ausdrücklich genannten) Agglomerationsvorteile, welche die damit verbundene Standortpolitik erklären könnten (BEGUIN 1992, S. 222f.; EATON/LIPSEY 1982, S. 58f.).

Das CHRISTALLER-System basiert auf Konkurrenzmeidung der Anbieter (siehe Kap. 2.3.1.3), so dass Lokalisierungsvorteile hier in der Tat unberücksichtigt bleiben (EPPLI/BENJAMIN 1994, S. 11). Es stellt sich aber die Frage, wie es sich mit Urbanisierungsvorteilen bzw. der Ballung branchenungleicher Anbieter aufgrund der Möglichkeit von Kopplungskäufen verhält, da derartige Angebotsstandorte in CHRISTALLERs Modell ja faktisch vorausgesetzt werden. Die dem statischen Teil der Theorie zugrunde liegende Annahme, dass stets der nächstliegende Angebotsstandort aufgesucht wird, ist insofern unmittelbar mit der Einkaufsstrategie verknüpft, da sie überhaupt nur tragbar ist, wenn zugleich Einzweckeinkäufe angenommen werden; sobald die Möglichkeit bzw. Notwendigkeit von Mehrzweckeinkäufen in Betracht gezogen wird, ist die „Nearest-Center-Annahme“ nicht mehr kompatibel zum Verhalten der Nutzenmaximierung bzw. Transportkostenminimierung, da Kopplungskäufe ja eine Senkung 
bzw. Minimierung des Aufwandes ermöglichen (EPPLI/BENJAMIN 1994, S. 8f.; FITTKAU 2004, S. 51f.; GHOSH 1986, S. 81ff.). Demnach existieren im Grundmodell der Theorie also keine Kopplungskäufe bzw. positiven Urbanisierungseffekte. Die Teile der Theorie, die über das Grundmodell hinausgehen, und insbesondere die Ausführungen zur Dynamik, beachten jedoch Agglomerationseffekte bzw. setzen diese voraus, wie im Folgenden aufgezeigt wird.

Bereits im statischen Teil werden Kopplungen am Beispiel zweier miteinander verbundener Besorgungen - dem Besuch von Arzt und Apotheke - besprochen: „[...] Mancher, der in der Apotheke etwas zu kaufen hat, wird im selben Gang, also mit den ohnehin schon verausgabten Wegekosten, den Arzt am Ort der Apotheke konsultieren, und nicht den Arzt, der an einem näheren, aber nur mit besonderen [d.h. zusätzlichen, d. Verf.] Wegekosten zu erreichenden Ort wohnt" (CHRISTALLER 1933, S. 48). Die räumliche Ballung komplementärer Anbieter reduziert also die konsumentenseitig zu tragenden Transportkosten und macht die Angebotsstandorte, die Kopplungen ermöglichen, attraktiver; es ergeben sich hierdurch negative Konsequenzen für die Angebotsstandorte mit der geringeren Ausstattung, da diese ggf. umgangen werden, was ihren Kundenzufluss mindert: „Es entzieht somit der zentrale Ort höherer Ordnung direkt den zentralen Orten niederer Ordnung die Kundschaft" (ebd.). Die Möglichkeit von Kopplungen hat einen positiven Einfluss auf die Marktgebiete einzelner Anbieter und somit des gesamten Angebotsstandortes, ,[...] als am zentralen Ort höherer Ordnung mehr Arten von zentralen Gütern angeboten werden als am zentralen Ort niederer Ordnung, es können also in einem Gang, mit einmaligen Wegekosten, gleichzeitig mehrere Arten von zentralen Gütern erworben werden. Dies wirkt sich wie eine generelle Verbilligung der in der größeren Stadt angebotenen zentralen Güter aus, wodurch [...] die Reichweite eines Gutes, das in dem größeren zentralen Ort angeboten wird, größer ist, als wenn es in einem kleineren zentralen Ort zum Angebot kommt" (ebd., S. 55).

Einzelne Anbieter in Agglomerationen verfügen also aufgrund ihrer räumlichen Nähe zu Betrieben anderer Branchen über ein größeres (weil gemeinsames) Marktgebiet, als wenn sie isoliert lokalisiert wären. Die höhere Nachfrage beeinflusst wiederum die Güterproduktion des einzelnen Anbieters, da von steigenden Skalenerträgen ausgegangen wird: „Nun wird in der Regel das gleiche zentrale Gut in einer größeren Stadt billiger produziert oder angeboten werden können als in einer kleineren Stadt, da die Produktion in großen Mengen billiger ist und auch der große Umsatz beim Verkauf einen geringeren Stückpreis zulässt" (ebd., S. 58). Die Ausweitung senkt also die Durchschnittskosten der Unternehmen, weswegen sie ihre Güter wiederum günstiger anbieten können, was ihre Nachfrage abermals erhöht: „[...] Man kann daher sagen, dass ein an einem größeren zentralen Ort produziertes oder angebotenes Gut eine größere Reichweite hat als das gleiche an einem kleineren zentralen Ort produzierte oder angebotene Gut" (ebd.).

Angebotsstandorte sind also umso attraktiver, je mehr Kopplungsmöglichkeiten sie bieten; umso ausgedehnter sind ihre Marktgebiete und somit die Marktgebiete aller dort lokalisierten Anbieter. Diese können daher ihre Verkaufspreise senken und somit noch mehr Kundschaft generieren. CHRISTALLERS Theorie berücksichtigt also Agglomerationseffekte; sie bestehen aus einer Wechselwirkung zwischen Urbanisierungsvorteilen und steigenden Skalenerträgen und beruhen auf der Möglichkeit von Kopplungen durch die räumliche Ballung verschiedenartiger, komplementärer Anbieter (BEGUIN 1992, S. 220ff.; FITTKAU 2004, S. $51 \mathrm{ff}$.). Die „[...] generelle Verbilligung der in der größeren Stadt angebotenen zentralen Güter [...." (CHRISTALLER 1933, S. 55) besteht einerseits darin, dass die Verbraucher beim Besuch 
von Angebotsstandorten mit großem Kopplungspotenzial ihre zu tragenden Transportkosten senken können, was einer Reduzierung des Gesamtpreises zentraler Güter gleichkommt, der ja die Transportkosten enthält (siehe Kap. 2.3.1.2); andererseits profitieren sie aber auch von einer Reduzierung des Abholpreises, da die Güterpreise an diesen Angebotsstandorten aufgrund steigender Skalenerträge günstiger angeboten werden.

Agglomerationseffekte werden in CHRISTALLERs räumlichem Markt also berücksichtigt; sie sind nicht Gegenstand der Zentrenhierarchie, umso relevanter werden sie aber im Rahmen des dynamischen Teils. Der Vollständigkeit halber sei erwähnt, dass nicht nur positive Agglomerationseffekte beschrieben werden: Agglomerationsnachteile ergeben sich in der Zentrale-Orte-Theorie v.a. aufgrund der hohen Nachfrage nach der endlichen Ressource Boden in den zentralen Orten höherer Ordnung, was zu höheren Bodenpreisen führt und so der Agglomeration entgegenwirkt (CHRISTALLER 1933, S. 99f.).

\subsubsection{Dynamik im Zentrale-Orte-System}

Der statische Teil der Theorie bildet nur die Grundüberlegung der Gesamttheorie, denn dieses ,[...] mathematisch-starre Schema ist in mancher Hinsicht unvollkommen, es ist in dieser Strenge sogar nicht richtig [...]" (CHRISTALLER 1933, S. 73) bzw. „[...] unvollkommen, ja im Grunde unrichtig und daher zu korrigieren [...]", so dass es notwendig ist, "die schlechthinige Tatsache der Veränderlichkeit jedes einzelnen Faktors zu berücksichtigen, also gewissermaßen das Zeitelement in abstrakter Form einzufügen“ (ebd., S. 76f.). In den "Vorgängen der Dynamik" setzt sich CHRISTALLER mit der zeitlichen Entwicklung des ZOSystems und ihren Erklärungsgrößen auseinander, was zugleich als der realitätsnähere Teil der Theorie ausgemacht wird, denn die dynamischen Betrachtungen „stehen der Wirklichkeit [...] näher als die rein statischen Beziehungen, sie machen den wirklicheren Teil der theoretischen Betrachtung aus" (ebd., S. 86). Nach der Auffassung einiger Autoren (z.B. FITTKAU 2004, S. 35f.; GÜSSEFELDT 2005, S. 47f.) bildet der statische Teil daher also nur einen Ausgangspunkt für die „wirkliche“ Theorie der zentralen Orte.

Die Zahl an Einflussfaktoren von innerhalb und/oder außerhalb des zentralörtlichen Systems, die und deren räumliche Auswirkungen skizziert werden, ist so groß, dass es weder nötig noch sinnvoll wäre, sie an dieser Stelle erschöpfend darzustellen; hinzu kommt, dass sie in sehr unterschiedlichen Graden der Ausführlichkeit behandelt und ungleich stark theoretisch fundiert werden. Zusammengefasst betrachtet werden folgende interdependente (!) Dynamisierungselemente besprochen (CHRISTALLER 1933, S. 86ff.):

- Nachfrageseitige Veränderungen: Hierzu zählen - sowohl auf das gesamte ZOSystem bezogen als auch regional differenziert - demographische Wachstums- und Schrumpfungsprozesse, Veränderungen in der Bevölkerungsstruktur (z.B. hinsichtlich der Beschäftigtenstruktur), in den Einkommensverhältnissen bzw. der Kaufkraft sowie den Präferenzstrukturen der Verbraucher. Wächst z.B. die Bevölkerung gleichmäßig in allen Nachfrageorten, bedeutet dies eine proportionale Steigerung der Nachfrage nach zentralen Gütern, die die Entstehung neuer Angebotsstandorte („,hilfszentrale Orte") ermöglicht bzw. erfordert; diese müssen möglichst weit von den bisherigen zentralen Orten entfernt sein (ebd., S. 89)

- Angebotsseitige Veränderungen: Hierzu zählen Zu- und Abnahmen von bestimmten Angebotsformen an bestimmten Angebotsstandorten, wobei nach der Elastizität der 
jeweiligen zentralen Güter differenziert wird, sowie dauerhafte Preisänderungen und kurzfristige Preisschwankungen. Besondere Berücksichtigung erfahren hier die Veränderungen der Attraktivität bzw. der Marktgebiete zentraler Orte unter der Bedingung hinzukommender oder wegbrechender Angebote (ebd., S. 95f. u. 109f.); diese Zusammenhänge spielen in der Agglomerationsproblematik eine wesentliche Rolle (siehe Kap. 2.3.1.6)

- Räumliche Veränderungen: Hier sind vorrangig die globalen oder regionalen Veränderungen des Transportkostenniveaus (z.B. Ausbau von Straßen oder die Verbilligung von ÖPNV-Systemen) zu nennen. Eine Transportkostensenkung hat z.B. Verbesserungen in der Erreichbarkeit von entfernten Angebotsstandorten zur Folge, was sowohl die räumliche Einkaufsorientierung (siehe Kap. 2.3.1.6) als auch die Wohnstandortwahl beeinflusst: Dass eine räumliche Trennung von Nachfrageorten („disperse Wohnorte“) und Angebotsstandorten ermöglicht bzw. begünstigt wird, fördert Suburbanisierungseffekte („Auflockerung der Städte“) (ebd., S. 108)

- Politische und gesamtwirtschaftliche Veränderungen: Diese Entwicklungen sind am wenigsten konkretisiert, sie beziehen sich auf Einflüsse von abseits des ZO-Systems; hierzu zählen u.a. Veränderungen in den politischen Grenzen oder allgemein gültige Veränderungen in den Produktionskosten sowie technischer Fortschritt (z.B. Verkehrs- und Kommunikationstechnologie)

CHRISTALLER skizziert im dynamischen Teil seiner Zentrale-Orte-Theorie also eine Reihe von Entwicklungsmöglichkeiten, die eine deutliche inhaltliche Erweiterung seines Grundmodells darstellen. Fernab dessen existieren viele separate Dynamisierungsansätze, die z.T. auf diesen Gedanken aufbauen (z.B. AlLEN/SANGLIER 1979 u. 1981, BÖKEMANN 1967, LANGE 1973, RATERS 1976). Ein ausschlaggebender Teil der Dynamik zentralörtlicher Systeme ist die Entstehung räumlicher Disparitäten der Ausstattung bzw. Versorgung im Kontext von (positiven) Agglomerationseffekten, die im Grundmodell noch nicht berücksichtigt werden.

\subsubsection{Agglomerationen und räumliche Disparitäten der Ausstattung}

Da die Möglichkeit von Kopplungskäufen einen zentralen Ort bzw. Angebotsstandort aus Sicht der Konsumenten attraktiver macht, wirkt sich dies positiv auf seine Kundenzuflüsse aus dem Marktgebiet aus (siehe Kap. 2.3.1.4). Für die Perspektive des Grundmodells, in der nur Einzweckeinkäufe stattfinden, ist dieser Gedanke ohne Belang, nicht jedoch dann, wenn Mehrzweckeinkäufe in Kombination mit einer Transportkostenminimierung angenommen werden und die Konsumenten in den Nachfrageorten ihre Einkaufsstättenwahl danach ausrichten. Dieser Zusammenhang schlägt sich in mehreren Gesichtspunkten der dynamischen Entwicklung von zentralörtlichen Systemen nieder.

Da die Attraktivität von Angebotsstandorten durch die Anzahl der dort angebotenen Güter ausgemacht wird, resultieren angebotsseitige Veränderungen, d.h. Hinzukommen bzw. Abbau einzelner Angebotsformen, notwendigerweise in der Veränderung dieser Attraktivität. Wird an einem zentralen Ort ein bestimmtes Gut nicht mehr angeboten (z.B. wegen der Schließung eines einzelnen Betriebs), kann dies unter der Bedingung, dass dieses Gut im Rahmen von Mehrzweckeinkäufen mit dem Erwerb eines anderen Gutes gekoppelt wird, zu einer Umlenkung der Kundenflüsse führen: Die Einkaufsorientierung der Verbraucher ändert sich dahingehend, dass sie - zwecks Aufwandsminimierung - einen weiter entfernten 
Angebotsstandort aufsuchen, an dem sie beide Güter erwerben können (CHRISTALLER 1933, S. 95f.). In einer Abwägung zwischen Transportkosten und Nutzen der Angebotsstandorte ist der weiter entferntere aufgrund seines Kopplungspotenzials nun also attraktiver als der nähere. Analog wirkt sich die Ausweitung des Angebots an einem Angebotsstandort in einer Steigerung der Gesamtnachfrage aus: „Nach gleichen Überlegungen wird ein zentraler Ort, der eine neue Art eines zentralen Gutes anbietet, eine höhere Zunahme des Verkaufs an zentralen Gütern überhaupt zu verzeichnen haben, als auf das neue zentrale Gut allein entfällt, einmal durch die Ersparung von Wegekosten für die disperse Bevölkerung, zum anderen durch Zuwanderung der Nachfrage nach den bisherigen zentralen Gütern aus den benachbarten Gebieten" (ebd., S. 96).

Die Attraktivität zentraler Orte spiegelt sich wiederum in der Größe ihres Marktgebietes: Eine Zunahme (bzw. Abnahme) an zentralen Gütern stärkt (bzw. schwächt) den jeweiligen zentralen Ort im Vergleich zu konkurrierenden Angebotsstandorten, da die räumliche Ausdehnung seines Marktgebietes wächst (bzw. schrumpft): „Eine Änderung der Bedeutung eines zentralen Orts wirkt unmittelbar auf eine Änderung der Reichweite der zentralen Güter [...] dadurch, dass mehrere Arten von zentralen Gütern ,in einem Gang', d.h. mit einmaliger Aufwendung der Wegekosten, erworben werden können [...] Die Folge von einer Vermehrung bzw. Verminderung der Anzahl von Güterarten, die an einem zentralen Ort angeboten werden, ist [...] eine Vermehrung bzw. Verminderung der Bedeutung des zentralen Orts; es vergrößert bzw. verringert sich entsprechend die Reichweite aller an ihm angebotenen Güterarten, weshalb die Bedeutung des Orts um mehr als nur um den Verbrauch der zusätzlichen bzw. abgängigen Güterarten steigt bzw. sinkt" (ebd., S. 109). Der Zuzug (bzw. Wegfall) eines einzelnen Anbieters betrifft also auch alle anderen Anbieter am selben Angebotsstandort in positiver (bzw. negativer) Weise, da sie über kundenseitige Kopplungen miteinander in Beziehung stehen.

Wenn nun die Kopplungsmöglichkeiten in den gut ausgestatteten Angebotsstandorten immer weiter ausgebaut werden, dehnen sich dementsprechend deren Marktgebiete auf Kosten der Orte mit geringerem Kopplungspotenzial aus, was wiederum die betriebswirtschaftliche Tragfähigkeit inres Angebotes beeinträchtigt: „Wird die Reichweite [...] vergrößert, so heißt das, dass das betreffende zentrale Gut, das bisher vielleicht an allen zentralen Orten niederer Ordnung angeboten werden musste, damit das ganze Land versorgt wird, nur noch an wichtigeren zentralen Orten angeboten zu werden braucht, wo das Angebot in größerer Menge erfolgen kann, da jetzt ein größeres Gebiet innerhalb der Reichweite liegt; mit der größeren Zentralisation der Produktion bzw. des Angebots ist aber in der Regel eine Verbilligung verbunden, was einen Vorsprung der zentralen Orte höherer Ordnung vor den zentralen Orten niederer Ordnung in Bezug auf dieses Gut mit sich bringt [...]" (ebd., S. 110f.). Aufgrund der Ausdehnung der Marktgebiete großer Angebotsstandorte wird also das Angebot in den kleineren möglicherweise grundsätzlich in Frage gestellt, wobei die Folge sein kann, „[...] dass die kleineren Märkte absterben“ (ebd., S. 111).

Agglomerationsvorteile durch die Möglichkeit von Kopplungskäufen und damit verknüpften Preissenkungen aufgrund von steigenden Skalenerträgen bei der Güterproduktion (z.B. Verkaufsflächenerweiterung eines Einzelhandelsbetriebs in Verbindung mit größeren Minimal- und Maximalumsätzen) werden also dahingehend wirksam, dass größere Angebotsstandorte gegenüber kleineren über eine bessere Marktposition verfügen. Dieser Effekt wird stärker, je mehr Angebot in den ranghohen zentralen Orten hinzukommt bzw. in 
den rangniedrigen zentralen Orten wegbricht; die räumlichen Disparitäten zwischen den Angebotsstandorten werden also zirkulär-kumulativ verstärkt, bis ggf. sogar kleinere zentrale Orte vollständig verschwunden sind und somit räumliche Versorgungslücken - auch bei Gütern niedrigen Ranges (!) - hinterlassen. Gesteigert werden kann dieser Effekt auch durch Veränderungen auf Betriebsformenebene, wenn aufgrund sich ausdehnender Marktgebiete gewisse zentrale Güter in ihrer Rangstufe steigen, da sie sukzessive von Anbietern mit größerer Sortimentsbreite und -tiefe angeboten werden, die tendenziell (nur) an ranghohen Angebotsstandorten lokalisiert sind; der Ausbau solcher Anbieter - als Beispiel werden Warenhäuser genannt - geht wiederum auf Kosten kleinerer Anbieter, die (auch) in kleineren Angebotsstandorten vorkommen, und somit auch zu Lasten dieser Orte (ebd., S. 102).

Auch nachfrageseitige Veränderungen können zu Lasten kleiner bzw. zu Gunsten großer Angebotsstandorte mit hohem Kopplungspotenzial gehen. Bei schwindender Kaufkraft im gesamten ZO-System sind Auswirkungen auf die Preisstruktur zu erwarten: In den kleinen Angebotsstandorten werden die Preise der Güter sinken, um weiterhin Kunden zu binden; dieser Trading-down-Effekt („Ausverkauferscheinung“) ist jedoch nur vorübergehend, da sich die Nachfrager langfristig in Richtung der besser ausgestatteten Angebotsstandorte orientieren, was zu Lasten der kleinen geht. Diese Aspekte werden noch verstärkt, wenn die Nachfrageelastizität der zentralen Güter berücksichtigt wird, d.h. die Zu- oder Abnahme der Nachfrage nach diesen Gütern unter den Bedingungen von Einkommens- und/oder Angebotsveränderungen; auch hier ist eine Stärkung ranghöherer zentraler Orte zu erwarten, da hochelastische Güter (Güter des mittel- und langfristigen Bedarfs mit großer oberer und unterer Reichweite) bevorzugt dort angeboten werden (ebd., S. 90 u. 92f.).

Einen weiteren wesentlichen Aspekt der dynamischen Theorie bilden Veränderungen des Transportkostenniveaus: Nach CHRISTALLER (1933, S. 105ff.) führt die Absenkung von Transportkosten (Z.B. geringere ÖPNV-Kosten, kürzere Fahrtzeiten) im ZO-System dazu, dass ein größerer Teil des Haushaltseinkommens der Konsumenten für die zentralen Güter selbst aufgewendet werden kann, was in einer höheren Nachfrage nach diesen Gütern bzw. einer steigenden realen Kaufkraft resultiert. Die Haushalte haben zudem die bequemere und/oder günstigere Möglichkeit, weiter entfernte Angebotsstandorte mit besserer Ausstattung (d.h. höheren Ranges) zu frequentieren, was zur Verschiebung der Nachfrage in Richtung dieser Orte führt. Die Höhe der Transportkosten beeinflusst also, ähnlich wie der Ausbau des Angebots, die räumliche Ausdehnung der Marktgebiete zentraler Orte, wobei diese umso mehr profitieren, je mehr Kopplungsmöglichkeiten sie bieten (ebd., S. 110f.).

In der dynamischen Betrachtung des zentralörtlichen Systems werden also deutlich die simultanen Wachstums- und Schrumpfungsprozesse zentraler Orte im Kontext von positiven Agglomerationseffekten aufgezeigt; das Kundenverhalten bringt einen Anreiz zur Ballung von Anbietern verschiedener Branchen mit sich, die über Kopplungsbeziehungen miteinander verbunden sind (Urbanisierungsvorteile). Das Ergebnis ist eine räumliche Konzentration des Angebotes von zentralen Gütern an großen Angebotsstandorten; diese wachsen, während kleine schrumpfen und ggf. sogar vollständig aufgegeben werden (d.h. Polarisierung der Angebotsstandorte). Angefacht wird dies noch durch eine bessere Erreichbarkeit weiter entfernter, spärlich gestreuter Angebotsstandorte hohen Ranges. Das Endresultat ist die Konzentration des Angebots an wenigen großen zentralen Orten und somit räumliche Disparitäten der Ausstattung bzw. Versorgung mit zentralen Gütern, was eine Folge des 
freien Marktgeschehens ist, „[...] eine Bevorzugung der großen Städte auf Kosten der kleinen, aus streng wirtschaftlichen Erwägungen heraus“ (ebd., S. 107).

Unberücksichtigt bleiben in dieser Betrachtung allerdings Lokalisierungsvorteile ${ }^{19}$. Außerdem wird das Kopplungsverhalten allein durch die Transportkostenminimierung erklärt, während andere mögliche Gründe keine Rolle spielen; dieses Konsumentenverhalten unterliegt selbst auch keiner Dynamik. Es existieren viele Erweiterungen der Zentrale-Orte-Theorie, die das Wirkungsgeflecht von Kopplungskäufen und Agglomerationen zum Gegenstand haben (z.B. BÖKEMANN 1967, EATON/LIPSEY 1982, FORSTER/BRUMMELL 1984, FUJITA et al. 1988, GHOSH 1986, KOHSAKA 1984, LANGE 1973, MULLIGAN 1984, VANDENBROUCKE 1995); ein diesbezüglich besonders hervorstechender Theorieansatz (LANGE 1973) wird in Kap. 2.3.3 besprochen. Zunächst soll aber die Theorie von LöscH (1944) diskutiert werden.

\subsubsection{Die Theorie der Wirtschaftsgebiete von LöscH}

\subsubsection{Grundlagen und Beziehungen zur Zentrale-Orte-Theorie}

Die Raumwirtschaftstheorie des Ökonomen LÖscH (1944), die er in seinem Werk Die räumliche Ordnung der Wirtschaft präsentiert, ist in ihrer Grundmotivation anderer Natur als die Theorie von CHRISTALLER (1933); wesentliche Kernaussagen beider Theorien insbesondere diejenigen mit der größten Relevanz für die vorliegende Arbeit - ähneln sich aber stark (Übersicht zu LöscHs Theorie siehe z.B. DEITERS 1978, GüSSEFELDT 2005, PARR 2002c). Der Ansatz von LÖSCH hat einen anderen Erklärungsgegenstand als die ZentraleOrte-Theorie: Während CHRISTALLER versuchte, eine Theorie zur Erklärung der faktisch bestehenden Hierarchie von Siedlungen bzw. Angebotsstandorten aufzustellen, ist der Ansatz von LÖSCH rein normativer Natur: Statt einem „Kapitulieren vor der Wirklichkeit“, d.h. der Erklärung tatsächlicher Phänomene, geht es dahin, ein optimales bzw. „vernünftiges“ Standortsystem zu entwickeln, denn „das eigentliche Geschäft der Ökonomen“ sei „nicht, die miserable Wirklichkeit zu erklären, sondern zu verbessern" (LÖSCH 1944, S. 2). Gegenstand der Theorie ist also nicht die tatsächliche, sondern eine ideale Raumstruktur; obligatorisch ist folglich die Annahme eines vollständig „rationalen“ Verhaltens (Nutzenmaximierung, vollständige Information) der Marktteilnehmer (PARR 2002c, S. 34).

Die räumliche Wirtschaft wird demnach maßgeblich von zwei gegenläufigen ökonomischen Kräften bestimmt, nämlich der „einzelwirtschaftlichen [...] Tendenz zur Maximierung des Vorteils“ (d.h. Nutzen- bzw. Gewinnmaximierung) und der "gesamtwirtschaftlichen [Tendenz] zur Maximierung der Selbständigen" (d.h. Markteintritt neuer Anbieter, so lange wie Gewinne zu erwarten sind) (LösCH 1944, S. 63). Die Zielgröße von LöscHs Theorie ist ein räumliches Gleichgewicht, als dessen Bedingungen er neben der Nutzen-/Gewinnmaximierung eine vollständige räumliche Abdeckung bei gleichzeitiger Nichtüberschneidung der Marktgebiete sowie freien Marktzutritt, ein Marktgleichgewicht und minimale Marktgebietsgrößen einzelner Anbieter voraussetzt (ebd., S. 64f.); die Annahmen entsprechen also im Wesentlichen denen CHRISTALLERS, nur dass sie von LÖSCH explizit genannt werden (DEITERS 1978, S. 24f.). Die Theorie bezieht sich zudem auf alle Wirtschaftszweige, wobei oftmals der primäre Sektor

\footnotetext{
${ }^{19}$ Zwar wird die Ballung von Konkurrenten an einem Angebotsstandort als Vorteil für die Konsumenten vermerkt, jedoch nicht aufgrund von Vergleichskäufen, sondern in Folge einer durch einen intensiven Wettbewerb induzierten Preissenkung (CHRISTALLER 1933, S. 92).
} 
ausgeklammert wird, da dessen Markt- und Standortbedingungen als grundsätzlich anders erachtet werden (LÖSCH 1944, S. 67). Die Theorie von LÖSCH ist also ausdrücklich auch auf konsumentenorientierte Dienstleistungen anwendbar, was sich daran zeigt, dass er selbst an vielen Stellen konkrete Bezüge zum Einzelhandel nimmt (z.B. S. 48, 51, 75 u. 291ff.).

In der Ableitung einer optimalen Wirtschaftslandschaft bezieht sich LÖSCH (1944, S. 71) auf verschiedene vorherige ökonomische sowie geographische Ansätze (u.a. vON THÜNEN, WEBER und CHRISTALLER); besondere Berücksichtigung erfährt jedoch die Theorie der monopolistischen Konkurrenz von CHAMBERLIN, die dem räumlichen Markt ausdrücklich zu Grunde gelegt wird (LÖSCH 1944, S. 49f. u. 74ff.). Ähnlich wie CHRISTALLER im Hinblick auf den statischen und dynamischen Teil differenziert auch LösCH zwischen vereinfachten Ausgangsbedingungen („Wirtschaftsgebiete unter einfachen Verhältnissen“, S. 71-96) und komplexeren Umständen („Wirtschaftsgebiete unter schwierigen Verhältnissen“, S. 96-154); die Grundlagen werden zuvor in den „Ausgewählten Standortfragen“ (S. 9-70) besprochen.

Genau wie CHRISTALLER identifiziert LÖSCH (1944, S. 72f.) Transportkosten als wesentlichen Bestandteil des räumlichen Marktes; diese bezeichnet er jedoch als Versandkosten, da er in seiner Theorie davon ausgeht, dass die Güter vom Angebotsstandort aus an die Konsumenten geliefert werden. Da aber die Versandkosten wiederum von den Verbrauchern getragen werden und somit den Gesamtpreis der Güter unmittelbar mitbestimmen, ist es für den weiteren theoretischen Inhalt irrelevant, welche Instanz das Gut im technischen Sinne tatsächlich transportiert (FITTKAU 2004, S. 45); der Einfluss der Transportkosten auf den Preis eines Gutes ist also kein anderer als in der Theorie der zentralen Orte ${ }^{20}$. Unter Berücksichtigung der Bereitschaft von Konsumenten, diese Transportkosten auf sich zu nehmen, ergibt sich die maximale Versendungsweite, die für jedes Gut verschieden ist (LÖSCH 1944, S. 74); dieser Begriff entspricht der oberen Grenze der Reichweite nach CHRISTALLER, ist also die äußere Grenze eines Marktgebietes. Das für eine betriebswirtschaftlich tragfähige Aufrechterhaltung des Angebots minimal nötige Marktgebiet wird als notwendige Versendungsweite bezeichnet (LösCH 1944, S. 80). Die Grundbedingungen sind also denen von CHRISTALLERS Theorie ähnlich; Unterschiede bestehen jedoch in der Relevanz und den Ausprägungsformen von Agglomerationseffekten.

\subsubsection{Agglomerationseffekte und die Bildung von Angebotsstandorten}

Das gesamte System von LÖSCH basiert auf der räumlichen Ballung von wirtschaftlichen Aktivitäten an bestimmten Orten. Diese Orte werden als Städte bezeichnet, wobei auch hier keine politisch-administrative Einheit gemeint ist, sondern eine „punktförmige Häufung nichtlandwirtschaftlicher Standorte [einzelner Betriebe, d. Verf.]" (LÖSCH 1944, S. 47), was CHRISTALLERS Definition von zentralen Orten gleichgesetzt wird (LÖSCH 1944, S. 87). Die Beweggründe für die Bildung von Agglomerationen bespricht LÖsCH in seinem Kapitel „Ursachen der Stadtbildung“ (S. 47-54), wobei er drei Formen von Agglomerationseffekten differenziert (ebd., S. 48ff.):

- „Vorteile der Massenherstellung“ in großen Einzelbetrieben (steigende Skalenerträge)

\footnotetext{
${ }^{20}$ Allerdings ist Löschs Vorstellung von Transportkosten enger gefasst als die von CHRISTALLER; er berücksichtigt lediglich reine Frachtkosten (LöSCH 1944, S. 73). Es handelt sich dabei also um einen Teil dessen, was bei CHRISTALLER als „objektive wirtschaftliche Entfernung“ bezeichnet wird (siehe Kap. 2.3.1.2). Für die Ableitung von Marktgebieten spielt die tatsächliche Form der Transportkosten jedoch ebenso keine Rolle.
} 
- „Häufung gleichartiger Unternehmen“ (aufgrund von Lokalisierungsvorteilen)

- „Häufung verschiedenartiger Unternehmen“ (aufgrund von Urbanisierungsvorteilen)

Diese Dreiteilung entspricht dem klassischen Verständnis von Agglomerationseffekten (siehe Kap. 2.1.1). Da für die vorliegende Arbeit nur die Agglomerationsvorteile im Einzelhandel von Interesse sind, werden auch nur diese im Folgenden berücksichtigt. Lokalisierungsvorteile im Einzelhandel entstehen u.a. über die Möglichkeit von Vergleichskäufen für die Konsumenten aufgrund der räumlichen Ballung im Wettbewerb stehender Anbieter: „An einigen Orten würden sich gleich mehrere solche Unternehmungen [gleichartige bzw. konkurrierende Anbieter, d. Verf.] festsetzen, [...] weil dies die Nachfrage für jede einzelne von ihnen erhöht, da die Käufer gewisser (nicht strikt vergleichbarer) Waren vorziehen, dort zu kaufen, wo sie verschiedene Ausführungen vergleichen können [...]" (LöscH 1944, S. 48). Hinzu kommen noch weitere Lokalisierungsvorteile, die jedoch für alle Wirtschaftszweige in unterschiedlicher Intensität gelten und bei konsumentenorientierten Dienstleistungen eher zu vernachlässigen sind, zumal es sich nicht um nachfrageseitige Agglomerationseffekte handelt (z.B. Nähe zu Zulieferern, Fachkräftepool etc.). Die Lokalisierungsvorteile können den Wettbewerbseffekt überlagern und eine so günstige Marktposition schaffen, dass für Konkurrenten an anderen Angebotsstandorten kein rentabler Marktzugang möglich ist (ebd., S. 48f.).

In Bezug auf die Vorteile räumlicher Ballung verschiedenartiger Anbieter aufgrund von Urbanisierungsvorteilen nennt LösCH die Möglichkeit von Kopplungskäufen: „Dass die Verbraucher insbesondere kleinere Einkäufe miteinander verbinden oder verschiedene Qualitäten nicht-standardisierter Güter vergleichen wollen, ist für die Stadtbildung nicht viel weniger wichtig als für das Entstehen besonderer Geschäftsviertel innerhalb der Stadt und von Warenhäusern innerhalb dieser Viertel. Ihr bloßes Nebeneinander senkt nicht bloß für die Erzeuger die Kosten (namentlich die allgemeinen), sondern erhöht auch die ihnen zufallende Nachfrage“ (ebd., S. 51).

Wie ChRISTALLER (siehe Kap. 2.3.1.4) leitet also auch LÖSCH eine Attraktionswirkung von Einzelhandelsagglomerationen gegenüber nicht-agglomerierten Angebotsstandorten ab. Im Vergleich zu CHRISTALLER geht LÖSCH jedoch nicht nur von Kopplungs- sondern auch von Vergleichskäufen aus; diese Ausführungen entsprechen insbesondere denen CHAMBERLINS (siehe Kap. 2.2.1.2). Werden Kopplungs- und Vergleichskäufe beim Einkauf angenommen, werden diejenigen Angebotsstandorte bevorzugt, die möglichst viel Potenzial hierzu bieten. Die Anbieter in diesen Agglomerationen profitieren daher von einer gesteigerten Nachfrage, da einerseits die Transportkostensenkung die Güternachfrage insgesamt erhöht und zudem die Möglichkeit des Warenvergleichs mehr Kunden anlockt; sie können ihre „Produktion“ ausdehnen, womit ihre Produktionsstückkosten sinken, da ja auch steigende Skalenerträge angenommen werden. Dies führt zu geringeren Abholpreisen, was sich wiederum positiv auf die Nachfrage auswirkt. Abgesehen von der expliziten Beachtung von Vergleichskäufen entspricht dies den Ausführungen CHRISTALLERS (siehe Kap. 2.3.1.4).

LÖSCH sieht diese nachfrageseitigen positiven Agglomerationseffekte einerseits als Grund für die existierende räumliche Ballung (z.B. in zentralen Innenstadtbereichen), andererseits auch als Basis für seine ideale Wirtschaftslandschaft: „In jedem Wirtschaftsgebiet ist es [...] vorteilhaft, die Marktnetze der einzelnen Güter an einem Punkt zur Deckung zu bringen“ (LÖSCH 1944, S. 52). Agglomerationsvorteile sind die „Ursachen der Stadtbildung“ und somit die Grundvoraussetzungen von LöScHs Theorie: „Wir behandeln Markträume [...], die aus 
dem Gegenspiel rein ökonomischer Kräfte sich ergeben, von denen die einen auf räumliche Versammlung hinwirken [Zentripetale Kräfte, d. Verf.], die anderen auf Zerstreuung [Zentrifugale Kräfte, d. Verf.]. Die konzentrierenden Kräfte sind die Vorteile der Spezialisierung und der Erzeugung im großen [Interne und externe Agglomerationsvorteile, d. Verf.], die auflockernden Kräfte sind die Vorteile der Vielseitigkeit und die Versandkosten [Transportkosten, d. Verf.]“ (ebd., S. 72). Neben den Annahmen zum Verhalten der Marktteilnehmer und dem Effekt von Transportkosten (siehe Kap. 2.3.2.1) sind also alle Ausführungen LösCHs stets vor dem Hintergrund zu verstehen, dass Unternehmer mit steigenden Skalenerträgen produzieren und aus den aufgezeigten Gründen Lokalisierungsund Urbanisierungsvorteile bestehen. Agglomerationsnachteile liegen einerseits in den steigenden Bodenpreisen (wie bei CHRISTALLER) sowie in einer Überlastung des Verkehrs und weiteren volkswirtschaftlichen Kosten (LÖSCH 1944, S. 51).

\subsubsection{Wirtschaftsgebiete unter „einfachen“ und „schwierigen“ Verhältnissen}

Im Grundmodell („Einfache Verhältnisse“) werden zunächst ähnliche Annahmen hinsichtlich des Raums und der sozio-demographischen Eigenschaften seiner Bewohner getroffen wie im ZO-Grundmodell, d.h. räumliche Homogenität und identische Nachfragereigenschaften (PARR 2002c, S. 34). Auf dieser Grundlage wird ein Markt- und Raumgleichgewicht in einem Markt mit monopolistischer Konkurrenz abgeleitet, wobei zunächst die Größe und danach die geometrische Form optimaler Marktgebiete bestimmt werden (LösCH 1944, S. 74f.):

- Ein einzelner Anbieter (Bierbrauer) beginnt mit dem Verkauf seines Gutes. Er wählt hierbei seinen Standort so, dass er für seine Kunden möglichst bequem und von den Konkurrenten möglichst weit entfernt ist und er somit das maximal mögliche Marktgebiet für sein angebotenes Gut ausschöpfen kann (Gewinnmaximierung); diese relative (räumlich bedingte) Monopolstellung sichert inm Sondergewinne, da er mehr verkauft als es nur zur Deckung der Produktionskosten nötig wäre

- Solange im Markt für dieses Gut Sondergewinne möglich sind, werden dadurch weitere Unternehmer motiviert, eine eigene Verkaufsstelle zu eröffnen (Prinzip der Maximierung selbständiger Existenzen); diese wählen ihren Standort ebenso nach dem Prinzip, sich von ihren Konkurrenten räumlich optimal zu differenzieren und treten in die geographischen "Nischen“ des Marktes ein. Hierdurch wird das maximal mögliche Marktgebiet jedes einzelnen Anbieters und damit seine Nachfrage sukzessive verkleinert

- Die Nachfrage der einzelnen Anbieter sinkt soweit, dass sie nur noch ihre Produktionskosten deckt und die Sondergewinne verschwunden sind; die maximal möglichen Marktgebiete entsprechen nun den minimal nötigen Marktgebieten. Der Markt ist - aus dem Blickwinkel der monopolistischen Konkurrenz - im Gleichgewicht

- Die einzelnen Anbieter sind auf den Ecken gleichseitiger Dreiecke angeordnet und verfügen somit über den größtmöglichen Abstand voneinander. Unter den genannten Ausgangsbedingungen sind hexagonale Marktgebiete aus geometrischen Gründen die optimale Form im Hinblick auf die vollständige Abdeckung des Raums

Ausgehend davon, dass jedes Gut ein eigenes minimal nötiges Marktgebiet hat, ergibt sich ein Netz von unzähligen übereinander liegenden Marktgebieten unterschiedlicher Größe (ebd., S. 81ff.). Unter der Annahme, dass es Güter gibt, deren maximales Marktgebiet gleich 
groß ist, werden zwecks Vereinfachung alle Güter, auf die dieses zutrifft, zu einer Güterklasse aggregiert, so dass ihre Ausdehnung identisch ist (ebd., S. 85); diese Überlegung ist der CHRISTALLERs im Hinblick auf die Bedarfsstufen der Güter und ihrer damit zusammenhängenden Reichweite durchaus ähnlich (siehe Kap. 2.3.1.3).

Die Tatsache, dass unzählige übereinander liegende Marktgebiete für die unterschiedlichen Güter bzw. Güterklassen existieren, bedeutet aber nicht, dass es Wechselwirkungen zwischen ihnen gibt. Bezogen auf den Einzelhandel wird also jedes Gut separat betrachtet, d.h. ein räumlich und sachlich monofinaler Einkauf ohne Kopplungs- oder Vergleichskäufe angenommen. Die Berücksichtigung von Agglomerationseffekten wird erst durch die Verbindung dieser Netze vorgenommen (FITTKAU 2004, S. 51f.; PARR 2002b, S. 39f.). Das Ziel hierbei ist eine Optimierung des Systems der Marktnetze: „Erstens legen wir die Netze so, dass alle wenigstens einen Mittelpunkt gemeinsam haben. Hier wird eine Großstadt entstehen mit allen Vorteilen einer bedeutenden örtlichen Nachfrage [gemeint sind die Agglomerationsvorteile aus den „Ursachen der Stadtbildung“, d. Verf.]. Zweitens drehen wir die Netze um diesen Mittelpunkt so, dass wir 6 Sektoren mit vielen und 6 mit wenigen Erzeugungsorten erhalten [...]. Bei dieser Anordnung fallen am meisten Standorte [Verkaufsbzw. Produktionsstätten, d. Verf.] zusammen, am meisten Einkäufe können am Ort erfolgen, die Summe der Mindestabstände der gewerblichen Standorte voneinander ist am kleinsten, und infolgedessen werden nicht nur die Transporte, sondern auch die Transportlinien auf ein Mindestmaß reduziert" (LösCH 1944, S. 86).

Die Berücksichtigung von Agglomerationsvorteilen geschieht also durch eine Rotation der Netze, wodurch ihre Anordnung so optimiert wird, dass möglichst viele Einzelstandorte geballt sind (Maximale Standortkoinzidenz), was ein Maximum an Kopplungsmöglichkeiten bei einer Minimierung der Transportkosten für die Konsumenten ermöglicht (PARR 2002b, S. 40). Die Netzrotation lässt sich auch als Resultat interdependenter Standortentscheidungen von Anbietern unterschiedlicher Güter interpretieren (GüSSEFELDT 2005, S. 73f.). Der Zusammenhang von Agglomerationsvorteilen und Transportkosten entspricht also dem in CHRISTALLERS Theorie (siehe Kap. 2.3.1.4). Analog bewirken steigende Skalenerträge niedrigere Verbraucherpreise: „Je größer die Ansammlung von Industrien, desto billiger sind offenbar im Durchschnitt die gewerblichen Güter. Der Stand ihrer Großhandelspreise ist darum am niedrigsten in der Großstadt" (LÖSCH 1944, S. 89).

Die ideale Wirtschaftslandschaft LöscHs wird unter der Annahme einer diskontinuierlichen, d.h. selbst bis zu einem gewissen Grad räumlich geballten Bevölkerung, weiter entwickelt, wobei auch eine Differenzierung in "städtereiche" und "städtearme“ Gebiete in der Wirtschaftslandschaft sowie ein System der Zuteilung von Marktgebieten zu Angebotsstandorten erfolgt ( $\mathrm{LÖSCH}$ 1944, S. 86ff.); eine Besprechung dieser weiteren Ausführungen soll hier ausbleiben, da das grundlegende Prinzip aufgezeigt und die Bedeutung von Agglomerationsvorteilen herausgearbeitet wurde (Ausführliche Erklärung und Diskussion der Inhalte siehe GüSSEFELDT 2005, S. 69ff.).

Ähnlich wie im dynamischen Teil der ZO-Theorie beschäftigen sich die „Wirtschaftsgebiete unter schwierigen Verhältnissen" mit der Aufhebung verschiedener restriktiver Annahmen der "einfachen Verhältnisse“; diese zielen jedoch nicht (primär) auf Veränderungen im Zeitverlauf, sondern auf (bereits bestehende) räumliche Unterschiede ab, d.h. schränken die genannten Homogenitätsbedingungen ein. Hierbei fokussiert LÖSCH (1944, S. 97ff.) die nachstehenden Gesichtspunkte: 
- Ökonomische Unterschiede (z.B. räumliche Preis- und Produktunterschiede sowie Unterschiede in den Transportkosten ${ }^{21}$ )

- Sozio-demographische Unterschiede (z.B. hinsichtlich der Konsumgewohnheiten)

- „Natürliche“ Unterschiede (d.h. naturräumliche Gegebenheiten)

- Politische Unterschiede (z.B. hinsichtlich der Grenzziehung)

\subsubsection{Die Wachstumstheorie zentralörtlicher Systeme von LANGE}

\subsubsection{Grundlagen und Analyserahmen}

Die Wachstumstheorie zentralörtlicher Systeme von LANGE (1973) gehört zu den Ansätzen zur Dynamisierung der Zentrale-Orte-Theorie von CHRISTALLER (1933), deren Fokus auf der Betrachtung von Agglomerationseffekten liegt; LANGES Ansatz bietet also sowohl eine Dynamisierung als auch eine eingehende Berücksichtigung des für die vorliegende Forschungsfrage wichtigen Zusammenhangs. Die Bezeichnung "Wachstumstheorie" ist hierbei insofern irreführend, als dass nicht nur Wachstumsprozesse, sondern parallel auch Schrumpfungs- und Stagnationsprozesse in einem ZO-System behandelt werden (HEINRITZ 1979, S. 146); es handelt sich also um einen theoretischen Ansatz zur Erklärung der Entwicklung räumlicher Disparitäten zwischen Angebotsstandorten.

Ein wesentlicher Aspekt der Theorie ist die Abkehr von den strikten Verhaltensannahmen neoklassischer Theorien (z.B. Gewinnmaximierung der Unternehmer, Nutzenmaximierung der Konsumenten, vollständige Information) zu Gunsten eines Handlungsspielraumes, der den Rahmen für die möglichen Entscheidungen der Nachfrager und Anbieter setzt; die Annahme eines homo oeconomicus würde alle hierzu inkompatiblen, aber real existierenden Verhaltensweisen als irrationale Abweichungen abstufen und von der theoretischen Betrachtung ausschließen. Das Ziel der Analyse des Konsumentenverhaltens ist demnach nicht die definitive Voraussage der Einkaufsstättenwahl (LANGE 1973, S. 9 u. 31). In ähnlicher Weise wird die Angebotsseite betrachtet; es wird nicht der Versuch der Bestimmung eines optimalen Standortes unternommen, sondern die Erklärung des tatsächlich gewählten (ebd., S. 89). Diese Grundüberlegungen unterscheiden sich also deutlich von den Vorstellungen CHRISTALLERS und LÖSCHS, die sich am Menschenbild des homo oeconomicus orientieren, und auch von anderen Ansätzen der ZO-Dynamisierung, denen ähnlich vereinfachte Annahmen zugrunde liegen (HEINRITZ 1979, S. 134f.).

Im Fokus von LANGES Theorie stehen die räumlichen Auswirkungen von Veränderungen des Konsums der privaten Haushalte auf ein Zentrale-Orte-System, wobei diese Orte als Geschäftszentren bezeichnet werden, die als "Gruppe von Geschäften“ unterschiedlicher Größe definiert sind (LANGE 1973, S. 10ff.). Je nach Betrachtungsebene kann ein Geschäftszentrum eine ganze Stadt (im administrativen Sinne), das Geschäftsviertel einer Innenstadt oder auch nur ein einzelner Straßenzug sein; entscheidend ist hierbei lediglich, dass der Angebotsstandort von Konsumenten als zusammengehörig wahrgenommen wird (ebd., S. 35f.). Diese „Geschäftszentren“ sind also (Einzelhandels-)Agglomerationen bzw.

\footnotetext{
${ }^{21}$ Wie CHRISTALLER diskutiert auch LÖSCH (1944, S. 122f.) Unterschiede in den Transportkosten, wobei auch hier eine allgemeine Senkung des Transportkostenniveaus eine Stärkung der am besten ausgestatten Angebotsstandorte mit sich bringt. Der Grund hierfür liegt ebenso in einer Aufwandsersparnis für die Verbraucher.
} 
Angebotsstandorte unterschiedlicher Größe und entsprechen im Wesentlichen der Definition eines „Zentralen Ortes“ (CHRISTALLER) oder einer „Stadt“ (LÖSCH).

Unter Berücksichtigung konsumenten- und unternehmerseitiger Verhaltensweisen und deren Interaktionen ergeben sich die Leitfragen von LANGES Untersuchung im Hinblick auf die Stabilität eines Systems von Angebotsstandorten: „Gibt es Bedingungen, unter denen Geschäftszentren relativ oder sogar absolut an Bedeutung verlieren? Kommt es regelmäßig zu einer solchen Bedingungskonstellation?" (LANGE 1973, S. 12). In diesem Zusammenhang analysiert LANGE zunächst das Konsumentenverhalten und dessen Einflussfaktoren und dann das damit verbundene Unternehmerverhalten, um daraus die Entwicklung des Systems von Angebotsstandorten aufzuzeigen ${ }^{22}$. Entsprechend der Abkehr von restriktiven Grundbedingungen und ökonomisch „optimalem“ Verhalten trifft LANGE keine definitiven Voraussagen - diese wären "reine Prophetie“ (ebd., S. 9) - sondern diskutiert stattdessen stets ausführlich diverse Varianten möglicher Entscheidungen und ihre Resultate.

\subsubsection{Determinanten und Ausprägungen des (räumlichen) Einkaufsverhaltens}

In der Theorie von LANGE wird das Konsumentenverhalten in einen nicht-räumlichen und einen räumlichen Aspekt getrennt, wobei sich ersteres in letzterem wiederfindet, sobald räumliche Aspekte - insbesondere die Notwendigkeit von Einkäufen bei einer räumlichen Trennung von Anbietern und Nachfragern - berücksichtigt werden. Völlig unabhängig vom räumlichen Einkaufsverhalten existieren zunächst individuelle Konsumgewohnheiten bzw. -notwendigkeiten, die zusammengefasst als Verbrauchsprofil bezeichnet werden. Das Verbrauchsprofil ist "die Menge der von einem Konsumenten oder einer Gruppe von Konsumenten in einem bestimmten Zeitraum nachgefragten Güter" (LANGE 1973, S. 15), wobei unter "Gütern" sowohl Waren als auch Dienstleistungen verstanden werden; dieses unterliegt einem zeitlichen Wandel und wird von verschiedenen Faktoren beeinflusst (z.B. Einkommen, Beschäftigung, Alter, Geschlecht, Freizeit, Werbung, Preis und Qualität des Angebots etc.), wobei das Einkommen (hier: das Pro-Kopf-Einkommen) die wichtigste Einflussgröße darstellt, da es den Konsum letztendlich am stärksten limitiert und der Konsum das Einkommen langfristig betrachtet nicht übersteigen kann (ebd., S. 18f.).

Die Wirkung des Einkommens auf das Verbrauchsprofil wird anhand der Theorie der Engelkurven (nach ENGEL 1857) hergeleitet, wobei sich der Zusammenhang zwischen Einkommen und Verbrauchsprofil wie folgt zusammenfassen lässt (LANGE 1973, S. 20ff.):

- Je höher (bzw. niedriger) die Verbrauchshäufigkeit eines Gutes ist, desto niedriger (bzw. höher) ist dessen Einkommenselastizität, d.h. desto weniger (bzw. mehr) erhöht sich die Nachfrage bei einem Einkommenszuwachs. So genannte Luxusgüter haben eine sehr hohe Einkommenselastizität, d.h. sobald das Initialeinkommen erreicht ist, ab dem der Erwerb dieser Güter überhaupt möglich ist, steigt deren Verbrauchshäufigkeit überproportional. Lebensnotwendige Güter sind unelastisch, d.h. bei einem Einkommenswachstum steigt ihr Konsum nur wenig. Konsumenten mit geringem Einkommen fragen vorwiegend Güter großer Verbrauchshäufigkeit (z.B.

\footnotetext{
${ }^{22}$ Die Berücksichtigung des politischen Einflusses wird von LANGE (1973, S. 8 u. 12f.) ausdrücklich eingefordert und als notwendig erachtet, jedoch von ihm selbst nicht geleistet.
} 
Nahrungsmittel) nach, weniger Güter mittlerer Verbrauchshäufigkeit (z.B. Bekleidung) und noch weniger Güter kleiner Verbrauchshäufigkeit (z.B. Autos)

- Ab einem bestimmten Punkt ist ein Sättigungsniveau der Verbrauchsmenge erreicht, ab dem mit steigenden Einkommen nicht mehr Güter dieses Typs verbraucht, sondern Varianten höherer Qualität konsumiert werden

- Steigt das Einkommen der Konsumenten, wirkt sich dies in dreierlei Hinsicht aus:

- Das Verhältnis der konsumierten Güter verschiebt sich zu Gunsten von Gütern mittlerer und kleiner Verbrauchshäufigkeit; je höher die Einkommen, desto mehr solcher Güter werden erworben

- Die absolute Anzahl der nachgefragten Güter erhöht sich, da neue Güterarten hinzukommen, die vorher in Ermangelung von verfügbarem Einkommen nicht erworben werden konnten

- Die konsumentenseitigen Ansprüche im Hinblick auf die Auswahl in den nachgefragten Güterklassen steigen; dies betrifft insbesondere Konsumenten, die bereits Erfahrungen mit der jeweiligen Güterart gemacht haben (z.B. nach mehrmaligem Kauf eines Autos)

Eine Umsetzung des Verbrauchsprofils in räumliches Konsumentenverhalten erfolgt durch die Definition des Besorgungsprofils, das die "Menge der von einem Konsumenten in einem bestimmten Zeitraum durchgeführten Besorgungen" umfasst. Eine Besorgung ist hierbei der „von einem Konsumenten mit einer Raumüberwindung verbundene durchgeführte oder versuchte Einkauf von Gütern, [...] ein Weg mit Start und Ziel" (LANGE 1973, S. 29) ${ }^{23}$. Dieser Einkauf umfasst eine Reihe von notwendigen Schritten, die in der Summe den gesamten Aufwand bzw. die gesamten Transport- und sonstige Transaktionskosten dieses Einkaufs repräsentieren (ebd., S. 33ff.):

- Die äußere Raumüberwindung bezieht sich auf alle Schritte des Einkaufs außerhalb des Angebotsstandortes, z.B. die PKW- oder ÖPNV-Fahrtzeit vom Aufenthaltsort der Konsumenten zum Angebotsstandort und zurück

- Die innere Raumüberwindung umfasst alle Kosten, die am Angebotsstandort selbst anfallen, z.B. Suchkosten bei der Parkplatzsuche und der anvisierten Produkte in der Verkaufsstelle; letztere steigen mit der Größe (Verkaufsfläche) der Anbieter

Einkäufe sind also notwendigerweise mit Transaktionskosten verbunden. Auch wenn keine Nutzenmaximierung bzw. Kostenminimierung angenommen wird, sind den Kapazitäten der räumlichen Interaktionen von Konsumenten aufgrund ihrer Zeiteinteilung und anderer Faktoren immer gewisse Grenzen gesetzt; es ist für sie daher nötig, die entstehenden Transport-/Transaktionskosten (im Sinne der investierten Zeit) zumindest einen kritischen Wert nicht übersteigen zu lassen (ebd., S. 32). Daher ist ein Minimum an Kopplungskäufen unerlässlich, jedoch auch nur ein Maximum an Kopplungskäufen möglich; der

\footnotetext{
${ }^{23}$ Hierbei werden nur stationäre Angebote berücksichtigt. Da es Formen des Distanzhandels gibt und so ein bestimmter Teil der nachgefragten Güter ohne Einkaufsfahrten erworben werden kann, wird nicht das gesamte Verbrauchsprofil in das Besorgungsprofil umgesetzt (LANGE 1973, S. 31f.).
} 
verbraucherseitige Handlungsspielraum wird also durch zwei Extreme beschnitten (ebd., S. 36ff.):

- Die minimal notwendige Kopplung ergibt sich aus der notwendigen Zeiteinsparung; da das Zeitkontingent begrenzt ist, ist ein gewisses Maß an Mehrzweckeinkäufen obligatorisch

- Die maximal mögliche Kopplung kommt hingegen dadurch zustande, dass einerseits bei einem Einkauf nicht unbegrenzt Zeit zur Verfügung steht und andererseits die konsumentenseitige Besorgungskapazität begrenzt ist, d.h. dass nur eine bestimmte Gütermenge im Zuge eines einzelnen Einkaufs transportierbar ist

Die Einflüsse der minimal nötigen und der maximal möglichen Kopplung auf den Handlungsspielraum der Konsumenten werden in Abb. 7 veranschaulicht.

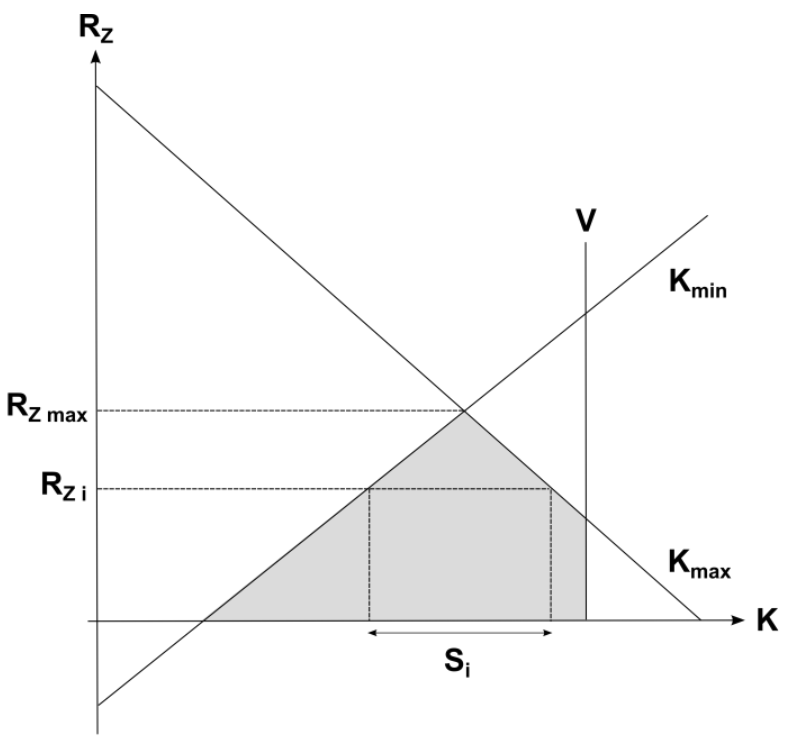

$$
\begin{aligned}
& \mathrm{R}_{\mathrm{Z}}=\text { Kosten der äußeren Raumüberwindung } \\
& \mathrm{K}=\text { Anzahl der bei einer Besorgung gekoppelten Güter } \\
& \mathrm{K}_{\min }=\text { Mindestkopplung } \\
& \mathrm{K}_{\max }=\text { Maximalkopplung } \\
& \mathrm{V}=\text { Besorgungskapazität } \\
& \mathrm{S}=\text { Spielraum } \\
& \mathrm{S}_{\mathrm{i}}=\text { Spielraum bei äußerer Raumüberwindung } \mathrm{R}_{\mathrm{Zi}}
\end{aligned}
$$

Abbildung 7: Der Handlungsspielraum der Konsumenten in der Theorie von LANGE Quelle: Eigene Darstellung nach KULKE (2005, S. 21), verändert

In Anlehnung an BöKEMANN (1967) differenziert LANGE (1973, S. 74) zudem das Kopplungsverhalten am Angebotsstandort:

- Die gleichzeitige Besorgung von Gütern gleicher Verbrauchshäufigkeit wird als horizontale Kopplung bezeichnet

- Die vertikale Kopplung umfasst die gleichzeitige Besorgung von Gütern unterschiedlicher Verbrauchshäufigkeit

Beide Formen der Kopplung können parallel während eines Einkaufs stattfinden. Zudem berücksichtigt LANGE auch Vergleichskäufe (z.B. S. 71, 99 u. 129ff.); diese liegen jedoch nicht im Zeitbudget der Konsumenten begründet, sondern in steigenden Ansprüchen.

Nach LANGE ist es nicht möglich, die Wahl eines Angebotsstandortes exakt vorauszusagen, da kein „rationales“ Verhalten im ökonomischen Sinne angenommen wird; es wird weder Nutzenmaximierung noch vollständige Information unterstellt (siehe Kap. 2.3.3.1). Das räumliche Einkaufsverhalten kann dementsprechend verschieden charakterisiert sein, je nachdem wie ausgeprägt die Konsumenten über das Angebot und den in Kauf zu 
nehmenden Aufwand (v.a. Transportkosten) informiert sind; hierbei greift LANGE auf die Gedanken von BAUMOL/IDE (1956) zurück. Dieser theoretische Ansatz hat u.a. die räumliche Einkaufsorientierung unter der Bedingung unvollständiger Information bzw. Unsicherheit zum Gegenstand. Der Grundgedanke ist ein probabilistisches Konsumentenverhalten, d.h. dass keine exakten Prognosen zur Einkaufsstättenwahl möglich sind, sondern nur Wahrscheinlichkeiten der Entscheidung für die zur Verfügung stehenden Angebotsstandorte, die von bestimmten Faktoren abhängen. Als Element, das die Einkaufswahrscheinlichkeit erhöht, wird in diesem Zusammenhang die Auswahl an Produkten identifiziert, die ein Angebotsstandort bietet; je mehr Güter dort offeriert werden, desto höher ist demnach die Wahrscheinlichkeit, bei einer Einkaufsfahrt dorthin die gewünschten Güter erwerben zu können, d.h. die eigenen (Konsum-)Bedürfnisse zu befriedigen (BAUMOL/IDE 1956, S. 93f.).

Es ergeben sich somit für unterschiedliche Informationsgrade diverse Möglichkeiten der Wahl zwischen mehreren Angebotsstandorten (LANGE 1973, S. 46ff.):

- Für den (unrealistischen) Fall, dass der Konsument eine komplette Marktübersicht hat und exakt über die Transportkosten Bescheid weiß, trifft er - wie bei CHRISTALLER und LÖSCH - seine Einkaufsstättenwahl nach der Entfernung. Hierbei entfallen jene Angebotsstandorte als Optionen, von denen bekannt ist, dass dort das gewünschte Angebot nicht vorgehalten wird und/oder der räumlich bedingte Aufwand zu hoch ist

- Der realistischere Fall ist jedoch, dass die Konsumenten nicht oder zumindest nicht exakt über das vorgehaltene Angebot und/oder den in Kauf zu nehmenden Aufwand informiert sind. Hierbei würde die Wahl am ehesten auf den Angebotsstandort treffen, bei dem die Erfüllung der Bedürfnisse am wahrscheinlichsten ist, auch wenn dieser vom Ausgangspunkt möglicherweise weiter entfernt liegt

- Bleiben - unabhängig vom Informationsgrad - nach dem Ausschlussvorgang nur noch zwei Angebotsstandorte übrig, so wäre hier unter ansonsten gleichen Bedingungen die Auswahl des näher gelegenen die wahrscheinlichste Konsequenz

Der Zusammenhang zwischen Einkommen bzw. Haushaltsbudget und Konsum schlägt sich im räumlichen Einkaufsverhalten nieder; dieses unterliegt vor dem Hintergrund steigender Haushaltseinkommen einiger Veränderungen (LANGE 1973, S. 70f.):

- Bei steigenden Einkommen werden mehr Güter konsumiert und neue Güter kommen hinzu, wobei zugleich der Auswahlanspruch hinsichtlich dieser Güter steigt. Dies erfordert Veränderungen in der Einkaufsorganisation, da eine größere Gütermenge eingekauft und eine umfangreichere Sortimentstiefe gewünscht wird. Zugleich herrscht keine vollständige Markttransparenz, so dass die Wahrscheinlichkeit eines „erfolgreichen“ Einkaufs mit dem Umfang des Angebots steigt. Es werden daraus folgend Angebotsstandorte umso mehr bevorzugt, je umfangreicher inr Angebot ist, d.h. je mehr Möglichkeiten von Kopplungs- und Vergleichskäufen sie bieten

- Das steigende Einkommen hat zudem zur Folge, dass die Konsumenten mobiler sind, da innen die Nutzung leistungsfähigerer (d.h. schnellerer und/oder bequemerer) Verkehrsmittel (insb. PKW) ermöglicht wird. Dies wirkt sich einerseits auf die Besorgungskapazität aus, da mehr Güter transportiert werden können (Steigerung der maximal möglichen Kopplung) und andererseits dahingehend, dass weiter 
entfernte, gut ausgestattete Angebotsstandorte, die vorher nicht zur Auswahl standen, erreichbar werden

\subsubsection{Betriebsformen- und Standortpolitik der Anbieter}

Die Analyse des Anbieterverhaltens erfolgt bei LANGE auf Basis der Marktphasentheorie von HEUSS (1965), die das Unternehmerverhalten im Zeitverlauf unter Berücksichtigung sich verändernder Einflussfaktoren und heterogener unternehmerischer Charaktereigenschaften zum Gegenstand hat. Ziel von LANGES Überlegungen ist die Betriebsformen- und Standortpolitik der Einzelhandelsanbieter, die im Sinne seines Theorieansatzes nicht die optimale, sondern die tatsächliche Standortwahl erklären soll; sie wird somit nicht als Reaktion eines homo oeconomicus auf das Marktgeschehen aufgefasst, sondern zielt darauf ab, das aktive Handeln der Unternehmer im Kontext differenzierter Verhaltenstypen und damit verbundener unterschiedlicher Ausnutzung der Handlungsparameter zu behandeln (LANGE 1973, S. 90f.). Den äußeren Rahmen für das Anbieterverhalten bildet das sich wandelnde Konsumentenverhalten.

Die evolutionsökonomische Marktphasentheorie erklärt die Entwicklung von Gütergruppen bzw. einzelnen Märkten. Den Schlüssel hierzu bildet die Differenzierung von vier Unternehmertypen (Pionierunternehmer, Imitatoren, konservative Unternehmer, immobile Unternehmer), die in vier unterschiedlichen, nicht exakt voneinander zu trennenden, Marktphasen (Experimentierphase, Expansionsphase, Ausreifungsphase, Stagnationsphase) aktiv sind. Den Ausgangspunkt bildet eine Produktinnovation (Überblick z.B. WITT 1987, S. 65f.). Dieses Konzept wird bei LANGE auf die Betriebsformen des Einzelhandels im Kontext des Konsumentenverhaltens angewandt, wobei ihre Standortwahl, die je nach Marktphase sehr unterschiedlich ist, besondere Berücksichtigung erfährt (LANGE 1973, S. 97ff.):

- In der Experimentierphase wird eine neue Betriebsform entwickelt, die sich in ihrer Sortiments- und Standortpolitik von den bisherigen unterscheidet. Hierfür ist es notwendig, das (räumliche) Einkaufsverhalten der Nachfrager abzuschätzen und eine Sortimentszusammenstellung vorzunehmen, die noch nicht durch andere Anbieter abgedeckt wird, d.h. komplementäre und/oder substitutive Güter in einer neuen und für die Kunden attraktiven Weise zu kombinieren; hierzu sind nur Pionierunternehmer fähig. Die Standortwahl erfolgt in Abhängigkeit der räumlichen Verteilung konkurrierender Anbieter (deren Sortiment sich teilweise mit dem eigenen deckt), der Erreichbarkeit bestehender und der Realisierbarkeit neuer Standorte. Je intensiver die Wettbewerbsbeziehungen sind, desto mehr müssen die Sortiments- bzw. Standortpolitik dies kompensieren; je größer die Sortimentsüberschneidung zwischen alten und neuen Betriebsformen ist, desto besser muss das interne Kopplungs- und Vergleichspotenzial des neuen Geschäfts ausgebaut sein. Ob Konkurrenzmeidung (Monopol der Lage) oder eine räumliche Ballung in Erwägung gezogen wird, hängt von der Standortstruktur ab; existiert z.B. schon eine ausgebaute Agglomeration mit guter Verkehrsanbindung, ist die Eröffnung der neuen Verkaufsstelle abseits davon in dezentraler Lage nur adäquat, wenn die eigene Attraktivität diesen Mehraufwand für die Konsumenten ausgleicht

- In der Expansionsphase treten die Imitatoren in den Markt ein. Sowohl die Pioniere als auch die Imitatoren tendieren dazu, ihre ersten neuen Verkaufsstellen zunächst an bestehenden gut ausgebauten Angebotsstandorten zu eröffnen, weil diese bereits 
eine hohe Kundenfrequenz bieten und das Investitionsrisiko vergleichsweise gering ist. Je umfangreicher ihre Kopplungsmöglichkeiten sind, desto unabhängiger sind sie aufgrund ihrer eigenen Anziehungskraft bei ihrer Standortwahl. Im Laufe der Expansionsphase beginnt eine Diffusion („Ausbreitung nach unten“) der neuen Betriebsform an weniger günstigere, d.h. geringer ausgestattete, Angebotsstandorte ${ }^{24}$

- Die Ausreifungsphase ist lang andauernd. Aufgrund von Einkommenssteigerungen ergibt sich eine erhöhte Nachfrage nach den Gütern, weshalb weitere neue Verkaufsstellen entstehen, und der konsumentenseitige Auswahlanspruch steigt. Ein Teil der Unternehmer stellt sich auf die neuen Konsumentenansprüche ein, während andere vormalige Pioniere bzw. Imitatoren zu konservativen Unternehmern werden. Es erfolgt eine Ausdifferenzierung der Betriebsformen in verschiedene Untertypen; initiative Unternehmer erweitern ihre Sortimentsbreite oder spezialisieren sich stärker, d.h. erhöhen ihre Sortimentstiefe in einem Bereich und entfernen andere Produkte aus dem Sortiment. Je wichtiger für den jeweiligen Angebotstyp die räumliche Nähe zu anderen Anbietern aufgrund von Kopplungs-/Vergleichsmöglichkeiten ist, desto eher wird die Diffusion gebremst. Die konservativen Unternehmer nehmen Anpassungen ihrer Sortiments- und Standortpolitik zeitversetzt und erst unter wirtschaftlichem Druck vor, während immobile Unternehmer nicht reagieren und teilweise ihr Geschäft mangels Nachfrage aufgeben müssen

- Im Laufe der Stagnationsphase verlagert sich der Schwerpunkt des Wettbewerbs vom interformalen (d.h. alte gegen neue Betriebsformen) zu einem sehr intensiven intraformalen Wettbewerb (d.h. zwischen den neuen Anbietern), da die Nachfrage nach den Gütern ihr Sättigungsniveau erreicht, also stagniert. Die Pioniere bzw. Imitatoren haben entweder den Markt verlassen oder sind selbst konservative Unternehmer geworden. Die letzte Marktphase wird von konservativen Unternehmern dominiert, die nur unter wirtschaftlichem Druck Veränderungen ihres Angebots vornehmen und hierzu auch nur bedingt in der Lage sind. Je nachdem wie intensiv sich die Konkurrenzsituation darstellt, müssen diese Wettbewerber nun ihre Position verbessern, während die immobilen Unternehmer keine Veränderungen vornehmen. Eine Attraktivitätssteigerung der Geschäfte kann, um die Kopplungsmöglichkeiten zu optimieren, durch die Aufnahme von Produkten anderer Bedarfsstufen ins Sortiment erreicht werden ${ }^{25}$; zudem können Marketing- und/oder Serviceaktivitäten gesteigert werden. Alle Aktivitäten sind mit Kostensteigerungen verbunden, die höher sind als die Absatzsteigerungen; es scheiden also viele der immobilen und einige der konservativen Unternehmer aus dem Markt aus, was eine Abnahme der absoluten Zahl an Verkaufsstellen mit sich bringt. Die Anbieter, die über eine ausreichende Marktmacht (z.B. Lagemonopol) verfügen, können die sinkende Nachfrage aber auch mit Preiserhöhungen kompensieren. Die Sortimentsausweitung erfordert zudem eine Vergrößerung der Verkaufsfläche. Beides resultiert in einer Ausdehnung der minimal nötigen und zugleich der maximal möglichen Marktgebiete. Die Tatsache, dass die

\footnotetext{
${ }^{24}$ Werden die ersten Verkaufsstellen beispielsweise in hoch frequentierten großstädtischen Citybereichen mit sehr großen Kopplungs-/Vergleichsmöglichkeiten eröffnet, erfolgt in der Expansionsphase eine Ausbreitung in Richtung kleinerer, als Einkaufsstandort weniger attraktiver Städte.

${ }^{25}$ Beispiel: Lebensmittelmärkte nehmen sukzessive Nicht-Lebensmittel (z.B. Bekleidung) in ihr Sortiment auf.
} 
Nachfrager nun einem ausgedünnten Netz von Verkaufsstellen gegenüberstehen, eröffnet neuen Pionierunternehmern die Möglichkeit, diese „Lücken“ mit einer neuen innovativen Betriebsform ${ }^{26}$ aufzufüllen

\subsubsection{Marktinteraktionen und Dynamik der Angebotsstandorte}

Der makroökonomische Hintergrund von LANGEs theoretischen Ausführungen liegt darin, dass über das Einkommen der privaten Haushalte und dessen Veränderung eine Verbindung zur gesamtwirtschaftlichen Entwicklung hergestellt wird (LANGE 1973, S. 19). Diese schlägt sich in einer Einkommenssteigerung in der Bevölkerung nieder, welche sich auf das Konsumentenverhalten in mehrerlei Hinsicht auswirkt: Da mehr Güter konsumiert werden und der Anspruch im Hinblick auf die Auswahl an diesen Gütern steigt, werden Angebotsstandorte mit großem Kopplungs-/Vergleichspotenzial bevorzugt; dies gilt insbesondere vor dem Hintergrund fehlender Markttransparenz und wird durch die steigende Nutzung leistungsfähiger Verkehrsmittel weiter verstärkt, da entferntere Angebotsstandorte besser erreichbar werden (siehe Kap. 2.3.3.2). Die Anbieter reagieren bei ihrer Standortwahl mit unterschiedlicher Intensität und Reaktionszeit auf die Konsumentenwünsche und stimmen ihr Sortiment dementsprechend ab und/oder wählen Standorte in räumlicher Nähe zu komplementären und/oder kompetitiven Anbietern (siehe Kap. 2.3.3.3).

Alle anderen Bedingungen konstant gelassen, führen diese nachfrage- und angebotsseitigen Ausgangsbedingungen dazu, dass sich die Marktgebiete von Angebotsstandorten umso mehr ausbreiten, je mehr komplementäre und kompetitive Anbieter dort lokalisiert sind, da dieser Umstand sie für die Konsumenten umso attraktiver macht (LANGE 1973, S. 71 u. 88). Es besteht also ein gemeinsames Marktgebiet aller Anbieter am Angebotsstandort, da „[...] die Reichweite [das Marktgebiet, d. Verf.] eines Gutes, das in dem größeren zentralen Ort angeboten wird, größer ist, als wenn es in einem kleineren zentralen Ort zum Angebot kommt" (CHRISTALLER 1933, S. 55).

Ausgehend von seiner Leitfrage diskutiert LANGE (1973, S. 125ff.) verschiedene Situationen, die unter den o.g. Ausgangsbedingungen ein System von Angebotsstandorten verändern:

- Nach der Innovation einer neuen Betriebsform werden die zugehörigen neuen Verkaufsstellen bevorzugt an bereits bestehenden Angebotsstandorten eröffnet, da diese Kopplungsmöglichkeiten und/oder eine gute Erreichbarkeit bieten. Aufgrund von Mehrzweckeinkäufen haben größere Angebotsstandorte grundsätzlich bessere Wachstumschancen als kleinere. Je kleiner (bzw. größer) das interne Kopplungspotenzial der neuen Anbieter ist, desto wichtiger (bzw. unwichtiger) ist die räumliche Nähe zu komplementären Anbietern. Je höher (bzw. niedriger) die Verbrauchshäufigkeit der angebotenen Güter der einzelnen Anbieter, desto kleiner (bzw. größer) ist ihr minimal notwendiges Marktgebiet, woraus folgt, dass umso kleiner (bzw. größer) der bestehende Angebotsstandort ausgebaut sein muss, an dem sie sich ansiedeln. Abgesehen davon, dass die neuen Anbieter ihre Verkaufsstellen zunächst an den großen bestehenden Angebotsstandorten eröffnen, da diese eine höhere Erfolgsaussicht bieten, endet in bestimmten Fällen die Diffusion

\footnotetext{
${ }^{26}$ Bezug nehmend auf die viel zitierte Arbeit zur Evolution der Betriebsformen im Lebensmitteleinzelhandel von AGERGARD et al. (1968) nennt LANGE (1973, S. 121) unter anderem Lebensmittel-Discounter als Beispiel hierfür.
} 
neuer Angebotsformen bevor die kleinsten Angebotsstandorte erreicht sind. Im Ergebnis bewirken also der Markteintritt und die Ausbreitung neuer Betriebsformen immer das Wachstum bereits bestehender Angebotsstandorte, und unter innen bevorzugt die großen; der Wachstumsprozess verläuft also asymmetrisch

- Dieser erste Fall berücksichtigte ausschließlich Agglomerationsvorteile aufgrund von Kopplungskäufen (Urbanisierungsvorteile). Wenn die Kunden auch Vergleichskäufe durchführen und sich die Anbieter spezialisieren (was sie der Marktphasentheorie nach früher oder später tun; siehe Kap. 2.3.3.3), fördert dies analog zum ersten Fall eine Agglomeration konkurrierender Anbieter (Lokalisierungsvorteile). Im Extremfall entstehen hoch spezialisierte "Cluster" (z.B. ein Straßenzug mit ausschließlich Antiquitätengeschäften), deren Marktgebiet so groß ist, dass in einer bestimmten Entfernung hierzu die Ansiedlung konkurrierender Anbieter nicht wirtschaftlich ist. Die räumlich ungleiche Entwicklung der Angebotsausstattung wird also noch verstärkt

- Befindet sich eine Betriebsform in der Stagnationsphase, führt dies zu einem Rückgang der Verkaufsstellen dieses Typs. Selbst wenn dieser Rückgang überall proportional verläuft, sind die negativen Effekte umso geringer (bzw. höher), je größer (bzw. kleiner) die Angebotsstandorte sind. An großen Angebotsstandorten können neue Verkaufsstellen eröffnet bzw. alte Geschäftsflächen übernommen werden. An kleinen Angebotsstandorten kann sich der Wegfall eines Teils von bestimmten Angebotstypen in mehrerlei Hinsicht negativ auswirken: Ungeachtet anderer Faktoren verliert der Angebotsstandort in jedem Fall Kopplungs- bzw. Vergleichsmöglichkeiten. Führt die Erosion des Angebotes dazu, dass einzelne Anbieter in einer lokalen Monopolstellung zurückbleiben, kann diese sie dazu verleiten, ihre sinkende Nachfrage mit Preiserhöhungen auszugleichen, wodurch das Preisniveau steigt; beides senkt die Attraktivität der kleinen Angebotsstandorte gegenüber den größeren

- Ähnlich wie die Ausbreitung neuer Betriebsformen wirkt sich auch der Markteintritt von geplanten Einkaufszentren aus. Wie neue Betriebsformen durchlaufen auch diese die vier Marktphasen, wobei ihre Spezialisierung in der Ausreifungsphase anhand ihrer Ausrichtung auf bestimmte Einkommens- bzw. Preisniveaus erfolgt. Die Ansiedlung neuer EKZ erfolgt aufgrund mangelnder Entwicklungsmöglichkeiten und hoher Bodenpreise nicht an bestehenden Angebotsstandorten; hierzu ist auch eine verkehrliche Erschließung notwendig. Je attraktiver (bzw. unattraktiver) die bestehenden Angebotsstandorte gegenüber dem neuen geplanten Angebotsstandort positioniert sind, desto entlastender (bzw. belastender) wirkt das neue EKZ für sie. Die Belastung (insbesondere für die kleineren Angebotsstandorte) besteht in steigendem Konkurrenzdruck, die Entlastung (insbesondere für die größeren) liegt hingegen darin, dass sie von der besseren Verkehrserschließung profitieren und die dortigen Bodenpreise (z.B. Geschäftsflächenmieten) abgemildert werden

Die zahlreichen Begebenheiten, die an dieser Stelle nur knapp zusammengefasst wurden, resultieren also stets darin, dass sich aufgrund von Agglomerationsvorteilen räumliche Ballungen bilden und sich bereits bestehende Unterschiede zwischen Angebotsstandorten weiter verstärken (Polarisierung der Angebotsstandorte). Auch wenn die Annahmen und Ausgangsbedingungen in LANGES Theorie weit komplexer sind als die von CHRISTALLER, entspricht das Ergebnis im Wesentlichen dessen Feststellung einer ,[...] Bevorzugung der großen Städte auf Kosten der kleinen [...]“ (CHRISTALLER 1933, S. 107), wenngleich dies bei 
LANGE gerade nicht, wie bei CHRISTALLER, „[...] aus streng wirtschaftlichen Erwägungen heraus“, d.h. als Ergebnis von Optimierungsverhalten in einem Markt, geschieht, sondern auf der Grundlage einer Reihe anderer Voraussetzungen, die mit den neoklassischen Optimierungs- und Gleichgewichtsprinzipen völlig inkompatibel sind.

Auch andere Erweiterungen der ZO-Theorie prognostizieren räumliche Ballungstendenzen aufgrund von Mehrzweckeinkäufen zur Senkung der konsumentenseitigen Transportkosten (z.B. GHOSH 1986, S. 86ff.; VANDENBROUCKE 1995, S. 80ff.); diese aus Simulationen bestehenden Gleichgewichtsmodelle gehen aber meist nicht darüber hinaus, die Aussagen von ChRISTALLER zu formalisieren, während LANGE ein neues Theoriegebäude aus verschiedenen Grundlagen herleitet. Ein wesentlicher Kerngedanke ist die Verknüpfung zur gesamtwirtschaftlichen Entwicklung, wobei der Nachfragezuwachs (Einkommenssteigerung) räumliche Disparitäten in einem System von Angebotsstandorten verstärkt anstatt sie auszugleichen (LANGE 1973, S. 88); bei CHRISTALLER resultiert hingegen die Entstehung von „hilfszentralen Orten“ aus einer Nachfragesteigerung (siehe Kap. 2.3.1.5). Die Theorie von LANGE bildet somit ein eigenständiges und komplexes Werk zur Erklärung von räumlichen Disparitäten der Ausstattung bzw. Versorgung. Kopplungs- und Vergleichskäufe werden hierbei als wichtigste Determinanten des Einkaufsverhaltens und des Geschäftserfolges von Anbietern herausgearbeitet, wobei, wie HEINRITZ et al. (2003, S. 58) kritisieren, eine Reihe anderer Faktoren in den Hintergrund treten. Da sich die genannten Aspekte des räumlichen Einkaufsverhaltens aber ebenso empirisch nachweisen lassen wie der Bedeutungsgewinn von Einzelhandelsagglomerationen in Verbindung mit dem Betriebsformenwandel, spricht KULKE (2005, S. 22 u. 2009, S. 179) der Theorie eine hohe empirische Relevanz zu.

\subsection{Der empirisch-induktive Standortansatz von NELSON}

\subsubsection{Standortfaktoren im Einzelhandel}

In seinem 1958 erschienenen Werk The Selection of Retail Locations erörtert NELSON die Standortfaktoren im Einzelhandel und anderen konsumentenorientierten Dienstleistungen, wobei der (positiven) Wirkung von (Einzelhandels-)Agglomerationen ein besonderes Gewicht zukommt. Sein Ansatz unterscheidet sich grundsätzlich von den anderen hier diskutierten Standorttheorien, da es sich hierbei nicht um deduktive Ableitungen handelt, sondern um empirisch gewonnene Erkenntnisse, die induktiv in allgemeingültige Aussagen übertragen werden (BROWN 1993, S. 201f.). Daher werden auch keine ausdrücklichen Annahmen hinsichtlich des Konsumenten-/Anbieterverhaltens oder des Raums postuliert, sondern die Aussagen beziehen sich auf tatsächlich stattgefundene bzw. stattfindende Gegebenheiten; auch werden NELSONs Ausführungen zumeist nicht (oder zumindest nicht explizit) mittels mikroökonomischer Begriffe und Zusammenhänge erklärt.

Auf dieser Grundlage stellt NELSON einen Standortfaktorenkatalog für den Einzelhandel auf, der in acht Elemente unterteilt wird. Diese sollten inm zufolge in der genannten Reihenfolge im Rahmen der unternehmerischen Standortpolitik (insb. bei der Eröffnung einer neuen oder der Verlagerung einer bestehenden Verkaufsstelle) beachtet werden; sie müssen aber nicht zwingend allesamt Berücksichtigung finden und schließen sich in einigen Fällen auch gegenseitig aus (NELSON 1958, S. 52ff.):

- Kunden- bzw. Kaufkraftpotenzial im Marktgebiet 
- Kundenfrequentierung des für die Eröffnung der neuen Verkaufsstelle anvisierten Angebotsstandortes hinsichtlich der eigenen Anziehungskraft (Generative business) und externer Frequenzbringer (Shared business bzw. Suscipient business)

- Regionalökonomisches Wachstumspotenzial des Marktgebietes hinsichtlich der Bevölkerung und der Haushaltseinkommen

- Möglichkeit einer räumlichen Positionierung zwischen dem Marktgebiet und den bestehenden Anbietern (d.h. Konkurrenzmeidung), um potenzielle Kundschaft der Konkurrenten vorher „abzufangen“ (Business interception)

- Gemeinsame Kundenanziehungskraft aller ungleichartigen (bzw. komplementären) und/oder gleichartigen (konkurrierenden) Anbieter am Angebotsstandort (Cumulative attraction)

- Kompatibilität der anderen Anbieter am anvisierten Angebotsstandort (Compatibility)

- Minderung des Wettbewerbsrisikos (Competitive hazard), d.h. (räumliche) Orientierung an den Konkurrenten, da ihre bestehenden Verkaufsstellen von einer erfolgreichen Standortwahl zeugen

- Qualität des Mikrostandortes (Immobilie bzw. Geschäftsfläche), d.h. kleinräumige Lageeigenschaften (z.B. Flächenzuschnitt, Verkehrstechnischer Zugang usw.)

Es existieren viele weitere Standortfaktorenkataloge für den Einzelhandel, die sich in ihren Kernaussagen nicht grundlegend von NELSONs Ansatz unterscheiden (Überblick z.B. KROL 2010, S. 61ff.; KULKE 2009, S. 143ff.; OVERFELD/JAHN 2009, S. 424ff.). In mehreren Punkten stellt NELSON jedoch die Vorteile von Agglomerationen ungleichartiger und/oder konkurrierender Anbieter in den Mittelpunkt. Abgesehen davon, dass diese auch allgemein das unternehmerische Risiko senken können, liegen die Vorzüge im Wesentlichen in den konsumentenseitigen Agglomerationsvorteilen. Hierbei werden drei Elemente identifiziert, die sich auf die Kundenfrequenz beziehen und in unterschiedlicher Gewichtung das Kundenbzw. Umsatzvolumen von Einzelhandelsanbietern beeinflussen (NELSON 1958, S. 53f.):

- Generative business: Umsatz, der auf die Anziehungskraft des Anbieters selbst zurückzuführen ist, d.h. der vom (Magnet-)Betrieb „selbst generiert“ wird. NELSON führt hier als Beispiel an, dass es sehr umsatzfördernd ist, wenn allgemein bekannt ist, dass der Anbieter eine große Auswahl (Sortimentstiefe) bereithält

- Shared business: Umsatz, der auf die Anziehungskraft der anderen Betriebe bzw. die gemeinsame Anziehungskraft aller Anbieter am Angebotsstandort zurückzuführen ist. Dieser Teil des Geschäftserfolges wird durch die Möglichkeit von Kopplungs- und Vergleichskäufen generiert. Bei branchengleichen bzw. konkurrierenden Anbietern „wirken“ Kumulationsvorteile (gemeinsame Anziehungskraft der Mitbewerber), bei andersartigen Anbietern Kompatibilitätsvorteile (d.h. die Angebotsformen sind untereinander kompatibel, da sie sich für eine Kopplung anbieten)

- Suscipient business: Umsatz, der weder durch das Geschäft selbst noch durch Geschäfte in der Nachbarschaft generiert wird, sondern durch Personen, die ein bestimmtes Ziel in der Nähe des Geschäftes haben und deshalb zu dessen Kunden werden; dieser Teil des Umsatzes wird durch externe Frequenzbringer beschert (z.B. Geschäfte am Flughafen oder in unmittelbarer Nähe der Arbeitsstätte) 
Prinzipiell lassen sich alle drei Erfolgselemente als Agglomerationsvorteile interner oder externer Art interpretieren; die hier im Fokus stehenden nachfrageseitigen Effekte sind aber die Facetten des shared business (Kumulations- und Kompatibilitätsvorteile).

\subsubsection{Das Prinzip der Konkurrenzanziehung (Kumulationsvorteile)}

In NELSONS Standortfaktorenkatalog spielt neben nachfrage- und immobilienbezogenen Aspekten auch der Faktor Konkurrenz eine wesentliche Rolle. Die Berücksichtigung der Konkurrenzstandorte bei der Standortwahl kann entweder in der Entscheidung für eine „Abfang"-Position (d.h. Konkurrenzmeidung) oder aber in einer bewussten Ansiedlung in unmittelbarer Nähe zu gleichartigen Anbietern resultieren (d.h. Konkurrenzanziehung) resultieren; in letztgenanntem Fall überwiegen also die Vorteile durch die kumulierte Anziehungskraft aller Anbieter gegenüber den Nachteilen des Wettbewerbs (NELSON 1958, S. 54). Bei diesen hier als Kumulationsvorteile bezeichneten Effekten handelt es sich gemäß der gängigen Abgrenzung (siehe Kap. 2.1.2) um Lokalisierungsvorteile. Der Ansatz von NELSON behandelt also die Agglomeration von gleichartigen Anbietern und wird oftmals als wichtigste und - gemeinsam mit dem HOTELLING-Modell (siehe Kap. 2.2.3) - als erste theoretische Basis für die räumliche Konzentrationen konkurrierender Einzelhandelsbetriebe aufgefasst (z.B. BROWN 1989c, S. 4; DAMIAN et al. 2011, S. 459).

Die Kernaussage dieser Theory of cumulative attraction (auch: cumulative generation) ist, dass kompetitive Anbieter für die Konsumenten attraktiver sind, wenn sie räumlich geballt lokalisiert sind, als wenn sie weit voneinander getrennt liegen: „A given number of stores dealing in the same merchandise will do more business if they are located adjacent or in proximity to each other than if they are widely scattered" (NELSON 1958, S. 58).

Ob bei der Standortwahl von Einzelhandelsbetrieben die Konkurrenznähe oder stattdessen eine Konkurrenzmeidung vorteilhaft ist, lässt sich nach NELSON (1958, S. 58) auf der Grundlage der Eigenanziehungskraft (Generative business) und dem Charakter der angebotenen Sortimente differenzieren:

- Je weniger (bzw. mehr) Aufwand beim Kauf betrieben wird und je standardisierter (bzw. ausdifferenzierter) die angebotenen Güter sind, desto eher sollte eine Konkurrenzmeidung (bzw. Konkurrenzballung) betrieben werden. Anbieter von stark ausdifferenzierten Gütern (z.B. hinsichtlich Design, Farbe usw.) sollten demnach eine Agglomeration mit Konkurrenten bevorzugen, Anbietern von standardisierten Gütern empfiehlt sich eher die Lokalisierung in einer „Abfang“-Position

- Je geringer (bzw. größer) die eigene Kundenanziehungskraft, desto wichtiger (bzw. unwichtiger) ist die räumliche Nähe zu Mitbewerbern

Der Grundgedanke der Konkurrenzanziehung bei NELSON ist also, dass das gemeinsame Auftreten von Konkurrenten für eine größere Auswahl sorgt und Vergleichskäufe ermöglicht. Dies gilt insbesondere für shopping goods, bei denen (modische) Präferenzen eine große Rolle spielen und der Preis und die Qualität zwischen den Produktvarianten sehr unterschiedlich sind (BROWN 1994, S. 555; EATON/LIPSEY 1979, S. 422). Als aus seiner Sicht besonders treffendes Beispiel wählt NELSON hierfür den Schuheinzelhandel: „Four shoe stores located close together will do more business than the same four stores located several blocks apart. When clustered, they become a kind of 'shoe center' and the total trading area of the four stores is enlarged by their proximity. Frequently their percentage 
share of business from that market area is also enlarged - that is, depth of penetration is increased as well as the size of the trade area" (NELSON 1958, S. 58).

Konkurrierende Anbieter gleicher Branche können nach NELSON also, wenn sie sich räumlich an einem Angebotsstandort konzentrieren, höhere Kunden-/Kaufkraftzuflüsse generieren als sie dies in der Summe als einzelne Anbieter könnten; hierfür sorgt ihr als implizit zusammengehörig empfundenes gemeinsames Angebot (hier: „shoe center"), dessen Resultat ein gemeinsames (größeres) Marktgebiet ist. Eine gemeinsame Anziehungskraft für die Konsumenten kommt allerdings nicht nur bei gleichen Anbietern zustande, sondern lässt sich auf verschiedenste Angebotskombinationen ausdehnen, was von NELSON als (Sortiments-)Kompatibilität bezeichnet wird.

\subsubsection{Das Prinzip der Kompatibilität (Kompatibilitätsvorteile)}

Nach NELSON spielt die Kombination verschiedener Sortimente bzw. Anbieter eine entscheidende Rolle für den betriebswirtschaftlichen Erfolg der Betriebe in einer Einzelhandelsagglomeration; insbesondere werden geplante Einkaufszentren dahingehend aufgebaut, dass sie einen optimierten Angebotsmix aus gleich- und ungleichartigen Anbietern beinhalten (NELSON 1958, S. 63f.). Sofern die unmittelbare räumliche Nähe eines Anbieters zu einem anderen - alle sonstigen Bedingungen konstant gelassen - dessen Kunden-/Kaufkraftzufluss positiv beeinflusst, liegt eine Kompatibilität zwischen diesen Anbietern vor; diese besteht entweder bei Anbietern von komplementären Gütern, die beim Einkauf miteinander gekoppelt werden, oder bei gleichartigen Gütern, die von den Konsumenten hinsichtlich der Warenqualität, des Preises usw. miteinander verglichen werden (ebd., S. 66). NELSON sieht also auch konkurrierende Anbieter als „kompatibel“ im Sinne der kumulierten Anziehungskraft (siehe Kap. 2.4.2) an; beide genannten Prinzipe Kumulations- und Kompatibilitätsvorteile - sind demnach nicht als voneinander losgelöst zu betrachten, sondern greifen ineinander. Diese hier so genannten Kompatibilitätsvorteile sind demnach zwar in erster Linie als Urbanisierungsvorteile zu interpretieren, jedoch auch als Lokalisierungsvorteile, wenn sie sich auf die Ballung von kompetitivem Angebot beziehen.

Basierend auf langjährigen empirischen Untersuchungen von mehreren hundert Einzelhandelsagglomerationen und über 100.000 individuellen Einkaufsfahrten hat NELSON induktiv seine Rule of retail compatibility (Gesetz der Agglomeration im Einzelhandel bei verbundenen Bedarfen) abgeleitet (NELSON 1958, S. 66f.; SCHENK 1979, S. 33); demnach besteht ein direkter Zusammenhang zwischen der Höhe des Kundenaustauschs zwischen zwei Geschäften und ihrer Umsatzhöhe: „Two compatible businesses located in close proximity will show an increase in business volume directly proportionate to the incidence of total consumer interchange between them, inversely proportionate to the ratio of the business volume of the larger store to that of the smaller store, and directly proportionate to the sum of the rations of purposeful purchasing to total purchasing in each of the two stores" (NELSON 1958, S. 66). Dieses "Gesetz" bezieht sich sowohl auf branchengleiche als auch branchenungleiche Agglomerationen, so lange die beiden Anbieter miteinander „verbunden“ sind; von NELSON ist auch eine mathematische Formalisierung dieser Regel vorgenommen worden (siehe Formel 1). Die Modellformel ist allerdings zur konkreten Berechnung insofern in ihrer Aussagekraft eingeschränkt, dass immer nur zwei Betriebe Berücksichtigung finden, was die mögliche Agglomerationswirkung von Dritten ausklammert (SCHENK 1979, S. 34). 


$$
V=I\left(V_{L}+V_{S}\right) \frac{V_{S}}{V_{L}}\left(\frac{P_{L}}{V_{L}}+\frac{P_{S}}{V_{S}}\right)
$$

$V=$ Absolute Umsatzsteigerung beider Geschäfte

I = Ausmaß des Kundenaustauschs

$V_{L}=$ Umsatzvolumen des größeren Geschäftes

$P_{L}=$ Geplante Käufe im größeren Geschäft

$V_{S}=$ Umsatzvolumen des kleineren Geschäftes

$P_{S}=$ Geplante Käufe im kleineren Geschäft

Dieselben empirischen Daten zum Konsumentenverhalten und den Handelsumsätzen, die dem genannten "Gesetz" zu Grunde liegen, hat NELSON außerdem in Matrizen zur Kompatibilität von Anbietern (Compatibility tables) verarbeitet; aus innen ist der jeweilige Kompatibilitätsgrad zwischen Angebotsformen des Einzelhandels sowie weiterer konsumentenorientierter Dienstleistungen an verschiedenen Typen von Angebotsstandorten (z.B. geplantes Einkaufszentrum, Innenstadtbereich) abzulesen. Der Grad der Kompatibilität wird operationalisiert durch den prozentualen Grad des Kundenaustauschs zwischen den beiden Angebotsformen, d.h. wie hoch der Anteil der Kunden ist, die den Besuch beider Anbieter miteinander verbinden (NELSON 1958, S. 78):

- Hoch kompatibel: $10-20 \%$

- Mäßig kompatibel: 5-10\%

- Schwach kompatibel: 1-5\%

- Inkompatibel: Kundenaustausch spielt keine Rolle

- Schädlich: Die räumliche Nähe hat - alle anderen Bedingungen konstant gelassen einen negativen Einfluss auf den Kunden-/Kaufkraftzufluss

In Tabelle 1 finden sich Auszüge aus der Kompatibilitätsmatrix für verschiedene Angebotsformen in mittleren bis großen Einzelhandelsagglomerationen (Einkaufszentren und mittelgroße Geschäftsstraßen). Aus der Tabelle ist beispielsweise ablesbar, dass Lebensmittelmärkte mit anderen Anbietern von Gütern des täglichen Bedarfs (z.B. Bäckerei, Metzgerei) vergleichsweise häufig gekoppelt werden, wohingegen Anbieter von Gartenartikeln keinen Einfluss haben und die räumliche Nähe zu einem Drive-in-Restaurant tendenziell schädlich ist. Möbel sind hingegen zu keiner anderen Angebotsform hoch kompatibel, jedoch zu den meisten schwach kompatibel. Bekleidungsanbieter sind vor allem mit anderen Bekleidungsanbietern sowie mit Schuhgeschäften kompatibel.

Kritisch anzumerken ist vor diesem Hintergrund, dass zur Operationalisierung der Schädlichkeit keine Angaben gemacht werden (BROWN 1994, S. 551); möglicherweise ist diese Kategorie über Vergleichsrechnungen zwischen Anbietern mit unterschiedlichem Umfeld (z.B. Nähe zu einer Tankstelle oder nicht) entstanden. Auch bleibt, wie NELSON (1958, S. 78) selbst anmerkt, die jeweilige Größe der untersuchten Anbieter bei der Analyse der Kompatibilität unberücksichtigt. Dennoch zeigen die Kompatibilitätsmatrizen von NELSON klare und plausible Tendenzen einer horizontalen und/oder vertikalen Kopplung im Sinne von LANGE (1973) auf (siehe Kap. 2.3.3). 


\begin{tabular}{|c|c|c|c|c|c|}
\hline \multirow[b]{2}{*}{$\begin{array}{l}\text { Angebots- } \\
\text { formen }\end{array}$} & \multicolumn{5}{|c|}{ Grad der Kompatibilität } \\
\hline & $\begin{array}{c}\text { Hoch } \\
\text { kompatibel }\end{array}$ & Mäßig kompatibel & $\begin{array}{l}\text { Schwach } \\
\text { kompatibel }\end{array}$ & Inkompatibel & Schädlich \\
\hline Lebensmittel & $\begin{array}{c}\text { Bäckerei } \\
\text { Metzgerei } \\
\text { Drogeriewaren }\end{array}$ & $\begin{array}{l}\text { Farben, Tapeten } \\
\text { Süßwaren }\end{array}$ & $\begin{array}{l}\text { Bücher } \\
\text { Blumen } \\
\text { Bekleidung }\end{array}$ & $\begin{array}{c}\text { Gartenartikel } \\
\text { Reparatur Haus- } \\
\text { haltsgegenstände }\end{array}$ & $\begin{array}{c}\text { Kfz-Reparatur } \\
\text { Begräbnisinstitut } \\
\text { Drive-in-Restaurant }\end{array}$ \\
\hline Eisenwaren & $\begin{array}{c}\text { Lebensmittel } \\
\text { Bäckerei } \\
\text { Metzgerei }\end{array}$ & $\begin{array}{c}\text { Farben, Tapeten } \\
\text { Gartenartikel }\end{array}$ & $\begin{array}{l}\text { Bücher } \\
\text { Blumen } \\
\text { Bekleidung }\end{array}$ & $\begin{array}{l}\text { Reparatur Haus- } \\
\text { haltsgegenstände } \\
\text { Bowling-Center }\end{array}$ & $\begin{array}{c}\text { Kfz-Reparatur } \\
\text { Begräbnisinstitut } \\
\text { Drive-in-Restaurant }\end{array}$ \\
\hline Bekleidung & $\begin{array}{l}\text { Bekleidung } \\
\text { Schuhe } \\
\text { Textilwaren }\end{array}$ & $\begin{array}{c}\text { Drogeriewaren } \\
\text { Möbel } \\
\text { Schmuck }\end{array}$ & $\begin{array}{c}\text { Lebensmittel } \\
\text { Bäckerei } \\
\text { Metzgerei }\end{array}$ & $\begin{array}{c}\text { Gartenartikel } \\
\text { Kfz-Handel } \\
\text { Bowling-Center }\end{array}$ & $\begin{array}{c}\text { Tankstelle } \\
\text { Drive-in-Restaurant } \\
\text { Begräbnisinstitut }\end{array}$ \\
\hline Möbel & & Haushaltsgeräte & $\begin{array}{l}\text { Lebensmittel } \\
\text { Eisenwaren } \\
\text { Kfz-Handel }\end{array}$ & $\begin{array}{l}\text { Reparatur Haus- } \\
\text { haltsgegenstände } \\
\text { Waschsalon }\end{array}$ & $\begin{array}{c}\text { Tankstelle } \\
\text { Drive-in-Restaurant } \\
\text { Begräbnisinstitut }\end{array}$ \\
\hline
\end{tabular}

Tabelle 1: NELSON - Kompatibilitätstabelle für verschiedene Angebotsformen (Auszüge)

Quelle: Eigene Darstellung nach NELSON (1958, S. 74f.), verändert

Die Überlegungen von NELSON sind, im Gegensatz zu den vorher diskutierten Ansätzen der Standorttheorie, als induktiv gewonnene "Gesetze" nicht an strikte Verhaltensannahmen oder bestimmte Menschenbilder gekoppelt; anders als z.B. bei der Theorie von CHRISTALLER erübrigt sich daher eine Kritik an unrealistischen Ausgangsbedingungen. Abgesehen von praktischen Einschränkungen der Kompatibilitätsformel ist das Werk von NELSON im Hinblick auf seine als mangelhaft empfundene Verallgemeinerbarkeit beanstandet worden (BROWN 1993, S. 202). Es steht jedoch außer Frage, die Kompatibilitätstabellen oder die Formel analog auf alle Angebotsstandorte übertragen zu wollen; vielmehr ist der Ansatz von NELSON als Ideengeber für eine intensive Beschäftigung mit Einzelhandelsagglomerationen zu verstehen. Die Grundidee - „[...] retail agglomerations are more than the sum of their parts“ (TELLER 2008, S. 383) - hat maßgeblich dazu beigetragen, auch die räumliche Ballung von konkurrierenden Anbietern ausführlich zu behandeln, was z.B. durch CHRISTALLERs Theorie nicht geleistet wurde. Analysen zur Kompatibilität von branchengleichen und -ungleichen Anbietern sind ein höchst aktueller Untersuchungsgegenstand (z.B. WOTRUBA 2014, S. 93f.). Zusammenfassend betrachtet bilden NELSONs Ausführungen zu Sortimentskompatibilität und Konkurrenzanziehung wichtige Ergänzungen zu den deduktiv abgeleiteten Standorttheorien.

\subsection{Räumliches Einkaufsverhalten aus der Marketing-Perspektive}

\subsubsection{Mehrfachorientierung, Anbieterloyalität und räumliches Einkaufsverhalten}

Abseits von den mikroökonomischen und standorttheoretischen Ansätzen ist das räumliche Einkaufsverhalten auch Gegenstand der Marketing-Forschung, deren Theorien und Modelle sich vorrangig an der Mikroökonomie und den Verhaltenswissenschaften orientieren. Zwar liegt der Fokus hierbei naturgemäß nicht auf räumlichen Phänomenen, jedoch spielen diese in vielen Ansätzen eine Rolle bzw. stellen die Konsequenz aus anderen Verhaltensmustern dar; im Vordergrund stehen hierbei die Wettbewerbsbeziehungen im Einzelhandel und deren 
Zusammenhang mit dem Kundenverhalten hinsichtlich z.B. der anbieterseitigen Preis- und Sortimentsstrategien, der Betriebsform, dem Einsatz von Werbung, der Kundenbindung oder dem Markteintritt neuer Anbieter (RAO 2012, S. 78ff.). Zudem existieren zur Erklärung von Konsumentenentscheidungen verhaltenswissenschaftlich orientierte Modelle, die (auch) die Einkaufsstättenwahl behandeln (können) und hierbei sozialpsychologische Faktoren (z.B. Einstellung, Lernprozesse) und/oder die Transaktionskosten des Entscheidungsprozesses (z.B. Informationsbeschaffung) in den Vordergrund stellen (MUNDELL 2013, S. 52ff.). Vor diesem Hintergrund ist es weder möglich noch notwendig, sämtliche Marketing-Ansätze mit (möglichen) räumlichen Implikationen zu diskutieren; stattdessen wird hier ein bestimmter Aspekt des Kundenverhaltens - Mehrfachorientierung in Abgrenzung zur Anbieterloyalität behandelt, der unmittelbar mit der räumlichen Einkaufsorientierung verbunden ist.

Vollkommene Einkaufsstättentreue bzw. Anbieterloyalität liegt dann vor, wenn sämtliche Einkäufe beim selben, favorisierten Anbieter erledigt werden. Viele Verbraucher sind jedoch mehrfachorientiert, d.h. teilen ihre Einkäufe auf mehrere Anbieter auf; hierbei ist es durchaus möglich, dass immer noch ein einzelner Markt für den Großteil der Einkäufe angesteuert wird (BALTAS et al. 2010, S. 37). Mehrfachorientierung ist vorrangig relevant beim Einkauf von Gütern des täglichen Bedarfs, die in regelmäßigen Abständen erworben werden, weshalb sich die diesbezüglichen Arbeiten meist auf den Lebensmitteleinkauf beschränken (z.B. GAURI et al. 2008, POPKOWSKI LESZCZYC et al. 2004, VROEGRIJK et al. 2013).

Nach den bisherigen theoretischen Ausführungen dürften bei Lebensmittelmärkten keine positiven Lokalisierungseffekte auftreten: Nach NELSON (1970) handelt es sich bei Lebensmitteln um Erfahrungsgüter, bei denen, im Gegensatz zu Suchgütern, kein Preis-/ Qualitätsvergleich am Angebotsstandort vorgenommen wird bzw. werden kann; die Anbieter müssten demnach Konkurrenzmeidung betreiben, d.h. keine Agglomerationen aufbauen (siehe Kap. 2.2.2). Die bisher als Vergleichskäufe bezeichnete Einkaufsstrategie bezieht sich auf Güter des mittel- und langfristigen Bedarfs bzw. shopping goods, deren Erwerb vergleichsweise teuer und der zugehörige Kaufprozess relativ langwierig ist; die z.B. von LÖSCH (1940) und NELSON (1958) identifizierten Vorteile der räumlichen Ballung kompetitiver Anbieter (siehe Kap. 2.3.2.2 u. 2.4.2) greifen in diesem Fall also nicht. Dies steht jedoch im Widerspruch zu der empirisch belegten Tatsache, dass LEH-Anbieter Agglomerationen bilden, und dies mitunter sogar bewusst (Standortkooperationen, siehe Kap. 1.3.3); dieses recht neue Phänomen kann also mit den bisher angeführten theoretischen Ansätzen nicht erklärt werden. Daher soll im Folgenden der Zusammenhang zwischen dem unterschiedlich begründeten Verhalten der Mehrfachorientierung beim Lebensmittelkauf und multifinalen Einkäufen bzw. der Bevorzugung von Agglomerationen erörtert werden.

Notwendigerweise sind mit einer Mehrfachorientierung auch räumliche Verhaltensweisen verbunden, da hierfür unterschiedliche Anbieter angesteuert werden müssen. Dies alleine erklärt jedoch noch keine kundenseitige Bevorzugung von Agglomerationen, denn Kunden mit Mehrfachorientierung können mehrere (Lebensmittel-)Märkte im Zuge eines Einkaufs in einer Wegekette verbinden (multifinaler Einkauf), sie aber genauso separat (z.B. in mehreren Einkaufsfahrten am selben oder an verschiedenen Tagen) aufsuchen (GIJSBRECHTS et al. 2008, S. 7f.). Wenn jedoch zusätzlich noch angenommen wird, dass der mit dem Einkauf verbundene Aufwand (z.B. Transportkosten) gesenkt bzw. minimiert werden soll (z.B. aufgrund beschränkter Zeit), ist es die logische Konsequenz, dass solche Angebotsstandorte bevorzugt werden, an denen mehrere dieser Anbieter lokalisiert sind (POPKOWSKI LESZCZYC 
et al. 2004, S. 86; VROEGRIJK et al. 2013, S. 609). Mehrfachorientierung kann also in der Verbindung des Besuchs mehrerer Anbieter an einem Angebotsstandort resultieren; dies würde bedeuten, dass auch für Anbieter von Erfahrungsgütern (hier: Lebensmittelmärkte) eine räumliche Ballung mit kompetitiven Anbietern betriebswirtschaftlich sinnvoll ist, d.h. dass auch positive Lokalisierungseffekte im Lebensmitteleinzelhandel existieren. Allerdings ist das damit verbundene Einkaufsverhalten nicht durch suchgüterbezogene Vergleichskäufe erklärbar, wie es in den vorher behandelten Standorttheorien angenommen wird.

Es werden insbesondere zwei Motive zur Erklärung von Mehrfachorientierung identifiziert, nämlich eine oftmals als Cherry-Picking bezeichnete gezielte Orientierung der Konsumenten an Sonderangeboten (z.B. FOX/HOCH 2005, GAURI et al. 2008, LAL/RAO 1997, POPKOWSKI LESZCZYC et al. 2004, TALUKDAR et al. 2010) und eine an Produkt- und Anbieterpräferenzen orientierte bewusste Frequentierung mehrerer kompetitiver Anbieter (z.B. GIJSBRECHTS et al. 2008, VROEGRIJK et al. 2013). Die in diesem Zusammenhang besprochenen Ansätze (Kap. 2.5.2) stellen keine geschlossene(n) Theorie(n) i.e.S. dar, sondern stehen exemplarisch für eine nachfrageorientierte Perspektive im Marketing, die darauf abzielt, diesbezügliche Kundentypen zu identifizieren und ihre Muster des Einkaufsverhaltens zu erklären.

\subsubsection{Motive der Mehrfachorientierung}

\subsubsection{Angebotsgesteuerte Einkaufsstättenwahl}

Die gezielte Orientierung von Einzelhandelskunden an Sonderangeboten wird zumeist mit dem Begriff des Cherry-Picking umschrieben. Die Kundengruppe der Cherry-Picker sucht systematisch nach Sonderangeboten bzw. nach dem jeweils geringsten Preis beim Einkauf bestimmter Güter; diese Kunden beschäftigen sich daher vor ihren Einkäufen sehr intensiv mit den Angeboten der jeweiligen Ketten (z.B. durch Kataloge, Internet) und frequentieren gezielt jene Anbieter, die Sonderangebote offerieren (Fox/HoCH 2005, S. 46). Im Extremfall („Extreme cherry pickers“) werden ausschließlich „Lockangebote“ und drastisch reduzierte Produkte gekauft, die - für sich betrachtet - den jeweiligen Einzelhandelsunternehmen keine Gewinne bescheren (TALUKDAR et al. 2010, S. 336f.). Diese Form der Mehrfachorientierung ist also durch eine persönliche Einstellung zur drastischen Preisorientierung motiviert.

In der Marketing-Forschung werden die Cherry-Picker häufig von serviceorientierten und („,normalen“) preisorientierten Kunden abgegrenzt, wobei die Gruppen über unterschiedliche (räumliche) Einkaufsmuster verfügen (POPKOWSKI LESZCZYC et al. 2004, S. 88f.):

- Serviceorientierte Käufer mit zeitlicher Beschränkung (Time-constrained service seekers) sind beim Einkauf sehr distanzsensibel, d.h. darauf bedacht, die eigenen mit dem Einkauf verbundenen Transport-/Transaktionskosten zu senken. Sie bevorzugen Anbieter mit Sonderangebotspolitik (z.B. Supermärkte), da Service und bequeme Erreichbarkeit die größten Rollen bei der Einkaufsstättenwahl spielen; abhängig von der Erreichbarkeit werden aber auch Discounter frequentiert. Sie neigen tendenziell zu Kopplungskäufen bei ihnen genehmen Anbietern

- Preisorientierte Käufer mit zeitlicher Beschränkung (Time-constrained price seekers) sind weniger distanzsensibel und daher bereit, weitere Einkaufswege zur Erfüllung ihrer Bedürfnisse hinzunehmen. Sie suchen bevorzugt Discounter auf, wobei auch sie 
zu Kopplungskäufen neigen; weniger günstige Anbieter werden jedoch im Zweifelsfall aus zeitlichen Gründen auch frequentiert

- Für die Cherry-Picker spielen hingegen die Zeit bzw. Einkaufswege kaum eine Rolle, d.h. sie sind nicht distanzsensibel; sie suchen systematisch die besten Angebote und frequentieren somit Anbieter aller Preisstrategien, sofern diese - als Sonderangebot oder Dauerniedrigpreis - den günstigsten Preis bieten. Cherry-Picker unternehmen eher keine sachlich multifinalen, sehr wohl aber räumlich multifinale Einkäufe

Eine andere Differenzierung wird von GAURI et al. (2008, S. 228ff.) vorgenommen, die auf die Suchstrategie der Kunden bezüglich günstiger Angebote abzielt:

- Auch wenn Kunden nicht aktiv vor dem Einkauf nach Sonderangeboten suchen, kann eine Suche nach dem günstigsten Preis „nebenbei“ während des Besuchs von Geschäften erfolgen (Incidental price search)

- Kunden mit hoher Einkaufsstättentreue warten die jeweiligen Sonderangebote ihres bevorzugten Anbieters ab und teilen ihre Einkäufe daher rein zeitlich auf (Temporal price search)

- Die eigentlichen Cherry-Picker suchen, je nach offerierten Angeboten, mehrere Anbieter auf (Spatial price search)

- Eine vierte Kundengruppe kombiniert die beiden letztgenannten Strategien der Suche nach Sonderangeboten (Spatiotemporal price search)

Diese Differenzierungen sind lediglich zwei Beispiele zur Identifikation von Konsumenten mit einer ausgeprägten angebotsgesteuerten Einkaufsstättenwahl. Die Einkaufsstrategie dieser Kunden ist nicht mit dem auf Suchgüter bezogenen Begriff der Vergleichskäufe zu fassen. Zwar ist im Fall der angebotsgesteuerten Einkaufsstättenwahl auch ein Preis-, aber i.d.R. kein Qualitätsvergleich am Angebotsstandort selbst möglich; die o.g. Definitionen beruhen zudem vorrangig darauf, dass sich diese Konsumenten bereits vor dem Einkauf über die aktuellen Preise informieren. In diesem Fall findet also sehr wohl auch ein Vergleich statt, nur nicht während, sondern vor dem Einkauf; daher wird diese Einkaufsstrategie hier als angebotsgesteuerte Vergleichskäufe benannt. Die bereits besprochenen, auf Suchgüter bezogenen Vergleichskäufe im Sinne von z.B. NELSON (1958) sollen im Folgenden daher als suchbezogene Vergleichskäufe bezeichnet werden. Angebotsgesteuerte Vergleichskäufe sind notwendigerweise räumlich multifinale Einkäufe, können zudem auch sachlich multifinal sein, wenn mehrere im Sonderangebot befindliche Produkte erworben werden.

\subsubsection{Komplementarität kompetitiver Anbieter}

Eine konsumentenseitige Mehrfachorientierung ist nicht nur über preisorientierte Käufe zu erklären. Eine alternative Sichtweise hierzu nehmen GIJSBRECHTS et al. (2008, S. 6ff.) und VROEGRIJK et al. (2013, S. 607ff.) ein, die von produkt- und anbieterbezogenen Präferenzen der Konsumenten ausgehen und daraufhin den Anreiz für die Frequentierung mehrerer kompetitiver (LEH-)Anbieter in ihrer Komplementarität zueinander sehen; diese besteht insbesondere zwischen kompetitiven Anbietern unterschiedlicher Betriebsformen, d.h. solche, die sich in interformalem Wettbewerb befinden. Der Grundgedanke hierbei ist, dass die Kunden Präferenzen für eine bestimmte Produktkategorie des einen Anbietertyps (z.B. Brot vom preisgünstigen LM-Discounter $X$ ) und für eine andere Produktkategorie des 
anderen Typs (z.B. Käse vom qualitätsorientierten Verbrauchermarkt Y) ausgebildet haben; daher frequentierten diese Kunden bei ihren Einkäufen beide Anbieter ( $X$ und $Y$ ). Diese Mehrfachorientierung basiert also auf einer bewussten und durch persönliche Präferenzen gesteuerten Kombination mehrerer Anbieter, deren Produkte optimal zusammengestellt werden. Dies gilt auch dann, wenn in manchen Produktkategorien hochwertige Varianten bevorzugt werden und bei anderen eine Discount-Orientierung vorherrscht (z.B. Frischfleisch vom ökologischen Bauernhof, Mineralwasser vom LM-Discounter), was Kennzeichen eines polarisierten Einkaufsverhaltens ist (HEINRITZ/POPP 2011, S. 1005f.).

Komplementarität zwischen kompetitiven Anbietern bzw. Betriebsformen entscheidet sich demnach daran, wie unähnlich sie sich im Hinblick auf die angebotenen Produktkategorien sind (positiver Effekt auf die Komplementarität, z.B. durch eine geringe Überschneidung bei exakt gleichen Produkten) und wie groß die Dominanz eines Anbieters gegenüber dem anderen ist (negativer Effekt auf die Komplementarität, z.B. durch eine größere Attraktivität eines Anbieters in vielen Produktkategorien). Die betreffenden Anbieter sollten also möglichst in unterschiedlichen Produktkategorien für die Kunden attraktiv sein, damit sie eine anziehende Kombination darstellen. Je komplementärer diese Anbieter, desto eher werden sie im Verbund aufgesucht (VROEGRIJK et al. 2013, S. 613f.). Tendenziell sind Anbieter unterschiedlicher Betriebsformen miteinander eher kompatibel als Anbieter derselben Betriebsform, wie anhand eines Komplementaritätsindex aufgezeigt wird (ebd., S. 616).

Der Begriff der Komplementarität ist bisher nur auf Güter bzw. Anbieter bezogen worden, die nicht substitutiv und über Kopplungskäufe miteinander verbunden sind. Die aufeinander aufbauenden Überlegungen von GIJSBRECHTS et al. (2008) und VROEGRIJK et al. (2013) zeigen, dass eine Komplementarität auch zwischen im Wettbewerb stehenden Anbietern möglich ist. Dieses Argument soll hier aufgegriffen und mit den Überlegungen von NELSON (1970) verknüpft werden (siehe Kap. 2.2.2): Eingekauft werden Erfahrungsgüter, die einem hohen Grad an Standardisierung unterliegen. Auch hier findet ein Vergleich statt, jedoch nicht vor oder während, sondern nach dem Kauf; da die Güter aber regelmäßig erworben werden, wird nicht nach jedem Kauf ein neuer Vergleich durchgeführt. Stattdessen bilden die Konsumenten auf der Grundlage ihrer Erfahrungen mit den einzelnen Produkten bzw. Anbietern Präferenzen für diese aus. Bei einer Einkaufsfahrt kann der Besuch dieser Anbieter dann miteinander verbunden und so das persönliche Güterbündel entsprechend den eigenen Präferenzen für Produkte bzw. Anbieter zusammengestellt werden. Da diese Einkaufsstrategie auf (früheren) Vergleichen, den daraus gebildeten Erfahrungen und den darauf aufbauenden Präferenzen basiert, soll sie im Folgenden als präferenz- und erfahrungsgesteuerte Vergleichskäufe bezeichnet werden. Bei dieser Einkaufsstrategie werden notwendigerweise mehrere Güter erworben und mehrere Anbieter frequentiert; es handelt sich hierbei also um einen räumlich und sachlich multifinalen Einkauf.

\subsection{Die Ansätze der New Economic Geography (NEG)}

Seit Beginn der 1990er Jahre ist, weitgehend unabhängig von der Wirtschaftsgeographie, ein verstärktes Interesse an räumlichen Aspekten in der Ökonomie festzustellen. Die seminalen Veröffentlichungen von KRUGMAN (1991a, b) etablierten eine für die Volkswirtschaftslehre neue Forschungsrichtung, die zusammengefasst als New Economic Geography (NEG) bekannt wurde (Ausführliche Selbstdarstellung siehe FUJITA et al. 2001, FUJITA/THISSE 2002; Überblick z.B. bei ROSSER 2011). Ausgehend von der empirischen Feststellung der Bildung 
von Agglomerationen verschiedener Industriebranchen in den USA (KRUGMAN 1991b, S. 11ff.), besteht das Anliegen der NEG in der Berücksichtigung des Raums in (mikro-) ökonomischen Modellen unter besonderer Fokussierung von Agglomerationen, was diese Ansätze auch für die vorliegende Arbeit interessant macht. Es existieren NEG-Modelle zu verschiedenen raumwirtschaftlichen Phänomenen, deren Grundannahmen unterschiedliche Komplexität aufweisen; neben dem Zentrum-Peripherie-Modell, dass im Allgemeinen als Grundmodell der NEG angesehen wird, wurden sowohl Modelle zu Städtehierarchien und der Evolution von Angebotsstandorten als auch zum internationalen Handel und zu sektoraler Spezialisierung aufgestellt (Überblick z.B. FUJITA/MORI 2005, S. 380ff.).

Im Gegensatz zu den Ansätzen von z.B. CHRISTALLER oder LöSCH, die ihre Inhalte verbal und/oder grafisch artikulieren, werden die Inhalte der NEG im Sinne ökonomischer Modelle endogenisiert, d.h. als mathematisch operationalisierte Momente in die Modellgleichungen der neoklassischen Ökonomie, die zuvor jene räumlichen Aspekte nicht berücksichtigte, integriert (GÜSSEFELDT 2005, S. 28; STERNBERG 2001, S. 171f.). Anders als in den genannten älteren Theorien ist der theoretische Kern der NEG vollständig mathematisiert; hieraus resultiert notwendigerweise ein sehr hohes Abstraktionsniveau, denn: „Economics tends [...] to follow the line of least mathematical resistance. We like to explain the world in terms of forces we know how to model, not in terms of those we don't" (KRUGMAN 1991b, S. 6). Die NEG-Modelle sind also immer vor dem Hintergrund zu deuten, dass sie nur jene Inhalte berücksichtigen (können), die mathematisierbar sind. Es ist daher nachvollziehbar, dass, wie die Schöpfer dieser neuen Theoriegeneration selbst anmerken (z.B. FUJITA et al. 2001, S. 6ff.; KRUGMAN 1998, S. 10f.), ihre Fortschritte maßgeblich neuen mathematischen Modellierungstechniken und den Möglichkeiten der EDV verdanken, da ohne diese "Modeling tricks" die Modelle nicht zu handhaben wären. Die NEG-Modelle sind also höchst abstrakte Abbilder der Wirklichkeit, die grundlegende Prinzipien veranschaulichen; sie sind keinesfalls als empirisch unmittelbar zugänglicher Ansatz zu verstehen.

Das Zentrum-Peripherie-Modell beinhaltet die räumliche Konzentration bzw. Dispersion von Wirtschaftsaktivitäten in Abhängigkeit von steigenden Skalenerträgen, Transportkosten und Faktormobilität (Arbeiter) vor dem Hintergrund monopolistischer Konkurrenz in einem räumlichen Markt, der aus zwei (bzw. drei) Regionen besteht (FUJITA et al. 2001, S. 61ff. u. 79ff.; kurzer Überblick z.B. bei STERNBERG 2001, S. 162f.). Die Modellinhalte sind in Form von acht verbundenen nicht-linearen Gleichungen zusammengefasst, die nicht analytisch (d.h. durch Ableitungen), sondern mittels numerischer Simulationen modelliert werden. Die Zielgröße des Modells ist die Verteilung der Wirtschaftstätigkeit auf die Regionen; diese variiert in Abhängigkeit des Transportkostenniveaus, das als Variable im Modell verändert wird. Hohe Transportkosten können dabei aufgrund der damit verbundenen Güterpreise zu einer gleichmäßigen Verteilung der Wirtschaftstätigkeit führen, während niedrige Transportkosten die räumliche Konzentration in einer Region bedingen können (FUJITA et al. 2001, S. 65ff.; ausführlicher Überblick zur Simulation siehe FROHWERK 2011, S. 121ff.).

Prinzipiell ist dieses Modell auf alle Wirtschaftszweige anwendbar; es existieren aber auch NEG-Modelle, die sich in ihrem Erklärungsgegenstand unmittelbar mit den Standorttheorien des Einzelhandels decken: So ist beispielsweise das Modell von FUJITA et al. (1999) eine NEG-gemäße, d.h. vollständig formalisierte, Ableitung einer Zentrale-Orte-Hierarchie im Sinne von CHRISTALLER; eine ähnliche Zielsetzung verfolgen TABUCHI/THISSE (2011). Von besonderer Bedeutung sind in diesem Zusammenhang die von FUJITA/THISSE (2002) 
aufgestellten stadtökonomischen Modelle zur Entstehung von Angebotsstandorten bzw. Einzelhandelsagglomerationen, denen ebenso die Marktform der monopolistischen Konkurrenz unterliegt. Für das Konsumentenverhalten wird Nutzenmaximierung unter der Bedingung unvollständiger Information angenommen; aus diesen Gründen ergeben sich als Einkaufsstrategien Kopplungskäufe aufgrund von Zeitersparnis und Vergleichskäufe zur Reduktion des Suchaufwandes und der Auswahlmaximierung (FUJITA/THISSE 2002, S. 219f.). In Zusammenhang mit der Standortwahl der Anbieter ergeben sich agglomerierte Angebotsstandorte und eine räumlich ungleiche Verteilung des Einzelhandelsangebotes als (Gleichgewichts-)Ergebnisse des unvollkommenen Marktes (ebd., S. 243ff.). Weitergeführt wird diese Thematik beispielsweise in einem Modell von TAKAHASHI (2013).

Unabhängig von Detailfragen sind die inhaltlichen Kernaussagen dieser Modelle bereits in den älteren Werken zur monopolistischen Konkurrenz (siehe Kap. 2.2) bzw. in den Raumwirtschaftstheorien (siehe Kap. 2.3) formuliert worden. Die streng mathematisierten NEG-Modelle weisen also im Hinblick auf jene inhaltlichen Aussagen, die für die vorliegende Arbeit relevant sind, keine Neuerungen gegenüber den älteren Ansätzen auf. Der Umstand, dass in die NEG-Modelle keine neuen Inhalte eingeflossen sind, sondern nur bereits bekannte Inhalte mathematisch modellierbar gemacht wurden, ist häufig Anlass zur Kritik gewesen (STERNBERG 2009, S. 114ff.). Diese Kritik ist sicherlich berechtigt, jedoch ist dies den NEG-Ökonomen bewusst und wird in Anbetracht des enormen Einflusses der NEG auf die zeitgenössische VWL auch in Kauf genommen (KRUGMAN 2011, S. 7). Dennoch bleibt festzustellen, dass die NEG keinen inhaltlichen Beitrag zu dieser Arbeit leisten kann, da sie einerseits keine Aussagen beinhaltet, die nicht bereits durch die früheren Theorien behandelt wurden (hierzu z.B. auch FITTKAU 2004 und GüSSEFELDT 2002, 2003 u. 2005), und andererseits die mathematische Operationalisierung dieser Inhalte und der Nachweis von Gleichgewichtssituationen für die vorliegende Arbeit nicht relevant ist. Echte inhaltliche Ergänzungen zur gegebenen Fragestellung bieten hingegen die Überlegungen aus den Marketing-Arbeiten zur Mehrfachorientierung beim Einkauf (siehe Kap. 2.5).

Allerdings ist die Etablierung der NEG in einer anderen Art und Weise sehr bedeutsam. Sie hat nämlich nicht nur dazu geführt, dass räumliche Fragestellungen - und hier insbesondere Agglomerationen auf unterschiedlichen Maßstabsebenen - in der Ökonomie massiv an Bedeutung gewonnen haben (siehe z.B. WORLD BANK 2009; zu empirischen Studien auf der Grundlage der NEG z.B. REDDING 2010) und auch damit verknüpfte einzelhandelsbezogene Fragestellungen in diesem Lichte untersucht werden (z.B. HANDBURY/WEINSTEIN 2011, YUO et al. 2004). Vor allem hat das Aufkommen der NEG die älteren theoretischen Ansätze wieder in den Vordergrund gerückt, die nun auch teilweise unter Rückgriff auf das neue Instrumentarium mikroökonomischer Modellbildung „aufgefrischt“ werden (z.B. FUJITA/THISSE 2002, TABUCHI/THISSE 2011, TAKAHASHI 2013). Insbesondere die Zentrale-Orte-Theorie (im Sinne des Gesamtwerks von CHRISTALLER, LÖSCH und ihren Nachfolgern) hat in diesem Kontext eine wahre „Wiederauferstehung“ erlebt (hierzu siehe insb. MULLIGAN et al. 2012). Vor diesem Hintergrund ist die von ihren Vertretern mitunter geforderte Weiterentwicklung der NEG im Sinne einer NNEG (New new economic geography) von großem Interesse, die zu einer Aufhebung der rigiden Modellannahmen beitragen soll und für die bereits erste Ansätze geliefert wurden (Überblick z.B. OTTAVIANO 2011). 


\section{$3 \quad$ Modellierung von Marktgebieten im Einzelhandel}

In diesem Kapitel werden die Modelle zur Abgrenzung und Segmentierung der Marktgebiete von Angebotsstandorten im Einzelhandel besprochen. Diese mathematisch-statistischen Ansätze besitzen einen eigenen theoretischen Überbau, stellen aber zugleich auch konkrete Methoden zur Analyse von Marktgebieten dar; sie bilden also eine Schnittstelle zwischen Theorie und Methodik, weshalb sowohl ihre inhaltichen Aussagen als auch ihre praktische Anwendbarkeit für diese Arbeit von Interesse sind. Vor diesem Hintergrund stehen die Fragen im Mittelpunkt, welche Modelle sich für eine empirische Analyse des räumlichen Einkaufsverhaltens eignen und inwieweit es möglich ist, Kopplungs- und Vergleichskäufe bzw. Agglomerationseffekte in diese Ansätze zu integrieren. Das Ziel der Erörterung ist eine Antwort auf die Frage, welcher Modellansatz eine Verbindung beider Aufgaben ermöglicht.

\subsection{Modelle des räumlichen Einkaufsverhaltens}

\subsubsection{Grundprinzip und Charakter der Modelle}

Die konsumentenorientierten Methoden zur Abgrenzung und Segmentierung von Marktgebieten im Einzelhande ${ }^{27}$ werden traditionell nach inrem Anwendungsbezug in theoretisch-deduktive und empirisch-induktive Methoden unterschieden (BOOTZ 1968, S. 66ff.; HUfF 1964, S. 34ff.; LÖFFLER 1998, S. 266ff.; MÜLLER-HAGEDORN/SCHUCKEL 2001, S. 92f.). Erstere nehmen eine Modellierung von Marktgebieten anhand mathematischer Modelle auf der Basis formalisierter inhaltlicher Annahmen vor; sie wenden also als allgemeingültig angesehene Prämissen auf einen einzelnen Untersuchungsgegenstand an. Bei den zweitgenannten Ansätzen wird eine Abgrenzung und Segmentierung von Marktgebieten mittels empirischer Daten zum Einkaufsverhalten (Befragungen am Angebotsstandort zur Kundenherkunft, Haushaltsbefragungen zur Einkaufsorientierung) vorgenommen; sie sind demnach nur auf bereits existierende Angebots- und Nachfragekonfigurationen anwendbar, während sich erstere auch für Simulationen und Prognosen eignen.

Diese Ansätze sind vielfältig weiterentwickelt worden, wobei die o.g. klare Unterscheidung nicht mehr aufrecht zu erhalten ist. Insbesondere ist eine Verbindung beider methodischer Zugänge möglich, z.B. durch die Berücksichtigung empirisch erhobener (objektiver und subjektiver) Einflussgrößen in die mathematischen Modelle. Einige Modellansätze besitzen zudem eine konkrete empirische Schnittstelle, da sie ökonometrische Modelle ${ }^{28}$ darstellen, in

\footnotetext{
${ }^{27}$ Einen Überblick zu den sehr heterogenen Methoden der Standortanalyse im Einzelhandel (u.a. Zonierungen, Checklisten, Analogverfahren, Marktgebietsmodelle) geben z.B. BERMAN/Evans 2013, S. 258ff.; HEINRITZ et al. 2003, S. 93ff.; LeVY/Weitz 2012, S. 199ff.; MüLlER-HAGEdORN/NATTER 2011, S. 174ff.; SCHRÖDER 2012, S. $67 \mathrm{ff}$.

${ }^{28}$ Ökonometrische Modelle konfrontieren theoretisch hergeleitete Hypothesen mit der Realität, d.h. mit empirischen Beobachtungen, unter Zuhilfenahme statistischer Methoden (insb. Regressionsanalyse). Ihr Ergebnis ist eine Modellfunktion, die anhand empirischer Daten kalibriert (d.h. an die Echtdaten möglichst gut angepasst) wurde. Sofern die im Modell berücksichtigten Erklärungsgrößen einen statistisch signifikanten Erklärungsbeitrag für die Zielvariable leisten, gehen sie mit einem Parameter in das Modell ein, der die Richtung und Stärke ihres Einflusses wiedergibt (Parametrisierung). Die Modelle beinhalten eine Störgröße, welche die Abweichungen der Modellformel von den empirischen Beobachtungen beinhaltet; sie repräsentiert alle Einflüsse auf die Zielgröße, die nicht (explizit) in das Modell aufgenommen werden (können), z.B. nicht-modellierbare individuelle Verhaltensweisen, zufällige Schwankungen oder Messfehler. Die Störgröße wird als zufallsbestimmt angenommen, während der Zusammenhang zwischen der Zielvariablen und den erklärenden Größen im Mittel durch die restliche Funktion beschrieben wird (Zum Grundprinzip ökonometrischer Modelle siehe z.B. ECKEY et al. 2011, S. 4ff.; GuJARATI/PorTer 2009, S. 3ff.; VON AUER 2013, S. 2ff.; WINKER 2010, S. 129ff.).
} 
denen der Einfluss der Erklärungsgrößen anhand empirischer Daten zum Einkaufsverhalten bestimmt wird (DION/CLIQUET 2006, S. 30ff.; VOGEL 2006, S. 164ff.). Sowohl die theoretischdeduktiven als auch die ökonometrischen Modellansätze, die hier gemeinsam als Modelle des räumlichen Einkaufsverhaltens zusammengefasst werden, haben das Einkaufsverhalten im Hinblick auf die Einkaufsstättenwahl und die Intensität der Konsumenteninteraktionen zum Gegenstand. Sie unterscheiden sich in ihrer Komplexität und ihren erklärenden Größen; dementsprechend heterogen werden sie in Bezug auf ihre theoretischen Grundlagen, ihre Anwendung und ihre Aussagekraft klassifiziert und bewertet (z.B. CLIQUET 2006, S. 138ff.; KLEIN 1992, S. 26ff; MUNDELL 2013, S. 31ff.; RASOULI/TIMMERMANS 2013, S. 140f.; SCHENK 2008, S. 43ff.; VOGEL 2006, S. 164ff.; TELLER/REUTTERER 2008, S. 128f.; TIHI/ORUC 2012, S. 37f.; TIMMERMANS 2012, S. 123ff.; ZIMMERMANN 2002, S. 102ff.).

Die Modelle des räumlichen Einkaufsverhaltens weisen jedoch einige zentrale gemeinsame Eigenschaften auf (RASOULI/TIMMERMANS 2013, S. 139f.; SCHENK 2008, S. 42ff.):

- Letztendliche Zielgrößen der Modelle sind die Interaktionen zwischen Konsumenten und Anbietern, d.h. Kunden- bzw. Kaufkraftflüsse von Nachfrageorten (z.B. Wohnorte der Konsumenten) zu Angebotsstandorten oder einzelnen Anbietern und ihre daraus resultierenden lokalen und gesamten Marktanteile

- Grundlage der Modelle sind Nutzenfunktionen, die den Konsumentennutzen in Abhängigkeit verschiedener angebots- und nachfrageseitiger Struktureigenschaften spezifizieren (siehe Formel 2); bei diesen Nutzenelementen (Teilnutzen) kann es sich um objektive und/oder subjektiv empfundene Eigenschaften handeln

$$
\begin{aligned}
& U_{i j}=f\left(A_{i}, A_{j}, d_{i j}\right) \\
& \mathrm{U}_{\mathrm{ij}}=\text { Nutzen der Alternative } \mathrm{j} \text { für den Nachfrager/Nachfrageort i } \\
& \mathrm{A}_{\mathrm{i}}=\text { Struktureigenschaft des Nachfragers/Nachfrageortes i } \\
& \mathrm{A}_{\mathrm{j}}=\text { Struktureigenschaft des Angebotsstandortes } \mathrm{j} \\
& \mathrm{d}_{\mathrm{ij}}=\text { Distanz (oder andere Transportkosten) zwischen Nachfrageort i und Angebotsstandort } \mathrm{j}
\end{aligned}
$$

- Die kundenseitig zu tragenden Transportkosten gehen als negativer Einflussfaktor in die Nutzenfunktion ein; mit steigender Distanz sinken demnach die Interaktionen zwischen Nachfrage- und Angebotsstandort

Die Modelle des räumlichen Einkaufsverhaltens basieren also auf der Verknüpfung von angebots- und nachfrageseitigen Attributen in einer Nutzenfunktion; diese beinhaltet eine konsumentenseitige Abwägung von bestimmten Attraktivitätseigenschaften der Anbieter und den mit einem Einkauf verbundenen Transport- bzw. im weiteren Sinne Transaktionskosten. Auf der Grundlage dieser Nutzenfunktion werden Marktanteile von Anbietern ermittelt; es handelt sich also um Marktanteilsmodelle, die in einem räumlichen Markt Anwendung finden. Der implizite Raumbezug besteht darin, dass dieser Markt räumlich segmentiert wird, d.h. lokale Marktanteile auf der Ebene von Gebieten modelliert werden; ein expliziter Raumbezug wird durch die Berücksichtigung der Transportkosten (z.B. Distanz) zwischen Nachfrage- und Angebotsstandorten hergestellt. Die Modelle können daher auch als Marktgebietsmodelle bezeichnet werden (CLIQUET 2006, S. 144f.). Die Transport-/Transaktionskosten können gemäß dem breiten ökonomischen Kostenbegriff (siehe Kap. 2.1) vielfältig ausgestaltet sein.

Viele Autoren (z.B. Cliquet 2006, S. 138ff.; KLEIN 1992, S. 26ff; ZimmeRmann 2002, S. 102ff.) zählen entweder alle oder zumindest einen Teil dieser Modelle zu den räumlichen 
Interaktionsmodellen, die einen disziplinübergreifenden Ansatz zur Abbildung menschlicher Interaktionen im Raum darstellen (z.B. Wanderungs- und Pendlerbewegungen, Einkaufsund Freizeitverkehr, Güter- und Investitionsströme). Die ersten dieser Modelle fußten auf einer Analogie zum Gravitationsgesetz von NEWTON (Gravitationsmodelle); dieses stellt für die Interaktionsmodelle jedoch nur eine mathematische Operationalisierung und keine theoretische Fundierung dar (ROY/THILL 2004, S. 339f.). Die inhaltliche Gemeinsamkeit der räumlichen Interaktionsmodelle ist, dass der Bewegung im Raum ein impliziter oder expliziter Entscheidungsprozess seitens der interagierenden Menschen zugrunde liegt, der auf einer Nutzenabwägung der Vor- und Nachteile möglicher Interaktionen basiert (FISCHER 2006, S. 29f.). Darüber hinaus stehen verschiedene theoretische Überlegungen hinter den Modellen.

Im Folgenden werden die theoretisch-deduktiven Modelle von HUFF (1962, 1963, 1964) sowie von REILLY (1929, 1931) und CONVERSE (1949) vorgestellt. Im Anschluss erfolgt die Auseinandersetzung mit zwei ökonometrischen Entscheidungs- bzw. Marktgebietsmodellen, dem Multiplicative Competitive Interaction Model von NAKANISHI/COOPER (1974) und dem diskreten Entscheidungsmodell nach MCFADDEN (1974). Diese Ansätze werden von den meisten Autoren (z.B. CliQUeT 2006, S. 138ff.; KLEIN 1992, S. 26ff; RASOULI/TIMMERMANS 2013, S. 140f.; SCHENK 2008, S. 43ff.) zu den Modellen des räumlichen Einkaufsverhaltens gezählt. Zudem wird mit den Multiagentensystemen für das Einkaufsverhalten (z.B. RAUH et al. 2012, SCHENK 2008) noch ein weiterer Ansatz behandelt.

\subsubsection{Theoretische Grundlagen der Modelle}

Die Modelle unterscheiden sich hinsichtlich ihrer entscheidungstheoretischen Grundlage, die sich auch in ihrer Zielgröße niederschlägt; von vielen Autoren (z.B. CLIQUET 2006, S. 139ff.; KUBIS/HARTMANN 2007, S. 45ff.; KLEIN 1992, S. 36ff.; TIHI/ORUC 2012, S. 37) werden sie diesbezüglich in deterministische und probabilistische Modelle unterteilt:

- Deterministische Modelle weisen einem Konsumenten bzw. einem Nachfrageort den Angebotsstandort mit dem höchsten Nutzen definitiv zu. Im Ergebnis haben Marktgebiete von Angebotsstandorten klar definierte Grenzen, die sich nicht überlappen, d.h. Nachfrageorte sind eindeutig einem Angebotsstandort zugeteilt

- Probabilistische Modelle treffen hingegen keine definitive Vorhersage der Entscheidung für einen Angebotsstandort, sondern modellieren als Zielgröße eine Auswahlwahrscheinlichkeit für jedes Individuum bzw. jeden Nachfrageort in Bezug auf die möglichen Angebotsstandorte

Den deterministischen Modellen von REILLY und CONVERSE wird häufig ein Mangel an expliziter theoretischer Fundierung attestiert (z.B. LÖFFLER 1998, S. 267f.); natürlich lassen sich auch diese Modelle nutzentheoretisch interpretieren (siehe Kap. 3.1.1), jedoch fehlen in den Originalwerken diesbezügliche Aussagen. Dies gilt jedoch nicht für die probabilistischen Modelle, die aus allgemeinen Entscheidungs- und Marktanteilsmodellen abgeleitet wurden bzw. konkrete Spezifikationen dieser Ansätze darstellen.

Die verhaltenswissenschaftliche Basis der probabilistischen Modelle bildet das Wahlaxiom von LUCE (1959); sowohl das HUFF-Modell als auch die ökonometrischen Modelle (MClModell, diskretes Entscheidungsmodell) bauen auf dieser theoretischen Grundlage zum Entscheidungsverhalten bzw. zur Form der Konsumentenentscheidung auf (CLIQUET 2006, S. 138; TIHI/ORUC 2012, S. 37). Dieses Basismodell nutzenorientierter Entscheidungstheorie 
unterstellt einen probabilistischen Zusammenhang zwischen Nutzen und Wahlentscheidung; demnach entspricht die Wahrscheinlichkeit, dass sich ein Konsument (I) für die Inanspruchnahme einer Alternative (j) entscheidet, dem Quotienten des Nutzens der Alternative $j$ für den Konsumenten $i$ und der Summe der Nutzenwerte aller Alternativen (siehe Formel 3). Die Zielgröße dieses Entscheidungsmodells ist also nicht die definitive konsumentenseitige Entscheidung für eine Alternative, was eine deterministische Zuordnung bedeuten würde, sondern die Auswahlwahrscheinlichkeit für die jeweiligen Alternativen. Begründet wird diese probabilistische Perspektive auf das Entscheidungsverhalten mit der Annahme, dass ein Konsument sich nicht mit Sicherheit für die Alternative entscheidet, die für inn mit dem größten Nutzen verbunden ist (ZIMMERMANN 2002, S. 136f.).

$$
p_{i j}=\frac{U_{i j}}{\sum_{a=1}^{A} U_{i j}}
$$

$p_{\mathrm{ij}}=$ Wahrscheinlichkeit, dass ein Entscheidungsträger i die Alternative $\mathrm{j}$ wählt

$\mathrm{U}_{\mathrm{ij}}=$ Nutzen aus der Alternative $\mathrm{j}$ für den Entscheidungsträger $\mathrm{i}$

Während in dieser Frage eine gemeinsame Basis von HuFF-Modell, MCl-Modell und diskretem Entscheidungsmodell gegeben ist, besteht ein wesentlicher Unterschied zwischen den Modellen, der sowohl die nutzentheoretische Grundlage als auch ihre konkrete Anwendung betrifft. Theoretisch-deduktive Modelle beinhalten formalisierte Annahmen und akzeptieren keine Abweichungen von der Modellfunktion; demgegenüber basieren ökonometrische Modelle auf der Überlegung, dass sich die untersuchten Zusammenhänge nicht vollständig erfassen lassen und immer ein nicht zu erklärender „Rest“ bleibt, der auf nicht-messbaren Einflüssen, Zufällen oder Messfehlern beruht (siehe Kap 3.1.1).

Übertragen auf (Konsumenten-)Entscheidungen ist diese Überlegung Gegenstand der Zufallsnutzentheorie (Random utility theory), die auf die Arbeiten von THURSTONE (1927) und MARSCHAK (1960) zurückgeht und den ökonometrischen Entscheidungsmodellen zu Grunde liegt. Demnach strebt ein Individuum bei einer Entscheidung danach, seinen Nutzen zu maximieren, eine vollständige Beobachtung oder „Messung“ dieses Nutzens ist jedoch nicht direkt möglich; er wird daher „zerlegt“ in eine deterministische Komponente (Repräsentativer Nutzen), die eine Operationalisierung des Nutzens in Form beobachtbarer Größen (Angebots-/Nachfragereigenschaften) darstellt, und eine stochastische Komponente, die alle Einflussfaktoren auf die Konsumentenentscheidung abdeckt, die im Modell nicht messbar sind (z.B. nicht beobachtete oder nicht beobachtbare Konsumenten- oder Angebotsattribute, Messfehler). Aus beiden Komponenten resultiert die in Formel 4 dargestellte allgemeine Nutzenfunktion (GonZÁLEZ-BENITO et al. 2000, S. 172f.; TRAIN 2009, S. 14f.).

$$
U_{i j}=V_{i j}+\varepsilon_{i j}
$$

$\mathrm{U}_{\mathrm{ij}}=$ Nutzen aus der Alternative $\mathrm{j}$ für den Entscheidungsträger $\mathrm{i}$

$V_{i j}=$ Erklärter (deterministischer) Teil des Nutzens

$\varepsilon_{i j}=$ Nicht erklärter (stochastischer) Teil des Nutzens

In den hier als theoretisch-deduktiv bezeichneten Modellen (z.B. HuFF-Modell) beinhaltet die Nutzenfunktion nur den deterministischen Teil, dessen Inhalt vorher nicht durch empirisch- 
ökonometrische Verfahren auf seine Aussagekraft hin überprüft wurde. Unabhängig von ihrer Zielgröße sind diese Modelle also in ihren mathematischen Eigenschaften deterministisch.

Abseits der entscheidungstheoretischen Herleitung bilden die ökonometrischen Modelle (MCl-Modell, diskretes Entscheidungsmodell) zugleich auch Marktanteilsmodelle (auch: Marktreaktionsmodelle) bzw. Spezifikationen allgemeiner Marktanteilstheoreme. Deren Grundaussage ist, dass der Marktanteil eines Produktes (bzw. Anbieters) gleich dem Quotienten aus bestimmten produktspezifischen (bzw. anbieterspezifischen) Eigenschaften und der Summe dieser Eigenschaften aller Produkte (bzw. Anbieter) ist (siehe Formel 5). Im Ergebnis stehen logisch konsistente Marktanteile zwischen null und eins, wobei die Summe der Marktanteile aller Objekte eins beträgt (CLIQUET 2006, S. 143f.; COOPER/NAKANISHI 2010, S. 21ff.). Als Erklärungsgrößen für den Marktanteil können z.B. die Marketingaufwendungen des Anbieters herangezogen werden (Fundamentaltheorem des Marktanteils nach KOTLER 1971) oder die (wahrgenommene) Attraktivität eines Produktes (Attraktivitätsmodell von BELL et al. 1975). Marktanteilsmodelle sind grundsätzlich auf verschiedene Objekttypen (Produkte, Marken, Unternehmen, Einkaufsstätten etc.) beziehbar. Ihre Erklärungsgrößen sind nicht festgelegt und können subjektive und/oder objektive sowie räumliche und/oder nichträumliche Inhalte abbilden (CLIQUET 2006, S. 144f.).

$$
s_{i}=\frac{A_{i}}{\sum_{j=1}^{m} A_{i}}
$$

$\mathrm{Si}_{\mathrm{i}}=$ Marktanteil des betrachteten Objektes i (z.B. Produkt, Marke, Einkaufsstätte)

$A_{i}=$ Attraktivität des Objektes $\mathrm{i}$ bzw. Marketingaufwendungen des Unternehmens mit Produkt $\mathrm{i}$

$\mathrm{m}=$ Zahl der betrachteten Objekte (z.B. Produkt, Marke, Einkaufsstätte)

Die Modelle des räumlichen Einkaufsverhaltens beruhen in theoretischer Hinsicht also auf verhaltenswissenschaftlichen Entscheidungsmodellen (Überblick: BALDERJAHN/SCHOLDERER 2007, S. 24ff.) und Marktanteilsmodellen (Überblick: COOPER/NAKANISHI 2010, S. 17ff.) aus dem Marketingbereich. Folgt man der Argumentation von COOPER/NAKANISHI (2010, S. 46ff.), sind diese Modelltypen ohnehin eng miteinander verbunden bzw. direkt ineinander überführbar, da Marktanteile letztlich vorherige Konsumentenentscheidungen repräsentieren. Dies gilt insbesondere dann, wenn die Erklärungsgrößen des Marktanteilsmodells die Attraktivität der Alternativen wiedergeben, die den Entscheidungsmodellen zugrunde liegt; das Konstrukt „Attraktivität“ entspricht in diesem Zusammenhang dem Konstrukt „Nutzen“.

\subsection{Theoretisch-deduktive Marktgebietsmodelle}

\subsubsection{Deterministische Modelle}

\subsubsection{Das Gesetz der Einzelhandelsgravitation von REILLY}

Das Law of Retail Gravitation (Gesetz der Einzelhandelsgravitation) von REILLY $(1929,1931)$ war das erste räumliche Interaktionsmodell für Marktgebiete im Einzelhandel. Zielgröße dieses "Gesetzes“ ist die Verteilung der Kaufkraftflüsse von einem Nachfrageort auf zwei Angebotsstandorte in Abhängigkeit interaktionsfördernder und -hemmender Faktoren. Es 
besagt, dass das Verhältnis der Umsätze zweier Angebotsstandorte (in diesem Fall: Städte) proportional zum Verhältnis ihrer Anziehungskraft und umgekehrt proportional zum Verhältnis ihrer Entfernungen zum Kundenquellort ist (siehe Formel 6) (REILLY 1931, S. 8f.). Als Attraktivitätsvariable verwendet REILLY die Bevölkerungsgröße der Städte, als Distanzvariable die PKW-Fahrtzeit; die Parameter $\alpha$ und $\lambda$ dienen ihrer Gewichtung.

$$
\frac{U_{1}}{U_{2}}=\left(\frac{A_{1}}{A_{2}}\right)^{\alpha}\left(\frac{d_{2}}{d_{1}}\right)^{\lambda}
$$

$U_{1}, U_{2}=$ Umsatz der Angebotsstandorte (1 und 2) aus einem zwischen innen liegenden Ort

$A_{1}, A_{2}=$ Attraktivität der Angebotsstandorte (1 und 2)

$\mathrm{d}_{1}, \mathrm{~d}_{2}=$ Distanz der Angebotsstandorte (1 und 2) zum zwischen ihnen liegenden Ort

$\alpha=$ Gewichtungsparameter der Attraktivität

$\lambda=$ Gewichtungsparameter der Entfernung

Die Konstruktion der Formel basiert nicht auf einer theoretischen Herleitung, sondern auf der Basis umfangreicher empirischer Daten aus Kundenherkunftsbefragungen in den 1920er Jahren in insgesamt 132 unterschiedlich großen US-amerikanischen Städten (REILLY 1931, S. 4ff.). Von REILLY wird kein Bezug zu vorherigen theoretischen Arbeiten vorgenommen; sein Modell erklärt das räumliche Einkaufsverhalten und die Struktur von Marktgebieten nicht, sondern verbleibt auf einer deskriptiven Ebene (HUFF 1962, S. 12; REILLY 1931, S. 32f.). In der praktischen Anwendung dieses Marktgebietsmodells offenbaren sich zudem weitere Einschränkungen, z.B. dass sich die Marktgebiete im Modell nicht überlappen können (was dessen deterministischen Charakter ausmacht) und immer nur zwei Angebotsstandorte betrachtet werden (HUFF 1962, S. 11f.; LÖSCH 1944, S. 292f.).

Die Gewichtungsparameter üben als Exponenten einen entscheidenden Einfluss auf das Modellergebnis aus; diese wurden von REILLY (1929, S. 48ff.) empirisch anhand inm vorliegender Daten (Stadtgröße, Entfernungen, Umsatzflüsse) ermittelt. Der Attraktivitätsterm wird, ohne dass dies mathematisch hergeleitet wird, mit einem Exponenten von $\alpha=1$ gewichtet, was einen linearen Einfluss der Stadtgröße auf den Kundenzufluss bedeutet. Da nun abgesehen vom Distanzexponenten alle Variablen der Gleichung bekannt sind, ist es möglich, diese nach $\lambda$ aufzulösen und somit diesen Parameter anhand der Echtdaten zu schätzen. In den meisten Untersuchungsgebieten ermittelte REILLY hierfür einen Wert für $\lambda$ zwischen 1,5 und 2,5, so dass der Gewichtungsexponent zwecks Vereinfachung auf $\lambda=2$ gesetzt wurde. In Einzelfällen werden aber auch deutlich höhere Parameterwerte erreicht.

\subsubsection{Die Breaking-Point-Formel von CONVERSE}

Eine Erweiterung von REILLYS Gesetz wurde durch CONVERSE (1949) vorgenommen, die zumeist als Breaking-Point-Formel bezeichnet wird. Dieser „Breaking Point“ lag als Überlegung bereits dem Modell REILLYS zu Grunde und unterstreicht den deterministischen Charakter dieser Modelle, wonach die Marktgebiete von Angebotsstandorten durch eine exakte Grenze getrennt sind; diese Grenze, an der der Einfluss einer Stadt vollständig endet und der Einfluss der anderen beginnt, stellt den „Breaking Point“ zwischen diesen beiden Angebotsstandorten dar (REILLY 1931, S. 8). Der Ansatz von CONVERSE stellt eine Umformung von REILLYs Gesetz dar, um diesen Grenzpunkt zu berechnen (siehe Formel 7). Die Zielgröße des Modells ist die Entfernung, bis zu welcher sich das Marktgebiet der beiden 
betrachteten Angebotsstandorte in Abhängigkeit von Attraktivität und Distanz ausdehnt (CONVERSE 1949, S. 384). In der Terminologie CHRISTALLERs würde dieser Punkt die obere Grenze der Reichweite der betrachteten Angebotsstandorte darstellen (siehe Kap. 2.3.1.2). Ein theoretischer Bezug wird jedoch auch von CONVERSE nicht vorgenommen.

$$
d_{1 b}=\frac{d_{12}}{1+\sqrt{\frac{A_{2}}{A_{1}}}} \quad d_{2 b}=\frac{d_{12}}{1+\sqrt{\frac{A_{1}}{A_{2}}}}
$$

$A_{1}=$ Attraktivität des Angebotsstandortes 1

$\mathrm{A}_{2}=$ Attraktivität des Angebotsstandortes 2

$\mathrm{d}_{1 \mathrm{~b}}=$ Distanz zwischen Angebotsstandort 1 und dem breaking-point $\mathrm{b}$

$\mathrm{d}_{2 b}=$ Distanz zwischen Angebotsstandort 2 und dem breaking-point $b$

\subsubsection{Das probabilistische Marktgebietsmodell von HufF}

\subsubsection{Herleitung und theoretische Fundierung}

Das Marktgebietsmodell von HUfF $(1962,1963,1964)$ ist, genau wie die Ansätze von REILLY und CONVERSE, ein konsumentenseitiges Modell theoretisch-deduktiver Natur; der große Unterschied zu diesen Arbeiten besteht aber in einer umfassenden theoretisch-inhaltlichen Auseinandersetzung sowie einer deutlichen Ausweitung der Funktionalität. Die Aufstellung des Modells wird von HUFF anhand einer Kritik an den Vorgängermodellen begründet und auf der Basis theoretischer Überlegungen und empirischer Erkenntnisse zum räumlichen Konsumentenverhalten fundiert. Bezüglich der deterministischen Modelle von REILLY und CONVERSE konstatiert HUFF (1962, S. 11ff.) mehrere praktische und inhaltliche Probleme:

- Der deterministische Charakter der Modelle, d.h. die vollständige Zuordnung von Nachfrageorten zu Angebotsstandorten mit einer definitiven Marktgebietsgrenze, ist nicht kompatibel zu den empirischen Erkenntnissen, nach denen sich Marktgebiete überschneiden

- Die Wirkung der Distanz - von REILLY im Durchschnitt mit einem Exponenten von $\lambda=$ 2 gewichtet - schwankt je nach Sortimentstyp und räumlicher Standortkonfiguration

- In inhaltlicher Hinsicht wird kritisiert, dass die Modelle von REILLY und CONVERSE nicht theoretisch fundiert sind und in erster Linie als Kalkulationswerkzeuge gebraucht werden, deren verhaltenswissenschaftliche Inhalte nicht aufgearbeitet sind

Aus den Erkenntnissen empirisch-induktiver Arbeiten zur Abgrenzung und Segmentierung von Marktgebieten fasst HUFF (1964, S. 34) vier Gesetzmäßigkeiten zusammen:

- Die Menge der Kunden, die einen Angebotsstandort aufsuchen, variiert mit der Entfernung zum Angebotsstandort

- Die Menge der Kunden, die verschiedene Angebotsstandorte aufsuchen, variiert mit der Sortimentsbreite und -tiefe der Anbieter

- Die Entfernungen, die Kunden zu Angebotsstandorten zurücklegen, variiert nach den Produktkategorien, die sie erwerben wollen 
- Die Anziehungskraft jedes Angebotsstandortes wird von der Nähe der Mitbewerber beeinflusst

Die entscheidungstheoretische Basis des HuFF-Modells ist das Wahlaxiom von LUCE (1959), das einen probabilistischen Zusammenhang zwischen Nutzen und Konsumentenverhalten postuliert (siehe Kap. 3.1.2). Auf dieser Grundlage unterstellt HuFF (1962, S. 14ff.) den Konsumenten bei der Wahl ihrer Einkaufsstätte(n) Unsicherheit bzw. unvollständige Information, da sie nicht in der Lage sind, den tatsächlichen Nutzen jeder Entscheidung objektiv zu erfassen. Insbesondere eine Differenzierung zwischen sehr ähnlichen Alternativen sei demnach für Konsumenten kaum möglich, so dass ihre Entscheidung für eine davon auch rein zufällig sein kann; demnach würden sie auch intuitiv verschiedene Alternativen ausprobieren. Aus diesen Gründen ist eine definitive Zuordnung der Konsumenten zu einzelnen Angebotsstandorten nicht möglich.

Das Bild eines durch Unsicherheit geprägten Konsumentenverhaltens findet sich sowohl in der probabilistischen Formulierung des Modells als auch in den erklärenden Größen. Auf dieser Basis diskutiert HUFF die nutzenstiftenden Elemente eines Angebotsstandortes bzw. einer Einkaufsfahrt, die die Einkaufsstättenwahl erklären; er bezieht sich hierbei auf die mikroökonomische Arbeit von BAUMOL/IDE (1956). Als wesentliches Attraktivitätsmerkmal von Angebotsstandorten wird dabei die dargebotene Auswahl bzw. Größe identifiziert. Da Konsumenten nicht mit Sicherheit wissen, ob sie die von ihnen nachgefragten Güter auch tatsächlich am jeweiligen Angebotsstandort bekommen, ist die Erfüllung dieser Wünsche umso wahrscheinlicher, je mehr Güter am Standort angeboten werden. Dementsprechend sind Konsumenten umso eher bereit, weitere Einkaufswege auf sich zu nehmen, je mehr Güter am jeweiligen Angebotsstandort verfügbar sind (BAUMOL/IDE 1956, S. 93; HUFF 1962, S. 17f.). Ein Angebotsstandort kann hierbei sowohl ein einzelner Anbieter als auch ein geplantes Einkaufszentrum oder eine "gewachsene“ Agglomeration mehrerer gleichund/oder ungleichartiger Anbieter sein (HUFF 1963, S. 85 u. 1964, S. 37).

Daraus resultiert ein grundsätzlich positiver Einfluss der Größe des Angebotes auf den wahrgenommenen Konsumentennutzen, wobei jedoch zwei alternative Ausprägungen dieser Wirkung möglich sind (siehe Abbildung 8): Die Auswahl bzw. Größe kann linear-proportional auf den Nutzen wirken (Kurve a), was bedeutet, dass jede Ausweitung der Sortimentsbreite bzw. -tiefe den Nutzen im gleichen Verhältnis steigert. Möglich ist aber auch ein nur unterproportionaler Einfluss (Kurve b), so dass der Nutzen mit fortschreitender Größe nicht mehr um die gleiche Menge zunimmt (Gesetz vom abnehmenden Grenznutzen). Dies wird damit begründet, dass durch die Vergrößerung des Angebotes auch der Einkaufsaufwand durch steigende Such- und Entscheidungskosten zunimmt und so die eigentlich positive Wirkung einer Sortimentsausweitung gemindert wird (BAUMOL/IDE 1956, S. 94f.; HUFF 1962, S. 17). Neben dem grundsätzlich positiven Effekt der Sortimentsbreite und -tiefe bzw. größerer interner Kopplungs- und Vergleichsmöglichkeiten berücksichtigt die zweite Variante (Kurve b) also auch die damit verbundenen Transaktionskosten ${ }^{29}$.

\footnotetext{
${ }^{29}$ Diese Überlegung spielt in der transaktionskostentheoretischen Betrachtung der Einkaufsstättenwahl eine essentielle Rolle; demnach kann die Ausweitung der Produktvielfalt aufgrund von Informationsüberlastung (Konsumentenverwirrung) und einer Entscheidungsunsicherheit („Qual der Wahl“) in einen negativen Effekt umschlagen (Überblick: RIEMENSCHNEIDER 2006, S. 68ff.). In diesem Zusammenhang wurde in Bezug auf die Wahl von Produktvarianten auch der Begriff der „tyranny of freedom [of choice]“ geprägt (z.B. DESMEULES 2002).
} 


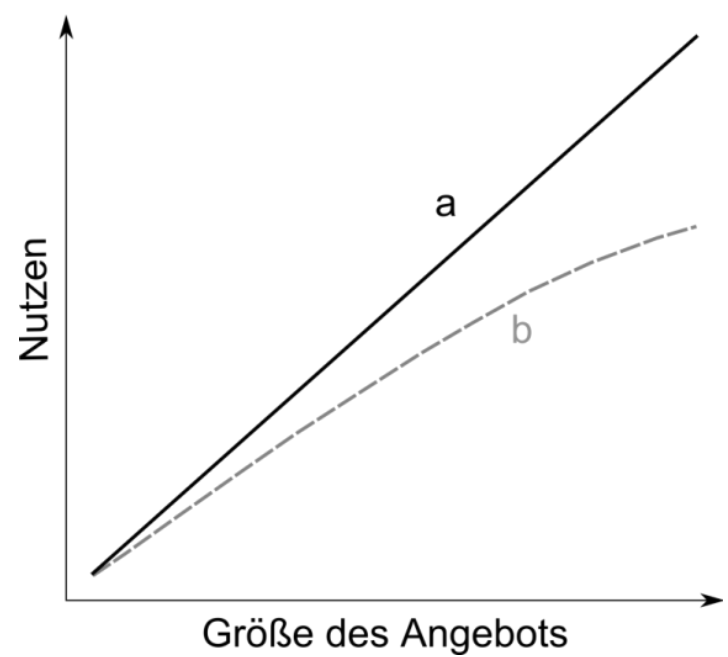

Abbildung 8: Wahrgenommener Konsumentennutzen der Angebotsgröße Quelle: Eigene Darstellung nach HUFF (1962, S. 18), verändert

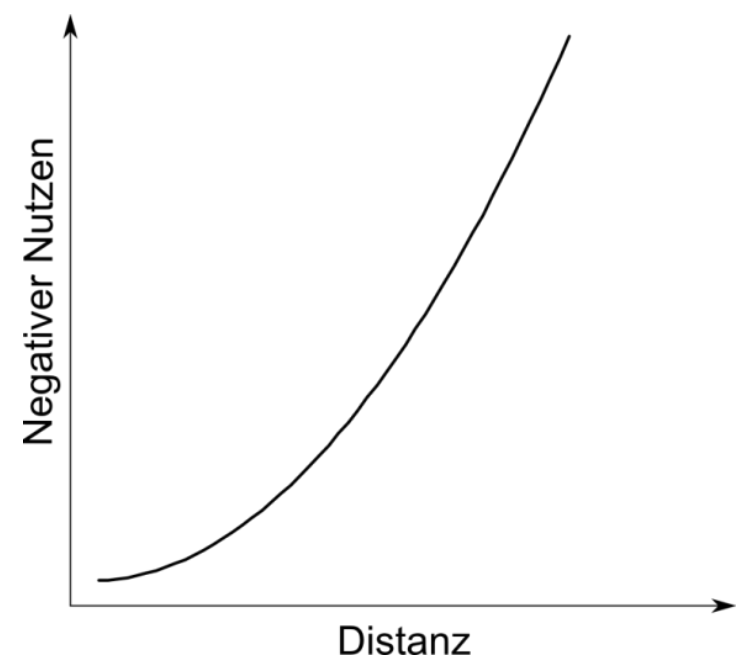

Abbildung 9: Wahrgenommener negativer Konsumentennutzen der Distanz Quelle: Eigene Darstellung nach HufF (1962, S. 19), verändert

Als zweite erklärende Größe fungieren, parallel zum Modell von BAUMOL/IDE (1956), die Transportkosten zwischen Nachfrageort und Angebotsstandort, welche die Anziehungskraft eines Angebotsstandortes mindern, d.h. einen interaktionshemmenden Faktor darstellen; räumliche Distanz wirkt demnach nutzenmindernd. Jedoch wird die Distanz nicht in ihrer realen Größe wahrgenommen, sondern wirkt überproportional negativ (siehe Abbildung 9). Dies wird damit erklärt, dass Konsumenten nur über ein begrenztes Zeitbudget verfügen und ihre zeitlichen Ressourcen auf verschiedene Aktivitäten aufteilen müssen. Wird für eine Aktivität (Einkaufen) mehr Zeit aufgewendet, steht für alle anderen notwendigerweise weniger Zeit zur Verfügung, so dass zwischen diesen wiederum eine erhöhte Konkurrenz um die Ressource Zeit besteht. Die konsumentenseitigen Opportunitätskosten steigen daher exponentiell an (HUFF 1962, S. 18f.) ${ }^{30}$.

\subsubsection{Mathematische Formalisierung}

Die theoretischen Überlegungen werden in einem nicht-linearen Modell operationalisiert. Als erklärende Variablen in der mathematischen Formalisierung seines Modells wählt HUFF (1962, S. 17ff.) die Verkaufsfläche eines Angebotsstandortes als Maß für die Größe des Angebotes und die Fahrtzeit zwischen Nachfrageort (Kundenwohnort) und Angebotsstandort als Maß für die Distanz. Die Verkaufsfläche wird aus pragmatischen Erwägungen heraus als Indikator genutzt, da eine Bestimmung der Zahl am jeweiligen Angebotsstandort offerierter Produkte bzw. Produkttypen äußerst aufwendig wäre. Da die Berücksichtigung der Distanz mit der konsumentenseitigen Zeitaufwendung begründet wird, sieht HUFF die Fahrtzeit zwischen Nachfrage- und Angebotsstandort als adäquates Maß für die Transportkosten an.

Daraus resultiert die in Formel 8 dargestellte multiplikative Nutzenfunktion. Da für die Distanz ein überproportionaler Einfluss angenommen wird, wird die Fahrtzeit mit einem negativen Exponenten $(\lambda)$ gewichtet (negative Potenzfunktion), der betragsmäßig größer als eins ist.

\footnotetext{
${ }^{30}$ Eine Überschätzung tatsächlicher Distanzen und Wegezeiten im Einkaufsverkehr sowie ein diesbezüglicher mit steigender Entfernung größerer Effekt sind mehrfach empirisch nachgewiesen worden (SCHÖLER 1981, S. 41ff.).
} 
Auch wenn eine degressiv-positive Wirkung der Angebotsgröße diskutiert wird ${ }^{31}$, erfolgt in der ursprünglichen Form des HuFF-Modells keine Gewichtung der Verkaufsfläche, was einen linear-proportionalen Zusammenhang zwischen Angebotsgröße und Nutzen bedeutet (HUFF 1962, S. 15ff.). In späteren Formulierungen des Modells (HUfF 1981, S. 117f.; HUfF/BATSELL 1975, S. 166) findet sich aber ein (positiver) Gewichtungsexponent $(\gamma)$ für die Verkaufsfläche. Wird, wie im ursprünglichen Modell, dieser Parameter ausgespart, entspricht dies einem Wert von $\gamma=1$; eine unter-lineare Gewichtung der Verkaufsfläche (siehe Kap. 3.2.2.1, Abb. 8 , Kurve b) wird demnach durch einen Parameter $\gamma$ zwischen null und eins ausgedrückt.

$$
U_{i j}=A_{j}^{\gamma} d_{i j}^{-\lambda}
$$

$\mathrm{U}_{\mathrm{ij}}=$ Wahrgenommener Nutzen des Angebotsstandortes $\mathrm{j}$ für die Konsumenten am Nachfrageort $\mathrm{i}$

$A_{j}=$ Attraktivität (=Größe der Verkaufsfläche) des Angebotsstandortes j

$\mathrm{d}_{\mathrm{ij}}=$ Transportkosten (=Fahrtzeit) zwischen Nachfrageort i und Angebotsstandort $\mathrm{j}$

$\lambda=$ Gewichtungsparameter der Distanz

$\gamma=$ Gewichtungsparameter der Größe

Die Nutzenfunktion drückt die konsumentenseitige Abwägung zwischen dem Nutzen des Besuchs eines Angebotsstandortes und den damit verbundenen Transportkosten aus. Die überproportionale Nutzenminderung der Transportkosten wird bereits im Modell von REILLY und anderen Interaktionsmodellen impliziert, aber nicht theoretisch begründet. Nach HUFF (1962, S. 19ff. u. 31) variiert der Distanzparameter je nach Einkaufszweck bzw. Sortiment, da die konsumentenseitige Distanzsensibilität diesbezüglich unterschiedlich ausgeprägt ist ${ }^{32}$. Es ist vor diesem Hintergrund notwendig, den Gewichtungsexponenten für den jeweiligen Untersuchungszweck und -raum individuell zu bestimmen (siehe Kap. 3.2.2.3).

Entsprechend dem probabilistischen Wahlaxiom von LUCE (1959) wird anhand der Nutzenfunktion eine Wahrscheinlichkeitsaussage formuliert: Die Wahrscheinlichkeit, dass die Konsumenten am Nachfrageort $i$ den Angebotsstandort $j$ aufsuchen, errechnet sich aus dem Quotienten des Nutzens des Angebotsstandortes $j$ für die Konsumenten am Nachfrageort $i$ und der Summe der Nutzen aller Alternativen (siehe Formel 9 bzw. 10). Im Ergebnis stehen Interaktionswahrscheinlichkeiten zwischen null und eins für jede Kombination von Nachfrageorten und Angebotsstandorten (HufF 1962, S. 14f.). Diese Zielgröße macht den probabilistischen Charakter des HuFF-Modells aus.

$$
p_{i j}=\frac{U_{i j}}{\sum_{a=1}^{A} U_{i j}}
$$

$\mathrm{p}_{\mathrm{ij}}=$ Wahrscheinlichkeit, dass die Kunden im Nachfrageort i den Angebotsstandort $\mathrm{j}$ frequentieren

\footnotetext{
${ }^{31}$ Alternativ bespricht HufF (1962, S. 30f.) auch die Gewichtung der Verkaufsfläche mittels einer logistischen Funktion, deren S-förmiger Verlauf die Nutzensteigerung durch die Größe unter Berücksichtigung der Überlegungen zum abnehmenden Grenznutzen noch realitätsnaher abbilden könnte; demnach würde der Nutzen durch eine Größenzunahme sowohl bei kleinen als auch bei großen Angebotsstandorten nur wenig steigen, während im mittleren Bereich der größenbedingte Nutzenzuwachs am höchsten ist.

${ }^{32}$ Auch wenn dieser Zusammenhang von HufF selbst nicht hergestellt wird, lässt sich die Größe des Parameters $\lambda$ als Determinante der Marktgebietsgröße im Sinne von CHRISTALLERs Konzept der oberen Grenze der Reichweite (siehe Kap. 2.3.1.2) interpretieren (GüsSEFELDT 2002, S. 355; OPENSHAw/VENERIS 2003, S. 1389).
} 


$$
p_{i j}=\frac{A_{j}^{\gamma} d_{i j}^{-\lambda}}{\sum_{a=1}^{A} A_{j}^{\gamma} d_{i j}^{-\lambda}}
$$

Im nächsten Schritt erfolgt der Übergang von einem Entscheidungsmodell in ein Marktanteils- bzw. Marktgebietsmodell. Die errechneten Interaktionswahrscheinlichkeiten für die einzelnen Kombinationen von Nachfrage- und Angebotsstandorten können mit dem Gesamtnachfragepotenzial in den Nachfrageorten verrechnet werden, so dass sich für alle Angebotsstandorte ein gebietsspezifisches Nachfragepotenzial ergibt (siehe Formel 11). Die Summe der Teilpotenziale aus allen Gebieten bildet das gesamte geschätzte Marktgebiet des jeweiligen Angebotsstandortes (siehe Formel 12). Das Nachfragepotenzial kann anhand der absoluten Kundenzahl und/oder der lokalen (gesamten oder sortimentsspezifischen) Kaufkraft berechnet werden (HUFF 1962, S. 34f.). Die errechnete Zielgröße des Modells (Interaktionswahrscheinlichkeit) wird also als (lokaler) Marktanteil interpretiert, worauf der praktische Einsatz des Modells in der Standortanalyse basiert (KUBIS/HARTMANN 2007, S. 46; MülleR-HAGEDORN/NATTER 2011, S. 200ff.).

$$
E_{i j}=p_{i j} C_{i}
$$

$E_{i j}=$ Erwartete Kunden-/Kaufkraftzuflüsse aus dem Nachfrageort i für den Angebotsstandort j

$\mathrm{C}_{\mathrm{i}}=$ Gesamtes Kunden-/Kaufkraftpotenzial am Nachfrageort i

$$
T_{j}=\sum_{i=1}^{n} E_{i j}
$$

$$
\mathrm{T}_{\mathrm{j}}=\text { Marktgebiet (bzw. Gesamtnachfragepotenzial) des Angebotsstandortes } \mathrm{j}
$$

\subsubsection{Bestimmung der Gewichtungsparameter}

Da die Gewichtungsparameter als Exponenten in die Modellgleichung eingehen, kommt innen für das Endergebnis eine entscheidende Bedeutung zu; selbst geringe Variationen in den Exponenten schlagen sich in großen Unterschieden in den geschätzten Kunden- bzw. Kaufkraftströmen nieder (KLEIN 2007, S. 59ff.; MüLLER-HAGEDORN/SCHUCKEL 1995b, S. 602f.). Die Größe der Parameter ist nicht definitiv festzusetzen, sondern variiert je nach räumlicher Konfiguration der Nachfrage- und Angebotsstandorte sowie nach Angebotsform bzw. Sortimentsbereich (LADEMANN 2007, S. 148f.). Es sind diverse Methoden zur Ermittlung dieser Parameter entwickelt worden; da im Ursprungsmodell nur eine Distanzgewichtung vorgenommen wird, beschränken sich viele Arbeiten auf die Bestimmung des Exponenten $\lambda$.

In seiner Pilotstudie ermittelte HUFF (1962, S. 22ff.) diesen Parameter anhand von empirischen Kunden-/Kaufkraftströmen mit Hilfe von Korrelationsanalysen zwischen echten und modellierten Marktanteilen; angefangen bei einem Startwert, wird $\lambda$ hierbei in einem iterativen Verfahren so lange angepasst, bis ein Maximum an Übereinstimmung zwischen Echt- und Modelldaten erreicht wird. HUfF ermittelte für den Sortimentsbereich Bekleidung einen Wert von $\lambda=3,191$ und für Möbel $\lambda=2,723$. Eine direkte statistische Ermittlung von Distanzexponenten in Interaktionsmodellen zeigt ISARD (1960, S. 494ff.) mit Hilfe von 
Distanzfunktionen auf, die durch Regressionsanalysen anhand von echten Interaktionsdaten geschätzt werden: Die tatsächliche Interaktionsintensität zwischen Ziel- und Quellorten wird als abhängige und die Distanz als unabhängige Variable in ein Regressionsmodell eingesetzt; aufgrund des nicht-linearen Zusammenhangs (Potenzfunktion) werden die Werte aber zunächst logarithmiert. Der Steigungsparameter der Regressionsgleichung kann als Exponent zur Distanzgewichtung in räumliche Interaktionsmodelle eingesetzt werden. Eine alternative Ableitung von $\lambda$ aus Differentialgleichungen zeigt BAKER (1996, S. 612f.).

Diese Ansätze haben jedoch gemeinsam, dass sie zwar einen Teil der Modellfunktion empirisch schätzen, jedoch die Gewichtung der Verkaufsfläche unterlassen, keine weiteren Variablen berücksichtigen und auch keine statistische/ökonometrische Verifikation des Gesamtmodells vornehmen; der theoretisch-deduktive Charakter des HUFF-Modells bleibt also, trotz partieller Anpassungen an die Empirie, erhalten. Demgegenüber existieren aber auch Ansätze, die nicht nur eine empirisch gestützte Schätzung aller Parameter, sondern auch eine Prüfung der Erklärungsgrößen auf statistische Signifikanz ermöglichen, d.h. das theoretisch-deduktive in ein ökonometrisches Modell umwandeln. Abgesehen von nichtlinearen, iterativen Schätztechniken zur Parametrisierung des Gesamtmodells (z.B. DREZNER 2006, DobBELSTEIN 2004, MARINOV/CZAMANSKI 2012) ist hier das Multiplicative Competitive Interaction Model (NAKANISHI/COOPER 1974) zu nennen, mit dem es möglich ist, die Gewichtungsparameter mittels linearer Regressionsanalyse zu schätzen (siehe Kap. 3.3.1).

Es existiert also eine Reihe von Verfahren zur Ermittlung des/der Gewichtungsparameter(s). Aus Vereinfachungsgründen und/oder mangels empirischer Daten zum Einkaufsverhalten bzw. zu tatsächlichen Marktgebieten wird in vielen Studien jedoch auf eine empirische Ermittlung verzichtet und eine bloße Definition des Parameters vorgenommen. Hierbei werden entweder ein einheitlicher Wert für das gesamte Untersuchungsgebiet (z.B. $\lambda=2)$ gesetzt (z.B. FITTKAU 2004, GÜSSEFELDT 2002, NEVIN/HOUSTON 1980), nach bestimmten Kriterien eine Abstufung von verschiedenen Werten (z.B. $\lambda=1,2$ und 3 für große, mittlere und kleine Angebotsstandorte) definiert (z.B. HUFF/LUTZ 1995) oder Widerstandsfaktoren aus Sekundärquellen benutzt (z.B. SCHÜRMANN 1999).

\subsubsection{Ablauf einer Marktgebietsanalyse}

Für eine Marktgebietsanalyse sind mehrere aufeinander folgende Schritte notwendig, wobei die Bestimmung der Gewichtungsparameter entweder vorher oder - während der Analyse durch die Anpassung an empirische Daten (siehe Kap. 3.2.2.3) erfolgt (HUFF 1962, S. 32ff.):

1. Einteilung des Gesamtgebietes in möglichst kleine Gebietseinheiten (z.B. statistische Bezirke); diese sind die Nachfrageorte (i)

2. Erhebung der Verkaufsflächengrößen aller analyserelevanten Angebotsstandorte (j) im Gesamtgebiet; diese bilden die Attraktivitätsvariablen $\left(A_{j}\right)$

3. Berechnung der Fahrtzeiten zwischen allen Nachfrage- und Angebotsstandorten $\left(d_{i j}\right)$

4. Berechnung der Interaktionswahrscheinlichkeiten $\left(p_{i j}\right)$

5. Darstellung der Interaktionswahrscheinlichkeiten in einer Karte mit Hilfe von Isolinien gleicher Interaktionswahrscheinlichkeit

6. Verrechnung der lokalen Kundenzahl $\left(C_{i}\right)$ mit der Interaktionswahrscheinlichkeit in allen Gebietseinheiten; im Ergebnis steht die zu erwartende Kundenzahl $\left(E_{i j}\right)$ 
7. Verrechnung des Kundenpotenzials $\left(E_{i j}\right)$ mit der durchschnittlichen lokalen Kaufkraft

Die Modellanalyse erfolgt in Form einer Interaktionsmatrix, die mittels Tabellenkalkulation erstellt und bearbeitet werden kann (KLEIN 2007, S. 58f.). Die Schritte 1 bis 4 und 6 sind zur Veranschaulichung in einer solchen Interaktionsmatrix mit drei Nachfrageorten $\left(i_{1}, i_{2}, i_{3}\right)$ und drei Angebotsstandorten $\left(j_{1}, j_{2}, j_{3}\right)$ schematisch dargestellt (siehe Tabelle 2). Schritt 5 ist beispielhaft in Abbildung 10 dargestellt, wobei sich die Interaktionswahrscheinlichkeiten auf den Anbieter $A_{1}$ in Abhängigkeit der Konkurrenzsituation beziehen.

\begin{tabular}{|c|c|c|c|c|c|c|c|c|}
\hline \multicolumn{2}{|c|}{$\begin{array}{c}\text { Nachfrage-I } \\
\text { Angebotsstandorte }\end{array}$} & \multicolumn{2}{|c|}{$\begin{array}{c}\text { Eingehende } \\
\text { Variablen }\end{array}$} & \multicolumn{2}{|c|}{ Verknüpfung im Modell } & \multicolumn{3}{|c|}{ Ergebnis } \\
\hline i & j & $d_{i j}$ & $A_{j}$ & $\mathrm{U}_{\mathrm{ij}}$ & $\Sigma U_{i j}$ & $\mathrm{p}_{\mathrm{ij}}$ & $C_{i}$ & $E_{i j}$ \\
\hline $\mathrm{i}_{1}$ & $j_{1}$ & $\mathrm{~d}_{\mathrm{i} 1 \mathrm{j} 1}$ & $A_{j 1}$ & $A_{j 1}^{\gamma} d_{i 1 j 1}{ }^{-\lambda}$ & $\sum U_{i 1 j}$ & $p_{i 1 j 1}$ & $\mathrm{C}_{i 1}$ & $p_{i j 11} C_{i 1}$ \\
\hline $\mathrm{i}_{1}$ & $j_{2}$ & $\mathrm{di}_{\mathrm{ij} 2} 2$ & $A_{j 2}$ & $\mathrm{~A}_{\mathrm{i} 2^{\gamma}}^{\gamma} \mathrm{d}_{11 j 2^{-\lambda}}$ & $\sum U_{i 1 j}$ & $\mathrm{p}_{\mathrm{i} 1 \mathrm{j} 2}$ & $\mathrm{C}_{i 1}$ & $p_{i 1 j 2} C_{i 1}$ \\
\hline$i_{1}$ & $j_{3}$ & $\mathrm{di}_{\mathrm{i} j \mathrm{j}}$ & $A_{j 3}$ & $A_{j ;}{ }^{\gamma} d_{i 1 j 3}{ }^{-\lambda}$ & $\Sigma U_{i i j}$ & $p_{i 1 j 3}$ & $\mathrm{C}_{i 1}$ & $p_{i 1 j 3} C_{i 1}$ \\
\hline $\mathrm{i}_{2}$ & $j_{1}$ & $\mathrm{di}_{22 j 1}$ & $A_{j 1}$ & $A_{j i}{ }^{\gamma} d_{i 2 j 1}{ }^{-\lambda}$ & $\Sigma U_{i 2 j}$ & $p_{i 2 j 1}$ & $\mathrm{C}_{\mathrm{i} 2}$ & $\mathrm{p}_{\mathrm{i} 2 \mathrm{j} 1} \mathrm{C}_{\mathrm{i} 2}$ \\
\hline $\mathrm{i}_{2}$ & $\mathrm{j}_{2}$ & $\mathrm{~d}_{\mathrm{i} 2 j 2}$ & $A_{j 2}$ & $\mathrm{~A}_{\mathrm{i} 2}^{\gamma} \mathrm{d}_{\mathrm{i} 222^{-\lambda}}$ & $\Sigma U_{i 2 j}$ & $p_{i 2 j 2}$ & $\mathrm{C}_{\mathrm{i} 2}$ & $\mathrm{p}_{\mathrm{izj2} 2} \mathrm{C}_{\mathrm{i} 2}$ \\
\hline $\mathrm{i}_{2}$ & $j_{3}$ & $d_{i 2 j 3}$ & $A_{j 3}$ & $A_{j ;}{ }^{\gamma} d_{i 2 j 3}{ }^{-\lambda}$ & $\Sigma U_{i 2 j}$ & $\mathrm{p}_{\mathrm{i} 2 \mathrm{j} 3}$ & $\mathrm{C}_{\mathrm{i} 2}$ & $\mathrm{p}_{\mathrm{i} 233} \mathrm{C}_{\mathrm{i} 2}$ \\
\hline $\mathrm{i}_{3}$ & $j_{1}$ & $d_{i 3 j 1}$ & $A_{j 1}$ & $A_{j i}{ }^{\gamma} d_{i 3 j 1}{ }^{-\lambda}$ & $\Sigma U_{i j j}$ & $p_{i j j 1}$ & $\mathrm{C}_{\mathrm{i} 3}$ & $\mathrm{p}_{\mathrm{ij31} 1} \mathrm{C}_{\mathrm{i} 3}$ \\
\hline $\mathrm{i}_{3}$ & $\mathrm{j}_{2}$ & $d_{i j 32}$ & $A_{j 2}$ & $A_{i 22^{\gamma}} d_{i 3 j 2^{-\lambda}}$ & $\Sigma U_{i 3 j}$ & $\mathrm{p}_{\mathrm{i} 3 \mathrm{j} 2}$ & $\mathrm{C}_{\mathrm{i} 3}$ & $\mathrm{p}_{i 3 j 2} \mathrm{C}_{\mathrm{i} 3}$ \\
\hline $\mathrm{i}_{3}$ & $\mathrm{j}_{3}$ & $\mathrm{~d}_{\mathrm{ij3} 3}$ & $A_{j 3}$ & $\mathrm{~A}_{\mathrm{i} 3}{ }^{\gamma} \mathrm{d}_{\mathrm{ij} j 3^{-\lambda}}$ & $\Sigma U_{i 3 j}$ & $\mathrm{p}_{\mathrm{i} j 33}$ & $\mathrm{C}_{\mathrm{i} 3}$ & $\mathrm{p}_{\mathrm{ij3} 3} \mathrm{C}_{\mathrm{i} 3}$ \\
\hline
\end{tabular}

Tabelle 2: HufF-Modell - Interaktionsmatrix (schematisch)

Quelle: Eigene Darstellung

Nachfrageorte

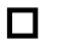

$\overbrace{0}^{\text {Anbieter }}$

Isolinien gleicher Interaktionswahrscheinlichkeiten von $A_{1}$

$50 \%$-Linie

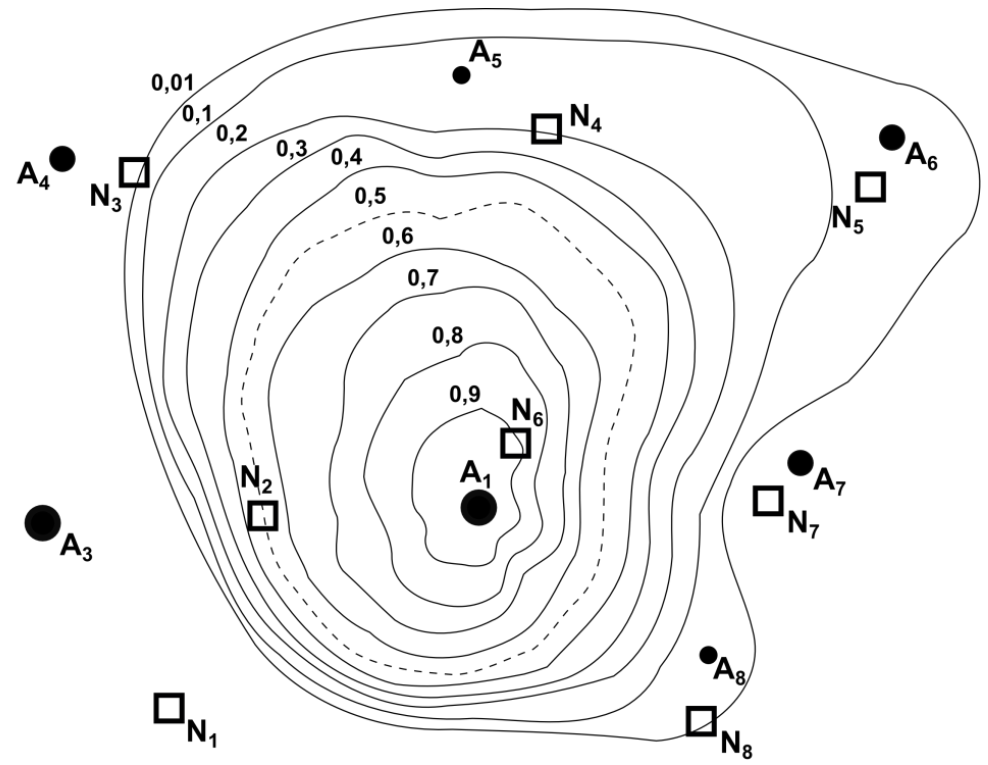

Abbildung 10: HufF-Modell - Marktgebiet mit Isowahrscheinlichkeitslinien (schematisch) Quelle: Eigene Darstellung 


\subsubsection{Kritik und Erweiterungen}

Das HUFF-Modell wurde seit seiner Entwicklung in unzähligen Arbeiten diskutiert, kritisiert und erweitert. Die wesentlichen Kritikpunkte sind durch den Entwickler selbst umfassend diskutiert worden und lassen sich wie folgt zusammenfassen (HUFF/BATSELL 1975, S. 166ff.):

- Das ursprüngliche Modell geht implizit von einer (räumlich) monofinalen Einkaufsfahrt aus, da Wechselwirkungen zwischen Anbietern unbeachtet bleiben; der Indikator der Attraktivität bildet nur (indirekt) interne Kopplungs- und Vergleichsmöglichkeiten ab

- Das Huff-Modell ist ein Gleichgewichtsmodell in dem Sinne, dass es einen Zustand darstellt, in dem keine Konsumentenentscheidungen mehr revidiert werden und eine endgültige Zuteilung der Kunden auf die Angebotsstandorte stattgefunden hat (Konsumentengleichgewicht)

- Das Grundmodell beinhaltet lediglich zwei erklärende Größen. Die Möglichkeit einer Erweiterung des Modells durch andere Erklärungsgrößen ist zwar gegeben, jedoch erschwert die nicht-lineare Struktur des Modells eine Prüfung der Signifikanz ihres Einflusses und die Ermittlung ihrer Parameter durch ökonometrische Methoden

Zudem gibt es im konkreten Modelleinsatz einige Problemquellen, die auf einer fehlerhaften Anwendung beruhen:

- Die Modellierung der Attraktivität durch die Verkaufsfläche birgt Unschärfen, wenn nur einzelne Sortimentsbereiche (z.B. Bekleidung) bei der Analyse betrachtet werden, jedoch die gesamte Verkaufsfläche (z.B. von Warenhäusern) als Attraktivitätsindikator benutzt wird

- Die Modellergebnisse können stark verzerrt werden, wenn das Untersuchungsgebiet falsch abgegrenzt wird und hierbei einzelne Angebotsstandorte unberechtigterweise berücksichtigt oder nicht berücksichtigt werden

Eng mit diesen Kritikpunkten verbunden ist die Frage nach der empirischen Tauglichkeit des HufF-Modells in der Standortanalyse. In seiner Pilotstudie stellt HuFF (1962, S. 26ff.) fest, dass zumindest in Teilbereichen große Abweichungen der Modellergebnisse von der Realität auftreten. Die Vorhersagequalität des Modells wird in der Literatur nicht einheitlich beurteilt, jedoch zeigt sich, dass im Hinblick auf die Auswahl der erklärenden Variablen und insbesondere ihre Gewichtung potenzielle Fehlerquellen bestehen, die das Ergebnis von HUFF-Modellanalysen stark beeinträchtigen können (CRAIG et al. 1984, S. 16ff.; LADEMANN 2007, S. 156ff.; LEE/PACE 2005, S. 54ff.; LÖFFLER 1998, S. 269f.). Die o.g. Kritikpunkte sind aber wiederholt angeführt und eine große Zahl an Modifikationen entwickelt worden.

Hierzu zählen insbesondere inhaltliche Erweiterungen des Modells durch Integration weiterer Erklärungsgrößen (z.B. Preisniveau, Parkmöglichkeiten, sozio-demographische Merkmale der Haushalte, Image der Anbieter) in die Nutzenfunktion (z.B. CADWALLADER 1975, DE Beule et al. 2014, Dobbelstein 2004, Dramowicz 2005, GaUtSCHI 1981, GRIFFITH 1982 , KIM et al. 2011, KNOBLICH et al. 1975, LeE/PACE 2005, NEVIN/HOuston 1980, OKORUWA et al. 1994, PAN et al. 2013, SPENCER 1978, StANLEY/SEWALL 1976). Beispielsweise zeigen CADWALLADER (1975) und STANLEY/SEWALL (1976) auf, wie nachfrageseitige subjektive Erklärungsgrößen ins Modell aufgenommen werden können; die Arbeit von DOBBELSTEIN (2004) berücksichtigt eine kundenspezifische Modellierung nach Lebensstilgruppen. Zudem ist die Modifikation der funktionalen Verknüpfung des Modells (insb. in Form alternativer 
Distanzfunktionen) häufig Gegenstand von Arbeiten gewesen (z.B. BUCKLIN 1971a, JENSENBUTLER 1972, KANHÄUSSER 2007, KLEIN/LÖFFLER 1988, OKORUWA et al. 1994); so formuliert etwa KANHÄUSSER (2007) eine Modellmodifikation mit einer S-förmigen Distanzfunktion.

Für den vorliegenden Fall sind insbesondere zwei Formen von Erweiterungen des HuFFModells von Interesse, nämlich einerseits die Berücksichtigung von Agglomerationseffekten im Modell und andererseits die Methoden zur empirischen bzw. ökonometrischen Schätzung des Modells und weitere Möglichkeiten zur Anpassung der Modellgüte an empirische Gegebenheiten. Zur Modifikation des Modells im Hinblick auf Agglomerationseffekte ist hier das Competing Destinations Model von FOTHERINGHAM (1985) zu nennen, auf dem mehrere weitere diesbezügliche HUFF-Modellanalysen fußen (z.B. LI/LIU 2012, ORPANA/LAMPINEN 2003, SCHÜRMANN 1999). Die Methoden zur Modellanpassung bzw. zur ökonometrischen Schätzung des Modells sind weit unübersichtlicher: Von besonderer Bedeutung ist hier das Multiplicative Competitive Interaction Model (MCI) von NAKANISHI/COOPER (1974), das eine direkte Umwandlung des HuFF-Modells in ein ökonometrisches Modell bei gleichzeitiger Möglichkeit zur inhaltlichen Erweiterung darstellt; dieses Modell wird häufig zur Analyse von Einkaufsentscheidungen bzw. Marktanteilen und Marktgebieten im Einzelhandel eingesetzt (z.B. Colomé PeRALES 2002, GonZÁleZ-Benito et al. 2000, KuBIS/HARTMANN 2007, SuÁREZVEGA et al. 2011, TIHI/ORUC 2012). Es existieren aber noch andere Methoden zur Parametrisierung (z.B. DoBbELSTEIN 2004, EPPLI/SHILLING 1996, LEE/PACE 2005, LI/LIU 2012, MARINOV/CZAMANSKI 2012, OKORUWA et al. 1994, O'KELLY 1999, YUE et al. 2012) und weitere mögliche Anpassungen der Modellgüte (z.B. DREZNER 2006, GüSSEFELDT 2002).

\subsubsection{Das Competing Destinations Model von FotheRINGHAM}

Ein konkreter Ansatz zur Integration von Agglomerationseffekten bzw. der Möglichkeit von Kopplungs- und Vergleichskäufen in das HufF-Modell ist das Competing Destinations Model von FOTHERINGHAM (1985); es liegt auch späteren diesbezüglichen Untersuchungen (u.a. LI/LIU 2012, ORPANA/LAMPINEN 2003, SchÜRMANN 1999) zu Grunde. Der Grundgedanke ist, dass Marktgebietsmodelle im Einzelhandel und im Speziellen das HuFF-Modell unzureichend spezifiziert sind, da sie die Interaktionseffekte (Agglomerations- bzw. Wettbewerbseffekte) zwischen den betrachteten Anbietern bzw. Angebotsstandorten nicht abbilden (können); die Nutzenfunktion des HuFF-Modells (siehe Kap. 3.2.2.2, Formel 9) sollte demnach um eine dritte Variable erweitert werden, die den relativen Standort in Bezug auf alle anderen möglichen Angebotsstandorte wiedergibt (siehe Formel 13) (FOTHERINGHAM 1985, S. 213f.).

$$
p_{i j}=f\left(A_{j}, C_{j}, d_{i j}\right)
$$

$\mathrm{p}_{\mathrm{ij}}=$ Wahrscheinlichkeit, dass die Kunden im Nachfrageort i den Angebotsstandort $\mathrm{j}$ frequentieren bzw. Marktanteil des

Angebotsstandortes j im Nachfrageort i

$A_{j}=$ Attraktivität des Angebotsstandortes j

$d_{i j}=$ Distanz zwischen Nachfragestandort i und Angebotsstandort j

$\mathrm{C}_{\mathrm{j}}=$ Messgröße für den relativen Standort des Anbieters $\mathrm{j}$

Als Messgröße für den „relativen Standort“ des jeweiligen Anbieters schlägt FOTHERINGHAM (1985, S. 213) die Formel zur Operationalisierung der Erreichbarkeit von HANSEN (1959) vor (siehe Formel 14). Diese im Kontext urbaner Landnutzungstheorien aufgestellte Gleichung ähnelt nicht zufällig den funktionalen Verknüpfungen der räumlichen Interaktionsmodelle, sondern ist aus den wanderungsbezogenen Interaktionsmodellen hergeleitet. Erreichbarkeit 
wird hierbei als Potenzial an Interaktionsmöglichkeiten definiert, d.h. die Summe aller Interaktionsmöglichkeiten aus einem Gebiet. Als interaktionsfördernder Aspekt wird die Größe des Gebietes angenommen, als hemmender Faktor die Distanz, die durch einen Exponenten gewichtet wird (HANSEN 1959, S. 73f.). Diese dritte Größe $\left(C_{j}\right)$ wird in späteren Studien (z.B. LI/LIU 2012, ORPANA/LAMPINEN 2003, SchÜRMANN 1999) als Zentralitäts- oder Konzentrationsvariable bezeichnet. Sie lässt sich interpretieren als Nutzen des Besuchs der anderen potenziellen Anbieter unter Berücksichtigung von deren Attraktivität bzw. Größe (interaktionsfördernde Wirkung) und der Distanz zu innen (interaktionshemmende Wirkung). Grundsätzlich sind auch andere Varianten von Konzentrationsvariablen mit vergleichbarer Grundaussage denkbar (ORPANA/LAMPINEN 2003, S. 324f.).

$$
C_{j}=\sum_{\substack{k \\ k \neq j}} \frac{A_{k}}{d_{j k}^{\lambda}}
$$

$A_{k}=$ Attraktivität des Angebotsstandortes $k$

$\mathrm{dij}_{\mathrm{ij}}=$ Distanz zwischen Angebotsstandort $\mathrm{j}$ und Angebotsstandort $\mathrm{k}$

$\lambda=$ Gewichtungsparameter der Distanz

Im Competing Destinations Model (siehe Formel 15) ist auch für die Konzentrationsgröße eine Gewichtung vorgesehen, welche die Richtung und Stärke des Einflusses wiedergibt. Ist der Gewichtungsexponent $(\beta)$ positiv, wirken positive Agglomerationseffekte; die räumliche Nähe zu anderen Anbietern erhöht dann die Interaktionswahrscheinlichkeit bzw. den eigenen Marktanteil. Dominieren die Wettbewerbseffekte, so ist der Parameter negativ; die räumliche Nähe zu anderen Anbietern beeinflusst dann also die Interaktionswahrscheinlichkeit negativ (FOTHERINGHAM 1985, S. 213f.). Die Attraktivitäts- und Konzentrationsvariablen werden mit einer Potenzfunktion gewichtet, die Distanz mit einer Exponentialfunktion; zur Bestimmung der Parameter werden jedoch keine Aussagen getroffen, da die Funktionsweise des Modells anhand von numerischen Simulationen erörtert wird.

$$
p_{i j}=\frac{A_{j}{ }^{\alpha} C_{j}{ }^{\beta} e^{\lambda d_{i j}}}{\sum_{j=1}^{n} A_{j}{ }^{\alpha} C_{j}{ }^{\beta} e^{\lambda d_{i j}}}
$$

$p_{i j}=$ Wahrscheinlichkeit, dass die Kunden im Nachfrageort i den Angebotsstandort j frequentieren bzw. Marktanteil des Angebotsstandortes j im Nachfrageort i

$A_{j}=$ Attraktivität des Angebotsstandortes $j$

$\mathrm{d}_{\mathrm{ij}}=$ Distanz zwischen Nachfragestandort $\mathrm{i}$ und Angebotsstandort $\mathrm{j}$

$\mathrm{C}_{\mathrm{j}}=$ Konzentrationsindex des Angebotsstandortes $\mathrm{j}$

$\alpha=$ Gewichtungsparameter der Attraktivität (Potenzfunktion)

$\beta=$ Gewichtungsparameter des Konzentrationsindexes (Potenzfunktion)

$\lambda=$ Gewichtungsparameter der Distanz (Exponentialfunktion)

$\mathrm{e}=$ Eulersche Zahl

Das Modell von FOTHERINGHAM ist also ein erster Ansatz zur expliziten Berücksichtigung von (positiven) Agglomerationseffekten im HUFF-Modell. LI/LIU (2012, S. 592f.) betonen deren Bedeutung für den betriebswirtschaftlichen Erfolg von Einzelhandelsbetrieben und würdigen daher den gezeigten Ansatz, attestieren aber auch zwei wesentliche Schwächen: 
- Das Competing Destinations Model berücksichtigt nur gleichartige/konkurrierende Anbieter, da die Konzentrationsvariable nur für diese gedacht ist, jedoch nicht ungleichartige Anbieter, die ebenso Agglomerationsvorteile (Urbanisierungsvorteile) aufgrund der Möglichkeit von Kopplungskäufen generieren können

- Da die Modellstruktur nur eine Konzentrationsvariable mit einer entweder positiven oder negativen Gewichtung vorsieht, kann das Modell Agglomerations- und Wettbewerbseffekte nicht gleichzeitig abbilden, sondern jeweils nur eines von beiden

\section{3 Ökonometrische Marktgebietsmodelle}

\subsubsection{Das Multiplicative Competitive Interaction Model von NAKANISHI/COOPER}

\subsubsection{Grundprinzip und Herleitung des Modells}

Das Multiplicative Competitive Interaction Model (kurz: MCl-Modell) wurde aus einer wirtschaftspsychologischen bzw. Marketing-Perspektive von NAKANISHI/COOPER (1974 u. 1982) entwickelt. Es bildet einerseits eine inhaltliche Generalisierung des HuFF-Modells und einen Transfer dieses Ansatzes in ein ökonometrisches Modell. Andererseits stellt es ein allgemeines Marktanteilsmodell auf dem Fundament der Marktanteilstheoreme dar. Die verhaltenswissenschaftliche Grundlage des $\mathrm{MCl}$-Modells ist aus den nutzentheoretischen Entscheidungsmodellen abzuleiten; das Modell unterstellt den Entscheidungsträgern ein probabilistisches Wahlverhalten (wie das HuFF-Modell) auf der Basis einer Nutzenfunktion mit einem deterministischen bzw. „erklärbaren“ und einem stochastischen bzw. „nicht erklärbarem“ Anteil (siehe Kap. 3.1.2).

Das MCI-Modell wird von NAKANISHI/COOPER (1974, S. 303) in ähnlicher Weise wie das HUFF-Modell operationalisiert (siehe Kap. 3.2.2.2), jedoch werden die erklärenden Variablen explizit nicht festgelegt. Auch wird offen gelassen, ob überhaupt räumliche Aspekte (z.B. Fahrtzeiten) in das Modell integriert werden bzw. ob es dafür genutzt wird, räumliche Märkte (z.B. Marktgebiete von Einkaufsstätten) oder nicht-räumliche Märkte (z.B. Marktanteile von Marken oder Unternehmen) zu analysieren. Die Zielgröße ist die Wahrscheinlichkeit, dass sich ein Konsument in der $i$-ten Entscheidungssituation für die Alternative $j$ entscheidet. Grundlage der Abwägung der Alternativen ist eine multiplikative Nutzenfunktion mit $h$ Eigenschaften der Alternative $j$, die jeweils mit dem Parameter $\gamma_{h}$ exponentiell gewichtet werden. Die Entscheidungswahrscheinlichkeit ergibt sich aus dem Produkt der gewichteten Teilnutzen dividiert durch die Summe aller Produkte (siehe Formel 16).

$$
p_{i j}=\frac{\left(\prod_{h=1}^{H} A_{h_{j}}^{\gamma_{h}}\right)}{\sum_{j=1}^{n}\left(\prod_{h=1}^{H} A_{h_{j}}^{\gamma_{h}}\right)}
$$

$\mathrm{p}_{\mathrm{ij}}=$ Wahrscheinlichkeit, dass sich ein Konsument in der i-ten Entscheidungssituation für die Alternative $\mathrm{j}$ entscheidet

$A_{h j}=h$-te Eigenschaft der Alternative j

$\gamma_{\mathrm{h}}=$ Gewichtungsparameter der Eigenschaft $\mathrm{h}$ 
Die ausschlaggebende Neuerung im MCl-Modell ist jedoch nicht die Einführung einer beliebigen Zahl von Erklärungsgrößen, sondern die Übertragung der Methodik empirischökonometrischer Marktanteilsanalyse auf das (inhaltlich generalisierte) Interaktionsmodell. Hatte die nicht-lineare Struktur des HuFF-Modells eine ökonometrische Schätzung der Parameter bisher unmöglich gemacht, zeigen NAKANISHI/COOPER (1974, S. 304ff.) einen Weg auf, das Modell zu linearisieren und einer empirisch gestützten Parametrisierung mittels konventioneller linearer Regressionsanalyse zugänglich zu machen:

- Ein Störterm $\left(\varepsilon_{i j}\right)$ wird hinzugefügt, der den stochastischen Teil der Modellgleichung repräsentiert, d.h. alle Einflüsse auf den Marktanteil, die im Modell nicht berücksichtigt werden bzw. werden können (z.B. nicht-beobachtbare Einflussgrößen, Spezifikations- oder Messfehler). Der Konsumentennutzen wird also in eine „erklärbare“ und eine „nicht-erklärbare“ Komponente aufgeteilt (siehe Kap. 3.1.2)

- Die nicht-lineare Modellgleichung (Formel 17) wird zunächst mittels geometrischer Mittelwerte standardisiert und dann logarithmiert, um die durch Potenzfunktionen gewährleistete Gewichtung linear darzustellen (Log-centering-transformation)

- Im Ergebnis steht ein multiples lineares Regressionsmodell mit $h$ verschiedenen Produkt- bzw. Anbietereigenschaften als unabhängige (d.h. erklärende) Variablen (siehe Formel 18). Als abhängige (d.h. zu erklärende) Variable fungieren empirisch beobachtete Marktanteile von Produkten oder Anbietern bzw. Entscheidungen, die z.B. anhand von Kundenbefragungen ermittelt werden

- Das Modell wird mit Hilfe der linearen Regressionsanalyse (Kleinste-QuadrateMethode) geschätzt. Diejenigen Produkt-/Anbietereigenschaften, die für die Ausprägung der Zielvariable einen statistisch signifikanten Beitrag leisten, werden mit einem Parameter in das Regressionsmodell aufgenommen, der die Richtung und die Stärke ihres Einflusses wiedergibt

$$
p_{i j}=\frac{\left(\prod_{h=1}^{H} A_{h_{i j}}^{\gamma_{h}}\right) \varepsilon_{i j}}{\sum_{j=1}^{n}\left(\prod_{h=1}^{H} A_{h_{j}}^{\gamma_{h}}\right) \varepsilon_{i j}}
$$

$\varepsilon_{i j}=$ Stochastischer Störterm bzw. Residuum (Abweichung der Modellfunktion von den Echtdaten)

$\log \left(\frac{p_{i j}}{\tilde{p}_{i}}\right)=\sum_{h=1}^{H} \gamma_{h} \log \left(\frac{A_{h_{j}}}{\widetilde{A}_{h_{j}}}\right)+\log \left(\frac{\varepsilon_{i j}}{\widetilde{\varepsilon}_{i}}\right)$

$\tilde{p}_{i}=$ Geometrischer Mittelwert von $p_{i}$

$\tilde{A}_{h i}=$ Geometrischer Mittelwert von $A_{h j}$

$\tilde{\varepsilon}_{\mathrm{i}}=$ Geometrischer Mittelwert von $\varepsilon_{\mathrm{i}}$

Die Modelldaten werden, ähnlich wie beim HuFF-Modell (siehe Kap. 3.2.2.4), in einer Interaktionsmatrix mit $i$ Entscheidungssituationen (bzw. Nachfrageorten) und $j$ Alternativen (bzw. Angebotsstandorten) abgetragen. Die Daten werden im o.g. Sinne transformiert, um 
daraufhin die Zusammenhänge zwischen Marktanteil und den unabhängigen Variablen statistisch ermitteln zu können. Die multiple lineare Regressionsanalyse liefert als Ergebnis eine Prüfung der Eingangsvariablen auf statistische Signifikanz, die geschätzten Parameter und ein Modellgütemaß (COOPER/NAKANISHI 2010, S. 110ff.; HUfF/MCCALLUM 2008, S. 23ff.). Nachdem die relevanten Variablen und die Ausprägung ihres Einflusses bestimmt wurden, werden die geschätzten Parameter in das ursprüngliche, nicht-transformierte Modell (Formel 17) eingesetzt, um als Modellergebnis logisch konsistente Marktanteile zwischen null und eins zu erhalten ${ }^{33}$. Die Parameter können entweder direkt als Exponenten in das Ursprungsmodell überführt werden (siehe Formel 19), was der Struktur des HuFF-Modells entspricht, oder in transformierter Form in einen anderen funktionalen Zusammenhang gebracht werden (siehe Formel 20 und 21) (NAKANISHI/COOPER 1982, S. 316f.). Das Modell kann nun auch zur Simulation bzw. Prognose (z.B. bei Neuansiedlungen von Einzelhandelsbetrieben) eingesetzt werden; die Anwendung entspricht dann der des HuFFModells (HUfF/McCALLUM 2008, S. 25ff.).

$$
\hat{p}_{i j}=\frac{\left(\prod_{h=1}^{H} A_{h_{j}} \hat{\gamma}_{h}\right)}{\sum_{j=1}^{n}\left(\prod_{h=1}^{H} A_{h_{j}}^{\hat{\gamma}_{h}}\right)}
$$

$\hat{p_{i j}}=$ Geschätzte(r) Interaktionswahrscheinlichkeiten/Marktanteil der Alternative j für den Entscheidungsträger $\mathrm{i}$

$\hat{\gamma_{\mathrm{hi}}}=\operatorname{Im}$ Regressionsmodell geschätzter Gewichtungsparameter der h-ten Eigenschaft

$$
\hat{y}_{i j}=\sum_{h=1}^{H} \hat{\gamma}_{h} \log \left(\frac{A_{h_{j}}}{\widetilde{A}_{h_{j}}}\right)
$$

$\hat{y}_{i j}=$ Transformierte Nutzenfunktion

$$
\hat{p}_{i j}=\frac{e^{\hat{y}_{i j}}}{\sum_{j=1}^{n} e^{\hat{y}_{i j}}}
$$

e = Eulersche Zahl

\subsubsection{Möglichkeiten und Probleme der Anwendung}

In einer MCl-Modellanalyse wird einerseits empirisch geprüft, ob eine bestimmte Produktoder Anbietereigenschaft einen Einfluss auf den Marktanteil hat, andererseits wird im Falle einer statistisch signifikanten Auswirkung bestimmt, wie dieser Einfluss charakterisiert ist. Das Modell kann prinzipiell auf alle Sachverhalte angewandt werden, in denen Marktanteile

\footnotetext{
${ }^{33}$ Das Regressionsmodell selbst verfügt über keine obere oder untere Begrenzung der Zielvariable, so dass hiermit theoretisch Marktanteile unter null oder über eins (bzw. über 100\%) berechnet werden könnten, die in der Summe nicht eins ergeben; solche Ergebnisse würden aber dem Grundprinzip von Marktanteilsmodellen (siehe Kap. 3.1.2) widersprechen, logisch konsistente Marktanteile zu ermitteln (NAKANISHI/COOPER 1982, S. 315).
} 
bzw. (Konsumenten-)Entscheidungen auf der Grundlage angebots- und/oder nachfrageseitiger Struktureigenschaften untersucht werden. Es kann sowohl in räumlicher (als Marktgebietsmodell) als auch in nicht-räumlicher Perspektive (als Marktanteilsmodell) genutzt werden; ebenso können objektive und/oder subjektive Struktureigenschaften als Erklärungsgrößen einfließen. Sofern das $\mathrm{MCl}$-Modell explizit räumlich auf Angebotsstandorte angewandt wird und die Transportkosten einen statistisch signifikanten Einfluss besitzen, ist sie Teil der Nutzenfunktion im Modell (CLIQUeT 2006, S. 144f.; HUfF/McCalLUM 2008, S. 4f.). Obwohl das $\mathrm{MCl}-M o d e l l$ allgemein formuliert und für verschiedene Formen von individuellen oder aggregierten (Konsumenten-)Entscheidungen konzipiert ist, wird es im Einzelhandel für gewöhnlich zur Modellierung lokaler Marktanteile auf der Ebene geographisch definierter Gebiete verwendet; es bildet also keine individuellen Entscheidungen ab, auch wenn diese die Grundlage lokaler Marktanteile darstellen, sondern aggregierte Entscheidungen auf der Ebene von Teilräumen (DION/CLIQUET 2006, S. 41).

In den MCl-Modellanalysen zur Einkaufsstättenwahl erfolgt die Ermittlung der empirischen Marktanteile, die die abhängige Variable im Modell darstellen, meistens auf der Grundlage von konsumentenseitigen Primärerhebungen; es werden hierbei insbesondere telefonische, schriftliche oder mündliche Haushaltsbefragungen zur Einkaufsorientierung benutzt (z.B. Colomé Perales 2002, Ghosh 1984, GonzÁlez-Benito et al. 2000, SuÁreZ-VeGA et al. 2011, TIHI/ORUC 2012). Das MCl-Modell zählt zu den Revealed-preference-Ansätzen, d.h. die Konsumenten werden nach ihrem tatsächlichen Einkaufsverhalten in der Vergangenheit befragt; hierbei wird beispielsweise nach dem am häufigsten besuchten Angebotsstandort oder nach allen besuchten und/oder in Frage kommenden gefragt (COLOMÉ PERALES 2002, S. 9ff.; HufF/McCALLUM 2008, S. 23). Point-of-sale-Erhebungen zur Abgrenzung von Marktgebieten werden nur selten benutzt (z.B. KUBIS/HARTMANN 2007).

Werden als erklärende Größen nur die Verkaufsfläche der Anbieter und die Fahrtzeit zwischen Nachfrage- und Angebotsstandorten verwendet, entspricht dies inhaltlich dem ursprünglichen HuFF-Modell. Das MCl-Modell ist dementsprechend dazu tauglich, dessen erklärende Variablen auf ihre Aussagekraft hin zu testen und somit das theoretisch-deduktive HufF-Modell zu verifizieren bzw. zu falsifizieren; in diesen Fällen sind die beiden genannten Einflussgrößen stets als statistisch signifikant befunden und entsprechend den theoretischen Vorstellungen HUFFs parametrisiert worden (z.B. GHOSH 1984, KUBIS/HARTMANN 2007, SUÁREZ-VEGA et al. 2011). Jedoch sind auch breiter angelegte Erweiterungen auf eine Vielzahl von Größen möglich, die objektiver und/oder subjektiver Natur sein können (z.B. Cliquet 1995, Colomé Perales 2002, GonzÁlez-Benito 2005, GonZÁlez-Benito et al. 2000, TIHI/ORUC 2012, TIMMERMANS 1981). Im Großteil der angeführten Studien wird das $\mathrm{MCl}-$ Modell nur zur Analyse der Einflussfaktoren von Marktgebieten genutzt, wohingegen Simulations- und Prognoseanwendungen eher selten sind (z.B. SUÁREZ-VEGA et al. 2011).

In der praktischen Anwendung des MCl-Modells können Probleme auftreten, die auf dessen mathematischen Eigenschaften beruhen. Da das Modell unter Zuhilfenahme des geometrischen Mittelwertes und Logarithmen linearisiert wird, dürfen die Ausprägungen der Modellvariablen weder negativ noch gleich null sein; alle Teilnutzenwerte (z.B. Distanz) und empirischen Marktanteile müssen also größer null sein (COOPER/NAKANISHI 2010, S. 153ff.). Sofern z.B. aus einzelnen Nachfrageorten keine Interaktionen mit einer oder mehreren Alternativen erhoben wurden, muss die zugrunde gelegte Interaktionsmatrix nachbearbeitet werden (z.B. Colomé PeRALES 2002, KuBis/HARTMANN 2007, TIHI/ORUC 2012). Wie bei allen 
(linearen) Regressionsmodellen besteht bei $\mathrm{MCl}$-Analysen zudem das Problem möglicher Verzerrungen der Parameter, wenn die grundsätzlichen Annahmen eines linearen Regressionsmodells (z.B. durch Heteroskedastizität oder Multikollinearität) verletzt werden (HARTMANN 2005, S. 35f.; TIMMERMANS 1993, S. 354).

\subsubsection{Das diskrete Entscheidungsmodell nach MCFADDEN}

\subsubsection{Grundprinzip und Herleitung des Modells}

In der Modellierung des räumlichen Einkaufsverhaltens und anderer raumbezogener Fragestellungen spielen mittlerweile Multinomiale Logitmodelle (MNL) zur Analyse individueller (Konsumenten-)Entscheidungen eine wesentliche Rolle (HUNT et al. 2004, S. 750ff.; MÜLLER-HAGEDORN/NATTER 2011, S. 209ff.). Dieser Modelltyp entstammt ursprünglich der Verkehrsökonomie und wurde von MCFADDEN (1974) zur Analyse der Verkehrsmittelwahl etabliert. Genauso wie das MCl-Modell bilden diese Modelle eine Spezifikation allgemeiner Marktanteilsmodelle und bauen auf verhaltenstheoretischen Grundlagen (siehe Kap. 3.1.2) auf (CLIQUET 2006, S. 143f.). Ihnen liegt ebenso eine nicht näher spezifizierte Nutzenfunktion zu Grunde (siehe Formel 22), die einen deterministischen bzw. „erklärbaren“ und einen stochastischen bzw. „nicht erklärbaren“ Teil (Störterm) enthält (TRAIN 2009, S. 14f.).

$$
U_{i j}=V_{i j}+\varepsilon_{i j}
$$

\footnotetext{
$\mathrm{U}_{\mathrm{ij}}=$ Nutzen aus der Alternative $\mathrm{j}$ für den Entscheidungsträger $\mathrm{i}$

$\mathrm{V}_{\mathrm{ij}}=$ Erklärter (deterministischer) Teil des Nutzens (Repräsentativer Nutzen)

$\varepsilon_{i j}=$ Nicht erklärter (stochastischer) Teil des Nutzens
}

Der inhaltliche Unterschied liegt darin, dass die abhängige Variable des Modells nicht der Marktanteil eines Produktes oder Anbieters ist, sondern die Wahlentscheidung eines Individuums oder Haushaltes für eine Alternative selbst; eine solche Wahlentscheidung ist eine absolute Größe (z.B. Kauf/Nicht-Kauf, Besuch/Kein Besuch), weswegen die Zielgröße eine diskrete (d.h. abzählbare) bzw. "qualitative" Variable darstellt. Modelle mit dieser Zielgröße werden für gewöhnlich als diskrete Entscheidungsmodelle (Discrete choice models) bezeichnet; diese Bezeichnung bezieht sich auf den Inhalt der Modelle, während der Begriff "Multinomiales Logitmodell“ bzw. MNL die zugrunde gelegte Analysetechnik (Logistische Regression) beschreibt (MOOSMÜLLER 2004, S. 206f.; TEMME 2007, S. 327f.). Diese Methode wird dann verwendet, wenn Zusammenhänge modelliert werden sollen, in denen die Zielvariable nicht metrisch-rational, sondern nominal skaliert ist und zwei (binärlogistische Regression) oder mehrere diskrete Ausprägungen (multinomiale logistische Regression) hat; die logistische Regression schätzt somit nicht die "Größe“ der nur qualitativ zu interpretierenden Zielvariable, sondern die Eintrittswahrscheinlichkeit einer bestimmten Ausprägung (z.B. Wahlentscheidung, Eintritt eines Ereignisses) (ROHRLACK 2007, S. 198f.).

Die Nutzenfunktion in diskreten Entscheidungsmodellen ist für gewöhnlich linear bzw. wird durch eine Transformation linearisiert (siehe Formel 23). Das mathematische Verhältnis zwischen Auswahlwahrscheinlichkeit und repräsentativem Nutzen wird durch eine logistische Funktion (siehe Formel 24) ausgedrückt, deren Verlauf S-förmig ist. Die vorhergesagten Werte der abhängigen Variablen liegen zwischen null und eins und summieren sich für jedes Individuum ( $I$ ) zu eins. Inhaltlich bedeutet der S-förmige Kurvenverlauf, dass bei Alternativen 
mit sehr hohem und sehr niedrigem Nutzen eine Nutzensteigerung nur sehr geringen Einfluss auf die Auswahlwahrscheinlichkeit hat; große Effekte hat die Steigerung des Nutzens im mittleren Bereich, wobei die stärksten Einflüsse im Bereich der 50\%-Marke liegen (TRAIN 2009, S. 36ff.). Mathematisch liegt dieses Vorgehen darin begründet, dass die logistische Funktion, die aus einer logistischen Regression hervorgeht, eine Begrenzung der Zielvariable auf einen Wertebereich zwischen null und eins (bzw. 0 und $100 \%$ ) herbeiführt und plausible Auswahlwahrscheinlichkeiten nur in diesem Bereich liegen. Mit einer konventionellen linearen Regression ist dies nicht möglich, da theoretisch auch Werte unter null und über eins geschätzt werden können, was dem Grundprinzip der Wahrscheinlichkeiten widerspricht (ERNSTE 2011, S. 353f.).

$V_{i j}=\beta^{\prime} x_{i j}$

$\mathrm{x}_{\mathrm{ij}}=$ Vektor von beobachteten Erklärungsgrößen (z.B. Eigenschaften der Alternative $\left.\mathrm{j}\right)$

$\beta=$ Gewichtungsparameter (empirisch ermittelt)

$$
p_{i j}=\frac{e^{V_{i j}}}{\sum_{j=1}^{n} e^{V_{i j}}}
$$

$p_{i j}=$ Wahrscheinlichkeit, dass sich ein Entscheidungsträger in der i-ten Entscheidungssituation für die Alternative j

entscheidet

$\mathrm{e}=$ Eulersche Zahl

Die Schätzung des Modells erfolgt nicht mit der OLS-Methode des konventionellen linearen Regressionsmodells, sondern mit der Maximum-Likelihood-Methode ${ }^{34}$ oder anderen Schätzmethoden; eine Prüfung des Modells erfolgt anhand der für dieses Verfahren entwickelten Modellgütemaße (TRAIN 2009, S. 60ff.). Wenn das Modell auf der Basis von Echtdaten parametrisiert wurde, wird die gewichtete Nutzenfunktion in das Modell zur Auswahlwahrscheinlichkeit (Formel 24) eingesetzt; auf dieser Grundlage ist auch hier eine Anwendung als Simulations- und Prognosemodell möglich, die der des HUFF- und des $\mathrm{MCl}$ Modells sehr ähnlich ist (MüLLER-HAGEDORN/NATTER 2011, S. 211f.).

\subsubsection{Möglichkeiten und Probleme der Anwendung}

Ebenso wie das $\mathrm{MCl}-$ Modell kann das diskrete Entscheidungsmodell prinzipiell auf verschiedenste Formen von (Konsumenten-)Entscheidungen angewandt werden; im Einzelhandelskontext wird es zur Analyse der (individuellen oder haushaltsbezogenen) Einkaufsstättenwahl auf der Grundlage von Nutzenfunktionen mit anbieter- und/oder nachfrageseitigen Erklärungsgrößen verwendet (z.B. ARENTZE et al. 2005, GIJSBRECHTS et al. 2008, GonZÁLEZ-BENITO et al. 2005b, PANCRAS et al. 2012, POPKOWSKI LESZCZYC et al. 2004, ReutTerer/Teller 2009, VROEGRIJK et al. 2013). Es ist mit diesen Modellen auch

\footnotetext{
${ }^{34}$ Das Maximum-Likelihood-Verfahren bildet neben dem OLS-Verfahren eine gängige Schätzmethode für Regressionsmodelle; es basiert darauf, diejenigen Parameter zu ermitteln, die mit der größten Wahrscheinlichkeit den Zusammenhang zwischen den Prädiktoren und der Zielvariable beschreiben (ERNSTE 2011, S. 374f.).
} 
möglich, die empirische Relevanz der erklärenden Größen des HuFF-Modells (Distanz, Verkaufsfläche) empirisch-ökonometrisch zu testen (z.B. LADEMANN 2007).

Die abhängigen Variablen in diskreten Entscheidungsmodellen bilden Wahlentscheidungen (z.B. Kauf der Marke X, Besuch des Anbieters Y) von individuellen Konsumenten oder Haushalten, die in Befragungen empirisch ermittelt werden (TEMME 2007, S. 329). Die Befragung erfolgt entweder anhand eines Revealed-Preference-Ansatzes (wie beim $\mathrm{MCl}$ Modell), bei dem tatsächliches Wahlverhalten der Vergangenheit abgefragt wird (z.B. ARENTZE et al. 2005, POPKOWSKI LESZCZYC et al. 2004), oder mit einem Stated-PreferenceAnsatz, bei dem mehrere (fiktive) Wahlalternativen und ihre Eigenschaften in einem Befragungsexperiment vorgegeben werden (z.B. BORGERS/VOSTERS 2011, BROOKS et al. 2004 u. 2008, DELLAERT et al. 1998, HSIAO 2009, OPPEWAL/HOLYOAKE 2004).

Im Hinblick auf die theoretischen Grundlagen, den Anwendungszweck und das methodische Vorgehen sind sich das diskrete Entscheidungsmodell und das MCl-Modell durchaus ähnlich; in der praktischen Anwendung besteht der Unterschied darin, dass $\mathrm{MCl}$-Modelle zumeist für aggregierte (Konsumenten-)Entscheidungen benutzt werden, wohingegen diskrete Entscheidungsmodelle individuelles, also disaggregiertes Verhalten modellieren (DION/CLIQUET 2006, S. 41f.). In technischer Hinsicht besteht der Vorteil, dass NichtInteraktionen (bzw. Entscheidungen gegen eine oder mehrere Alternativen) explizit mitbehandelt werden und nicht, wie beim MCl-Modell, unter Umständen eine Korrektur der Interaktionsmatrix notwendig ist (siehe Kap. 3.3.1.2). Allerdings impliziert das diskrete Entscheidungsmodell die Wahl einer Alternative unter Ausschluss anderer (z.B. Haupteinkaufsquelle für Lebensmittel wie bei LADEMANN 2007), wohingegen das MCI-Modell zumindest theoretisch alle Alternativen abbilden kann.

Die Berechnung der Entscheidungs-/Interaktionswahrscheinlichkeiten erfolgt im diskreten Entscheidungsmodell ebenso auf der Grundlage einer nicht-linearen Verknüpfungsfunktion (Formel 24); die zu Grunde gelegte Nutzenfunktion (Formel 23) ist jedoch linear in ihren Parametern (was im MCl-Modell durch eine mehrstufige Transformation erreicht wird). Auch in Logit-Modellen kann daher das Problem der Multikollinearität bestehen und alternative Schätzmethoden erforderlich machen (CAMMINATIELLO/LUCADAMO 2010, S. 94ff.). Weiterhin sind mit Logit-Analysen spezifische Probleme hinsichtlich der Interpretation der Modelle verbunden. Die ermittelten Parameter sind im Gegensatz zum linearen Regressionsmodell schwieriger zu interpretieren; so lässt sich aus innen zwar die Richtung, jedoch nicht die Stärke des Einflusses der Prädiktoren ablesen. Es ist also nur eine indirekte Interpretation der Parameter möglich ${ }^{35}$. Ein weiteres Problem besteht in der Deutung der Modellgütemaße, da ein normiertes und unmissverständlich interpretierbares Gütemaß wie bei linearen Regressionsmodellen $\left(R^{2}\right)$ für Logit-Modelle nicht existiert (HOETKER 2007, S. 334ff.).

Aufgrund von inhaltlichen und mathematischen Einschränkungen des MNL-Modells sind mehrere darauf aufbauende, komplexere Verfahren entwickelt worden, z.B. zur Verschachtelung von Entscheidungen (Nested-Logit-Modell) oder zur Berücksichtigung der

\footnotetext{
${ }^{35}$ Hierfür kann z.B. die odds ratio aus den Parametern bestimmt werden, die anzeigt, wie sich das Chancenverhältnis bei der Erhöhung einer erklärenden Variable um eine Einheit verändert (ROHRLACK 2007, S. 204f.). Aus den Modellergebnissen lassen sich zudem Elastizitäten für die einzelnen Merkmale bzw. Teilnutzen mathematisch ableiten (TRAIN 2009, S. 57ff.; Anwendungsbeispiel: LADEMANN 2007, S. 153ff.).
} 
Heterogenität von Entscheidungsträgern durch eine vorherige Klassifizierung anhand des Auswahlverhaltens (Latent-Class-Modell). Diese Verfahren sind jedoch insofern schwer anwendbar, als dass die komplizierten mathematischen Vorgänge in vielen gängigen Softwarepaketen nicht implementiert sind (TEMME 2007, S. 330ff.).

\subsection{Multiagentensysteme}

In den 2000er Jahren ist mit den Multiagentensystemen ein weiterer Ansatz zur Modellierung von räumlichem Einkaufsverhalten hinzugetreten (z.B. RASOULI/TIMMERMANS 2013, RAUH et al. 2007 u. 2012, SCHENK 2008), der jedoch bisher kaum oder gar nicht als Methode der Standortanalyse in der gängigen Literatur der Handelsforschung wahrgenommen wurde. Multiagentensysteme basieren auf einer Simulation des Verhaltens mehrerer "Abbilder“ realer Individuen (Agenten) untereinander; sie können in diesem System beispielswiese miteinander kommunizieren und sich gegenseitig beeinflussen (SCHENK 2008, S. 48ff.). Eine Modellierung durch Multiagentensysteme kann sowohl Elemente theoretisch-deduktiver als auch ökonometrischer Ansätze enthalten; sie ist zudem prinzipiell mit dem Prinzip der räumlichen Interaktionsmodelle vereinbar (z.B. BIRKIN/HEPPENSTALL 2011).

Das zu Grunde gelegte Entscheidungsverhalten bei der Wahl der Einkaufsstätte wird auch in agentenbasierten Modellierungen als probabilistisch angenommen; die Grundlage bildet eine Nutzenfunktion mit angebots- und nachfragespezifischen Attributen sowie Gewichtungen durch individuelle Präferenzen (siehe Formel 25) (RAUH et al. 2012, S. 14f.). Der formale Charakter der Nutzenfunktion ist nicht zwingend festgelegt; sie kann, wie in diesem Beispiel, linear-additiv oder auch anderweitig funktional verknüpft sein (SCHENK 2008, S. 85f.).

$$
p_{i j}=\frac{\sum_{k} P_{i k} A_{j k}}{\sum_{g} \sum_{k} P_{i k} A_{j k}}
$$

$\mathrm{p}_{\mathrm{ij}}=$ Wahrscheinlichkeit, dass ein Entscheidungsträger i den Anbieter $\mathrm{j}$ aufsucht

$P_{i k}=$ Präferenz des Entscheidungsträgers $\mathrm{i}$ für die anbieterseitige Eigenschaft $\mathrm{k}$

$A_{\mathrm{j} k}=$ Ausprägung der Eigenschaft $\mathrm{k}$ beim Anbieter $\mathrm{j}$

In der Studie zur Modellierung des Einkaufsverhaltens im Lebensmitteleinzelhandel mit Multiagentensystemen von SCHENK (2008) kommen sowohl empirische Erhebungsmethoden und ökonometrische Analysen als auch theoretisch hergeleitete Modellfunktionen zum Einsatz. Die Relevanz von bestimmten Angebotsattributen (z.B. Produktqualität, Sortiment, Wohnungsnähe) in Abhängigkeit von sozio-demographischen Merkmalen wird mittels binärer Logit-Modelle (Beispiel siehe Formel 26) ermittelt, die anhand von Befragungsdaten parametrisiert wurden (SCHENK 2008, S. 79ff.). Das vorliegende Beispiel ist dahingehend zu interpretieren, dass mit steigender Größe des Haushalts und steigendem Einkommen die Relevanz der Nähe zum Wohnort beim Einkauf von Lebensmitteln abnimmt.

$$
Y=-0,122 \text { FamGr-0,011FamEnk }+1,261
$$

$Y=$ Nennung des Attributes „Wohnungsnähe“ als bedeutsam beim Lebensmitteleinkauf

FamGr = Haushaltsgröße

FamEnk = Haushaltseinkommen 
Auf dieser Grundlage werden individuelle Präferenzwerte geschätzt und im nächsten Schritt mit den objektiv messbaren Attributen der Anbieter kombiniert. Die funktionale Verknüpfung zur Abbildung der Interaktionen zwischen Nachfragern und Anbietern erfolgt über linearadditive Nutzenfunktionen, in die die Distanz zwischen den Nachfragern und den Anbietern sowie die relevanten Angebotsattribute eingehen; diese werden sowohl über die empirisch ermittelten Präferenzwerte als auch über Wahrnehmungsfunktionen gewichtet (siehe Formel 27). Diese Wahrnehmungsfunktionen werden in einer Simulation unter Rückgriff auf Echtdaten (hier: Geschäftsumsätze) parametrisiert (SCHENK 2008, S. 85ff.). Die Aufstellung der individuellen Nutzenfunktionen verläuft also als deduktives Modell mit individueller, empirisch fundierter Gewichtung.

$$
U_{i j}=\frac{1}{b\left(d_{i j}\right)} \sum_{K} P_{i K} a_{K}\left(A_{j K}\right)
$$

$U_{i j}=$ Nutzen der Alternative (bzw. des Anbieters) j für den Entscheidungsträger $\mathrm{i}$

$K=$ Anzahl Kriterien

$\mathrm{d}_{\mathrm{ij}}=$ Distanz zwischen Nachfrager und Anbieter

$\mathrm{P}_{\mathrm{i}}=$ Präferenz des Entscheidungsträgers $\mathrm{i}$

$A j=$ Attribut des Anbieters $j$

$a_{k}, b=$ Wahrnehmungsfunktionen der K Anbieterattribute bzw. der Distanz

Die kalkulierten Nutzenfunktionen bilden in Kombination mit weiteren inhaltlichen Spezifikationen die Grundlage für die Modellierung des Einkaufsverhaltens in einer Computersimulation $\left(\mathrm{SeSAm}{ }^{36}\right)$, die für verschiedene Prognosezwecke eingesetzt werden kann (SCHENK 2008, S. 131ff.). Diese Modellierungsmethode ist also als Ansatz aus dem Bereich der Künstlichen Intelligenz außerordentlich komplex. Für Multiagentensysteme im Einzelhandel ist aber nicht nur leistungsfähige Simulationssoftware notwendig, sondern auch eine große Menge an Daten; abgesehen von der Erhebung verschiedener Geschäftsattribute werden insbesondere detaillierte Individualdaten zu den Nachfragern, d.h. kleinräumige Bevölkerungsdaten zu Haushaltsstrukturen, benötigt (RAUH et al. 2012, S. 15f.; SCHENK 2008, S. 152f.). Der Modellierung von SCHENK lagen nicht nur Geschäftsumsätze aller betrachteten Lebensmittelmärkte, sondern auch kleinräumige Haushaltsdaten (u.a. Haushaltsgröße und Einkommen) aus dem Untersuchungsgebiet (Umeå/Schweden, rd. 80.000 Einwohner) vor; allerdings sind derartige Analysen auch - mit Einschränkungen - bei einer weniger gut ausgebauten Datenlage möglich (RAUH et al. 2012, S. 19ff.).

Weiterhin ist anzumerken, dass zwar die Relevanz der Modellvariablen grundsätzlich gruppen- bzw. individualspezifisch in einer Vorstudie untersucht werden kann (siehe oben), ihr Einfluss in der Nutzenfunktion selbst aber nicht direkt, wie bei den ökonometrischen Modellen, geprüft wird. Es ist möglich, die Modellfunktionen über Echtdaten (z.B. Umsätze) anzupassen und für die Anpassung Gütemaße zu formulieren (RAUH et al. 2012, S. 20; SCHENK 2008, S. 90ff.), jedoch findet nicht notwendigerweise eine Signifikanzprüfung im Sinne ökonometrischer Analyse statt bzw. ist diese losgelöst von der Modellierungstechnik des Multiagentensystems.

\footnotetext{
${ }^{36}$ Die Computersimulationssoftware selbst wurde nicht im Rahmen der Studie entwickelt, sondern stammt aus dem Fachbereich der Informatik (Zur Software siehe SCHENK 2008, S. 76ff.).
} 


\section{$4 \quad$ Agglomerationsvorteile im Einzelhandel - Stand der Forschung}

In diesem Kapitel werden die empirischen Befunde verschiedener Arbeiten besprochen, die den Themenkomplex von (positiven) Agglomerationseffekten im Einzelhandel im Kontext des Konsumentenverhaltens behandeln. Die Untersuchungen sind in angebotsorientierte (z.B. Bildung von Standortkooperationen, direkte "Messung“ von Agglomerationseffekten) und nachfrageorientierte Ansätze (d.h. Analyse des Einkaufsverhaltens) gegliedert; hierbei sind die Arbeiten auf der Grundlage von Modellen des räumlichen Einkaufsverhaltens (Kap. 3) von besonderer Relevanz. Ziel der Erörterung der empirischen Befunde ist es aufzuzeigen, welche Aspekte des dargelegten Zusammenhangs bereits bearbeitet wurden, wie dies geschehen ist und welche Lücken sich in den bisherigen Ansätzen offenbaren, die es in dieser Arbeit zu füllen gilt. Ferner ist dieser Blick auf den Stand der Forschung hilfreich zum Aufbau des eigenen Untersuchungsdesigns.

\subsection{Angebotsorientierte Studien}

\subsubsection{Branchenspezifische Agglomerations- und Dispersionsmuster}

Die räumliche Verteilung von Einzelhandelsangebot ist bereits in verschiedenen Kontexten und Untersuchungsräumen analysiert worden; meist handelt es sich dabei um großräumige Untersuchungen für eine oder mehrere Städte, in denen die Agglomerationstendenzen von Einzelhandels- und Dienstleistungsbranchen beleuchtet werden. Im Regelfall beziehen sich die Arbeiten auf branchenspezifische Standortmuster der Konkurrenzanziehung (aufgrund von Lokalisierungsvorteilen) bzw. -meidung (aufgrund von Wettbewerbseffekten).

In den kanadischen Städten Vancouver und Calgary untersuchen KRIDER/PUTLER (2013) die Standortverteilung von 54 Einzelhandelsbranchen sowie weiteren konsumentenorientierten Dienstleistungen mit dem Ziel der Aufarbeitung branchenspezifischer Standortmuster der Agglomeration bzw. der Konkurrenzmeidung. Als Datengrundlage dienen georeferenzierte Adressen zur Lokalisierung der einzelnen Geschäfte und geostatistische Maße (Ripley's K, Kulldorff's D) zur Messung der Ballung (KRIDER/PUTLER 2013, S. 131ff.). Die ermittelten Ballungsgrade werden zu vier Standortverteilungsmustern zusammengefasst, die von der starken räumlichen Konzentration einer Branche („Hyperagglomeration“) bis zur räumlichen Dispersion (Konkurrenzmeidung) reichen. Abgesehen von Unterschieden zwischen den Untersuchungsstädten offenbaren sich eindeutige Tendenzen: Insbesondere Anbieter mittelund langfristiger Güter (z.B. Bekleidung, Schuhe, Elektroartikel, Möbel) und Spezialanbieter (z.B. Delikatessengeschäfte) neigen zu einer mehr oder minder starken kleinräumlichen Ballung. Demgegenüber betreiben u.a. nicht-spezialisierte Lebensmitteleinzelhändler (z.B. Supermärkte) sowie Tankstellen, Spirituosengeschäfte, Apotheken und gastronomische Anbieter (z.B. Eisladen) eher eine Meidung von Konkurrenten (ebd., S. 140ff.). Zu ähnlichen Ergebnissen kommt auch SADAHIRO (2001, S. 244ff.) bei der Analyse der Standortmuster von Einzelhandels- und Dienstleistungsbranchen in Yokohama (Japan).

PICONE et al. (2009) ergründen die Standortmuster von Spirituosengeschäften und anderen alkoholverkaufenden Angebotsformen (Kioske, Lebensmittelmärkte, Tankstellen, Bars) in fünf US-amerikanischen Großstädten. Zur Messung von Agglomerationen werden mehrere geostatistische Maße (Ripley's K, Nearest-Neighbor-Index) verwendet (PICONE et al. 2009, S. 465ff.). Im Ergebnis werden heterogene Ballungs- bzw. Vermeidungsmuster festgestellt, 
die sich vor allem durch die anbieterseitige Fähigkeit zur Produktdifferenzierung (siehe Kap. 2.2.1) erklären lassen: Spirituosengeschäfte treten aufgrund ihrer Substituierbarkeit am geringsten geballt auf, wobei auch Lebensmittelmärkte tendenziell verstreut lokalisiert sind. Die größten Ballungen weisen hochdifferenzierte Angebotsformen (insb. Bars) auf, da sie eine sich ergänzende Funktion („Bar hopping“) besitzen (ebd., S. 468ff.).

Die Arbeit von ECKERT et al. (2013) behandelt branchenspezifische Agglomerations- und Dispersionsmuster in geplanten Einkaufszentren; hierzu wird die Geschäftsflächennutzung in 90 kanadischen Einkaufszentren im Hinblick auf kleinräumige Branchenballungen mit Hilfe von Nähemaßen untersucht und im Anschluss durch Regressionsmodelle geprüft, welche Eigenschaften der Center die Standortmuster beeinflussen (ECKERT et al. 2013, S. 627f.). Im vorliegenden Fall unterliegen insbesondere Anbieter von Damenbekleidung sowie Juweliere und einzelhandelsnahe Dienstleistungen einer besonderen kleinräumigen Ballung, während diese für Anbieter von Herrenbekleidung und Schuhgeschäfte nicht aufgezeigt werden kann. Die Anbieter, denen positive Lokalisierungseffekte zugesprochen werden, sind i.d.R. abseits der Eingänge der Center lokalisiert, während sich die ergänzenden Dienstleistungsbetriebe tendenziell im Eingangsbereich befinden. In einigen EKZ wird eine starke Clusterbildung festgestellt, während in anderen die Lokalisierung zufällig erscheint. Die Regressionsmodelle zeigen mitunter nur schwache und wenig interpretierbare Ergebnisse (ebd., S. 628ff.).

Im Unterschied zu den o.g. Studien berücksichtigen ÖNER/LARSSON (2013) ausdrücklich die räumliche Ballung nicht-kompetitiver Anbieter; sie untersuchen die Standortmuster von drei Angebotstypen (Bekleidung, Haushaltswaren, Spezialgeschäfte) in den schwedischen Städten Stockholm, Göteborg und Malmö. Hierfür wird eine in Schweden vorliegende Datenbank von allen Arbeitsstätten, ihrer Branchen und räumlicher Koordinaten genutzt und die Stadtgebiete in kleinräumige Gitter $(250 \times 250 \mathrm{~m})$ aufgeteilt. Der Ballungsgrad wird mit Regressionsmodellen (Poisson-Modelle) analysiert; als abhängige Variable fungiert die Zahl von Verkaufsstellen einer bestimmten Branche in den Planquadraten, als erklärende Variablen das Vorkommen jeweils anderer Branchen sowie weitere standortbezogene Größen (ÖNER/LARSSON 2013, S. 6ff.). Die Ergebnisse zeigen z.B., dass das Vorkommen von Bekleidungsgeschäften positiv vom gleichzeitigen Vorhandensein von Spezialgeschäften und Second-hand-Läden beeinflusst wird, während sich ein negativer Zusammenhang zu Anbietern von Haushaltsgegenständen zeigt. Die Standortverteilungen werden anhand der Fristigkeit der angebotenen Güter erklärt; demnach besteht die Komplementarität von Anbietern in gleichen oder ähnlichen Besuchsfrequenzen (ebd., S. 12ff.).

Zusammenfassend betrachtet ist also häufig eine Agglomerationstendenz insbesondere bei Anbietern des mittel- und langfristigen Bedarfs festgestellt worden, die mit ihrer Fähigkeit zur Produktdifferenzierung und der daraus resultierenden Ermöglichung von Vergleichskäufen einhergeht. Lebensmittelmärkte lokalisieren sich hingegen nicht in großen Agglomerationen mit einer Vielzahl kompetitiver Anbieter, sondern in kleineren Standortkooperationen (siehe Kap. 4.1.2) oder in Gewerbegebieten und Einkaufszentren. Diese Standortmuster lassen sich allerdings mit der oben angeführten Messmethodik nicht abbilden, u.a. weil einzelne Betriebsgrößen (z.B. anhand der Verkaufsfläche) nicht berücksichtigt werden. 


\subsubsection{Bildung und Ausgestaltung von Standortkooperationen kompetitiver Anbieter}

Die gezielte Bildung strategischer Standortkooperationen von eigentlich im Wettbewerb zueinander stehenden Anbietern ist ein recht neues Phänomen; insbesondere im Lebensmitteleinzelhandel ist die Einrichtung solcher kleiner Agglomerationen verstärkt zu beobachten. Eine häufige Standortkonfiguration besteht in der Kombination aus einem Verbrauchermarkt, einem LM-Discounter sowie ergänzendem Lebensmittelangebot und komplementären Angebotstypen (SCHRAMM-KLEIN 2012, S. 504f.). Auch wenn die räumliche Nähe von Anbietern nicht automatisch als Folge bewusster betrieblicher Entscheidungen interpretiert werden kann, so sind doch eindeutige Tendenzen einer zunehmenden Agglomerationsneigung auf der Grundlage standortpolitischer Strategien nachweisbar.

Eine Studie der GfK Geomarketing GmbH (STEGNER et al. 2010) zeigt den Trend zur Bildung strategischer Standortkooperationen im deutschen Lebensmitteleinzelhandel auf. Dieser Typ von Angebotsstandort wird anhand von georeferenzierten Anbieterdaten ermittelt, wobei für die Identifikation einer Standortkooperation eine Entfernungsgrenze von 80 Metern (Luftlinie) angesetzt wird. Bezogen auf die untersuchten Discount-Filialisten (Aldi, Lidl) und Verbrauchermärkte (Edeka, Rewe) lässt sich im Zeitraum von 2006 bis 2010 eine deutliche Tendenz zur Bildung von Standortkooperationen feststellen: Bei allen vier Vertriebslinien haben Standorte in derartigen Kleinagglomerationen überproportional zugenommen. Jeweils über ein Fünftel der Aldi- und Rewe-Verkaufsstellen (21,2 bzw. 21,5 \%) sind in Standortgemeinschaften mit der jeweilig ergänzenden Betriebsform (Verbrauchermarkt bzw. LM-Discounter) lokalisiert. Von allen Edeka-Verkaufsstellen sind ein Sechstel (16,9\%) und von den Lidl-Verkaufsstellen ein Zehntel $(10,0 \%)$ in Standortgemeinschaften vertreten (Stand: 2010). Besonders häufig anzutreffende Kombinationen sind Edeka und Aldi, Rewe und Aldi sowie Rewe und Lidl (STEGNER et al. 2010, S. 3ff.).

Zu ähnlichen Ergebnissen kommt JÜRGENS (2012a, b u. 2013) bei seiner Untersuchung zur Standortpolitik von Lebensmitteldiscountern in Schleswig-Holstein. Eine Standortkooperation von Lebensmittelmärkten wird auf der Grundlage von georeferenzierten Anbieterdaten durch eine maximale Luftlinienentfernung von 150 Metern operationalisiert, womit der relevante Radius deutlich höher liegt als in der o.g. Studie. Dementsprechend hoch fällt der Anteil der Discounter-Verkaufsstellen aus, der in Standortgemeinschaften mit anderen Discountern oder Verbrauchermärkten lokalisiert ist; insbesondere die Kombination von Edeka- und AldiMärkten, die über ein Viertel (26,2\%) aller Aldi-Filialen ausmachen, sticht hierbei hervor. Die Kombination von Lidl- und Edeka-Märkten macht einen deutlich geringeren Anteil (8,0 \%) der Lidl-Filialen aus. Die Agglomerationen sind dahingehend aufgebaut, dass ein Discounter jeweils einen wesentlich größeren Verbrauchermarkt ergänzt. Allerdings sind auch Standortgemeinschaften von Lidl- und Aldi-Märkten (12,1\% der Aldi-Märkte) zu beobachten. Bezüglich der Standortpolitik der zuständigen Edeka-Regionalgesellschaft wird anhand von Expertengesprächen belegt, dass Standortkooperationen mit LM-Discountern ausdrücklich gesucht werden, wobei hierfür Aldi bevorzugt wird (JÜRGENS 2012a, S. 40 u. 2013, S. 51ff.).

Die Bildung von gemeinschaftlichen Standorten lässt sich auch bei anderen Branchen des Einzelhandels empirisch nachweisen: Am Beispiel des Möbeleinzelhandels in Deutschland zeigt MARSTALLER (2011, S. 39f.), dass von 2.348 erfassten Möbelmärkten verschiedener Betriebsformen überwiegende Teile in Agglomerationen mit kompetitiven Anbietern lokalisiert sind; insbesondere Möbelfachmärkte sind häufig in Standortkooperationen eingebettet (zu 65 $\%)$. Auf der Grundlage von Clusteranalysen wird gezeigt, dass es verschiedene Typen von 
Agglomerationen im Möbeleinzelhandel gibt (z.B. Ballung exklusiver Einrichtungsgeschäfte, Kombinationen von Fachmärkten und Möbeldiscountern sowie mehrerer Fachmärkte).

Einen Blick in die nähebedingte Kooperation von konkurrierenden Betrieben geben REN et al. (2011) am Beispiel des Elektronikeinzelhandels in den USA. Hierzu werden zwei landesweit präsente Filialisten hinsichtlich ihrer Produktvielfalt und -differenzierung im Angebot von Digitalkameras untersucht. Ob die jeweiligen Verkaufsstellen im Wettbewerb zueinander stehen, wird über ihre räumliche Nähe zueinander bestimmt; die Anbieter befinden sich entweder in einer Monopolstellung (kein Mitbewerber im 10-Meilen-Radius), im Wettbewerb zueinander (Mitbewerber im 10-Meilen-Radius) oder im „kollokierten Wettbewerb“ (Mitbewerber in unmittelbarer Nähe). Für jede Kombination aus im Wettbewerb stehenden Anbietern wird die Überschneidung ihrer Artikelgruppen ermittelt. Bei allen Anbietern wird außerdem der Grad ihrer Produktvielfalt im betrachteten Sortimentsbereich erhoben (REN et al. 2011, S. 1014ff.). Im Ergebnis zeigen sich deutliche Muster der Sortimentspolitik in Abhängigkeit der Ausprägung des räumlichen Wettbewerbs: Anbieter, die im Wettbewerb zu anderen Anbietern in derselben Region stehen, zeichnen sich durch eine größere Produktvielfalt aus als Monopolisten. Die Sortimentspolitik von kollokierten Anbietern basiert demgegenüber auf einer Differenzierungsstrategie; Produktüberschneidungen mit ihren nah gelegenen Mitbewerbern werden tendenziell vermieden, um schädliche Wettbewerbseffekte zu verringern und stattdessen von Agglomerationsvorteilen zu profitieren (ebd., S. 1019ff.).

An diesen Beispielen zeigt sich, dass nicht nur die Existenz von Agglomerationen eigentlich konkurrierender Einzelhandelsanbieter empirisch nachweisbar ist, sondern dass diese oftmals auf eine bewusste Strategie der unternehmerischen Standortpolitik zurückzuführen ist. Der Wunsch zur Bildung von Standortkooperationen mit Mitbewerbern lässt sich auch anhand der Filialisten des deutschen Lebensmitteleinzelhandels belegen, da in einigen Fällen die Planung derartiger Kombinationsstandorte offen als Teil der Expansionskriterien formuliert wird (siehe Anhang, Tab. A 1).

\subsubsection{Operationalisierung von (positiven) Agglomerationseffekten}

Während in den o.g. Arbeiten der Fokus auf der Existenz und Bildung von Agglomerationen liegt, wird im Hinblick auf Einkaufszentren sowie ungeplante Agglomerationen auch häufig versucht, Agglomerationsvorteile als solche nachzuweisen. Ein gängiges Vorgehen hierfür besteht in der Analyse der Determinanten von Zielgrößen des betriebswirtschaftlichen Erfolgs von Agglomerationen unter Berücksichtigung verschiedener Ballungsindikatoren.

DAMIAN et al. (2011) untersuchen den Einfluss der Magnetbetriebe auf den wirtschaftlichen Erfolg von 35 geplanten Einkaufszentren derselben Entwicklungsgesellschaft in Portugal und Spanien. Die Analyse erfolgt auf der Grundlage von Korrelationskoeffizienten und linearen Regressionsmodellen, wobei als abhängige Variablen der Gesamtumsatz des jeweiligen Einkaufszentrums, die Besucherzahlen, die durchschnittlichen Besucherausgaben und die Mietpreise für die Geschäftsflächen der Nicht-Magnetbetriebe fungieren. Neben den erklärenden Variablen zu den Magnetbetrieben werden weitere Kontrollvariablen (z.B. Parkplatzangebot) einbezogen (DAMIAN et al. 2011, S. 462f.). Die Analyse zeigt, dass sowohl die Zahl der Magnetbetriebe (v.a. Lebensmittelmärkte) als auch ihre Größe (Verkaufsfläche) einen starken positiven Effekt auf den Gesamtumsatz der Einkaufszentren hat und auch deren Besucherzufluss positiv von der Zahl der Magnetbetriebe beeinflusst wird. Die 
Geschäftsflächenmieten spiegeln den betriebswirtschaftlichen Erfolg der kleineren bzw. Nicht-Magnetanbieter wieder und steigen mit der Zahl und dem Umsatz der Magnetbetriebe. Die durchschnittlichen Besucherausgaben können hingegen nicht hierdurch erklärt werden (ebd., S. 463ff.). Dennoch zeigt die Studie die Präsenz und Größe von Magnetbetrieben als wesentliche Erfolgsfaktoren von geplanten Einkaufszentren auf; umgekehrt zeigen GATZLAFF et al. (1994, S. 101ff.) am Beispiel von US-amerikanischen Einkaufszentren, dass der Verlust von Magnetbetrieben einen starken Rückgang der Geschäftsflächenmieten (durchschnittlich $26,1 \%$ ) zur Folge hat, was als Folge des Attraktivitätsverlustes gedeutet wird.

Die Mietpreise als Indikator der Standortqualität bzw. des betriebswirtschaftlichen Erfolges bilden ebenso die Grundlage vieler anderer Arbeiten, die ähnliche positive Zusammenhänge zwischen Agglomerationsindikatoren und Mietniveau finden bzw. Mietpreise als Ergebnis wahrgenommener Agglomerationsvorteile identifizieren (z.B. DES ROSIERS et al. 2005, YUO et al. 2011). Eine tiefere Differenzierung der standortbezogenen Erfolgsfaktoren geplanter Agglomerationen nehmen DES ROSIERS et al. (2009) am Beispiel von elf kanadischen Einkaufszentren vor. Angebotsseitig werden „Kernkategorien“ definiert, bei denen positive Agglomerationseffekte als stark angenommen werden (z.B. Bekleidung, Elektroartikel). Die mit der Präsenz weniger großer Anbieter einhergehende Konzentration des Angebots auf wenige Produktvarianten (gemessen mit einem Herfindahl-Index) sollte dahingehend einen negativen Effekt ausüben. Der Einfluss der erklärenden Variablen auf das Mietniveau wird mit loglinearen Regressionsmodellen analysiert; als weitere Variable fungiert u.a. das Alter der Einkaufszentren (DES ROSIERS et al. 2009, S. 170ff.). Im Ergebnis zeigen sich positive Effekte durch das Angebotspotenzial der Kernkategorien, die überwiegend zu den „shopping goods" zählen und negative Effekte durch das Vorkommen von kurzfristigen bzw. „niederrangigen“ Angebotsformen (z.B. Frisör, Wäscherei). Eine geringere Vielfalt der Produktvarianten beeinflusst das Mietniveau hingegen negativ (ebd., S. 177ff.).

Ähnliche Effekte lassen sich auch abseits von geplanten Einkaufszentren nachweisen. GaRATE/PENNINGTON-Cross (2013) untersuchen mit Hilfe von Regressionsmodellen den Einfluss der räumlichen Nähe von kompetitiven Anbietern auf die Flächenproduktivität von Lebensmittelmärkten in Chile; als weitere Kontrollgrößen werden u.a. die Verkaufsfläche der Anbieter, ihr Alter sowie eine Reihe weiterer angebots- und nachfrageseitiger Variablen in die Modelle aufgenommen. Es zeigt sich, dass zwischen den betrachteten Betriebsformen große Unterschiede bestehen: Während in einigen Kombinationen (z.B. SB-Warenhaus und Supermarkt) keine signifikanten Effekte festgestellt werden, profitieren insbesondere kleine LM-Läden und Supermärkte von der Nähe zu Hypermärkten (SB-Warenhäuser) und/oder LM-Discountern. Discounter werden hingegen negativ durch die räumliche Nähe zu SBWarenhäusern beeinflusst (GARATE/PENNINGTON-CROSS 2013, S. 12ff.).

ZHU et al. (2011) untersuchen die Wettbewerbsbeziehungen zwischen Lebensmittelmärkten im Umland von Chicago, die mit dem Markteintritt eines LM-Discounters konfrontiert werden. Es werden Regressionsmodelle mit den täglichen Umsätzen von zwei Mitbewerbern vor und nach der Eröffnung des konkurrierenden Anbieters als Zielvariable geschätzt. Die beiden Mitbewerber sind gleichzeitig dem Markteintritt des Discounters ausgesetzt, jedoch befindet sich ein Markt in unmittelbarer Nachbarschaft zum neuen Konkurrenten, der andere mehrere Meilen vom eingetretenen Mitbewerber entfernt (ZHU et al. 2011, S. 143f.). Im betrachteten Zeitraum (zwei Jahre) werden die Umsatzzahlen beider etablierter Märkte durch den Markteintritt beeinträchtigt; der benachbarte Markt verzeichnet allerdings in den 
Produktkategorien, die sich mit dem neuen Mitbewerber überschneiden, deutlich geringere Einbußen als der vom Discounter weiter entfernte Markt. Zudem erhöhen sich seine Umsatzzuflüsse in den vom neuen Discounter nicht abgedeckten Sortimentsbereichen, während der andere Markt in nahezu allen Kategorien große Rückgänge zu verzeichnen hat. Die Umsatzverlagerungen werden als Urbanisierungsvorteile durch die Nachbarschaft zu komplementären Anbietern interpretiert, die Kopplungskäufe ermöglichen (ebd., S. 145ff.).

In Bezug auf verschiedene Einzelhandelsbranchen untersuchen ESTEBAN-BRAvo et al. (2012) den Einfluss räumlicher Nähe von kompetitiven und komplementären Anbietern auf den Geschäftserfolg, der jedoch nicht durch Umsatzzahlen oder Mietpreise gemessen wird, sondern anhand von Befragungen der Geschäftsführer zum betrieblichen Erfolg. Es zeigt sich, dass die Höchstwerte der Zufriedenheit von Anbietern erreicht werden, die sich entweder in einer sehr starken Ballung befinden und dort Agglomerationsvorteile durch Kopplungs- und Vergleichskäufe erzielen, oder in monopolähnlichen Stellungen, in denen sie von ihrer Angebotsmacht profitieren. Zwischen Konkurrenznähe und betriebswirtschaftlichem Erfolg ergibt sich also, graphisch ausgedrückt, ein U-förmiger Zusammenhang; eine hohe räumliche Ballung wirkt sich also ebenso positiv aus wie eine starke Konkurrenzmeidung, während im Mittelfeld Wettbewerbseffekte dominieren. Ähnlich der Untersuchung von REN et al. (2011) (siehe Kap. 4.1.2) werden außerdem Hinweise für eine Abstimmung der Sortimentspolitik auf den Standort gefunden (ESTEBAN-BRAVO 2012 et al., S. 32ff.).

In einer Serie von Untersuchungen (u.a. TELLER 2008, TELLER/ELMS 2010 u. 2012, TELLER/REUTTERER 2008, TELLER et al. 2010) wird die konsumentenseitig wahrgenommene Attraktivität sowohl von geplanten Einkaufszentren als auch gewachsenen Agglomerationen analysiert. Die Grundlage dieser mittels Strukturgleichungsmodellen durchgeführten Studien sind modellanalytisch hergeleitete „latente Variablen“, die auf die Konsumentenzufriedenheit abzielen (z.B. Gesamtattraktivität, Kundenzufriedenheit, Wiederbesuchsabsicht) und letztlich die theoretisch geschlussfolgerten Attraktivitätsmerkmale von Einzelhandelsagglomerationen bilden. Hierbei werden wesentliche Struktureigenschaften wie z.B. der Angebotsmix, die Parkmöglichkeiten sowie verschiedene Maße für die Einkaufsatmosphäre als erklärende Größen geprüft. Als Ergebnis dieser zumeist auf der Grundlage von Point-of-saleBefragungen durchgeführten Studien sind stets positive Effekte der Ballung von Anbietern und Branchen auf die Kundenwahrnehmung festgestellt worden; so übt beispielsweise der Angebotsmix einen starken positiven Einfluss auf die wahrgenommene Gesamtattraktivität (z.B. TELLER/REUTTERER 2008, S. 134ff.) oder die Kundenzufriedenheit und die nachhaltige Kundenbindung (z.B. TELLER 2008, S. 394ff.; TELLER/ELMS 2010, S. 33ff.) aus.

Einzelne Studien betrachten auch die Wahrnehmung von (positiven) Agglomerationseffekten durch die Einzelhandelsanbieter selbst: Anhand der Befragung von Mietern in geplanten Einkaufszentren versuchen TELLER/SCHNEDLITZ (2012), die an solchen Angebotsstandorten relevanten positiven Agglomerationseffekte aus unternehmerischer Sicht zu identifizieren. Die Eigentümer bzw. Geschäftsführer mussten 35 Items (z.B. Straßenanbindung, Mietermix) bewerten, die mit Hilfe einer Faktorenanalyse zu sechs Hauptkomponenten aggregiert wurden. Hierbei werden infrastrukturelle Aspekte außerhalb (z.B. Erreichbarkeit) und innerhalb des Centers (z.B. Reinigung) sowie der Angebotsmix als wichtigste Einflussgrößen identifiziert, während gemeinsame Management- und Marketingmaßnahmen einen vergleichsweise geringen Stellenwert einnehmen (TELLER/SCHNEDLITZ 2012, S. 1049ff.). 
Am Beispiel verschiedener Branchen in Belfast untersucht BRowN (1987) mit Hilfe einer Unternehmensbefragung die Einschätzung der Händler zum Einfluss der unmittelbaren räumlichen Nähe eines gleichartigen Anbieters auf ihren Geschäftserfolg. Die Einstellung zur Konkurrenznähe variiert stark zwischen den betrachteten Branchen; hohe Ablehnungswerte werden bei Lebensmittelmärkten, Anbietern des Lebensmittelhandwerks und Apotheken erreicht. Anbieter mittel- und langfristiger Bedarfsbereiche sind der räumlichen Nähe zu Mitbewerbern hingegen tendenziell positiv eingestellt, was insbesondere auf Bekleidungsund Schuhhändler sowie Juweliere, und, in geringerer Intensität, auch auf Anbieter von Möbeln, Heimwerkerbedarf und Elektronikartikeln zutrifft (BROWN 1987, S. 134ff.).

Einen anderen Analyseweg schlägt POPIEN (1989) ein, der Agglomerationsvorteile indirekt misst, indem er die Geschäftsflächennutzung im Zeitverlauf analysiert. Hierzu wird der Zusammenhang zwischen den Kopplungsmöglichkeiten und dem Leerstand von Flächen im Zeitraum von 1981 bis 1986 in mehreren bayerischen Städten betrachtet; die Standortpersistenz von Anbietern wird also als Indikator für die Standortqualität übersetzt. Das Kopplungspotenzial der Geschäftsflächen wird anhand der anderen Anbieter in vordefinierten rautenförmigen Reichweiten ermittelt (POPIEN 1989, S. 135f.). Im Durchschnitt sind im veranschlagten Zeitraum $11,7 \%$ der untersuchten Einzelhandelsbetriebe aufgelöst worden, wobei - abgesehen von absoluten Streulagen - der Anteil von „Auflösestandorten“ mit steigenden Kopplungsmöglichkeiten deutlich sinkt. Dies ist als Hinweis auf eine geringere Attraktivität von Standorten mit geringem Kopplungspotenzial zu werten (ebd., S. 138ff.).

Die Untersuchungen zeigen verschiedene Wege auf, wie Agglomerationseffekte im Einzelhandel auf der Angebotsseite operationalisierbar gemacht werden können. Abseits der unterschiedlichen methodischen Zugänge werden durchgängig Lokalisierungs- und/oder Urbanisierungsvorteile empirisch erwiesen, wenngleich diese offensichtlich nicht für alle Branchenkombinationen und an allen Typen von Angebotsstandorten gleichermaßen wirken.

\subsubsection{Auswirkungen von (innerstädtischen) Einkaufszentren}

Die Ansiedlung von neuen geplanten Einkaufszentren wird meist mit einer erstarkenden Wettbewerbsintensität assoziiert, was sich z.B. an den kontroversen Diskussionen um innerstädtische Einkaufszentren zeigt (siehe Kap. 1.4.2.2). Es gibt jedoch Hinweise dafür, dass derartige Markteintritte nicht etwa (nur) Wettbewerbseffekte induzieren, sondern positive Einflüsse auf die anliegenden Anbieter haben (können). Viele Wirkungsanalysen betrachten aber nur einzelne Ansiedlungen von Einkaufszentren (z.B. HOPFINGER/SCHMIDT 2010, MOSSIG/DORENKAMP 2008), wobei ein einheitliches Bild bei diesen auch methodisch kaum vergleichbaren Ansätzen nicht auszumachen ist. Daher beschränkt sich dieser Überblick auf großräumiger angelegte Studien.

Im US-amerikanischen Kontext untersuchen HARDIN/WOLVERTON (2000) und HARDIN et al. (2002) die Determinanten der Mietpreise von ungeplanten Einzelhandelsagglomerationen geringerer Größe (Neighborhood center, Community center), wobei das (maximale bzw. minimale) Mietniveau den betriebswirtschaftlichen Erfolg bzw. die Standortqualität anzeigen soll (ähnlich den Untersuchungen zum Erfolg der geplanten Einkaufszentren, siehe Kap. 4.1.3). Die Analyse erfolgt über zwei verbundene Regressionsmodelle, wobei im ersten Fall die Leerstandsquote, im zweiten Fall das Mietniveau als Zielvariablen formuliert wird. Die Verbindung der Modelle besteht darin, dass beide Größen im jeweils anderen Modell eine 
der erklärenden Variablen bilden, was den wechselseitigen Zusammenhang abbildet. Um Agglomerationsvorteile zu berücksichtigen, werden diesbezügliche Erklärungsgrößen (z.B. Nähe zum nächsten EKZ) in die Modelle aufgenommen. Unter Kontrolle der Effekte einer Reihe anderer Größen (z.B. Kaufkraft, Größe des eigenen Angebotes) werden in beiden Fällen signifikant positive Einflüsse der räumlichen Nähe zu Einkaufszentren gefunden (HARDIN et al. 2002, S. 168ff.; HARDIN/WOLVERTON 2000, S. 308ff.). Die Nähe zu EKZ bedeutet in diesem Fall also eher eine Aufwertung der etablierten Angebotsstandorte.

Die o.g. Untersuchungen berücksichtigen jedoch nur eine Momentaufnahme; mit den Arbeiten von JUNKER/KÜHN (2009) und LADEMANN (2011) sind aber zwei Längsschnittstudien zu den Auswirkungen innerstädtischer Einkaufszentren in Deutschland durchgeführt worden. Im ersten Fall basiert die Feststellung von Auswirkungen auf einem Vergleich der innerstädtischen Einzelhandelssituation vor und nach der Ansiedlung eines EKZ in zwölf Städten (u.a. Erfurt, Osnabrück, Regensburg). Als Indikatoren werden u.a. die Entwicklung der 1a-Lagen (z.B. hinsichtlich des Filialisierungsgrades und der Passantenfrequenzen), der gesamtstädtischen Zentralität und der Verschiebung von Lagestrukturen (1a-, 1b-, Nebenund Randlage) berücksichtigt. Die Ergebnisse zeigen kein eindeutiges Bild, wobei tendenziell kleinen, baulich integrierten Einkaufszentren eine verhalten positive Wirkung zugesprochen wird, während solche in innerstädtischen Randlagen als eher schädlich eingestuft werden (JUNKER/KÜHN 2009, S. 67ff.).

Wesentlich umfangreicher analysiert LADEMANN (2011) die Effekte von 97 Einkaufszentren in 80 Städten im Zeitraum von 1990 bis 2008 und greift hierbei neben Befragungen der relevanten Industrie- und Handelskammern auf Zeitreihen der innerstädtischen Ladenmieten zurück, die - ähnlich den o.g. Studien - als Proxyvariable für die Standortqualität bzw. die Lagewertigkeit fungieren. Die Mietentwicklung wird hierbei insgesamt und in Abhängigkeit von Stadt- und EKZ-Größen analysiert und in (Panel-)Regressionsmodellen der CenterEröffnung gegenübergestellt; aufgrund des langen Untersuchungszeitraumes ist es auch möglich, den Trend in der Mietpreisentwicklung vor der Ansiedlung zu berücksichtigen. Das Urteil der IHK-Befragten im Hinblick auf die Auswirkungen in den Innenstädten fällt in Bezug auf die Leerstandsquoten sowie andere Aspekte (z.B. Besucherfrequenz) tendenziell positiv aus; negative Effekte werden am ehesten in den innerstädtischen Streulagen festgestellt (LADEMANN 2011, S. 156ff.). In der Analyse der Mietpreisentwicklungen zeigen sich in unterschiedlicher Weise positive Effekte der EKZ-Ansiedlung auf die innerstädtischen Mietpreise: Während in vielen Fällen ein ohnehin positiver Trend verstärkt wird, sind andernorts vor der Ansiedlung sinkende Ladenmieten wieder gestiegen; die Strukturbrüche in der Zeitreihe, die mit der Ansiedlung auftreten, sind statistisch signifikant (ebd., S. 164ff.). In den Panel-Regressionen werden neben der EKZ-Eröffnung der bisherige Mietpreistrend sowie weitere standortspezifische Erklärungsgrößen einbezogen; die Modelle zeigen, dass es im Mittel vor der Ansiedlung Negativtrends gab, die mit der Eröffnung umgekehrt wurden. Eine auf den Modellen aufbauende Marktsimulation zeigt unter der kontrafaktischen Bedingung der Nicht-Ansiedlung deutlich sinkende Mietniveaus (ebd., S. 183ff.).

Im Gegensatz zu vielen Aussagen bezüglich negativer Auswirkungen von (innerstädtischen) Einkaufszentren (z.B. „Angriff auf die City“ von BRUNE et al. 2006) zeigen die empirischen Erkenntnisse, dass eine reine Wettbewerbsperspektive deutlich zu kurz greift. Im Gegenteil lassen sich positive Agglomerationseffekte durch benachbarte Einkaufszentren nachweisen, deren Entfaltung aber augenscheinlich entscheidend davon abhängt, wie nah diese den 
gewachsenen Angebotsstandorten sind. Nicht explizit geprüft wurden in diesem Zusammenhang hingegen Effekte der Sortimentspolitik; andere empirische Erkenntnisse (siehe Kap. 4.1.3) zeigen aber, dass auch die Sortimentsüberschneidung bzw. -differenzierung von räumlich geballten kompetitiven Anbietern eine wichtige Rolle spielt.

\subsection{Konsumentenseitige Studien}

\subsubsection{Einkaufsverhalten am Angebotsstandort}

Die Untersuchung des Einkaufsverhaltens am Angebotsstandort stellt die wahrscheinlich älteste Forschungslinie im Kontext von Einzelhandelsagglomerationen dar; insbesondere in der deutschsprachigen Geographie gewannen ab den 1970er Jahren die Ansätze der Aktionsraumforschung und der Zeitgeographie an Bedeutung, deren Einflüsse sich in der Konsumentenverhaltensforschung niederschlugen. Die Grundidee dieser Ansätze ist die Betrachtung des menschlichen Verhaltens im Raumkontext unter Berücksichtigung zeitlicher Beschränkungen (HEINRITZ et al. 2003, S. 136ff.). Im Einkaufsverhalten erwächst dadurch die Notwendigkeit der Kopplung mehrerer Tätigkeiten (z.B. Besorgungen), wie es z.B. in der Theorie von LANGE (siehe Kap. 2.3.3) thematisiert wird. In Folge dessen ist v.a. das Kopplungsverhalten beim Einkauf ins Zentrum des Forschungsinteresses gerückt und wurde in diesem Zusammenhang regelmäßig nachgewiesen (z.B. HEINRITZ 1979b, POPP 1979, POPP 1998). Auch neuere Arbeiten beschäftigen sich mit dem Phänomen der Kopplung, z.B. im Hinblick auf Kopplungen von Einkaufs-, Freizeit- und Arbeitsaktivitäten (KöHLER 2012).

Eine besonders ausführliche Auseinandersetzung mit Kopplungs- und Vergleichskäufen am Angebotsstandort nehmen HEINRITZ/THEIS (1997) am Beispiel von Bekleidungsgeschäften in mehreren bayerischen Städten vor. Insgesamt werden 1.064 Personen zum Zweck und der vorausgehenden Planung ihrer Einkaufsfahrt, der Kopplung von mehreren Geschäften sowie hinsichtlich ihrer sozio-demographischen Eigenschaften befragt. Je nach Befragungsstandort werden im Durchschnitt 1,57 bis 2,79 Geschäfte aufgesucht. Es zeigt sich, dass die maximale Entfernung, bis zu der Kopplungen ausgehend vom Befragungsstandort stattfinden, mit der Größe des gesamten Angebotsstandortes steigt; am Samplepoint in der Augsburger City werden Kopplungen bis zu einer Distanz von 750 Metern erfasst, während im kleinen Einkaufszentrum PEP in München-Neuperlach die äußere Grenze 150 Meter beträgt (HEINRITZ/THEIS 1997, S. 224ff.). Zudem variiert die Neigung zu Kopplungen mit dem Einkaufszweck sowie nach Personengruppen; beispielsweise wird sowohl bei der jüngsten Konsumentengruppe (bis 30 Jahre) als auch bei der ältesten (ab 60 Jahre) ein deutlich ausgeprägteres Kopplungsverhalten nachgewiesen als bei den 30-60jährigen. Auch ergibt sich ein Zusammenhang zwischen der Größe des Angebotsstandortes und dem Anteil der geplanten bzw. spontanen Geschäftsbesuche; tendenziell liegt der Anteil von Spontanbesuchen an den größeren Angebotsstandorten deutlich höher (ebd., S. 228ff.).

Ausgehend von den Fragestellungen, ob innerstädtische Einkaufszentren in die Citybereiche eingebettet sind und diese davon profitieren, fasst MONHEIM (2007) mehrere Fallstudien zu Kopplungsbeziehungen zwischen Einkaufszentren und gewachsenen Innenstadtbereichen in 14 deutschen Städten zusammen; diese basieren auf Point-of-sale-Befragungen, die jeweils in den Einkaufszentren und/oder der umgebenden Innenstadt durchgeführt wurden. Hierbei zeigt sich, dass unabhängig von der spezifischen Konfiguration der Angebotsstandorte Kopplungen zwischen beiden Polen stattfinden, jedoch, je nach Stadt und Wochentag, in 
sehr unterschiedlicher Intensität. In einzelnen Fällen beträgt der Anteil an Besuchern von innenstadtintegrierten EKZ, die auch die Innenstadt aufsuchen, zwischen 60 und $80 \%$. Innenstadtnahe Zentren (Entfernung: 400-1.500 Meter) generieren tendenziell deutlich geringere Austauschgrade (MONHEIM 2007, S. 25ff.). Diese ermittelten Effekte spiegeln auch die Erkenntnisse aus einigen angebotsseitigen Studien zu den Auswirkungen von EKZ wider (siehe Kap. 4.1.4), wonach die Ausprägung der Auswirkungen geplanter Agglomerationen für gewachsene Strukturen entscheidend von der Nähe zu ihnen abhängt.

NEWMARK/PLAUT (2005) beschäftigen sich mit multifinalen Einkäufen der Besucher von vier geplanten Einkaufszentren in Prag, deren Einkaufswege über Point-of-sale-Befragungen erhoben werden. Im Gesamtüberblick zeigt sich, dass 42,3\% aller Besucher die Einkaufszentren aus mehreren Gründen (z.B. Lebensmitteleinkauf, Einkauf weiterer Güter, Restaurantbesuch) aufsuchen und 18,1 \% den Besuch mit anderen Zwecken außerhalb verbinden. In der Organisation der Einkaufswege ergeben sich Unterschiede zwischen soziodemographischen Gruppen, Typen von Einkaufsfahrten und EKZ-spezifischen Umständen. Beispielsweise werden bei männlichen Besuchern mehr externe Kopplungen, bei weiblichen Besuchern mehr EKZ-interne Kopplungen festgestellt. Das Haushaltseinkommen beeinflusst die Neigung zu Mehrzweckeinkäufen positiv; mit steigendem Budget erhöht sich die Affinität zu internen und externen Kopplungen. Ebenso erhöht sich die Kopplungsneigung mit steigender Anreisezeit vom Ausgangsort (NEWMARK/PLAUT 2005, S. 177ff.).

Räumlich und sachlich multifinale Einkäufe lassen sich also vielfältig im Einkaufsverhalten am Point of sale nachweisen. Allerdings haben alle Studien zum Einkaufsverhalten am Point of sale die Problematik gemein, dass sie nur diejenigen Konsumenten erfassen (können), die sich bereits für einen Besuch der betrachteten Angebotsstandorte entschieden haben; es fehlt eine Kontrollgruppe bzw. die Berücksichtigung aller potenziellen Konsumenten im Marktgebiet bleibt aus. Zudem drängt sich, wie MONHEIM (2007, S. 24) feststellt, die Frage der Übertragbarkeit auf, da einheitliche Untersuchungsdesigns praktisch nicht existieren.

\subsubsection{Modellanalytische Untersuchungen}

\subsubsection{1 Überblick zum bisherigen Stand}

Da es das Ziel der vorliegenden Arbeit ist, Agglomerationseffekte im Einzelhandel mit Hilfe von Marktgebietsmodellen (siehe Kap. 3) zu analysieren, sind die bisherigen Ansätze hierzu von besonderem Interesse. FOTHERINGHAM (1985) hat bereits einen theoretischen Ansatz zur Integration von Agglomerationseffekten ins HuFF-Modell geleistet (siehe Kap. 3.2.3). Die hier besprochenen Untersuchungen umfassen empirische Analysen auf der Basis von ökonometrischen Entscheidungs- bzw. Marktgebietsmodellen (siehe Kap. 3.3). Studien auf der Grundlage von Stated-Choice-Befragungsexperimenten bleiben hierbei unberücksichtigt.

ARENTZE et al. (2005) untersuchen die kundenseitige Wahl zwischen zwei Einkaufszentren in der niederländischen Provinz Nordbrabant anhand von Nested-Logit-Modellen, die mehrere hintereinander geschaltete Entscheidungsstufen abbilden können. Im Zuge der Erhebung werden 1.704 Haushalte nach ihren bevorzugten Einkaufszentren und ihren Einkäufen von Lebensmitteln, Bekleidung und Schuhen sowie sonstigen Gütern darin befragt; für alle drei Sortimentsbereiche werden separate Modelle geschätzt und zudem sozio-demographische Segmentierungen der Haushalte vorgenommen. Als erklärende Größen werden mehrere Agglomerationsvariablen zur Abbildung der räumlichen Nähe zu kompetitiven Anbietern 
sowie die Fahrtzeit zum Angebotsstandort und dessen Verkaufsfläche in die Nutzenfunktionen aufgenommen (ARENTZE et al. 2005, S. 110f.). Die Ergebnisse zeigen negative Einflüsse der Fahrtzeit und positive Einflüsse der Verkaufsfläche auf den Kundenzufluss. Ebenso beeinflussen die Agglomerationsvariablen die Einkaufsentscheidung signifikant positiv (ebd., S. 111ff.). Zusätzlich werden Modelle ohne Agglomerationsvariablen geschätzt, die somit die Wahl der Einkaufsstätte nur über die Größen Verkaufsfläche und Fahrtzeit erklären. Im Vergleich zeigen die Modelle mit Agglomerationsvariablen eine deutlich bessere Anpassung an die Echtdaten, da die anderen Modelle die Einkaufsfahrten in die größeren Einkaufszentren systematisch unterschätzen (ebd., S. 113f.).

Auf der Grundlage von Latent-Class-Modellen untersuchen POPKOWSKI LESZCZYC et al. (2004) die Einkaufsstättenwahl im Lebensmitteleinzelhandel im suburbanen Umland einer neuseeländischen Stadt. Hierzu werden in einer telefonischen Haushaltsbefragung 200 Personen nach ihren Einkaufshäufigkeiten bei bestimmten Anbietern sowie hinsichtlich ihrer Wahrnehmung der Anbieter (Image) und einer Reihe sozio-demographischer Eigenschaften (u.a. Haushaltsgröße, Einkommen) befragt. Auf dieser Datengrundlage werden zwei diskrete Entscheidungsmodelle geschätzt: Die Nutzenfunktion des ersten Modells wird anhand von Präferenzwerten für die Anbieter, der Distanz vom Kundenwohnort zu innen sowie mehrerer haushaltsbezogener Größen (u.a. Haushaltsgröße, Einkommen) spezifiziert; im zweiten Modell werden zusätzlich zwei Agglomerationsvariablen aufgenommen: Die Anzahl anderer Lebensmittelmärkte im selben Gemeindebezirk soll die Möglichkeit zu Vergleichskäufen abbilden, während eine Dummy-Variable für das Vorkommen eines Einkaufszentrums im selben Bezirk die Möglichkeit von Kopplungskäufen anzeigen soll. Das zweite Modell zeigt eine deutlich bessere Anpassung an die Echtdaten (POPKOWSKI LESZCZYC et al. 2004, S. 88ff.). Die Befragten werden anhand ihres Einkaufsverhaltens in preisorientierte Käufer, serviceorientierte Käufer und Cherry-Picker gruppiert (siehe Kap. 2.5.2.1). Zwischen den Kundensegmenten zeigen sich Unterschiede in den Parametern der Nutzenfunktionen, die auf eine differenzierte Attraktivitätswahrnehmung der alternativen Lebensmittelmärkte hinweisen: Die Distanz wirkt bei zeitlich eingeschränkten Kunden negativ, während CherryPicker nicht distanzsensibel reagieren. Die Agglomerationsvariablen haben einen positiven Effekt für serviceorientierte Kunden, jedoch nicht für die anderen Gruppen (ebd., S. 94ff.).

Zur Analyse der Marktgebiete von SB-Warenhäusern in Sarajevo nutzen TIHI/ORUC (2012)

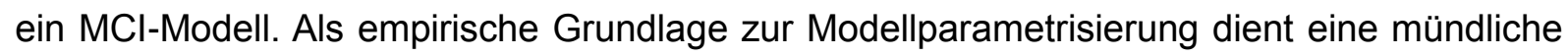
Haushaltsbefragung von 240 Personen zu ihren Einkäufen. Das Stadtgebiet wird in neun Nachfrageorte aufgeteilt, deren lokale Marktanteile die abhängige Variable im Modell darstellen. Als erklärende Variablen werden anbieterbezogene Attribute (u.a. Verkaufsfläche), die Fahrtzeit zwischen Nachfrage- und Angebotsstandort sowie haushaltsbezogene Größen in das MCl-Modell aufgenommen. Um Agglomerations- bzw. Wettbewerbseffekte zu erfassen, wird außerdem das von FOTHERINGHAM (1985) formulierte Konzentrationsmaß (siehe Kap. 3.2.3) einbezogen, das die Konzentration hinsichtlich konkurrierender SBWarenhäuser abbildet (TIHI/ORUC 2012, S. 39ff.). Im Ergebnis zeigen sich unterlinear positive Effekte der Verkaufsfläche und negative Effekte der Fahrtzeit; auch weitere angebots- oder nachfragebezogene Attribute zeigen signifikante Wirkungen. Die Nähe zu Mitbewerbern, gemessen durch die Konzentrationsvariable, wirkt negativ auf die lokalen Marktanteile, was auf die Dominanz von Wettbewerbseffekten gegenüber (positiven) Agglomerationseffekten 
schließen lässt (ebd., S. 43ff.). Allerdings werden hier nur direkte Mitbewerber berücksichtigt und z.B. andere Betriebsformen ausgeschlossen.

Auch LI/LIU (2012) greifen die Gedanken von FOTHERINGHAM (1985) in ihrer Untersuchung zu Agglomerations- und Wettbewerbsbeziehungen zwischen SB-Warenhäusern (Wal-Mart, Kmart) in Cincinnati (USA) auf. Hierzu verwenden sie ein modifiziertes HuFF-Modell unter Berücksichtigung von zwei Konzentrationsvariablen, die 1.) die räumliche Nähe zu direkten Mitbewerbern (Wettbewerbseffekte) und 2.) zu komplementären Anbietern (positive Agglomerationseffekte) ausdrücken. Die Grundidee besteht darin, dass bis zu einer bestimmten räumlichen Nähe Agglomerationsvorteile wirken (agglomeration area) und sich darüber hinaus eine Zone anschließt, in der Wettbewerbseffekte dominieren (competition area) (LI/LIU 2012, S. 592f.). Als Konzentrationsvariablen werden die Anzahl bzw. die Verkaufsflächen der Anbieter in einem bestimmten Luftlinienradius bestimmt. In die Agglomerationsvariable gehen die Verkaufsstellen einer Reihe anderer Filialisten ein, von denen ein positiver Näheeffekt erwartet wird; die Wettbewerbsvariable setzt sich aus unmittelbaren Konkurrenten zusammen (LEH-Filialisten ähnlicher Betriebsformen). Es wird ein HuFF-Modell unter Berücksichtigung der Agglomerationsvariablen aufgestellt und eine Umsatzschätzung anhand von Kaufkraftdaten vorgenommen, wobei Gewichtungsparameter für die Distanz und die Agglomerationsvariable einfließen. Die Umsatzfunktion der Anbieter wird um die Wettbewerbsvariable erweitert. Da für die Distanz ein Gewichtungsexponent von zwei gesetzt wird, müssen noch die Gewichtungsexponenten der Agglomerations- und der Wettbewerbsvariable sowie die Radien der agglomeration area bzw. der competition area bestimmt werden. Die Umsatzfunktion wird linearisiert und über die konventionelle lineare Regressionsanalyse parametrisiert, während die nicht-lineare HuFF-Funktion iterativ angepasst wird. Hierbei werden verschiedene Werte für die Zonenradien und die Exponenten geprüft, wobei geschätzte Umsatzdaten der Anbieter die Zielvariable darstellen (ebd., S. 594ff.). Die größte Varianzaufklärung der Modelle wird bei einem Radius für die Zone positiver Agglomerationseffekte von $1,13 \mathrm{~km}$ und für die Zone negativer Wettbewerbseffekte von 3,22 km erreicht; der Parameter der Agglomerationsvariable ist positiv, der der Wettbewerbsvariable negativ. Das erweiterte Modell liefert eine deutlich bessere Anpassung an die Echtdaten als ein konventionelles HuFF-Modell (ebd., S. 596ff.).

Auf einer ähnlichen Datengrundlage nehmen ORPANA/LAMPINEN (2003) eine Modellierung der Marktgebiete von Lebensmittelmärkten verschiedener Betriebsformen in zwei finnischen Regionen vor. Es werden zum Vergleich sowohl Logitmodelle als auch HUFF- bzw. MClModelle jeweils mit und ohne Konzentrationsvariable, die die Nähe zu Mitbewerbern ausdrücken, getestet. Zudem wird in mehreren Varianten eine Zeitkonstante zur Abbildung der fixen Transaktionskosten berücksichtigt; in jedes Modell werden die Verkaufsflächen der Anbieter sowie die Fahrtzeiten zu innen aufgenommen (ORPANA/LAMPINEN 2003, S. 322ff.). Als Datengrundlage fungieren Kaufkraftdaten sowie Umsatz- und Standortdaten der Anbieter. Die Modelle werden unter Nutzung der Maximum-Likelihood-Methode geschätzt, wobei die bestmögliche Übereinstimmung der modellierten Kaufkraftzuflüsse mit den realen Umsätzen der Anbieter angestrebt wird (ebd., S. 330ff.). Die Modelle werden auf ihren Erklärungsgehalt überprüft; im Ergebnis zeigt sich, dass sie sich diesbezüglich nur gering unterscheiden. Die geringste Fehlerquote wird mit dem komplexesten der Modelle, einem hierarchischen Logit-Modell, erreicht, das sowohl die Konzentrationsvariable als auch die Zeitkonstante sowie betriebsformenspezifische Gewichtungsparameter enthält. Der 
Distanzeffekt ist negativ und bei SB-Warenhäusern deutlich geringer als bei anderen Betriebsformen; die Verkaufsfläche wirkt positiv. Die Konkurrenznähe schlägt sich negativ nieder, wobei auch hier der Effekt bei SB-Warenhäusern am stärksten ist (ebd., S. 336ff.).

Einen anderen Schwerpunkt fokussieren GIJSBRECHTS et al. (2008) und VROEGRIJK et al. (2013), die Mehrfachorientierung im Lebensmitteleinzelhandel untersuchen, die sie anhand der Komplementarität von kompetitiven Anbietern erklären (siehe Kap. 2.5.2.2). Sie ermitteln Logit-Modelle u.a. zur Erklärung des Einkaufsmusters (Mehrfachorientierung oder nicht) und zur Wahl der Einkaufsstätte bzw. der Wahl einer Kombination zweier Einkaufsstätten. Auf der Grundlage von Daten aus dem niederländischen GfK-Haushaltspanel zu 906 Haushalten über den Zeitraum eines Jahres zeigen GIJSBRECHTS et al. (2008, S. 12ff.), dass mehrfachorientierte Kunden tendenziell weniger affin gegenüber großen Verbrauchermärkten sind und demgegenüber wesentlich höhere Ausgaben in LM-Discountern (z.B. Aldi) tätigen. Häufige Verknüpfungen finden zwischen Discountern und anderen Betriebsformen (insb. Supermärkten) statt. Die Modelle, die die Möglichkeit zur Mehrfachorientierung einbeziehen, erreichen eine deutlich bessere Anpassung an die Echtdaten als alternativ geschätzte Modelle ohne deren Berücksichtigung (ebd., S. 16ff.).

VROEGRIJK et al. (2013) analysieren die Auswirkungen der Markteintritte von LM-Discountern (Aldi, Lidl); hierzu werden Einkaufswege aus vierjährigen GfK-Paneldaten für die Schätzung von Logit-Modellen zur Wahl des Einkaufsmusters und des Anbieters bzw. der Kombination von Anbietern benutzt. Es werden 194 niederländische Teilräume betrachtet, in denen in diesem Zeitraum die Ansiedlung eines Discounters stattfand, wobei die Einkaufsorientierung von 703 Haushalten erfasst wird. In die Analyse wird zudem ein auf die Sortimentsstruktur bezogenes Maß für die Komplementarität von Anbietern gleicher Branchen (siehe Kap. 2.5.2.2) einbezogen (VROEGRIJK et al. 2013, S. 610ff.). Insgesamt zeigt sich, dass durch den Markteintritt der Discounter die Anbieterloyalität ab- bzw. die Mehrfachorientierung zunimmt und die neuen Anbieter sehr hohe Komplementaritäten zu den bestehenden Anbietern (insb. Super-/Verbrauchermärkte) aufweisen. In den Entscheidungsmodellen zur Wahl der Einkaufsstätte(n) zeigen die Komplementaritätswerte einen signifikanten positiven Effekt auf die Auswahl eines Anbieters oder der Kombination aus mehreren; d.h. je komplementärer zwei Anbieter sind, desto eher werden sie im Verbund aufgesucht (ebd., S. 615ff.).

Die Modelle werden für Simulationsläufe verwendet, um den Effekt des Markteintritts zu modellieren; hierbei zeigt sich, dass zwar alle Mitbewerber Marktanteile verlieren, jedoch auf der kleinräumigen Ebene diejenigen Mitbewerber die geringsten Verluste hinnehmen müssen, die hohe Komplementaritäten zu den Discountern aufweisen und in unmittelbarer Nähe zu diesen lokalisiert sind. Eine kontrafaktische Variation der Standortkonfigurationen zeigt einen U-förmigen Effekt auf die Kaufkraftverluste; demnach sind benachbarte Standorte ebenso vergleichsweise wenig betroffen wie sehr weit entfernte (ebd., S. 620ff.). Dieser Effekt wurde bereits in einigen angebotsseitigen Studien beschrieben (siehe Kap. 4.1.3).

\subsubsection{Bewertung der bisherigen Ansätze und weiterer Forschungsbedarf}

Es sind also bereits einige Ansätze zur Analyse von (positiven) Agglomerationseffekten in nachfrageseitigen Modellen formuliert worden. Diese beziehen sich fast ausschließlich nur auf den Lebensmitteleinzelhandel (Ausnahme: ARENTZE et al. 2005). Die Untersuchungen fokussieren zudem weitgehend die Ballung kompetitiver Anbieter, d.h. bilden Lokalisierungs- 
und/oder Wettbewerbseffekte ab, während Urbanisierungseffekte bzw. Kopplungspotenzial nur in zwei Studien (LI/LIU 2012, POPKOWSKI LESZCZYC et al. 2004) integriert werden.

Zudem ist anzumerken, dass der Agglomerationsgrad bzw. die räumliche Nähe - die für die Ausprägung von Agglomerationseffekten entscheidend ist - in den meisten Studien nur ansatzweise abgebildet wird. So wird z.B. in dem ansonsten sehr komplexen Modell von POPKOWSKI LESZCZYC et al. (2004) die tatsächliche „Nähe“ zu den Mitbewerbern bzw. zu den Einkaufszentren gar nicht berücksichtigt: Da nur die kompetitiven Anbieter in den gesamten Gemeindebezirken ausgezählt werden, kann nicht zwischen benachbarten Anbietern und weiter entfernten im selben Bezirk differenziert werden (zumal die Bezirke unterschiedlich groß sein können); das Vorkommen eines Einkaufszentrums wird dementsprechend über eine Dummy-Variable abgebildet. Das Potenzial für Kopplungs- und Vergleichskäufe wird also faktisch ohne Berücksichtigung räumlicher Nähe modelliert; selbiges gilt für ARENTZE et al. (2005) in Bezug auf Einkaufszentren. In den Untersuchungen von GIJSBRECHTS et al. (2008) und VROEGRIJK et al. (2013) werden Agglomerationseffekte ohnehin nicht direkt dargestellt, was auch nicht Ziel der Autoren ist. Das von VROEGRIJK et al. (2013) eingeführte Komplementaritätsmaß für kompetitive Anbieter stellt eine innovative Operationalisierung der sortimentsbezogenen Ergänzung von Betriebsformen dar, bildet jedoch keine Konzentration ab; es bezieht sich zudem nur auf die Kombination von zwei Verkaufsstellen.

Eine differenzierte Betrachtung der kleinräumigen Komponenten räumlicher Märkte wird insbesondere bei LI/LIU (2012) vorgenommen, wobei die entscheidenden Neuerungen darin bestehen, dass die "Reichweite“ von Agglomerationseffekten einbezogen wird und dass neben kompetitiven auch komplementäre Anbieter berücksichtigt werden. Die Variablen zur räumlichen Konzentration beinhalten jedoch, genau wie bei POPKOWSKI LESZCZYC et al. (2004), keine Distanzgewichtung, sondern definieren alle Betriebe innerhalb bestimmter Umkreise als förderlich bzw. schädlich. In den Arbeiten von ORPANA/LAMPINEN (2003) und TIHI/ORUC (2012) wird hingegen das Konzentrationsmaß nach FOTHERINGHAM (1985) benutzt, welches das Interaktionspotenzial distanzgewichtet abbildet. Das Vorgehen von TIHI/ORUC (2012) kommt der Grundidee dieser Forschungsarbeit am nächsten, wobei hier entsprechend der Absicht der Autoren, Wettbewerbseffekte zu integrieren - nur direkte Mitbewerber in den Konzentrationsvariablen berücksichtigt werden, während andere, ggf. komplementäre Betriebsformen ausgeschlossen werden. Wie bei ORPANA/LAMPINEN (2003) beeinflusst die Konzentration in Bezug auf direkte Mitbewerber den eigenen Kundenzufluss negativ; in Verbindung mit den Erkenntnissen von GIJSBRECHTS et al. (2008) und VROEGRIJK et al. (2013) zur Komplementarität von Betriebsformen weist dies darauf hin, dass zumindest im Lebensmitteleinzelhandel bei der Analyse von Marktgebieten unter Berücksichtigung von Agglomerationseffekten zwischen Betriebsformen differenziert werden sollte.

Für die Untersuchungen von ORPANA/LAMPINEN (2003) und LI/LIU (2012) gilt außerdem die wesentliche Einschränkung, dass ihre Ergebnisse nicht auf empirischen Daten zu den Marktgebieten basieren, sondern auf (geschätzten) Gesamtumsätzen der Anbieter; der tatsächliche empirische Nachweis eines Effekts auf das Kundenverhalten kann hier also, streng betrachtet, gar nicht erbracht werden.

Nach Betrachtung der bisherigen sachrelevanten modellgestützten Untersuchungen ist festzustellen, dass insbesondere eine gleichzeitige Berücksichtigung von Urbanisierungsund Lokalisierungseffekten (d.h. Kopplungs- und Vergleichskäufe) in Marktgebietsmodellen notwendig ist; diese ist bisher nicht befriedigend geleistet worden. Zudem ist sicherzustellen, 
dass die räumliche Konzentration akkurat abgebildet wird, wozu insbesondere das Modell von FOTHERINGHAM (1985) im Stande ist, das bisher aber kaum zum Einsatz gekommen ist. Zumindest in Bezug auf den Lebensmitteleinzelhandel ist es in Anbetracht der bisherigen Ergebnisse (Wettbewerbseffekte, Komplementarität) sinnvoll, zwischen Betriebsformen zu differenzieren, was bisher in Marktgebietsanalysen unterblieben ist. Genauso ist eine Ausweitung derartiger Untersuchungen auf andere Branchen als den Lebensmittelhandel notwendig. Ein empirischer Rückgriff auf „echtes“ Einkaufsverhalten ist dabei obligatorisch. 


\section{$5 \quad$ Untersuchungsgegenstand und Methodik}

In diesem Kapitel wird auf der Grundlage der Theorien, der Marktgebietsmodelle und der Empirie zu Agglomerationseffekten im Einzelhandel der Untersuchungsgegenstand dieser Arbeit genauer dargestellt und das methodische Vorgehen erläutert. Zunächst werden der theoretische Rahmen zusammengefasst und die Untersuchungshypothesen abgeleitet. Im Anschluss wird die empirische Umsetzung der Analyse von Marktgebieten im Einzelhandel unter Berücksichtigung von Agglomerationseffekten vorgestellt.

\subsection{Aufbau der Untersuchung}

\subsubsection{Theoretischer Rahmen}

Die vorgestellten Arbeiten aus der Mikroökonomie, der Standorttheorie und dem Marketing treffen explizite Aussagen zur Existenz und Bildung von Einzelhandelsagglomerationen ungleichartiger und/oder gleichartiger bzw. kompetitiver Anbieter und dem damit verbundenen räumlichen Einkaufsverhalten (siehe Kap. 2). Die Marktgebietsmodelle bieten nicht nur einen empirischen Zugang, sondern jeweils auch eigene theoretische Inhalte zur Einkaufsstättenwahl (siehe Kap. 3.1 bzw. 3.2.2.1). Die themenrelevanten Inhalte dieser sehr heterogenen Arbeiten sollen hier zusammengeführt werden, um darauf aufbauend die eigenen Untersuchungshypothesen abzuleiten. Hierbei wird keinesfalls die Aufstellung eines universellen Erklärungsansatzes der Einkaufsstättenwahl angestrebt, sondern die Erarbeitung eines theoretischen Rahmens für diese Untersuchung, der die wesentlichen Aussagen o.g. Arbeiten integriert und die Marktgebiete von Angebotsstandorten unter Berücksichtigung von Agglomerationseffekten in den Vordergrund stellt.

Zunächst lässt sich auf der Grundlage der Theorien und der Marktgebietsmodelle eine Reihe von (konsumentenseitigen) Rahmenbedingungen des Einkaufs zusammenfassen, welche die Einkaufsstättenwahl beeinflussen:

- Das Haushaltseinkommen ist eine Determinante des Konsums jedweder Güter; es ist endlich und setzt somit dem Güterkauf selbst und den zusätzlichen wirtschaftlichen Kosten des Einkaufsvorgangs eine Obergrenze (z.B. CHRISTALLER 1933, insb. LANGE 1973). Darüber hinaus sieht LANGE darin noch eine dynamische Komponente dahingehend, dass mit steigendem Einkommen sowohl mehr als auch höherwertige Güter gekauft werden sowie dass sich die kundenseitigen Ansprüche hinsichtlich der Auswahl im Einzelhandel erhöhen

- Mindestens ebenso wichtig ist die Tatsache, dass für den Einkauf ein beschränktes Zeitbudget vorliegt und der Einkauf dahingehend mit anderen Tätigkeiten konkurriert; die zeitliche Beschränkung ist Gegenstand nahezu aller Erklärungsbeiträge zur Einkaufsstättenwahl (z.B. CHRISTALLER 1933, HufF 1962, insb. LANGE 1973)

- Zudem sind die Konsumenten unvollständig informiert, d.h. sie wissen niemals exakt über das komplette innen zur Verfügung stehende Angebot Bescheid und können die dargebotenen Alternativen nicht objektiv bzw. im ökonomischen Sinne „rational“ bewerten. Abgesehen von den frühen Raumwirtschaftstheorien (CHRISTALLER 1933, 
LÖSCH 1944) wird für die Konsumenten theorieintern stets unvollständige Information angenommen (z.B. HUFF 1962, LANGE 1973, NELSON 1970, WOLINSKY 1983)

- Die Verfügbarkeit von Verkehrsmitteln zur Durchführung eines Einkaufs stellt ein weiteres Element dar und hängt mit dem Einkommen ebenso zusammen wie mit der zur Verfügung stehenden Zeit (LANGE 1973)

- Es existiert ein grundsätzliches kundenseitiges Interesse an Einzelhandelsanbietern bzw. Angebotsstandorten mit einer großen Sortimentsbreite und -tiefe; deren "Größe“ wirkt somit für die Konsumenten attraktivitätssteigernd, was insbesondere in den standorttheoretischen Ansätzen und den Marktgebietsmodellen ein zentrales Erklärungsmoment darstellt (z.B. HUFF 1962, LANGE 1973). Dies hat mehrere Gründe: Einerseits ist die für den Einkauf zur Verfügung stehende Zeit begrenzt, so dass aus Zeitmangel stets eine gewisse Menge an Gütern im Zuge eines Einkaufs erworben werden muss, andererseits besteht ein Anspruch hinsichtlich der Auswahl an Produktvarianten. Da die Sortimentsbreite/-tiefe definiert, wie viele Güter im Zuge eines Einkaufs besorgt bzw. wie viele Produktvarianten miteinander verglichen werden können, stellt sie ein wesentliches Merkmal der Attraktivität von einzelnen Anbietern bzw. Angebotsstandorten dar (z.B. LANGE 1973, NELSON 1958). Zudem können sich die Konsumenten wegen ihrer unvollständigen Markttransparenz niemals absolut sicher sein, die gewünschten Produkte am Angebotsstandort erwerben zu können; je "größer" dieser jedoch ist, desto höher ist die Chance der Bedürfniserfüllung (z.B. BAUMOL/IDE 1956, HUFF 1962, LANGE 1973)

- Aufgrund früherer Einkaufserfahrungen, bestimmter Anbieterimages sowie Werbung und weiterer Faktoren bilden die Konsumenten zudem Präferenzen für bestimmte Produktvarianten und/oder Anbieter aus; es werden jene Anbieter bei der Einkaufsstättenwahl bevorzugt, für die oder deren Produktvarianten Präferenzen bestehen. Deren Berücksichtigung als Bedingung für die Einkaufsstättenwahl ist insbesondere Gegenstand der mikroökonomischen (z.B. CHAMBERLIN 1933, WOLINSKY 1983) und der Marketing-Ansätze (z.B. GIJSBRECHTS et al. 2008)

Da einerseits unvollständige Information und andererseits Präferenzen der Konsumenten vorliegen, handelt es sich bei der Anbieter-Nachfrager-Interaktion im Einzelhandel - in mikroökonomischer Terminologie - um einen unvollkommenen Markt (z.B. CHAMBERLIN 1933, FUJITA/THISSE 2002, LANGE 1973, WOLINSKY 1983). Hinzu kommt, dass mit Einkäufen notwendigerweise Transportkosten sowie weitere Transaktionskosten verbunden sind:

- Transportkosten fallen im stationären Einzelhandel durch die Raumüberwindung beim Einkauf, d.h. den Weg zum Angebotsstandort und zurück, an; sie werden in nahezu allen theoretischen Erklärungen der Einkaufsstättenwahl berücksichtigt und bilden insbesondere in den standorttheoretischen Ansätzen (z.B. CHRISTALLER 1933, LANGE 1973, LÖSCH 1944) sowie in den Marktgebietsmodellen (insb. HUFF 1962) eine entscheidende bzw. die wichtigste Erklärungsgröße des räumlichen Marktes. Transportkosten wirken negativ auf die Frequentierung der Anbieter bzw. Angebotsstandorte; mit steigender Entfernung sinkt der Kundenzufluss aus ihrem Marktgebiet (z.B. BAUMOL/IDE 1956, ChRISTALLER 1933, HufF 1962, LANGE 1973, LÖsCH 1944). Zudem argumentiert HUFF (1962), dass die für den Einkaufsweg 
investierte Zeit überproportional wahrgenommen wird, da sie mit anderen Tätigkeiten konkurriert (Opportunitätskosten)

- Durch z.B. die Parkplatzsuche von PKW-Kunden und den Kundenlauf in der Verkaufsstelle sind zudem unmittelbar vor und während des Einkaufs weitere Transportkosten zu verzeichnen (z.B. HUFF 1962, GIJSBRECHTS et al. 2008, WOLINSKY 1983)

Der andere Teil der Transaktionskosten ergibt sich aufgrund der unvollständigen Information der Konsumenten:

- Durch Recherchen zu z.B. Sonderangeboten, der Verfügbarkeit von Produkten oder den Öffnungszeiten entstehen vor dem Einkauf Informationsbeschaffungskosten (z.B. NELSON 1970). Anbieter mit einer großen Sortimentsbreite/-tiefe erhöhen die Chance der Bedürfniserfüllung und reduzieren diese Kosten (z.B. HUFF 1962, LANGE 1973)

- Während des Einkaufs fallen Suchkosten (Suche nach bestimmten Produkten bzw. Produktvarianten) und Entscheidungskosten („Qual der Wahl“) an (z.B. HUFF 1962, NELSON 1970, WOLINSKY 1983). Mit einem größeren Sortimentsumfang ist eine Steigerung der Such- und Entscheidungskosten verbunden, was die Anziehungskraft der "Größe“ für die Konsumenten wiederum einschränkt (abnehmender Grenznutzen) (z.B. BAUMOL/IDE 1956, HUfF 1962, LANGE 1973)

Die Kernaussage nahezu aller genannten Ansätze (z.B. BAUMOL/IDE 1956, GIJSBRECHTS et al. 2008, HUFF 1962, LANGE 1973) ist, dass die Einkaufsstättenwahl von nutzensteigernden und nutzenmindernden Faktoren abhängt und die Konsumenten eine Abwägung zwischen diesen treffen; alle Marktgebietsmodelle (insb. HuFF 1962) stellen diese Abwägung explizit in formalisierter Form dar. Die nutzensteigernden Faktoren bilden die Attraktivität eines Anbieters ab, während die verschiedenen Formen von Transaktionskosten nutzenmindernde Faktoren darstellen; ein nutzenminderndes Element (z.B. Transportkosten) kann durch ein nutzensteigerndes Element (z.B. Auswahl) ausgeglichen werden und umgekehrt.

In diesem Zusammenhang bildet die Möglichkeit der Tätigung von räumlich und/oder sachlich multifinalen Einkäufen ein nutzensteigerndes Element:

- Für die Kunden ist es möglich, über Kopplungskäufe bei komplementären Anbietern Transportkosten (insb. Zeit) zu sparen (z.B. An- und Abreisezeit, Parkplatzsuche). Hierzu gehören horizontale Kopplungskäufe, d.h. zwischen Gütern derselben Bedarfsstufe (z.B. gemeinsamer Einkauf von Brot und Butter, Kauf eines Computers im Elektromarkt und eines dazu passenden Computertischs im benachbarten Möbelmarkt) und vertikale Kopplungskäufe, d.h. zwischen Gütern unterschiedlicher Bedarfsstufen (z.B. Verbindung des Einkaufs von Drogerie- und Baumarktartikeln). Daher sind Angebotsstandorte, die Kopplungskäufe ermöglichen, unter sonst gleichen Bedingungen attraktiver als solitäre Verkaufsstellen (z.B. CHRISTALLER 1933, FUJITA/THISSE 2002, LÖSCH 1944, NELSON 1958; insb. LANGE 1973)

Die räumliche Nähe von branchengleichen bzw. im Wettbewerb stehenden Anbietern ermöglicht Vergleichskäufe und wirkt sich ebenso positiv auf die konsumentenseitig wahrgenommene Attraktivität aus:

- Bei Suchgütern wird für den Kauf viel Zeit investiert und ein Vergleich z.B. hinsichtlich der Qualität und des Preises während des Einkaufs in der/den Verkaufsstelle(n) 
vorgenommen (Beispiele: Suche nach Schuhen in mehreren Schuhgeschäften, Vergleich verschiedener Waschmaschinenmodelle in mehreren Elektronikmärkten); diese hier als suchgesteuerte Vergleichskäufe bezeichneten Einkäufe reduzieren den Informationsmangel der Konsumenten und umfassen das „Shopping“ im eigentlichen Sinne (z.B. FuJITA/THISSE 2002, Lösch 1944; insb. LANGE 1973, NeLsON 1958, NELSON 1970, WOLINSKY 1983)

- Güter des kurzfristigen Bedarfs (v.a. Nahrungsmittel) sind meist Erfahrungsgüter und unterliegen zudem einem sehr hohen Grad der Standardisierung; ihr Vergleich findet i.d.R. nicht in der Verkaufsstelle statt, sondern nach dem Kauf. Da diese Güter aber regelmäßig erworben werden, wird nicht im Zuge jedes Kaufs neu verglichen (NELSON 1970); eine „Suche“ im o.g. Sinne findet hier also nicht statt. Der Besuch mehrerer kompetitiver Anbieter im Zuge eines Einkaufs (z.B. Lebensmittelmärkte) kann eine Form der Mehrfachorientierung sein, die darauf fußt, dass Konsumenten auf der Basis ihrer Erfahrungen Präferenzen für bestimmte Produktkategorien bei jeweiligen Anbietern ausbilden (Beispiel: Brot von Anbieter X, Butter von Anbieter Y). Bei einem Einkauf werden diese Anbieter miteinander verbunden, um den persönlichen Warenkorb im Sinne der eigenen Präferenzen zu optimieren (z.B. GIJSBRECHTS et al. 2008, VROEGRIJK et al. 2013); da zumindest in der Vergangenheit ein Vergleich stattgefunden hat, werden diese Käufe hier als präferenz- und erfahrungsgesteuerte Vergleichskäufe bezeichnet

- Alternativ kann die Mehrfachorientierung auch die Folge einer systematischen Wahrnehmung von Sonderangeboten verschiedener Anbieter auf der Basis von Vorinformationen sein (Cherry-Picking) und in einem räumlich multifinalen Einkauf resultieren (z.B. GAURI et al. 2008, POPKOWSKI LESZCZYC et al. 2004); hier findet ein (Preis-)Vergleich vor dem Einkauf statt, so dass diese Käufe hier als angebotsgesteuerte Vergleichskäufe bezeichnet werden

Die fünf aufgezeigten räumlichen Einkaufsstrategien schließen sich nicht gegenseitig aus; so können beispielsweise Vergleichskäufe zugleich auch zeitsparend sein oder Kopplungskäufe sich an Präferenzen orientieren. Bei Kopplungs- und Vergleichskäufen ist für die miteinander verbundenen Anbieter eine räumliche Nähe zueinander nicht zwingend vorausgesetzt; diese erleichtert jedoch die gemeinsame Frequentierung bzw. spart Transportkosten. Daher wirkt die Möglichkeit von Kopplungs- und Vergleichskäufen als zusätzlicher Attraktivitätsfaktor einzelner Anbieter. Die Konsumenten sind unter diesen Bedingungen bereit, beim Einkauf größere Transportkosten in Kauf zu nehmen, d.h. weitere Einkaufswege zurückzulegen und mehr Zeit zu investieren, als sie dies für den Besuch eines einzelnen Anbieters tun würden (z.B. LANGE 1973, NELSON 1958, WOLINSKY 1983). Es wirken also Agglomerationsvorteile im Einzelhandel, die nachfrageseitig sind, da sie auf Konsumentenverhalten beruhen:

- Anbieter in Agglomerationen können unter ansonsten gleich bleibenden Bedingungen größere Kundenströme aus ihrem Marktgebiet generieren als nicht-agglomerierte Anbieter. Eine Standortwahl in räumlicher Nähe zu Anbietern anderer Branchen ist daher für Einzelhandelsbetriebe sinnvoll, wenn sie hinsichtlich ihrer Sortimente komplementär sind und somit Kopplungskäufe ermöglichen; in diesem Fall wirken positive Urbanisierungseffekte (z.B. CHRISTALLER 1933, LANGE 1973, LÖSCH 1944, NELSON 1958). Die räumliche Nähe zu gleichartigen bzw. kompetitiven Anbietern ist vorteilhaft, wenn positive Lokalisierungseffekte aufgrund der Möglichkeit von 
Vergleichskäufen die zwischen Konkurrenten auftretenden Wettbewerbseffekte überlagern (z.B. NELSON 1958, NELSON 1970, WOLINSKY 1983). Auch zwischen kompetitiven Anbietern kann es also eine Komplementarität geben (z.B. VROEGRIJK et al. 2013). Nur für vollständig substituierbare Anbieter standardisierter Güter ist hingegen die Konkurrenzmeidung vorteilhaft, um eine monopolähnliche Stellung zu erreichen (z.B. CHAMBERLIN 1933, LÖSCH 1944)

- Aufgrund dieser Agglomerationsvorteile ballen sich Anbieter an bestimmten Angebotsstandorten, während in Solitärlagen Angebot abgebaut wird. Das Resultat sind räumliche Disparitäten des Angebots auf mehreren Maßstabsebenen, die sich zirkulär-kumulativ verstärken können (z.B. CHRISTALLER 1933, FUJITA/THISSE 2002, LÖSCH 1944, WOLINSKY 1983; insb. LANGE 1973)

Die dargestellten Zusammenhänge lassen sich bezüglich des hier im Mittelpunkt stehenden räumlichen Einkaufsverhaltens in vier aufeinander aufbauende Aussagen zusammenfassen:

1. Die Einkaufsstättenwahl stellt das Ergebnis einer (impliziten) Abwägung der nutzensteigernden (Attraktivität) und der nutzenmindernden Eigenschaften (Transaktionskosten) der zur Verfügung stehenden Alternativen dar

2. Einzelhandelsagglomerationen reduzieren die bei Einkäufen anfallenden Transportkosten sowie weitere Transaktionskosten und ermöglichen eine bessere Erfüllung der konsumentenseitigen Ansprüche und Präferenzen

3. Unter ansonsten gleichen Bedingungen bevorzugen die Konsumenten jene Einzelhandelsanbieter, die aufgrund ihrer räumlichen Nähe zu anderen Anbietern die Möglichkeit von Kopplungs- und/oder Vergleichskäufen bieten. Sie sind zur Wahrnehmung dieser Anbieter zudem bereit, längere Einkaufswege zu akzeptieren

4. Anbieter in Agglomerationen können unter ansonsten gleichen Bedingungen größere Kundenströme aus ihrem Marktgebiet generieren als nichtagglomerierte Anbieter

\subsubsection{Ableitung von Untersuchungshypothesen}

Die Ziele des empirischen Teils dieser Arbeit sind die Prüfung, ob agglomerierte Einzelhandelsanbieter größere Marktgebiete generieren können und die Überführung der Ergebnisse in ein Marktgebietsmodell. Auf der Grundlage des theoretischen Konzeptes (Kap. 5.1.1) lassen sich Untersuchungshypothesen ableiten, die in einer ökonometrischen Analyse empirischer Marktgebiete geprüft werden sollen. Da die Eigenanziehungskraft von Anbietern elementarer Bestandteil von Marktgebietsmodellen ist und in jedem Fall als Kontrollgröße fungieren müsste, um die Agglomerationseffekte zu isolieren, beziehen sich die ersten beiden Hypothesen hierauf. Ausgehend von den theoretischen Arbeiten besteht die Attraktivität eines Einzelhandelsbetriebes maßgeblich in dessen Sortimentsbreite und -tiefe.

$H_{1 a}$ : Die Sortimentsbreite und -tiefe von Einzelhandelsanbietern wirken positiv auf die Kundenströme aus dem Marktgebiet

Mit einer größeren Sortimentsbreite und -tiefe bzw. größeren internen Kopplungs- und Vergleichsmöglichkeiten steigen aber zugleich auch die Transaktionskosten des Einkaufs 
aufgrund des anbieterinternen Mehraufwandes (Such- und Entscheidungskosten, Kundenlauf etc.); der Größeneffekt birgt daher auch einen Nachteil. Die Kundenzuflüsse eines Anbieters steigen daher nicht linear-proportional mit der Größe an, sondern werden um den nachteiligen Effekt nach unten korrigiert.

\section{$H_{1 b}$ : Der positive Effekt der Sortimentsbreite und -tiefe ist unterlinear}

Die konsumentenseitig zu tragenden Transportkosten stellen den Hauptteil der mit einem Einkauf verbundenen Transaktionskosten dar; je höher die Transportkosten, desto geringer müssen demnach unter ansonsten gleichbleibenden Bedingungen die Kundenzuflüsse eines Anbieters aus dem Marktgebiet sein.

\section{$\mathbf{H}_{2 \mathrm{a}}$ : Die konsumentenseitig zu tragenden Transportkosten wirken negativ auf die Kundenströme aus dem Marktgebiet}

Ein Einkauf bzw. eine Einkaufsfahrt benötigt eine gewisse Zeit, die für andere Tätigkeiten nicht mehr aufgewendet werden kann (Opportunitätskosten); die Transportkosten werden daher überproportional als Belastung wahrgenommen bzw. eingeschätzt.

\section{$\mathrm{H}_{2 \mathrm{~b}}$ : Der negative Effekt der konsumentenseitig zu tragenden Transportkosten ist überlinear}

Die ersten vier Hypothesen entsprechen somit den theoretischen Überlegungen von HUFF (1962), die er in seinem Marktgebietsmodell umsetzt. Die übrigen sieben Hypothesen beziehen sich auf den inhaltlichen Kern der Untersuchung, d.h. auf die Attraktivitätswirkung von Einzelhandelsagglomerationen. In den (Standort-)Theorien herrscht Einigkeit darüber, dass Kopplungskäufe fester Bestandteil des räumlichen Einkaufsverhaltens sind, da hierdurch Transportkosten bzw. Einkaufszeit gespart werden können. Auch empirisch lassen sich Kopplungskäufe am Angebotsstandort nachweisen (siehe Kap. 4.2.1). Daher muss sich die Möglichkeit von Kopplungskäufen durch die Nähe zu ungleichartigen bzw. komplementären Anbietern positiv auf die Einkaufsstättenwahl der Konsumenten bzw. den Kundenzufluss auswirken (Urbanisierungsvorteile).

$\mathrm{H}_{3 a}$ : Die räumliche Nähe zu Einzelhandelsanbietern anderer Branchen wirkt positiv auf die Kundenströme aus dem Marktgebiet

Den anbieterinternen Kopplungs- und Vergleichsmöglichkeiten (Sortimentsbreite und -tiefe) wird ein nur unterlinear positiver Effekt zugesprochen, was auf den mit größerem Angebot ebenso steigenden Such- und Entscheidungskosten basiert (siehe oben). Das Aufsuchen weiterer Anbieter ist stets mit zusätzlichen Transaktionskosten dieser Art (sowie weiteren Transportkosten) verbunden. Daher ist es plausibel, auch für externe Kopplungs- und Vergleichsmöglichkeiten einen unterlinear positiven Effekt anzunehmen.

$\mathrm{H}_{3 \mathrm{~b}}$ : Der positive Effekt der räumlichen Nähe zu anderen Anbietern ist unterlinear

Wie im vorigen Kapitel besprochen wurde, ist auch die räumliche Nähe zu branchengleichen bzw. kompetitiven Anbietern vorteilhaft (Lokalisierungsvorteile), da sie - je nach Angebotstyp bzw. Sortimentsbereich - suchgesteuerte, präferenzgesteuerte oder angebotsgesteuerte Vergleichskäufe ermöglicht.

$\mathrm{H}_{4 \mathrm{a}}$ : Die räumliche Nähe zu Einzelhandelsanbietern der gleichen Branche (Mitbewerber) wirkt positiv auf die Kundenströme aus dem Marktgebiet 
Analog zum hypothetischen Effekt der Urbanisierungsvorteile wird aufgrund steigender Transaktionskosten durch den Besuch mehrerer Anbieter ebenso ein unterlinear positiver Effekt der Nähe zu Anbietern der gleichen Branche erwartet.

\section{$\mathbf{H}_{4 \mathrm{~b}}$ : Der positive Effekt der räumlichen Nähe zu Einzelhandelsanbietern der gleichen Branche ist unterlinear}

Entscheidungen für die Einkaufsstätte stellen Abwägungen zwischen nutzensteigernden und nutzenmindernden Faktoren dar; diese sind miteinander substituierbar. In den besprochenen Theorien wird einvernehmlich die Aussage vertreten, dass die Möglichkeit von Kopplungs-/ Vergleichskäufen als Attraktivitätsmerkmal einzelner Anbieter $\left(\mathrm{H}_{3 \mathrm{a}, \mathrm{b}}, \mathrm{H}_{4 \mathrm{a}, \mathrm{b}}\right)$ die Konsumenten veranlassen kann, hierfür höhere Transportkosten auf sich zu nehmen, um von den Agglomerationen zu profitieren (Vergleichskäufe) und ggf. insgesamt Transport-/ Transaktionskosten zu sparen (Kopplungskäufe). Die negative Wirkung der An- und Abreise(zeit) zu Anbietern $\left(\mathrm{H}_{2 \mathrm{a}}, \mathrm{H}_{2 \mathrm{~b}}\right)$ ist demnach umso geringer, je mehr Kopplungs- und Vergleichskäufe am Angebotsstandort möglich sind. Wenn nun in einem Modell zur Einkaufsstättenwahl keine Agglomerationseffekte berücksichtigt werden (was der Regelfall ist), finden sich die daraus herrührenden Attraktivitätsunterschiede indirekt in der Wirkung der anderen Größen (insb. der Transportkosten) wieder. Der negative Effekt der Transportkosten wäre dann schwächer ausgeprägt als er es eigentlich ist, da er implizit die (positiven) Agglomerationseffekte beinhaltet. Folgerichtig muss in einem Modell, das Agglomerationseffekte berücksichtigt, die negative Wirkung der Transportkosten stärker sein als in einem Vergleichsmodell ohne Agglomerationseffekte.

\section{$\mathrm{H}_{5}$ : Der negative Effekt der Transportkosten ist stärker, wenn im Modell zugleich der Effekt der Möglichkeit von Kopplungs- und Vergleichskäufen berücksichtigt wird}

Die o.g. Hypothesen zur Konkurrenznähe $\left(\mathrm{H}_{4 a}, \mathrm{H}_{4 b}\right)$ berücksichtigen noch keine Unterschiede zwischen den Betriebsformen der Anbieter. Aus dem Blickpunkt von heterogenen Kundenpräferenzen und dem betriebsformenspezifischen Zusammenspiel verschiedener Formen von Transaktionskosten leiten GIJSBRECHTS et al. (2008) bzw. VROEGRIJK et al. (2013) her, dass der Agglomerations- bzw. Wettbewerbseffekt von Anbietern der gleichen Branche entscheidend von der Komplementarität ihrer Betriebsformen abhängig ist; demnach müssten Anbieter ungleicher Betriebsformen zueinander eher komplementär und somit für Vergleichskäufe deutlich besser geeignet sein als jene, die im intraformalen Wettbewerb zueinander stehen. In einigen Marktgebietsanalysen (ORPANA/LAMPINEN 2003, TIHI/ORUC 2012) wird ein negativer Effekt der räumlichen Nähe zu Konkurrenten der gleichen Betriebsform nachgewiesen, die Wirkung der Nähe zu Anbietern anderer Betriebsformen wurde jedoch noch nie überprüft. Zumindest in Bezug auf den Lebensmitteleinzelhandel müssen diese Unterschiede daher Berücksichtigung finden, wobei für Anbieter derselben Branche und Betriebsform ein (negativer) Wettbewerbseffekt angenommen wird.

\section{$\mathrm{H}_{6 \mathrm{a}}$ : Die räumliche Nähe zu Einzelhandelsanbietern der gleichen Branche und der gleichen Betriebsform wirkt negativ auf die Kundenströme aus dem Marktgebiet}

Dementsprechend sind aufgrund der Agglomeration mit konkurrierenden Anbietern anderer Betriebsformen positive Effekte auf den Kundenzufluss zu erwarten, da diese zueinander eher komplementär sind. 


\section{$H_{6 b}$ : Die räumliche Nähe zu Einzelhandelsanbietern der gleichen Branche und einer anderen Betriebsform wirkt positiv auf die Kundenströme aus dem Marktgebiet}

\subsubsection{Umsetzung in ein Marktgebietsmodell und Operationalisierung}

Die aufgestellten Hypothesen lassen sich mit Hilfe eines empirisch-ökonometrischen Marktgebietsmodells überprüfen, das die Interaktionswahrscheinlichkeit bzw. den lokalen Marktanteil eines Anbieters als Zielgröße hat (siehe Formel 28). Hierbei besteht der Anspruch, beide beschriebenen Effekte (Urbanisierungs- und Lokalisierungseffekte) in ein Modell zu integrieren und so zu operationalisieren, dass sowohl die räumliche Nähe selbst als auch die Attraktivität der potenziellen Kopplungs- und Vergleichsmöglichkeiten widergespiegelt wird; ein solcher Schritt ist bisher noch nicht vollzogen worden (siehe Kap. 4.2.2). Der deterministische Teil der Nutzenfunktion (siehe Formel 29) besteht dann aus den vier Teilnutzen, die Gegenstand der Hypothesen sind (Eigenattraktivität des Anbieters, Transportkosten, Nähe zu anderen Anbietern, Nähe zu branchengleichen Anbietern); deren empirisch ermittelte Parameter zeigen einerseits die Richtung und andererseits die Größe ihrer Wirkung auf die Einkaufsentscheidungen bzw. Marktgebiete, wodurch die einzelnen Hypothesen verifiziert oder falsifiziert werden.

$$
p_{i j}=\frac{U_{i j}}{\sum U_{i j}}
$$

$\mathrm{p}_{\mathrm{ij}}=$ Interaktionswahrscheinlichkeit/Marktanteil von Nachfrageort i für Anbieter $\mathrm{j}$

$\mathrm{U}_{\mathrm{ij}}=$ (Deterministischer) Nutzen des Anbieters $\mathrm{j}$ für die Konsumenten in Nachfrageort i

$$
U_{i j}=f\left(A_{j}, d_{i j}, K_{A_{j}}, K_{K_{j}}\right)
$$

$\mathrm{A}_{\mathrm{i}}=$ Eigenattraktivität des Anbieters $\mathrm{i}$

$d_{i j}=$ Transportkosten für den Weg von Nachfrageort i zu Anbieter j

$\mathrm{K}_{\mathrm{Aj}}=$ Räumliche Konzentration des Anbieters j mit anderen Einzelhandelsanbietern

$\mathrm{K}_{\mathrm{Kj}}=$ Räumliche Konzentration des Anbieters j mit branchengleichen (konkurrierenden) Einzelhandelsanbietern

Gegenstand der empirischen Arbeit sind die Einkaufsorientierung bei bzw. die Marktgebiete von Lebensmittelmärkten, Elektronikmärkten, Baumärkten sowie Möbel- und Einrichtungsmärkten in einem Gebiet mit sieben Gemeinden (davon drei Mittelzentren) in Südniedersachsen/Ostwestfalen (siehe Kap. 5.2.1). Somit werden die Ansätze, die sich bis dato allein auf den Lebensmitteleinzelhandel beschränkt haben (siehe Kap. 4.2.2), um Angebotstypen bzw. Sortimentsbereiche des mittel- und langfristigen Bedarfs erweitert. Zudem handelt es sich hierbei um Branchen, deren Betriebsformen bzw. neue Verkaufsstellen zumeist großflächig sind und daher hinsichtlich ihrer raumordnerischen und städtebaulichen Auswirkungen (siehe Kap. 1.3.2) eine wichtige Rolle in der planungsrechtlichen Beurteilung von Neuansiedlungen spielen.

In der vorliegenden Arbeit wird ein $\mathrm{MCl}$-Modell zur ökonometrischen Analyse empirischer Marktgebiete verwendet. Hierfür spricht einerseits, dass das Modell in statistischer Hinsicht vergleichsweise einfach handhabbar ist, da es letztlich auf der linearen Regressionsanalyse bzw. dem Verfahren der Kleinste-Quadrate-Schätzung beruht, deren Parameterermittlung 
und Modellgütekriterien ausführlich dokumentiert und sicher interpretierbar sind. Da das MCl-Modell (auch) aus dem HuFF-Modell entwickelt wurde, fungieren dessen inhaltliche Aussagen zudem als Interpretationsmuster für MCI-Modellanalysen, was insbesondere die inhaltliche Interpretation der geschätzten Parameter betrifft. Eine MCl-Modellanalyse ermöglicht also die direkte Überprüfung aller Hypothesen. Umgekehrt sind die Ergebnisse von MCl-Modellanalysen unmittelbar in das HuFF-Modell überführbar, das im Kontext der betrieblichen Standortplanung und vor allem regelmäßig in Gutachten zur Verträglichkeit von Einzelhandelsansiedlungen eingesetzt wird; das MCl-Modell bildet also wiederum einen Analyserahmen für das HuFF-Modell. Die Analyse bzw. die Hypothesen beziehen sich hierbei nicht auf individuelles, sondern auf aggregiertes Einkaufsverhalten; ersteres ist mit dem MCl-Modell zwar grundsätzlich möglich, jedoch mit Schwierigkeiten verbunden (Lücken in der Interaktionsmatrix, siehe Kap. 3.3.1.2), so dass hier, wie bei MCI-Anwendungen üblich (z.B. GonZÁLEZ-BEnito et al. 200, KuBIS/HARTMANN 2007, SuÁREZ-VEGA et al. 2011, TIHI/ORUC 2012), mit lokalen Marktanteilen $\left(p_{i j}\right)$ gearbeitet wird.

Es stellt sich nun die Frage, wie die theoretischen Konstrukte, von denen in den Hypothesen ein maßgeblicher Einfluss auf das räumliche Einkaufsverhalten angenommen wird, in Indikatoren übersetzt und für die konkrete empirische Analyse operationalisiert werden. Im HUFF-Modell wird die Eigenattraktivität von Anbietern $\left(A_{j}\right)$ mit ihrer Sortimentsbreite/-tiefe bzw. den internen Kopplungs- und Vergleichsmöglichkeiten erklärt und mit der Verkaufsfläche der Anbieter operationalisiert; die Verwendung dieser Variable ist äußerst sinnvoll, da es deutlich aufwendiger ist, die Sortimentsbreite bzw. -tiefe anderweitig zu bestimmen (siehe Kap. 3.2.2.2). Im Einklang mit dem HUFF-Modell sowie anderen empirischökonometrischen Arbeiten zu Marktgebieten mit MCI-Modellen (z.B. KUBIS/HARTMANN 2007, SUÁREZ-VEGA et al. 2011) oder diskreten Entscheidungsmodellen (z.B. ARENTZE et al. 2005) wird auch hier die Attraktivität von Anbietern $\left(A_{j}\right)$ durch ihre Verkaufsfläche ausgedrückt.

Die Transportkosten werden, ebenso entsprechend dem HUFF-Modell, mit der PKW-Fahrtzeit von den Wohnorten der Kunden zu den Anbietern operationalisiert $\left(d_{i j}\right)$; hiermit wird also, nach den theoretischen Überlegungen von HUFF, der Zeitverlust des Einkaufsweges (Opportunitätskosten) ausgedrückt. Dies soll nicht unterstellen, dass für jeden Einkauf ein PKW genutzt wird, jedoch wird davon ausgegangen, dass die Raumüberwindung in jedem Fall „Zeit kostet“ und diese nicht nur von der räumlichen Distanz, sondern auch von der tatsächlichen Verkehrsführung abhängig ist. In methodisch ähnlich gelagerten Arbeiten werden außer der PKW-Fahrtzeit (z.B. SUÁREZ-VEGA et al. 2011) auch die räumliche (Straßen-)Distanz (z.B. POPKOWSKI LESZCZYC et al. 2004) oder die euklidische Distanz (Luftlinie) genutzt (z.B. VROEGRIJK et al. 2013). Für die Nutzung der Fahrtzeit als Indikator sprechen allerdings einerseits die theoretische Begründung und andererseits ihr höherer Erklärungsgehalt; der Zusammenhang zwischen PKW-Fahrtzeit und der unter Nutzung des ÖPNV wird vor diesem Hintergrund separat geprüft.

Die Abbildung der Kopplungs- bzw. Vergleichsmöglichkeiten erfolgt auf der Grundlage der Idee von FOTHERINGHAM (1985), wonach die räumliche Nähe zu anderen Anbietern durch eine Konzentrationsvariable ausgedrückt wird, in die alle anderen Anbieter mit einem Attraktivitätsmaß und der Entfernung zu ihnen einfließen (siehe Kap. 3.2.3). Diese Agglomerationsvariablen beinhalten also in ähnlicher Weise wie die Marktgebietsmodelle eine Abwägung zwischen der Eigenattraktivität anderer Anbieter und dem Weg zu innen und bilden somit eine Nutzenfunktion. Anders als durch Dummy-Variablen oder die Anzahl von 
Anbietern (z.B. POPKOWSKI LESZCZYC et al. 2004) oder Distanzen zum nächstliegenden Anbieter lässt sich durch die Berücksichtigung aller jeweils relevanten Anbieter und der (exponentiell gewichteten) Distanz das Konstrukt „Agglomeration“ als Kontinuum ausdrücken, wobei der Nutzen durch andere Anbieter umso höher ist, je näher und attraktiver diese sind. Die ursprüngliche Formulierung von FOTHERINGHAM bezog sich nur auf die räumliche Nähe zu Mitbewerbern und wurde bisher auch nur hierfür genutzt (z.B. TIHI/ORUC 2012). Da sowohl die räumliche Nähe zu gleichartigen/kompetitiven Anbietern als auch die Nähe zu anderen Anbietern in einem Modell abgebildet werden sollen, werden zwei Konzentrationsvariablen gebildet; die erste $\left(K_{A j}\right)$ bildet die räumliche Nähe zu anderen Anbietern und somit das Potenzial für Kopplungskäufe ab, während die zweite $\left(K_{K j}\right)$ die Nähe zu Mitbewerbern, also das Potenzial für Vergleichskäufe, abbildet. Als Attraktivitätsmaß wird ebenso die Verkaufsfläche der Anbieter und als Distanzmaß die Straßenentfernung genutzt.

Tabelle 3 zeigt eine Gegenüberstellung der in das Modell einfließenden erklärenden Variablen und ihres theoretisch-inhaltlichen Hintergrundes.

\begin{tabular}{|c|c|c|c|c|}
\hline \multicolumn{4}{|c|}{ Element der Nutzenfunktion } & \multirow{2}{*}{$\begin{array}{l}\text { Hypothetische } \\
\text { Wirkung }\end{array}$} \\
\hline Theoretisches Konstrukt & Indikator & Modellvariable & Operationalisierung & \\
\hline $\begin{array}{l}\text { Attraktivität durch interne } \\
\text { Kopplungs- und } \\
\text { Vergleichsmöglichkeiten } \\
\text { (Sortimentsbreite/-tiefe) }\end{array}$ & $\begin{array}{l}\text { Größe des Angebotes } \\
\text { (Sortimentsbreite } \\
\text { und -tiefe) von }\end{array}$ & $A_{j}$ & $\begin{array}{l}\text { Verkaufsfläche des } \\
\quad \text { Anbieters } j\end{array}$ & $\begin{array}{l}\text { unterlinear positiv } \\
\qquad\left(\mathrm{H}_{1 \mathrm{a}}, \mathrm{H}_{1 \mathrm{~b}}\right)\end{array}$ \\
\hline $\begin{array}{c}\text { Transaktionskosten des } \\
\text { Einkaufs }\end{array}$ & Anbieter $j$ & & & \\
\hline $\begin{array}{l}\text { Transaktionskosten des } \\
\text { Einkaufs }\end{array}$ & $\begin{array}{l}\text { Opportunitätskosten } \\
\text { der Einkaufsfahrt von } \\
\text { Ort i zu Anbieter j }\end{array}$ & $d_{i j}$ & $\begin{array}{l}\text { Fahrtzeit von Ort i zu } \\
\text { Anbieter } j\end{array}$ & $\begin{array}{c}\text { überlinear negativ } \\
\left(\mathrm{H}_{2 \mathrm{a}}, \mathrm{H}_{2 b}\right) \text {, stärker bei } \\
\text { Berücksichtigung von } \\
\mathrm{K}_{\mathrm{Aj}} \text { und } \mathrm{K}_{\mathrm{kj}}\left(\mathrm{H}_{5}\right)\end{array}$ \\
\hline $\begin{array}{l}\text { Attraktivität durch die } \\
\text { Möglichkeit von } \\
\text { Kopplungskäufen } \\
\text { (Urbanisierungsvorteile) }\end{array}$ & $\begin{array}{l}\text { Potenzial für } \\
\text { Kopplungskäufe des } \\
\text { Anbieters } j\end{array}$ & $K_{A_{j}}$ & $\begin{array}{l}\text { Konzentrationsvariable } \\
\text { für den Anbieter } j \\
\text { bezüglich allen a } \\
\text { anderen Anbietern }\end{array}$ & $\begin{array}{l}\text { unterlinear positiv } \\
\quad\left(\mathrm{H}_{3 \mathrm{a}}, \mathrm{H}_{3 \mathrm{~b}}\right)\end{array}$ \\
\hline $\begin{array}{l}\text { Attraktivität durch die } \\
\text { Möglichkeit von } \\
\text { Vergleichskäufen } \\
\text { (Lokalisierungsvorteile) }\end{array}$ & $\begin{array}{l}\text { Potenzial für } \\
\text { Vergleichskäufe des } \\
\text { Anbieters } j\end{array}$ & $K_{K_{j}}$ & $\begin{array}{l}\text { Konzentrationsvariable } \\
\text { für den Anbieter } j \\
\text { bezüglich allen } k \\
\text { anderen Anbietern }\end{array}$ & $\begin{array}{c}\text { unterlinear positiv } \\
\left(\mathrm{H}_{4 a}, \mathrm{H}_{4 b}\right), \\
\text { Unterschiede nach } \\
\text { Betriebsformen }\left(\mathrm{H}_{6 \mathrm{a}},\right. \\
\left.\mathrm{H}_{6 b}\right)\end{array}$ \\
\hline
\end{tabular}

Tabelle 3: MCI-Modellvariablen - Konstrukte, Indikatoren, Operationalisierung

Quelle: Eigene Darstellung

\subsubsection{Benötigte Daten, Form der Datenerhebung und Weiterverarbeitung}

Sämtliche in das hier genutzte $\mathrm{MCl}-$ Modell einfließenden Inhalte müssen empirisch erhoben und weiterverarbeitet bzw. anhand von sekundär erfassten Rohdaten generiert werden. Das letztendliche Ziel der Datenerhebung und -verarbeitung ist die Aufstellung einer Interaktionsmatrix mit $i$ (Nachfrageorte) $\times j$ (Anbieterstandorte) Einträgen, die entsprechend den Vorgaben der MCl-Modellanalyse aufbereitet wird (Transformation der Daten durch geometrische Mittelwerte und Logarithmieren), so dass sie der ökonometrischen Analyse mittels linearer Regression zugänglich ist (siehe Kap. 3.3.1.1). Hierbei stellen, jeweils 
transformiert, die lokalen Marktanteile $\left(p_{i j}\right)$ die abhängige (zu erklärende) Variable und die Elemente der Nutzenfunktion ( $\left.d_{i j}, A_{j}, K_{A j}, K_{K j}\right)$ die unabhängigen Variablen (Prädiktoren) dar.

Die Einkaufsentscheidungen bzw. lokalen Marktanteile werden in den meisten methodisch ähnlich gelagerten Arbeiten über Haushaltsbefragungen erhoben (z.B. POPKOWSKI LESZCZYC et al. 2004, SUÁREZ-VEGA et al. 2011, TIHI/ORUC 2012); in seltenen Fällen werden hierfür Point-of-sale-Erhebungen zur Kundenherkunft durchgeführt (z.B. KUBIS/HARTMANN 2007, O'KELLY 1999). Bei Befragungen am Angebotsstandort zur empirischen Abgrenzung von Marktgebieten ergibt sich stets das Problem, dass nur tatsächliche Besucher erfasst werden und diejenigen Konsumenten außer Acht gelassen werden, die aus verschiedenen Gründen keinen oder andere Angebotsstandorte aufsuchen; es fehlt also in jedem Fall eine Kontrollgruppe bzw. ein Teil der Einwohner des Marktgebietes. Hinzu kommt, dass die Kundenherkunft zeitlich variiert und sowohl die Größe als auch die sozio-demographische Zusammensetzung der Grundgesamtheit unbekannt sind, was die Erhebung einer im engeren Sinne repräsentativen Stichprobe praktisch unmöglich macht (HEINRITZ 1999, S. 34ff.). Daher wird zur Erhebung der Einkaufsorientierung (Einkäufe von $h$ Befragten aus allen $i$ Nachfrageorten bei allen $j$ Anbietern), die später zu lokalen Marktanteilen aggregiert $\left(p_{i j}\right)$ wird, eine Haushaltsbefragung durchgeführt.

Alle erklärenden Größen des Modells beinhalten anbieterseitige Daten; hierzu zählen neben deren Namen und Branchen ihre räumliche Referenzierung (Standort der Verkaufsstelle bzw. Adresse) und die Größe ihrer Verkaufsfläche. Die beiden letztgenannten Informationen werden sowohl für die Operationalisierung der Attraktivität der untersuchungsrelevanten Anbieter $\left(A_{j}\right)$ als auch für die jeweiligen Konzentrationsvariablen $\left(K_{A j}, K_{K j}\right)$ und die Fahrtzeiten von den Nachfrageorten zu ihnen $\left(d_{i j}\right)$ benötigt. Für die Berechnung des Kopplungspotenzials $\left(K_{A j}\right)$ kommen prinzipiell alle Verkaufsstellen des Einzelhandels im Untersuchungsgebiet in Frage; ebenso ist es notwendig, die Anbieter der im Fokus stehenden Angebotsformen erst einmal zu identifizieren. Aus diesen Gründen muss im gesamten Untersuchungsgebiet eine Vollerhebung des Einzelhandelsbestandes vorgenommen werden. Um die Daten später in Geographischen Informationssystemen (GIS) weiterverarbeiten zu können, ist es notwendig, dass diese georeferenziert (d.h. mit Koordinaten in einem räumlichen Bezugssytem) im Vektorformat (d.h. als geometrisches Objekt mit bestimmten Eigenschaften) vorliegen. Daher wird der Einzelhandelsbestand kartiert und in einer Datenbank abgelegt, die eine GISAnbindung ermöglicht. Hierbei wird, flankierend zur Erhebung vor Ort, auf Informationen aus gebiets- und themenrelevanten Sekundärquellen zurückgegriffen.

Weiterhin müssen Sekundärdaten verwendet werden, die - neben den Anbieterstandorten für die Berechnung der Fahrtzeiten $\left(d_{i j}\right)$ notwendig sind. Abgesehen davon, dass die Nachfragestandorte (Gemeinden bzw. Ortsteile) ebenso wie die Einzelhandelsanbieter georeferenziert vorliegen müssen, ist insbesondere das Vorhandensein eines Straßennetzes für das Untersuchungsgebiet notwendig. Hiermit ist es möglich, in Kombination mit den Anbieter- und Nachfragestandorten, mittels GIS-Netzwerkfunktionen Fahrtzeiten bzw. Straßendistanzen zu kalkulieren.

Tabelle 4 zeigt eine Zusammenfassung der für die Berechnung der Modellvariablen benötigten Daten, ihrer Erhebung und Weiterverarbeitung. 


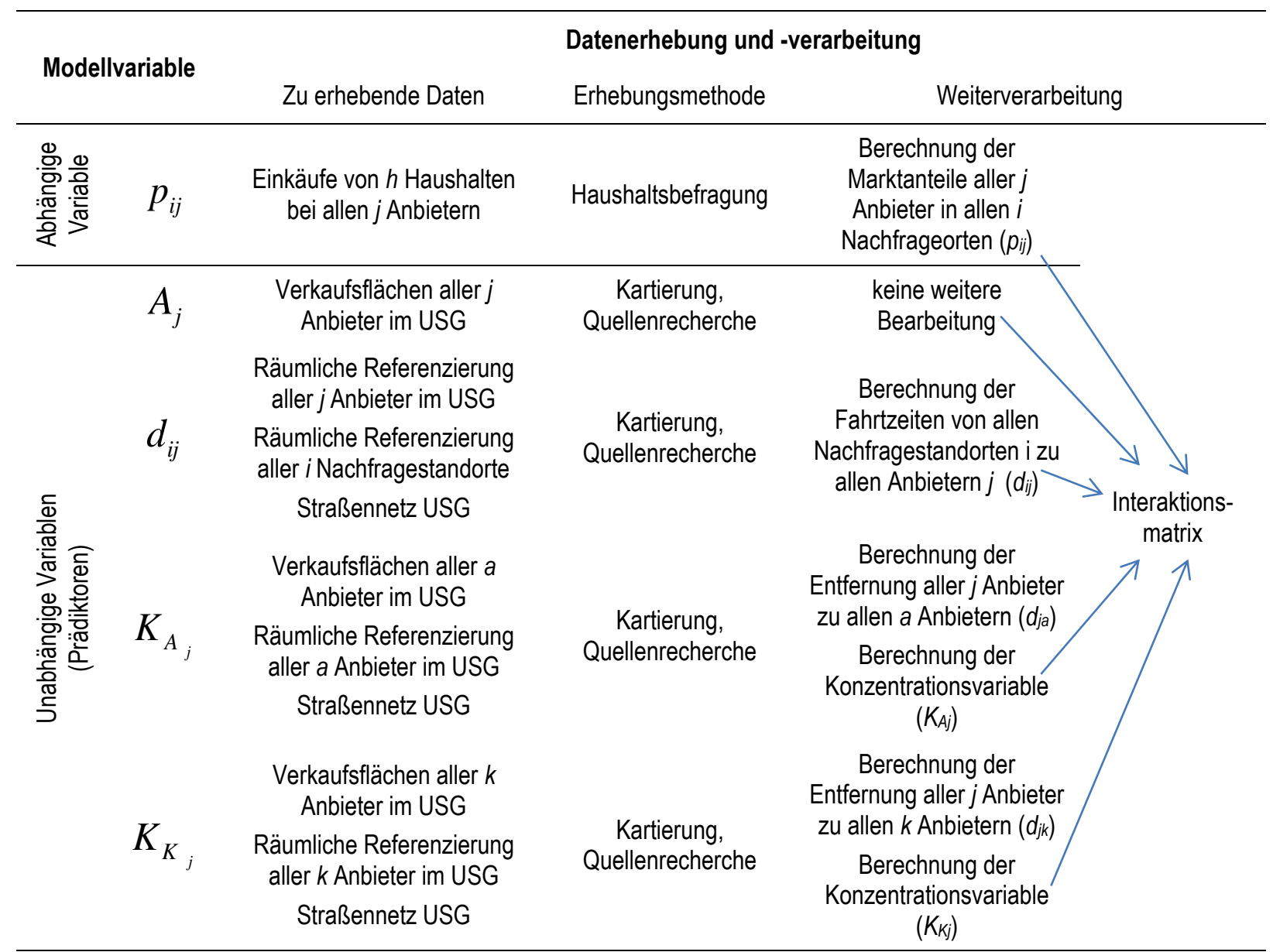

Tabelle 4: MCI-Modellvariablen - Datenerhebung und -verarbeitung

Quelle: Eigene Darstellung; USG = Untersuchungsgebiet

\subsection{Empirische Durchführung}

\subsubsection{Untersuchungsgebiet}

Im räumlichen Fokus dieser Forschungsarbeit steht der Einzelhandel in den drei angrenzenden Mittelzentren Holzminden (Landkreis Holzminden, Südniedersachsen), Höxter und Beverungen (beide Landkreis Höxter, Ostwestfalen). In diesen Gemeinden ist, zumindest aus den betrachteten Bereichen (Lebensmittelmärkte, Elektromärkte, Baumärkte, Möbelmärkte), der Großteil aller derzeit etablierten Einzelhandelsunternehmen (u.a. Aldi Nord, Edeka Gruppe, Metro Group bzw. MediaSaturn, Rewe Group, Schwarz-Gruppe, Tengelmann-Gruppe) bzw. deren Vertriebslinien vertreten. In den Kernstadtbereichen existieren typische klein-/mittelstädtische zentrale Geschäftsbereiche mit Fußgängerzonen und dezentral gelegene Gewerbegebiete mit großflächigen Einzelhandelsbetrieben verschiedenen Typs (Einkaufsparks) sowie weitere Formen von Angebotsstandorten bzw. Agglomerationen (z.B. Standortkooperation, geplantes Einkaufszentrum) (Einen Überblick zur allgemeinen Einzelhandelssituation geben insb. die kommunalen Einzelhandelskonzepte: Beverungen - STADT+HANDEL 2011, Holzminden - CIMA 2004, Höxter - JUNKER UND KRUSE 2009).

Zudem sind in diesem Gebiet seit den 2000er Jahren diverse Einzelhandelsansiedlungen geplant und/oder durchgeführt worden, die mitunter höchst umstritten waren/sind und sogar 
zu juristischen Auseinandersetzungen geführt haben: Hierzu zählen u.a. die Ansiedlungen von Media Markt in Holzminden (z.B. TAH 02.02.2008 u. 14.03.2008) und Kaufland in Höxter (z.B. NW 28.05.2009, 28.01.2011 u. 17.04.2012) sowie die geplante Verlagerung von zwei Lebensmittelmärkten (Aldi, Rewe) in eine Standortkooperation in Beverungen (z.B. NW 18.12.2010 u. 16.07.2011); das Gebiet steht also auch beispielhaft für die raumplanerische Relevanz des Struktur- und Standortwandels im Einzelhandel. Auf die lokale Situation und Entwicklung wird in der Ergebnisdarstellung (Kap. 6) weiter eingegangen.

Es stellt sich hierbei die Frage nach der exakten Abgrenzung des Untersuchungsgebietes.

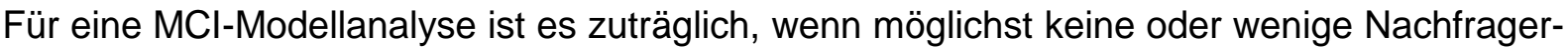
Anbieter-Interaktionen in der Interaktionsmatrix unausgefüllt bleiben, da aufgrund der Modelltransformation (geometrische Mittelwerte, Logarithmieren) keine Ausprägungen der Variablen von null oder darunter akzeptiert werden (COLOMÉ PERALES 2002, S. 67f.; COOPER/NAKANISHI 2010, S. 153ff.). Ebenso muss das Untersuchungsgebiet so definiert werden, dass der Großteil der Einkaufsinteraktionen innerhalb dieses abgegrenzten Gebietes stattfindet und dadurch Verzerrungen und ein Informationsverlust minimiert werden. Demnach sollten möglichst wenige Einkäufe der Einwohner außerhalb getätigt werden und möglichst wenige Einkaufsbesuche von außerhalb des Untersuchungsgebietes stattfinden (HUFF/MCCALLUM 2008, S. 9f.). Beide Vorgaben sind in der Praxis nur über eine Kompromisslösung umsetzbar, da die Wahrscheinlichkeit nicht ausgefüllter Zellen in der Interaktionsmatrix notwendigerweise steigt, je größer das Untersuchungsgebiet ist.

Daher wurden in der vorliegenden Untersuchung neben den drei betreffenden Gemeinden mit ihren insgesamt 29 Ortsteilen noch die Samtgemeinde Boffzen bzw. ihre fünf Ortsteile als Nachfrageorte berücksichtigt. Wie den empirischen Erhebungen aus den kommunalen Einzelhandelskonzepten und anderen Gutachten zu entnehmen ist (z.B. BULWIENGESA AG 2010, S. 23ff.; CIMA 2004, S. 51ff.; NORD/LB 2002, S. 32ff.; JUNKER UND KRUSE 2009, S. 70ff.; STADT+HANDEL 2011, S. 29ff.), sind diese Gemeinden und ihre Ortsteile über wechselseitige Einkaufsinteraktionen miteinander verbunden, wobei insbesondere die Kernstadtbereiche der drei Mittelzentren als wichtigste Einkaufsorte hervortreten. Andere angrenzende Gebietskörperschaften (z.B. Samtgemeinde Bevern im LK Holzminden, Stadt Borgentreich im LK Höxter) werden ausgeschlossen, da sie nur Bestandteile der Marktgebiete einzelner Zentren sind. Karte 1 und Tabelle 5 zeigen die räumliche Struktur und die wichtigsten Informationen zu den Untersuchungsgemeinden.

Das Untersuchungsgebiet besteht demnach aus sieben Gemeinden, von denen drei in den jeweiligen Landesraumordnungsprogrammen (LROP Niedersachsen, LEP NordrheinWestfalen) den raumordnerischen Rang eines Mittelzentrums haben (Beverungen, Holzminden, Höxter); hinzu kommen zwei Grundzentren (Boffzen, Lauenförde) und zwei Gemeinden ohne zentralen Rang (Derental, Fürstenberg). Die Untersuchungsgemeinden gehören zu den Landkreisen Holzminden (Niedersachsen) und Höxter (NordrheinWestfalen), die in der siedlungsstrukturellen Klassifikation des BBSR als „ländlicher Raum“ klassifiziert werden (BBSR 2013a); der Landkreis Holzminden gilt hierbei als „dünn besiedelter ländlicher Kreis“, Höxter als „ländlicher Kreis mit Verdichtungsansätzen“ (BBSR 2013b). Die Gemeinden bilden nach Klassifikation des BBSR (2013c) Klein- bzw. Mittelstädte, die - mit Ausnahme Höxters - in ihrer Bevölkerungszahl schrumpfen. Insgesamt setzen sich die Untersuchungsgemeinden aus 34 Teilgebieten (Ortsteile) mit einer Bevölkerung von 70.534 Einwohnern bzw. 34.987 Haushalten zusammen. 


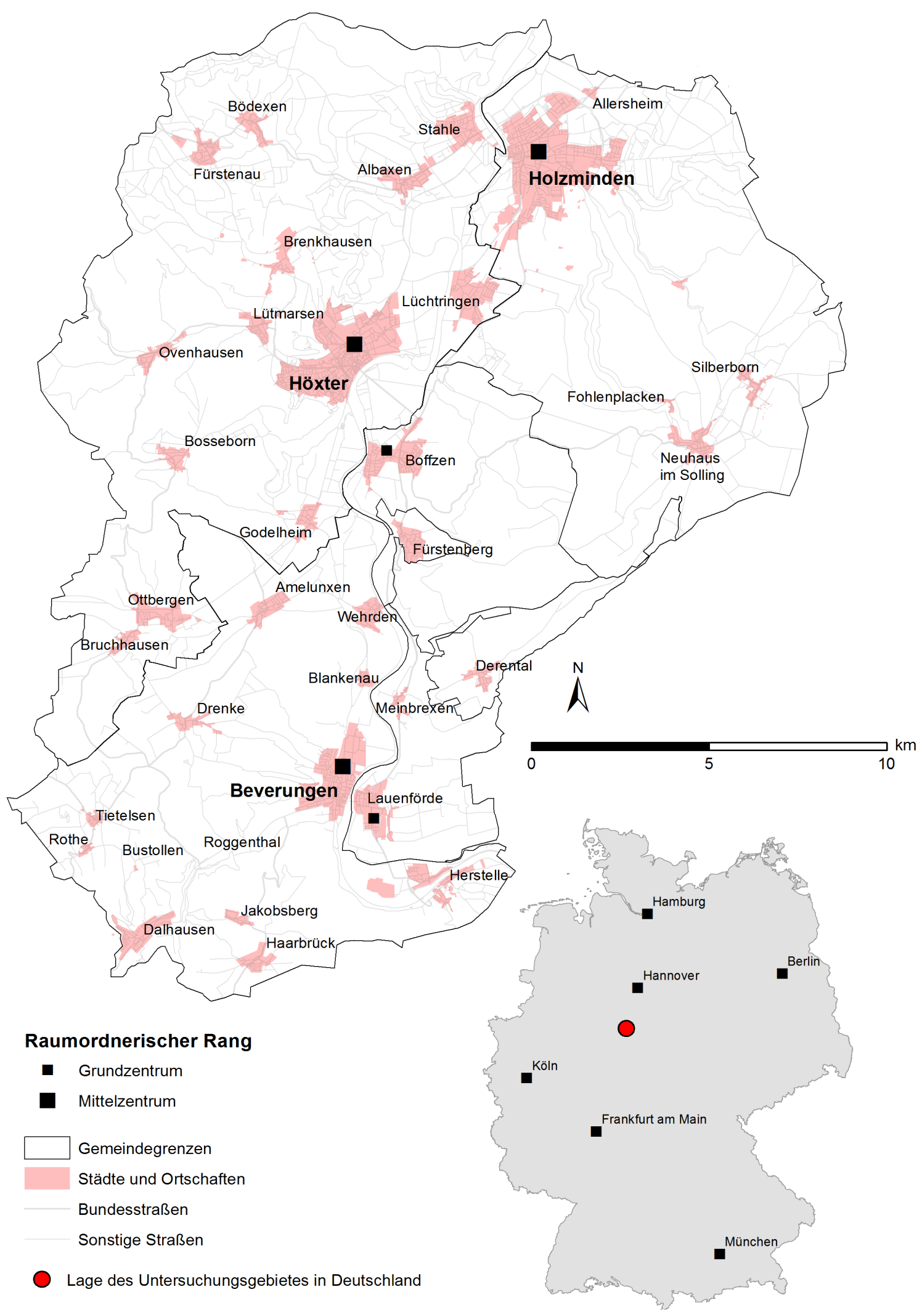

Karte 1: Lage und räumliche Struktur des Untersuchungsgebietes

Quelle: Eigene Darstellung, Datengrundlage: OpenStreetMap, Landkreis Holzminden, Bezirksregierung Detmold 
Räumliches Einkaufsverhalten und Standortpolitik im Einzelhandel unter Berücksichtigung von Agglomerationseffekten

\begin{tabular}{|c|c|c|c|c|c|c|}
\hline Gemeinde, AGS & $\begin{array}{l}\text { Kreis, } \\
\text { Bundesland }\end{array}$ & $\begin{array}{l}\text { Raumordnerischer } \\
\text { Rang (2012) }\end{array}$ & $\begin{array}{l}\text { BBR-Gemeindetyp } \\
\text { (2011) }\end{array}$ & $\begin{array}{l}\text { Ortsteile } \\
(2012)\end{array}$ & $\begin{array}{l}\text { Einwohner } \\
\text { (2012) }\end{array}$ & $\begin{array}{c}\text { Haushalte } \\
\text { (2011) }\end{array}$ \\
\hline $\begin{array}{l}\text { Beverungen } \\
\text { (05762008) }\end{array}$ & $\begin{array}{l}\text { Höxter, } \\
\text { NRW }\end{array}$ & Mittelzentrum & $\begin{array}{l}\text { Größere Kleinstadt, } \\
\text { schrumpfend }\end{array}$ & 12 & 13.811 & 6.478 \\
\hline $\begin{array}{l}\text { Boffzen, SG Boffzen } \\
(03255004)\end{array}$ & $\begin{array}{l}\text { Holzminden, } \\
\text { NDS }\end{array}$ & Grundzentrum & $\begin{array}{l}\text { Kleine Kleinstadt, } \\
\text { schrumpfend }\end{array}$ & 1 & 2.668 & \multirow[t]{2}{*}{1.657} \\
\hline $\begin{array}{l}\text { Derental, SG Boffzen } \\
\text { (03255009) }\end{array}$ & $\begin{array}{l}\text { Holzminden, } \\
\text { NDS }\end{array}$ & Kein Rang & $\begin{array}{l}\text { Kleine Kleinstadt, } \\
\text { schrumpfend }\end{array}$ & 1 & 660 & \\
\hline $\begin{array}{l}\text { Fürstenberg, SG } \\
\text { Boffzen (03255014) }\end{array}$ & $\begin{array}{l}\text { Holzminden, } \\
\text { NDS }\end{array}$ & Kein Rang & $\begin{array}{l}\text { Kleine Kleinstadt, } \\
\text { schrumpfend }\end{array}$ & 1 & 1.141 & 558 \\
\hline $\begin{array}{l}\text { Holzminden } \\
\text { (03255023) }\end{array}$ & $\begin{array}{l}\text { Holzminden, } \\
\text { NDS }\end{array}$ & Mittelzentrum & $\begin{array}{l}\text { Kleinere Mittelstadt, } \\
\text { schrumpfend }\end{array}$ & 4 & 19.835 & 10.330 \\
\hline Höxter (05762020) & $\begin{array}{l}\text { Höxter, } \\
\text { NRW }\end{array}$ & Mittelzentrum & $\begin{array}{l}\text { Kleinere Mittelstadt, } \\
\text { stabil }\end{array}$ & 13 & 29.941 & 14.746 \\
\hline $\begin{array}{l}\text { Lauenförde, SG } \\
\text { Boffzen (03255026) }\end{array}$ & $\begin{array}{l}\text { Holzminden, } \\
\text { NDS }\end{array}$ & Grundzentrum & $\begin{array}{l}\text { Kleine Kleinstadt, } \\
\text { schrumpfend }\end{array}$ & 2 & 2.478 & 1.200 \\
\hline Insgesamt & -- & -- & -- & 34 & 70.534 & 34.987 \\
\hline
\end{tabular}

Tabelle 5: Profil des Untersuchungsgebietes

Quelle: Eigene Darstellung, Datengrundlage: Landesamt für Statistik Niedersachsen, IT.NRW, MB Research, BBSR, Landkreis Holzminden, Bezirksregierung Detmold

\subsubsection{Erfassung des Einzelhandelsangebotes}

\subsubsection{Materialsammlung und Expertengespräche}

Für die Aufarbeitung der Angebotssituation im Untersuchungsgebiet wurden verschiedene Sekundärquellen recherchiert. Diese sollten einerseits eine generelle Übersicht zur einzelhandelsbezogenen Ausgangssituation im Untersuchungsgebiet liefern und andererseits als Hilfestellung für die eigene Vollerhebung des Einzelhandelsbestandes dienen.

Um einen Überblick zum Einzelhandelsbestand und dessen Entwicklung zu bekommen, wurde insbesondere auf die in mehreren Gemeinden erstellten Einzelhandelsgutachten zurückgegriffen. Hierzu zählen die kommunalen Einzelhandelskonzepte der Städte Beverungen (GMA 1999, STADT+HANDEL 2011), Holzminden (CIMA 2004) und Höxter (JUNKER UND KRUSE 2005 u. 2009) sowie mehrere im Kontext der Bauleitplanung erstellte Gutachten zur Beurteilung der Auswirkungen bzw. der Verträglichkeit von Einzelhandelsansiedlungen (BBE HANDELSBERATUNG 2007 u. 2011, BULWIENGESA AG 2010, CIMA 2010). Beide Formen von Gutachten werden von den Stadt-/Gemeinderäten als Gesamtkonzept beschlossen bzw. dem jeweiligen Bebauungsplan angehängt und im Rahmen der gesetzlich vorgeschriebenen Beteiligung der Öffentlichkeit (§ 3 Abs. 2 BauGB) publiziert. Die Einzelhandelskonzepte beinhalten Vollerhebungen des Einzelhandelsbestandes und geben somit Hinweise auf die Größe und Verteilung des Angebots, wodurch einerseits die eigene Erhebung zielgerichteter wird und andererseits eine Plausibilitätsprüfung dieser ermöglicht wird. Zumindest partiell beinhalten sie, ebenso wie die Verträglichkeitsgutachten, auch Verkaufsflächenangaben zu einzelnen Anbietern sowie weitere Informationen, z.B. zu früheren und/oder geplanten Verlagerungen. 
Ergänzend wurden aus den regionalen Tageszeitungen (TAH = Täglicher Anzeiger Holzminden, NW = Neue Westfälische Höxter/Beverungen) während der gesamten Bearbeitungszeit aktuelle Berichte zu einzelhandelsbezogenen Themen gesammelt sowie frühere Beitrage recherchiert, sofern diese öffentlich digital verfügbar waren (siehe Anhang, Tab. A 4). Als weitere Informationsgrundlage dienten die letzten (verfügbaren) Handels- und Gaststättenzählungen (HGZ) in den Untersuchungsgemeinden, die über die statistischen Landesämter Nordrhein-Westfalens bzw. Niedersachsens beschafft wurden.

$\mathrm{Zu}$ Beginn der Recherchephase wurden im Sommer 2009 zudem mehrere Expertengespräche mit lokalen Verantwortlichen aus dem Bereich der kommunalen Verwaltung (Stadtplanung) und des Stadtmarketings geführt (siehe Anhang, Tab. A 5). Diese Gespräche sollten primär den Zweck erfüllen, weitere Informationen zur Aufarbeitung der Ausgangssituation im Untersuchungsgebiet zu liefern. Gegenstand der Gespräche waren neben den allgemeinen Einzelhandelsstrukturen der Gemeinden insbesondere die Neuansiedlungen, Verlagerungen und Schließungen von (baurechtlich relevanten bzw. großflächigen) Einzelhandelsbetrieben in den Jahren zuvor sowie Anfragen und Planungen hinsichtlich zukünftiger Ansiedlungen. Die Experteninterviews wurden durch einen einfachen Gesprächsleitfaden gestützt, mitgeschnitten und im Anschluss stichwortartig transkribiert.

Ergänzend zu den anderweitigen Quellen sind durch die Interviewpartner in einigen Fällen zudem weitere relevante Informationen bereitgestellt worden. Hierzu zählen ein zum Zeitpunkt der Kontaktaufnahme nicht mehr öffentlich verfügbares Gutachten und alte Bebauungspläne zu früheren Einzelhandelsansiedlungen. In zwei Fällen lagen darüber hinaus vollständige bzw. selektiv geführte Listen des örtlichen Einzelhandelsbestandes inklusive weiterer Angaben (z.B. Adresse, Branche, Verkaufsfläche) vor.

\subsubsection{Vollerhebung und Kartierung der Einzelhandelsanbieter}

Für die Bearbeitung der vorliegenden Fragen war die Erfassung des gesamten Einzelhandelsangebotes im Untersuchungsgebiet inklusive einer Reihe von zugehörigen Anbieterinformationen, die letztendlich direkt oder indirekt in das MCl-Modell einfließen, notwendig. Um den eigenen Datensatz bei Bedarf schneller aktualisieren zu können, wurden zudem die für Einzelhandelsnutzungen geeigneten leerstehenden Geschäftsflächen ${ }^{37}$ ebenso berücksichtigt. Ferner sind auch zum Zeitpunkt der Erhebung bekannte Planungen von Einzelhandelsansiedlungen erfasst worden.

Um die Vollerhebung systematisch durchführen zu können, wurde im ersten Schritt eine tabellenbasierte Datenbank (MS Access) zu den Einzelhandelsanbietern im Untersuchungsgebiet mit den interessierenden Variablen (u.a. Name, Adresse, Branche, Verkaufsfläche, Betriebsform) erstellt (Übersicht der erfassten Informationen siehe Anhang, Abb. A 1). Jeder Datenbankeintrag (d.h. jedes aufgenommene Objekt) bekommt hierbei zudem eine individuelle ID-Nummer zugewiesen. Die Zuordnung der Branche erfolgte anhand der Wirtschaftszweigklassifikationen (WZ 2008) des Statistischen Bundesamtes, deren kleinteilige Abgrenzung später in neun Branchenkategorien zusammengefasst wurde

\footnotetext{
${ }^{37}$ Als Merkmale für eine mögliche Einzelhandelsnutzung wurden hierbei angelegt, dass dort entweder vorher nachgewiesenermaßen Einzelhandel lokalisiert war oder dass die Geschäftsfläche bestimmte einzelhandelsrelevante Kriterien (Erdgeschosslage, Schaufenster) erfüllt. In den bereits vorliegenden Listen zum Einzelhandelsbestand sind Leerstände bereits integriert gewesen.
} 
(Übersicht zu den eigenen Branchenkategorien siehe Anhang, Tab. A 6). Hierbei wurden einzelne Angebotsformen mit berücksichtigt, die in der amtlichen Statistik nicht dem Einzelhandel zugerechnet werden, jedoch aufgrund ihrer ähnlichen Anbieter-KundenInteraktion und der räumlichen Nähe zu Einzelhandelsbetrieben dieser Branche zugerechnet werden können und zumeist auch in Einzelhandelsgutachten als solche aufgenommen werden (z.B. Verkaufsstellen von Bäckereien, Metzgereien und Floristen).

Zunächst sind in die Datenbank sämtliche Betriebe und ihre relevanten Daten eingetragen worden, die bereits über die verschiedenen Einzelhandelsgutachten oder bestehende Listen (siehe Kap. 5.2.2.1) bekannt waren; hierzu zählen insbesondere viele der großflächigen Einzelhandelsbetriebe, deren Verkaufsflächen sowie weitere Informationen bereits in den vorliegenden Gutachten oder Zeitungsartikeln dokumentiert waren. Im nächsten Schritt wurden die restlichen Einzelhandelsanbieter über eigene Kartierungen erhoben. Hierbei wurden Name, Branche und Adresse im Zuge der Begehung aufgenommen und die Verkaufsflächengröße entweder beim Personal bzw. der Geschäftsführung erfragt oder - in Ausnahmefällen - selbst geschätzt. Im Zuge von Vor-Ort-Recherchen wurden zudem weitere Informationen zur örtlichen Angebotssituation und/oder einzelnen Anbietern durch Gespräche mit Einzelhändlern oder ortskundigen Repräsentanten der Gemeinden (z.B. Tourismusmarketing) generiert; hierzu zählten beispielsweise Hinweise auf schwer zu findende Anbieter in Solitärlagen oder frühere bzw. geplante Besetzungen von Leerständen.

Die Kartierung wurde mittels GPS (Global Positioning System) durchgeführt, um die räumliche Position der Objekte möglichst genau zu bestimmen und die Daten später in Geographischen Informationssystemen (GIS) weiterverarbeiten zu können. Die aus der Quellenrecherche bereits bekannten Anbieter/Geschäftsflächen wurden auf demselben Wege nachkartiert und bei Bedarf (z.B. bei Anbieterwechsel oder Geschäftsaufgabe) inhaltlich aktualisiert. Um ein möglichst realistisches Bild der Erreichbarkeit der Einzelhandelsbetriebe zu bekommen, wurde die GPS-Markierung der Anbieter auf der Höhe des Eingangs zur Geschäftsfläche bzw. zum Gebäude vorgenommen.

Die GPS-Datensätze wurden ausgelesen, in die GIS-Software ESRI ArcGIS überführt und in ein Punkt-Shapefile ${ }^{38}$ konvertiert. Mit Hilfe von öffentlich verfügbaren Satellitenbildern und Grundkarten wurden die Positionen der GPS-Markierungen bei Bedarf manuell den Gebäudeeingängen angepasst, da bei GPS-gestützten Kartierungen Ungenauigkeiten aufgrund schlechten Empfangs des Satellitensignals auftreten können. Durch die eindeutige ID-Nummer der erhobenen Objekte konnte eine Verknüpfung zwischen den räumlichen Daten (Shapefile) und den Sachdaten (Tabelle in der Datenbank) hergestellt werden, so dass im Ergebnis ein georeferenzierter Vektordatensatz (Typ Punkt) mit allen Einzelhandelsanbietern und Leerständen im Untersuchungsgebiet und den zugehörigen Anbieterinformationen zur Verfügung stand. Dieser Datensatz repräsentiert den Einzelhandelsbestand der Gemeinden im Untersuchungsgebiet vom Stand März 2012.

\footnotetext{
${ }^{38}$ Shapefiles bilden ein weitläufig etabliertes Format für vektorbasierte Geodaten und können mittlerweile von allen gängigen Geographischen Informationssystemen gelesen und weiterverarbeitet werden. Ein Shapefile besteht aus mehreren Einzeldateien, die unter anderem die räumliche Position der Objekte in einem Bezugsbzw. Projektionssystem, die damit verbundenen Sachdaten in Form einer dBASE-Tabelle, die Verknüpfung der Geo- und Sachdaten über einen eindeutigen Index sowie - optional - die Definition des Projektionssystems selbst enthalten. Die Geoobjekte, die in Shapefiles enthalten sind, können punkt-, linien- oder flächenförmig sein (zum Datenmodell der Shapefiles siehe ESRI 1998).
} 


\subsubsection{Identifikation der untersuchungsrelevanten Anbieter}

Aufbauend auf dem Datensatz mit allen Einzelhandelsanbietern im Untersuchungsgebiet mussten die untersuchungsrelevanten Anbieter, d.h. jene, deren Marktgebiete analysiert werden, identifiziert werden. Für die Abgrenzung der fokussierten Angebotstypen (Lebensmittelmärkte, Elektronikmärkte, Bau- und Heimwerkermärkte, Möbel- und Einrichtungsmärkte) wurden folgende Definitionen zu Grunde gelegt:

- Unter der Bezeichnung Lebensmittelmärkte werden hier die sog. Vollsortimenter des Lebensmitteleinzelhandels sowie Lebensmitteldiscounter zusammengefasst; diese Märkte entsprechen sich in ihrem Kerngeschäft (Güter des täglichen Bedarfs) hinsichtlich ihrer Sortimentsbreite weitgehend, unterscheiden sich jedoch in ihrer Sortimentstiefe insofern, dass diese bei LM-Discountern deutlich geringer ausgeprägt ist (LADEMANN 2013, S. 9ff.). Das Sortiment umfasst hauptsächlich, jedoch nicht ausschließlich, Nahrungs- und Genussmittel sowie Gesundheits- und Pflegeprodukte, wobei die Sortimentsbreite sämtliche Sortimentsgruppen umfasst, die nach der Klassifikation von GFK GEOMARKETING (2013) diesen Hauptgruppen zugerechnet werden $^{39}$. Die Abgrenzung der Betriebsformen wurde nach der Definition von NIELSEN (2012) vorgenommen; sie wurden in Supermärkte (klein: 100-399 qm Verkaufsfläche, groß: 400 bis 999 qm), Verbrauchermärkte (klein: 1.000 bis 2.499 qm, groß: ab 2.500 qm) und Lebensmitteldiscounter unterteilt, wobei letztere unabhängig von ihrer Verkaufsfläche aufgrund ihrer Dauerniedrigpreispolitik und ihrer begrenzten Sortimentstiefe als solche definiert werden. Hierzu zählen z.B. Aldi und Lidl (LMDiscounter), zu den Vollsortimentern z.B. Rewe und Edeka (je nach Größe Superoder Verbrauchermärkte). Anbieter mit Verkaufsflächen unter 100 qm wurden nicht als untersuchungsrelevant berücksichtigt

- Die hier als Elektronikmärkte bezeichneten Anbieter umfassen alle Verkaufsstellen dieser Branche, deren Sortimentsbreite folgende Sortimentsobergruppen der GFK GEOMARKETING (2013) abdeckt: Elektronische Haushaltsgeräte und Leuchten (Elektrogroßgeräte: z.B. Waschmaschinen und Kühlschränke, Elektrokleingeräte: z.B. Toaster und Staubsauger, Lampen und Leuchten), Unterhaltungselektronik (z.B. Fernseher, Radios und Spielkonsolen) und elektronische Medien (z.B. DVDs), Informationstechnologie (Computer, Zubehör und Software) und Telekommunikation (Telefone, Mobiltelefone und Zubehör) sowie Foto (z.B. Fotoapparate, Digitalkameras und Zubehör). Zu diesem Angebotstyp gehören in erster Linie die Fachmärkte des Elektronikeinzelhandels (z.B. Media Markt, Saturn, Expert, ProMarkt), die häufig großflächig (über 800 qm Verkaufsfläche) sind, mindestens jedoch über 500 qm Verkaufsfläche verfügen (SCHNEDLITZ et al. 2012, S. 263ff.)

- Die untersuchungsrelevanten Bau- und Heimwerkermärkte wurden anhand der Definition des zugehörigen Branchenverbandes BHB (2013) abgegrenzt; hiernach sind alle Anbieter dieser Branche als Bau- und Heimwerkermärkte zu bezeichnen, die

\footnotetext{
${ }^{39}$ Das Marktforschungsinstitut GFK GEOMARKETING (2013) differenziert für den deutschen Einzelhandel insgesamt 17 Sortimentsobergruppen, die wiederum in über 60 Untergruppen segmentiert werden. Die Obergruppe der Nahrungs- und Genussmittel umfasst 26 Untergruppen, darunter z.B. Brot- und Backwaren, Fleisch, Käse, Obst, Gemüse, Konserven, Süßwaren sowie alkoholfreie und alkoholische Getränke. Zu den Gesundheits- und Körperpflegeprodukten zählen u.a. freie medizinische Artikel, Körperpflege-, Kosmetik- und Hygieneprodukte sowie Wasch-, Putz- und Reinigungsmittel.
} 
über mindestens 1.000 qm beheizte Verkaufsfläche verfügen und schwerpunktmäßig Bau- und Heimwerker- sowie Gartenartikel anbieten. Diese Sortimentsbereiche entsprechen nach GFK GEOMARKETING (2013) der Sortimentsobergruppe der baumarktspezifischen Sortimente (u.a. Baustoffe, Werkzeuge, Farben, Tapeten, Tiernahrung und Haustierzubehör, Autozubehör sowie Pflanzen und Gartenartikel)

- Als Möbel- und Einrichtungsmärkte wurden alle Anbieter klassifiziert, deren Sortiment hauptsächlich der Sortimentsobergruppe Einrichtungsbedarf (Möbel, Haus- und Heimtextilien) der GFK GEOMARKETING (2013) zuzuordnen ist

\subsubsection{Erfassung der räumlichen Einkaufsorientierung}

\subsubsection{Auswahl der Befragungsmethode}

Um die räumliche Einkaufsorientierung im Untersuchungsgebiet auf Ortsteilebene zu erfassen, war eine Haushaltsbefragung notwendig, da bei Marktgebietserhebungen am Angebotsstandort (z.B. KUBIS/HARTMANN 2007, O'KELLY 1999) wesentliche Informationen bzw. Personengruppen nicht berücksichtigt werden (siehe Kap. 5.1.4) und der Anspruch bestand, der eigenen Modellanalyse tatsächliches Einkaufsverhalten zu Grunde zu legen und daher keine Modellkalibrierung anhand von sekundär ermittelten Umsatzdaten o.ä. (z.B. ORPANA/LAMPINEN 2003, LI/LIU 2012) vorzunehmen. Haushaltsbefragungen lassen sich telefonisch, mündlich (persönliches Interview), schriftlich-postalisch (Fragebogen per Brief) oder online (digitaler Fragebogen) durchführen. Alle vier Verfahren haben spezifische Vorund Nachteile, die u.a. den Einfluss des Interviewers, die Beschränkung der Stichprobe und die mit der Erhebung verbundenen Aufwände (Zeit, Kosten) betreffen (Überblick zu Befragungsverfahren und ihren Vor- und Nachteilen siehe z.B. BEREKOVEN et al. 2009, S. 92ff.; DiEKMANN 2008, S. 437ff.; HÄDER 2010, S. 187ff.; SCHNELL et al. 2011, S. 351ff.).

In ähnlich gearteten Untersuchungen zu Marktgebieten im Einzelhandel auf der Grundlage von empirischem Einkaufsverhalten und einer Analyse mittels HUFF-, MCl- oder diskretem Entscheidungsmodell werden zur Erfassung von Einkaufsentscheidungen bzw. Marktanteilen entweder telefonische Befragungen oder persönliche Interviews eingesetzt. Schriftlichpostalische Befragungen wie in der Grundlagenstudie von HUFF (1962) und andere Verfahren sind hierbei Ausnahmefälle (siehe Tabelle 6). Die Zielgruppe der Befragungen sind hierbei i.d.R. nicht Einzelpersonen (wie z.B. bei Wahlumfragen), sondern Haushalte.

Im vorliegenden Fall wurde eine telefonische Haushaltsbefragung durchgeführt, da für andere Befragungsformen keine finanziellen bzw. personellen Ressourcen zur Verfügung standen. Telefonische Befragungen bieten den Vorteil, dass mit gegenüber anderen Befragungsformen vergleichsweise kurzen Felderhebungszeiten eine relativ hohe Stichprobenzahl erhoben werden kann und abseits der Gebühren für tatsächlich durchgeführte Gespräche keine weiteren Kosten anfallen. Als Nachteil der Telefonbefragung wird häufig angeführt, dass ein Zugriff auf die komplette Grundgesamtheit nicht möglich ist, da nicht alle Haushalte über ein Festnetztelefon verfügen und ein wachsender Anteil der Bevölkerung nicht (mehr) über ein Festnetztelefon, sondern (nur) über Mobiltelefone erreichbar ist (HÄDER 2010, S. 191ff.; SCHNELL et al. 2011, S. 357ff.). Der Anteil der sog. "Mobile-Onlys“, die ausschließlich über einen Mobilfunk-Anschluss erreichbar sind, wird in Deutschland auf 6-8 \% der Telefonnutzer geschätzt. Die Abdeckung durch Festnetztelefonie ist rückläufig und wird derzeit bei etwa $90 \%$ der Bevölkerung angesetzt, wobei gleichzeitig 
die Abdeckung durch Mobiltelefonie auf etwa $85 \%$ geschätzt wird. Gemeinsam betrachtet ist durch die Verbreitung von Mobiltelefonen der Anteil der in Deutschland per Telefon erreichbaren Bevölkerung auf über $99 \%$ angestiegen (FUCHS 2012, S. 53f.). Für ein deutsches Untersuchungsgebiet bietet sich eine Telefonbefragung also durchaus an.

\begin{tabular}{|c|c|c|}
\hline Studie & Untersuchungsgegenstand/-ort & Erhebungs-/Analysemethodik \\
\hline ARENTZE et al. (2005) & $\begin{array}{l}\text { Einkaufszentren, Provinz } \\
\text { Nordbrabant (Niederlande) }\end{array}$ & $\begin{array}{l}\text { Telefonische Haushaltsbefragung (Zufallsauswahl), } n=1.704 \\
\text { Diskretes Entscheidungsmodell }\end{array}$ \\
\hline CLIQUET (1995) & $\begin{array}{l}\text { Möbelmärkte, vier Kantone im } \\
\text { Département Calvados (Frankreich) }\end{array}$ & $\begin{array}{l}\text { Persönliche Haushaltsbefragung (Zufallsauswahl), } n=760 \\
\text { MCl-Modell }\end{array}$ \\
\hline $\begin{array}{l}\text { COLOMÉ PERALES } \\
(2002)\end{array}$ & $\begin{array}{l}\text { Lebensmittelmärkte, Milton Keynes } \\
\text { (Großbritannien) und Barcelona } \\
\text { (Spanien) }\end{array}$ & $\begin{array}{l}\text { Persönliche Passantenbefragung ( } 2 \text { Samplepoints je Stadt), } \\
n=200 \text { (Barcelona) bzw. } 99 \text { (Milton Keynes) } \\
\text { MCl-Modell }\end{array}$ \\
\hline GHOSH (1984) & $\begin{array}{l}\text { Lebensmittelmärkte, Stadt im } \\
\text { Mittelwesten der USA }\end{array}$ & $\begin{array}{l}\text { Persönliche Haushaltsbefragung (Zufallsauswahl), } n=300 \\
\text { MCl-Modell }\end{array}$ \\
\hline $\begin{array}{l}\text { GONZÁLEZ-BENITO } \\
(2005)\end{array}$ & $\begin{array}{l}\text { Lebensmittelmärkte, Madrid } \\
\text { (Spanien) }\end{array}$ & $\begin{array}{l}\text { Telefonische Haushaltsbefragung (Extern beschaffte Daten: } \\
\text { DYMPANEL), } n=443 \\
\text { MCI-Modell mit Logit-Funktion }\end{array}$ \\
\hline $\begin{array}{l}\text { GONZÁLEZ-BENITO et } \\
\text { al. }(2000)\end{array}$ & $\begin{array}{l}\text { Lebensmittelmärkte, Vorort } \\
\text { Salamanca (Spanien) }\end{array}$ & $\begin{array}{l}\text { Persönliche Haushaltsbefragung (Zufallsauswahl), } n=302 \\
\text { MCl-Modell }\end{array}$ \\
\hline $\begin{array}{l}\text { GONZÁLEZ-BENITO et } \\
\text { al. (2005) }\end{array}$ & $\begin{array}{l}\text { Lebensmittelmärkte, Salamanca } \\
\text { (Spanien) }\end{array}$ & $\begin{array}{l}\text { Persönliche Haushaltsbefragung (Zufallsauswahl), } n=584 \\
\text { Diskretes Entscheidungsmodell }\end{array}$ \\
\hline HUfF (1962) & $\begin{array}{l}\text { Geplante Einkaufszentren, drei } \\
\text { Regionen im suburbanen Umland } \\
\text { von Los Angeles (USA) }\end{array}$ & $\begin{array}{l}\text { Schriftliche Haushaltsbefragung (Kontaktierung aller } \\
\text { Haushalte), } n=123 \text { bzw. } 331 \text { bzw. } 312 \\
\text { HuFF-Modell (iterative Schätzung) }\end{array}$ \\
\hline $\begin{array}{l}\text { KUBIS/HARTMANN } \\
(2007)\end{array}$ & $\begin{array}{l}\text { Geplante Einkaufszentren, Region } \\
\text { Halle-Leipzig (Deutschland) }\end{array}$ & $\begin{array}{l}\text { Point-of-sale-Erhebung (Kfz-Kennzeichen), } n=6.070 \\
\text { MCI-Modell }\end{array}$ \\
\hline LADEMANN (2007) & $\begin{array}{l}\text { Lebensmittelmärkte, Göttingen } \\
\text { (Deutschland) }\end{array}$ & $\begin{array}{l}\text { Persönliche Passantenbefragung (4 Samplepoints), } n=399 \\
\text { Diskretes Entscheidungsmodell }\end{array}$ \\
\hline $\begin{array}{l}\text { POPKOWSKI LESZCZYC } \\
\text { et al. (2004) }\end{array}$ & $\begin{array}{l}\text { Lebensmittelmärkte, suburbanes } \\
\text { Umland einer Großstadt im Norden } \\
\text { Neuseelands }\end{array}$ & $\begin{array}{l}\text { Telefonische Haushaltsbefragung (Zufallsauswahl), } n=200 \\
\text { Diskretes Entscheidungsmodell }\end{array}$ \\
\hline $\begin{array}{l}\text { REUTTERER/TELLER } \\
(2009)\end{array}$ & $\begin{array}{l}\text { Lebensmittelmärkte, Großstadt in } \\
\text { Österreich }\end{array}$ & $\begin{array}{l}\text { Selbst administrierte Haushaltsbefragung (geschichtete } \\
\text { Zufallsauswahl), } \mathrm{n}=408 \\
\text { Diskretes Entscheidungsmodell }\end{array}$ \\
\hline $\begin{array}{l}\text { SUÁREZ-VEGA et al. } \\
\text { (2011) }\end{array}$ & $\begin{array}{l}\text { Hypermärkte (= SB-Warenhäuser), } \\
\text { Gran Canaria (Spanien) }\end{array}$ & $\begin{array}{l}\text { Telefonische Haushaltsbefragung (Zufallsauswahl), } n=812 \\
\text { MCI-Modell }\end{array}$ \\
\hline TIHI/ORUC (2012) & $\begin{array}{l}\text { Hypermärkte (= SB-Warenhäuser), } \\
\text { Sarajevo (Serbien) }\end{array}$ & $\begin{array}{l}\text { Persönliche Haushaltsbefragung (Zufallsauswahl), } n=240 \\
\text { MCI-Modell }\end{array}$ \\
\hline $\begin{array}{l}\text { VROEGRIJK et al. } \\
\text { (2013) }\end{array}$ & $\begin{array}{l}\text { Lebensmittemärkte, } 194 \text { Gebiete in } \\
\text { den Niederlanden }\end{array}$ & $\begin{array}{l}\text { Telefonische Haushaltsbefragung (Zufallsauswahl), } n=703 \\
\text { (Extern beschaffte Daten: GfK-Haushaltspanel) } \\
\text { Diskretes Entscheidungsmodell }\end{array}$ \\
\hline
\end{tabular}

Tabelle 6: Methodisches Vorgehen in ausgewählten Marktgebietsanalysen

Quelle: Eigene Darstellung 


\subsubsection{Aufbau und Inhalt des Fragebogens}

Für die Haushaltsbefragung wurde unter Rückgriff auf inhaltlich ähnlich gelagerte Studien ein standardisierter Fragebogen zur Erfassung der räumlichen Einkaufsorientierung der Haushalte im Untersuchungsgebiet entwickelt. Da bei telefonischen Befragungen im Gegensatz zu schriftlich-postalischen oder persönlichen Befragungen eine Reihe von Möglichkeiten des Interviewers (z.B. visuelle Hilfen, Einschätzung des Befragten und seiner Umgebung) nicht gegeben bzw. eingeschränkt sind, empfehlen SCHNELL et al. (2011, S. 361ff.) für die Konstruktion des Erhebungsinstrumentes die Beachtung einiger Grundsätze:

- Der Fragebogen muss so strukturiert sein, dass er für den Interviewer einfach zu handhaben und für den Befragten leicht zu verstehen ist, da etwaige Störungen des Befragungsablaufs (z.B. hinsichtlich des Verständnisses oder der Aufmerksamkeit des Befragten) vom Interviewer kaum korrigiert werden können

- Während bei schriftlichen und persönlichen Befragungen das Vertrauen und die Motivation des Befragten durch ein Begleitschreiben oder eine persönliche Vorstellung aufgebaut werden, muss dies bei Telefonbefragungen durch eine verbale Einleitung geschehen; in dieser Einleitungsphase sollten daher u.a. der ganze Name des Interviewers und die Quelle des Anrufs (Universität etc.) genannt und über den Zweck und Ablauf des Gesprächs (z.B. Untersuchungsthema, anonyme Auswertung, Freiwilligkeit, ungefähre Dauer des Interviews) informiert werden

- Die Einstiegsfrage soll das Interesse des Befragten aufrecht erhalten und dabei (in inhaltlicher Hinsicht) leicht und angenehm zu beantworten sein

- Die Fragen müssen leicht und verständlich sein, weswegen auf lange, komplizierte Fragen oder die Vorgabe zu vieler Antwortmöglichkeiten verzichtet werden sollte; ebenso sollten die Frage-Antwort-Schemata nicht häufig gewechselt werden

Daher wurde der hier genutzte Fragebogen in seinen Inhalten und seiner Struktur so einfach wie möglich gehalten; er gliedert sich in einen Teil zur Erfassung der räumlichen Einkaufsorientierung hinsichtlich der vier untersuchten Angebotstypen (Lebensmittelmärkte, Elektronikmärkte, Bau-/Heimwerkermärkte, Möbelmärkte) und einen sozio-demographischen Teil, in dem einzelne Eigenschaften des Befragten (Alter, Berufsstatus) bzw. des Haushalts (Mitglieder) abgefragt wurden. Der Fragebogen wurde so konzipiert, dass das gesamte Telefongespräch unter normalen Bedingungen (d.h. beispielsweise keine übermäßigen Rückfragen oder Ablenkungen vom Thema) in rund fünf Minuten durchzuführen ist.

In der Einleitung stellten die Interviewer sich selbst sowie den Untersuchungsgegenstand (ohne hierbei die konkrete Thematik der Kopplungs- und Vergleichskäufe bzw. Einzelhandelsagglomerationen anzusprechen) und das Auswahlverfahren (Zufallsauswahl aus einem digitalen Telefonbuch) vor, versicherten den Angerufenen die Anonymität ihrer Angaben und eine Gesprächslänge von nicht mehr als fünf Minuten. Zugleich wurde ausdrücklich darauf hingewiesen, dass es sich bei dem Anruf nicht um eine kommerzielle (z.B. privatwirtschaftliche Marktforschung) oder gar illegale Aktivität (z.B. unerlaubte telefonische Werbung) handelt, sondern um eine wissenschaftliche Forschungsarbeit; hierbei wurde bei Bedarf auf die Internetpräsenz des Urhebers der Studie (Mitarbeiter-Homepage der Universität) verwiesen. Vor den Fragen bezüglich der räumlichen Einkaufsorientierung wurde nach der allgemeinen Einkaufshäufigkeit im jeweiligen Sortimentsbereich gefragt; die 
erste Frage des Fragebogens bezog sich auf die Einkaufshäufigkeit bei Lebensmitteln („Wie häufig im Monat kaufen Sie ungefähr Lebensmittel ein?“). Somit wurde die „leichteste“ Frage an den Anfang gestellt, da davon ausgegangen werden kann, dass jeder Haushalt unabhängig von Einkommen oder Lebensstil zumindest gelegentlich Lebensmittel einkauft.

Es stellt sich bei derartigen Erhebungen die Frage, mit welcher konkreten Frageformulierung die räumliche Einkaufsorientierung ermittelt wird; hierfür existieren verschiedene Varianten:

- Nach Huff/McCallum (2008, S. 23) kann bei MCI-Modellanalysen beispielsweise der Anbieter erfragt werden, der „normalerweise“ aufgesucht oder der vom Befragten bevorzugt wird; alternativ können aber auch Besuchsanteile mehrerer Anbieter erhoben werden (z.B. „Von zehn Einkäufen finden wie viele bei Anbieter X statt?")

- Insbesondere in Studien mit diskreten Entscheidungsmodellen werden die Befragten nach einem Anbieter gefragt, was der Zielgröße dieser Modelle (diskrete Wahl einer Alternative unter Ausschluss der anderen) entspricht. Hierbei wird vor allem nach der Haupteinkaufsquelle gefragt (z.B. LADEMANN 2007, TELLER/REUTTERER 2009), wie auch in einigen MCl-Studien (z.B. GHOSH 1984, TIMMERMANS 1981)

- In anderen Untersuchungen werden Besuchsanteile (z.B. POPKOWSKI LESZCZYC et al. 2004, TIHI/ORUC 2012) oder getätigte monetäre Ausgaben (z.B. GONZÁLEZ-BENITO et al. 2005) bei allen betrachteten Anbietern in einem bestimmten Zeitraum abgefragt. Die in einigen Fällen genutzten extern beschafften Paneldaten enthalten mitunter die Einkäufe als auch die Ausgaben von privaten Haushalten (z.B. GfK-Haushaltspanel bei VROEGRIJK et al. 2013)

- In seiner seminalen Studie ermittelt HuFF (1962) die räumliche Einkaufsorientierung durch die Frage nach dem Ziel des letzten Einkaufs und der Haupteinkaufsquelle für die von inm betrachteten Sortimentsbereiche. ARENTZE et al. (2005) fragen zunächst nach den beiden am häufigsten besuchten Anbietern, wählen daraufhin einen der beiden zufällig aus und stellen zum letzten dort getätigten Einkauf Fragen

Diese Frageformulierungen sind sich grundsätzlich ähnlich, unterscheiden sich jedoch in ihren Anforderungen an die Befragten und den produzierten Informationen. Bei der Frage nach der „Haupteinkaufsquelle“ bzw. dem „normalerweise“ aufgesuchten Anbieter werden in quantitativer Hinsicht Informationen geschmälert, da nur ein Anbieter erfragt wird; außerdem impliziert die Frage, dass es einen Anbieter gibt, der "hauptsächlich“ angesteuert wird. Das für die Analyse verwendete $\mathrm{MCl}-$ Modell geht wie sein theoretisch-deduktiver Vorläufer (HUFF-Modell) von einer probabilistischen Einkaufsstättenwahl aus, die eine (geplante oder zufällige) Mehrfachorientierung beim Einkauf explizit einschließt; hierbei können durchaus mehrere oder gar keine „Haupteinkaufsquellen“ vorliegen, weswegen die Frageformulierung in diesem Zusammenhang nicht sinnvoll ist. Sowohl die Angabe einer Haupteinkaufsquelle als auch die Erfragung von Besuchs- oder Ausgabenanteilen sind zudem sehr anfällig für Antwortverzerrungen durch Falschangaben (Over-/Underreporting), die entweder bewusst aus Gründen sozialer Erwünschtheit oder unbewusst durch schlichtes Unwissen gemacht werden (HARDMEIER/FONTANA 2006, S. 55ff.). Im Kontext gesellschaftlicher Images von Produkten und Anbietern im Einzelhandel muss soziale Erwünschtheit in jedem Fall 
berücksichtigt werden ${ }^{40}$; andererseits ist anzunehmen, dass Befragte i.d.R. auch keine exakten Angaben zu ihren Einkaufshäufigkeiten oder -ausgaben machen können, selbst wenn sie dies wollten. Eine Befragung nach dem bevorzugten Anbieter beinhaltet bereits implizit dessen Image und eignet sich daher nicht zur Erfassung des realen Verhaltens.

Zusammengefasst darf also den Befragten während der Erhebung keine oder möglichst wenig Gelegenheit zur subjektiven Wertung der innen zur Verfügung stehenden Einzelhandelsanbieter gegeben werden. In der Erhebung der Einkaufsorientierung sollte daher nicht das vom Befragten subjektiv bevorzugte oder das als "typisches" oder "häufigstes" wahrgenommene Einkaufsziel abgefragt werden, sondern das bzw. die tatsächlichen Einkaufsziele; hierbei dürfen die Befragten wiederum nicht überfordert werden. Hierfür bietet sich das Frageverfahren nach dem oder den zuletzt aufgesuchten Anbietern an, wobei allerdings der Aspekt der Mehrfachorientierung einfließen sollte. In der hier durchgeführten Befragung wurde daher in allen vier betrachteten Bereichen jeweils nach den letzten drei getätigten Einkäufen gefragt, unabhängig davon ob es sich hierbei um „typische“ Einkäufe und/oder solche bei „bevorzugten“ Anbietern handelte oder warum diese dort stattgefunden haben. Somit wird das Risiko einer Falschangabe aufgrund von sozialer Erwünschtheit deutlich gesenkt, da nicht das "Lieblingsgeschäft“ erfragt wird, sondern die tatsächlich stattgefundenen Einkäufe unabhängig von Anbieterpräferenzen; zugleich wird einer möglichen Mehrfachorientierung Rechnung getragen. Die Erfragung der letzten Einkäufe bildet zudem eine zusätzliche Zufallskomponente, da auch „untypische“, d.h. abseits vom üblichen Muster getätigte, oder „zufällige“ bzw. Spontaneinkäufe erfasst werden.

Der Fragebogen wurde im Dezember 2011 einem Pretest mit 20 zufällig ausgewählten Einwohnern des Untersuchungsgebietes unterzogen; hierbei zeigte sich, dass beim Verständnis bzw. der Beantwortung der Fragen keine Probleme auftraten. Abgesehen von der Streichung einer sozio-demographischen Frage, die regelmäßig nicht beantwortet wurde (Einkommen), konnte der Fragebogen somit unverändert für die Haupterhebung genutzt werden. Um eine spätere Weiterverarbeitung mittels SPSS zu gewährleisten, wurde der Fragebogen (siehe Anhang, Abb. A 2) mit SPSS Data Entry (Version 4) in ein digitales Eingabeformular umgesetzt, das im Zuge der Telefonbefragung bzw. der Dateneingabe eingesetzt wurde.

\subsubsection{Durchführung der Haushaltsbefragung}

Genau wie bei schriftlichen und mündlichen Befragungen ein Adresspool vorhanden sein muss, um die (potenziellen) Teilnehmer herauszufiltern, ist auch bei Telefonbefragungen eine Auswahlgrundlage notwendig, welche die im Untersuchungsgebiet befindlichen Telefonanschlüsse enthält; hierfür können konventionelle Telefonbücher verwendet werden (z.B. POPKOWSKI LESZCZYC et al. 2004, SUÁREZ-VEGA et al. 2011). Im Fall extern beschaffter Daten (z.B. VROEGRIJK et al. 2013) liegen den anbietenden Marktforschungsinstituten ggf.

\footnotetext{
${ }^{40}$ Hierzu zeigen Niessen/Hamm (2007) am Beispiel des Einkaufs von Bio-Produkten einen großen Widerspruch zwischen bekundetem und tatsächlichem Kaufverhalten auf; im Vergleich von selbst eingeschätzten und durch Einkaufstagebücher erhobenen Einkaufshäufigkeiten zeigt sich, dass der Einkauf von Bio-Produkten bei fast allen untersuchten Gruppen als weit höher angegeben wurde als er in der Realität erfolgte (Overreporting). An einem anderen Beispiel (Lidl) lässt sich zeigen, dass negative Schlagzeilen zwar die in Befragungen bekundeten Einkaufsentscheidungen für oder gegen die betroffenen Einzelhandelsanbieter negativ beeinflussen, ihre tatsächlichen Umsätze darunter jedoch nicht notwendigerweise leiden (WIRTSCHAFTSWOCHE 09.02.2009).
} 
auch eigene Teilnehmerkarteien vor. Für die vorliegende Befragung wurden hierfür die Daten einer Telefonbuch-DVD für Deutschland verwendet (TVG VERLAG 2011). Nach Angaben des Anbieters beinhaltet dieses digitale Telefonbuch (Stand: 2011) die offiziellen Adress- und Telefondaten der Kunden der Deutschen Telekom und weiteren Netzanbietern sowie auch Mobilfunknummern, wobei die Teilnehmerdaten von den Netzanbietern stammen und durch eigene Datenrecherchen angereichert werden. Die Nutzung solcher Telefon-CDs/DVDs ist in deutschen Markt- und Sozialforschungsstudien nicht unüblich und bietet - neben geringen Kosten - die Vorteile, dass die Einträge in ein anderes Format exportiert (z.B. MS Excel) und dort weiterverarbeitet werden können und dass es möglich ist, bei Nicht-Antworten bzw. Ablehnungen sofort Ersatzobjekte zu generieren (SCHNELL et al. 2011, S. 283f.).

Die Mindesthöhe der Stichprobe wurde bei $1 \%$ der Haushalte im Untersuchungsgebiet angesetzt, was dem Vorgehen bei der Datenerhebung zur amtlichen Repräsentativstatistik (Mikrozensus) entspricht (STATISTISCHES BUNDESAMT 2012). Ausgehend von der in den Untersuchungsgemeinden befindlichen Grundgesamtheit von 34.987 Haushalten (siehe Kap. 5.2.1) bedeutet dies eine Mindesthöhe von 350 Interviews. Um Repräsentativität im statistischen Sinne zu gewährleisten, ist es notwendig, dass die Ziehung der Stichprobe nach dem Zufallsprinzip erfolgt (Zufallsstichprobe), wobei jedes Element der Grundgesamtheit dieselbe Wahrscheinlichkeit hat, in die Stichprobe zu gelangen (SCHNELL et al. 2011, S. 265ff.). In dieser Haushaltsbefragung wurde eine einfache Zufallsauswahl vorgenommen, indem der gesamte Datenbestand für die sieben Untersuchungsgemeinden in eine Tabelle (MS Excel) exportiert und mit Hilfe eines Zufallsgenerators neu angeordnet wurde; der Datensatz wurde dann nach dieser zufälligen Reihenfolge abgearbeitet.

Die Kontaktierung der potenziellen Teilnehmer und die Interaktion mit innen erfolgten auf der Grundlage der Richtlinien zu telefonischen Befragungen des Arbeitskreises Deutscher Marktund Sozialforschungsinstitute (ADM 2008). Entsprechend dieser Vorgaben wurde die Anrufzeit auf einen Zeitraum von 9-21 Uhr festgelegt. Die Telefonanrufe erfolgten in einem System mit vier Schichten (9-12 Uhr, 12-15 Uhr, 15-18 Uhr, 18-21 Uhr), wobei die Befrager so eingeteilt wurden, dass in den Drei-Stunden-Schichten in etwa gleich viele Anrufe getätigt wurden. Sofern ein Anschluss nicht erreicht wurde, wurde dieser jeweils in den drei anderen Zeitfenstern nochmalig kontaktiert; blieben auch diese Anrufe unbeantwortet, wurde der Anschluss als „nicht erreicht“ eingeordnet. Wenn ein erreichter Teilnehmer nach Beginn des Gesprächs aufgelegt oder anderweitig signalisiert hat, nicht teilnehmen zu wollen, wurde dieser Anschluss als „abgelehnt“ klassifiziert. Bei erreichten Anschlüssen wurde jeweils das Haushaltsmitglied befragt, das schwerpunktmäßig für Einkäufe zuständig ist bzw. hierüber Aussagen treffen kann; bei Bedarf wurde in Einzelfällen durch den Befragten eine weitere Person (z.B. Ehemann/-frau) hinzugeholt. Sofern die befragten Personen angaben, keine Zeit zu haben, aber generelles Interesse an der Befragung artikulierten, wurden spätere Gesprächstermine vereinbart.

Die Befragung fand im Januar/Februar 2012 statt. Da die Datensätze aus dem digitalen Telefonbuch neben den Rufnummern auch die Adressen der registrierten Anschlussinhaber beinhalten, konnten diese nach erfolgreich durchgeführtem Interview dem jeweiligen Teil des Untersuchungsgebietes (34 Ortsteile, siehe Kap. 5.2.1) zugeteilt werden. Diese räumliche Referenzierung der Befragten ist für die spätere Kalkulation von lokalen Marktanteilen unabdingbar gewesen. 


\section{3 Ökonometrische Analyse mittels MCl-Modell}

\subsubsection{Datenaufbereitung}

\subsubsection{Neusegmentierung und Georeferenzierung der Nachfrageorte}

Im ersten Schritt der Aufbereitung musste der Siedlungsstruktur des Untersuchungsgebietes Rechnung getragen werden. Unter den insgesamt 34 Ortsteilen befinden sich Teilgebiete mit sehr geringen Einwohnerzahlen (unter 1.000 Einwohner, wobei zu dieser Gliederungsebene keine Haushaltszahlen vorliegen), so dass auch die hier theoretisch zu erreichende Stichprobenzahl dementsprechend gering wäre. Je geringer die Stichprobengröße auf lokaler Ebene ist, desto eher kann der Fall auftreten, dass bestimmte Nachfrager-AnbieterInteraktionen nicht erfasst werden und somit eine große Anzahl leerer Zellen in der späteren Interaktionsmatrix zurückbleibt. Da die Linearisierung des $\mathrm{MCl}$-Modells nur Werte der eingehenden Variablen (hier: lokaler Marktanteil) oberhalb von null akzeptiert, müssten hier in jedem Fall Nachbearbeitungen der Daten vorgenommen werden (COOPER/NAKANISHI 2010, S. 153ff.). Da solche Korrekturen stets Verzerrungen der Ausgangsdaten mit sich bringen, ist es sinnvoll, den Effekt nicht ausgefüllter Felder von vorn herein abzumildern. Einige Ortschaften sind zudem sogar so klein, dass bei einer anvisierten Stichprobe von 350 Befragten unter der Annahme einer der Grundgesamtheit exakt gleichen räumlichen Verteilung die Zahl der befragten Personen unter eins liegen würde. Hierzu zählen beispielsweise der zu Beverungen gehörige Ortsteil Rothe (158 Einwohner) oder der Holzminden angehörende Ortsteil Mühlenberg (96 Einwohner).

Es ist vor diesem Hintergrund bei der Anwendung des MCl-Modells möglich und auch üblich, bei Bedarf die Größen der Nachfrageorte zu homogenisieren bzw. diese zu größeren Einheiten zusammenzufassen (z.B. GHOSH 1984, TIHI/ORUC 2012). Daher wurden zur weiteren Bearbeitung kleine, benachbarte Ortsteile zu größeren Teilgebieten mit mindestens 1.000 Einwohnern aggregiert. Hierbei wurden stets die am nahesten beieinander liegenden Ortschaften zu einem neuen Gebiet zusammengeschlossen, bis dieses die gesetzte Grenze der Bevölkerungsgröße erreicht bzw. überschritten hatte. Notwendigerweise sind bei diesem Vorgehen auch einzelne Ortschaften über 1.000 Einwohner mit deutlich kleineren benachbarten Ortschaften fusioniert worden. Mit diesem Verfahren wurden die 34 Ortsteile des Untersuchungsgebietes zu 19 Teilgebieten (z.B. „Beverungen-Nordost“, „Höxter-Süd“) zusammengefasst. Im Ergebnis ist nur die Gemeinde Derental (Samtgemeinde Boffzen) und in Ermangelung weiterer Orte in räumlicher Nähe das Gebiet „Beverungen-West“ mit einer Einwohnerzahl unter 1.000 Personen zurückgeblieben. Die Kernstadtgebiete sowie größere Ortsteile (z.B. Höxter-Stahle) sind aufgrund ihrer Größe eigene Gebiete geblieben (siehe Anhang, Tabelle A 2 und A 3). Diese Teilgebiete bildeten die Basis aller weiteren (nachfragebezogenen) Berechnungen.

Um die Nachfrageorte als Vektordaten in späteren GIS-Analysen verwenden zu können, wurde ein Punkt-Shapefile mit den 19 Teilgebieten erstellt. Die Punktmarkierung wurde hierbei jeweils im Siedlungszentrum des Ortes (bei Teilgebieten bestehend aus mehreren Ortsteilen: Siedlungszentrum des bevölkerungsbezogen größten Ortes) gesetzt. 


\subsubsection{Berechnung der lokalen Marktanteile}

Das vorläufige Ergebnis der Haushaltsbefragung zu den letzten Einkäufen in den relevanten Bereichen (siehe Kap. 5.2.3) waren empirisch ermittelte Einkäufe der befragten Haushalte bei den jeweiligen Anbietern; diese bildeten im Folgenden die Grundlage für die Berechnung empirischer lokaler Marktanteile. Da die Adressen der Befragten aus der Telefonliste vorlagen, konnten diese den Ortsteilen, in denen sie wohnen, und somit auch den 19 Teilgebieten des Untersuchungsgebietes (siehe Kap. 5.3.1.1) zugeordnet werden. Tabelle 7 zeigt diese Befragungsrohdaten schematisch anhand der Einkäufe von neun befragten Haushalten $(h)$ aus drei Nachfrageorten ( $l$ ) bei drei Anbietern ( $)$.

\begin{tabular}{|c|c|c|c|c|}
\hline \multirow{2}{*}{$\begin{array}{l}\text { Fall bzw. befragter } \\
\text { Haushalt }(h)\end{array}$} & \multirow{2}{*}{ Wohnort (i) } & \multicolumn{3}{|c|}{ Empirisch ermittelte Einkäufe des Haushalts $h$ bei Anbieter $j\left(E_{h}\right)$} \\
\hline & & $\mathrm{j}_{1}$ & $\mathrm{j}_{2}$ & $\mathrm{j}_{3}$ \\
\hline 1 & $\mathrm{i}_{1}$ & $E_{h 1 j 1}$ & $E_{h 1 j 2}$ & $E_{h 1 j 3}$ \\
\hline 2 & $\mathrm{i}_{1}$ & $E_{h 2 j 1}$ & $E_{h 2 j 2}$ & $E_{h 2 j 3}$ \\
\hline 3 & $\mathrm{i}_{1}$ & $E_{h 3 j 1}$ & $E_{h 3 j 2}$ & $E_{h 3 j 3}$ \\
\hline 4 & $\mathrm{i}_{2}$ & $E_{h 4 j 1}$ & $E_{h 4 j 2}$ & $E_{n 4 j 3}$ \\
\hline 5 & $\mathrm{i}_{2}$ & $E_{h 5 j 1}$ & $E_{h 5 j 2}$ & $E_{h 5 j 3}$ \\
\hline 6 & $\mathrm{i}_{2}$ & $E_{h 6 j 1}$ & $E_{h 6 j 2}$ & $E_{h 6 j 3}$ \\
\hline 7 & $i_{3}$ & $E_{h 7 j 1}$ & $E_{h 7 j 2}$ & $E_{h 7 j 3}$ \\
\hline 8 & $i_{3}$ & $E_{h 8 j 1}$ & $E_{h 8 j 2}$ & $E_{h 8 j 3}$ \\
\hline 9 & $\mathrm{i}_{3}$ & $E_{h 9 j 1}$ & $E_{h 9 j 2}$ & $E_{h 9 j 3}$ \\
\hline
\end{tabular}

Tabelle 7: MCI-Modell - Empirisch ermittelte Einkäufe (schematisch)

Quelle: Eigene Darstellung

Die empirisch ermittelten Einkäufe der Haushalte bei den jeweiligen Anbietern $\left(E_{h j}\right)$ wurden im nächsten Schritt auf der Ebene der 19 Teilgebiete $(I)$ summiert $\left(E_{i j}\right)$. Die lokalen Marktanteile der $j$ Anbieter in den $i$ Nachfrageorten wurden auf der Grundlage der allgemeinen Formel zur Kalkulation von Marktanteilen (COOPER/NAKANISHI 2010, S. 18) aus dem Quotienten der getätigten Einkäufe beim Anbieter $j$ aus Nachfrageort $i$ und der Summe aller getätigten Einkäufe aus Nachfrageort $i$ berechnet (siehe Formel 30). Wie in allen Marktgebietsanalysen, deren empirische Grundlage nicht Umsatz- bzw. Kaufkraft-, sondern Kundenströme sind (z.B. GHOSH 1984, TIHI/ORUC 2012), handelt es sich bei diesen lokalen Marktanteilen also genau genommen um Interaktionsanteile und somit um eine messbare Repräsentation dessen, was im HuFF-Modell die Zielgröße (Interaktionswahrscheinlichkeit) darstellt.

$p_{i j}=\frac{E_{i j}}{\sum E_{i}}$

$p_{i j}=$ Marktanteil des Anbieters $j$ in Nachfrageort i

$E_{i j}=$ Empirisch ermittelte Einkäufe aus Nachfrageort $i$ bei Anbieter $j$

$\Sigma \mathrm{E}_{\mathrm{i}}=$ Summe aller Einkäufe aus Nachfrageort $\mathrm{i}$

Um sicherzustellen, dass jedes Feld der Interaktionsmatrix, also jede $i \times j$-Kombination ausgefüllt ist, was die spätere Transformation des Modells voraussetzt, mussten die 
Marktanteile jedoch noch dahingehend korrigiert werden (Ähnliches Beispiel siehe HARTMANN 2005, S. 63). Hierfür wird mitunter so verfahren, dass die Nachfrageorte immer weiter aggregiert werden, bis alle lokalen Marktanteile größer null sind (z.B. COLOMÉ PeRALES 2002, TIHI/ORUC 2012). Diese Methode birgt allerdings das Problem einer so starken Zusammenfassung der Nachfrageorte, dass kleinräumige Interaktionsmuster nicht mehr abgebildet werden können. Außerdem kann davon ausgegangen werden, dass von einigen Nachfrageorten zu bestimmten Angebotsstandorten nur so wenige Interaktionen stattfinden (wenn sie überhaupt stattfinden), dass es unwahrscheinlich ist, sie über eine Stichprobe überhaupt zu erfassen. Daher wurde hier, analog zu HARTMANN (2005) bzw. KUBIS/HARTMANN (2007), diese Korrektur darüber vorgenommen, dass die ermittelten Einkäufe jedes Anbieters $\left(E_{h j}\right)$ um eins erhöht und auf dieser Grundlage die lokalen Marktanteile $\left(p_{i j}\right)$ berechnet wurden (Formel 30). Im Ergebnis stand nun eine Matrix mit den lokalen Marktanteilen aller $j$ Anbieter in allen $i$ Nachfrageorten (schematische Darstellung auf der Grundlage des o.g. Beispiels siehe Tabelle 8).

\begin{tabular}{ccc}
\hline Nachfrageort $(i)$ & Anbieter $(j)$ & Marktanteil von Anbieter $j$ in Nachfrageort $i\left(p_{i j}\right)$ \\
\hline $\mathrm{i}_{1}$ & $\mathrm{j}_{1}$ & $\mathrm{p}_{\mathrm{ijj} 1}$ \\
$\mathrm{i}_{1}$ & $\mathrm{j}_{2}$ & $\mathrm{p}_{\mathrm{iij} 2}$ \\
$\mathrm{i}_{1}$ & $\mathrm{j}_{3}$ & $\mathrm{p}_{\mathrm{i} 1 \mathrm{j} 3}$ \\
$\mathrm{i}_{2}$ & $\mathrm{j}_{1}$ & $\mathrm{p}_{\mathrm{i} j \mathrm{j}}$ \\
$\ldots$ & $\ldots$ & $\ldots$ \\
$\mathrm{i}_{3}$ & $\mathrm{j}_{3}$ & $\mathrm{p}_{\mathrm{i} 3 \mathrm{j} 3}$ \\
\hline
\end{tabular}

Tabelle 8: MCl-Modell - Lokale Marktanteile (schematisch)

Quelle: Eigene Darstellung

\subsubsection{Berechnung der Fahrtzeiten}

Im nächsten Schritt mussten die Fahrtzeiten zwischen den 19 Nachfrageorten und allen untersuchungsrelevanten Anbietern ermittelt werden. Prinzipiell existieren hierfür unzählige frei verfügbare GIS-basierte Routenplaner-Dienste (z.B. Google Maps, ViaMichelin); allerdings wäre die manuelle Kalkulation aller benötigten Fahrtzeiten bzw. Entfernungen so langwierig (Beispiel: 19 Nachfrageorte x 10 Anbieter $=190$ einzelne Routen), dass es zeiteffizienter war, diese Aufgabe mit Hilfe einer Netzwerkanalyse ${ }^{41}$ in ArcGIS zu lösen. Die Generierung eines einzelnen Straßennetzes hat zudem den Vorteil, dass neue räumliche Konfigurationen (z.B. neue Start-/Endpunkte, neue Straßen) sofort integriert und weiterverarbeitet werden können. In der Analyse von Marktgebieten im Einzelhandel finden

\footnotetext{
${ }^{41}$ Netzwerke stellen eine der wesentlichsten Funktionen in Geographischen Informationssystemen dar, da sie zur Modellierung von Verkehrssystemen unterschiedlichen Typs (Transportnetzwerke) oder anderer Formen von realen Netzsystemen (z.B. Rohrleitungsnetze) verwendet werden können. Netzwerke im GIS sind Vektordaten, die, basierend auf der mathematischen Graphentheorie, aus Kanten (einzelne Strecken, z.B. Straßen) und Knoten (Verknüpfungsstellen der Strecken, z.B. Straßenkreuzungen) bestehen. Um Entfernungen oder Fahrtzeiten zu modellieren, ist ein Netzwerk notwendig, dessen Kanten gewichtet sind (z.B. durch Streckenlänge und/oder Geschwindigkeit). Hiermit ist es z.B. möglich, einzelne Routen zwischen einem Start- und Zielpunkt, Fahrtzeitradien um einen Zielpunkt (z.B. Erreichbarkeit eines Lebensmittelmarktes) oder eine Distanzmatrix zwischen einer Reihe von Start- und Zielpunkten automatisch zu generieren. Software zur Routenplanung basiert auf diesem Datenmodell (Überblick zu Netzwerkanalysen im GIS siehe z.B. DE LANGE 2013, S. 372ff.).
} 
Netzwerkanalysen zur Modellierung von Wegstrecken bzw. Fahrtzeiten vereinzelt Verwendung (z.B. FITTKAU 2004, SUÁREZ-VEGA et al. 2011).

Um ein routenfähiges Straßennetzwerk im GIS zu erstellen, mussten zunächst Datengrundlagen zum Straßenverlauf im Untersuchungsgebiet beschafft werden; hierbei wurde auf die Shapefiles der Geofabrik $\mathrm{GmbH}$ zurückgegriffen, die regelmäßig aus aktuellen Daten des OpenData-WebGIS OpenStreetMap (OSM) generiert werden und ebenso frei zugänglich sind (www.geofabrik.de). Aus dem dort vorgehaltenen Datenbestand (u.a. Straßen, Gewässer, Ortschaften, Gebäude) wurden die Straßenverläufe der Bundesländer Nordrhein-Westfalen und Niedersachsen als Linien-Shapefiles besorgt und anhand der als Flächen-Shapefile vorliegenden Grenzen der Untersuchungsgemeinden auf diesen relevanten Bereich beschnitten. Die OSM-Straßendaten sind, wie NEIS et al. (2012, S. 5ff.) zeigen, nicht nur seit Ende der 2000er Jahre massiv angewachsen, sondern mittlerweile im Hinblick auf ihre Vollständigkeit sogar den Datensätzen mancher kommerziell vertriebener Navigationssoftware überlegen. Sie enthalten u.a. Straßentypen, zugelassene Höchstgeschwindigkeiten, Straßennamen sowie Kennzeichnungen ob es sich um eine Einbahnstraße oder eine Brücke (d.h. kein Knoten bzw. Übergang zu kreuzenden Kanten) handelt; keines dieser Attribute liegt jedoch in den Datensätzen vollständig vor.

Das Straßen-Shapefile (Stand: September 2011) wurde um nicht für den PKW-Verkehr verfügbare Wege (z.B. Fahrradwege) bereinigt. Um auf dieser Grundlage Fahrtzeiten zu berechnen, mussten zunächst die Gewichtungen der Streckenabschnitte definiert werden. Sofern eine zulässige Maximalgeschwindigkeit im Datensatz angegeben war, wurde diese übernommen; in allen anderen Fällen wurden den Straßen je nach Typ im Datensatz Maximalgeschwindigkeiten zugewiesen (u.a. für Überlandstraßen $100 \mathrm{~km} / \mathrm{h}$, innerorts 50 $\mathrm{km} / \mathrm{h}$, Straßen in Wohngebieten $30 \mathrm{~km} / \mathrm{h}$ ). Mittels ArcGIS wurden die Längen der Linienelemente des Shapefiles (d.h. Streckenabschnitte) ermittelt und anschließend mit der Geschwindigkeit zu einer streckenspezifischen Fahrtzeit verrechnet. Um möglichen Verkehrshindernissen Rechnung zu tragen, wurden hierfür $80 \%$ der zulässigen Maximalgeschwindigkeit zu Grunde gelegt (siehe Formel 31), was etwa den PKWGeschwindigkeiten auf dem Straßennetz von FITTKAU (2004) und den Annahmen der Erreichbarkeitsmodelle des BBSR (2013d) entspricht. Auf dieser Grundlage wurde über die zugehörige ArcGIS-Funktion ein Straßennetzwerk mit den abschnittspezifischen Fahrtzeiten als Kostenfaktor erstellt (zum Ablauf siehe ESRI 2013a).

$t_{n}=\left(\frac{l_{n}}{0,8 G_{\max _{n}}}\right) 60$

$t_{n}=$ Fahrtzeit auf dem Streckenabschnitt $n$ in Minuten

$l_{n}=$ Länge des Streckenabschnitts $n$ in $\mathrm{km}$

$\mathrm{G}_{\max \mathrm{n}}=$ Maximal zugelassene Geschwindigkeit auf dem Streckenabschnitt $\mathrm{n}$ in $\mathrm{km} / \mathrm{h}$

Da die Nachfrageorte ( $I$ ) und untersuchungsrelevanten Anbieter (j) als Punkt-Shapefiles vorlagen, konnten auf der Grundlage des Straßennetzwerks Fahrtzeiten für alle Kombinationen aus Nachfrageorten (Startpunkte) und Anbietern (Zielpunkte) berechnet werden. Hierbei wurde jeweils die schnellste Strecke im bestehenden Netzwerk auf der Grundlage des hierfür typischerweise genutzten und in den ArcGIS-Netzwerkfunktionen implementierten Dijkstra-Algorithmus ermittelt (DE LANGE 2013, S. 116ff.; ESRI 2013b). Die 
Fahrtzeit für eine gesamte Route $(m)$ setzt sich aus der Summe der Fahrtzeiten in Minuten auf allen einzelnen, hierfür nötigen Streckenabschnitten $\left(t_{n}\right)$ zusammen. Da in den OSMDaten nur teilweise Daten zu Ampeln und anderen Verzögerungselementen enthalten waren, konnten diese Daten nicht für die Erstellung des Netzwerks benutzt werden; stattdessen wurden auf jede kalkulierte Route pauschal zwei Minuten addiert (siehe Formel 32). Die kalkulierten Fahrtzeiten wurden stichprobenartig mit den Ergebnissen mehrerer WebRoutenplaner zu verschiedenen Tageszeiten verglichen, wobei nur geringe Abweichungen festgestellt wurden.

$d_{m}=\left(\sum t_{n}\right)+2$

$\mathrm{d}_{\mathrm{m}}=$ Fahrtzeit der Route $\mathrm{m}$ in Minuten

\subsubsection{Berechnung der Konzentrationsvariablen}

Im nächsten Schritt wurden die zwei im Fokus stehenden erklärenden Variablen des hier genutzten $\mathrm{MCl}$-Modells berechnet: die Konzentrationsvariablen für die Abbildung der räumlichen Nähe zu anderen bzw. konkurrierenden Anbietern. Diese von FOTHERINGHAM (1985) vorgeschlagenen Modellgrößen bilden die Summe aller möglichen Interaktionen und lassen sich als Nutzen des Besuchs anderer potenzieller Anbieter bei einem Einkauf interpretieren, wobei deren Größe als interaktionsfördernde Wirkung und die Distanz zu innen als interaktionshemmende Wirkung berücksichtigt werden (ORPANA/LAMPINEN 2003, S. 324f.). Auf dieser Grundlage wurden für die untersuchungsrelevanten Anbieter zwei Konzentrationsvariablen berechnet: Die erste $\left(K_{A j}\right)$ stellt die Konzentration in Bezug auf Einzelhandelsanbieter anderer Branchen dar (siehe Formel 33), die zweite $\left(K_{K_{j}}\right)$ die Konzentration hinsichtlich der Anbieter der gleichen Branche (siehe Formel 34).

Als Attraktivitätsmaß der anderen Anbieter $\left(A_{a}\right.$ bzw. $\left.A_{k}\right)$ wurde hier ebenso, wie auch von FOTHERINGHAM (1985) vorgeschlagen, die Verkaufsfläche genutzt. Leider finden sich in den einschlägigen Quellen (FOTHERINGHAM 1985, ORPANA/LAMPINEN 2003, TIHI/ORUC 2012) für die Konzentrationsvariablen keine Überlegungen oder Anweisungen für die Gewichtung der Verkaufsfläche, so dass sie in der dieser Berechnung unterbleibt. Als Maß für die Entfernung zwischen den untersuchungsrelevanten Anbietern (f) und den anderen (a) bzw. konkurrierenden Anbietern $(k)$ wird die Straßenentfernung in Kilometern verwendet, um möglichst keine Verkehrsmittelwahl bei den (möglichen) räumlich multifinalen Einkäufen vorzugeben. Entsprechend der Formulierung von FOTHERINGHAM (1985) wurden die Distanzen mit einem Exponenten $(\lambda)$ gewichtet; da dieser weder bekannt noch ohne weiteres empirisch zu ermitteln ist und ebenso keine diesbezüglichen Vorgaben oder Empfehlungen existieren, wurde er, wie in anderen Studien, in denen keine empirische Gewichtung vorliegt (siehe Kap. 3.2.2.3), auf $\lambda=2$ festgelegt. Dies bedeutet einen vergleichsweise hohen Distanzwiderstand, was zur Folge hat, dass direkt benachbarte Anbieter (z.B. in einer Standortkooperation oder einem Einkaufszentrum) sehr stark ins Gewicht fallen, während weit entfernte den Wert der Konzentrationsvariablen nur gering erhöhen; es wird also der Vorstellung von LI/LIU (2012) Rechnung getragen, dass sich Agglomerationseffekte nur innerhalb einer bestimmten Grenze entfalten (siehe Kap. 4.2.2.1). 


$$
K_{A_{j}}=\sum_{\substack{a \\ a \neq j}} \frac{A_{a}}{d_{j a}^{\lambda}}
$$

$\mathrm{K}_{\mathrm{Aj}}=$ Konzentrationsvariable für die Ballung des Anbieters j mit allen a Anbietern

$A_{a}=$ Verkaufsfläche des Anbieters a

$\mathrm{d}_{\mathrm{j} a}=$ Entfernung $(\mathrm{km})$ von Anbieter $\mathrm{j}$ zu Anbieter a

$$
K_{K_{j}}=\sum_{\substack{k \\ k \neq j}} \frac{A_{k}}{d_{j k}^{\lambda}}
$$

$\mathrm{K}_{\mathrm{Kj}}=$ Konzentrationsvariable für die Ballung des Anbieters $\mathrm{j}$ mit allen $\mathrm{k}$ Anbietern

$A_{k}=$ Verkaufsfläche des Anbieters $k$

$\mathrm{d}_{\mathrm{jk}}=$ Entfernung $(\mathrm{km})$ von Anbieter j zu Anbieter $\mathrm{k}$

Die Kalkulation der Entfernungen erfolgte in ArcGIS auf der Grundlage des bereits für die Fahrtzeiten erstellten Straßennetzwerks (siehe Kap. 5.3.1.3). Berücksichtigt wurden hierbei jeweils alle anderen bzw. konkurrierenden Anbieter im gesamten Untersuchungsgebiet. Im Ergebnis standen also zwei Distanzmatrizen mit allen $j \times a$ - bzw. $j \times k$-Straßenentfernungen, die daraufhin mit den Verkaufsflächen der $a$ bzw. $k$ Anbieter verrechnet und jeweils für alle $j$ Anbieter summiert wurden. Die Konzentrationsvariablen sind also so aufgebaut, dass sie größer null sind (was die spätere Modelltransformation auch voraussetzt) und keine obere Grenze besitzen. Für spätere Modellvarianten wurden nach demselben Verfahren für die Lebensmittelmärkte noch betriebsformenspezifische Konzentrationsvariablen und weitere zur räumlichen Nähe im Hinblick auf Apotheken und Drogeriemärkte gebildet.

\subsubsection{Erstellung der Interaktionsmatrix und Transformation}

Alle für die Untersuchung relevanten Daten (lokale Marktanteile, Attraktivitätswerte, Fahrtzeiten, Konzentrationsvariablen) lagen in separaten Tabellen vor, die in einer MSAccess-Datenbank schrittweise verknüpft wurden. Im Ergebnis stand eine Interaktionsmatrix mit allen Kombinationen aus Nachfrageorten $(I)$ und Anbietern $(J)$ mit allen zugehörigen Informationen. Tabelle 9 zeigt eine schematische Interaktionsmatrix im Stil o.g. Beispiele und

\begin{tabular}{|c|c|c|c|c|c|c|}
\hline \multirow{2}{*}{$\begin{array}{l}\text { Nachfrageort } \\
\text { (i) }\end{array}$} & \multirow{2}{*}{$\begin{array}{l}\text { Anbieter } \\
\text { (j) }\end{array}$} & \multirow{2}{*}{$\begin{array}{l}\text { Marktanteil von Anbieter } \\
j \text { in Nachfrageort } i\left(p_{i j}\right)\end{array}$} & \multirow{2}{*}{$\begin{array}{l}\text { Fahrtzeit von Nachfrageort } i \\
\quad \text { zu Anbieter } j\left(\mathrm{~d}_{\mathrm{i} i \mathrm{i}}\right)\end{array}$} & \multicolumn{3}{|c|}{$h$ Attribute von Anbieter $j$} \\
\hline & & & & $A_{h 1 j}$ & $A_{h 2 j}$ & $A_{h 3 j}$ \\
\hline $\mathrm{i}_{1}$ & $j_{1}$ & $p_{i 1 j 1}$ & $d_{i 1 j 1}$ & $A_{h 1 j 1}$ & $A_{h 2 j 1}$ & $A_{h 3 j 1}$ \\
\hline$\dot{i}_{1}$ & $\mathrm{j}_{2}$ & $p_{i 1 j 2}$ & $d_{i 1 j 2}$ & $A_{h 1 j 2}$ & $A_{h 2 j 2}$ & $A_{h 3 j 2}$ \\
\hline $\mathrm{i}_{1}$ & $j_{3}$ & $\mathrm{p}_{\mathrm{i} 1 \mathrm{j} 3}$ & $d_{i 1 j 3}$ & $A_{h 1 j 3}$ & $A_{h 2 j 3}$ & $A_{h 3 j 3}$ \\
\hline $\mathrm{i}_{2}$ & $\mathrm{j}_{1}$ & $\mathrm{p}_{\mathrm{i} 2 j 1}$ & $d_{i 2 j 1}$ & $A_{h 1 j 1}$ & $A_{h 2 j 1}$ & $A_{h 3 j 1}$ \\
\hline$\ldots$ & $\cdots$ & $\cdots$ & $\cdots$ & $\ldots$ & $\ldots$ & $\ldots$ \\
\hline$i_{3}$ & $\mathrm{j}_{3}$ & $\mathrm{p}_{i j 33}$ & $d_{i 3 j 3}$ & $A_{h 1 j 3}$ & $A_{h 2 j 3}$ & $A_{h 2 j 3}$ \\
\hline
\end{tabular}
drei Anbieterattributen $\left(A_{h j}\right)$.

Tabelle 9: MCl-Modell - Interaktionsmatrix (schematisch)

Quelle: Eigene Darstellung 
Im letzten Schritt war die Transformation der Variablen durch geometrische Mittelwerte und Logarithmieren notwendig, um eine transformierte Interaktionsmatrix zu erhalten, die im Sinne des MCl-Modells als Datensatz in einer linearen Regressionsanalyse bearbeitet werden kann. Hierzu wurden zunächst von allen betrachteten Struktureigenschaften der Anbieter $\left(A_{j}, K_{A j}, K_{K j}\right)$ und den jeweiligen Distanzen von den Nachfrageorten $i$ zu allen $j$ Anbietern $\left(d_{i j}\right)$ die geometrischen Mittelwerte (siehe Formel 35) gebildet und die jeweiligen Ausprägungen durch diese dividiert. Im Anschluss sind die Logarithmen der Variablenspalten berechnet worden (HUFF/MCCALLUM 2008, S. 23f.; NAKANISHI/COOPER 1974, S. 304ff.). Tabelle 10 zeigt schematisch eine transformierte Interaktionsmatrix, d.h. den Aufbau des für die Regressionsanalyse präparierten Datensatzes, im Stil der o.g. Beispiele.

$$
\begin{gathered}
\bar{x}_{\text {geom. }}=\sqrt[n]{\prod_{i=1}^{n} x_{i}}(35) \\
\overline{\mathrm{x}}_{\text {geom. }}=\text { Geometrisches Mittel der } \mathrm{n} \text { Zahlen } \mathrm{x}_{1}, \ldots, \mathrm{x}_{\mathrm{n}}
\end{gathered}
$$

\begin{tabular}{|c|c|c|c|c|c|c|}
\hline \multicolumn{2}{|c|}{$\begin{array}{l}\text { Einkaufs- } \\
\text { interaktionen }\end{array}$} & \multirow{2}{*}{$\begin{array}{c}\text { Zu erklärende Größe } \\
\text { (= abhängige Variable) } \\
\log \left(p_{\mathrm{ij}} / \tilde{p}_{\mathrm{i}}\right)\end{array}$} & \multicolumn{4}{|c|}{ Erklärende Größen (= unabhängige Variablen) } \\
\hline $\mathbf{i}$ & j & & $\log \left(d_{i j} / \tilde{d}_{i}\right)$ & & $\log \left(A_{h j} / \tilde{A}_{h j}\right)$ & \\
\hline$\dot{i}_{1}$ & $\mathrm{j}_{1}$ & $\log \left(p_{i 1 j 1} / \tilde{p}_{i 1}\right)$ & $\log \left(d_{i j 11} / \tilde{d i 1}_{11}\right)$ & $\log \left(A_{h 1 j 1} / \tilde{A}_{h 1 j}\right)$ & $\log \left(A_{n 2 j 1} / \tilde{A}_{h 2 j}\right)$ & $\log \left(A_{h 31} / \tilde{A}_{h 3 j}\right)$ \\
\hline $\mathrm{i}_{1}$ & $\mathrm{j}_{2}$ & $\cdots$ & $\ldots$ & $\ldots$ & $\ldots$ & $\ldots$ \\
\hline $\mathrm{i}_{1}$ & $\mathrm{j}_{3}$ & $\ldots$ & $\ldots$ & $\ldots$ & $\ldots$ & $\ldots$ \\
\hline $\mathrm{i}_{2}$ & $j_{1}$ & $\ldots$ & $\ldots$ & $\ldots$ & $\ldots$ & $\ldots$ \\
\hline$\cdots$ & $\cdots$ & $\cdots$ & $\cdots$ & $\cdots$ & $\cdots$ & $\cdots$ \\
\hline$\dot{i}_{3}$ & $\mathrm{j}_{3}$ & $\ldots$ & $\ldots$ & $\ldots$ & $\ldots$ & $\ldots$ \\
\hline
\end{tabular}

Tabelle 10: MCl-Modell - Transformierte Interaktionsmatrix (schematisch)

Quelle: Eigene Darstellung

Vor der Erstellung der transformierten Interaktionsmatrix wurde für die Lebensmittelmärkte noch eine Datenmodifikation vorgenommen, die darauf abzielt, die Unterschiedlichkeit der Betriebsformen zu berücksichtigen und hierbei gleichzeitig die Zahl unausgefüllter Zellen in der Interaktionsmatrix weiter zu senken. Die berücksichtigten Lebensmittelanbieter umfassen kleine und großer Super- und Verbrauchermärkte sowie LM-Discounter (siehe Kap. 5.2.2.3); diese verfügen jedoch unter ansonsten gleich bleibenden Bedingungen bereits über sehr unterschiedlich große Marktgebiete, was sich bereits an ihren Standortanforderungen (siehe Anhang, Tab. A 1) ablesen lässt. In der Markt- bzw. Standortanalyse werden beispielsweise vereinfachend Radien von fünf Kilometern für Supermärkte und LM-Discounter oder zehn Kilometer für Verbrauchermärkte angenommen (KOSCHNY/LISCHKA 2009, S. 418). Daher wurde die Interaktionsmatrix für die Marktgebiete der Lebensmittelmärkte vor der Transformation noch betriebsformenspezifisch um Einträge mit großen Entfernungswerten und (nahezu) keinen erfassten Interaktionen bereinigt; hierbei wurde darauf geachtet, dass die verbleibenden Einträge in der Interaktionsmatrix noch mindestens $95 \%$ der registrierten Einkäufe abdecken. 


\subsubsection{Modellschätzung und Modellüberprüfung}

\subsubsection{Schätzung und Interpretation des Modells}

Der Vorteil einer $\mathrm{MCl}-$ Modellanalyse besteht darin, die Parameter mittels konventioneller (multipler) linearer Regressionsanalyse, d.h. über die Methode der kleinsten Quadrate, schätzen zu können, da der funktionale Zusammenhang des HuFF-Modells durch geometrische Mittelwerte und Logarithmieren linearisiert wird. Aus dem theoretischdeduktiven Modell wird also ein ökonometrisches Modell (NAKANISHI/COOPER 1974, S. 304ff.). Diese Nachbearbeitung der erhobenen Untersuchungsdaten in eine transformierte Interaktionsmatrix, d.h. in "regression-ready data" (HUFF/MCCALLUM 2008, S. 23f.), ist im letzten Schritt vollzogen worden (siehe Kap. 5.3.1.5), so dass die Daten nun für eine lineare Regressionsanalyse bereitstanden, die im Folgenden in ihren Grundzügen besprochen wird.

Die Methode der kleinsten Quadrate stellt das Standardverfahren zur Parametrisierung von linearen Regressionsmodellen dar, was vor allem der relativen Einfachheit dieser Methode geschuldet ist (VON AUER 2013, S. 55ff.). Hierbei wird von einem (theoretisch begründeten) funktionalen Zusammenhang zwischen einer abhängigen Variablen $(y)$ und einer oder mehreren $(n)$ unabhängigen (d.h. erklärenden) Variablen $\left(x_{1}, x_{2}, \ldots, x_{n}\right)$ ausgegangen (siehe Formel 36). Über Echtdaten von $i$ Beobachtungen der Variablenausprägungen von $x$ und $y$ wird eine möglichst gute Anpassung des Modells an die Echtdaten angestrebt. Diese Anpassung verläuft über die Modellparameter $\left(a, b_{1}, b_{2}, \ldots, b_{n}\right)$, die in die Funktion eingesetzt werden. Der Parameter $b$ entspricht der Steigung einer Ausgleichsgerade durch eine Punktwolke von $x$ und $y$ und repräsentiert die Richtung und die Stärke des Einflusses des Prädiktors auf die Zielvariable; ist $b$ positiv (bzw. negativ), hat der Prädiktor einen positiven (bzw. negativen) Einfluss auf $y$, d.h. die Ausgleichsgrade steigt (bzw. fällt). Der Parameter $a$ ist der Achsenabschnitt (Schnittpunkt zwischen Ausgleichsgerade und y-Achse) und gibt den Wert von $y$ bei $x=0$ an. Zudem wird im Zuge der Schätzung dem Modell ein Fehlerterm $(\varepsilon)$ hinzugefügt, der die Residuen (Abweichungen des y-Echtwertes vom modellierten y-Wert) abbildet (siehe Formel 37) (BACKHAUS et al. 2000, S. 7ff.).

$$
\begin{aligned}
& y=f\left(x_{1}, x_{2}, \ldots, x_{n}\right) \\
& \mathrm{y}=\text { Abhängige Variable } \\
& \mathrm{x}=\text { Unabhängige bzw. erklärende Variable } \\
& \mathrm{n}=\text { Anzahl erklärender Variablen }
\end{aligned}
$$

$$
\begin{aligned}
& y_{i}=a+b_{1} x_{1 i}+b_{2} x_{2 i}+\ldots+b_{n} x_{n i}+\varepsilon_{i} \\
& \mathrm{i}=\text { Anzahl Beobachtungen } \\
& \mathrm{n}=\text { Anzahl Prädiktoren } \\
& y_{i}=\text { Ausprägung der abhängigen Variable y bei Beobachtung } \mathrm{i} \\
& a=\text { Konstante (Achsenabschnitt) } \\
& \mathrm{x}_{\mathrm{ni}}=\text { Ausprägung des } \mathrm{n} \text {-ten Prädiktors bei Beobachtung } \mathrm{i} \\
& b_{n}=\text { Regressionskoeffizient des } n \text {-ten Prädiktors (Steigung) } \\
& \varepsilon_{i}=\text { Residuum, d.h. Abweichung des y-Echtwertes (yi) vom modellierten y-Wert (ŷj) }
\end{aligned}
$$

$\hat{y}_{i}=a+b_{1} x_{1 i}+b_{2} x_{2 i}+\ldots+b_{n} x_{n i}$

$\hat{y}_{\mathrm{i}}=$ Modellierte Ausprägung der abhängigen Variable bei Beobachtung $\mathrm{i}$ 
Die ursprüngliche Grundidee der Methode der kleinsten Quadrate ist, dass die Parameter soweit angepasst werden, dass die Summe der quadrierten Abweichungen der Echt- von den Modelldaten $\left(\sum \varepsilon_{l}^{2}\right)$ minimal ist, was für die Methode namensprägend war. Die Parameter lassen sich aber auch analytisch über Schätzgleichungen bestimmen, was die Basis der heutzutage angewandten Kleinste-Quadrate-Methode darstellt. Das parametrisierte Modell (Formel 38) kann auch zur Interpolation bzw. Prognose verwendet werden (Ausführliche Darstellung zum Verfahren der Kleinste-Quadrate-Methode siehe z.B. BACKHAUS et al. 2000, S. 10ff.; ECKEY et al. 2011, S. 24ff.; VON AUER 2013, S. 52ff.).

In der MCl-Modellanalyse wird ein lineares Regressionsmodell mit den Daten der transformierten Interaktionsmatrix berechnet. Die transformierten Marktanteile fungieren hierbei als abhängige Variable und die Struktureigenschaften der Alternativen (d.h. die Teilnutzen) als Prädiktoren. In MCl-Modellen wird für gewöhnlich der Achsenabschnitt a (Konstante in der Regressionsgleichung) bei der Schätzung ausgeschlossen, d.h. eine Regression durch den Ursprung durchgeführt (HUfF/MCCALLUM 2008, S. 23ff.; NAKANISHI/COOPER 1982, S. 315ff.). Im vorliegenden Fall wurde auf der Grundlage der zu prüfenden Hypothesen (siehe Kap. 5.1.2) und der theoretischen Modellformulierung (siehe Kap. 5.1.3) das in Formel 39 dargestellte Modell geschätzt.

$\log \left(\frac{p_{i j}}{\tilde{p}_{i}}\right)=b_{1} \log \left(\frac{d_{i j}}{\tilde{d}_{i}}\right)+b_{2} \log \left(\frac{A_{j}}{\widetilde{A}_{j}}\right)+b_{3} \log \left(\frac{K_{A_{j}}}{\widetilde{K}_{A_{j}}}\right)+b_{4} \log \left(\frac{K_{K_{j}}}{\widetilde{K}_{K_{j}}}\right)+\log \left(\frac{\varepsilon_{i j}}{\widetilde{\varepsilon}_{i j}}\right)$

$p_{i j}=$ Marktanteil von Anbieter $j$ in Nachfrageort $i$

$\mathrm{d}_{\mathrm{ij}}=$ Fahrtzeit von Nachfrageort i zu Anbieter $\mathrm{j}$

$A_{j}=$ Verkaufsfläche des Anbieters $j$

$\mathrm{K}_{\mathrm{Aj}}=$ Konzentrationsvariable für den Anbieter $\mathrm{j}$ für die Nähe zu anderen Einzelhandelsanbietern

$\mathrm{K}_{\mathrm{kj}}=$ Konzentrationsvariable für den Anbieter j für die Nähe zu gleichartigen Einzelhandelsanbietern

$\tilde{p}_{\mathrm{i}}=$ Geometrischer Mittelwert von allen $\mathrm{p}_{\mathrm{i}}$

$\tilde{\mathrm{d}}_{\mathrm{i}}=$ Geometrischer Mittelwert von allen $\mathrm{d}_{\mathrm{ij}}$

$\tilde{A}_{i}=$ Geometrischer Mittelwert von allen $A_{j}$

$\mathrm{K}_{\mathrm{Aj}}=$ Geometrischer Mittelwert von allen $\mathrm{K}_{\mathrm{Aj}}$

$\mathrm{K}_{\mathrm{kj}}=$ Geometrischer Mittelwert von allen $\mathrm{K}_{\mathrm{kj}}$

$b_{1}, b_{2}, b_{3}, b_{4}=$ Geschätzte Parameter

$\varepsilon_{\mathrm{ij}}=$ Residuen

Bei MCl-Modellanalysen (z.B. KUBIS/HARTMANN 2007, TIHI/ORUC 2012) werden die konventionellen Modellgütestatistiken der linearen Regressionsanalyse zur Prüfung und Interpretation der Modellfunktion herangezogen (BACKHAUS et al. 2000, S. 19ff.):

- Das Bestimmtheitsmaß $\left(R^{2}\right)$ gibt die Güte der Anpassung des Modells an die Echtdaten wieder; es beinhaltet den Anteil der von der Regressionsfunktion erklärten Varianz und ist somit zwischen null und eins normiert. Das korrigierte Bestimmtheitsmaß (Korr. $R^{2}$ ) berücksichtigt die Anzahl der Prädiktoren im Modell und berichtigt $R^{2}$ um diesen Einfluss

- Unter Berücksichtigung der Varianz sowie der Zahl der Prädiktoren und der Stichprobengröße prüft die F-Statistik, ob das Gesamtmodell auf einem vorgegebenen Niveau einer Irrtumswahrscheinlichkeit statistisch signifikant ist, d.h. 
sich mit einer hohen Wahrscheinlichkeit die ermittelten Zusammenhänge in der Grundgesamtheit finden

- Die t-Statistik prüft die einzelnen Parameter auf ihre statistische Signifikanz, d.h. auf ihren Einfluss auf die Zielvariable

- Für das Gesamtmodell und die ermittelten Parameter werden Standardfehler (mittlere Abweichung des ermittelten Wertes vom „echten“ Wert der Grundgesamtheit) und Konfidenzintervalle der Parameter (Intervall für den „echten“ Wert der Parameter) ausgegeben

- Die ermittelten Parameter beziehen sich i.d.R. auf unterschiedliche Maßeinheiten und sind daher bezüglich ihrer Einflussstärke untereinander nicht zu vergleichen. Standardisierte Regressionskoeffizienten $(\beta)$ normieren die Parameter und erlauben somit eine Vergleichbarkeit

Der Kern der Analyse ist die inhaltliche Überprüfung der Untersuchungshypothesen (siehe Kap. 5.1.2); diese erfolgt in ökonometrischen Modellen vorrangig durch die Prüfung der Wirkung der ermittelten Parameter (z.B. Hat die Fahrtzeit einen Einfluss auf die lokalen Marktanteile von Anbietern? D.h. übt dieser Prädiktor einen statistisch signifikanten Einfluss auf die Zielvariable aus?), ihrer Wirkungsrichtung (z.B. $\mathrm{H}_{2 \mathrm{a}}$ : Hat die Fahrtzeit einen negativen Einfluss auf die lokalen Marktanteile von Anbietern? D.h. ist ihr Parameter negativ?) und ihrer Größe (z.B. $\mathrm{H}_{2 \mathrm{~b}}$ : Hat die Fahrtzeit einen überlinear negativen Effekt auf die lokalen Marktanteile von Anbietern? D.h. ist ihr Parameter betragsmäßig größer eins?).

\subsubsection{2 Überprüfung und Sicherstellung der Modellgüte}

Um die Modellergebnisse im vollen Umfang interpretieren zu können, werden für lineare Regressionsmodelle statistische Ausgangsbedingungen formuliert, die erfüllt sein müssen, was jedoch häufig nicht der Fall ist. Keine der Bedingungen bedeutet jedoch, dass bei ihrer Verletzung ein Modell vollständig unbrauchbar wird, sondern lediglich, dass die ermittelten Parameter verzerrt und/oder nicht mehr „effizient“" (d.h. die bestmöglichen Parameter mit der kleinsten Streuung) sind. Allerdings besteht auch die Gefahr, dass die Teststatistiken (z.B. tTest zur Prüfung der Signifikanz einer erklärenden Variable) unbrauchbar werden, was die inhaltliche Interpretation der Modelle empfindlich einschränkt (ECKEY et al. 2011, S. 40ff.; VON AUER 2013, S. 75ff. u. 145ff.). In vielen MCl-Modellanalysen werden gar keine Tests auf Verletzung dieser Bedingungen durchgeführt bzw. dokumentiert; auch bei HuFF/McCALLUM (2008, S. 23ff.) finden sich diesbezüglich keine Aussagen. Von einigen Autoren (u.a. GONZÁLEZ-BENITO et al. 2000, NAKANISHI 1976, TIHI/ORUC 2012, TIMMERMANS 1981) wird das Datenproblem der Multikollinearität besprochen und das Modell daraufhin getestet bzw. Behandlungsmöglichkeiten implementiert. KUBIS/HARTMANN (2007) und TIHI/ORUC (2012) prüfen ihre Modelle auf Heteroskedastizität, wobei TIHI/ORUC noch weitere Voraussetzungen (keine Autokorrelation der Residuen, Normalverteilung der Residuen, Linearität des Modells) testen. Um die Modellanalyse abzusichern, werden alle genannten Voraussetzungen geprüft.

Multikollinearität bedeutet, dass nicht nur die Prädiktoren mit der Zielvariable, sondern auch zwei oder mehr Prädiktoren untereinander korrelieren. Perfekte Multikollinearität kann für gewöhnlich ausgeschlossen werden, da dies eine exakte Korrelation bzw. vollständige Vorhersagbarkeit einer erklärenden Variablen aus einer anderen bedeuten würde. Imperfekte Multikollinearität (d.h. Korrelation bis zu einem gewissen Grad) besteht hingegen 
sehr häufig ${ }^{42}$. Ist sie schwach ausgeprägt, kann sie auch vernachlässigt werden. Je stärker sie ist, desto eher können verzerrte Parameter die Folge sein, so dass die Einflüsse der einzelnen Prädiktoren nicht mehr korrekt identifiziert werden können; die Effizienz der Schätzung bleibt jedoch erhalten (ASSENMACHER 2002, S. 147ff.; ECKEY et al. 2011, S. 83ff.; VON AUER 2013, S. 523ff.). In der vorliegenden Modellierung wurde auf das in der ökonometrischen Fachliteratur (z.B. ECKEY et al. 2011, S. 92f.; PODDIG et al. 2008, S. 379f.) häufig empfohlene Verfahren der Variance Inflation Factors (VIF) zur Aufdeckung von Multikollinearität zurückgegriffen, das auch von TIHI/ORUC (2012) benutzt wird. Die VIFWerte werden für jeden Prädiktor im Modell berechnet und sind ein Indikator dafür, dass durch dem Modell hinzugefügte Prädiktoren das Bestimmtheitsmaß $R^{2}$ zwar steigt, diese Veränderung jedoch auf einer kollinearen Beziehung basiert (Berechnung siehe z.B. ECKEY et al. 2011, S. 92). Der VIF-Minimalwert beträgt eins (d.h. keinerlei Multikollinearität); in der Literatur wird der kritische Grenzwert für problematische Multikollinearität i.d.R. bei VIF $=5$ bzw. 10 angegeben (z.B. GuJARATI/PORTER 2009, S. 340; PODDIG et al. 2008, S. 379f.; URBAN/MAYERL 2008, S. 232). Im vorliegenden Fall wurde die Grenze bei VIF $=5$ angesetzt.

Für den Fall, dass Multikollinearität im Sinne einer Überschreitung des o.g. Grenzwertes festgestellt wird, sind mehrere Optionen zur Problembehebung möglich:

- In Bezug auf das MCl-Modell wendet NAKANISHI (1976, S. 26ff.) zur Lösung für Multikollinearitätsprobleme eine vorhergehende Faktorenanalyse an. Hierbei werden die Variablen anhand ihrer Zusammenhänge zu Faktoren („latenten Variablen“) zusammengefasst, die anstatt der Einzelgrößen als unabhängige Variablen ins Modell aufgenommen werden. Hierdurch wird das Multikollinearitätsproblem beseitigt, jedoch ist gegenüber dieser rein statistischen Lösung einzuwenden, dass sie notwendigerweise einen deutlichen Informationsverlust darstellt und die einzelnen unabhängigen Variablen nicht mehr inhaltlich als (ökonomische) Erklärungsgrößen identifizierbar und interpretierbar sind (ASSENMACHER 2002, S. 159)

- Timmermans (1981, S. 45ff.) wendet in seinem von Multikollinearität betroffenen MCIModell eine andere Schätzmethode (Ridge Regression) an, deren geschätzte Parameter jedoch bewusst verzerrt sind

- Häufig wird auch die Option genannt, stark korrelierende Prädiktoren aus dem Modell auszuschließen, wobei hier wiederum die Gefahr einer Fehlspezifikation besteht (ASSENMACHER 2002, S. 155; PODDIG et al. 2008, S. 383). Das MCl-Modell von TIHI/ORUC (2012, S. 43) wird auf diese Weise „korrigiert"

- Cliquet (1995, S. 285f.) und GonZÁlez-Benito et al. (2000, S. 175f.) nutzen eine schrittweise Regression zur Beseitigung von Multikollinearität durch den Ausschluss redundanter Variablen; auch bei HUfF/MCCALLUM (2008, S. 25) kommt dieses Verfahren zum Einsatz, wenn auch nicht ausdrücklich benannt

\footnotetext{
${ }^{42}$ In inhaltlicher Hinsicht könnte das Auftreten von Multikollinearität bedeuten, dass die zugrunde gelegte Theorie insofern inkorrekt ist, als dass sie einen überflüssigen kausalen Zusammenhang postuliert (ASSENMACHER 2002, S. 155). Denkbar ist jedoch auch, dass die Erklärungsgrößen deswegen nicht voneinander statistisch unabhängig sind, weil zwischen ihnen ein plausibler theoretisch fundierter Zusammenhang besteht (GüSSEFELDT 1999, S. 299f.). Im vorliegenden Fall wäre z.B. ein positiver statistischer Zusammenhang zwischen der Verkaufsfläche der Anbieter und der Fahrtzeit vom Kundenwohnort denkbar, was sich etwa damit erklären ließe, dass großflächige Einzelhandelsbetriebe vorwiegend in nicht-integrierten Lagen abseits des Siedlungsmittelpunktes lokalisiert sind.
} 
Abseits davon schlägt die Fachliteratur noch eine Reihe weiterer Verfahren vor, die zumeist darauf abzielen, die Einflüsse korrelierender Prädiktoren zu eliminieren, indem das Modell durch Hilfsregressionen in mehrere Gleichungen zerlegt wird und anhand der jeweiligen Residuen Resteinflüsse der von Multikollinearität betroffenen Variablen bestimmt und in ein neues Modell aufgenommen werden; hierzu zählen die partielle Pfadanalyse (GüSSEFELDT 1999, S. 299ff.) und die Orthogonalisierung (PODDIG et al., S. 383f.). Diese Verfahren beinhalten jedoch das Problem, dass - im Fall von kollinearen Beziehungen - nicht mehr die „vollen“ Einflüsse der erklärenden Variablen gemessen werden und die geschätzten Parameter nicht mehr im hier angedachten Sinne interpretierbar sind; diese Ansätze sind für die Bildung einer Modellgleichung, die später zu Simulationszwecken ins HuFF-Modell eingesetzt werden kann, nicht zielführend. Unabhängig davon ob in den hier geschätzten Modellen Multikollinearität im Sinne o.g. Grenzwerte festgestellt wurde, erfolgte daher neben der konventionellen Regressionsanalyse noch eine separate schrittweise Regression, deren Einzelheiten in Kap. 5.3.2.3 besprochen werden.

Wenn die Streuung der Residuen in einem linearen Regressionsmodell über alle Ausprägungen der erklärenden Variablen konstant ist bzw. sich nicht signifikant unterscheidet, liegt Homoskedastizität vor. Ist die Streuung hingegen von einem oder mehreren Prädiktoren statistisch abhängig, liegt Heteroskedastizität vor, was bedeuten kann, dass die ermittelten Parameter nicht im o.g. Sinne effizient sind und die Modellgütestatistiken ggf. Fehlaussagen treffen (ECKEY et al. 2011, S. 98ff.; vON AUER 2013, S. 393ff.). Um dieses residuenbezogene Merkmal zu prüfen, wurden die hier geschätzten Modelle analog zu KUBIS/HARTMANN (2007) und TIHI/ORUC (2012) einem Test auf Heteroskedastizität unterzogen. Die diesbezüglichen Testverfahren basieren darauf, dass über Hilfsregressionen der Einfluss der Modellprädiktoren auf die (quadrierten) Residuen geprüft wird; ihr Ergebnis ist die Prüfung ob eine statistisch signifikante Heteroskedastizität vorliegt. Wenn die Diagnose sehr explorativ verläuft, d.h. nichts über die mögliche Heteroskedastizität bekannt ist, wird hierfür der White-Test empfohlen. Der Test prüft die Einflüsse der erklärenden Variablen sowie ihrer Quadrate und Kreuzprodukte. Das Ergebnis besteht hierbei, wie bei den anderen Tests, in einer Teststatistik, mit der eine sich signifikant niederschlagende Heteroskedastizität sichtbar wird (ADKINS 2013, S. 170ff.; vON AUER 2013, S. 400ff.). Im vorliegenden Fall wurde daher der White-Test verwendet (Berechnung siehe z.B. VON AUER 2013, S. 406f.).

Wird Heteroskedastizität festgestellt und als schwerwiegend empfunden, bestehen prinzipiell zwei Möglichkeiten der Problembehebung:

- Der verallgemeinerte Kleinste-Quadrate-Ansatz basiert auf einer Gewichtung der Regressionsschätzung mit den betroffenen Variablen oder den Residuen bzw. mit einer Transformation dieser Werte (z.B. Quadratwurzel, Potenz). Das Ergebnis des Verfahrens sind Parameterwerte, die um den Einfluss der Heteroskedastizität korrigiert wurden. Allerdings erfordert das Verfahren ein ausführliches Wissen über die relevanten Variablen und eine Entscheidung darüber, wie die Funktion gewichtet wird, wobei naturgemäß auch Fehlschlüsse möglich sind (ADKINS 2013, S. 177ff.; VON AUER 2013, S. 407ff.). In Bezug auf MCI-Modelle zeigen NAKANISHI/COOPER (1974, S. 306ff.), dass bei einem von Heteroskedastizität betroffenen Modell durch eine verallgemeinerte KQ-Schätzung die ermittelten Parameter von denen der normalen KQ-Schätzung abweichen, jedoch in ihrer Wirkungsrichtung und 
Größenordnung sowie hinsichtlich ihres signifikanten Erklärungsbeitrages der normalen KQ-Schätzung entsprechen

- Als deutlich unkompliziertere Alternative stellt sich das Huber-White-Verfahren dar; es ermittelt dieselben Parameter wie eine normale Schätzung, jedoch gegen die störenden Einflüsse robuste (d.h. im Zweifelsfall höhere) Standardfehler (heteroscedasticity-robust standard errors, kurz: HC-robust) sowie i.d.R. breitere Konfidenzintervalle der Parameter. Die Hypothesentests (F-Statistik, t-Statistik) werden hierdurch trotz Heteroskedastizität wieder gültig (ADKINS 2013, S. 176f.; vON AUER 2013, S. 412ff.). Wie HAYES/CAI (2007, S. 713f.) zeigen, ist es jedoch möglich, dass ein Prädiktor, der bei einer konventionellen Schätzung signifikant wirkt, bei einer HC-robusten Schätzung nicht mehr als signifikant hervortritt

Auf Basis der in der Literatur ausgesprochenen Empfehlung (z.B. HAYES/CAI 2007, S. 411f.; VON AUER 2013, S. 412f.) wurden alle Modelle mit dem Huber-White-Verfahren geschätzt, da für die erste Variante zu große methodische Unsicherheiten bestehen (v.a. Gewichtung). In der Darstellung der Modellgütekriterien werden daher die Ergebnisse der Huber-WhiteSchätzung gezeigt und mit denen einer konventionellen KQ-Schätzung verglichen.

Analog zum Vorgehen von TIHI/ORUC (2012) wurden die Modelle jeweils noch hinsichtlich der folgenden statistischen Annahmeverletzungen getestet:

- Zur Prüfung auf Autokorrelation (Korrelation der Residuen) wurde der Durbin-WatsonTest vorgenommen (VON AUER 2013, S. 438ff.)

- Zur Prüfung der Residuen auf Normalverteilung wurde der Doornik-Hansen-Test in Kombination mit einer grafischen Auswertung (Diagramm zur Residuenverteilung) vorgenommen (ADKINS 2013, S. 72ff.)

- Die Linearität des Modells wurde mit dem Ramsey-RESET-Test geprüft (VON AUER 2013, S. 312ff.). Hierbei muss bedacht werden, dass es sich beim MCl-Modell um einen eigentlich nicht-linearen Zusammenhang handelt, der bereits linearisiert wurde und - selbst bei einem ungünstigen Testergebnis - eine weitere Linearisierung (z.B. durch Logarithmen) schon allein mathematisch nicht möglich wäre

Sofern nicht anders angegeben, wurde bei allen Modellgütestatistiken und weiteren Tests stets das übliche Signifikanzniveau von $95 \%$ zu Grunde gelegt, d.h. ein statistisches Ergebnis wird dann als "gültig“ akzeptiert, wenn die statistische Wahrscheinlichkeit eines Irrtums (Irrtumswahrscheinlichkeit $p$ ) bei unter fünf Prozent liegt. Die in den Kapiteln 5.3.2.1 und 5.3.2.2 beschriebenen Schätzungen und Überprüfungen der MCl-Modelle wurden mit gretl (Version 1.9) vorgenommen. In die auf ökonometrische Modelle spezialisierte OpenSource-Software sind alle hier aufgeführten Analysetechniken implementiert bzw. in Funktionspaketen (sols - standardisierte Koeffizienten) verfügbar (hierzu insb. ADKINS 2013).

\subsubsection{Schrittweise Regression}

Zusätzlich zur oben beschriebenen Modellschätzung und -überprüfung wurde analog zu CLIQUET (1995) und GONZÁLEZ-BENITO et al. (2000) sowie der exemplarischen Darstellung von HufF/MCCALLUM (2008) eine schrittweise Regression zur Bildung der MCl-Modelle durchgeführt. Dieses Verfahren basiert auf der konventionellen Kleinste-Quadrate-Methode und erweitert diese durch ein Verfahren zur Auswahl der ins Modell aufzunehmenden 
Variablen; hierbei wird auf die Methode der partiellen Korrelation zurückgegriffen. Bei der schrittweisen Regression werden die Prädiktoren nach bestimmten Kriterien nacheinander in das Regressionsmodell aufgenommen und separat auf ihren zusätzlichen Erklärungsbeitrag hin geprüft. Ziel dieser Methode ist die Identifikation und der Ausschluss redundanter Variablen und - damit verbunden - die Eindämmung von Multikollinearität. Zur genauen Ausprägung des Auswahlverfahrens und der zu Grunde gelegten Kriterien existieren verschiedene Varianten (BORTZ/SCHUSTER 2010, S. 358).

Eine schrittweise Regression zur Prüfung eines multiplen linearen Regressionsmodells $(y=a$ $\left.+b_{1} x_{1}+b_{2} x_{2}+\ldots+b_{n} x_{n}\right)$ verläuft schematisch wie folgt (URBAN/MAYERL 2008, S. 112f.):

- Zunächst wird geprüft, welcher der Prädiktoren $\left(x_{1}, x_{2}, \ldots, x_{n}\right)$ am stärksten mit der Zielvariable $(y)$ korreliert. Mit diesem wird ein einfaches Regressionsmodell $(y=a+$ $b x)$ geschätzt und ein Bestimmtheitsmaß $\left(R^{2}\right)$ dieses Modells berechnet. Der in diesem Modell benutzte Prädiktor wird aus allen anderen zur Verfügung stehenden Variablen herauspartialisiert, d.h. diese werden um den statistischen Einfluss dieser ersten benutzten Variable bereinigt; dadurch verändern sich die Korrelationen der übrig gebliebenen Variablen mit der Zielvariablen

- Aus den übrig gebliebenen Prädiktoren wird auf der Grundlage der zuletzt ermittelten Korrelationen wieder der mit der größten Korrelation identifiziert und ins obige Regressionsmodell aufgenommen. Es wird wiederum ein Bestimmtheitsmaß dieses Modells berechnet und daraufhin geprüft, ob hierdurch ein signifikanter Zuwachs der Varianzaufklärung erfolgt ist. Sofern der Zuwachs signifikant ist, wird abermals der Einfluss auch dieses Prädiktors aus den anderen Variablen herauspartialisiert, was nochmals die Korrelationen zwischen den übrigen Variablen und der Zielvariablen beeinflusst. Wird kein signifikanter $R^{2}$-Zuwachs festgestellt, wird die Schätzung abgebrochen

- Auf der Grundlage der neuen Korrelationswerte wird der nächste Prädiktor mit der höchsten Korrelation aufgenommen, in ein neues Modell gebildet und im o.g. Sinne bewertet. Dieser Vorgang wird so häufig wiederholt wie erklärende Variablen vorhanden sind und diese eine signifikante Erhöhung von $R^{2}$ herbeiführen

Die partielle Korrelation wirkt hier also als Filterfunktion für kollineare Variablen, da sie den „Rest-Einfluss“ der getesteten Variablen bestimmt, weshalb in der schrittweisen Regression nur jene Prädiktoren aufgenommen werden, die auch für sich genommen einen signifikanten Beitrag zur Erklärung der Zielvariablen leisten; die ermittelten Parameter sind hierbei genau wie bei der konventionellen linearen Regressionsanalyse zu interpretieren. In der Literatur (z.B. BORTZ/SCHUSTER 2010, S. 358; URBAN/MAYERL 2008, S. 113f.) wird ausdrücklich darauf hingewiesen, dass eine schrittweise Regression niemals sachlogische Erwägungen und eine theoretische Fundierung ersetzen kann und ein schrittweise gebildetes Modell nicht das „Richtige“ oder „Beste“ sein muss; beispielsweise besteht das Risiko, dass eigentlich wirksame Variablen aus dem Modell ausgeschlossen werden. Daher wird das schrittweise Verfahren hier als Ergänzung der in Kap. 5.3.2.1 und 5.3.2.2 vorgestellten Analyse genutzt und diesen Ergebnissen gegenübergestellt.

Im vorliegenden Fall wurde die in SPSS (Version 18) implementierte Methode der schrittweisen Regression (Stepwise) genutzt (BÜHL 2010, S. 410f.). Als Grenzwerte der für oder gegen eine Aufnahme von Variablen sprechenden Irrtumswahrscheinlichkeiten wurden 
hierbei die Standardwerte zu Grunde gelegt (Put-in-Kriterium für die Aufnahme einer Variablen auf Grundlage der Partialkorrelation: $p<5 \%$, Put-out-Kriterium für den Ausschluss einer Variablen: $p>10 \%$ ).

\subsubsection{Berücksichtigung räumlicher Nicht-Stationarität}

Bei der Anwendung von Regressionsmodellen auf räumliche Phänomene tritt ganz allgemein die Frage in den Vordergrund, ob die analysierten Beziehungen über den gesamten Untersuchungsraum konstant ausgeprägt sind oder ob stattdessen von einer räumlichen Nicht-Stationarität auszugehen ist; dies bedeutet, dass zwar grundsätzlich die postulierten Wirkungszusammenhänge über das gesamte betrachtete Gebiet bestehen, jedoch in differenzierter Ausprägung. In humangeographischen Zusammenhängen liegt die Vorstellung nahe, dass das menschliche Handeln aufgrund von unterschiedlichen Wertvorstellungen und Präferenzen räumlich variiert (CHARLTON et al. 2006, S. 1f.). Auch in Bezug auf Marktgebietsmodelle ist dies mehrfach diskutiert worden; zum Beispiel argumentiert BUCKLIN (1971b, S. 495f.), dass der Distanzexponent selbst in einem großen Zusammenhang mit der Entfernung zu den Angebotsstandorten steht bzw. mit ihr zusammen ansteigt. GHOSH (1984, S. 426f.) bespricht ausführlich die Problematik räumlich nichtstationärer Zusammenhänge in Marktgebietsmodellen und geht in diesem Zusammenhang von einer räumlich variierenden Wahrnehmung von Teilnutzenelementen aus, die auf zwei Ursachen zurückgeführt werden:

- Eine Variation in den sozio-ökonomischen Eigenschaften der Konsumenten führt dazu, dass die zur Verfügung stehenden Einkaufsoptionen räumlich differenziert wahrgenommen werden. Hierzu zählen beispielsweise die zwischen Haushalten mit höheren und niedrigeren Einkommen unterschiedliche Mobilitätsbereitschaft, die sich demnach in einer geringeren bzw. höheren Distanzwahrnehmung ausdrücken kann und somit auch die Einkaufsstättenwahl beeinflusst

- Auch die Standortkonfiguration der zur Verfügung stehenden Anbieter, die letztlich die räumliche Wettbewerbssituation widerspiegelt, beeinflusst die Wahrnehmung ihrer Struktureigenschaften durch die Verbraucher. Die Wahrnehmung der Distanz bzw. Fahrtzeit kann beispielsweise davon abhängen, wie nah die nächstmögliche Alternative ist; je weiter diese entfernt ist, desto geringer wäre demnach die Distanzsensibilität der Konsumenten. Allgemeiner ausgedrückt würde dies bedeuten, dass die Wahrnehmungsfunktionen der Teilnutzen umso stärker (negativ oder positiv) ausgeprägt sind, je größer die Wettbewerbsintensität ist

In der Konsequenz müssten in MCl-Modellanalysen ortsspezifische Parameter geschätzt werden, wofür die konventionelle lineare Regressionsanalyse keine Lösung bietet. Daher wurde für die vorliegende Untersuchung ein relativ neues Verfahren angewandt, mit dem es möglich ist, räumliche Nicht-Stationarität in Regressionsmodellen zu berücksichtigen: Die geographisch gewichtete Regression (Geographically Weighted Regression, kurz: GWR) basiert auf dem Grundprinzip der konventionellen linearen (einfachen oder multiplen) Regressionsanalyse und ist somit zum MCl-Modell kompatibel. Die Methode wurde für geographische Zwecke entwickelt und etabliert und ermöglicht die Modellierung von räumlich nicht konstant wirkenden Zusammenhängen; sie findet daher in wirtschafts- und sozialwissenschaftlichen bzw. humangeographischen Fragestellungen eine immer größere 
Anwendung (z.B. ECKEY et al. 2005, HELBICH/GÖRGL 2010, MüLLER 2012; Überblick z.B. WHEELER 2014).

Im Gegensatz zur konventionellen Regressionsanalyse, mit der ein globales Modell, d.h. mit denselben Parametern für den gesamten Untersuchungsraum, aufgestellt wird, ermittelt die GWR ortsspezifische Parameter für jedes Geoobjekt (z.B. Punkt- oder Flächenform) im Untersuchungsraum (siehe Formel 40). Die Gewichtung ist hierbei distanzabhängig und besteht darin, dass näher zusammen liegende Objekte stärker berücksichtigt werden als weiter entfernte. Neben örtlichen Regressionskoeffizienten werden ferner ortsspezifische Teststatistiken und auch ein lokales Bestimmtheitsmaß $\left(R^{2}\right)$ berechnet (CHARLTON et al. 2006, S. 2ff.). Eine Voraussetzung für die Anwendung ist, dass neben dem eigentlichen Datensatz $\left(y, x_{1}, x_{2}, \ldots, x_{n}\right)$ die zu betrachtenden Objekte (hier: Nachfrageorte des Untersuchungsgebietes) georeferenziert verfügbar sind, was im vorliegenden Fall gewährleistet ist (siehe Kap. 5.3.1.1).

$$
\begin{aligned}
& y_{i}=a_{\left(k_{1}, k_{2}\right)}+b_{1\left(k_{1}, k_{2}\right)} x_{1 i}+b_{2\left(k_{1}, k_{2}\right)} x_{2 i}+\ldots+b_{n\left(k_{1}, k_{2}\right)} x_{n i}+\varepsilon_{i\left(k_{1}, k_{2}\right)} \\
& \mathrm{i}=\text { Anzahl Beobachtungen } \\
& \mathrm{n}=\text { Anzahl Prädiktoren } \\
& \mathrm{y}_{\mathrm{i}}=\text { Ausprägung der abhängigen Variable y bei Beobachtung i } \\
& \mathrm{a}=\text { Konstante (Achsenabschnitt) } \\
& \mathrm{x}_{\mathrm{ni}}=\text { Ausprägung des n-ten Prädiktors bei Beobachtung i } \\
& \mathrm{b}_{\mathrm{n}}=\text { Regressionskoeffizient des n-ten Prädiktors (Steigung) } \\
& \left.\varepsilon_{\mathrm{i}}=\text { Residuum, d.h. Abweichung des y-Echtwertes (yi) vom modellierten y-Wert ( } \hat{\mathrm{y}}_{\mathrm{i}}\right) \\
& \mathrm{k}_{1}, \mathrm{k}_{2}=\text { Räumliche Koordinaten des Beobachtungsobjektes i }
\end{aligned}
$$

Sowohl die Parameter als auch die Modellgüte können hierbei lokal sehr stark variieren. Wie HELBICH/GÖRGL (2010, S. 109) zeigen, ist es durchaus möglich, dass unabhängige Variablen in einzelnen Gebieten keinen und in anderen Gebieten einen sehr hohen Einfluss auf die Zielvariable haben. Auch die Vorzeichen der Koeffizienten können sich verändern, was bedeutet, dass ein Prädiktor in bestimmten Gebieten einen positiven, in anderen Gebieten einen negativen Einfluss ausübt. Ganz allgemein trägt die GWR-Schätzung im Regelfall zu einer höheren Varianzaufklärung des Gesamtmodells $\left(R^{2}\right)$ bei (z.B. HELBICH/GöRGL 2010, S. 109; WHEELER 2014, S. 1450ff.) und ist dabei imstande, plausibel angenommene räumlich variierende Zusammenhänge zu modellieren. Die Methode ist also als Optimierung eines ansonsten theoretisch und empirisch abgesicherten Globalmodells zu verstehen und kann in diesem Zusammenhang auch zur explorativen Analyse eingesetzt werden.

In der vorliegenden Untersuchung wurden ergänzend zu den regulären $\mathrm{MCl}$-Modellen unter Anwendung der konventionellen linearen Regression (Kap. 5.3.2.1 und 5.3.2.2) und der schrittweisen Regression (Kap. 5.3.2.3) noch jeweils Varianten auf Basis der GWR berechnet. Da GWR-Modelle in ESRI ArcGIS (ab Version 10) implementiert sind, wurde hierfür diese Software mit den zugehörigen Standardeinstellungen verwendet (ESRI $2013 \mathrm{C}$, d). Die GWR-Analyse erfolgte im vorliegenden Fall mit dem Sinn einer Modelloptimierung, da hier keine Hypothesen zu räumlich nicht-stationären Zusammenhängen geprüft werden sollten. Das Ergebnis besteht also in räumlich differenzierten Nutzenfunktionen; jeder Nachfrageort wird mit eigenen Regressionskoeffizienten versehen. Die ermittelten Parameter und Modellgütestatistiken wurden mit den Ergebnissen der konventionellen Schätzungen verglichen und zu Übersichtszwecken kartografisch dargestellt. 


\section{$6 \quad$ Darstellung der Ergebnisse}

In diesem Kapitel werden die empirischen Untersuchungsergebnisse dargestellt ${ }^{43}$; die Reihenfolge entspricht hierbei der tatsächlichen Vorgehensweise (Kap. 5). Zunächst werden kurz die Ergebnisse der Angebotserhebung sowie - exemplarisch - die Ergebnisse der einzelnen Modellschritte gezeigt. Im Hauptteil erfolgen die deskriptive Auswertung der Haushaltsbefragung und die Darstellung der Modellierungsergebnisse und der Modellgütestatistiken und somit die statistische Interpretation der MCI-Modelle. Die inhaltliche Interpretation der Ergebnisse erfolgt in Kapitel 7.

\subsection{Einzelhandelsangebot und Standortstruktur}

\subsubsection{Bestand des Einzelhandelsangebotes}

\subsubsection{Einzelhandelsangebot im Untersuchungsgebiet}

Der erste Auswertungsschritt bestand in der Aufarbeitung des Einzelhandelsangebotes im Untersuchungsgebiet, um darauf aufbauend die untersuchungsrelevanten Anbieter zu identifizieren. Auf der Grundlage der hier verwendeten Einzelhandelsdefinition (siehe Kap. 5.2.2.2) wurden in den sieben Gemeinden insgesamt 584 Einzelhandelsanbieter mit einer gesamten Verkaufsfläche von 171.221 qm erfasst. Tabelle 11 zeigt die Verteilung des erhobenen Einzelhandelsangebotes auf der Ebene der Gemeinden (Stand: März 2012). Der Großteil des Angebots - ca. $75 \%$ aller Einzelhandelsbetriebe und ca. $90 \%$ der gesamten Verkaufsfläche - ist in den Kernstadtbereichen der drei Mittelzentren Beverungen, Holzminden und Höxter lokalisiert.

\begin{tabular}{lcc}
\hline Gemeinde & Verkaufsstellen & Verkaufsfläche [qm] \\
\hline Beverungen & 127 & 33.039 \\
davon Kernstadt & 96 & 31.029 \\
Boffzen (SG Boffzen) & 17 & 3.155 \\
Derental (SG Boffzen) & 2 & 180 \\
Fürstenberg (SG Boffzen) & 6 & 585 \\
Holzminden & 196 & 58.570 \\
davon Kernstadt & 185 & 57.690 \\
Höxter & 226 & 73.547 \\
davon Kernstadt & 161 & 65.758 \\
Lauenförde (SG Boffzen) & 10 & 2.145 \\
\hline Insgesamt & $\mathbf{5 8 4}$ & $\mathbf{1 7 1 . 2 2 1}$ \\
\hline
\end{tabular}

Tabelle 11: Einzelhandelsangebot im Untersuchungsgebiet nach Gemeinden Quelle: Eigene Darstellung, Datengrundlage: Eigene Erhebungen und Berechnungen

\footnotetext{
${ }^{43}$ Zwischen- und Teilergebnisse dieser Untersuchung sind bereits im Rahmen zweier wissenschaftlicher Aufsätze (WIELAND 2012 u. 2013) veröffentlicht worden.
} 
Ausgehend von der zusammengefassten Branchenkategorisierung (siehe Anhang, Tabelle A 6) ergibt sich die in Tabelle 12 dargestellte Verteilung des Einzelhandelsangebotes im Untersuchungsgebiet auf die acht Branchen und eine Restkategorie (Sonstiges). Der größte Anteil an Anbietern und Verkaufsfläche fällt auf den Lebensmitteleinzelhandel (Sortimentsschwerpunkt) ab; hierzu zählen neben den Lebensmittelmärkten auch Verkaufsstellen des Lebensmittelhandwerks (Bäckereien, Metzgereien) sowie weitere Fachund Spezialgeschäfte (z.B. Reformhaus, Weinhandlung). Der zweitgrößte Anteil an Verkaufsfläche entfällt auf den Bereich Bau/Garten, wobei hier neben den Bau- und Heimwerkermärkten, die den Großteil der Verkaufsfläche ausmachen, auch etwa Blumenläden (Pflanzen und Gartenbedarf) oder Spezialgeschäfte des Heimwerkerbedarfs (z.B. Farben, Tapeten) hinzuzählen. Eine vollständige Aufstellung der branchenspezifischen Ausstattung der Ortsteile mit Einzelhandelsangebot findet sich im Anhang (Tabelle A 6).

\begin{tabular}{lcc}
\hline Branche & Verkaufsstellen & Verkaufsfläche [qm] \\
\hline Apotheken & 25 & 1.196 \\
Bau/Garten & 49 & 34.680 \\
Bekleidung & 64 & 22.035 \\
Drogerie & 19 & 5.214 \\
Elektrohaushaltsgeräte/Unterhaltungselektronik & 42 & 10.438 \\
Lebensmittel & 213 & 43.341 \\
Möbel/Einrichtungsgegenstände & 30 & 20.996 \\
Schuhe/Lederwaren & 21 & 4.641 \\
Sonstige & 121 & 28.680 \\
\hline EH insgesamt & $\mathbf{5 8 4}$ & 171.221 \\
\hline
\end{tabular}

Tabelle 12: Einzelhandelsangebot im Untersuchungsgebiet nach Leitbranchen Quelle: Eigene Darstellung, Datengrundlage: Eigene Erhebungen und Berechnungen

\subsubsection{Untersuchungsrelevantes Einzelhandelsangebot}

Die untersuchungsrelevanten Einzelhandelsanbieter wurden anhand des Kriterienkatalogs in Kap. 5.2.2.3 abgegrenzt. Nach dieser Definition sind im Untersuchungsgebiet insgesamt 27 Lebensmittelmärkte, vier Bau-/Heimwerkermärkte, fünf Elektronikmärkte sowie zehn Anbieter von Möbeln und Einrichtungsgegenständen identifiziert worden, die im weiteren Verlauf der Untersuchung berücksichtigt wurden. Insgesamt umfassen die Lebensmittelmärkte eine Verkaufsfläche von rd. 31.000 qm, die Baumärkte rd. 21.000 qm, die Elektronikmärkte rd. 7.000 qm und die Möbel- und Einrichtungsmärkte rd. 17.000 qm. Bei den (häufig großflächigen) Fachmärkten beschränkt sich das Angebot im Hinblick auf die räumliche Verteilung der Anbieter und insbesondere der Verkaufsfläche im Wesentlichen auf die drei Mittelzentren. Lebensmittelmärkte nach der hier zu Grunde gelegten Definition finden sich dagegen auch in mehreren kleinen unterzentralen Gemeinden bzw. kleinen Ortsteilen. Tabelle 13 fasst das untersuchungsrelevante Angebot (insgesamt 46 Anbieter) nach Gemeinden zusammen. Die erfassten Lebensmittelmärkte setzen sich nach der hier zu Grunde gelegten Abgrenzung der Betriebsformen (siehe Kap. 5.2.2.3) aus vier Supermärkten, 10 Verbrauchermärkten und 13 Lebensmittel-Discountern zusammen. 
Räumliches Einkaufsverhalten und Standortpolitik im Einzelhandel unter Berücksichtigung von Agglomerationseffekten

\begin{tabular}{|c|c|c|c|c|c|c|c|c|}
\hline \multirow[b]{2}{*}{ Gemeinde } & \multicolumn{2}{|c|}{$\begin{array}{l}\text { Lebensmittel- } \\
\text { märkte }\end{array}$} & \multicolumn{2}{|c|}{$\begin{array}{l}\text { Bau-/Heimwerker- } \\
\text { märkte }\end{array}$} & \multicolumn{2}{|c|}{ Elektronikmärkte } & \multicolumn{2}{|c|}{$\begin{array}{l}\text { Möbel-/Einrichtungs- } \\
\text { märkte }\end{array}$} \\
\hline & Anzahl & VKF [qm] & Anzahl & VKF [qm] & Anzahl & VKF [qm] & Anzahl & VKF [qm] \\
\hline Beverungen & 5 & 4.958 & 1 & 2.493 & 1 & 1.200 & 3 & 1.780 \\
\hline Boffzen (SG Boffzen) & 2 & 1.700 & 0 & 0 & 0 & 0 & 0 & 0 \\
\hline Derental (SG Boffzen) & 0 & 0 & 0 & 0 & 0 & 0 & 0 & 0 \\
\hline Fürstenberg (SG Boffzen) & 0 & 0 & 0 & 0 & 0 & 0 & 0 & 0 \\
\hline Holzminden & 8 & 11.919 & 1 & 3.000 & 3 & 4.250 & 4 & 4.400 \\
\hline Höxter & 11 & 10.709 & 2 & 15.242 & 1 & 1.450 & 3 & 10.395 \\
\hline Lauenförde (SG Boffzen) & 1 & 1.800 & 0 & 0 & 0 & 0 & 0 & 0 \\
\hline Insgesamt & 27 & 31.086 & 4 & 20.735 & 5 & 6.900 & 10 & 16.575 \\
\hline
\end{tabular}

Tabelle 13: Untersuchungsrelevante Anbieter nach Gemeinden

Quelle: Eigene Darstellung, Datengrundlage: Eigene Erhebungen und Berechnungen

In Kap. 1.2.2 sind die hier genutzten Typen von Angebotsstandorten bzw. Agglomerationen definiert worden. Die 46 untersuchungsrelevanten Einzelhandelsbetriebe wurden dementsprechend diesen Typen zugeteilt (siehe Tabelle 14). Der Großteil der (häufig großflächigen) Anbieter befindet sich in dezentralen Lagen, vorrangig in den Gewerbegebieten (im Sinne von § 8 BauNVO) der Mittelzentren bzw. in Sondergebieten ( 11 BauNVO), die unmittelbar an Gewerbegebiete angrenzen; hierzu gehören das Gewerbegebiet Zum Osterfeld in Beverungen, das Gewerbegebiet Bülte in Holzminden und die Gewerbegebiete Zur Lüre und Pfennigbreite in Höxter (siehe auch Karte 2). Angrenzend an das Höxteraner Gewerbegebiet Zur Lüre befinden sich mit einem OBI-Baumarkt (siehe Abb. 11) und dem Möbelmarkt Weser Wohnwelt die beiden größten untersuchungsrelevanten Anbieter (jeweils über 10.000 qm Verkaufsfläche). Im Holzmindener Gewerbegebiet Bülte befinden sich zwei Elektrofachmärkte (Expert, Media Markt) und zudem der größte Lebensmittelmarkt des Untersuchungsgebietes (SBWarenhaus Kaufland) und ein LM-Discounter (Aldi).

\begin{tabular}{rccccc}
\hline Angebotsstandort-/Lagetyp & $\begin{array}{c}\text { Lebens- } \\
\text { mittel- } \\
\text { märkte }\end{array}$ & $\begin{array}{c}\text { Bau- } \\
\text { märkte }\end{array}$ & $\begin{array}{c}\text { Elektronik- } \\
\text { märkte }\end{array}$ & $\begin{array}{c}\text { Möbel-I } \\
\text { Einrichtungs- } \\
\text { märkte }\end{array}$ & Gesamt \\
\hline $\begin{array}{r}\text { Agglomeration (Innenstadt), zentral } \\
\text { Agglomeration (Gewerbegebiet), dezentral }\end{array}$ & 1 & 0 & 0 & 1 & 2 \\
Agglomeration (Einkaufszentrum), dezentral & 1 & 3 & 4 & 5 & 17 \\
Agglomeration (Standortkooperation), dezentral & 6 & 0 & 0 & 1 & 7 \\
Agglomeration (Nachbarschafts-/Dorfzentrum), & 1 & 0 & 0 & 0 & 1 \\
zentral & & & & 3 & 14 \\
keine Agglomeration, dezentral & 10 & 1 & 0 & 4 \\
keine Agglomeration, Streulage & 3 & 0 & 1 & 0 & 4 \\
\hline Gesamt & $\mathbf{2 7}$ & $\mathbf{4}$ & $\mathbf{5}$ & 10 & $\mathbf{4 6}$ \\
\hline
\end{tabular}

Tabelle 14: Untersuchungsrelevante Anbieter nach Lagetypen

Quelle: Eigene Darstellung, Datengrundlage: Eigene Erhebungen und Berechnungen 


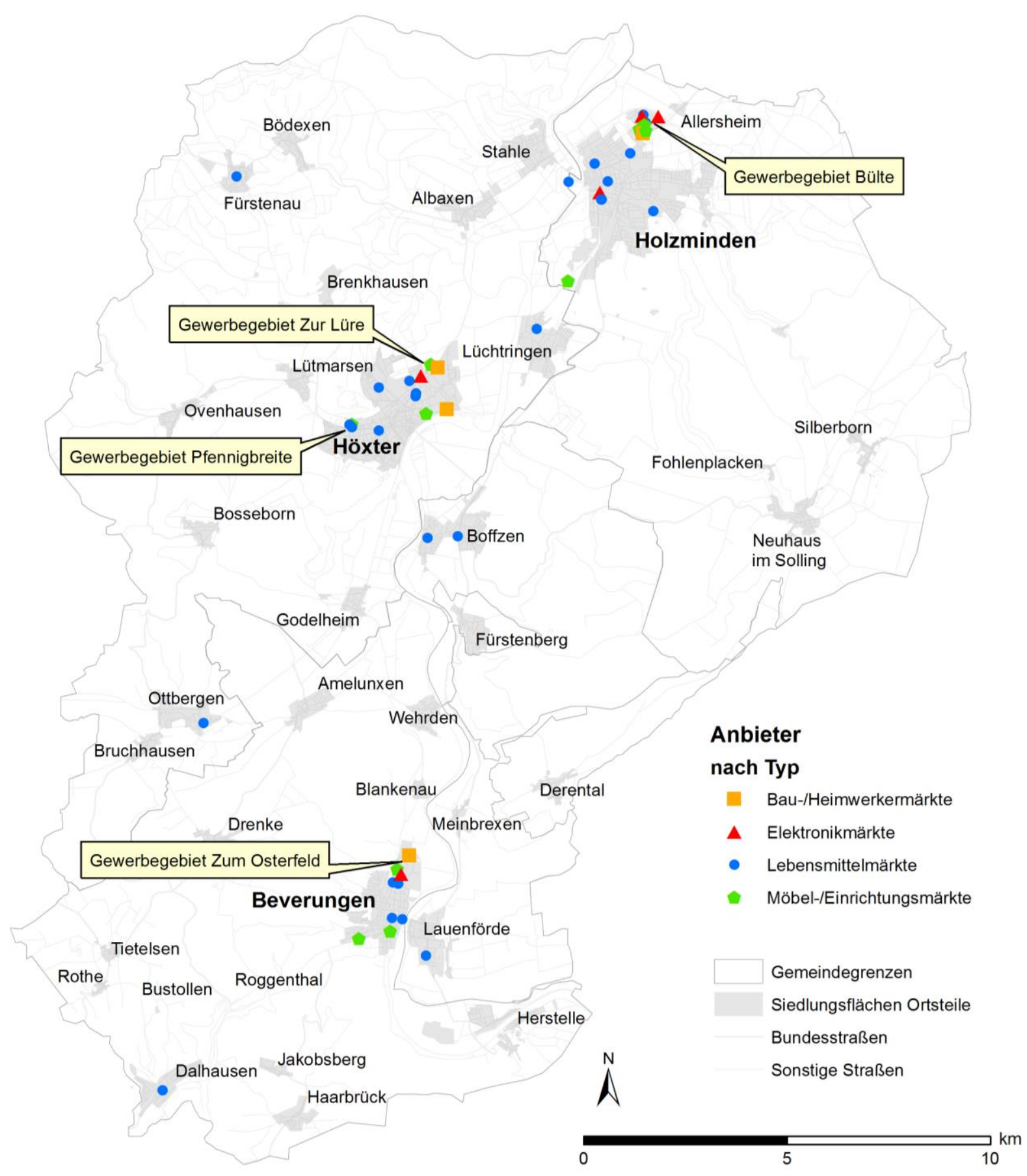

Karte 2: Untersuchungsrelevante Anbieter im Untersuchungsgebiet

Quelle: Eigene Darstellung, Datengrundlage: Eigene Erhebungen, Kartengrundlage: OpenStreetMap/Geofabrik

Nur zwei der untersuchungsrelevanten Anbieter (ein Lebensmittelmarkt, ein Möbelgeschäft) sind in Innenstadtbereichen lokalisiert. Vier Anbieter (drei Lebensmittelmärkte, ein Elektronikmarkt) befinden sich in Streulagen. Mehrere Lebensmittelmärkte sind in Standortkooperationen lokalisiert, z.B. in Form von Kombinationen aus Verbrauchermärkten und LM-Discountern (Beispiel siehe Abb. 12). Im gesamten Untersuchungsgebiet findet sich mit dem Minipreis Center in Beverungen am Rand des Kernstadtgebietes lediglich ein Angebotsstandort, der als (kleines) Einkaufszentrum klassifiziert werden kann (siehe Abb. 13); als Magnetanbieter fungiert hier ein Minipreis-Lebensmittelmarkt. Außerhalb der 
Kernstadtbereiche sind nur vereinzelt untersuchungsrelevante Anbieter lokalisiert; hierzu zählen nicht-großflächige Supermärkte (z.B. Beverungen-Dalhausen, Höxter-Lüchtringen) und großflächige Verbrauchermärkte (z.B. Höxter-Stahle, Lauenförde-Hauptort). Die Dorfzentren der unterzentralen oder nicht zentralen Gemeinden und Ortsteile verfügen nur noch sehr rudimentär über Einzelhandelsangebot und sind in diesem Zusammenhang von einem sehr hohen Vorkommen leerstehender Geschäftsflächen betroffen; hierzu zählen v.a. die Dorfzentren der Gemeinden Lauenförde (siehe Abb. 14) und Fürstenberg ${ }^{44}$.

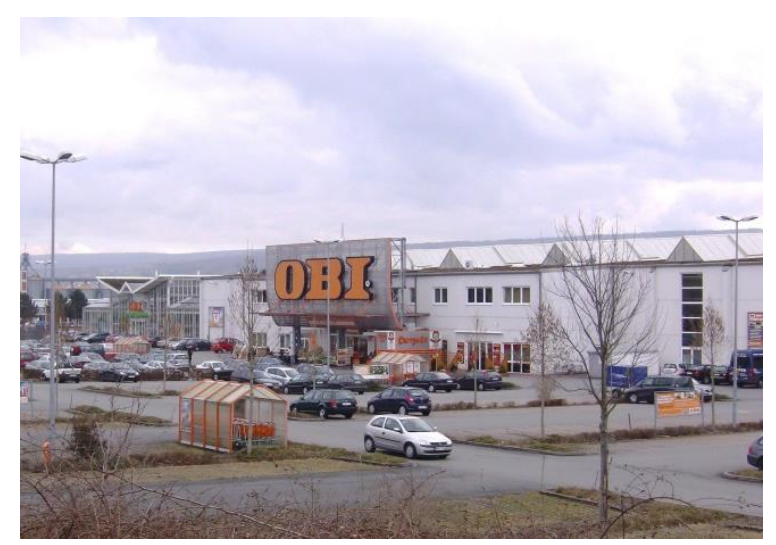

Abbildung 11: OBI-Baumarkt, Höxter-

\section{Kernstadt}

Quelle: Eigene Aufnahme (Februar 2011)

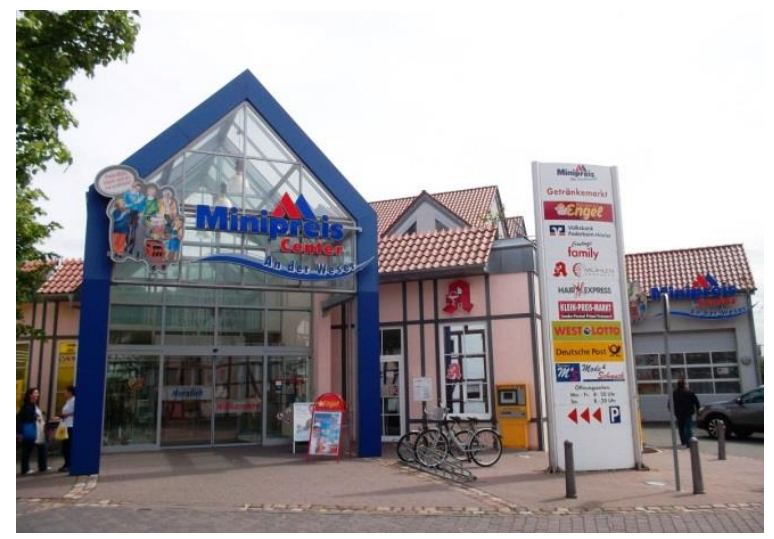

Abbildung 13: Einkaufszentrum Minipreis Center An der Weser, Beverungen-Kernstadt

Quelle: Eigene Aufnahme (Mai 2012)

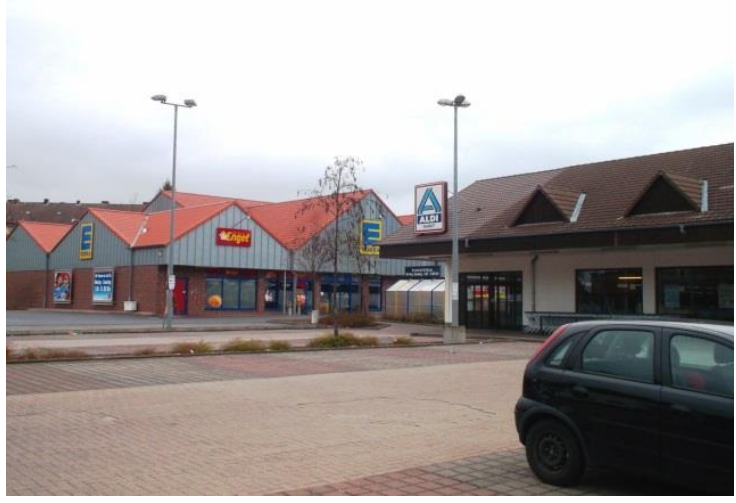

Abbildung 12: Standortkooperation Lebensmittelmärkte, Holzminden-Kernstadt Quelle: Eigene Aufnahme (April 2012)

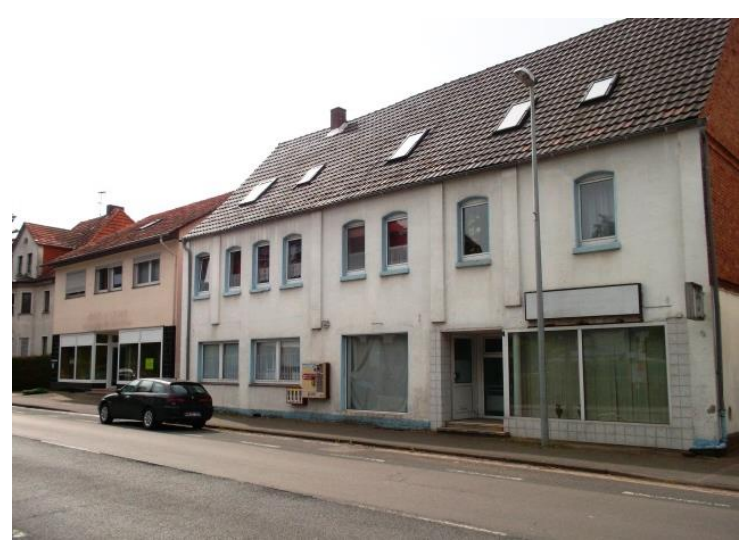

Abbildung 14: Leerstände Ortszentrum, Lauenförde Quelle: Eigene Aufnahme (Mai 2012)

Durch die Berücksichtigung der vorliegenden Einzelhandelsgutachten sowie Berichten aus den lokalen Tageszeitungen und den im Vorfeld geführten Expertengesprächen konnten zudem ansatzweise die jüngeren Entwicklungen des untersuchungsrelevanten Angebotes (Zeitraum: seit 2007) sowie die zum Zeitpunkt der Untersuchung geplanten Ansiedlungen zusammengetragen werden. Besonders erwähnenswert sind hier insbesondere die umstrittenen Ansiedlungen eines Elektrofachmarktes (Media Markt) im Holzmindener

\footnotetext{
${ }^{44}$ In Lauenförde sind neben den zehn vorhandenen Einzelhandelsbetrieben noch weitere neun Leerstände erfasst worden (darunter die frühere Geschäftsfläche des aktuellen Rewe-Marktes). In Fürstenberg wurden sechs Einzelhandelsanbieter und zwölf Leerstände erfasst (u.a. ein ehemaliger Edeka-Supermarkt).
} 
Gewerbegebiet Bülte und eines Kaufland-Marktes in Höxter. Eine in Beverungen geplante Verlagerung in eine Standortkooperation (Rewe und $A / d l$ ) wurde nicht genehmigt.

\begin{tabular}{|c|c|c|c|}
\hline Gemeinde & Anbieter & Vorgang & Ablauf und Status \\
\hline \multirow[t]{2}{*}{ Beverungen } & \multirow{2}{*}{$\begin{array}{l}\text { Aldi (LM-Discounter, } \\
\text { ca. } 700 \text { qm), Rewe } \\
\text { (Verbrauchermarkt, } \\
\text { ca. } 1.400 \text { qm) }\end{array}$} & \multirow{2}{*}{$\begin{array}{l}\text { Verlagerung, Bildung } \\
\text { Standortkooperation } \\
\text { (südlicher Stadtrand) }\end{array}$} & $\begin{array}{l}\text { Keine Empfehlung im Einzelhandelskonzept } \\
\text { (STADT+HANDEL 2011) }\end{array}$ \\
\hline & & & Ablehnung des Bauantrags \\
\hline \multirow[t]{5}{*}{ Holzminden } & \multirow{5}{*}{$\begin{array}{l}\text { Media Markt } \\
\text { (Elektrofachmarkt, ca. } \\
2.700 \text { qm) }\end{array}$} & $\begin{array}{l}\text { Neuansiedlung } \\
\text { (Gewerbegebiet Bülte) }\end{array}$ & $\begin{array}{l}\text { Protest von Nachbargemeinden und Mitbewerbern } \\
\text { gegen geplante Ansiedlung, öffentliche Diskussion }\end{array}$ \\
\hline & & $\begin{array}{l}\text { Bebauungsplan Nr. 12a } \\
\text { „Bülte neu“-11. Änderung }\end{array}$ & $\begin{array}{l}\text { Ansiedlungsverträglichkeit durch Gutachten bestätigt } \\
\text { (BBE HANDELSBERATUNG 2007) }\end{array}$ \\
\hline & & & Genehmigung durch Stadtrat \\
\hline & & & $\begin{array}{l}\text { Klage der Stadt Höxter am Verwaltungsgericht } \\
\text { Hannover gegen den Bebauungsplan } \rightarrow \text { abgewiesen }\end{array}$ \\
\hline & & & Eröffnung 2008 \\
\hline \multirow[t]{4}{*}{ Holzminden } & \multirow{4}{*}{$\begin{array}{l}\text { Rewe } \\
\text { (Verbrauchermarkt, } \\
\text { ca. } 1.400 \mathrm{qm} \text { ) }\end{array}$} & $\begin{array}{l}\text { Neuansiedlung (Streulage, } \\
\text { östliches Stadtgebiet) }\end{array}$ & $\begin{array}{l}\text { Ansiedlungsverträglichkeit durch Gutachten bestätigt } \\
\text { (CIMA 2011) }\end{array}$ \\
\hline & & \multirow{3}{*}{$\begin{array}{l}\text { Bebauungsplan Nr. } 91 \\
\text { "Zwischen Charlotten- und } \\
\text { Sollingstraße" }\end{array}$} & $\begin{array}{l}\text { Anwohnerproteste aufgrund von befürchteter } \\
\text { Lärmbelastung }\end{array}$ \\
\hline & & & Genehmigung durch Stadtrat \\
\hline & & & Eröffnung 2013 \\
\hline \multirow[t]{2}{*}{ Holzminden } & \multirow{2}{*}{$\begin{array}{l}\text { Preis Rebell } \\
\text { (Möbeldiscounter, ca. } \\
7.000 \text { qm), } \\
\text { Küchenmarkt (ca. } \\
4.600 \text { qm) }\end{array}$} & $\begin{array}{l}\text { Neuansiedlung } \\
\text { (Gewerbegebiet Bülte) }\end{array}$ & $\begin{array}{l}\text { Ansiedlungsverträglichkeit durch Gutachten bestätigt } \\
\text { (BBE HANDELSBERATUNG 2011) }\end{array}$ \\
\hline & & $\begin{array}{l}\text { Bebauungsplan Nr. 12a } \\
\text { „Bülte neu“ - 14. Änderung }\end{array}$ & $\begin{array}{l}\text { Protest von innerstädtischen Einzelhändlern bzw. } \\
\text { Citymarketing-Initiative }\end{array}$ \\
\hline \multirow[t]{2}{*}{ Holzminden } & \multirow[t]{2}{*}{ Hagebau (Baumarkt) } & $\begin{array}{l}\text { Neuansiedlung } \\
\text { (Gewerbegebiet Bülte) }\end{array}$ & $\begin{array}{l}\text { Ansiedlungsverträglichkeit durch Gutachten bestätigt } \\
\text { (GMA 2012) }\end{array}$ \\
\hline & & $\begin{array}{l}\text { Bebauungsplan Nr. 12a } \\
\text { „Bülte neu“-15. Änderung }\end{array}$ & \\
\hline \multirow[t]{5}{*}{ Höxter } & \multirow{5}{*}{$\begin{array}{l}\text { Kaufland (SB- } \\
\text { Warenhaus, ca. } 4.000 \\
\text { qm) }\end{array}$} & $\begin{array}{l}\text { Neuansiedlung (Streulage, } \\
\text { innenstadtnah) }\end{array}$ & \multirow{2}{*}{$\begin{array}{l}\text { Protest von Anwohnern und innerstädtischen } \\
\text { Einzelhändlern, insgesamt sieben Klagen (u.a. } \\
\text { aufgrund von befürchteter Lärm- und } \\
\text { Verkehrsbelastung) }\end{array}$} \\
\hline & & \multirow{4}{*}{$\begin{array}{l}\text { Bebauungsplan Nr. 8/66 } \\
\text { "Brenkhäuser Straße/ } \\
\text { Albaxer Straße" }\end{array}$} & \\
\hline & & & $\begin{array}{l}\text { Ansiedlungsverträglichkeit durch Gutachten bestätigt } \\
\text { (BULWIENGESA AG 2010) }\end{array}$ \\
\hline & & & Genehmigung durch Stadtrat \\
\hline & & & Eröffnung November 2012 \\
\hline \multirow[t]{2}{*}{ Höxter } & \multirow{2}{*}{$\begin{array}{l}\text { Weser Wohnwelt } \\
\text { (Möbelfachmarkt, ca. } \\
10.000 \text { gm) }\end{array}$} & \multirow{2}{*}{$\begin{array}{l}\text { Erweiterung auf } 17.000 \mathrm{qm} \\
\text { Verkaufsfläche }\end{array}$} & Protest von naheliegender Gemeinde (Steinheim) \\
\hline & & & Fertigstellung voraussichtlich 2017 \\
\hline \multirow{3}{*}{$\begin{array}{l}\text { Lauenförde } \\
\text { (SG } \\
\text { Boffzen) }\end{array}$} & \multirow{3}{*}{$\begin{array}{l}\text { Rewe } \\
\text { (Verbrauchermarkt, } \\
1.300 \mathrm{qm} \text { ) }\end{array}$} & \multirow[t]{3}{*}{$\begin{array}{l}\text { Verlagerung und } \\
\text { Erweiterung }\end{array}$} & $\begin{array}{l}\text { Protest von Anwohnern, Gründung einer } \\
\text { Bürgerinitiative }\end{array}$ \\
\hline & & & Genehmigung durch Gemeinderat \\
\hline & & & Eröffnung September 2010 \\
\hline
\end{tabular}

Tabelle 15: Jüngere Entwicklungen und Planungen im Untersuchungsgebiet

Quelle: Eigene Darstellung, Datengrundlage: NW (versch. Ausg.), TAH (versch. Ausg.), Expertengespräche Ernst, Schwager, Schwingel, Wolff 


\subsubsection{Erreichbarkeit und Fahrtzeiten}

Im Anschluss an die Georeferenzierung aller Einzelhandelsbetriebe und die Identifikation der untersuchungsrelevanten Anbieter wurden auf der Grundlage eines Straßennetzwerks im GIS (siehe Kap. 5.3.1.3) PKW-Fahrtzeiten zwischen allen 19 Nachfrageorten und den 46 betreffenden Anbietern kalkuliert. Die Fahrtzeitwerte betragen zwischen 2,03 Minuten (Beverungen-Dalhausen - Edeka, Beverungen-Dalhausen; der Markt liegt unmittelbar im Dorfzentrum) und 31,21 Minuten (Holzminden-Sollingortschaften - Edeka, BeverungenDalhausen). Insgesamt ist die Spannweite der Erreichbarkeitswerte bei den Lebensmittelmärkten deutlich höher, da sie räumlich gleichmäßiger verteilt sind als die betrachteten Fachmärkte und daher sowohl geringe als auch sehr hohe Fahrtzeitwerte vorkommen. Die anderen Anbieter (Elektronik-, Bau- und Möbelmärkte) sind weitgehend auf die Kernstadtbereiche der drei Mittelzentren konzentriert (siehe Kap. 6.1.1.2), weshalb sie sehr ähnliche Erreichbarkeiten von den Nachfrageorten aufweisen.

In diesem Zusammenhang wurde geprüft, ob die hier verwendete PKW-Fahrtzeit auch für mögliche Nutzer öffentlicher Verkehrsmittel aussagekräftig ist bzw. ob verschieden hohe PKW- und ÖPNV-Fahrtzeiten in etwa im selben Verhältnis zueinander stehen. Hierzu wurde aus allen kalkulierten PKW-Fahrtzeiten eine Zufallsstichprobe von 20 Routen gezogen und hierfür die jeweiligen ÖPNV-Verbindungen ermittelt (Schnellste Verbindung zuzüglich einer Pauschale von fünf Minuten für den Zu- und Abgang, Abfrage www.bahn.de). Stellt man die ermittelten PKW- und ÖPNV-Fahrtzeiten gegenüber, lässt sich zunächst feststellen, dass diese grob im selben Verhältnis zueinander stehen und dass zudem in vielen Fällen eine ÖPNV-Nutzung beim Einkauf in Anbetracht der langen Fahrtzeiten eher unrealistisch ist. Im Durchschnitt beträgt die ÖPNV-Route (zumeist Bus, gelegentlich mit Zuganteil) das 3,2fache der PKW-Fahrtzeit (siehe Abb. 15).

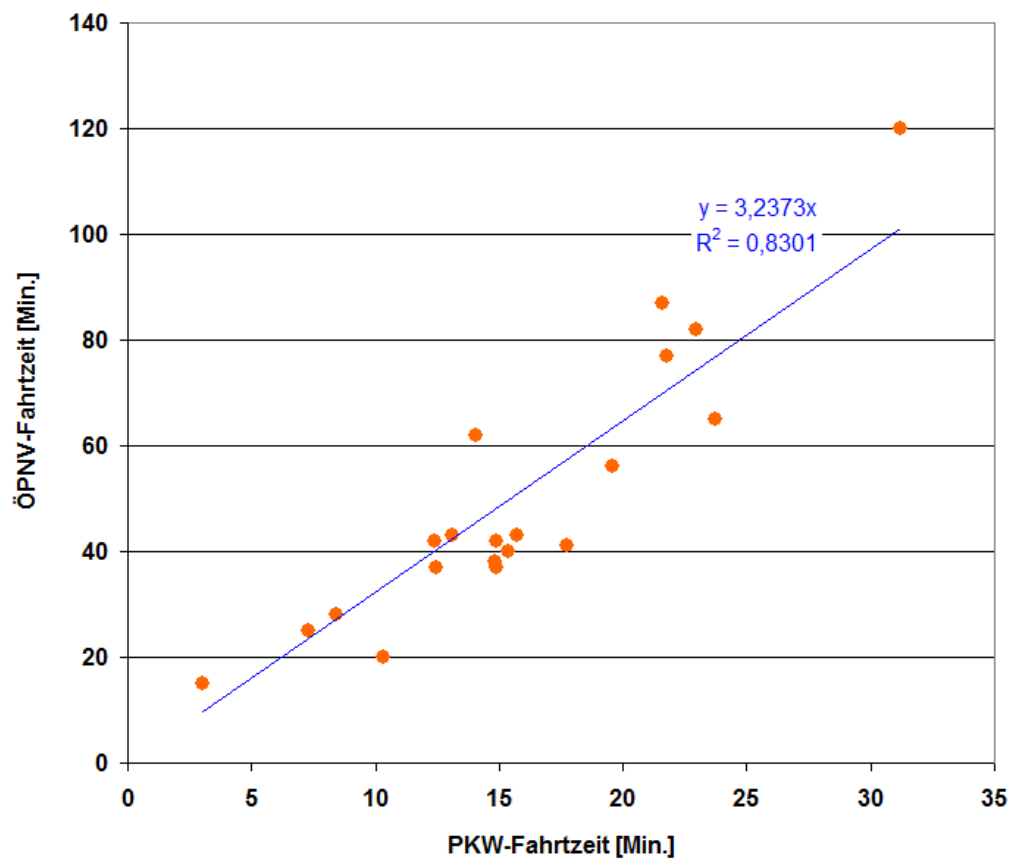

Abbildung 15: Zusammenhang zwischen PKW- und ÖPNV-Fahrtzeit

Quelle: Eigene Darstellung, Datengrundlage: Abfrage www.bahn.de, Eigene Berechnungen 
Karte 3 zeigt exemplarisch die Erreichbarkeiten der vier untersuchungsrelevanten Baumärkte in Schritten von fünf Minuten. Deutlich zu erkennen ist, dass vom Großteil des Untersuchungsgebietes aus zumindest ein Baumarkt in maximal 15 Minuten erreichbar ist.

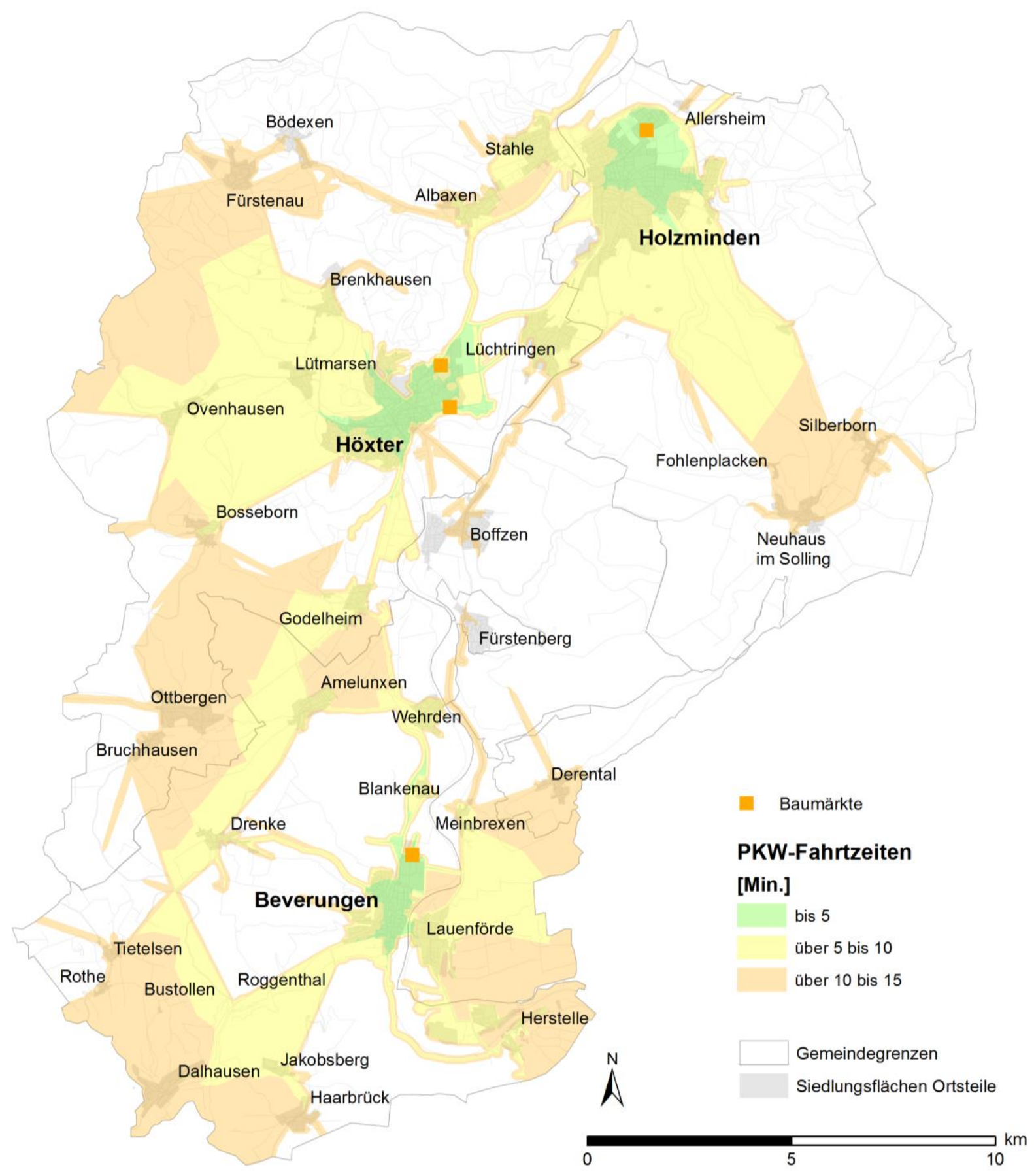

Karte 3: Berechnung von Fahrtzeiten - Beispiel Baumärkte

Quelle: Eigene Darstellung, Datengrundlage: Eigene Berechnungen, Kartengrundlage: OpenStreetMap/Geofabrik

\subsubsection{Ausprägung der räumlichen Konzentration von Anbietern}

Die räumliche Konzentration der untersuchungsrelevanten Anbieter wurde über die Berechnung von Konzentrationsvariablen nach dem Vorschlag von FOTHERINGHAM (1985) ermittelt (siehe Kap. 5.3.1.4). Die Karten 4 und 5 zeigen die Konzentrationswerte im Hinblick 
auf branchengleiche (d.h. konkurrierende) und andere (d.h. nicht-branchengleiche) Anbieter am Beispiel der Elektronikmärkte (farbliche Abgrenzung der Punkte). Um die Funktionsweise der Konzentrationsvariablen zu verdeutlichen, werden zudem die VKF-Größen der Anbieter dargestellt (Größe der Punkte). Hierbei zeigt sich beispielsweise, dass der Expert-Fachmarkt im Holzmindener Gewerbegebiet Bülte den höchsten konkurrentenbezogenen Konzentrationswert aufweist, da er in unmittelbarer Nähe des größten Elektronikanbieters (Media Markt-Fachmarkt) lokalisiert ist. Da der Expert-Markt deutlich kleiner dimensioniert ist als Media Markt, ist dessen Konzentrationswert hingegen geringer (siehe Karte 4).

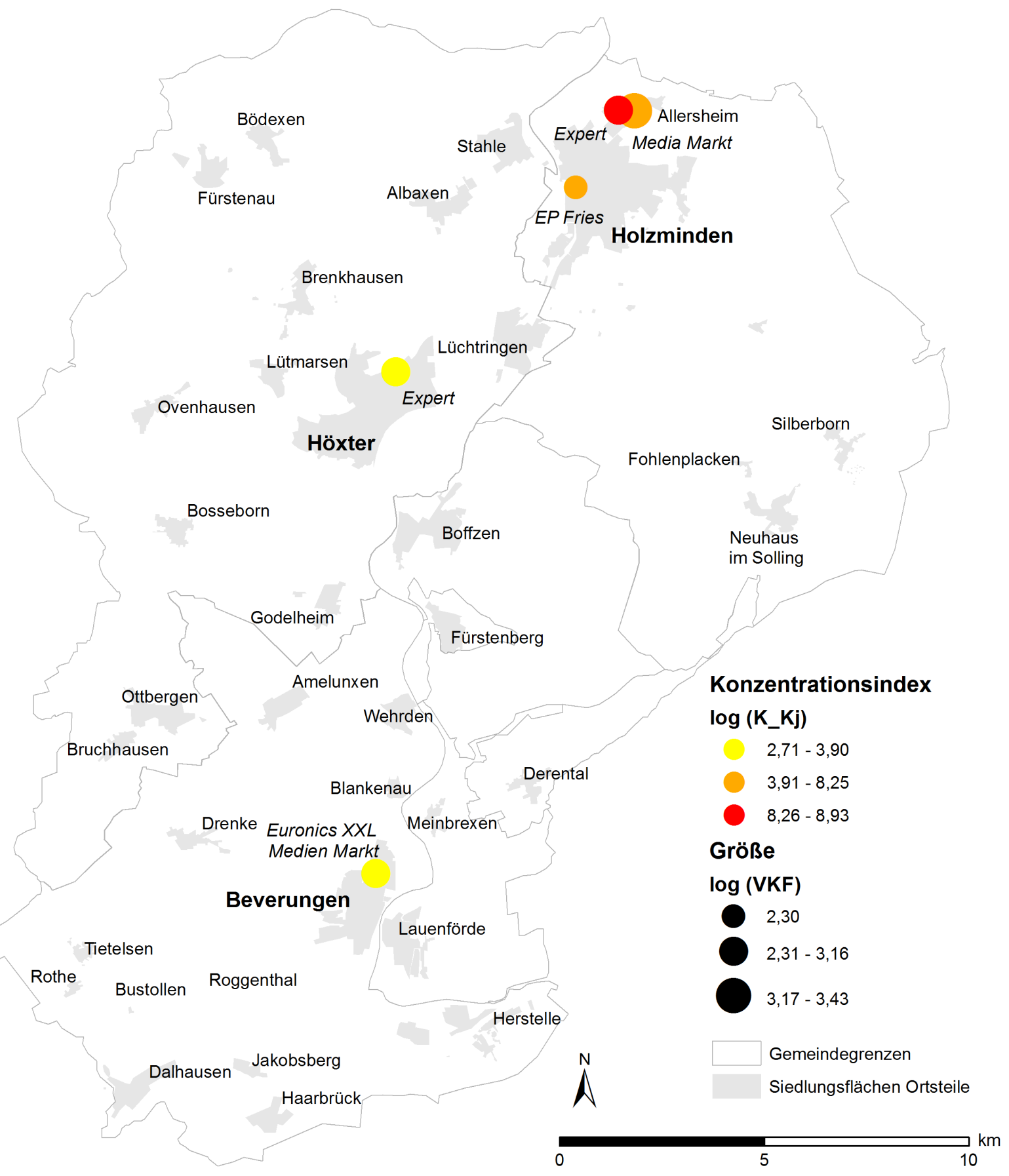

Karte 4: Konzentrationsvariable für gleichartige Anbieter - Beispiel Elektronikmärkte Quelle: Eigene Darstellung, Datengrundlage: Eigene Erhebungen und Berechnungen, Kartengrundlage: OpenStreetMap/Geofabrik 
Der allgemeine Konzentrationswert - bezogen auf alle anderen Anbieter - fällt anders aus: Die höchste Ausprägung der Konzentrationsvariable wird beim Expert-Fachmarkt in Höxter erreicht, was auf die unmittelbare räumliche Nähe zu diversen dort angesiedelten großfächigen Einzelhandelsbetrieben (z.B. OBI-Baumarkt, Möbelhaus Weser Wohnwelt) zurückzuführen ist. Relativ gering ist hingegen die räumliche Konzentration des EuronicsMarktes in Beverungen, in dessen Nachbarschaft sich nur wenige Einzelhandelsanbieter befinden. Der Holzmindener Media Markt befindet sich am äußeren Rand des Gewerbegebietes und weist daher eine geringere Konzentration auf als der Expert-Markt.

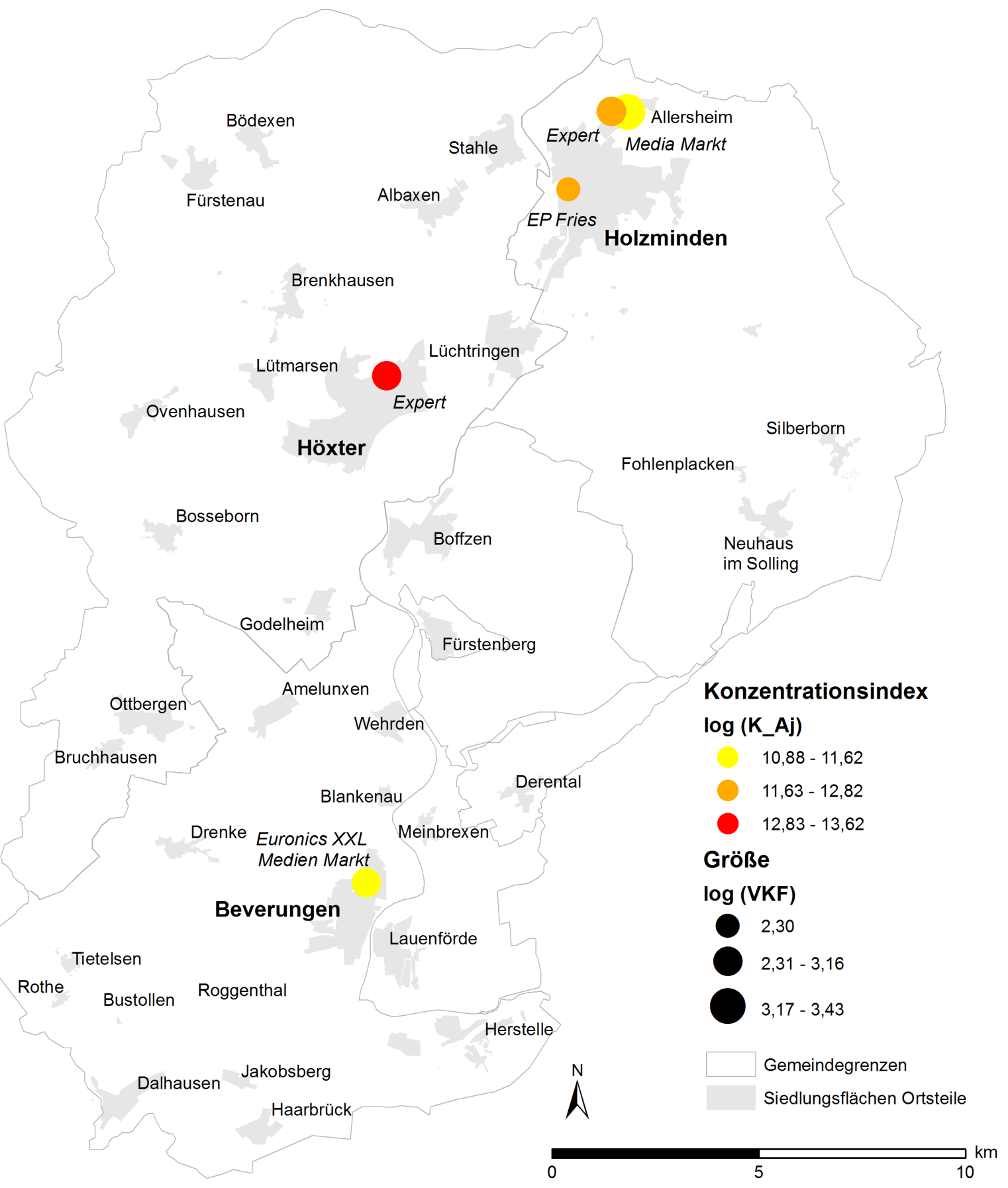

Karte 5: Konzentrationsvariable allgemein - Beispiel Elektronikmärkte

Quelle: Eigene Darstellung, Datengrundlage: Eigene Erhebungen und Berechnungen, Kartengrundlage:

OpenStreetMap/Geofabrik 


\subsection{Ergebnisse der Haushaltsbefragung}

\subsubsection{Eigenschaften der Stichprobe und erfasste Einkäufe}

In der telefonischen Haushaltsbefragung im Winter 2012 wurden insgesamt 1.838 Anrufe getätigt. Hiervon wurde in 839 Fällen $(45,6 \%$ ) niemand erreicht (nach mehrmaligem Anrufversuch, siehe Kap. 5.2.3.3) und in weiteren 587 Fällen (31,9\%) eine Ablehnung durch die kontaktierte Person ausgesprochen. Die Größe der effektiven Stichprobe beträgt 412 befragte Haushalte, was einer Ausschöpfungsquote von 22,4\% entspricht. Tabelle 16 zeigt die befragten Haushalte aufgeschlüsselt nach Untersuchungsgemeinden und Uhrzeiten. Die aus der Zufallsauswahl befragten Haushalte entsprechen weitgehend der tatsächlichen Einwohnerverteilung im Untersuchungsgebiet, wobei die Stadt Holzminden leicht unter- und die Teilbereiche der Samtgemeinde Boffzen in Relation zu ihrer tatsächlichen Größe etwas überrepräsentiert sind. Eine relative Mehrheit von 35,4 \% aller Interviews wurde im Zeitraum von 15-18 Uhr geführt, wobei die wenigsten Interviews in der Mittagszeit (12-15 Uhr) stattgefunden haben, was insbesondere auf die unterdurchschnittliche telefonische Erreichbarkeit in diesem Zeitfenster zurückzuführen ist.

\begin{tabular}{lccccc}
\hline \multirow{2}{*}{ Gemeinde } & $\begin{array}{c}\text { Befragte } \\
\text { Haushalte }\end{array}$ & $9-12$ Uhr & Befragung nach Uhrzeit [Anteil in \%] \\
& $12-15$ Uhr & $15-18$ Uhr & 18-21 Uhr \\
\hline Beverungen & 94 & 20,2 & 13,8 & 43,6 & 22,3 \\
Boffzen (SG Boffzen) & 24 & 58,3 & 12,5 & 4,2 & 25,0 \\
Derental (SG Boffzen) & 12 & 41,7 & 25,0 & 8,3 & 25,0 \\
Fürstenberg (SG Boffzen) & 13 & 53,8 & 0,0 & 23,1 & 23,1 \\
Holzminden & 84 & 28,6 & 16,7 & 34,5 & 20,2 \\
Höxter & 160 & 25,6 & 14,4 & 43,1 & 16,9 \\
Lauenförde (SG Boffzen) & 25 & 48,0 & 16,0 & 8,0 & 28,0 \\
\hline Insgesamt & $\mathbf{4 1 2}$ & $\mathbf{2 9 , 6}$ & $\mathbf{1 4 , 6}$ & $\mathbf{3 5 , 4}$ & $\mathbf{2 0 , 4}$ \\
\hline
\end{tabular}

Tabelle 16: Haushaltsbefragung - Befragte Haushalte nach Gemeinden und Uhrzeiten

Quelle: Eigene Darstellung, Datengrundlage: Eigene Erhebungen und Berechnungen, $n=412$

In drei Fällen wurde von Seiten der befragten Personen die Angabe sozio-demographischer Informationen verweigert bzw. das Interview in diesem letzten Teil des Fragebogens abgebrochen. Die erfragten sozio-demographischen Eigenschaften der übrigen 409 Haushalte werden in Tabelle 17 zusammengefasst. In Bezug auf das Alter der jeweils befragten Person dominiert die Altersgruppe der 45- bis unter 65-Jährigen; eine deutliche Abweichung von den Gesamtanteilen ergibt sich in der Gemeinde Derental und der Stadt Holzminden. Die durchschnittliche Haushaltsgröße der befragten Haushalte liegt bei 2,4 Personen und variiert zwischen 2,0 und 2,6. Durchschnittlich stehen 88,3\% der befragten Haushalte nach eigenen Angaben ein PKW zur Verfügung, wobei dieser Wert zwischen den Untersuchungsgemeinden nur gering schwankt.

Erwartungsgemäß konnten nahezu alle Befragten die drei letzten Lebensmitteleinkäufe angeben, so dass bezüglich dieser Angebotsform 1.235 einzelne Einkäufe erfasst werden konnten. Insgesamt wurden 1.059 Einkäufe bei Elektronikanbietern erfasst (abzüglich 
Online-Einkäufe: 987), 1.011 Einkäufe bei Bau-/Heimwerkermärkten und 721 Einkäufe bei Anbietern von Möbeln und Einrichtungsgegenständen (siehe Tabelle 18).

\begin{tabular}{|c|c|c|c|c|c|c|c|c|}
\hline \multirow{2}{*}{ Gemeinde } & \multicolumn{6}{|c|}{$\begin{array}{l}\text { Alter und Geschlecht der befragten Person } \\
\text { [Anteil in \%] }\end{array}$} & \multirow{2}{*}{$\begin{array}{l}\text { Durchschnittliche } \\
\text { Haushaltsgröße } \\
\text { [Personen] }\end{array}$} & \multirow{2}{*}{$\begin{array}{l}\text { PKW zur } \\
\text { Verfügung } \\
\text { [Anteil în \%]. }\end{array}$} \\
\hline & $\begin{array}{c}\text { unter } \\
30\end{array}$ & $\begin{array}{l}30 \text { bis } \\
\text { unter } 45\end{array}$ & $\begin{array}{l}45 \text { bis } \\
\text { unter } 65\end{array}$ & $\begin{array}{l}65 \text { und } \\
\text { älter }\end{array}$ & $\mathrm{m}$ & w & & \\
\hline Beverungen & 8,6 & 17,2 & 39,8 & 34,4 & 39,1 & 60,9 & 2,5 & 92,4 \\
\hline Boffzen (SG Boffzen) & 4,2 & 29,2 & 25,0 & 41,7 & 33,3 & 66,7 & 2,6 & 87,5 \\
\hline Derental (SG Boffzen) & 0,0 & 50,0 & 41,7 & 8,3 & 16,7 & 83,3 & 2,6 & 91,7 \\
\hline Fürstenberg (SG Boffzen) & 7,7 & 23,1 & 38,5 & 30,8 & 23,1 & 76,9 & 2,2 & 84,6 \\
\hline Holzminden & 6,1 & 9,8 & 37,8 & 46,3 & 51,2 & 48,8 & 2,0 & 84,3 \\
\hline Höxter & 5,0 & 23,1 & 39,4 & 32,5 & 37,9 & 62,1 & 2,6 & 86,9 \\
\hline Lauenförde (SG Boffzen) & 4,0 & 28,0 & 28,0 & 40,0 & 48,0 & 52,0 & 2,2 & 96,0 \\
\hline Insgesamt & 5,9 & 20,5 & 37,7 & 35,9 & 40,1 & 59,9 & 2,4 & 88,3 \\
\hline
\end{tabular}

Tabelle 17: Haushaltsbefragung - Sozio-demographische Eigenschaften der befragten Haushalte Quelle: Eigene Darstellung, Datengrundlage: Eigene Erhebungen und Berechnungen, $n=409$

\begin{tabular}{lccccc}
\hline Gemeinde & $\begin{array}{c}\text { Lebensmittel- } \\
\text { märkte }\end{array}$ & $\begin{array}{c}\text { Elektronik- } \\
\text { märkte* }^{*}\end{array}$ & Baumärkte & $\begin{array}{c}\text { Möbel-/ } \\
\text { Einrichtungsmärkte }\end{array}$ & Gesamt \\
\hline Beverungen & 281 & 237 & 231 & 179 & 928 \\
Boffzen (SG Boffzen) & 72 & 58 & 66 & 44 & 240 \\
Derental (SG Boffzen) & 36 & 36 & 36 & 21 & 129 \\
Fürstenberg (SG Boffzen) & 39 & 37 & 39 & 20 & 135 \\
Holzminden & 252 & 205 & 198 & 142 & 797 \\
Höxter & 480 & 417 & 366 & 282 & 1.545 \\
Lauenförde (SG Boffzen) & 75 & 69 & 75 & 33 & 252 \\
\hline Insgesamt & 1.235 & 1.059 & 1.011 & 721 & 4.026 \\
\hline
\end{tabular}

Tabelle 18: Haushaltsbefragung - Erfasste Einkäufe

Quelle: Eigene Darstellung, Datengrundlage: Eigene Berechnungen; * inkl. Online-Einkäufe

\subsubsection{Empirische Marktgebiete der untersuchungsrelevanten Anbieter}

\subsubsection{Lebensmittelmärkte}

Aus den Angaben der befragten Haushalte zu den letzten Einkäufen wurden im nächsten Schritt die lokalen Marktanteile der untersuchungsrelevanten Anbieter auf der Aggregationsebene der 19 Teilgebiete berechnet (siehe Kap. 5.3.1.2). Karte 6 stellt auf dieser Ebene die lokalen Marktanteile der Lebensmittelmärkte (farbliche Abgrenzung) und die erfassten Einkäufe (Größe der Kreisdiagramme) dar; aus Gründen der Übersichtlichkeit (insgesamt 27 Anbieter) sind lediglich die Verbrauchermärkte einzeln abgegrenzt. 
Räumliches Einkaufsverhalten und Standortpolitik im Einzelhandel unter Berücksichtigung von Agglomerationseffekten

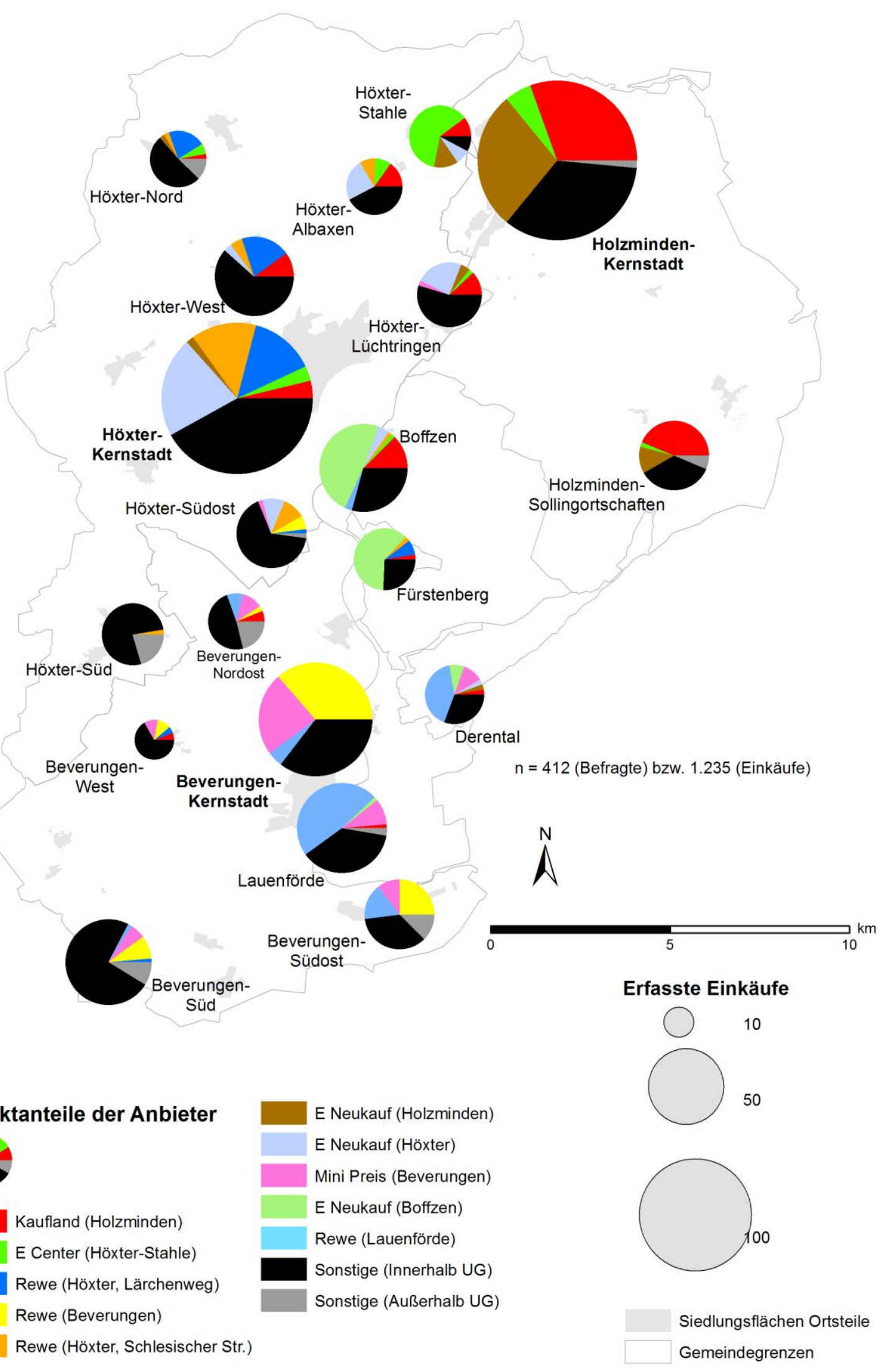

Karte 6: Lebensmittelmärkte - Lokale Marktanteile und erfasste Einkäufe

Quelle: Eigene Darstellung, Datengrundlage: Eigene Erhebungen und Berechnungen, Kartengrundlage:

OpenStreetMap/Geofabrik 
Insgesamt zeigt sich eine überwiegend lokal geprägte Einkaufsorientierung beim Besuch von Lebensmittelmärkten im Untersuchungsgebiet, d.h. die räumliche Ausdehnung der Marktgebiete ist vergleichsweise eng begrenzt. Im Teilgebiet Holzminden-Kernstadt entfallen ca. $30 \%$ der erfassten Einkäufe auf den im Gewerbegebiet lokalisierten Kaufland-Markt und weitere ca. $28 \%$ auf den Edeka Neukauf-Verbrauchermarkt, der sich in einer kleinen Standortkooperation mit einem Aldi-Markt befindet; auch die Haushalte in den Sollingortschaften sind fast ausschließlich in Richtung der Kernstadt orientiert. Der KauflandMarkt als mit Abstand größter Anbieter im Untersuchungsgebiet generiert weiterhin in den naheliegenden Höxteraner Ortsteilen lokale Marktanteile zwischen 10 und $15 \%$, wird aber aus weiter entfernten Nachfrageorten nur noch selten frequentiert. Die Haushalte in den Teilgebieten der Samtgemeinde Boffzen orientieren sich überwiegend in Richtung Boffzen und Höxter; zudem spielt der in Beverungen lokalisierte Minipreis-Verbrauchermarkt noch eine signifikante Rolle bei der Einkaufsorientierung. Die Einkäufe in den Beverunger Ortsteilen entfallen ebenso schwerpunktmäßig auf die Anbieter in der Beverunger Kernstadt. Auch die Haushalte in den Ortsteilen Höxters sind primär auf das Angebot in der Kernstadt fokussiert, wobei je nach räumlicher Nähe zu anderen Mittelzentren auch dort lokalisierte Anbieter vereinzelt wahrgenommen werden.

Der mitunter lokal sehr hohe Anteil sonstiger Anbieter im Untersuchungsgebiet (schwarze Farbe) ist fast vollständig auf die vorwiegend in den Kernstädten lokalisierten LM-Discounter (u.a. Aldi, Lidl, Netto) zurückzuführen; von besonderer Relevanz sind hier die insgesamt fünf Aldi-Märkte im Untersuchungsgebiet, während die Filialen anderer LM-Discounter kaum messbare überlokale Kundenzuflüsse verbuchen können. Die in den Kernstädten Holzmindens und Höxters angesiedelten Netto-Märkte verzeichnen beispielsweise selbst dort nur lokale Marktanteile zwischen 1 und $3 \%$. Die Supermärkte (u.a. zugehörig zur Edeka-Kooperative) spielen ebenso nur eine sehr lokale Rolle: Der Edeka-Supermarkt in Beverungen-Dalhausen erreicht zwar beispielsweise im zugehörigen Teilgebiet BeverungenSüd einen lokalen Marktanteil von $42 \%$, wird jedoch aus anderen Teilgebieten nicht frequentiert. In einigen Randgebieten (z.B. Beverungen-Südost, Höxter-Süd) entfallen Anteile von Einkäufen in Höhe von 10 bis $20 \%$ auf Lebensmittelmärkte außerhalb des Untersuchungsgebietes (graue Farbe). Insgesamt entfallen 1.142 der insgesamt 1.235 erfassten Lebensmitteleinkäufe auf die 27 untersuchungsrelevanten Anbieter, was einem Anteil von $92,5 \%$ entspricht.

\subsubsection{Elektronikmärkte}

Karte 7 zeigt die lokalen Marktanteile der fünf untersuchungsrelevanten Elektromärkte im Untersuchungsgebiet. Die sonstigen Anbieter innerhalb des Untersuchungsgebietes (schwarze Farbe) beziehen sich auf andere lokale Elektronikanbieter, die nicht als untersuchungsrelevant berücksichtigt wurden (z.B. Fachgeschäfte für „Weiße Ware“ oder „Braune Ware"); sie sind i.d.R. in den Kernstadtgebieten lokalisiert und verzeichnen auch weitgehend nur dort Marktanteile in nennenswertem Umfang. Anbieter außerhalb des Untersuchungsgebietes (graue Farbe) spielen nur eine geringe Rolle (z.B. Media MarktStandorte in den nächstliegenden Oberzentren Göttingen oder Paderborn). Die insgesamt 72 registrierten Online-Einkäufe wurden in dieser Kartendarstellung bereits unberücksichtigt gelassen. Insgesamt entfallen 813 der 1.059 erfassten Einkäufe (entspricht 76,8\%) auf die fünf untersuchungsrelevanten Anbieter, die sich ausschließlich in den Kernstadtgebieten von Beverungen, Holzminden und Höxter befinden. 
Räumliches Einkaufsverhalten und Standortpolitik im Einzelhandel unter Berücksichtigung von Agglomerationseffekten
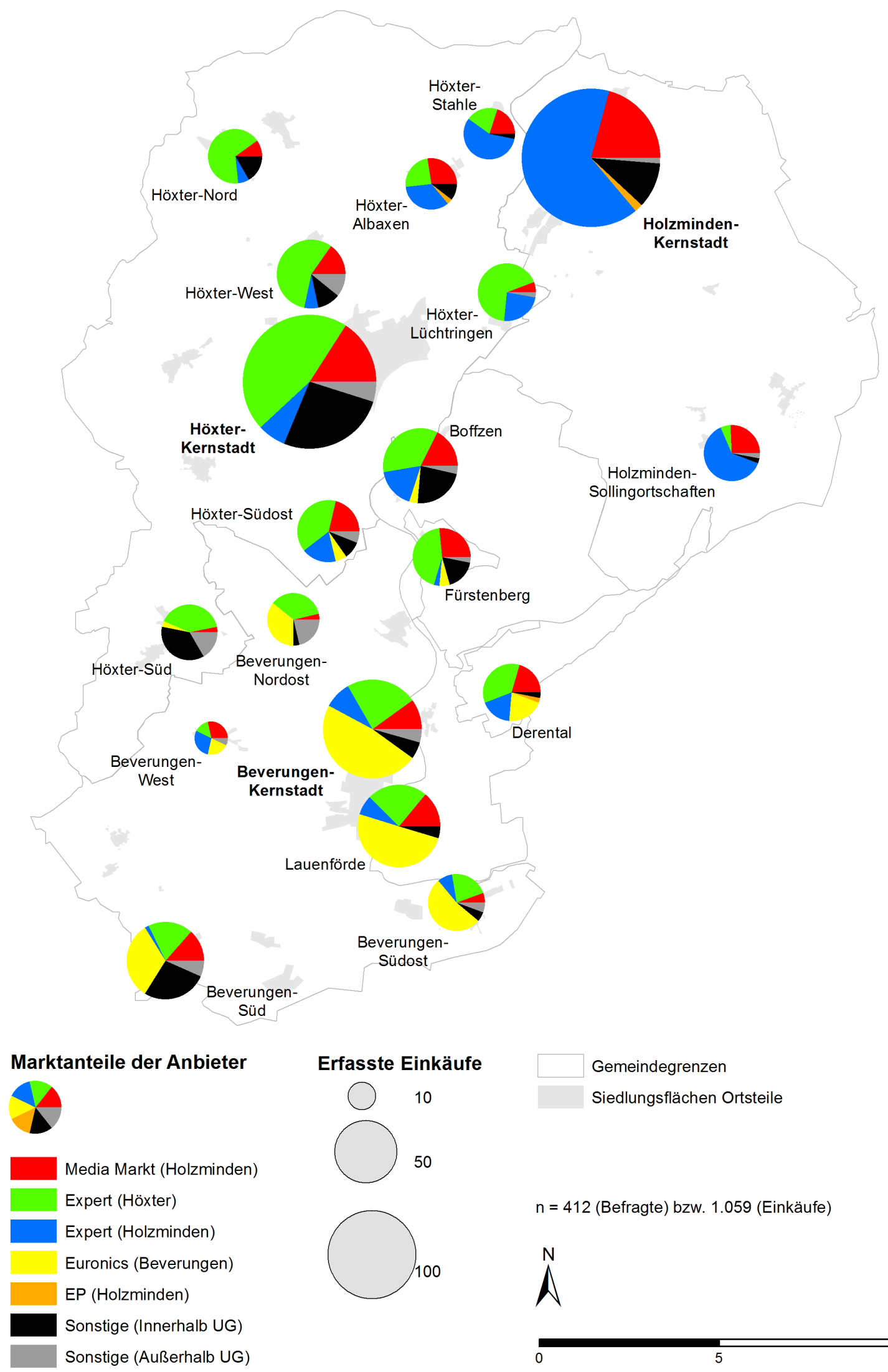

Gemeindegrenzen
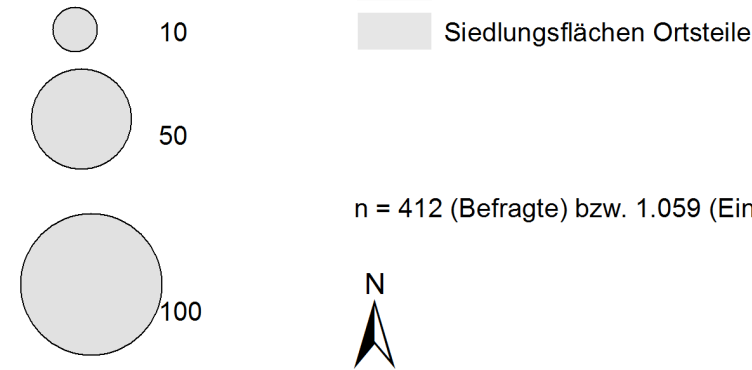

n = 412 (Befragte) bzw. 1.059 (Einkäufe)

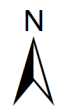

Karte 7: Elektronikmärkte - Lokale Marktanteile und erfasste Einkäufe

Quelle: Eigene Darstellung, Datengrundlage: Eigene Erhebungen und Berechnungen, Kartengrundlage:

OpenStreetMap/Geofabrik 
Der Media Markt im Holzmindener Gewerbegebiet Bülte als größter aller betrachteten Anbieter erreicht auffälligerweise in keinem der 19 Teilgebiete eine relative oder gar absolute Mehrheit an lokalen Marktanteilen, d.h. ist in keinem Gebiet als "Marktführer" zu identifizieren. Auf lokaler Ebene (Holzminden-Kernstadt) wird ein Marktanteil von 19,4\% registriert; höhere Marktanteile werden in einigen naheliegenden Teilgebieten registriert (z.B. Holzminden-Sollingortschaften: 25,7\%, Höxter-Albaxen: 26,7\%). Allerdings lassen sich aus allen Teilgebieten Einkaufsinteraktionen mit diesem Elektrofachmarkt nachweisen, was auf keinen der anderen Anbieter zutrifft. Die beiden in Holzminden und Höxter lokalisierten Expert-Märkte generieren Kundenzuflüsse aus fast allen Gebieten, wobei der Holzmindener Markt auch Kunden aus Höxter-Kernstadt anzieht, der dort angesiedelte Markt jedoch umgekehrt nicht aus der Kernstadt Holzmindens. Die größte absolut registrierte Zahl an Einkäufen entfällt auf den Höxteraner Expert-Markt. Der größte lokale Marktanteil wird vom Holzmindener Expert-Markt in Holzminden-Kernstadt erreicht $(61,1 \%)$. Die Bedeutung des Euronics-Elektrofachmarktes in Beverungen ist überwiegend auf die Ortsteile Beverungens und Teile der Samtgemeinde Boffzen beschränkt (Höchstwert von 52,8 \% in BeverungenSüdost). Das EP-Fachgeschäft mit Elektrovollsortiment in der Holzmindener Kernstadt ist bei der räumlichen Einkaufsorientierung im Untersuchungsgebiet nur von nachrangiger Bedeutung: Dortige Einkäufe wurden nur in drei Teilgebieten erfasst.

Insgesamt zeigt sich also eine starke Marktdurchdringung der Expert-Märkte, die auch, aber nicht allein, durch die räumliche Nähe zu den Nachfrageorten bestimmt sein kann; so lassen sich beispielsweise auch aus dem südlichen Beverungen Einkaufsinteraktionen mit dem Holzmindener Markt erfassen, obwohl zwei weitere Märkte (Expert Höxter, Euronics Beverungen) deutlich näher gelegen sind. Auffällig ist außerdem der vergleichsweise geringe Kundenzufluss des Media Markt-Marktes. Exemplarisch für die Erhebungsergebnisse finden sich die empirischen Marktgebiete der Elektronikmärkte und separat die registrierten OnlineElektronikeinkäufe im Anhang (Tabellen A 8 bzw. A 9).

\subsubsection{Bau- und Heimwerkermärkte}

Karte 8 zeigt die lokalen Marktanteile der vier untersuchungsrelevanten Anbieter (Bau- und Heimwerkermärkte) im Untersuchungsgebiet, die - ebenso wie die Elektronikanbieter - auf die Kernstadtgebiete der drei Mittelzentren verteilt sind. Von den insgesamt 1.011 registrierten Einkäufen entfallen 909 Einkäufe auf diese vier Baumärkte, was einem Anteil von 89,9 \% entspricht. Die Relevanz anderer Anbieter im Untersuchungsgebiet (z.B. Fachgeschäfte oder spezialisierte Fachmärkte wie die Hammer Heimtex-Märkte in Holzminden und Höxter; schwarze Farbe) sind nur in sehr geringem Umfang als Einkaufsziele genannt worden. Ebenso geringe lokale Marktanteile entfallen auf Bau- und Heimwerkermärkte außerhalb des Untersuchungsgebiets (z.B. OBI-Märkte in den nächstliegenden Ober- und Mittelzentren; graue Farbe).

Deutlich zu erkennen ist die Marktdurchdringung des mit Abstand größten Baumarktes $O B I$, der in der Höxteraner Kernstadt lokalisiert ist; auf inn entfallen 525 der 909 Einkäufe bei untersuchungsrelevanten Anbietern, was einem Anteil von 57,8 \% entspricht. Dieser Markt erreicht lokale Marktanteile zwischen 32,1 \% (Beverungen-Süd) und 81,0 \% (Höxter-Stahle); im Gebiet Höxter-Kernstadt entfallen 65,9 \% aller erfassten Einkäufe auf diesen Anbieter. Über ein deutlich begrenzteres Marktgebiet verfügt der im selben Teilgebiet beheimatete Hagebaumarkt, dessen Kunden im Wesentlichen aus dem näheren Umfeld stammen. 
Räumliches Einkaufsverhalten und Standortpolitik im Einzelhandel unter Berücksichtigung von Agglomerationseffekten
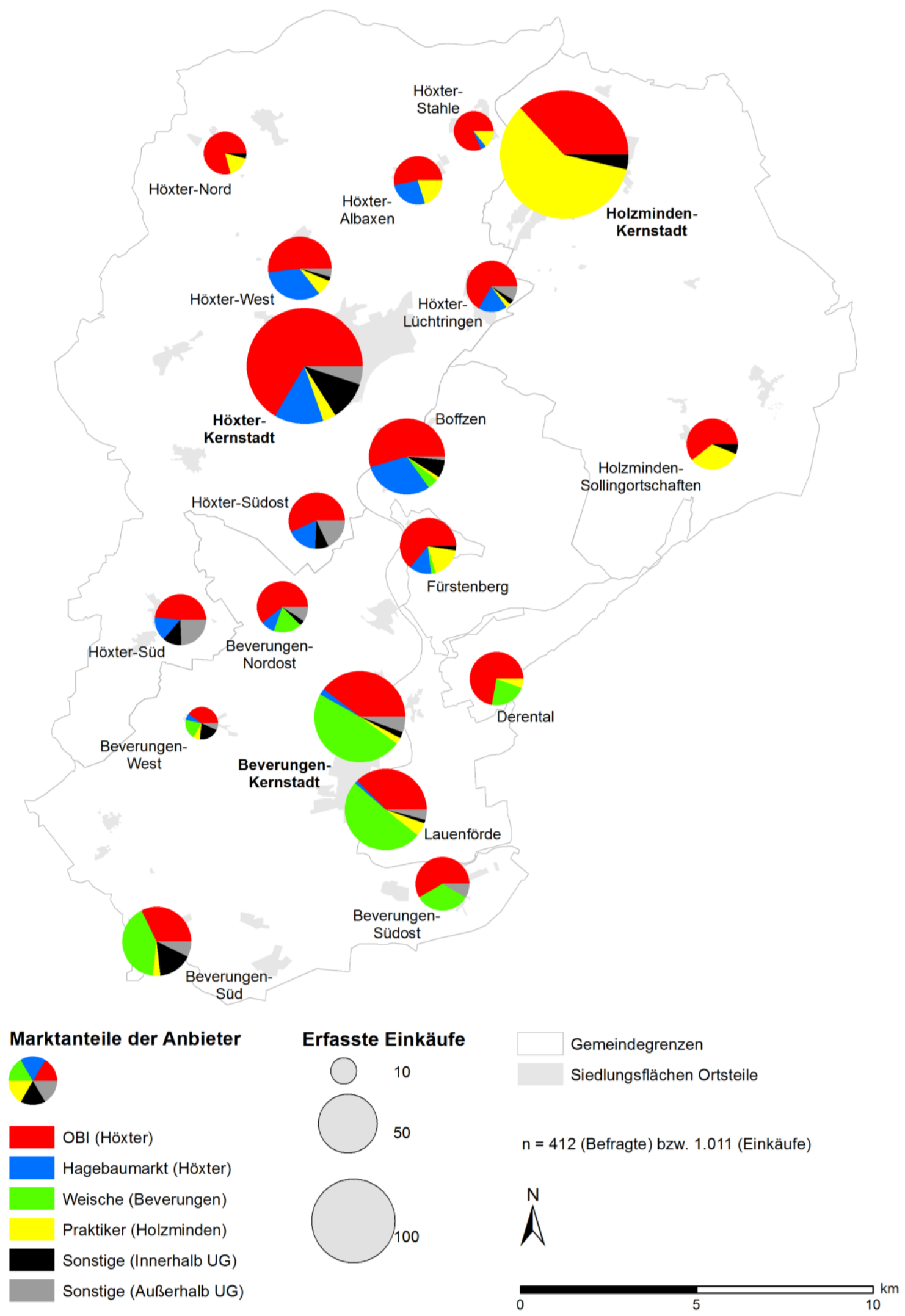

Karte 8: Baumärkte - Lokale Marktanteile und erfasste Einkäufe

Quelle: Eigene Darstellung, Datengrundlage: Eigene Erhebungen und Berechnungen, Kartengrundlage:

OpenStreetMap/Geofabrik 
Ähnlich eingeschränkt ist die Marktabdeckung der beiden anderen Anbieter: Die PraktikerFiliale im Holzmindener Gewerbegebiet Bülte und insbesondere der vertikal nicht-integrierte Einzelbetrieb Weische in Beverungen generieren ihre Kundenzuflüsse im Wesentlichen aus ihrer Standortgemeinde. Der Praktiker-Markt kann zudem geringe Besuchsanteile aus einigen Teilgebieten Höxters und Beverungens generieren; vor Ort (Holzminden-Kernstadt) erreicht er einen lokalen Marktanteil von 59,4\%, wobei auch von hier 36,9\% der erfassten Einkäufe im Höxteraner $O B /$-Markt stattfinden.

\subsubsection{Möbelmärkte}

Die kleinräumliche Verteilung der insgesamt 721 erfassten Einkäufe bei Möbelanbietern wird in Karte 9 dargestellt. Sehr deutlich zu erkennen ist die Marktdominanz des zur Einkaufskooperation VME gehörenden Möbelmarktes Weser Wohnwelt, der den mit Abstand größten untersuchungsrelevanten Anbieter im Untersuchungsgebiet darstellt. Der im Kernstadtbereich Höxters lokalisierte großflächige Markt erreicht lokale Marktanteile von 12,9 $\%$ (Höxter-Südost) bis 53,5 \% (Beverungen-Süd) und stellt weitgehend distanzunabhängig den am meisten frequentierten untersuchungsrelevanten Anbieter in allen Teilgebieten des Untersuchungsgebietes dar. Die in den drei Kernstadtbereichen beheimateten Filialen des Dänischen Bettenlagers sind in diesem Zusammenhang nur von lokaler Relevanz, d.h. sie werden überörtlich kaum frequentiert. Die restlichen Einkäufe innerhalb des Untersuchungsgebietes (schwarze Farbe) verteilen sich auf sechs weitere Möbelanbieter, die z.T. Möbeldiscounter darstellen und/oder im Schwerpunkt Gebrauchtmöbel anbieten und ebenso nur lokale Bedeutung besitzen (z.B. Möbel Bitter in Beverungen-Kernstadt, Vertiko in Holzminden-Kernstadt).

Viel deutlicher und zugleich relevanter für die weitere Verarbeitung im Rahmen dieser Analyse ist jedoch die festgestellte Tatsache, dass der Anteil an Einkäufen außerhalb des Untersuchungsgebietes (graue Farbe) sehr hoch liegt. Von den 712 erfassten Einkäufen fanden 385 außerhalb statt, was einem Anteil von 53,4 \% entspricht. Diese Einkäufe wurden vorwiegend in den großen Möbelhäusern der nächstliegenden Oberzentren (z.B. Göttingen, Kassel, Paderborn) getätigt. Umgekehrt deckt demnach die hier durchgeführte Analyse mit 46,6 \% weniger als die Hälfte aller Einkäufe der befragten Haushalte im Untersuchungsgebiet ab. Weiterhin besteht das Problem, dass die Zahl der registrierten Einkäufe vergleichsweise gering ist; dies ist darauf zurückzuführen, dass im Rahmen der Haushaltsbefragung viele Möbeleinkäufe eine so lange Zeit zurückreichen, dass sie nicht angegeben wurden bzw. werden konnten. Aus diesen beiden genannten Gründen wurden die Möbeleinkäufe im Folgenden bei den MCl-Modellanalysen nicht mehr berücksichtigt, da sich auf dieser Grundlage ohnehin kein aussagekräftiges Modell bilden ließe. Für $\mathrm{MCl}$ Modellanalysen sollten möglichst viele Einkäufe bzw. Anbieter durch das Modell abgedeckt sein (siehe Kap. 5.2.1); obwohl hierfür keine fest definierte Grenze existiert, ab der von einer ausreichenden Abdeckung gesprochen werden kann, ist die vorliegende Datenlage, die nur weniger als die Hälfte aller Einkäufe einschließt, definitiv nicht ausreichend. 
Räumliches Einkaufsverhalten und Standortpolitik im Einzelhandel unter Berücksichtigung von Agglomerationseffekten

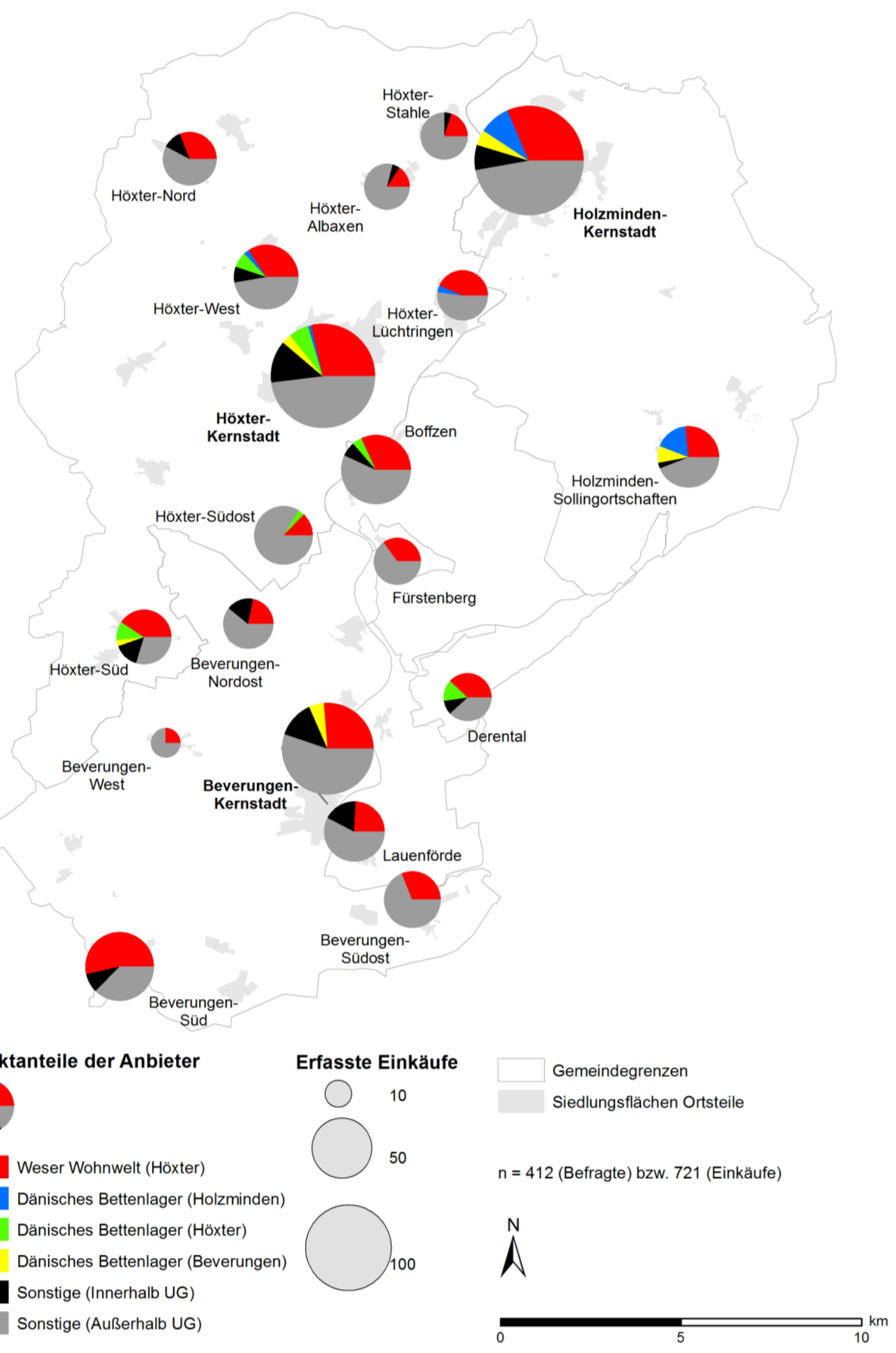

Karte 9: Möbelanbieter - Lokale Marktanteile und erfasste Einkäufe

Quelle: Eigene Darstellung, Datengrundlage: Eigene Erhebungen und Berechnungen, Kartengrundlage:

OpenStreetMap/Geofabrik 


\subsection{MCl-Modellanalyse}

\subsubsection{Lebensmittelmärkte}

\subsubsection{MCl-Modell}

Im Anschluss an die Ermittlung der empirischen Marktanteile als abhängige (zu erklärende) Variable (siehe Kap. 6.2) und der erklärenden Variablen (siehe Kap. 6.1) wurden die Daten im Sinne des MCl-Modells transformiert (siehe Kap. 5.3.1.5) und darauf aufbauend die linearen Regressionsmodelle geschätzt (siehe Kap. 5.3.2.1). Tabelle 19 fasst die Modellergebnisse des MCl-Modells für die Marktgebiete der Lebensmittelmärkte zusammen; darunter fallen die ermittelten Regressionskoeffizienten sowie die besprochenen Modelldiagnosen zur Beurteilung der statistischen Aussagekraft (siehe Kap. 5.3.2.2).

\begin{tabular}{|c|c|c|c|c|c|c|c|c|c|c|c|}
\hline \multirow{3}{*}{$\begin{array}{l}\text { Prädiktoren } \\
\log \left(d_{i j} / G M d_{i}\right)\end{array}$} & \multicolumn{2}{|c|}{ Koeffizienten } & \multirow{3}{*}{$\begin{array}{l}\text { VIF } \\
1,065\end{array}$} & \multicolumn{4}{|c|}{ Modell 1} & \multicolumn{4}{|c|}{ Modell 2 (HC1) } \\
\hline & \multirow{2}{*}{$\frac{b}{-1,747}$} & \multirow{2}{*}{$\frac{\beta}{-0,781}$} & & \multirow{2}{*}{$\frac{S F}{0,0882}$} & \multirow{2}{*}{$\frac{p}{* \star *}$} & \multicolumn{2}{|c|}{ KI (Min./Max.) } & \multirow{2}{*}{$\frac{\text { SF }}{0,0899}$} & \multirow{2}{*}{$\frac{\mathrm{p}}{* * *}$} & \multicolumn{2}{|c|}{ KI (Min./Max.) } \\
\hline & & & & & & $-1,920$ & $-1,573$ & & & $-1,924$ & $-1,570$ \\
\hline $\log \left(A_{j} / G M A_{j}\right)$ & 0,658 & 0,330 & 1,179 & 0,0828 & *** & 0,495 & 0,821 & 0,0852 & $* \star *$ & 0,490 & 0,826 \\
\hline $\log \left(K_{A_{j}} / G M K_{A_{j}}\right)$ & $-0,090$ & $-0,104$ & 1,822 & 0,0445 & * & $-0,177$ & $-0,002$ & 0,0455 & * & $-0,179$ & 0,000 \\
\hline $\log \left(K_{k_{j}} / G M K_{k_{j}}\right)$ & 0,083 & 0,176 & 1,760 & 0,0240 & *** & 0,036 & 0,130 & 0,0237 & *** & 0,037 & 0,130 \\
\hline \multicolumn{12}{|l|}{ Gesamtmodell } \\
\hline $\mathrm{R}^{2}$ & 0,596 & & & & & & & & & & \\
\hline Korr. $\mathrm{R}^{2}$ & 0,591 & & & \multirow{2}{*}{\multicolumn{8}{|c|}{ Abhängige Variable: $\log \left(\mathrm{p}_{\mathrm{ij}} / \mathrm{GM} \mathrm{p}_{\mathrm{i}}\right)$}} \\
\hline$p$ (F-Test) & $* * *$ & & & & & & & & & & \\
\hline Modelldiagnose & & & & \multirow{4}{*}{\multicolumn{8}{|c|}{$\begin{array}{r}\text { Signifikanzniveaus }(p):{ }^{* * *}=99,9 \%,{ }^{* *}=99 \%,{ }^{*}=95 \%, x=\text { nicht signifikant } \\
\text { GM }=\text { Geometrischer Mittelwert, } b=\text { Unstandardisierter Koeffizient, } \\
\beta=\text { Standardisierter Koeffizient, VIF = Variance Inflation Factor, } \\
\text { SF = Standardfehler des Koeffizienten, } \\
\text { KI }=\text { Konfidenzintervall des Koeffizienten (95\%) }\end{array}$}} \\
\hline White & $* * *$ & & & & & & & & & & \\
\hline Ramsey-RESET & $x$ & & & & & & & & & & \\
\hline Doornik-Hansen & $x$ & & & & & & & & & & \\
\hline
\end{tabular}

Tabelle 19: $\mathrm{MCl}-$ Modell für die Marktgebiete der Lebensmittelmärkte

Quelle: Eigene Darstellung, Datengrundlage: Eigene Erhebungen und Berechnungen

Neben den nicht-standardisierten Regressionskoeffizienten (b) sind die standardisierten Koeffizienten $(\beta)$ angegeben, die eine direkte Vergleichbarkeit der Stärke des Einflusses der erklärenden Variablen ermöglichen. Der VIF-Wert ist der Indikator für (mögliche) Multikollinearität der einzelnen Variablen im Zusammenhang des Gesamtmodells. Für das Modell werden das Bestimmtheitsmaß $\left(R^{2}\right)$, das korrigierte Bestimmtheitsmaß (Korr. $\left.R^{2}\right)$ und die Prüfung des Gesamtmodells auf Signifikanz ( $p$ (F-Test)) angegeben. Die Modelldiagnosen dokumentieren die Ergebnisse der Tests auf die Annahmenverletzungen eines Regressionsmodells (White-Test auf Heteroskedastizität, Ramsey-RESET-Test auf Linearität, Doornik-Hansen-Test auf Normalverteilung der Residuen). Ferner werden zwei Modellschätzungen miteinander verglichen: Die erste (Modell 1) zeigt die Ergebnisse einer konventionellen KQ-Schätzung, die zweite (Modell 2) dokumentiert die Ergebnisse einer Analyse mit heteroskedastizitätsrobusten Standardfehlern (HC1). Auf die ermittelten Parameter, den Erklärungsgehalt des Modells und die Diagnose möglicher Kollinearität hat 
dieses Verfahren keinen Einfluss; sehr wohl sind aber unterschiedliche Standardfehler (SF), Signifikanzniveaus der erklärenden Variablen $(p)$ und Konfidenzintervalle der Parameter $(K I)$ möglich, weshalb diese Werte für beide Schätzungen separat angegeben werden.

Sowohl im regulären als auch im Modell mit heteroskedastizitätsrobusten Inferenzstatistiken wird für alle vier getesteten erklärenden Variablen (Fahrtzeit $d_{i j}$, Angebotsgröße $A_{j}$, Konzentrationsvariablen $K_{A j}$ und $\left.K_{K j}\right)$ bzw. ihre transformierten Ausprägungen $\left(\log \left(d_{i j} / G M d_{i}\right)\right.$, $\left.\log \left(A_{j} / G M A_{j}\right), \log \left(K_{A j} / G M K_{A j}\right), \log \left(K_{K j} / G M K_{K j}\right)\right)$ ein statistisch signifikanter Einfluss auf die Zielvariable ( $p_{i j}$, transformiert: $\left.\log \left(p_{i j} / G M p_{i}\right)\right)$ nachgewiesen. Im Fall der Verkaufsfläche, der Fahrtzeit und des konkurrentenbezogenen Konzentrationswertes ergibt sich eine Irrtumswahrscheinlichkeit von unter 0,1\% bzw. ein Signifikanzniveau von mindestens 99,9 $\%$; die allgemeine Konzentrationsvariable erreicht ein Signifikanzniveau von $95 \%$. Ausgehend von den standardisierten Regressionskoeffizienten bildet die Fahrtzeit mit $\beta=$ -0,781 die erklärende Variable mit dem höchsten Einfluss im Modell; dieser negative Einfluss auf die Zielvariable (abzulesen am Vorzeichen) schlägt sich in einem nicht-standardisierten, d.h. auf die Maßeinheit bezogenen, Parameter von $b=-1,747$ nieder. Der zweitgrößte Einfluss wird von der Größenvariable (Verkaufsfläche) mit einem Parameter von $b=0,658$ ( $\beta$ $=0,330$ ) ausgeübt; sie wirkt demnach positiv auf die (transformierten) lokalen Marktanteile. Von den berücksichtigten Konzentrationsvariablen wirkt das konkurrentenbezogene Maß positiv $(b=0,176)$ und die allgemeine Konzentrationsvariable negativ $(b=-0,090)$. Der Modelleinfluss erstgenannter Variable ist hierbei deutlich größer $(\beta=0,176)$ als der der zweiten $(\beta=-0,104)$. Das unkorrigierte Bestimmtheitsmaß des Modells $\left(R^{2}\right)$ beträgt 0,596 und in korrigierter Form 0,591; ausgehend von letztgenanntem Wert klärt das Modell also $59,1 \%$ an Varianz der Variablenausprägungen auf.

Der White-Test zeigt ein statistisch signifikantes Ergebnis, d.h. im Modell wird Heteroskedastizität diagnostiziert, weshalb die inferenzstatistischen Ergebnisse der HC1Schätzung der ersteren vorzuziehen sind. Hierbei unterscheiden sich erwartungsgemäß die Standardfehler und die Konfidenzintervalle der Regressionskoeffizienten; sie sind bei der zweiten Schätzung i.d.R. höher bzw. breiter, wenngleich die ermittelten Signifikanzniveaus innerhalb derselben Stufe liegen und somit der empirische Wirkungsnachweis der erklärenden Variablen auch unter der Bedingung von Heteroskedastizität erbracht werden kann. Der vergleichsweise geringe Einfluss der allgemeinen Konzentrationsvariablen wird hierbei auch über die Konfidenzintervalle dieses Parameters dokumentiert: Der „echte“ Wert liegt zu $95 \%$ zwischen -0,179 und 0,000 (HC1-Schätzung), was einem nicht vorhandenen Einfluss entsprechen würde. Die Vertrauensintervalle der anderen Schätzer variieren ebenso stark, jedoch in einer Spanne plausibler Werte desselben Vorzeichens (z.B. Fahrtzeit: Minimum -1,924 / Maximum: -1,570).

Der Ramsey-Linearitätstest gibt kein signifikantes Anzeichen für eine Nicht-Linearität, auch die Normalverteilungsannahme (Doornik-Hansen-Test) ist gewährleistet. Ebenso bewegen sich die VIF-Werte zur Diagnose von Multikollinearität zwischen 1,065 und 1,822 und somit in der Nähe des Minimalwertes (VIF = 1) und deutlich unterhalb des kritischen Grenzwertes von VIF $=5$. Abgesehen von der Heteroskedastizitätsproblematik, die durch die robuste Schätzung behoben wurde, finden sich demnach keine Annahmenverletzungen eines linearen Regressionsmodells. Es ist also davon auszugehen, dass die ermittelten Parameterwerte im Sinne der statistischen Hypothesenprüfung und ihrer Grenzen (Irrtumswahrscheinlichkeiten) ein hinreichendes Abbild der Grundgesamtheit darstellen. 
Ergänzend zu dieser Modellschätzung ist eine schrittweise Regression durchgeführt worden (siehe Kap. 5.3.2.3), deren Ergebnisse für die Marktgebiete der Lebensmittelmärkte in Tabelle 20 dargestellt werden. An zusätzlichen Modelldiagnosen werden hierbei nur jene angegeben, die auch von der genutzten Software bereitgestellt werden. Neben den (nichtstandardisierten und standardisierten) Koeffizienten ( $b$ und $\beta$ ) und den Signifikanzprüfungen (p) sind dies ebenso VIF-Werte sowie Bestimmtheitsmaße $\left(R^{2}\right)$, die Veränderungen der Bestimmtheitsmaße durch eine Aufnahme der weiteren Variablen (Veränd. $R^{2}$ ) und die Prüfung einer hierdurch erreichten signifikanten Verbesserung des Modells (Sign. Veränd.). Die Schritte entsprechen hierbei der Reihenfolge der ins Modell aufgenommenen Variablen, d.h. in Schritt 1 ist die Variable mit dem höchsten Erklärungswert integriert worden etc.

\begin{tabular}{|c|c|c|c|c|c|}
\hline \multirow{2}{*}{ Prädiktoren } & & \multicolumn{4}{|c|}{ Modell bzw. Schritt } \\
\hline & & Schritt 1 & Schritt 2 & Schritt 3 & Schritt 4 \\
\hline \multirow{4}{*}{$\log \left(d_{i j} / G M d_{i}\right)$} & $b$ & $-1,575$ & $-1,700$ & $-1,724$ & $-1,747$ \\
\hline & $\beta$ & $-0,704$ & $-0,760$ & $-0,771$ & $-0,781$ \\
\hline & $\mathrm{p}$ & $* * *$ & $* * *$ & $* * *$ & $* * *$ \\
\hline & VIF & 1,000 & 1,038 & 1,048 & 1,065 \\
\hline \multirow{4}{*}{$\log \left(A_{j} / G M A_{j}\right)$} & $b$ & -- & 0,584 & 0,602 & 0,658 \\
\hline & $\beta$ & -- & 0,293 & 0,301 & 0,330 \\
\hline & $\mathrm{p}$ & -- & $* * *$ & $* * *$ & $* * *$ \\
\hline & VIF & -- & 1,038 & 1,045 & 1,179 \\
\hline \multirow{4}{*}{$\log \left(K_{k_{j}} / G M K_{K_{j}}\right)$} & $b$ & - & -- & 0,052 & 0,083 \\
\hline & $\beta$ & -- & -- & 0,109 & 0,176 \\
\hline & $p$ & -- & -- & ** & $* * *$ \\
\hline & VIF & -- & -- & 1,013 & 1,760 \\
\hline \multirow{4}{*}{$\log \left(\mathrm{K}_{\mathrm{Aj}} / \mathrm{GM} \mathrm{K}_{\mathrm{Aj}}\right)$} & $b$ & -- & - & - & $-0,090$ \\
\hline & $\beta$ & -- & -- & -- & $-0,104$ \\
\hline & $p$ & - & -- & -- & * \\
\hline & VIF & -- & -- & -- & 1,822 \\
\hline \multicolumn{6}{|l|}{ Gesamtmodell } \\
\hline $\mathrm{R}^{2}$ & & 0,496 & 0,578 & 0,590 & 0,596 \\
\hline Veränd. $\mathrm{R}^{2}$ & & -- & 0,083 & 0,012 & 0,006 \\
\hline Korr. $\mathrm{R}^{2}$ & & -- & 0,575 & 0,586 & 0,590 \\
\hline \multirow[t]{3}{*}{ Sign. Veränd. } & & -- & $* * *$ & $* *$ & * \\
\hline & & & & \multicolumn{2}{|c|}{ Abhängige Variable: $\log \left(\mathrm{p}_{\mathrm{ij}} / \mathrm{GM} \mathrm{p}_{\mathrm{i}}\right)$} \\
\hline & & & \multicolumn{3}{|c|}{$\begin{array}{r}\text { Signifikanzniveaus (p): }{ }^{* *}=99,9 \%,{ }^{* *}=99 \%,{ }^{*}=95 \%, x=\text { nicht signifikant } \\
\text { GM }=\text { Geometrischer Mittelwert, } b=\text { Unstandardisierter Koeffizient, } \\
\beta=\text { Standardisierter Koeffizient, VIF = Variance Inflation Factor }\end{array}$} \\
\hline
\end{tabular}

Tabelle 20: MCl-Modell für die Marktgebiete der Lebensmittelmärkte - Schrittweise Regression Quelle: Eigene Darstellung, Datengrundlage: Eigene Erhebungen und Berechnungen 
Im Zuge der schrittweisen Regressionsanalyse wurde im ersten Schritt die Fahrtzeit ins Modell aufgenommen, die alleine eine Varianzaufklärung von 49,6\% $\left(R^{2}=0,496\right)$ erreicht. Im zweiten Schritt erfolgte die Aufnahme der Größenvariablen mit einem $R^{2}$-Zuwachs von 8,3 \%. Die Berücksichtigung der Konzentrationsvariablen für die konkurrierenden Anbieter im dritten Schritt erhöht das Bestimmtheitsmaß abermals um 1,2 \%. Auch die allgemeine Konzentrationsvariable wird im vierten Schritt mit einer dadurch induzierten Erhöhung der Varianzaufklärung um 0,6 \% ins Modell aufgenommen. In jedem Schritt wird eine signifikante Verbesserung des Modellerklärungsgehaltes diagnostiziert, wenngleich diese, gemessen in Prozentpunkten, vergleichsweise gering ist: Während die Fahrtzeit bereits nahezu zur Hälfte der Varianzaufklärung beiträgt, bewirken die restlichen drei Variablen insgesamt nur weitere $10 \%$. Abgesehen davon, dass die berechneten VIF- und $\beta$-Werte naturgemäß denen aus der ersten Schätzung entsprechen, stimmt auch die Reihenfolge des schrittweisen Vorgehens mit den Ergebnissen der ersten Regressionsanalyse überein. Deutlich wird außerdem, dass die Fahrtzeit, die als am stärksten wirkende Einflussgröße zuerst ins Modell aufgenommen wird, von Schritt zu Schritt an Einflussstärke hinzugewinnt, was sich an den Steigerungen der $b$ - und $\beta$-Werte ablesen lässt; selbiges gilt für den Größenindikator.

Ausgehend von der Kontrolle der Ergebnisse durch die Nutzung zweier Verfahren können die Ergebnisse also als statistisch belastbar und somit auch als inhaltlich interpretierbar angesehen werden. Werden die Parameter in die Schätzgleichung (siehe Kap. 5.3.2.1) eingesetzt, ergibt sich die exemplarisch in Formel 41 dargestellte Regressionsgleichung.

$$
\begin{aligned}
& \log \left(\frac{p_{i j}}{\tilde{p}_{i}}\right)=-1,747 \log \left(\frac{d_{i j}}{\tilde{d}_{i}}\right)+0,658 \log \left(\frac{A_{j}}{\tilde{A}_{j}}\right)-0,090 \log \left(\frac{K_{A_{j}}}{\tilde{K}_{A_{j}}}\right) \\
& +0,083 \log \left(\frac{K_{K_{j}}}{\tilde{K}_{K}}\right)+\log \left(\frac{\varepsilon_{i j}}{\widetilde{\varepsilon}_{i j}}\right) \\
& \mathrm{p}_{\mathrm{ij}}=\text { Marktanteil von Anbieter j in Nachfrageort i } \\
& \mathrm{dij}_{\mathrm{ij}}=\text { Fahrtzeit von Nachfrageort i zu Anbieter } \mathrm{j} \\
& \mathrm{A}_{\mathrm{j}}=\text { Verkaufffläche des Anbieters } \mathrm{j} \\
& \mathrm{K}_{\mathrm{Aj}}=\text { Konzentrationsvariable für den Anbieter j für die Nähe zu anderen Einzelhandelsanbietern } \\
& \mathrm{K}_{\mathrm{kj}}=\text { Konzentrationsvariable für den Anbieter j für die Nähe zu gleichartigen Einzelhandelsanbietern } \\
& \tilde{p}_{\mathrm{i}}=\text { Geometrischer Mittelwert von allen } \mathrm{p}_{\mathrm{i}} \\
& \tilde{\mathrm{d}}_{\mathrm{i}}=\text { Geometrischer Mittelwert von allen dij } \\
& \tilde{A}_{\mathrm{i}}=\text { Geometrischer Mittelwert von allen } \mathrm{A}_{\mathrm{j}} \\
& \mathrm{K}_{\mathrm{Aj}}=\text { Geometrischer Mittelwert von allen } \mathrm{K}_{\mathrm{Aj}} \\
& \mathrm{K}_{\mathrm{kj}}=\text { Geometrischer Mittelwert von allen } \mathrm{K}_{\mathrm{kj}} \\
& \varepsilon_{\mathrm{ij}}=\text { Residuen }
\end{aligned}
$$

\subsubsection{MCl-GWR-Modell}

Um mögliche räumliche Nicht-Stationarität durch Inhomogenitäten der Nachfrage- und Angebotsstruktur zu berücksichtigen und zugleich die Varianzaufklärung der Modelle zu erhöhen, wurden zusätzlich räumlich variierende Modelle mit Hilfe der geographisch gewichteten Regression (GWR) geschätzt (siehe Kap. 5.3.2.4); hierbei wurden für alle 19 Teilgebiete (d.h. Nachfrageorte) eigene Parameter sowie Modellgütestatistiken (z.B. $R^{2}$ ) 
ermittelt. Tabelle 21 zeigt eine Zusammenfassung des GWR-Modells für die Marktgebiete der Lebensmittelmärkte. Es werden hierfür jeweils die lokalen Minima und Maxima der nichtstandardisierten Regressionskoeffizienten $(b)$ angegeben, d.h. die in den Teilgebieten jeweils niedrigste und die höchste erreichte Ausprägung der Parameter. Als Indikatoren der Modellgüte werden neben dem Bestimmtheitsmaß des Gesamtmodells $\left(R^{2}\right)$ und einem korrigierten Bestimmtheitsmaß auch das lokale Minimum und Maximum dieser Werte gezeigt. Auf die Darstellung lokaler Standardfehler wird aus Gründen der Übersichtlichkeit verzichtet. Sonstige Modelldiagnosen werden durch die benutzte Software nicht erstellt und erübrigen sich auch insofern, als dass die statistischen Zusammenhänge bereits durch die Inferenzstatistiken der konventionellen Schätzung (siehe Kap. 6.3.1.1) erwiesen wurden. Karte 10 visualisiert die lokal variierenden Parameter und das Bestimmtheitsmaß in Form von Quantilen, d.h. in Schritten von $25 \%$ (jeweils farbige Abgrenzung).

\begin{tabular}{|c|c|c|c|c|c|c|}
\hline \multirow[b]{2}{*}{ Prädiktoren } & \multicolumn{2}{|c|}{ b } & \multicolumn{4}{|c|}{$\mathrm{R}^{2}$} \\
\hline & Lokal Min. & Lokal Max. & Gesamtmodell & Lokal Min. & Lokal Max. & Korr. \\
\hline $\log \left(A_{j} / G M A_{j}\right)$ & $-0,489$ & 1,326 & \multirow{4}{*}{0,737} & \multirow{4}{*}{0,234} & \multirow{4}{*}{0,964} & \multirow{4}{*}{0,60} \\
\hline $\log \left(d_{i j} / G M d_{i}\right)$ & $-2,646$ & 8,711 & & & & \\
\hline $\log \left(K_{A_{j}} / G M K_{A j}\right)$ & $-0,923$ & 0,408 & & & & \\
\hline $\log \left(K_{k_{j}} / G M K_{K j}\right)$ & $-0,566$ & 0,565 & & & & \\
\hline
\end{tabular}

Tabelle 21: GWR-Modell für die Marktgebiete der Lebensmittelmärkte (Zusammenfassung)

Quelle: Eigene Darstellung, Datengrundlage: Eigene Erhebungen und Berechnungen

Erwartungsgemäß ist die Varianzaufklärung des lokal angepassten Modells insgesamt etwas höher als die des konventionellen Regressionsmodells: Das unkorrigierte Bestimmtheitsmaß $\left(R^{2}\right)$ liegt bei $0,737(73,7 \%)$, das korrigierte bei 0,604 (60,4\%). Lokal schwankt jedoch die Modellanpassung erheblich: Die lokalen $R^{2}$-Werte bewegen sich in einem Wertebereich von 0,234 (Teilgebiet Höxter-Albaxen) und 0,964 (Beverungen-Südost). Ebenso stark variieren die ermittelten Parameter, wobei sich mitunter sogar ihr Vorzeichen (d.h. die Richtung ihres Einflusses) verändert: In zwei Teilgebieten (Derental, Höxter-Albaxen) ist der statistische Einfluss der Fahrtzeit im Modell positiv, in allen anderen negativ, wobei die Ausprägung des Parameters zwischen $-0,52$ und $-2,65$ schwankt. In ähnlicher Weise ergibt sich für die Größenvariable ein Fall negativer Ausprägung (Beverungen-Südost) und ansonsten Variationen zwischen 0,08 und 1,33. Auch für die Konzentrationsvariablen zeigen sich jeweils Wirkungen unterschiedlicher Richtung.

Die in der konventionellen Modellschätzung ermittelte Wirkungsrichtung wird also im GWRModell nicht in jedem Fall bestätigt. Insgesamt zeigt sich die Tendenz, dass die Teilgebiete mit unplausiblen bzw. nicht der konventionellen Schätzung entsprechenden Parametern auch zugleich diejenigen mit der geringsten Varianzaufklärung sind (z.B. Höxter-Albaxen). In der räumlichen Streuung der Parameterwerte und der Bestimmtheitsmaße ist im Kartenbild kein deutliches Muster zu erkennen, z.B. dass größere/kleinere Teilgebiete aufgrund einer höheren/niedrigeren Teilstichprobengröße besser/schlechter abgebildet werden würden. Diese Umstände lassen Zweifel aufkommen, ob diese GWR-Schätzung die Abbildungskraft des MCl-Modells für die Lebensmittelmärkte wirklich verbessert hat und ob die massiven lokalen Variationen der Parameterwerte überhaupt inhaltlich-theoretisch erklärbar sind. 
Räumliches Einkaufsverhalten und Standortpolitik im Einzelhandel unter Berücksichtigung von Agglomerationseffekten

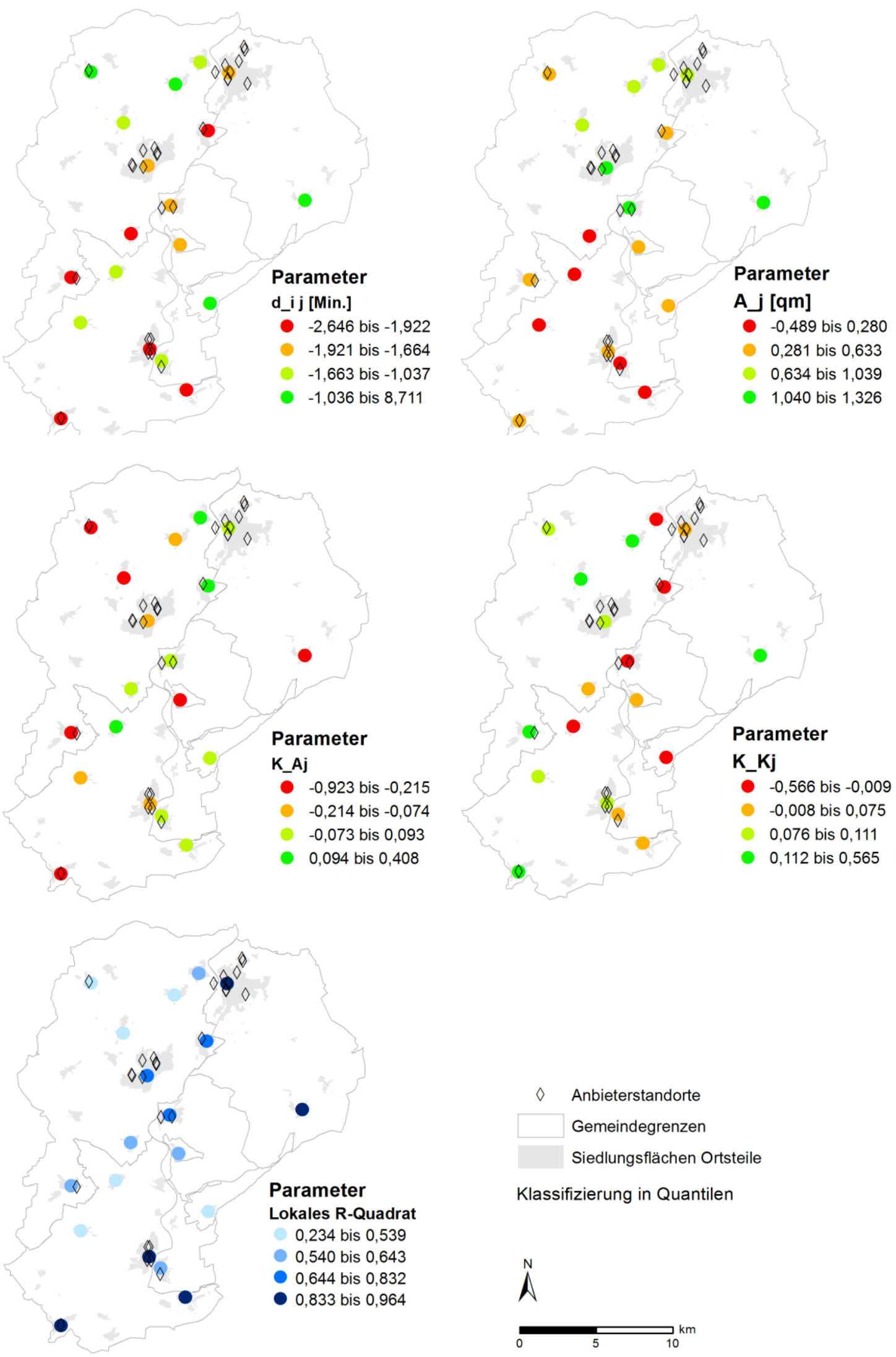

Karte 10: GWR-Modell für die Marktgebiete der Lebensmittelmärkte

Quelle: Eigene Darstellung, Datengrundlage: Eigene Erhebungen und Berechnungen, Kartengrundlage: OpenStreetMap/Geofabrik 


\subsubsection{MCI-Modell für LM-Vollsortimenter}

Um die betriebsformenspezifischen Hypothesen $\left(\mathrm{H}_{6 a}, \mathrm{H}_{6 \mathrm{~b}}\right.$; siehe Kap. 5.1.2) überprüfen zu können, wurden die empirischen Marktgebiete der Lebensmittelmärkte dementsprechend separiert, d.h. jeweils nur auf der Ebene der Lebensmittel-Vollsortimenter (Supermärkte und Verbrauchermärkte) und Discounter berechnet. Zusätzlich wurden nach dem etablierten Muster für die jeweils betrachteten Anbieter zwei neue Konzentrationsvariablen - eine für die räumliche Konzentration mit Vollsortimentern $\left(K_{V j}\right)$ und eine für die Ballung mit LMDiscountern $\left(K_{D j}\right)$ - gebildet (siehe Kap. 5.3.1.4). Diese neuen Variablen wurden nach denselben Maßgaben transformiert (siehe Kap. 5.3.1.5) und im MCl-Modell getestet; in den betriebsformenspezifischen Modellen ersetzen sie die übergreifende Konzentrationsvariable für branchengleiche Anbieter $\left(K_{K j}\right)$. Unverändert berücksichtigt wird die allgemeine Konzentrationsvariable für Anbieter anderer Branchen $\left(K_{A j}\right)$. Tabelle 22 zeigt die Ergebnisse der Schätzung und die Modelldiagnosen des MCl-Modells für die Marktgebiete der Lebensmittel-Vollsortimenter.

\begin{tabular}{|c|c|c|c|c|c|c|c|c|c|c|c|}
\hline \multirow{3}{*}{$\begin{array}{l}\text { Prädiktoren } \\
\log \left(d_{i j} / G M d_{i}\right)\end{array}$} & \multicolumn{2}{|c|}{ Koeffizienten } & \multirow{3}{*}{$\begin{array}{c}\text { VIF } \\
1,081\end{array}$} & \multicolumn{4}{|c|}{ Modell 1} & \multicolumn{4}{|c|}{ Modell 2 (HC1) } \\
\hline & \multirow{2}{*}{$\frac{b}{-1,803}$} & \multirow{2}{*}{$\frac{\beta}{-0,821}$} & & \multirow{2}{*}{$\frac{S F}{0,106}$} & \multirow{2}{*}{$\frac{p}{* * *}$} & \multicolumn{2}{|c|}{ KI (Min./Max.) } & \multirow{2}{*}{$\frac{S F}{0,107}$} & \multirow{2}{*}{$\frac{p}{* * *}$} & \multicolumn{2}{|c|}{ KI (Min./Max.) } \\
\hline & & & & & & $-2,013$ & $-1,592$ & & & $-2,014$ & $-1,591$ \\
\hline $\log \left(A_{j} / G M A_{j}\right)$ & 0,571 & 0,301 & 1,073 & 0,079 & $* * *$ & 0,415 & 0,727 & 0,082 & $* * *$ & 0,408 & 0,734 \\
\hline $\log \left(K_{A_{j}} / G M K_{A j}\right)$ & 0,009 & 0,011 & 2,906 & 0,066 & $x$ & $-0,122$ & 0,139 & 0,060 & $x$ & $-0,110$ & 0,127 \\
\hline $\log \left(K_{D j} / G M K_{D j}\right)$ & 0,063 & 0,148 & 1,745 & 0,026 & * & 0,011 & 0,115 & 0,025 & * & 0,015 & 0,112 \\
\hline $\log \left(K_{v_{j}} / G M K_{v_{j}}\right)$ & $-0,116$ & $-0,130$ & 1,947 & 0,058 & * & $-0,230$ & $-0,002$ & 0,056 & * & $-0,226$ & $-0,006$ \\
\hline
\end{tabular}

\section{Gesamtmodell}

$\mathrm{R}^{2} \quad 0,667$

Korr. $R^{2} \quad 0,659$

$\mathrm{p}$ (F-Test) $\quad$ ***

Abhängige Variable: $\log \left(\mathrm{p}_{\mathrm{ij}} / \mathrm{GM} \mathrm{p}_{\mathrm{i}}\right)$

Modelldiagnose

White

Ramsey-RESET

Doornik-Hansen
Signifikanzniveaus (p): ${ }^{* * *}=99,9 \%,{ }^{* *}=99 \%,{ }^{*}=95 \%, x=$ nicht signifikant $\mathrm{GM}=$ Geometrischer Mittelwert, $\mathrm{b}=$ Unstandardisierter Koeffizient, $\beta=$ Standardisierter Koeffizient, VIF = Variance Inflation Factor, SF = Standardfehler des Koeffizienten, $\mathrm{KI}=$ Konfidenzintervall des Koeffizienten (95\%)

Tabelle 22: MCI-Modell für die Marktgebiete der LM-Vollsortimenter

Quelle: Eigene Darstellung, Datengrundlage: Eigene Erhebungen und Berechnungen

Die Varianzaufklärung des Modells für die Vollsortimenter von 66,7 \% $\left(R^{2}=0,667\right)$ bzw. 65,9 $\%$ (korr. $R^{2}=0,659$ ) liegt höher als die des Modells für alle Lebensmittelmärkte (siehe Kap. 6.3.1.1). Sämtliche VIF-Werte liegen auch hier unterhalb der konservativ angesetzten kritischen Grenze von VIF $=5$, sodass auf der Grundlage der etablierten Grenzwerte starke Verzerrungen aufgrund von Multikollinearitätseffekten ausgeschlossen werden können. Ebenso gab der Ramsey-Test keinen Hinweis auf Probleme aufgrund von Nicht-Linearität und auch im Doornik-Hansen-Test zur Prüfung der Residuen auf Normalverteilung wurde keine Verletzung dieser Annahme attestiert. Allerdings wurde auch hier durch den WhiteTest Heteroskedastizität nachgewiesen, so dass die Inferenzstatistiken des zweiten, heteroskedastizitätsrobusten Modells betrachtet werden müssen. 
Von den fünf getesteten Variablen erreichen vier ein Signifikanzniveau von mindestens 95 \%. Die Einflussstärke der Fahrtzeit ist hierbei wiederum am größten, worauf der $\beta$-Wert von $-0,821$ hinweist; der nicht-standardisierte Regressionskoeffizient $(b)$ beträgt $-1,803$, so dass auch hier ein überlinear negativer Einfluss dieses Prädiktors auf die Zielvariable festgestellt werden kann. Die Größe des Angebots (Verkaufsfläche) stellt mit $b=0,571$ bzw. $\beta=0,301$ den zweitgrößten Einflussfaktor im Modell dar und beeinflusst die lokalen Marktanteile positiv. Das Vorzeichen des Parameters für die allgemeine Agglomerationsvariable ist ebenso positiv, was entgegen des Modells für alle Lebensmittelmärkte auf einen fördernden Einfluss der Ausprägungen dieser Variable auf die Zielvariable hindeutet; jedoch ist der Einfluss dieses Prädiktors nicht signifikant, und auch die 95-\%-Konfidenzintervalle (Minimum: $-0,110$ / Maximum: 0,127) weisen auf eine nicht zu definierende Auswirkung hin. Die Konzentrationsvariable für die räumliche Nähe zu LM-Discountern ( $K_{D j}$, transformiert) besitzt die drittgrößte Wirkung im Modell $(\beta=0,148)$ und schlägt sich mit einem Koeffizienten von $b=0,063$ als positiver Einfluss im Modell nieder. Die Konzentrationsvariable für die anderen Vollsortimenter ( $K_{V j}$, transformiert) wirkt negativ $(b=-0,116 / \beta=-0,130)$. Die beiden Konzentrationsvariablen für branchengleiche Anbieter erreichen ein Signifikanzniveau von 95 \%, während die Verkaufsfläche und die Fahrtzeit auf einem 99,9-\%-Niveau signifikant sind.

\subsubsection{MCI-Modell für LM-Discounter}

Entsprechend dem MCI-Modell für die Marktgebiete der LM-Vollsortimenter wurde ein separates Modell für die LM-Discounter mit dementsprechenden zusätzlichen Variablen $\left(K_{D j}\right.$, $K_{V j}$; jeweils transformiert) geschätzt. Tabelle 23 zeigt die Ergebnisse dieser Modellbildung. Die Modelldiagnosen entsprechen den anderen Modellen (White-Test signifikant, Ramseyund Doornik-Hansen-Test nicht signifikant), allerdings ist die Varianzaufklärung mit $56,5 \%$ $\left(R^{2}=0,565\right)$ bzw. 55,0\% (korr. $\left.R^{2}=0,550\right)$ geringer.

\begin{tabular}{|c|c|c|c|c|c|c|c|c|c|c|c|}
\hline \multirow{3}{*}{$\begin{array}{l}\text { Prädiktoren } \\
\log \left(d_{i j} / G M d_{i}\right)\end{array}$} & \multicolumn{2}{|c|}{ Koeffizienten } & \multirow{3}{*}{$\begin{array}{c}\text { VIF } \\
1,062\end{array}$} & \multicolumn{4}{|c|}{ Modell 1} & \multicolumn{4}{|c|}{ Modell 2 (HC1) } \\
\hline & \multirow{2}{*}{$\frac{b}{-1,726}$} & \multirow{2}{*}{$\frac{\beta}{-0,757}$} & & \multirow{2}{*}{$\frac{\text { SF }}{0,143}$} & \multirow{2}{*}{$\frac{p}{* * *}$} & \multicolumn{2}{|c|}{ KI (Min./Max.) } & \multirow{2}{*}{$\frac{S F}{0,133}$} & \multirow{2}{*}{$\frac{p}{* * *}$} & \multicolumn{2}{|c|}{ KI (Min./Max.) } \\
\hline & & & & & & $-2,001$ & $-1,443$ & & & $-1,989$ & $-1,462$ \\
\hline $\log \left(A_{j} / G M A_{j}\right)$ & 0,977 & 0,190 & 1,901 & 0,432 & * & 0,123 & 1,832 & 0,473 & * & 0,040 & 1,914 \\
\hline $\log \left(K_{A_{j}} / G M K_{A_{j}}\right)$ & $-0,256$ & $-0,278$ & 2,921 & 0,095 & ** & $-0,444$ & $-0,067$ & 0,094 & ** & $-0,441$ & $-0,070$ \\
\hline $\log \left(K_{D j} / G M K_{D j}\right)$ & $-0,069$ & $-0,124$ & 2,304 & 0,051 & $x$ & $-0,170$ & 0,033 & 0,052 & $x$ & $-0,172$ & 0,034 \\
\hline $\log \left(K_{v_{j}} / G M K_{v_{j}}\right)$ & 0,130 & 0,328 & 3,457 & 0,045 & ** & 0,041 & 0,219 & 0,042 & ** & 0,047 & 0,213 \\
\hline
\end{tabular}

Gesamtmodell

$\mathrm{R}^{2}$

0,565

Korr. $R^{2} \quad 0,550$

$\mathrm{p}$ (F-Test) $\quad$ ***

Abhängige Variable: $\log \left(\mathrm{p}_{\mathrm{ij}} / \mathrm{GM} \mathrm{p}_{\mathrm{i}}\right)$

\section{Modelldiagnose}

White

Ramsey-RESET

Doornik-Hansen

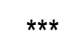

$\mathrm{X}$

$\mathrm{X}$
Signifikanzniveaus (p): ${ }^{* * *}=99,9 \%,{ }^{* *}=99 \%,{ }^{*}=95 \%, x=$ nicht signifikant $\mathrm{GM}=$ Geometrischer Mittelwert, $\mathrm{b}=$ Unstandardisierter Koeffizient, $\beta=$ Standardisierter Koeffizient, VIF = Variance Inflation Factor, SF = Standardfehler des Koeffizienten, $\mathrm{KI}=$ Konfidenzintervall des Koeffizienten (95\%)

Tabelle 23: MCI-Modell für die Marktgebiete der LM-Discounter

Quelle: Eigene Darstellung, Datengrundlage: Eigene Erhebungen und Berechnungen 
Abermals bildet die Fahrtzeit den einflussreichsten Prädiktor $(\beta=-0,757)$ mit einem negativen Vorzeichen bzw. einer negativen Wirkung auf die Zielvariable; der nichtstandardisierte Regressionskoeffizient beträgt $b=-1,726$, wobei das höchstmögliche Signifikanzniveau von 99,9 \% erreicht wird. Abweichend von den beiden anderen auf Lebensmittelmärkte bezogenen Modellen macht die Verkaufsfläche nur den viergrößten Einfluss im Modell aus $(\beta=0,190)$, wobei der nicht-standardisierte Koeffizient mit $b=0,977$ wiederum deutlich höher liegt als bei den anderen Schätzungen; das Signifikanzniveau dieses Prädiktors liegt bei $95 \%$. Den zweitgrößten Einfluss im Modell $(\beta=0,328)$ hat die Konzentrationsvariable bezüglich der räumlichen Nähe zu LM-Vollsortimentern, die mit einem Parameter von $b=0,130$ positiv auf die Zielvariable wirkt. Die allgemeine Konzentrationsvariable hat die drittgrößte, in diesem Fall negative Wirkung $(b=-0,256 / \beta=$ -0,278). Diese beiden Agglomerationsvariablen erreichen jeweils ein Signifikanzniveau von $99 \%$, während der negative Einfluss der Konzentrationsvariable für die Nähe zu anderen Discountern $(b=-0,069 / \beta=-0,124)$ das Minimalniveau von $95 \%$ unterschreitet, d.h. nicht statistisch signifikant im Sinne der vordefinierten Grenzwerte ist. Wie in den anderen Fällen wird der kritische Wert von VIF $=5$ bei keiner der Variablen erreicht.

\subsubsection{Elektronikmärkte}

\subsubsection{MCl-Modell}

Die Schätzergebnisse sowie die Modelldiagnosen des MCl-Modells für die Marktgebiete der Elektronikmärkte werden in Tabelle 24 dargestellt. Die Varianzaufklärung des Modells ist mit einem Wert von $R^{2}=0,770$ (korrigiertes $R^{2}=0,762$ ) deutlich höher als in den Modellen zu den Lebensmittelmärkten (siehe Kap. 6.3.1). Der Ramsey-RESET-Test auf Nicht-Linearität brachte ebenso wie der Doornik-Hansen-Test auf Normalverteilung der Störgrößen kein signifikantes Ergebnis. Abermals diagnostiziert der White-Test jedoch Heteroskedastizität.

\begin{tabular}{|c|c|c|c|c|c|c|c|c|c|c|c|}
\hline \multirow{3}{*}{$\begin{array}{l}\text { Prädiktoren } \\
\log \left(d_{i j} / G M d_{i}\right)\end{array}$} & \multicolumn{2}{|c|}{ Koeffizienten } & \multirow{3}{*}{$\begin{array}{c}\text { VIF } \\
1,157\end{array}$} & \multicolumn{4}{|c|}{ Modell 1} & \multicolumn{4}{|c|}{ Modell 2 (HC1) } \\
\hline & \multirow{2}{*}{$\frac{b}{-1,632}$} & \multirow{2}{*}{$\frac{\beta}{-0,603}$} & & \multirow{2}{*}{$\frac{S F}{0,147}$} & \multirow{2}{*}{$\frac{p}{* * *}$} & \multicolumn{2}{|c|}{ KI (Min./Max.) } & \multirow{2}{*}{$\begin{array}{c}\text { SF } \\
0,135\end{array}$} & \multirow{2}{*}{$\frac{p}{* * *}$} & \multicolumn{2}{|c|}{ KI (Min./Max.) } \\
\hline & & & & & & $-1,924$ & $-1,341$ & & & $-1,901$ & $-1,364$ \\
\hline $\log \left(A_{j} / G M A_{j}\right)$ & 0,951 & 0,720 & 1,094 & 0,070 & $* * *$ & 0,813 & 1,089 & 0,061 & $* * *$ & 0,830 & 1,073 \\
\hline $\log \left(K_{A_{j}} / G M K_{A_{j}}\right)$ & 0,336 & 0,275 & 1,109 & 0,065 & $* * *$ & 0,207 & 0,464 & 0,069 & $* * *$ & 0,199 & 0,472 \\
\hline $\log \left(K_{k_{j}} / G M K_{K_{j}}\right)$ & 0,101 & 0,211 & 1,180 & 0,026 & $* * *$ & 0,049 & 0,153 & 0,028 & $* * *$ & 0,046 & 0,156 \\
\hline
\end{tabular}

Gesamtmodell

$\mathrm{R}^{2}$

0,770

Korr. $R^{2} \quad 0,762$

$\mathrm{p}$ (F-Test) ***

Abhängige Variable: $\log \left(p_{i j} / G M p_{i}\right)$

\section{Modelldiagnose}

White

Ramsey-RESET

Doornik-Hansen

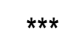

$X$

$\mathrm{X}$
Signifikanzniveaus (p): ${ }^{* *}=99,9 \%,{ }^{* *}=99 \%,{ }^{*}=95 \%, x=$ nicht signifikant $\mathrm{GM}=$ Geometrischer Mittelwert, $\mathrm{b}=$ Unstandardisierter Koeffizient, $\beta=$ Standardisierter Koeffizient, VIF = Variance Inflation Factor, SF = Standardfehler des Koeffizienten, $\mathrm{KI}=$ Konfidenzintervall des Koeffizienten (95\%)

Tabelle 24: MCI-Modell für die Marktgebiete der Elektronikmärkte

Quelle: Eigene Darstellung, Datengrundlage: Eigene Erhebungen und Berechnungen 
Alle vier Variablen sind - auch in der heteroskedastizitätsrobusten Schätzung (Modell 2) statistisch signifikant auf dem 99,9-\%-Niveau. Den am standardisierten Koeffizienten gemessenen stärksten Einfluss im Modell übt die Größenvariable (Verkaufsfläche) aus ( $b=$ $0,951 / \beta=0,720$ ); ihr Vorzeichen ist positiv, was eine fördernde Wirkung auf die Höhe der Zielvariablen anzeigt. Die Fahrtzeit schlägt mit einem Koeffizienten von $b=-1,632$ negativ zu Buche und bildet die zweiteinflussreichste Variable im Modell $(\beta=-0,603)$. Beide Konzentrationsvariablen - für Anbieter der gleichen und anderer Branchen - haben eine statistisch signifikant positive Wirkung auf die Zielvariablen. Der allgemeine K-Wert wirkt mit einem maßeinheitsbezogenen Koeffizienten von $b=0,336$ und stellt den drittgrößten Einfluss $\operatorname{dar}(\beta=0,275)$. Die Konzentrationsvariable für die Nähe zu branchengleichen Anbietern wird mit einem Parameter von $b=0,101$ versehen (standardisiert: $\beta=0,211$ ). In der heteroskedastizitätsrobusten Schätzung sind die Standardfehler und die Konfidenzintervalle der Schätzer teilweise höher, teilweise aber auch niedriger als im ersten Modell. Die Konfidenzintervalle bewegen sich in einem plausiblen Spektrum; es gibt keine Umkehrungen im Vorzeichen der Parameter. Die VIF-Werte zur Diagnose von Multikollinearität liegen nur wenig oberhalb des Minimalwertes $(V I F=1)$ und sind von der gesetzten kritischen Grenze für ernsthafte Kollinearitätseffekte $(V I F=5)$ weit entfernt.

Tabelle 25 zeigt die Ergebnisse der schrittweisen Regression des MCl-Modells für die Marktgebiete der Elektronikmärkte. Die Variable mit der stärksten Korrelation, die zuerst ins Modell aufgenommen wird, ist, anders als in den Modellen für die Lebensmittelmärkte, die Größenvariable (Verkaufsfläche); sie wirkt in diesem ersten Schritt positiv mit einem Koeffizienten von $b=0,796$ bzw. $\beta=0,602$. Im zweiten Schritt wird die Fahrtzeit ins Modell integriert $(b=-1,526 / \beta=-0,564)$. Diese beiden Einflussgrößen tragen zu $67,5 \%\left(R^{2}=\right.$ $0,675)$ bzw. korrigiert zu 66,8 \% (Korr. $\left.R^{2}=0,668\right)$ der Varianzaufklärung des Modells bei. Im dritten Schritt wird zunächst die allgemeine Konzentrationsvariable aufgenommen, was einen Zuwachs an Varianzaufklärung von $5,7 \%$ beisteuert (Veränd. $R^{2}=0,057$ ). Im vierten Schritt erfolgt schlussendlich der Eintritt der konkurrentenbezogenen Konzentrationsvariablen, die die Varianzaufklärung um weitere 3,8 \% erhöht. Allen vier Größen wird hier also, wie in der ersten Schätzung, ein signifikanter Einfluss attestiert (Signifikanzniveau jeweils 99,9\%); ebenso sorgt die Aufnahme der weiteren Variablen in jedem Fall zu einer signifikanten Verbesserung der Varianzaufklärung.

Die Reihenfolge der schrittweisen Regression entspricht den Ergebnissen der ersten Modellschätzung. Auffällig ist hierbei, dass der Größenindikator die stärkste Wirkung hat und den größten Beitrag zur Varianzaufklärung (36,3\%) leistet. Die Fahrtzeit ist nur der zweitgrößte Einflussgeber und sorgt für eine Erhöhung der Varianzaufklärung von 31,2 \%. Der Einfluss der Verkaufsfläche steigt zunächst vom ersten bis zum dritten Schritt und sinkt dann wieder leicht ab. Die Fahrtzeit hat hingegen im vierten, finalen Modell die stärkste Wirkung. Die o.g. Modelldiagnosen und die weitere Überprüfung durch die schrittweise Regression lassen auch hier den Schluss zu, dass das Modell im statistischen Sinne ausreichend abgesichert ist, um damit Aussagen zur Grundgesamtheit zu treffen. Als einzige Annahmeverletzung kristallisiert sich auch hier die Heteroskedastizität heraus, deren Effekt allerdings durch den Rückgriff auf die heteroskedastizitätsrobuste Schätzung ausgeglichen wird. Die Signifikanzprüfung des statistischen Einflusses einzelner Größen fällt in jeder Modellvariante im Hinblick auf die Kategorien (99,9\%/99\%/95 \%) identisch aus. 


\begin{tabular}{|c|c|c|c|c|c|}
\hline \multirow{2}{*}{ Prädiktoren } & & \multicolumn{4}{|c|}{ Modell bzw. Schritt } \\
\hline & & Schritt 1 & Schritt 2 & Schritt 3 & Schritt 4 \\
\hline \multirow{4}{*}{$\log \left(A_{j} / G M A_{j}\right)$} & $b$ & 0,796 & 0,893 & 0,975 & 0,951 \\
\hline & $\beta$ & 0,602 & 0,675 & 0,738 & 0,720 \\
\hline & $\mathrm{p}$ & $* * *$ & $* * *$ & $* * *$ & $* * *$ \\
\hline & VIF & 1,000 & 1,017 & 1,085 & 1,094 \\
\hline \multirow{4}{*}{$\log \left(d_{i j} / G M d_{i}\right)$} & $b$ & -- & $-1,526$ & $-1,447$ & $-1,632$ \\
\hline & $\beta$ & -- & $-0,564$ & $-0,534$ & $-0,603$ \\
\hline & $\mathrm{p}$ & -- & $* * *$ & $* * *$ & $* * *$ \\
\hline & VIF & -- & 1,017 & 1,032 & 1,157 \\
\hline \multirow{4}{*}{$\log \left(K_{A_{j}} / G M K_{A j}\right)$} & $b$ & -- & -- & 0,305 & 0,336 \\
\hline & $\beta$ & -- & -- & 0,250 & 0,275 \\
\hline & $\mathrm{p}$ & -- & -- & $* * *$ & $* * *$ \\
\hline & VIF & -- & -- & 1,091 & 1,109 \\
\hline \multirow{4}{*}{$\log \left(K_{k_{j}} / G M K_{K_{j}}\right)$} & $b$ & -- & -- & -- & 0,101 \\
\hline & $\beta$ & -- & -- & -- & 0,211 \\
\hline & $p$ & -- & -- & -- & $* * *$ \\
\hline & VIF & -- & -- & -- & 1,180 \\
\hline \multicolumn{6}{|l|}{ Gesamtmodell } \\
\hline $\mathrm{R}^{2}$ & & 0,363 & 0,675 & 0,732 & 0,770 \\
\hline Veränd. $\mathrm{R}^{2}$ & & -- & 0,312 & 0,057 & 0,038 \\
\hline Korr. $\mathrm{R}^{2}$ & & -- & 0,668 & 0,723 & 0,760 \\
\hline \multirow[t]{3}{*}{ Sign. Veränd. } & & -- & $* * *$ & $* * *$ & $* * *$ \\
\hline & & & & \multicolumn{2}{|c|}{ Abhängige Variable: Log $\left(p_{i j} / G M p_{i}\right)$} \\
\hline & & & \multicolumn{3}{|c|}{$\begin{array}{r}\text { Signifikanzniveaus }(p):{ }^{* * *}=99,9 \%,{ }^{* *}=99 \%,{ }^{*}=95 \%, x=\text { nicht signifikant } \\
\text { GM }=\text { Geometrischer Mittelwert, } b=\text { Unstandardisierter Koeffizient, } \\
\beta=\text { Standardisierter Koeffizient, VIF = Variance Inflation Factor }\end{array}$} \\
\hline
\end{tabular}

Tabelle 25: MCl-Modell für die Marktgebiete der Elektronikmärkte - Schrittweise Regression

Quelle: Eigene Darstellung, Datengrundlage: Eigene Erhebungen und Berechnungen

\subsubsection{MCl-GWR-Modell}

Analog zur Darstellung im Fall der Lebensmittelmärkte (siehe Kap. 6.3.1.2) erfolgt in Tabelle 26 die Zusammenfassung des GWR-Modells und in Karte 11 eine (karto-)grafische Darstellung der räumlichen Variation der ermittelten Parameter und der Varianzaufklärung $\left(R^{2}\right)$. Zunächst ist festzustellen, dass in der geographisch gewichteten Schätzung eine leicht höhere Varianzaufklärung erreicht wird: Der $R^{2}$-Wert des Gesamtmodells beträgt $0,778(77,8$ \%) bzw. in korrigierter Form 0,762 (76,2\%). Auf lokaler Ebene der 19 Teilgebiete schwankt die Varianzaufklärung mit Werten zwischen 0,764 (Teilgebiet Höxter-Süd) und 0,777 (Holzminden-Sollingortschaften) nur außerordentlich gering, wobei die höchsten Werte tendenziell im Nordosten des Untersuchungsgebietes und die niedrigsten Werte im Südwesten erreicht werden. 
Die Spannweite der ermittelten räumlich differenzierten Parameter ist deutlich geringer als im GWR-Modell für die Marktgebiete der Lebensmittelmärkte; auch gibt es keine Veränderungen in ihrem Vorzeichen bzw. ihrer Wirkungsrichtung. Die Koeffizienten für den Größenindikator decken einen Bereich von 0,897 bis 0,999 ab und bleiben somit in jedem Fall im unterlinearen Spektrum. Der Koeffizient der Fahrtzeit variiert zwischen -1,655 und $-1,523$. Während die räumliche Variation der Wirkung der allgemeinen Konzentrationsgröße nur sehr gering ist (Minimum: 0,304 / Maximum: 0,362), ist die Streuung des Einflusses der konkurrentenbezogenen Größe wesentlich deutlicher (Minimum: 0,074 / Maximum: 0,114). Insgesamt entspricht diese GWR-Modellierung den Ergebnissen der konventionellen Schätzung und stellt in diesem Zusammenhang also eine kleinräumliche Konkretisierung des vorher parametrisierten MCl-Modells dar, ohne dass sich unplausible Werte abzeichnen würden.

\begin{tabular}{lcccccc}
\hline & \multicolumn{2}{c}{$\mathbf{b}$} & \multicolumn{2}{c}{$\mathbf{R}^{2}$} & \\
Prädiktoren & Lokal Min. & Lokal Max. & Gesamtmodell & Lokal Min. & Lokal Max. & Korr. \\
\hline $\log \left(A_{j} / G M A_{j}\right)$ & 0,897 & 0,999 & & & \\
$\log \left(d_{i j} / G M d_{i}\right)$ & $-1,655$ & $-1,523$ & 0,778 & 0,764 & 0,777 & 0,762 \\
$\log \left(K_{A j} / G M K_{A j}\right)$ & 0,304 & 0,362 & & & \\
$\log \left(K_{k j} / G M K_{k j}\right)$ & 0,074 & 0,114 & & & \\
\hline
\end{tabular}

Tabelle 26: GWR-Modell für die Marktgebiete der Elektronikmärkte (Zusammenfassung)

Quelle: Eigene Darstellung, Datengrundlage: Eigene Erhebungen und Berechnungen

Auffällig ist allerdings die Variation der Parameter: Tendenziell werden bei allen vier ins Modell integrierten erklärenden Variablen die betragsmäßig höchsten Ausprägungen im nördlichen bzw. nordöstlichen Teil des Untersuchungsgebietes (Kernstadt Holzminden und Umfeld) festgestellt. Im Teilgebiet Holzminden-Kernstadt werden drei Maxima der Parameter erreicht (Fahrtzeit, Verkaufsfläche, Konzentrationsvariable für branchengleiche Anbieter). Im direkt benachbarten Teilgebiet Höxter-Stahle werden fast genauso hohe Werte dieser Größen erreicht und zudem der höchste Wert des Parameters für die allgemeine $K$-Variable. Die lokalen Minima aller vier Parameterwerte finden sich im Teilgebiet Beverungen-Süd im Südwesten des betrachteten Untersuchungsgebietes. 


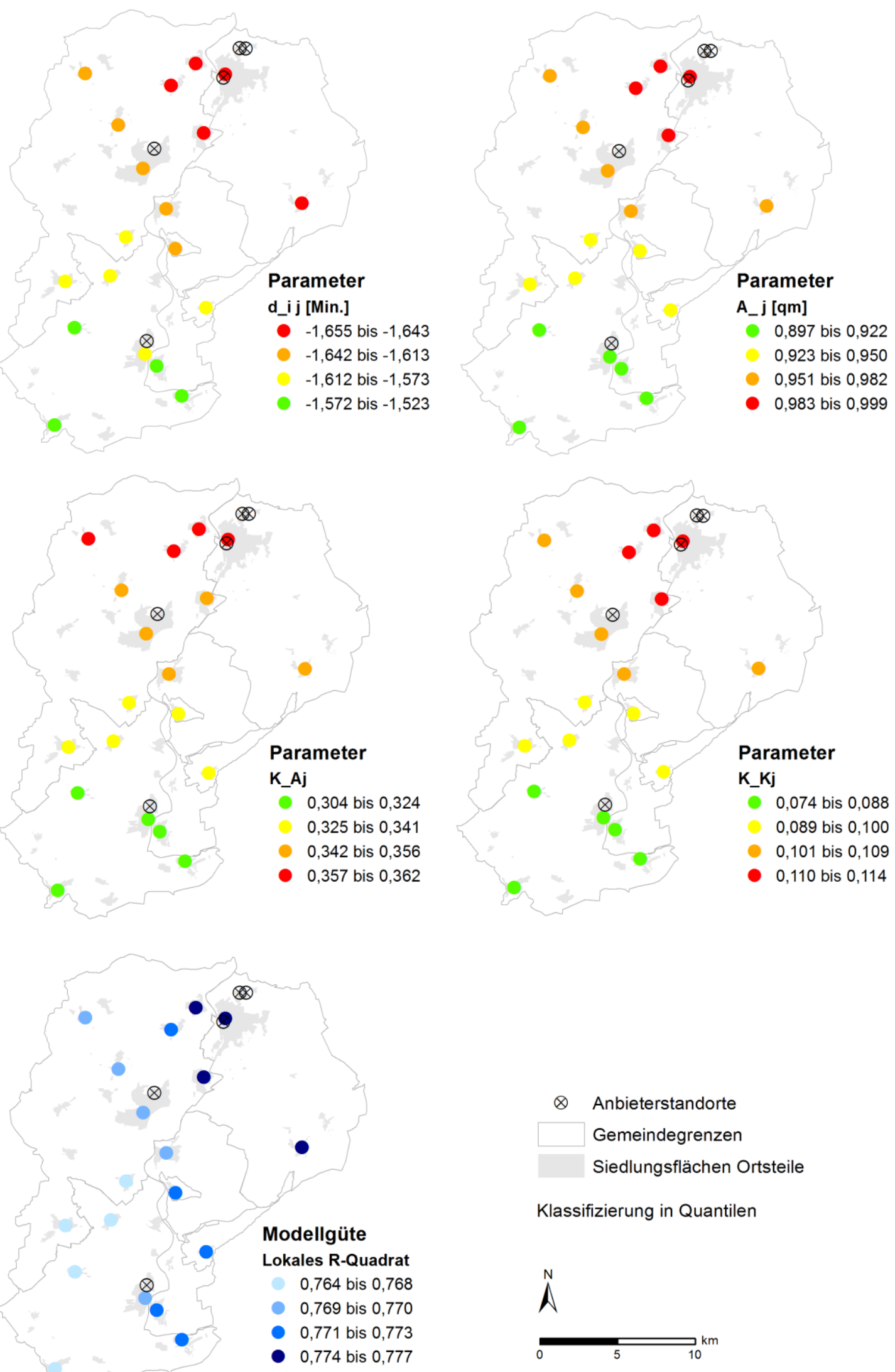

Karte 11: GWR-Modell für die Marktgebiete der Elektronikmärkte

Quelle: Eigene Darstellung, Datengrundlage: Eigene Erhebungen und Berechnungen, Kartengrundlage:

OpenStreetMap/Geofabrik 


\subsubsection{Baumärkte}

\subsubsection{MCl-Modell}

In Tabelle 27 sind die Ergebnisse des MCl-Modells für die Marktgebiete der Bau- und Heimwerkermärkte dargestellt. Ähnlich den anderen Modellen gibt der White-Test auf Heteroskedastizität ein signifikantes Ergebnis zurück (95-\%-Niveau), während der RamseyTest (Nicht-Linearität) und der Doornik-Hansen-Test (Prüfung der Residuen auf Normalverteilung) keinen Rückschluss auf Verletzung dieser Annahmen begründen. Das Gesamtmodell verfügt über eine Varianzaufklärung von $80,0 \%\left(R^{2}=0,800\right)$ bzw. im korrigierten Bestimmtheitsmaß von 79,2\% (Korr. $\left.R^{2}=0,792\right)$.

\begin{tabular}{|c|c|c|c|c|c|c|c|c|c|c|c|}
\hline \multirow{3}{*}{$\begin{array}{l}\text { Prädiktoren } \\
\text { Log (dij / GM di) }\end{array}$} & \multicolumn{2}{|c|}{ Koeffizienten } & \multirow{3}{*}{$\begin{array}{c}\text { VIF } \\
1,118\end{array}$} & \multicolumn{4}{|c|}{ Modell 1} & \multicolumn{4}{|c|}{ Modell 2 (HC1) } \\
\hline & \multirow{2}{*}{$\frac{b}{-2,100}$} & \multirow{2}{*}{$\frac{\beta}{-0,620}$} & & \multirow{2}{*}{$\frac{S F}{0,189}$} & \multirow{2}{*}{$\frac{p}{* * *}$} & \multicolumn{2}{|c|}{ KI (Min./Max.) } & \multirow{2}{*}{$\frac{S F}{0,157}$} & \multirow{2}{*}{$\frac{p}{* * *}$} & \multicolumn{2}{|c|}{ KI (Min./Max.) } \\
\hline & & & & & & $-2,476$ & $-1,723$ & & & $-2,412$ & $-1,787$ \\
\hline $\log \left(A_{j} / G M A_{j}\right)$ & 1,368 & 0,659 & 1,739 & 0,144 & $* * *$ & 1,081 & 1,656 & 0,123 & $* * *$ & 1,122 & 1,615 \\
\hline $\log \left(K_{\mathrm{Aj}} / \mathrm{GM} \mathrm{K} \mathrm{K}_{\mathrm{Aj}}\right)$ & 0,259 & 0,188 & 1,627 & 0,092 & ** & 0,074 & 0,443 & 0,091 & ** & 0,077 & 0,440 \\
\hline $\log \left(K_{K_{j}} / G M K_{k j}\right)$ & $-0,173$ & $-0,156$ & 1,313 & 0,067 & * & $-0,307$ & $-0,040$ & 0,080 & * & $-0,332$ & $-0,015$ \\
\hline
\end{tabular}

\section{Gesamtmodell}

$R^{2}$

$$
0,800
$$

$\begin{array}{ll}\text { Korr. } & R^{2} \\ p(\text { F-Test }) & 0,792\end{array}$

Modelldiagnose

White

Ramsey-RESET $\quad x$

Doornik-Hansen $\quad x$
Abhängige Variable: $\log \left(\mathrm{p}_{\mathrm{ij}} / \mathrm{GM} \mathrm{p}_{\mathrm{i}}\right)$

Signifikanzniveaus (p): ${ }^{* *}=99,9 \%,{ }^{* *}=99 \%,{ }^{*}=95 \%, x=$ nicht signifikant GM $=$ Geometrischer Mittelwert, $b=$ Unstandardisierter Koeffizient, $\beta=$ Standardisierter Koeffizient, VIF = Variance Inflation Factor, SF = Standardfehler des Koeffizienten, $\mathrm{KI}=$ Konfidenzintervall des Koeffizienten (95\%)

Tabelle 27: MCI-Modell für die Marktgebiete der Baumärkte

Quelle: Eigene Darstellung, Datengrundlage: Eigene Erhebungen und Berechnungen

Alle vier getesteten Variablen haben eine statistisch signifikante Wirkung auf die Zielvariable. Ähnlich wie im Modell für die Elektronikmärkte besitzt auch hier die Verkaufsfläche mit einem standardisierten Regressionskoeffizienten von $\beta=0,659$ den größten Einfluss; der nichtstandardisierte Parameter $(b)$ beträgt 1,368 und zeigt somit eine positive, überlineare Wirkung auf. Etwas geringer fällt mit $\beta=-0,620$ bzw. $b=-2,100$ der Einfluss der Fahrtzeit im Modell aus. Beide Konzentrationsvariablen wirken in signifikanter Weise, wobei die allgemeine Konzentrationsvariable als drittgrößter Faktor mit einem positiven Einfluss zu Buche schlägt $(b=0,259 / \beta=0,188)$. Die auf branchengleiche Anbieter bezogene Konzentrationsvariable beeinflusst die Ausprägungen der Zielvariablen negativ $(b=-0,173$ / $\beta=-0,156)$. Die Verkaufsfläche und die Fahrtzeit befinden sich auf dem 99,9-\%Signifikanzniveau, die Agglomerationsvariablen auf dem 99- bzw. 95-\%-Niveau. Trotz Unterschieden in den Standardfehlern und Konfidenzintervallen - diese sind in der heteroskedastizitätsrobusten Schätzung (Modell 2) teilweise höher, teilweise niedriger als in Modell 1 - ergeben sich keine Unterschiede in der Beurteilung des signifikanten Einflusses der erklärenden Variablen. Sämtliche variablenbezogenen VIF-Werte liegen weit unterhalb 
des kritischen Wertes von VIF $=5$, so dass auch in diesem Modell keine ernsthaften Kollinearitätsprobleme diagnostiziert werden.

\begin{tabular}{|c|c|c|c|c|c|}
\hline \multirow{2}{*}{ Prädiktoren } & & \multicolumn{4}{|c|}{ Modell bzw. Schritt } \\
\hline & & Schritt 1 & Schritt 2 & Schritt 3 & Schritt 4 \\
\hline \multirow{4}{*}{$\log \left(A_{j} / G M A_{j}\right)$} & $b$ & 1,389 & 1,438 & 1,194 & 1,368 \\
\hline & $\beta$ & 0,669 & 0,693 & 0,575 & 0,659 \\
\hline & $p$ & $* * *$ & $* * *$ & $* * *$ & $* * *$ \\
\hline & VIF & 1,000 & 1,002 & 1,357 & 1,739 \\
\hline \multirow{4}{*}{$\log \left(d_{i j} / G M d_{i}\right)$} & $b$ & -- & $-1,839$ & $-2,059$ & $-2,100$ \\
\hline & $\beta$ & -- & $-0,543$ & $-0,608$ & $-0,620$ \\
\hline & $p$ & -- & $* * *$ & $* * *$ & $* * *$ \\
\hline & VIF & -- & 1,002 & 1,110 & 1,118 \\
\hline \multirow{4}{*}{$\log \left(K_{A j} / G M K_{A j}\right)$} & $b$ & -- & -- & 0,330 & 0,259 \\
\hline & $\beta$ & -- & -- & 0,240 & 0,188 \\
\hline & $p$ & -- & -- & $* * *$ & ** \\
\hline & VIF & -- & -- & 1,480 & 1,627 \\
\hline \multirow{4}{*}{$\log \left(K_{K_{j}} / G M K_{K_{j}}\right)$} & $b$ & -- & -- & -- & $-0,173$ \\
\hline & $\beta$ & -- & -- & -- & $-0,156$ \\
\hline & $p$ & -- & -- & -- & * \\
\hline & VIF & -- & - & -- & 1,313 \\
\hline \multicolumn{6}{|l|}{ Gesamtmodell } \\
\hline $\mathrm{R}^{2}$ & & 0,448 & 0,742 & 0,781 & 0,800 \\
\hline Veränd. $\mathrm{R}^{2}$ & & -- & 0,295 & 0,039 & 0,019 \\
\hline Korr. $\mathrm{R}^{2}$ & & -- & 0,735 & 0,772 & 0,789 \\
\hline Sign. Veränd. & & -- & $* * *$ & $* * *$ & $*$ \\
\hline
\end{tabular}

Signifikanzniveaus (p): ${ }^{* * *}=99,9 \%,{ }^{* *}=99 \%,{ }^{*}=95 \%, x=$ nicht signifikant $\mathrm{GM}=$ Geometrischer Mittelwert, $b=$ Unstandardisierter Koeffizient, $\beta=$ Standardisierter Koeffizient, $\mathrm{VIF}=$ Variance Inflation Factor

Tabelle 28: MCI-Modell für die Marktgebiete der Baumärkte - Schrittweise Regression

Quelle: Eigene Darstellung, Datengrundlage: Eigene Erhebungen und Berechnungen

Die in Tabelle 28 dargestellte schrittweise Regressionsanalyse bestätigt das Ergebnis der konventionellen Schätzungen. Die Reihenfolge der ins Modell aufgenommenen Variablen entspricht den bereits festgestellten Einflussgrößen. Die Größenvariable (Verkaufsfläche) trägt allein zu 44,8 \% der Varianzaufklärung bei, zusätzliche 29,5 \% werden durch Hinzunahme der Fahrtzeit erreicht. Durch die Aufnahme der Konzentrationsvariablen wird die Varianzaufklärung des Modells um insgesamt 5,8 Prozentpunkte erhöht. Der statistische Einfluss der Verkaufsfläche steigt zunächst von Schritt 1 zu Schritt 2, wird dann in Schritt 3 nach unten korrigiert und im vierten, finalen Schritt wieder erhöht. Die quantifizierte Wirkung 
der Fahrtzeit steigt von Schritt 2 zu Schritt 4, während die Wirkungsintensität der allgemeinen Konzentrationsvariablen im letzten Schritt deutlich nach unten korrigiert wird. Wie in den anderen Fällen sind die Ergebnisse und Modelldiagnosen aller Schätzungen miteinander konsistent. Das Modell ist somit als im statistischen Sinne aussagekräftig zu betrachten und eröffnet somit die Möglichkeit einer abgesicherten inhaltlichen Interpretation.

\subsubsection{MCl-GWR-Modell}

Das mit Hilfe der geographisch gewichteten Regression geschätzte Modell für die Marktgebiete der Baumärkte wird in Tabelle 29 zusammengefasst und durch Karte 12 visualisiert. Wie in den vorherigen Modellen wird auch im GWR-Modell für die Baumärkte eine etwas höhere Varianzaufklärung erreicht $\left(R^{2}=0,836 /\right.$ korr. $\left.R^{2}=0,799\right)$. Ähnlich wie im Fall der Elektronikmärkte schwanken die lokalen $R^{2}$-Werte mit einem Minimum von 0,790 und einem Maximum von 0,845 zwischen den 19 Teilgebieten nur gering. Die höchsten Ausprägungen werden im Süden (z.B. Beverungen-Kernstadt, Beverungen-Südost) und im Nordosten des Untersuchungsgebietes erreicht, die geringsten in Höxter-Kernstadt und dem näheren Umfeld (z.B. Boffzen, Höxter-Südost).

\begin{tabular}{|c|c|c|c|c|c|c|}
\hline \multirow[b]{2}{*}{ Prädiktoren } & \multicolumn{2}{|c|}{ b } & \multicolumn{4}{|c|}{$R^{2}$} \\
\hline & Lokal Min. & Lokal Max. & Gesamtmodell & Lokal Min. & Lokal Max. & Korr. \\
\hline $\log \left(A_{j} / G M A_{j}\right)$ & 1,184 & 1,464 & \multirow{4}{*}{0,836} & \multirow{4}{*}{0,790} & \multirow{4}{*}{0,845} & \multirow{4}{*}{0,799} \\
\hline $\log \left(d_{i j} / G M d_{i j}\right)$ & $-2,676$ & $-1,697$ & & & & \\
\hline $\log \left(K_{A j} / G M K_{A j}\right)$ & 0,210 & 0,566 & & & & \\
\hline $\log \left(K_{k_{j}} / G M K_{K_{j}}\right)$ & $-0,214$ & $-0,010$ & & & & \\
\hline
\end{tabular}

Tabelle 29: GWR-Modell für die Marktgebiete der Baumärkte (Zusammenfassung)

Quelle: Eigene Darstellung, Datengrundlage: Eigene Berechnungen

Die räumliche Variation der Parameterwerte ist höher als im Modell für die Marktgebiete der Elektronikmärkte, jedoch gibt es auch hier keine Umkehrungen der Vorzeichen. Der nichtstandardisierte Koeffizient (b) der Verkaufsfläche variiert zwischen 1,184 (Höxter-Nord) und 1,464 (Beverungen-Südost). Der Parameter für die Fahrtzeit erreicht sein Minimum (also in diesem Fall die stärkste Wirkung) bei -2,676 (Beverungen-Süd) und sein Maximum bei -1,697 (Höxter-Nord). Ähnliche Schwankungen ergeben sich für die Koeffizienten der beiden Konzentrationsvariablen. Tendenziell lässt sich feststellen, dass die höchsten Ausprägungen der Parameterwerte in den südlichen Teilgebieten des Untersuchungsgebietes erreicht werden; für die geringsten Ausprägungen lässt sich hingegen kein eindeutiger räumlicher Trend feststellen. Zwischen den erklärenden Variablen sind aber auch Unterschiede in ihrer kleinräumlichen Wirkung zu verzeichnen: Die Konzentrationsvariable für die Konkurrenten schlägt sich beispielsweise auch im Norden bzw. Nordosten des Untersuchungsgebietes verstärkt nieder. Ähnlich wie im GWR-Modell für die Elektronikmärkte bewegen sich die räumlichen Variationen der Parameter allesamt in einem plausiblen Bereich und sind konsistent mit dem konventionellen Regressionsmodell, was ebenso für eine Plausibilität der Modellparametrisierung spricht. 


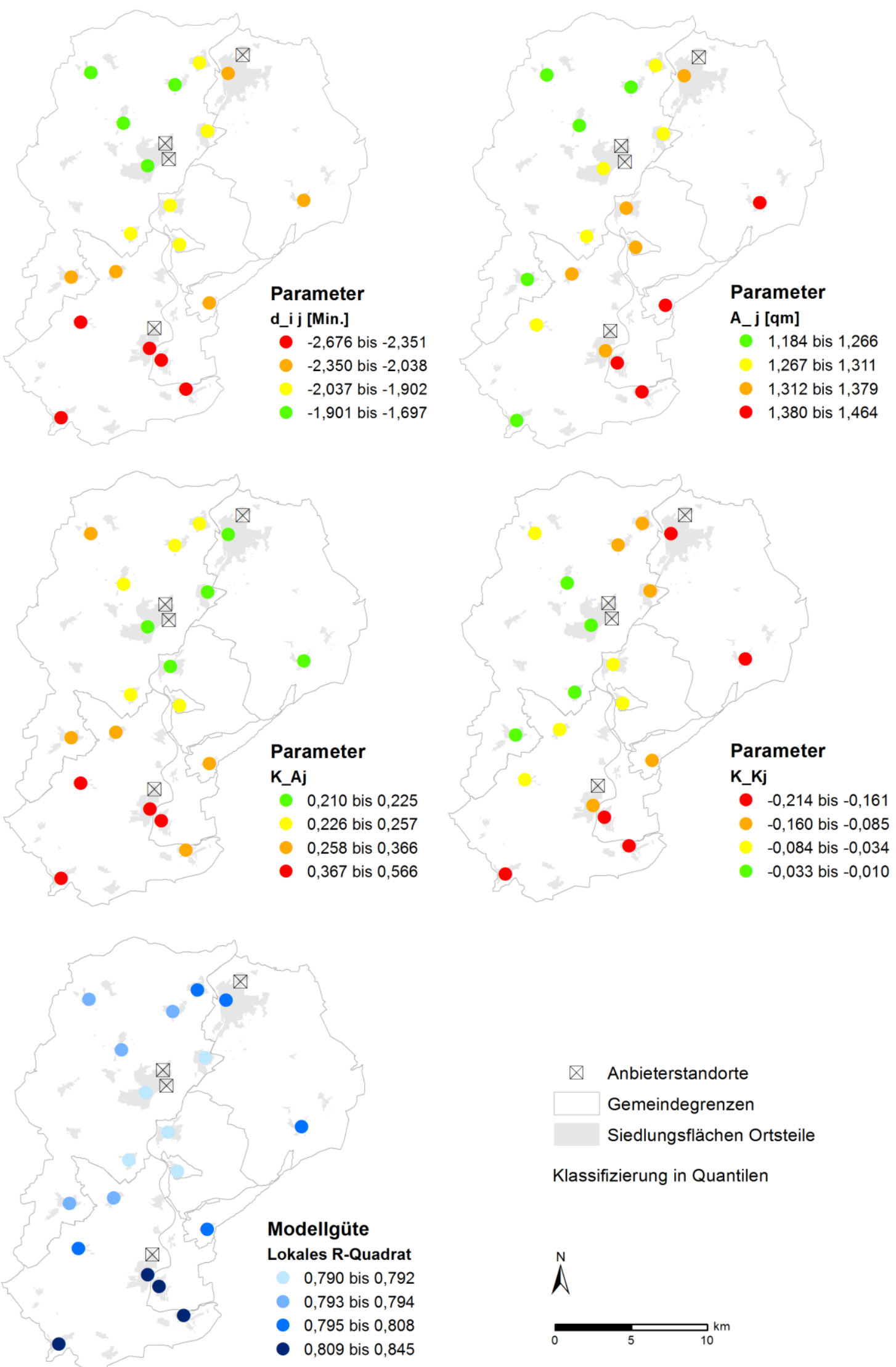

Karte 12: GWR-Modell für die Marktgebiete der Baumärkte

Quelle: Eigene Darstellung, Datengrundlage: Eigene Erhebungen und Berechnungen, Kartengrundlage: OpenStreetMap/Geofabrik 


\subsubsection{Zusammenfassende Betrachtung der Modelle}

Bevor im folgenden Kapitel die inhaltliche Interpretation der Ergebnisse erfolgt, müssen noch einige allgemeine Feststellungen im Hinblick auf die Modellanalysen getroffen werden:

- Die MCl-Modelle sind hinsichtlich möglicher Annahmenverletzungen, die im Zusammenhang ökonometrischer Modellbildung häufig angesprochen werden, getestet worden. Als einziges Problem stellte sich vor diesem Hintergrund die durch ein etabliertes Testverfahren diagnostizierte Heteroskedastizität heraus; möglichen hierdurch auftretenden Verzerrungen wurde allerdings durch die Nutzung heteroskedastizitätsrobuster Inferenzstatistiken begegnet. Abseits davon wurden bei keinem der Modelle Anzeichen dahingehend festgestellt, dass sie aufgrund z.B. von Multikollinearität oder anderen Problemquellen verzerrt oder anderweitig in ihrer Aussagekraft eingeschränkt sind. Die Modelle sind als im statistischen Sinne abgesichert zu betrachten und somit inhaltlich interpretierbar

- Ebenso sind mehrere Modellschätzungen vorgenommen worden (konventionelle Regressionsanalyse, schrittweise Regression). Die schrittweise durchgeführten Regressionsanalysen bestätigten stets die Ergebnisse der ersten Schätzung, was eine zusätzliche Plausibilisierung darstellt

- In nahezu allen Fällen wurden statistisch signifikante Einflüsse der hier im Fokus stehenden erklärenden Variablen zur räumlichen Konzentration mit anderen Anbietern festgestellt; die Berücksichtigung dieser Größen in den Modellen führte immer zu einer signifikanten Erhöhung der Varianzaufklärung der Modelle. Der gemessene Einfluss der Konzentrationsvariablen ist jedoch durchgängig im Vergleich zu den anderen Variablen relativ klein

- Die in den Modellen für die Elektronik- und Baumärkte erreichte Varianzaufklärung ist deutlich höher als in allen Modellen für die Marktgebiete der Lebensmittelmärkte

- Die Nutzung der geographisch gewichteten Regression (GWR) brachte im Fall der Elektronik- und Baumärkte eine kleinräumige Konkretisierung der räumlich stationären Modelle, in der räumliche Variationen in einem plausiblen Maß abgebildet wurden. Das MCl-GWR-Modell für die Marktgebiete der Lebensmittelmärkte zeigt hingegen in einigen Fällen deutlich abweichende und mitunter völlig unplausible Ausprägungen der Parameterwerte 


\section{$7 \quad$ Interpretation und Diskussion der Ergebnisse}

In diesem Kapitel werden zunächst die inhaltlichen Ergebnisse der Modellanalysen besprochen und in diesem Zusammenhang die in Kap. 5 hergeleiteten Hypothesen überprüft. Anschließend werden die Modellergebnisse gesondert für die drei untersuchten Angebotstypen bzw. Branchen besprochen und die Ergebnisse vor dem Hintergrund der Berücksichtigung räumlicher Nicht-Stationarität diskutiert. Die Modelle werden zwecks weiterer Überprüfung einem Benchmarking unterzogen, d.h. kontrolliert, ob es ggf. alternative Modellspezifikationen gibt, die einen höheren Erklärungsgehalt besitzen. Eine weitere Überprüfung des inhaltlichen Gehaltes und zugleich eine Demonstration der Funktionsweise der Modelle werden in Form von Simulationsrechnungen durchgeführt; hierbei werden die geschätzten Modelle zur „Voraussage“ zweier zukünftiger Szenarien genutzt. An die Auseinandersetzung mit den Modellen schließt sich eine Besprechung der praktischen Implikationen der Ergebnisse an (z.B. hinsichtlich der Nahversorgung). Im Anschluss erfolgt eine kritische Reflektion des Vorgehens in dieser Forschungsarbeit, wobei sowohl die allgemeinen als auch die studienspezifischen Problemfelder (d.h. potenzielle Fehlerquellen und Einschränkungen der vorliegenden Arbeit) besprochen werden.

\subsection{Inhaltliche Interpretation der Modellergebnisse}

\subsection{1 Überprüfung der Hypothesen}

In Kap. 5.1.2 sind insgesamt elf Untersuchungshypothesen abgeleitet worden, die sich auf die Teilergebnisse der Modellanalysen beziehen. Die ersten vier Hypothesen $\left(\mathrm{H}_{1 \mathrm{a}}, \mathrm{H}_{1 \mathrm{~b}}, \mathrm{H}_{2 \mathrm{a}}\right.$, $\mathrm{H}_{2 b}$ ) beinhalten hierbei die Grundaussagen des HuFF-Modells, während die sieben anderen Hypothesen $\left(\mathrm{H}_{3 a}, \mathrm{H}_{3 b}, \mathrm{H}_{4 a}, \mathrm{H}_{4 b}, \mathrm{H}_{5}, \mathrm{H}_{6 a}, \mathrm{H}_{6 b}\right)$ die Kernfragestellungen dieser Arbeit (Einfluss räumlicher Ballung auf die Kundenfrequentierung bzw. die Marktgebiete von Einzelhandelsanbietern) betreffen. Da die Modelle umfangreich überprüft und als statistisch abgesichert befunden wurden (siehe Kap. 6.3.4), steht ihrer inhaltlichen Interpretation nichts entgegen. Die Hypothesen lassen sich jeweils an der Wirkungsrichtung und -größe der ermittelten Regressionskoeffizienten (Parameter) und ihrem inferenzstatistisch festgestellten Einfluss (d.h. Test auf einen statistisch signifikanten Einfluss) überprüfen.

Tabelle 30 zeigt eine Zusammenfassung der Hypothesenprüfungen, jeweils aufgeschlüsselt nach den Modellen für die Marktgebiete der drei untersuchten Angebotsformen (Lebensmittelmärkte, Elektronikmärkte, Bau- und Heimwerkermärkte). Eine Hypothese gilt dann als bestätigt, wenn 1.) ein signifikanter Einfluss der betreffenden erklärenden Variablen festgestellt wurde und 2.) die Wirkungsrichtung und -größe dieser Variablen der inhaltlichen Aussage der Hypothese entspricht. Wird eine Hypothese nicht bestätigt, kann dies demnach darauf zurückzuführen sein, dass kein signifikanter Einfluss festgestellt wurde, d.h. das vorgegebene Signifikanzniveau von (mindestens) $95 \%$ nicht erreicht wurde. Andererseits kann aber auch eine den Hypothesen widersprechende Wirkungsrichtung oder -größe festgestellt worden sein, d.h. ein als positiv (bzw. negativ) angenommener Einfluss stellt sich als negativ (bzw. positiv) heraus bzw. ein als unter-linear (bzw. über-linear) angenommener Einfluss zeigt sich als über-linear (bzw. unter-linear). Sofern die Ablehnung einer Hypothese erfolgt, ist daher der Grund hierfür gekennzeichnet. Prinzipiell ist auch eine Kombination beider Gründe möglich, wenngleich dieser Fall in der vorliegenden Arbeit nicht eintrat. 


\begin{tabular}{|c|c|c|c|c|}
\hline \multirow{2}{*}{ Hypothese } & \multirow{2}{*}{ Modellgröße } & \multicolumn{3}{|c|}{ Modell / Angebotstyp } \\
\hline & & Lebensmittelmärkte & Elektronikmärkte & Bau-/Heimwerkermärkte \\
\hline $\mathrm{H}_{1 \mathrm{a}}$ & $A_{j}$ & bestätigt & bestätigt & bestätigt \\
\hline $\mathrm{H}_{1 \mathrm{~b}}$ & $A_{j}$ & bestätigt & bestätigt & nicht bestätigt* \\
\hline $\mathrm{H}_{2 \mathrm{a}}$ & $\mathrm{d}_{\mathrm{ij}}$ & bestätigt & bestätigt & bestätigt \\
\hline $\mathrm{H}_{2 \mathrm{~b}}$ & $d_{i j}$ & bestätigt & bestätigt & bestätigt \\
\hline $\mathrm{H}_{3 \mathrm{a}}$ & $\mathrm{K}_{\mathrm{Aj}}$ & nicht bestätigt ${ }^{*}$ & bestätigt & bestätigt \\
\hline $\mathrm{H}_{3 \mathrm{~b}}$ & $\mathrm{~K}_{\mathrm{Aj}}$ & nicht bestätigt* & bestätigt & bestätigt \\
\hline $\mathrm{H}_{4 \mathrm{a}}$ & $\mathrm{K}_{\mathrm{kj}}$ & bestätigt & bestätigt & nicht bestätigt* \\
\hline $\mathrm{H}_{4 b}$ & $\mathrm{~K}_{\mathrm{kj}}$ & bestätigt & bestätigt & nicht bestätigt* \\
\hline $\mathrm{H}_{5}$ & $d_{i j}$ & bestätigt & bestätigt & bestätigt \\
\hline $\mathrm{H}_{6 \mathrm{a}}$ & $K_{v_{j}}, K_{D j}$ & $\begin{array}{l}\text { Vollsortimenter: bestätigt, } \\
\text { Discounter: nicht bestätigt }{ }^{+}\end{array}$ & nicht geprüft & nicht geprüft \\
\hline $\mathrm{H}_{6 \mathrm{~b}}$ & $K_{V_{j}}, K_{D j}$ & $\begin{array}{l}\text { Vollsortimenter: bestätigt, } \\
\text { Discounter: bestätigt }\end{array}$ & nicht geprüft & nicht geprüft \\
\hline
\end{tabular}

${ }^{*}=$ nicht bestätigt aufgrund abweichender Wirkungsrichtung oder -größe ${ }^{+}=$nicht bestätigt aufgrund von Unterschreitung des Signifikanzniveaus

Tabelle 30: Überprüfung der Hypothesen

Quelle: Eigene Darstellung

Die ersten beiden Hypothesen $\left(\mathrm{H}_{1 \mathrm{a}}, \mathrm{H}_{1 \mathrm{~b}}\right)$ beziehen sich auf die Attraktivitätswirkung von Einzelhandelsanbietern aufgrund ihrer Sortimentsbreite und -tiefe, hier operationalisiert durch ihre Verkaufsfläche in qm $\left(A_{j}\right)$. Die Größe des Angebots sollte nach den theoretischen Annahmen grundsätzlich ein Attraktivitätsmerkmal darstellen, da hierdurch anbieterinterne Kopplungs- und Vergleichskäufe ermöglicht werden $\left(\mathrm{H}_{1 \mathrm{a}}\right)$; nach den Überlegungen von BAUMOL/IDE (1956) und HUFF (1962) bringt ein großes Angebot jedoch auch steigende Suchund Entscheidungskosten mit sich, weshalb der positive Einfluss der Sortimentsbreite/-tiefe nur unter-linear sein müsste $\left(\mathrm{H}_{2 \mathrm{a}}\right)$. Im vorliegenden Fall konnte entsprechend der ersten Hypothese für alle drei betrachteten Angebotsformen ein positiver Effekt der Verkaufsfläche festgestellt werden, was die grundsätzliche Attraktivitätswirkung der Größe des Angebotes von Einzelhandelsbetrieben empirisch bestätigt; die (lokalen) Marktanteile der Anbieter steigen also mit ihren internen Kopplungs- und Vergleichsmöglichkeiten. Im Fall der Lebensmittel- und Elektronikmärkte ist dieser Einfluss unter-linear (Verifikation von $\mathrm{H}_{1 \mathrm{~b}}$ ), bei den Baumärkten hingegen über-linear, so dass in diesem Fall die Hypothese einer degressiv-positiven Wirkung nicht bestätigt werden kann.

Die dritte und vierte Hypothese $\left(\mathrm{H}_{2 \mathrm{a}}, \mathrm{H}_{2 \mathrm{~b}}\right)$ beziehen sich auf den Effekt der durch den Einkaufsweg notwendigerweise anfallenden Transaktionskosten des Einkaufs, d.h. die Transportkosten, hier operationalisiert anhand der Fahrtzeit $\left(d_{i j}\right)$. Bezogen auf alle drei untersuchten Angebotsformen lässt sich übereinstimmend ein negativer Effekt der Fahrtzeit auf die lokalen Marktanteile von Anbietern feststellen $\left(\mathrm{H}_{2 \mathrm{a}}\right)$, der über-linear ist $\left(\mathrm{H}_{2 \mathrm{~b}}\right)$. Die Wirkung der Transportkosten ist also überproportional negativ, d.h. mit steigender Reisezeit zum Angebotsstandort sinkt dessen Kundenzufluss in progressiv-exponentieller Weise. Dass eine distanzabhängige Nachfrage das konstituierende Element räumlicher Märkte von 
konsumentenorientierten Dienstleistungen ist, stellt die zentrale Erklärungsgröße in den Raumwirtschaftstheorien von CHRISTALLER (1933) und LÖSCH (1944) sowie weiteren Ansätzen mit Raumbezug dar. Im Modell von HUFF (1962) wird zusätzlich der über-lineare Einfluss der Transportkosten betont, da Einkaufswege mit anderen Tätigkeiten konkurrieren (Opportunitätskosten) und daher von Seiten der Konsumenten als überproportional „belastend“ empfunden werden; in seiner seminalen Arbeit konnte HUFF diese Aussage für verschiedene Angebotsformen bereits empirisch bestätigen.

Die Untersuchungsergebnisse zu den ersten vier Hypothesen sind zudem konsistent mit den Resultaten anderer empirischer Marktgebietsanalysen (vorrangig $\mathrm{MCl}-$ Modelle), in denen ebenso die Verkaufsfläche (Proxyvariable für die Attraktivität von Anbietern und Angebotsstandorten) und ein Transportkostenmaß als Einflussfaktoren von Marktgebieten im Einzelhandel geprüft wurden. In diesen Untersuchungen wurden regelmäßig ein überlinearer negativer Effekt des jeweiligen Transportkostenmaßes beim Einkaufsverkehr und ein unter-linearer positiver Effekt der Angebotsgröße festgestellt (z.B. KUBIS/HARTMANN 2007, MARINOV/CZAMANSKI 2012, SUÁREZ-VEGA et al. 2011, TIHI/ORUC 2012). Die Resultate der hier durchgeführten Modellanalysen verifizieren also nicht nur die ersten vier Hypothesen (mit einer Ausnahme: $\mathrm{H}_{1 \mathrm{~b}}$ bei Baumärkten) und somit die Erklärungsgrößen des HuFFModells, sondern sind vor dem Hintergrund früherer Ergebnisse auch sehr plausibel, was die Aussagekraft der Modelle nochmals unterstreicht.

In den Hypothesen $\mathrm{H}_{3 a}$ und $\mathrm{H}_{3 b}$ wird angenommen, dass die räumliche Nähe zu Anbietern anderer Branchen einen unter-linearen positiven Einfluss auf die Kundenzuflüsse eines Anbieters aus seinem Marktgebiet hat, da hierdurch horizontale und vertikale Kopplungen mit anderen Anbietern ermöglicht bzw. erleichtert werden. Die Möglichkeit von Kopplungskäufen ist ein zentrales Erklärungsmoment der Standortattraktivität, das von NELSON (1958) und insbesondere LANGE (1973) in den Vordergrund gerückt wird und zu den positiven Agglomerationseffekten (genauer gesagt: Urbanisierungseffekten) gehört. In der vorliegenden Untersuchung kann in Bezug auf Elektronik- und Baumärkte empirisch belegt werden, dass die Kundenfrequentierung dieser Anbieter durch die Nähe zu Anbietern anderer Branchen (operationalisiert durch die Konzentrationsvariable $K_{A j}$ ) positiv beeinflusst wird; je höher das Kopplungspotenzial, desto höher ist demnach - unter ansonsten gleichen Bedingungen - der (lokale) Marktanteil dieser Anbieter. Im Fall der Lebensmittelmärkte kann diese Hypothese jedoch nicht bestätigt werden, da ein signifikant negativer Einfluss der allgemeinen Konzentrationsvariable festgestellt wird; demnach beeinflusst in diesem Fall die räumliche Ballung mit andersartigen Anbietern die Einkaufsentscheidungen negativ bzw. mindert die Kundenströme aus dem Marktgebiet ab.

Die Hypothesen $\mathrm{H}_{4 a}$ und $\mathrm{H}_{4 b}$ beziehen sich auf Lokalisierungsvorteile durch die räumliche Nähe zu branchengleichen bzw. konkurrierenden Anbietern aufgrund der Möglichkeit für die Kunden, verschiedene Formen von Vergleichskäufen am Angebotsstandort durchzuführen; die Ballung mit konkurrierenden Einzelhandelsbetrieben (Konzentrationsvariable $K_{K j}$ ) müsste demnach einen unter-linearen positiven Effekt auf den Kundenzufluss der untersuchten Anbieter haben. Bei Anbietern eher substituierbarer (weil standardisierter) Güter können Vergleichskäufe Ausdruck einer Mehrfachorientierung aufgrund von Präferenzen und Erfahrungen bzw. der gezielten Suche nach Sonderangeboten sein; diese MarketingPerspektive (z.B. POPKOWSKI LESZCZYC et al. 2004, VROEGRIJK et al. 2013) erklärt daher die räumliche Ballung von konkurrierenden Einzelhandelsbetrieben mit Sortimenten des 
täglichen Bedarfs. Im vorliegenden Fall kann diese Hypothese für die Lebensmittelmärkte bestätigt werden; die untersuchten Anbieter dieser Branche profitieren im Hinblick auf ihren Kundenzufluss durch die räumliche Nähe zu ihren Mitbewerbern. Auch im Fall der Elektronikmärkte kann ein positiver Einfluss der Konkurrenznähe nachgewiesen werden. Bei diesen Anbietern von Suchgütern zeigen sich stärkere Kundenzuflüsse aus dem Marktgebiet aufgrund der Möglichkeit von suchgesteuerten Vergleichskäufen; dies wird vielfach in den klassischen Standorttheorien beschrieben und insbesondere von NELSON (1958) in den Vordergrund gerückt („Shared business“ aufgrund von Kumulationsvorteilen). Nicht bestätigt wurde die Hypothese einer positiven Wirkung jedoch bei den Baumärkten.

Die auf die Veränderung des Fahrtzeiteffektes in den schrittweise gebildeten Modellen abzielende Hypothese $\mathrm{H}_{5}$ bestätigt sich in allen drei Fällen: Die Einflussstärke des Transportkostenmaßes nimmt in den Modellen mit der fortschreitenden Berücksichtigung weiterer Erklärungsgrößen (insb. der Konzentrationsvariablen) zu. Dies ist damit erklärbar, dass ein Modell ohne Berücksichtigung von Konzentrationsmaßen die (positive) Wirkung von Agglomerationen bereits implizit enthält; werden alle hier untersuchten Erklärungsgrößen im Modell berücksichtigt, wird der Fahrtzeiteffekt um die Einflüsse der räumlichen Ballung korrigiert und somit der „wahre“ Einfluss herausgefiltert. Dieser Einfluss ist erwartungsgemäß höher, da die (positiven) Auswirkungen der räumlichen Ballung auf den Kundenzufluss bereits durch die Konzentrationsvariablen abgedeckt werden. Daran zeigt sich indirekt die Substituierbarkeit von Transportkosten und dem gesteigerten Nutzen durch räumlich geballtes Angebot; die Kunden sind in Anbetracht der Möglichkeit von Kopplungs- und Vergleichskäufen bereit, weitere Einkaufswege in Kauf zu nehmen.

Im Fall der Lebensmittelmärkte ist zusätzlich die betriebsformenspezifische Ballung als Einflussfaktor überprüft worden $\left(\mathrm{H}_{6 \mathrm{a}}, \mathrm{H}_{6 \mathrm{~b}}\right)$, um einer möglichen Komplementarität zwischen eigentlich kompetitiven Anbietern Rechnung zu tragen (Zentrale Aussage von VROEGRIJK et al. 2013). Es zeigt sich hierbei, dass die räumliche Nähe zu branchengleichen Anbietern einer anderen Betriebsform einen positiven Effekt auf die Kundenzuflüsse aus dem Marktgebiet hat und die Nähe zu betriebsformengleichen Anbietern einen negativen; im letztgenannten Fall überwiegen dann offensichtlich Konkurrenz- gegenüber positiven Agglomerationseffekten. Demnach wirkt für LM-Discounter die Nähe zu Vollsortimentern positiv und umgekehrt. In einem Fall (Räumliche Nähe der LM-Discounter zu anderen LMDiscountern) konnte die Hypothese aufgrund einer Unterschreitung des Signifikanzniveaus nicht bestätigt werden, wenngleich die Richtung des Einflusses der Hypothese $\mathrm{H}_{6 a}$ (negative Wirkung) entspricht.

\subsubsection{Branchenspezifische Aspekte}

\subsubsection{Lebensmittelmärkte}

Die Marktgebiete der hier untersuchten Lebensmittelmärkte sind in hohem Maße durch die Nähe des Kundenwohnortes zum Angebotsstandort bestimmt; dies zeigt sich sowohl daran, dass die Fahrtzeit im Modell den mit Abstand stärksten Effekt hat (siehe standardisierter Regressionskoeffizient), als auch daran, dass die mit dieser Erklärungsgröße einhergehende Varianzaufklärung sehr hoch ist (Veränderung des Bestimmtheitsmaßes $R^{2}$ im schrittweisen Regressionsmodell). Die Einkaufsentscheidung beim Lebensmitteleinkauf wird hier also vorrangig durch die von den Kunden notwendigerweise einzusetzenden Transaktionskosten 
des Einkaufsweges (Transportkosten) bestimmt; der lokale Marktanteil der Anbieter sinkt mit steigender Fahrtzeit weit überproportional. Die Sortimentsbreite und -tiefe (Verkaufsfläche) spielt demgegenüber eine geringere Rolle. Wie auch LADEMANN (2007) in seiner Untersuchung zu Lebensmitteleinkäufen mittels Logit-Modellen feststellt, reagieren demnach die Kunden in ihrer räumlichen Einkaufsorientierung sensibler auf die Nähe bzw. Entfernung zu Anbietern als auf die Größe ihres Angebots. Dieses Ergebnis entspricht grundsätzlich den Vorstellungen von u.a. CHRISTALLER (1933), wonach Güter niederer Ordnung - zu denen Güter des täglichen Bedarfs wie Nahrungsmittel gehören - nur über eine vergleichsweise geringe obere Reichweite (maximal mögliches Marktgebiet) verfügen; im Gegenzug müssen die in ihrer Sortimentsbreite und -tiefe eingeschränkten Anbieter (kleinere Supermärkte, Discounter) auch nur eine geringe untere Reichweite (minimal nötiges Marktgebiet) generieren, um betriebswirtschaftlich tragfähig zu sein (siehe Anhang, Tab. A 1).

Grundsätzlich bestätigt sich dies auch bei separater Betrachtung der Betriebsformen. Ist der Fahrtzeiteffekt bei LM-Vollsortimentern (Supermärkte, Verbrauchermärkte) und LMDiscountern ähnlich (hoch) ausgeprägt, so zeigt sich hingegen eine deutlich differenziertere Kundenreaktion auf die Angebotsgröße: Bei den Vollsortimentern stellt die Sortimentsbreite/ -tiefe (Verkaufsfläche) zwar den zweitwichtigsten Effekt im Modell dar, entfaltet jedoch nur eine weit unter-lineare Wirkung. Eine Sortimentsausweitung, die sich in einer Vergrößerung der Verkaufsfläche niederschlägt, sorgt demnach nur für stark unterproportionale Zuwächse an Kundenzufluss aus dem Marktgebiet. Ein weitaus mächtigerer Verkaufsflächeneffekt (nur knapp unterhalb der Linearität) lässt sich hingegen bei den Discountern feststellen.

Ausgehend von den theoretischen Überlegungen zur Attraktivitätswirkung der Angebotsgröße (insb. BAUMOL/IDE 1956, HUFF 1962) ist dies mit bei den Vollsortimentern vergleichsweise hohen Such- und Entscheidungskosten sowie weiteren Transaktionskosten (z.B. Parkplatzsuche, Wartezeit an den Kassen) zu erklären. Discounter decken einerseits mittlerweile die Sortimentsbreite von Vollsortimentern ab, so dass sie - zumindest prinzipiell - einen vollständigen Lebensmitteleinkauf für einen Privathaushalt ermöglichen. Andererseits baut ihr Betriebskonzept auf einer stark beschränkten Sortimentstiefe bei relativ kleinen Verkaufsflächen auf; eine „Qual der Wahl“ bzw. die „tyranny of freedom [of choice]“ (DESMEULES 2002) ist hier ebenso wenig gegeben wie lange Kundenlaufwege in den Verkaufsräumen. Diese betriebsformenspezifischen Unterschiede lassen sich also anhand der Marktauftritte der Anbieter erklären. Die Verkaufsflächengrößen der hier betrachteten LM-Discounter variieren zudem zwischen 650 und 1.200 qm und somit deutlich geringer als dies zwischen den Vollsortimentern der Fall ist (zwischen 300 und 5.800 qm); der stärkere Effekt dürfte also auch auf die geringere Varianz der Ausprägungen zurückzuführen sein.

Werden alle Lebensmittelmärkte gemeinsam betrachtet, hat die räumliche Ballung mit anderen Einzelhandelsbetrieben einen negativen Effekt auf den Kundenzufluss. Dies würde bedeuten, dass die Möglichkeit von horizontalen und vertikalen Kopplungskäufen die Einkaufsentscheidungen eher zu Ungunsten von Märkten mit hohem Kopplungspotenzial beeinflusst; dieses Ergebnis widerspricht den zu Grunde gelegten theoretischen Aussagen u.a. von CHRISTALLER (1933), LANGE (1973) und NELSON (1958), wonach externes Kopplungspotenzial ein wichtiges Attraktivitätsmerkmal von Angebotsstandorten darstellt. Bei betriebsformenspezifischer Betrachtung stellt sich jedoch heraus, dass die Nähe zu Anbietern anderer Branchen bei den untersuchten LM-Vollsortimentern gar keinen Einfluss entfaltet und im Fall der LM-Discounter eine starke negative Wirkung besitzt, die sogar 
größer ist als die eigene Angebotsgröße der Anbieter (ausgehend von den standardisierten Regressionskoeffizienten bildet die allgemeine Konzentrationsvariable mit negativem Vorzeichen den drittgrößten Effekt im Modell; siehe Kap. 6.3.1.4). Dass die Hypothesen zu positiven Auswirkungen von Kopplungsmöglichkeiten bei Lebensmittelmärkten abgelehnt werden müssen, ist also vor allem auf die Discounter zurückzuführen.

Es stellt sich vor diesem Hintergrund die Frage, ob beim Lebensmitteleinkauf tatsächlich keine Urbanisierungsvorteile aufgrund der Möglichkeit von Kopplungskäufen existieren, wenn dieses Einkaufsverhalten am Angebotsstandort doch schon unzählige Male empirisch nachgewiesen wurde (siehe Kap. 4.2.1). Dieser scheinbare Widerspruch ist mit hoher Wahrscheinlichkeit durch die bestehende Standortkonfiguration zu erklären, wie sie im Untersuchungsgebiet und in ähnlicher Weise auch andernorts vorherrscht: Bei nahezu allen betrachteten Lebensmittelmärkten besteht Kopplungspotenzial für (zumindest horizontale) Kopplungen in Form anderer Anbieter von Gütern des täglichen Bedarfs; beispielsweise befinden sich ausnahmslos in allen 27 Fällen eine oder mehrere Verkaufsstellen des Lebensmittelhandwerks (Bäckerei, Fleischerei) entweder auf einer angemieteten Fläche im Ein- und Ausgangsbereich des Marktes selbst oder in dessen unmittelbarer Nachbarschaft. In einer Agglomeration (nach der hier genutzten Definition: mindestens drei Betriebe) befinden sich zudem 14 der 27 Märkte (siehe Kap. 6.1.1.2). Es deutet sich also an, dass relevante Kopplungsmöglichkeiten regelmäßig gegeben sind und sich diese in ihrer Ausprägung nicht in dem Maße unterscheiden, dass sie einen relevanten anziehenden Effekt generieren könnten.

Hinzu kommt, dass bei der Operationalisierung der Kopplungsmöglichkeiten im vorliegenden Fall (Konzentrationsvariable) nicht zwischen Branchen unterschieden wurde (siehe Kap. 5.3.1.4); es ist wahrscheinlich, dass bestimmte Angebotsformen (z.B. Bekleidung, Möbel) keinerlei Relevanz für Kopplungen beim Lebensmitteleinkauf besitzen. Dies entspricht tendenziell den Kompatibilitätsmatrizen von NELSON (1958) und auch den aktuellen Erkenntnissen aus der Marktforschung von WOTRUBA (2014), wonach Kopplungen eher zwischen Anbietern von Gütern derselben Bedarfsstufe bzw. Einkaufshäufigkeit gekoppelt werden; z.B. besteht bei Textil- und Baumärkten wenig bis gar keine Kompatibilität zu Lebensmittelmärkten.

Auffällig ist der starke negative Effekt des Kopplungspotenzials bei den Marktgebieten der LM-Discounter. Dieses Ergebnis ist anhand eines Zusammenhangs interpretierbar, der in der vorliegenden Untersuchung unberücksichtigt geblieben ist und auf den Zweck und die Organisation des Einkaufs abzielt: Bei einer Untersuchung zur Einkaufsstättenwahl in Österreich zeigen REUTTERER/TELLER (2009) auf, dass flächenintensivere Betriebsformen (z.B. Verbrauchermärkte) tendenziell für Großeinkäufe aufgesucht werden, während LMDiscounter in höherem Maße den Zweck von Ergänzungskäufen erfüllen, die mit geringem Zeitaufwand durchgeführt werden. Es ist plausibel anzunehmen, dass in diesen Fällen keine Kopplungskäufe stattfinden und tendenziell Angebotsstandorte aufgesucht werden, die einen möglichst schnellen Einkauf unter Minimierung etwaiger Verzögerungen (z.B. durch Verkehrsbelastungen wie Staus, Parkplatzsuche) ermöglichen; hierfür bieten sich anstatt von Gewerbegebieten oder Einkaufszentren eher kleinere Standortkooperationen mit Vollsortimentern an, worauf auch der positive Effekt der Konkurrenznähe hindeutet.

Bei der gemeinsamen, betriebsformenunabhängigen Betrachtung aller Lebensmittelmärkte wirkt die räumliche Nähe zu anderen Lebensmittelmärkten positiv auf den Kundenzufluss 
aus dem Marktgebiet. Unter ansonsten gleich bleibenden Bedingungen steigen also die lokalen Marktanteile von diesen Anbietern aufgrund der Ballung mit branchengleichen Märkten; dieses Ergebnis weist auf positive, konsumentenseitige Lokalisierungseffekte im Lebensmitteleinzelhandel hin. Die damit verbundene Einkaufsstrategie entspricht aber nicht den Überlegungen von u.a. NELSON (1958) zu suchbezogenen Vergleichskäufen und einer darauf aufbauenden Konkurrenzanziehung, die er ausdrücklich für Anbieter von ausdifferenzierten Gütern formulierte (Beispiel: Schuhgeschäfte); stattdessen deuten die positiven Effekte der Konkurrenznähe bei Lebensmittelmärkten auf eine gemeinsame Anziehungskraft aufgrund von Komplementaritäten (im Sinne von u.a. VROEGRIJK et al. 2013) oder der Möglichkeit zur gezielten Wahrnehmung von Sonderangeboten bzw. „CherryPicking“ (u.a. POPKOWSKI LESZCZYC et al. 2004) hin.

Einen genaueren Einblick hinsichtlich der Substituierbarkeit bzw. Komplementarität von Anbietern bietet die betriebsformenspezifische Betrachtung: Sowohl bei den Vollsortimentern als auch bei den Discountern zeigt sich, dass die räumliche Nähe zu Konkurrenten der jeweils gleichen Betriebsform den eigenen Kundenzufluss mindert; ein Vollsortimenter (bzw. Discounter) profitiert demnach nicht von Agglomerationsvorteilen durch die Ballung mit anderen Vollsortimentern (bzw. Discountern). Dieses Ergebnis entspricht den Feststellungen anderer empirischer Untersuchungen: Auch ORPANA/LAMPINEN (2003) und TIHI/ORUC (2012) berücksichtigen in ihren Marktgebietsanalysen von Lebensmittelmärkten die Nähe zu Anbietern der gleichen Branche und Betriebsform und stellen diesbezüglich negative Einflüsse auf die Einkaufsentscheidungen bzw. die Kundenzuflüsse aus dem Marktgebiet fest. Zwischen Anbietern derselben Betriebsform im Lebensmitteleinzelhandel dominieren demnach die intraformalen Wettbewerbseffekte aufgrund einer tendenziell starken Substituierbarkeit des Angebotes bzw. geringer Komplementarität.

Ein positiver Effekt bei LM-Vollsortimentern könnte theoretisch aus der Ermöglichung von Cherry-Picking hervorgehen, da diese - im Gegensatz zur Dauerniedrigpreispolitik der Discounter - Kunden durch Sonderangebote gewinnen und so z.B. eine Verknüpfung des Besuchs mehrerer Verbrauchermärkte plausibel wäre. Dieser Effekt konnte hier nicht festgestellt werden, womöglich weil Cherry-Picking von geringer Relevanz ist oder sich die damit verbundene Mehrfachorientierung nicht in einem räumlichen Einkaufsmuster niederschlägt, in dem agglomerierte Anbieter bevorzugt werden. Nach POPKOWSKI LESZCZYC et al. (2004) sind Kunden mit dieser Preissuchstrategie wenig bis gar nicht sensibel für die mit Einkäufen verbundenen Transaktionskosten; eine Reduktion dieser, wie sie durch Einzelhandelsagglomerationen ermöglicht wird, müsste daher für Cherry-Picker eher irrelevant sein, da bei ihren Einkäufen auf den damit verbundenen Aufwand nicht achten.

Bisher noch nicht empirisch nachgewiesen wurde der positive Effekt der Nähe zu Anbietern jeweils anderer Betriebsformen auf den Kundenzufluss der Lebensmittelmärkte: LMDiscounter profitieren tendenziell von der Ballung mit LM-Vollsortimentern und umgekehrt. Im Fall der Discounter schlägt sich der Konzentrationseffekt sogar stärker nieder als die eigene Angebotsgröße und alle anderen erklärenden Variablen mit Ausnahme des Transportkostenmaßes (abzulesen an den standardisierten Regressionskoeffizienten, siehe Kap. 6.3.1.4). Hier zeigt sich das insbesondere von VROEGRIJK et al. (2013) vertretene Prinzip der Komplementarität zwischen Betriebsformen derselben Branche: Die Kunden suchen für ihre Einkäufe mehrere Betriebsformen und/oder Anbieter auf, um ihren persönlichen Warenkorb mit Gütern des täglichen Bedarfs entsprechend den eigenen 
Präferenzen zusammenzustellen. Konsequenterweise ist dies am besten möglich, wenn mehrere Anbieter dieses Typs räumlich nah zueinander lokalisiert sind; Agglomerationen von Vollsortimentern und Discountern (sowie ggf. weiteren LEH-Betrieben) bieten demnach die beste Möglichkeit, dem Anspruch von mehrfachorientierten Kunden bei erfahrungs- und präferenzgesteuerten Vergleichskäufen gerecht zu werden. Positive Agglomerationseffekte überwiegen hier also gegenüber dem interformalen Wettbewerb.

Diese kundenseitig bedingten Lokalisierungsvorteile spiegeln sich auch in der Standortpolitik der Einzelhandelsunternehmen wider: Im Untersuchungsgebiet existieren mehrere Agglomerationen unterschiedlicher Größe, in denen sowohl ein Vollsortimenter als auch ein Discounter präsent sind, darunter auch kleinere Standortkooperationen von Anbietern dieser beiden Betriebsformen (z.B. Edeka- und Aldi-Markt zzgl. ergänzendem Angebot); auch ist die Bildung eines weiteren Kombinationsstandortes (Vollsortimenter und Discounter) in der Untersuchungsstadt Beverungen geplant gewesen, jedoch nicht genehmigt worden (siehe Kap. 6.1.1.2). Die Ergebnisse anderer Untersuchungen mit dem Fokus auf die Standortpolitik der Angebotsseite (Handelsunternehmen) unterstreichen die festgestellten Muster der Einkaufsorientierung; demnach suchen Filialisten des Lebensmitteleinzelhandels bei ihrer Expansion mitunter gezielt die Nähe zu Mitbewerbern anderer Betriebsformen und bauen Standortkooperationen auf, wie etwa JüRGENS (2012a u. 2013) am Beispiel von Edeka und Aldi in Norddeutschland zeigt. Auch sind die Ergebnisse der ökonometrischen MCl-Analyse konsistent mit den kontrafaktualen Modellsimulationen von VROEGRIJK et al. (2013) und den Umsatzanalysen von ZHU et al. (2011), wonach bei Markteintritten von LM-Discountern diejenigen Konkurrenten die geringsten Umsatzverluste hinnehmen müssen, die durch räumliche Nähe und Komplementarität zu den Discountern gekennzeichnet sind.

\subsubsection{Elektronikmärkte}

In den MCl-Modellanalysen zu den Marktgebieten der Elektronikmärkte sind, anders als in den anderen Fällen, sämtliche vorher formulierten Hypothesen verifiziert worden (siehe Kap. 7.1.1). Den größten Einfluss auf die Einkaufsstättenwahl macht hierbei nicht der Zeitverlust des Einkaufsweges, sondern die Eigenattraktivität der Anbieter aus (dokumentiert durch die standardisierten Koeffizienten, siehe Kap. 6.3.2.1). Die Größe des Angebots - hier steht die Sortimentstiefe im Vordergrund, da alle betrachteten Betriebe die gleiche Sortimentsbreite abdecken - fördert den Kundenzufluss in beinahe linear-proportionaler Weise (nichtstandardisierter Koeffizient liegt knapp unter eins). Hier zeigt sich die Bedeutung der Auswahl bei Anbietern von mittel- und langfristigen Gütern, für deren Erwerb vergleichsweise viel Zeit und Kaufkraft investiert werden und Preis- bzw. Warenvergleiche eine wichtige Rolle spielen (z.B. Kauf einer Waschmaschine oder eines Kaffeevollautomaten). Im Sinne von CHRISTALLER (1933) besteht das Angebot von Elektronikmärkten aus Gütern höherer Ordnung bzw. größerer Reichweite; im Gegensatz zu den Gütern des täglichen bzw. kurzfristigen Bedarfs steht daher die Eigenattraktivität des Anbieters im Vordergrund, wobei die Kunden zur Inkaufnahme deutlich weiterer Einkaufswege als beim Lebensmitteleinkauf bereit sind. Mit steigenden Transportkosten (Fahrtzeiten) sinken dennoch die lokalen Marktanteile der Elektronikmärkte unter ansonsten gleichen Voraussetzungen über-linear.

Alle untersuchten Elektromärkte befinden sich an Angebotsstandorten mit vergleichsweise hohem Potenzial für horizontale und vertikale Kopplungskäufe, zumeist in Gewerbegebieten oder in deren Umfeld und umgeben von anderen großflächigen Fachmärkten (z.B. Bau- oder 
Möbelmärkte) und Lebensmittelmärkten. Der insbesondere von LANGE (1973) und NELSON (1958) betonte positive Effekt des externen Kopplungspotenzials auf die Standortattraktivität findet sich in den Marktgebieten der Elektronikmärkte wieder; je größer die Ballung mit Anbietern anderer Branchen, desto höher sind unter ansonsten gleichen Bedingungen die lokalen Marktanteile der Anbieter. Entsprechend den Hypothesen zur gleichzeitigen Erhöhung der Such- und Entscheidungskosten steigen die Marktanteile mit steigenden Kopplungsmöglichkeiten jedoch weit unter-linear.

Eine Differenzierung nach horizontalen und vertikalen Kopplungsmöglichkeiten eröffnet sich aufgrund der allgemeinen Formulierung der verwendeten Konzentrationsvariablen nicht; allerdings ist es naheliegend, dass die Kopplungseffekte vorwiegend andere Fachmärkte mit Sortimenten derselben Bedarfsstufe betreffen (Horizontale Kopplung). Hierfür spricht einerseits, dass die untersuchten LM-Märkte selbst nicht von vertikalem Kopplungspotenzial profitieren (siehe Kap. 7.1.2.1). Andererseits ermöglicht ein Angebotsstandort mit mehreren Fachmärkten (Beispiel: Elektronik-, Bau-, Möbelmärkte) die Verbindung des Einkaufs unmittelbar komplementärer Güter, die z.B. im Zusammenhang mit der Wohneinrichtung getätigt werden können (Beispiele: Flachbildfernseher und Fernsehtisch, Badezimmermöbel und -lampen). Abseits davon können sich hinter den hier festgestellten positiven Effekten durch Kopplungsmöglichkeiten auch Vergleichskäufe verbergen: Obwohl die untersuchten Fachmärkte (Elektronik- und Baumärkte) zwar als branchenungleiche Anbieter aufgefasst wurden, so besteht zwischen innen dennoch eine Sortimentsüberschneidung (Beispiele: Lampen und Leuchten). In jedem Fall spiegeln die Ergebnisse deutlich wider, dass die berücksichtigten Elektronikmärkte von der Nähe zu anderen Angebotsformen profitieren.

Ebenso positiv wirkt sich die räumliche Nähe zu konkurrierenden Elektronikmärkten auf die Einkaufsorientierung der Kunden und somit auf die Kundenfrequentierungen aus dem Marktgebiet aus; je größer die räumliche Konzentration in Bezug auf Mitbewerber, desto höher sind, ceteris paribus, die lokalen Marktanteile der untersuchten Elektronikmärkte. Das Konzept der Konkurrenzanziehung im Sinne von NELSON (1958) findet hier also empirische Bestätigung. Bei den in Elektronikmärkten dargebotenen Sortimenten handelt es sich überwiegend um solche Güter, für deren Erwerb suchgesteuerte Vergleichskäufe durchgeführt werden (siehe oben). Es ist eine plausible Vorstellung, dass insbesondere bei größeren Anschaffungen (z.B. Kaffeevollautomat, Waschmaschine, Computer) Preis- und Warenvergleiche durchgeführt werden; dies gilt speziell dann, wenn Produkte zunächst physisch begutachtet werden (z.B. Farbe, Design, tatsächliche Größe) oder die Preispolitik des Anbieters die Möglichkeit zum Herunterhandeln des Preises ermöglicht ${ }^{45}$. Daher ist die Möglichkeit, mehrere Märkte in räumlicher Nähe zueinander oder gar am selben Angebotsstandort aufzusuchen, ein Kriterium der Standortattraktivität für die Konsumenten. Dies entspricht auch den in anderen Studien festgestellten Standortmustern, wonach Elektronikanbieter (und andere Anbieter von Gütern des mittel- und langfristigen Bedarfs) tendenziell räumlich geballt auftreten (z.B. KRIDER/PUTLER 2013; siehe Kap. 4.1.1). Ein hervortretendes Beispiel hierfür aus dem Untersuchungsgebiet ist das von großflächigen Einzelhandelsbetrieben geprägte Gewerbegebiet Bülte (Holzminden-Kernstadt), in dem zwei Elektrofachmärkte angesiedelt sind (Media Markt und Expert).

\footnotetext{
${ }^{45}$ In Bezug auf Elektrofachgeschäfte und -fachmärkte wird häufig berichtet, dass unter Verweis auf die Preise der jeweiligen Konkurrenten Preisnachlässe in der Verkaufsstelle verhandelbar sind (z.B. DIE WELT 2012).
} 
Weiterhin sind die (zumeist filialisiert oder kooperativ organisierten) Elektrofachmärkte und -fachgeschäfte in ihrer Sortimentspolitik nicht im selben Maße standardisiert wie etwa Lebensmittel-Discounter: Wie REN et al. (2011) am Beispiel von US-Filialisten des Elektronikeinzelhandels zeigen, besteht für Anbieter im „kollokierten Wettbewerb“ (d.h. in Konkurrenznähe) durchaus die Möglichkeit einer Differenzierungsstrategie zum Zweck der Vermeidung von Preiskämpfen bei sich überschneidenden Sortimenten bzw. einzelnen Artikeln; auch EsteBAN-BRAvo et al. (2012) finden Hinweise hierfür. Solche (informell organisierten) Standortkooperationen in Form von Sortimentsabsprachen können dazu beitragen, (schädliche) Wettbewerbseffekte in positive Agglomerationseffekte umzuwandeln; ob dies im vorliegenden Fall geschieht oder geschehen ist, war nicht Gegenstand dieser Untersuchung ${ }^{46}$, stellt jedoch eine interessante Fragestellung dar.

Darüber hinaus ist, entsprechend den Überlegungen von u.a. ESTEBAN-BRAvo et al. (2012) und LI/LIU (2012), anzunehmen, dass die Lokalisierungsvorteile nur bis zu einer bestimmten Grenze wirken und darüber hinaus Wettbewerbseffekte zwischen den Märkten die Oberhand gewinnen. In Anbetracht der Standortkonfiguration - großflächige Märkte in allen drei Kernstadtgebieten des Untersuchungsgebietes - und der schnellen PKW-bezogenen Verkehrsanbindung ist es zudem unwahrscheinlich, dass einer oder mehrere dieser Anbieter eine starke räumliche Monopolstellung erreichen könnten; hierfür sprechen der vergleichsweise geringe Fahrtzeiteffekt und, damit verbunden, die deutlich festzustellende Mehrfachorientierung der Haushalte im Untersuchungsraum (zumindest die berücksichtigten Fachmärkte werden aus nahezu jedem Nachfrageort angesteuert; siehe Kap. 6.2.2.2).

\subsubsection{Bau- und Heimwerkermärkte}

Ähnlich den Elektronikmärkten besteht auch im Fall der Bau- und Heimwerkermärkte der stärkste Einfluss auf die Einkaufsstättenwahl in der Größe des Angebots; es zeigt sich also, dass die Distanz- bzw. Fahrtzeitsensibilität der Konsumenten beim Lebensmitteleinkauf deutlicher ausgeprägt ist als beim Kauf von Gütern des mittel- und langfristigen Bedarfs. Entgegen den Hypothesen und den Ergebnissen der anderen Angebotsformen wirkt der Größenindikator (Verkaufsfläche) jedoch oberhalb der Linearität, d.h. mit größerer Verkaufsfläche steigen, unter ansonsten gleichen Bedingungen, die lokalen Marktanteile überproportional. Die Auswahl im Baumarktangebot wiegt offensichtlich schwerer als mögliche Nachteile aufgrund von konsumentenseitigen Such- und Entscheidungskosten. Für Baumärkte existieren, wie für Elektronikmärkte, diesbezüglich keine Vergleichswerte, jedoch findet LADEMANN (2007) für Möbelhäuser einen ähnlichen Effekt. Hieraus erklärt sich die empirisch festgestellte Marktdominanz des OBI-Marktes in der Kernstadt Höxters (siehe Kap. 6.2.2.3). Wie in allen anderen Fällen haben - entsprechend den Überlegungen von HuFF (1962) - die konsumentenseitigen Transportkosten (Fahrtzeit) einen über-linearen negativen Einfluss auf den Kundenzufluss aus dem Marktgebiet.

Für die Analyse des Effekts der Kopplungsmöglichkeiten gilt dasselbe wie im Fall der Elektronikmärkte: Es besteht ein unter-linearer positiver Zusammenhang zwischen der räumlichen Ballung mit Anbietern anderer Branchen und den lokalen Marktanteilen der

\footnotetext{
${ }^{46}$ In Bezug auf das „Elektronik-Cluster“ im Holzmindener Gewerbegebiet Bülte wurde in einem Experteninterview, das ein Jahr nach der Media Markt-Eröffnung geführt wurde, auf eine derartige Kooperation bzw. Absprache zwischen den Betreibern dieser beiden Märkte hingewiesen; allerdings beruhte diese Einschätzung auf einem subjektiven Urteil bzw. nicht offiziell bestätigten Aussagen.
} 
Anbieter. Die Bau- und Heimwerkermärkte sind ebenso vorrangig in Gewerbegebieten und anderen größeren Agglomerationen in Nachbarschaft anderer Fachmärkte lokalisiert, so dass horizontale Kopplungskäufe mit diesen möglich sind. Hinzu kommt, dass aufgrund von Sortimentsüberschneidungen zwischen Bau-, Elektronik- und Möbelmärkten auch Vergleichskäufe denkbar sind, die im vorliegenden Fall nicht als solche identifiziert werden können (siehe Kap. 7.1.2.2).

Auffällig ist, dass - im Gegensatz zu den beiden anderen betrachteten Angebotsformen - für die räumliche Nähe zu direkten Mitbewerbern im Fall der Baumärkte ein negativer Effekt diagnostiziert wird. Sofern sich die Überlegungen von VROEGRIJK et al. (2013) auf andere Sortimentsbereiche übertragen lassen, kann die ungünstige Auswirkung der Konkurrenznähe - ähnlich wie bei der betriebsformenspezifischen Betrachtung der LM-Märkte - auf die fehlende Komplementarität der Baumarkt-Vertriebslinien zurückzuführen sein. Demnach wären sowohl angebots- und präferenzgesteuerte als auch suchgesteuerte Vergleichskäufe im Sinne von u.a. NELSON (1958) im Baumarktsektor irrelevant, da das Angebot dieser Märkte kaum differenziert bzw. leicht substituierbar ist; räumliche Nähe zu Konkurrenten wäre daher als Wettbewerbstreiber zu vermeiden und stattdessen ein Lagemonopol im Sinne von z.B. CHAMBERLIN (1933) anzustreben, da keine positiven Lokalisierungseffekte in Form eines Kundenaustauschs bzw. eines gemeinsamen Marktgebietes bestünden.

Dies scheint sich auch in der Standortkonfiguration niederzuschlagen: Im Gegensatz zu den betrachteten Lebensmittel- und Elektronikmärkten existieren im Untersuchungsgebiet keine Angebotsstandorte mit mehr als einem Baumarkt; während Standortkooperationen von Lebensmittelmärkten und Agglomerationen mit mehreren Elektronikanbietern vorzufinden sind, besteht diesbezüglich kein Äquivalent für Baumärkte. Dies kann natürlich die Folge einer auf Konkurrenzmeidung ausgelegten Standortpolitik sein, was dafür sprechen würde, dass kundenseitig bedingte Lokalisierungsvorteile tatsächlich keine Rolle in dieser Branche spielen. Anders als im Fall von Lebensmittelmärkten oder Möbelmärkten (z.B. MARSTALLER 2011) existiert für Baumärkte kein empirischer Beleg für die bewusste Bildung von Standortkooperationen.

Allerdings ist im vorliegenden Fall noch eine andere Erklärung möglich, die den UrsacheWirkungs-Zusammenhang umkehrt: Nach der Argumentation von u.a. ESTEBAN-BRAvo et al. (2012) und LI/LIU (2012) wirken sich Lokalisierungsvorteile nur bis zu einer bestimmten Reichweite aus, bis zu der ein Kundenaustausch im Sinne von unterschiedlich motivierten Vergleichskäufen stattfindet; ist diese Grenze überschritten, überwiegt der Wettbewerb zwischen den konkurrierenden Anbietern (U-förmiger Effekt). Es ist daher durchaus plausibel anzunehmen, dass sich die Vorteile der Konkurrenznähe im vorliegenden Fall gar nicht herausbilden können, da die Märkte schlicht zu weit voneinander entfernt sind, um positive Effekte durch die Ermöglichung von Vergleichskäufen zu induzieren. Demnach könnte die aktuelle Standortkonfiguration den Wettbewerbseffekt fördern, obwohl hypothetisch positive Effekte der Konkurrenznähe möglich wären. Hierfür spricht auch, dass an allen Angebotsstandorten im Untersuchungsgebiet spezialisierte Anbieter derselben Branche existieren, die keine Bau- und Heimwerkermärkte im Sinne der hier genutzten Definition (siehe Kap. 5.2.2.3) darstellen, jedoch das Angebot dieser Märkte ergänzen bzw. vertiefen (z.B. Gartenfachmärkte, Fachmärkte für Raumgestaltung); diese Anbieter wurden im vorliegenden Fall der allgemeinen räumlichen Konzentration zugerechnet, stellen aber prinzipiell Mitbewerber dar. Dass im Baumarktsektor kategorisch keine Lokalisierungsvorteile 
vorzufinden wären und daher die Meidung branchengleicher Anbieter stets einen Standortvorteil bedeuten würde, lässt sich anhand der vorliegenden Ergebnisse also nicht einwandfrei feststellen.

\subsubsection{Zwischenfazit: Marktgebiete im Einzelhandel unter Berücksichtigung von Agglomerationseffekten}

Insgesamt zeigt sich, dass die theoretisch hergeleiteten Hypothesen in den meisten Fällen verifiziert werden können. Abgesehen von einer erneuten empirischen Bestätigung der erklärenden Größen des HUFF-Modells konnte nachgewiesen werden, dass die räumliche Nähe zu branchengleichen/konkurrierenden bzw. andersartigen Einzelhandelsanbietern die konsumentenseitige Einkaufsstättenwahl und die damit verbundenen Kundenströme aus dem Marktgebiet im Regelfall beeinflusst. Auffällig ist hierbei, dass dieser (zumeist positive) Einfluss in seiner Intensität deutlich hinter den sonstigen Erklärungsgrößen (Angebotsgröße, Transportkosten bzw. Fahrtzeit) zurückbleibt; dies ist sowohl an den nicht-standardisierten und standardisierten Regressionskoeffizienten als auch am Beitrag zur Varianzaufklärung der Agglomerationsvariablen abzulesen. Dieser Umstand liegt aller Wahrscheinlichkeit nach im Marktauftritt der untersuchten Anbieter begründet: Bei den berücksichtigten Lebensmittel-, Elektronik- und Baumärkten handelt es sich fast ausschließlich um größere (bzw. im baurechtlichen Sinne großflächige) Betriebe, die national und international operierenden Handelsfilialisten bzw. -kooperativen angehören; sie stellen in den meisten Fällen an ihrem Angebotsstandort selbst „Magnetbetriebe“ dar und generieren ihren Kundenzufluss vorrangig durch ihre Eigenattraktivität (in der Terminologie von NELSON 1958: „Generative business“). Insbesondere im Fall der Lebensmittelmärkte mit ihrem Angebot an Gütern des täglichen Bedarfs fällt zudem noch die Kundennähe als wichtigster Einflussfaktor ins Gewicht.

Der festgestellte Einfluss räumlicher Ballung mit branchengleichen und -ungleichen Betrieben auf die eigene Kundenabschöpfung aus den Marktgebieten ist in den meisten Fällen positiv; unter ansonsten gleichen Bedingungen wachsen - stark unterproportional mit steigender räumlicher Ballung auch die lokalen Marktanteile der Anbieter. Möglichkeiten für Kopplungs- und Vergleichskäufe erweisen sich demnach als ein Standortmerkmal, das den Kundenzufluss fördert. Dies zeigt die Existenz von positiven Agglomerationseffekten (Lokalisierungs- und Urbanisierungsvorteile) auf, die aus dem Kundenverhalten herrühren (d.h. konsumentenseitige Agglomerationsvorteile); sie beruhen auf einem Kundenaustausch bzw. einem gemeinsamen (und daher größeren) Marktgebiet aufgrund der Ermöglichung bestimmter, mitunter sehr unterschiedlich motivierter Einkaufsstrategien (Horizontale und vertikale Kopplungskäufe; suchgesteuerte, präferenz- und erfahrungsgesteuerte sowie angebotsgesteuerte Vergleichskäufe). Dass diese Einkaufsstrategien grundsätzlich vorkommen, ist bereits empirisch erwiesen worden (z.B. durch POS-Befragungen); dass sich auch ein Effekt auf die Einkaufsstättenwahl bzw. die damit verknüpften Marktgebiete von Einzelhandelsbetrieben ergibt, konnte in dieser Analyse erstmals nach einzelnen Effekten differenziert und branchenübergreifend belegt werden.

Die empirisch festzustellende Tatsache einer räumlichen Ballung von Einzelhandelsangebot (z.B. in Standortkooperationen, Einkaufsparks oder geplanten Einkaufszentren) lässt sich somit plausibel anhand des Nachfragerverhaltens untermauern. Vor diesem Hintergrund ist die in den Raumwirtschafts- und Standorttheorien (u.a. CHRISTALLER 1933, LANGE 1973) angenommene Polarisierung von Angebotsstandorten (unter anderem) durch das räumliche 
Einkaufsverhalten erklärbar: Wird ein Betrieb (z.B. Lebensmittel-Discounter, Bau- oder Elektrofachmarkt) geschlossen oder verlagert, beeinträchtigt dies auch andere Betriebe am selben Angebotsstandort in zumeist negativer Weise, da die gemeinsame Anziehungskraft der Agglomeration gemindert wird. Umgekehrt können Neuansiedlungen sowohl von andersartigen als auch von konkurrierenden Anbietern den übrigen Betrieben zu einem höheren Kundenzufluss verhelfen. In der unternehmerischen Standortpolitik besteht demnach ein betriebswirtschaftlicher Anreiz zur räumlichen Ballung, dessen Kehrseite der Rückzug aus weniger agglomerierten Angebotsstandorten bzw. Streulagen sein kann und somit deren Bedeutungsverlust forciert, während große Angebotsstandorte wachsen.

Agglomerationseffekte zeigen sich also als wichtige Einflussfaktoren der Marktgebiete von Einzelhandelsanbietern; sie sind jedoch - zumindest im vorliegenden Fall - nicht so ausschlaggebend wie es die Theorie von LANGE (1973) suggeriert, in der räumliche Ballung als nahezu wichtigste Determinante identifiziert wird. Auch ist ihr Effekt differenziert zu beurteilen, da er je nach Angebotstyp und Betriebsform unterschiedlich ausgeprägt ist: Wie die Ergebnisse für die Lebensmittelmärkte zeigen, ist eine pauschale „Je mehr, desto besser"-Aussage hinsichtlich der Kopplungsmöglichkeiten zumindest nicht immer zutreffend. Offensichtlich ist hier auch eine weitere Differenzierung der für das Kopplungspotenzial relevanten Angebotsformen notwendig, um Aussagen zur Evidenz von positiven Urbanisierungseffekten im Lebensmitteleinzelhandel zu tätigen.

Ungleich schwieriger ist die Ballung von kompetitiven Anbietern zu beurteilen, da sich diese in einem komplizierten Wirkungsgeflecht aus Wettbewerbs- und Monopoleffekten einerseits (Monopolistischer Wettbewerb im Sinne von CHAMBERLIN 1933) und (positiven) Agglomerationseffekten andererseits bewegen: Die Konkurrenznähe zeigt sich als stark von der Kombination der Betriebsformen abhängig, was demonstriert, dass Komplementarität nicht nur zwischen unterschiedlichen gekoppelten Bedarfen, sondern auch zwischen eigentlich konkurrierenden Anbietern besteht. Diese Zusammenhänge werden von den älteren Standorttheorien nicht berücksichtigt, sondern sind erst unter Rückgriff auf MarketingAnsätze (z.B. POPKOWSKI LESZCZYC et al. 2004, VROEGRIJK et al. 2013) erklärbar. Ebenso stellt sich die Frage der räumlichen Reichweite von Lokalisierungsvorteilen im Einzelhandel, d.h. jene Grenze, bis zu der noch Vergleichskäufe unterschiedlichen Typs stattfinden; sofern dieser Gedanke (u.a. ESTEBAN-BRAVo et al. 2012, LI/LIU 2012) berücksichtigt wird, konnte in Bezug auf die Baumärkte nicht einwandfrei geklärt werden, ob nicht doch positive Effekte durch Konkurrenznähe auftreten (können).

Die grundsätzliche Feststellung, dass die Bildung von Einzelhandelsagglomerationen im Spiegel des Kundenverhaltens betriebswirtschaftlich tendenziell sinnvoll ist, wird durch die genannten Einschränkungen aber nicht abgemildert. Die hier gebildeten Modelle leisten ihren Beitrag zum Verständnis dieses Phänomens, da sie eine Analyse und Modellierung der Marktgebiete von Einzelhandelsanbietern im Zusammenhang von räumlichem Wettbewerb und Agglomerationseffekten ermöglichen. Diese Ergebnisse sind in praktischer Hinsicht (z.B. für Standortanalysen oder Planungsprozesse) höchst relevant (siehe Kap. 7.3). Zunächst stellen sich aber die Fragen, wie belastbar diese Modelle etwa im Hinblick auf weitere Erklärungsgrößen und ihren konkreten Einsatz in der Modellierung von Kundenströmen sind und wie sie ggf. noch verbessert werden können. Bevor eine generelle Auseinandersetzung mit den Möglichkeiten und Grenzen der vorliegenden Untersuchung erfolgt, wird daher zunächst den Fragen nach einer Modelloptimierung bzw. -erweiterung nachgegangen. 


\subsection{Optimierung, Erweiterung und Anwendung der eigenen Modelle}

\subsubsection{Zur Berücksichtigung räumlicher Nicht-Stationarität}

Die Berücksichtigung räumlich differenzierter Nutzenfunktionen in Marktanteils- bzw. Marktgebietsmodellen war ein zusätzliches Ziel der vorliegenden Untersuchung. Nach den Überlegungen von GHOSH (1984) ist davon auszugehen, dass die kundenseitige Wahrnehmung der Teilnutzen (z.B. Größe des Angebots, Fahrtzeit) aufgrund von Unterschieden in der Standortkonfiguration (z.B. Nähe zur nächstmöglichen Alternative) und der Haushaltsstruktur (z.B. Einkommen, Mobilitätsbereitschaft) räumlich variiert. Die ökonometrischen Marktgebietsmodelle wurden daher zusätzlich mit Hilfe der Methode der geographisch gewichteten Regression (GWR) geschätzt, die für jeden Nachfrageort eigene Parameter ermittelt (siehe Kap. 5.3.2.4). Hierbei zeigt sich, dass die GWR-Schätzung im Fall der Lebensmittelmärkte mitunter unplausible und vom stationären Modell grob abweichende Ergebnisse geliefert hat (siehe Kap. 6.3.1.2); aufgrund dieses unbefriedigenden Ergebnisses wird an dieser Stelle auf eine inhaltiche Interpretation dieses Modells verzichtet. Die GWRModelle für die Elektronik- und Baumärkte zeigten sich hingegen als konsistent mit den stationären Modellen und verbessern deren Erklärungsgehalt durch kleinräumige Anpassungen, was sie einer inhaltlichen Deutung zugänglich macht.

Im GWR-Modell für die Elektronikmärkte hält sich die räumliche Variation der Parameter in Grenzen, wobei kein Wechsel der Wirkungsrichtung festzustellen ist. Der stärkste Effekt aller Teilnutzen ist im nördlichen bzw. nordöstlichen Teil des Untersuchungsraumes festzustellen, wobei die Ausprägungen nach Süden hin abnehmen; die betragsmäßig höchste Ausprägung der Parameter (stärkste negative Wirkung der Fahrtzeit bzw. stärkste positive Wirkung der anderen erklärenden Variablen) wird in den Teilgebieten Holzmindens sowie den östlichen und nordöstlichen Teilgebieten Höxters erreicht. Diese auffällige Tendenz lässt sich in Anlehnung an die Gedanken von GHOSH (1984) anhand der Standortkonfiguration der Elektronikmärkte erklären: Drei der Märkte sind im Teilgebiet Holzminden-Kernstadt lokalisiert, ein weiterer in Höxter-Kernstadt; die Haushalte in den betreffenden Teilgebieten genießen demnach eine vergleichsweise gute Ausstattung bzw. Erreichbarkeit von Elektronikmärkten verschiedener Handelsketten bzw. -kooperativen (u.a. Expert, Media Markt). Diese Angebotsvielfalt bei gleichzeitig ähnlich kurzen Fahrtzeiten zu den Märkten bringt notwendigerweise mit sich, dass diese in einem intensiven Wettbewerbsverhältnis zueinander stehen, da im Zweifelsfall mehrere Mitbewerber ohne großen Aufwand verfügbar sind; es ist somit plausibel anzunehmen, dass die Kunden in diesen Gebieten sensibler auf die attraktivitätsfördernden und -hemmenden Eigenschaften der Anbieter reagieren - wobei neben dem eigenen Angebot auch die Möglichkeit von Kopplungs- und Vergleichskäufen ein Attraktivitätsmerkmal darstellt. Weniger „,anspruchsvoll“ sind demnach Kunden im Süden des Untersuchungsgebietes, deren Einkaufsalternativen v.a. hinsichtlich der Erreichbarkeit ungünstiger sind; dieser Umstand fördert in begrenztem Umfang die Monopolstellung der dortigen Anbieter.

Die MCl-GWR-Ergebnisse der Elektronikmärkte sind also durch räumlich differenzierte Wettbewerbsbeziehungen zu erklären, wofür spricht, dass alle berücksichtigten Merkmale der Märkte in der Ausprägung ihrer Wirkung die gleiche eindeutige räumliche Tendenz aufweisen. Dies ist bei den Baumärkten nicht in diesem Maße der Fall, wobei auch hier die Wirkungsrichtung der erklärenden Variablen räumlich konstant ist, nicht aber die Intensität 
dieser Wirkung. Die stärksten Ausprägungen der Koeffizienten für die Fahrtzeit und die Angebotsgröße werden im Süden und Nordosten des Untersuchungsraumes identifiziert, die schwächsten im Nordwesten; anders stellt sich demgegenüber die räumliche Variation des Konzentrationseffektes dar. Ausgehend von den Überlegungen zum GWR-Modell für die Elektronikmärkte müssten die größten Ausschläge dort registriert werden, wo aufgrund der räumlichen Konkurrenzsituation die größte Wettbewerbsintensität vorherrscht, was im Fall der Baumärkte das Kernstadtgebiet Höxters inklusive umliegender Teilräume wäre; dies ist jedoch nicht zu beobachten. Eine darüber hinausgehende plausible Erklärung für die festgestellten Variationen lässt sich auf der verfügbaren Daten- und Informationslage nicht darlegen; mögliche räumlich variierende Unterschiede in den Konsumpräferenzen, die ebenso ursächlich sein könnten, sind in der vorliegenden Untersuchung nicht erfasst bzw. berücksichtigt worden. Im GWR-Modell für die Baumärkte bleibt also nur die Feststellung, dass durch diese Methode die Modellanpassung kleinräumig optimiert werden konnte, ohne dass hierbei offensichtliche und erklärbare Marktgebietsmuster identifiziert werden konnten.

Insgesamt erweist sich die Modellbildung mit Hilfe der GWR-Methode zwar als grundsätzlich interessant, jedoch nur bedingt aufschlussreich, sofern es nicht möglich ist, räumliche Variationen auch inhaltlich-theoretisch zu unterfüttern; dieses Kriterium wird im vorliegenden Fall höchstens beim Marktgebietsmodell für die Elektronikmärkte erfüllt. Diese Methode hat demnach ihre Stärken eher in der explorativen Analyse oder - sofern bereits konkrete Hypothesen vorliegen - in der räumlichen Konkretisierung eines bereits empirisch nachgewiesenen und theoretisch fundierten Wirkungszusammenhangs. Zudem besteht die Möglichkeit unverwertbarer Ergebnisse, ohne dass hierfür eine plausible Erklärung zu finden wäre, wie es im Fall der Lebensmittelmärkte geschehen ist; dies unterstreicht die Aussage, dass Modelle unter Berücksichtigung räumlich variierender Zusammenhänge nur dann angewendet werden sollten, wenn die grundsätzlichen Inhalte bereits in einem stationären Modell aufgearbeitet worden sind.

\subsubsection{Modellvergleiche zur Abbildungsqualität}

Die Berücksichtigung der hier verwendeten Konzentrationsgrößen bedeutet einerseits einen nicht unerheblichen Aufwand; in der praktischen Marktgebietsanalyse ist daher ihr zusätzlicher Erklärungsgehalt ein wichtiges Kriterium. Andererseits bestünde die Möglichkeit, dass andere Erklärungsgrößen die Marktgebiete der Einzelhandelsanbieter besser erklären könnten als die hier verwendeten. Ein weiterer Baustein in wesensverwandten Untersuchungen ist daher die kritische Überprüfung der Ergebnisse anhand von ModellBenchmarkingtests. Die Grundidee besteht hierbei darin, die Abbildungsqualität der geschätzten Modelle mit alternativen Varianten zu vergleichen; vor dem Hintergrund möglicher Fehlspezifikationen in ökonometrischen Modellen - deren Folge interpretative Fehlschlüsse sein könnten - bildet dieses Vorgehen eine zusätzliche Maßnahme zur Qualitätssicherung und zugleich die Option zur Aufstellung plausibler Modellerweiterungen mit zusätzlichem Erklärungsgehalt. In der Untersuchung von ARENTZE et al. (2005) werden hierzu Entscheidungsmodelle mit und ohne die im Fokus stehenden Variablen gebildet und die Anpassungsgüte beider Modelle an die Echtdaten miteinander verglichen. GIJSBRECHTS et al. (2008) und VROEGRIJK et al. (2013) beschreiten einen anderen Weg, indem mehrere Modellvarianten mit anderen (zusätzlichen bzw. alternativen) Erklärungsgrößen aufgestellt 
und mit dem eigentlichen Modell verglichen werden. In der vorliegenden Untersuchung wurden beide Möglichkeiten ausgeschöpft.

Im ersten Schritt wird hierzu die Aussagekraft der Ergebnisse durch ihren Einsatz in einer HuFF-Marktgebietsanalyse (siehe Kap. 3.2.2.4) getestet; die Modellvariablen und die Parameter werden also in einem deterministischen Marktgebietsmodell benutzt, wobei der Begriff "deterministisch“ hier im Sinne einer "exakten“ Modellvoraussage ohne wahrscheinlichkeitstheoretische Elemente bzw. ohne „Rest“größe (Residuum) zu verstehen ist und sich nicht auf die inhaltliche Zielgröße des Modells bezieht. Wie von HUFF/McCALLUM (2008) dargestellt, werden die ermittelten Parameter als Gewichtungsexponenten ins HUFFModell eingesetzt und damit die Kundenströme im Untersuchungsgebiet modelliert: Für alle Nachfrage- und Angebotskombinationen werden Interaktionswahrscheinlichkeiten geschätzt (siehe Formel 42) und mit dem lokalen Nachfragepotenzial verrechnet. Als lokales Nachfragepotenzial werden hierbei die in der Haushaltsbefragung tatsächlich ermittelten Einkäufe bei den untersuchungsrelevanten Anbietern eingesetzt; die Marktgebietsmodelle zeigen also, wie sich diese registrierten Einkäufe (z.B. bei Lebensmittelmärkten: 1.098 Einkäufe) verteilen. Verwendet werden zwei verschiedene Nutzenfunktionen für jeden betrachteten Angebotstyp, deren Ergebnisse miteinander verglichen werden: Eine Modellvariante entspricht dem Ergebnis der Regressionsanalyse ohne Berücksichtigung der Konzentrationsvariablen und somit dem jeweils zweiten Schritt der schrittweisen Regression (Modell 2); die andere Variante ist das vierte, finale Modell inklusive aller vier Größen (Modell 4; siehe Kap. 6.3). Tabelle 31 zeigt die jeweils verwendeten Nutzenfunktionen.

$$
p_{i j}=\frac{U_{i j}}{\sum U_{i j}}
$$

$p_{i j}=$ Wahrscheinlichkeit, dass die Kunden im Nachfrageort i den Angebotsstandort j frequentieren

$\mathrm{U}_{\mathrm{ij}}=$ Wahrgenommener Nutzen des Angebotsstandortes $\mathrm{j}$ für die Konsumenten am Nachfrageort $\mathrm{i}$

\begin{tabular}{lll}
\hline Modell / Angebotstyp & \multicolumn{1}{l}{ Nutzenfunktion } \\
\hline Lebensmittelmärkte & Modell 2 & $U_{i j}=A_{j}{ }^{0,584} d_{i j}{ }^{-1,700}$ \\
& Modell 4 & $U_{i j}=A_{j}{ }^{0,658} d_{i j}{ }^{-1,747} K_{K_{j}}{ }^{0,083} K_{A_{j}}{ }^{-0,090}$ \\
\hline Elektronikmärkte & Modell 2 & $U_{i j}=A_{j}{ }^{0,893} d_{i j}{ }^{-1,526}$ \\
\hline Baumärkte & Modell 4 & $U_{i j}=A_{j}{ }^{0,951} d_{i j}{ }^{-1,632} K_{K_{j}}{ }^{0,101} K_{A_{j}}{ }^{0,336}$ \\
\hline
\end{tabular}

Tabelle 31: Modellvergleich - Verwendete Nutzenfunktionen

Quelle: Eigene Darstellung

Die Ergebnisse beider Modelle lassen sich zunächst anhand der Anpassungsgüte an die Echtwerte vergleichen; hierzu wurden - ähnlich dem Vorgehen bei der Kleinste-Quadrate- 
Schätzung in der Regressionsanalyse - die Abweichungen der tatsächlich registrierten gesamten Einkäufe bei den Anbietern von den modellierten Einkäufen berechnet und danach quadriert. Die Summe aller quadrierten Abweichungen $\left(\Sigma\left(\varepsilon^{2}\right)\right)$ bildet demnach ein Gütemaß für die Marktgebietsmodelle, wobei aufgrund der Berücksichtigung quadrierter Werte große Abweichungen überproportional ins Gewicht fallen. Tabelle 32 zeigt einen Vergleich der Abweichungswerte für die beiden HUFF-Modellvarianten bezüglich der drei betrachteten Angebotsformen. Hierbei ist deutlich zu erkennen, dass in jedem der drei Fälle das jeweilige Modell 4 (in dem die Agglomerationsvariablen berücksichtigt werden) gegenüber Modell 2 (ohne Agglomerationsvariablen) eine geringere Summe quadrierter Abweichungen aufweist. Insbesondere im Fall der Elektronik- und Baumärkte wird die Anpassung an die Echtwerte sehr deutlich verbessert; die Verringerung der Summe quadrierter Abweichungen im Modell für die Lebensmittelmärkte ist zwar ebenso unverkennbar, jedoch in ihrer Ausprägung deutlich geringer. Die Anpassung an die Echtdaten ist also auch dann offensichtlich besser, wenn die Konzentrationsvariablen in einem "geschlossenen" HuFF-Modell verwendet werden, wie es regelmäßig z.B. in Verträglichkeitsbeurteilungen zum Einsatz kommt.

\begin{tabular}{llc}
\hline Modell / Angebotstyp & & $\boldsymbol{\Sigma}\left(\boldsymbol{\varepsilon}^{2}\right)$ \\
\hline Lebensmittelmärkte & Modell 2 & $13.233,89$ \\
(1.098 Einkäufe) & Modell 4 & $11.553,88$ \\
& Modell 2 & $27.387,32$ \\
Elektronikmärkte & Modell 4 & $3.527,86$ \\
Baumärkte & Modell 2 & $4.891,71$ \\
(909 Einkäufe) & Modell 4 & 201,09 \\
\hline
\end{tabular}

Tabelle 32: Modellvergleich - Summe der quadrierten Abweichungen

Quelle: Eigene Darstellung

Die Anpassungsgüte auf der Ebene der einzelnen Anbieter wird in den Grafiken 16 bis 18 dokumentiert; hier sind jeweils die empirisch ermittelten und die modellierten Einkäufe beider Modellvarianten abgebildet ${ }^{47}$. Am wenigsten eindeutig ist die Gegenüberstellung der Marktgebietsmodelle für die Lebensmittelmärkte: Zwar liegen die geschätzten Kundenströme aus Modell 4 mehrheitlich näher an den empirisch ermittelten Einkäufen als die von Modell 2, jedoch ergeben sich in einzelnen Fällen noch gravierende Abweichungen; insbesondere die Einkäufe beim größten aller berücksichtigten Anbieter (Kaufland, Holzminden-Kernstadt) werden gegenüber den empirischen Werten stark unterschätzt. Systematisch überschätzt werden die Verkaufsstellen bestimmter Unternehmen bzw. Vertriebslinien (Netto, NP), was darauf hinweist, dass hier ggf. zusätzliche Erklärungsgrößen sinnvoll sein könnten (z.B. die Vertriebslinien), die (indirekt) die Anbieterpräferenzen abbilden und das Modell auf diese Weise korrigieren. Auffällig ist, dass Modell 2 insbesondere die Einkäufe bei den Anbietern unterschätzt, die sich in Standortkooperationen bzw. in unmittelbarer Nähe zu branchengleichen Anbietern befinden (z.B. Aldi Hol.-Kernstadt 1, Edeka Hol.-Kernstadt, Aldi, Hx.-Kernstadt 1); auch dies zeigt die Sinnhaftigkeit der Berücksichtigung der Konzentrationsgrößen. Insgesamt wird die Abbildungsqualität des Marktgebietsmodells

\footnotetext{
${ }^{47}$ Diese Form der Gegenüberstellung ist der Arbeit von LADEMANN (2007) nachempfunden, der auf diese Weise die Ergebnisse zweier Modelltypen (HuFF-Modell, diskretes Entscheidungsmodell) mit Echtdaten vergleicht.
} 
hierdurch also deutlich verbessert, obwohl noch mitunter starke Abweichungen festzustellen sind.

Grundlegend anders stellen sich die Modellvergleiche bei den Elektronik- und Baumärkten dar; wie bereits die Bestimmtheitsmaße der Regressionsmodelle angedeutet haben, ist die Anpassung an die Echtdaten hier deutlich besser. Im Fall der Elektronikmärkte (Abb. 17) wird bei Modell 4 (mit Konzentrationsvariablen) stets eine eindeutig bessere Anpassung an die tatsächlichen Einkäufe erreicht als durch Modell 2; abgesehen von einem Anbieter weichen die modellierten Einkäufe des finalen Modells nur wenig von den tatsächlichen ab. Auch hier zeigt sich in Modell 2 eine Überschätzung von großen (Media Markt HolzmindenKernstadt) und/oder eher isolierten Anbietern (Euronics Beverungen), was auf die Überbetonung der Eigenattraktivität und der räumlichen Konkurrenzsituation bzw. der NichtBerücksichtigung von Agglomerationsvorteilen zurückzuführen ist. In Modell 4 werden die modellierten Einkäufe bei diesen Anbietern hingegen deutlich herunter- und die der ExpertMärkte heraufkorrigiert. In ähnlicher Weise bietet das vollständige Modell auch bei den Baumärkten (Abb. 18) eine deutlich bessere Anpassung an die Echtwerte der Einkäufe.

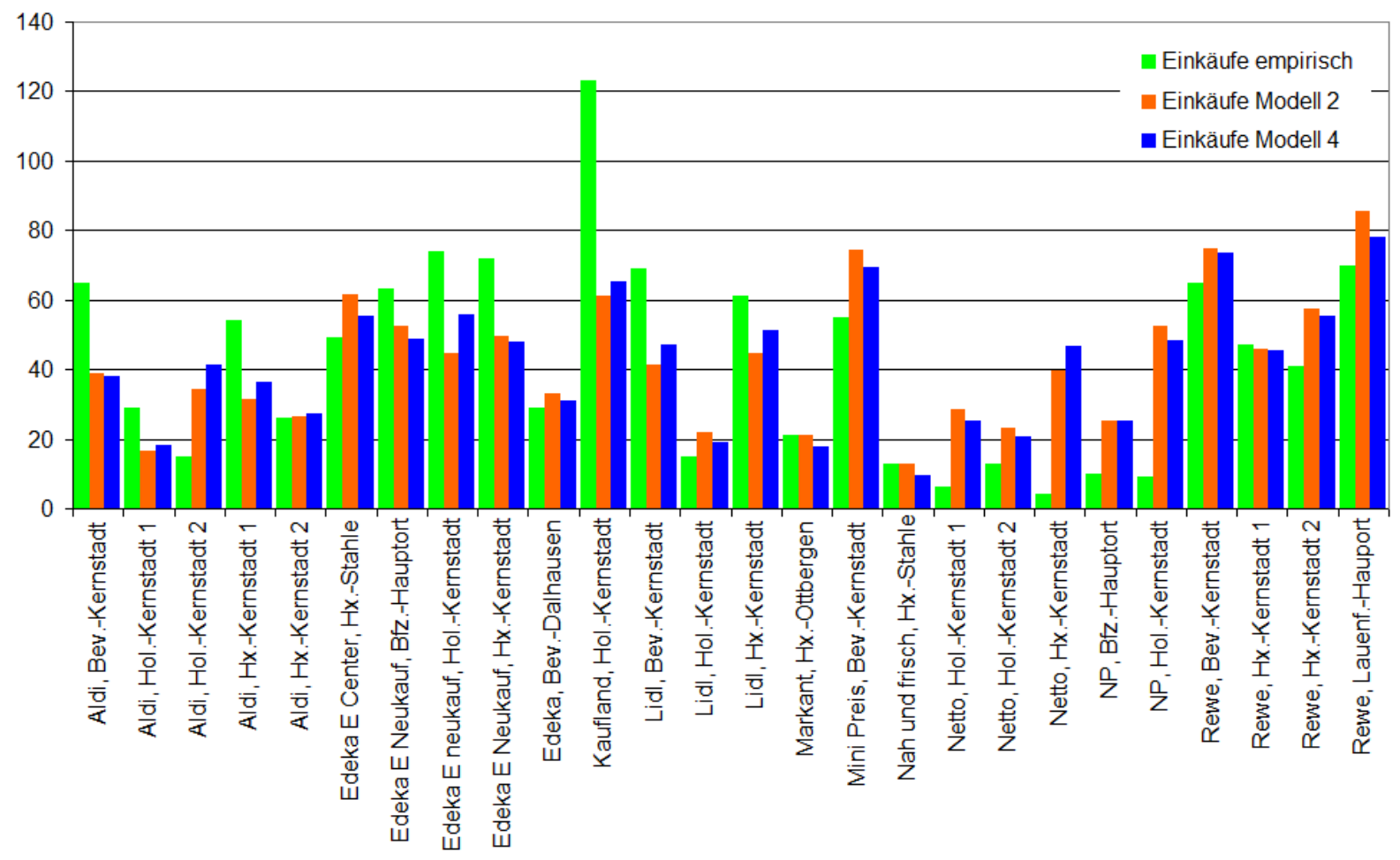

Abbildung 16: Modellvergleich - Lebensmittelmärkte Quelle: Eigene Darstellung 


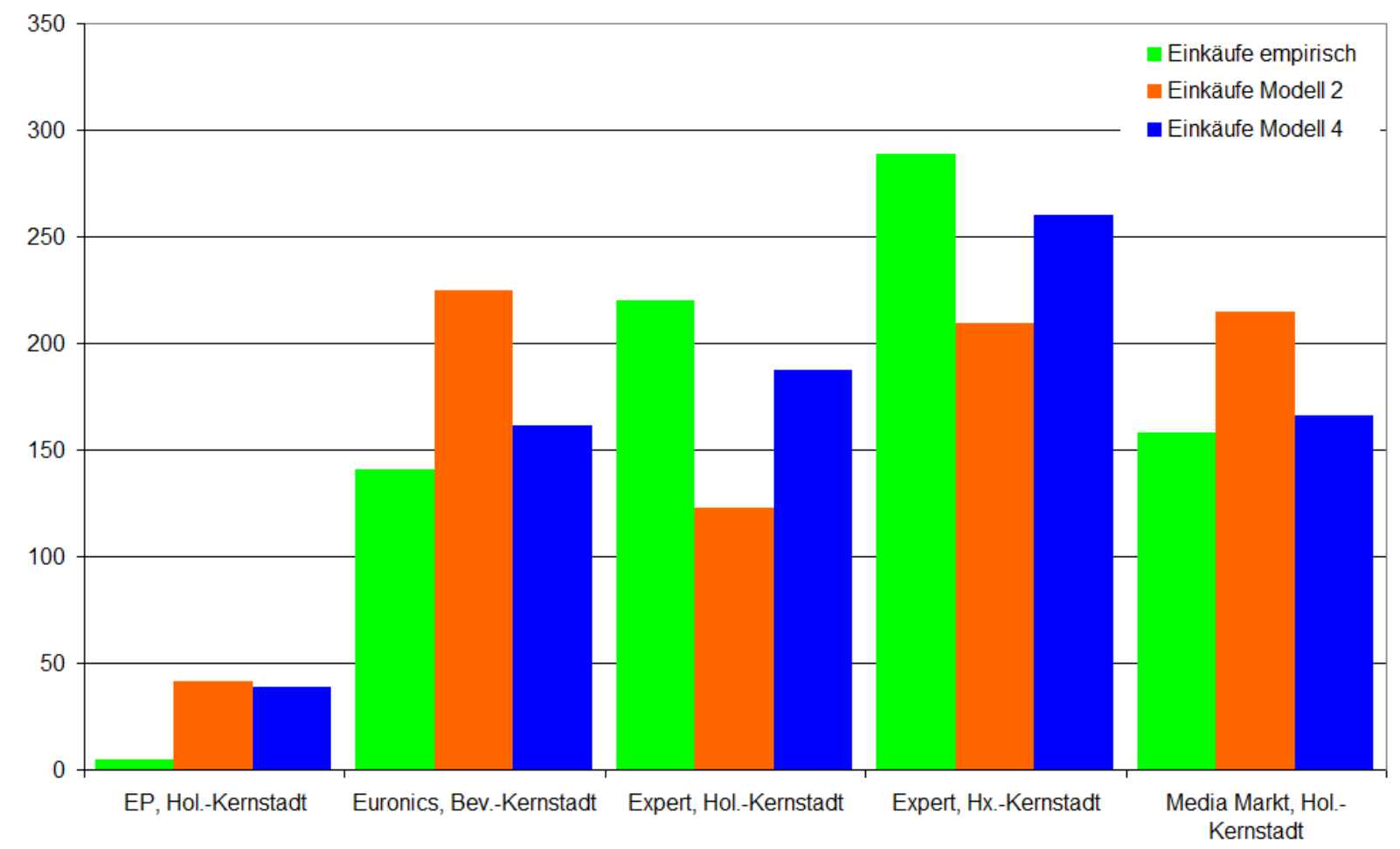

Abbildung 17: Modellvergleich - Elektronikmärkte

Quelle: Eigene Darstellung

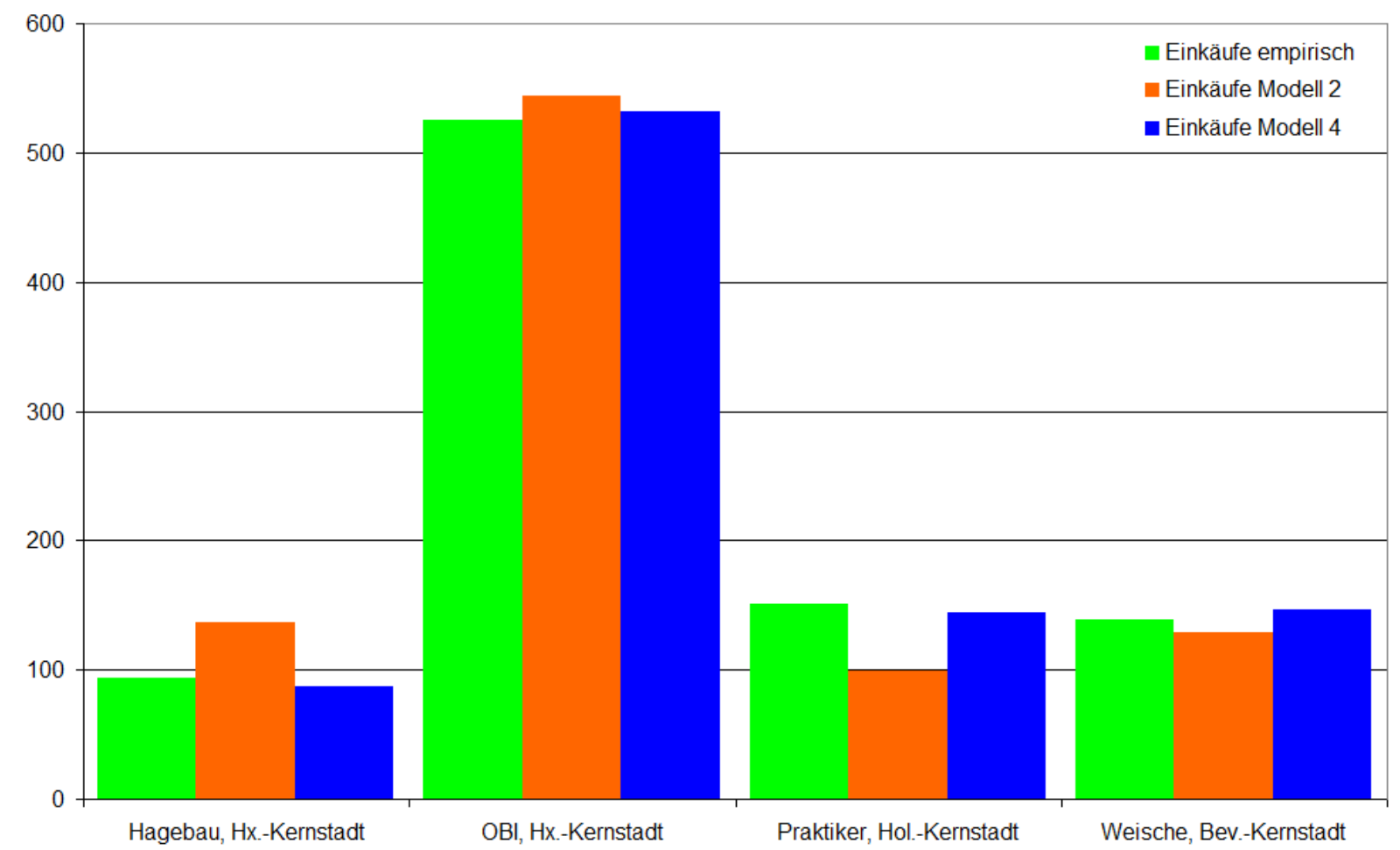

Abbildung 18: Modellvergleich - Bau- und Heimwerkermärkte

Quelle: Eigene Darstellung

Es existiert keine eindeutig definierte Grenze, mit der ein bezüglich des Erklärungsgehaltes "gutes“ von einem „schlechten“ Marktgebietsmodell zu unterscheiden ist. Offensichtlich werden die empirisch ermittelten Einkäufe bei den Elektronik- und Baumärkten durch ein mit 
Konzentrationsvariablen erweitertes HuFF-Modell im vorliegenden Fall recht gut geschätzt; das Marktgebietsmodell für die Lebensmittelmärkte produziert hingegen - trotz deutlich besserer Anpassung und der richtigen Tendenz - mitunter recht hohe Abweichungen. Insgesamt konnte jedoch der Beweis erbracht werden, dass die Berücksichtigung von Agglomerationsvariablen die Aussagekraft aller Modelle erkennbar verbessert. Um die Abbildungsqualität zu optimieren, wären weitere Anpassungsverfahren denkbar (z.B. GÜSSEFELDT 2002), die jedoch an dieser Stelle nicht weiter verfolgt werden; stattdessen werden im nächsten Schritt inhaltliche Erweiterungen des Modells für die Marktgebiete der Lebensmittelmärkte vorgenommen, die zugleich eine weitere Prüfung des Modells darstellen.

\subsubsection{Modellerweiterungen am Beispiel der Lebensmittelmärkte}

Sowohl in der $\mathrm{MCl}$-Analyse als auch in der Übertragung ins HuFF-Modell ist festgestellt worden, dass die Anpassungsqualität des Modells für die Marktgebiete der LM-Märkte noch ausbaufähig ist. Damit verbunden stellt sich die Frage, ob es ggf. bessere Spezifikationen des Modells gibt, d.h. solche, die mit (zusätzlichen oder ausgetauschten) Erklärungsgrößen eine bessere Modellanpassung ermöglichen. In Anlehnung an die Modell-Benchmarkingtests von GIJSBRECHTS et al. (2008) und VROEGRIJK et al. (2013) wurden daher verschiedene Alternativspezifikationen des genannten Modells formuliert und nach dem Schema des $\mathrm{MCl}$ Modells mittels multipler Regressionsanalyse geschätzt (siehe Kap. 5.3.2). Hierzu wurden folgende zusätzliche Erklärungsgrößen gebildet und in unterschiedlichen Kombinationen in das Modell aufgenommen:

- Ergänzend zu den bisher genutzten Größen zur Operationalisierung des Potenzials für Kopplungs- und Vergleichskäufe wurden nach derselben Berechnungsformel (siehe Kap. 5.3.1.4) zwei weitere Agglomerationsvariablen gebildet, die der Konkretisierung des horizontalen Kopplungspotenzials dienen: Die Variable $K_{A p o} j$ drückt die räumliche Ballung der Lebensmittelmärkte in Bezug auf Apotheken aus, wobei insgesamt 25 Apotheken im Untersuchungsgebiet lokalisiert sind. Analog wird über die Variable $K_{\text {Drog } j}$ die Ballung mit Drogeriemärkten abgebildet, von denen zum Untersuchungszeitpunkt 13 Verkaufsstellen existierten (Rossmann, Schlecker und Ihr Platz $\left.{ }^{48}\right)$. Die Apotheken sind nur in Ausnahmefällen an denselben Angebotsstandorten lokalisiert wie die Lebensmittelmärkte; gemeinsame Angebotsstandorte von LM-Märkten und Drogeriemärkten sind nicht vorzufinden.

- Für alle Unternehmen bzw. deren Vertriebslinien, die mehrere Verkaufsstellen im Untersuchungsgebiet unterhalten, wurden Dummy-Variablen erstellt. Diese sind in konventionellen Regressionsmodellen benutzbar mit dem Ziel, "qualitative“ bzw. nicht-metrische Informationen in einem binären Schema $(1=$ Zustand trifft zu, $0=$ Zustand trifft nicht zu) darzustellen. Die einzelnen Variablen (z.B. $A L D I=1$ bzw. 0 , $R E W E=1$ bzw. 0) geben damit die Zugehörigkeit der jeweiligen Anbieter zu einem Unternehmen bzw. einer Vertriebslinie wieder; diese Größen spiegeln also indirekt

\footnotetext{
${ }^{48}$ Im Zusammenhang der Unternehmensinsolvenz des Schlecker-Konzerns im Jahr 2012 wurden alle im Untersuchungsgebiet befindlichen Schlecker- sowie die dem Unternehmen zugehörigen Ihr Platz-Filialen (sechs bzw. drei Verkaufsstellen mit ca. 1.590 bzw. 1.005 qm Verkaufsfläche) geschlossen. Die Schließung erfolgte im April/Mai 2012 und somit kurz nach der Fertigstellung der finalen Angebotserhebung; daher sind diese Verkaufsstellen hier noch berücksichtigt worden.
} 
alle mit der jeweiligen Handelskette bzw. dem jeweiligen Markennamen verbundenen Attribute wieder (z.B. Image, Preisniveau) und sollen dazu beitragen, qualitative Informationen im Modell zu berücksichtigen und hierdurch die Anpassungsgüte zu steigern. Dies ist insbesondere vor dem Hintergrund sinnvoll, dass die Abweichungen des Modells sehr anbieterspezifisch sind (z.B. Netto; siehe Kap. 7.2.2)

- Weiterhin wurde das Preisniveau der Vertriebslinien $\left(P l_{j}\right)$ in mehreren Modellvarianten geprüft, gemessen als Summe der Einzelpreise eines standardisierten Warenkorbs der jeweils billigsten Variante eines Produktes (Messeinheit: €). Dieser Preisindex wurde nicht selbst berechnet, sondern aus einer externen Datengrundlage beschafft $(D I S Q 2012)^{49}$. Vom Preisniveau ist - unter Berücksichtigung der anderen Teilnutzen (z.B. Angebotsgröße) - von einem negativen Effekt auf die lokalen Marktanteile bzw. Einkaufsentscheidungen auszugehen (nachgewiesen von z.B. LADEMANN 2007)

Unter Berücksichtigung dieser weiteren erklärenden Variablen wurden vier Modellvarianten mit unterschiedlichen Kombinationen der Variablen gebildet. Tabelle 33 zeigt die Schätzergebnisse der Regressionsanalyse für diese Modelle unterschiedlicher Spezifikation. Die Schätzung erfolgte entsprechend dem vorherigen Vorgehen (siehe Kap. 5.3.2). Auf eine Darstellung einiger Modellgütestatistiken und -vergleiche wurde hier aus Gründen der Übersichtlichkeit verzichtet. Alle Modelle wurden mit der HC1-Schätzung gebildet, wobei sich auch hier gegenüber den konventionellen Schätzungen keine Unterschiede in der Signifikanzprüfung der erklärenden Variablen zeigten. Angegeben sind die standardisierten Regressionskoeffizienten (außer bei den Dummy-Variablen) sowie die VIF-Werte und - als Kriterium der Modellaussagekraft - das unkorrigierte und korrigierte Bestimmtheitsmaß $R^{2}$.

\footnotetext{
${ }^{49}$ Das Deutsche Institut für Servicequalität (DISQ) führt jährlich einen Vergleich der größeren Vertriebslinien im Lebensmitteleinzelhandel durch. Hierzu gehört auch eine Preisanalyse, bei der von 27 Produkten des täglichen Bedarfs die jeweils günstigste Variante gekauft und die Preise aller Artikel zu einem standardisierten Warenkorb addiert werden. Die zum Zeitpunkt der Untersuchung aktuellste Preisanalyse stammt aus dem Mai 2012; hierbei variierten die standardisierten Warenkörbe zwischen 25,64 € (Aldi Nord) und 27,57 € (Edeka) (DISQ 2012).
} 
Räumliches Einkaufsverhalten und Standortpolitik im Einzelhandel unter Berücksichtigung von Agglomerationseffekten

\begin{tabular}{|c|c|c|c|c|c|}
\hline \multirow{2}{*}{ Prädiktoren } & & \multicolumn{4}{|c|}{ Modell } \\
\hline & & Variante 1 & Variante 2 & Variante 3 & Variante 4 \\
\hline \multirow{4}{*}{$\log \left(d_{i j} / G M d_{i}\right)$} & $b$ & $-1,740$ & $-1,780$ & $-1,694$ & $-1,775$ \\
\hline & $\beta$ & $-0,778$ & $-0,796$ & $-0,757$ & $-0,793$ \\
\hline & $p$ & $* * *$ & $* * *$ & $* * *$ & $* * *$ \\
\hline & VIF & 1,079 & 1,086 & 1,040 & 1,091 \\
\hline \multirow{4}{*}{$\log \left(A_{j} / G M A_{j}\right)$} & $b$ & 0,661 & 0,732 & 0,565 & 0,739 \\
\hline & $\beta$ & 0,331 & 0,367 & 0,283 & 0,370 \\
\hline & Sig. & $* * *$ & $\star * *$ & $* * *$ & $* * *$ \\
\hline & VIF & 1,605 & 1,405 & 1,057 & 2,201 \\
\hline \multirow{4}{*}{$\log \left(K_{k_{j}} / G M K_{k j}\right)$} & $b$ & 0,056 & 0,046 & -- & 0,065 \\
\hline & $\beta$ & 0,119 & 0,098 & -- & 0,138 \\
\hline & Sig. & ** & * & -- & * \\
\hline & VIF & 1,256 & 2,206 & -- & 3,137 \\
\hline \multirow{4}{*}{$\log \left(K_{A j} / G M K_{A j}\right)$} & $b$ & -- & $-0,115$ & -- & $-0,160$ \\
\hline & $\beta$ & -- & $-0,134$ & -- & $-0,186$ \\
\hline & Sig. & -- & ** & -- & ** \\
\hline & VIF & -- & 2,066 & -- & 3,331 \\
\hline \multirow{4}{*}{$\begin{array}{c}\log \left(K_{\text {Apo j } /} /\right. \\
\left.\text { GM K } K_{\text {Apo j }}\right)\end{array}$} & $b$ & $-0,040$ & -- & -- & $-0,034$ \\
\hline & $\beta$ & $-0,066$ & -- & -- & $-0,056$ \\
\hline & Sig. & $x$ & -- & -- & $x$ \\
\hline & VIF & 5,068 & -- & -- & 6,428 \\
\hline \multirow{4}{*}{$\begin{array}{l}\log \left(K_{\text {Drog j } /}\right. \\
\left.\text { GM K } K_{\text {Drog }}\right)\end{array}$} & $b$ & $-0,010$ & -- & -- & 0,057 \\
\hline & $\beta$ & $-0,018$ & -- & -- & 0,106 \\
\hline & Sig. & $\mathrm{x}$ & -- & -- & $\mathrm{x}$ \\
\hline & VIF & 4,057 & -- & -- & 5,730 \\
\hline \multirow{4}{*}{$\log \left(\mathrm{Pl}_{\mathrm{j}} / \mathrm{GM} \mathrm{P \textrm {I } _ { \mathrm { j } }}\right)$} & $b$ & $-2,972$ & -- & $-2,871$ & -- \\
\hline & $\beta$ & $-0,073$ & -- & $-0,071$ & -- \\
\hline & Sig. & + & -- & + & -- \\
\hline & VIF & 1,145 & -- & 1,019 & -- \\
\hline \multirow{3}{*}{ Aldi (Dummy) } & $\mathrm{b}$ & -- & 0,163 & -- & 0,158 \\
\hline & Sig. & -- & $* * *$ & -- & $* * *$ \\
\hline & VIF & -- & 1,328 & -- & 4,125 \\
\hline \multirow{3}{*}{ Lidl (Dummy) } & $b$ & -- & 0,077 & -- & 0,061 \\
\hline & Sig. & -- & $x$ & -- & $x$ \\
\hline & VIF & -- & 1,062 & -- & 2,572 \\
\hline \multirow{3}{*}{ Rewe (Dummy) } & $\mathrm{b}$ & -- & $-0,093$ & -- & $-0,083$ \\
\hline & Sig. & -- & * & -- & * \\
\hline & VIF & -- & 1,172 & -- & 2,787 \\
\hline
\end{tabular}




\begin{tabular}{|c|c|c|c|c|c|}
\hline \multirow{2}{*}{$\begin{array}{l}\text { Prädiktoren } \\
\text { (Fortsetzung) }\end{array}$} & & \multicolumn{4}{|c|}{ Modell (Fortsetzung) } \\
\hline & & Variante 1 & Variante 2 & Variante 3 & Variante 4 \\
\hline & $b$ & -- & 0,059 & -- & 0,081 \\
\hline \multirow[t]{3}{*}{ Edeka (Dummy) } & Sig. & -- & + & -- & + \\
\hline & VIF & -- & 1,069 & -- & 4,224 \\
\hline & $b$ & -- & $-0,276$ & -- & $-0,299$ \\
\hline \multirow[t]{3}{*}{ NP (Dummy) } & Sig. & -- & $* * *$ & -- & $* * *$ \\
\hline & VIF & -- & 1,042 & -- & 1,636 \\
\hline & $b$ & -- & $-0,220$ & -- & $-0,229$ \\
\hline \multirow[t]{2}{*}{ Netto (Dummy) } & Sig. & -- & $* * *$ & -- & $* * *$ \\
\hline & VIF & -- & 1,074 & -- & 2,455 \\
\hline \multicolumn{6}{|l|}{ Modellgüte } \\
\hline $\mathrm{R}^{2}$ & & 0,598 & 0,666 & 0,583 & 0,669 \\
\hline \multirow[t]{2}{*}{ Korr. $\mathrm{R}^{2}$} & & 0,590 & 0,655 & 0,580 & 0,655 \\
\hline & & \multicolumn{4}{|c|}{$\begin{array}{r}\text { GM = Geometrischer Mittelwert } \\
--=\text { nicht im Modell berücksichtigt }\end{array}$} \\
\hline
\end{tabular}

Tabelle 33: MCI-Modell Lebensmittelmärkte - Alternative Spezifikationen

Quelle: Eigene Darstellung

Im ersten Modell (Variante 1) wurde die allgemeine Konzentrationsvariable ausgespart und stattdessen die spezifischen Größen für Apotheken und Drogeriemärkte eingesetzt; zusätzlich wurde das DISQ-Preisniveau im Modell berücksichtigt. Die Angebotsgröße $\left(A_{j}\right)$, die Fahrtzeit $\left(d_{i j}\right)$ sowie die konkurrentenbezogene Konzentrationsvariable $\left(K_{K j}\right)$ entfalten einen ähnlichen Einfluss wie im Ausgangsmodell (siehe Kap. 6.3.1.1). Wie zu erwarten, hat das Preisniveau der Kette unter ansonsten gleichen Bedingungen einen negativen Effekt auf die lokalen Marktanteile; obwohl der Gesamteinfluss im Modell gering ist, wirken sich nur geringe Preisänderungen stark auf den Kundenzufluss aus, was der deutlich über-linear negative Effekt ( $b=-2,972)$ anzeigt. Die räumliche Nähe zu Apotheken und Drogeriemärkten hat keinen signifikanten Einfluss auf den Kundenzufluss aus dem Marktgebiet; zudem wird im Hinblick auf mögliche Kollinearitätseffekte der kritische Wert von VIF $=5$ bei der Apotheken-Variable leicht überschritten. Die Varianzaufklärung dieses Modells $\left(R_{2}=0,598\right.$ bzw. Korr. $R_{2}=0,590$ ) ist nicht höher bzw. besser als im ursprünglichen Modell.

In der zweiten Variante wurde das ursprünglich geschätzte Modell durch die DummyVariablen, die indirekt die Eigenschaften der jeweiligen Kette (u.a. Image) widerspiegeln, angereichert; auf die Preis-Variable wird hierbei verzichtet, da das Preisniveau der Anbieter bereits durch die Dummy-Variablen abgedeckt wird. Im Vergleich zum Ausgangsmodell $\left(R^{2}=\right.$ 0,596 bzw. Korr. $R^{2}=0,591$; siehe Kap. 6.3.1.1) wird durch die Berücksichtigung der Vertriebslinie bzw. des Unternehmens eine Erhöhung der Varianzaufklärung um sieben Prozentpunkte erreicht $\left(R^{2}=0,666\right.$ bzw. Korr. $\left.R^{2}=0,655\right)$. Die meisten der DummyVariablen haben einen signifikanten Effekt auf die lokalen Marktanteile; beispielsweise wirkt die Zugehörigkeit zu Aldi positiv, während Netto und NP negative Einflüsse induzieren. Dies 
entspricht den Feststellungen in der Modellüberprüfung, wonach das Modell ohne Berücksichtigung der Vertriebslinie genau jene Einkäufe unterschätzt $(A / d i)$ bzw. überschätzt (Netto und NP) (siehe Kap. 7.2.2). Dieses Ergebnis lässt sich als Spiegel der lokalen Kundenpräferenzen für bestimmte Ketten interpretieren; demnach ist insbesondere Aldi beliebt, während es Netto und NP im Auge der Konsumenten offensichtlich an Attraktivität mangelt. Die Wirkung der beiden Agglomerationsvariablen entspricht im Wesentlichen derjenigen im Ausgangsmodell, d.h. auch eine direkte Berücksichtigung der Vertriebslinien überlagert diesen Effekt nicht.

In der dritten Modellvariante wird vollständig auf Agglomerationsvariablen verzichtet und neben den aus dem HuFF-Modell stammenden Größen (Angebotsgröße, Fahrtzeit) nur noch das Preisniveau berücksichtigt; dessen negative Wirkung entspricht in ihrer Größenordnung der in Variante 1. Die Varianzaufklärung des Modells $\left(R_{2}=0,583\right.$ bzw. korr. $\left.R_{2}=0,580\right)$ ist jedoch geringer als im ursprünglichen Modell, in das die Konzentrationsgrößen eingeflossen sind. Auch zeigt sich, dass die Effekte der Eigenattraktivität bzw. der Transportkosten geringer ausgeprägt sind als in den Modellen mit Konzentrationsvariablen, was Gegenstand einer der zu Grunde gelegten Hypothesen $\left(\mathrm{H}_{5}\right)$ gewesen ist; diese Auswirkungen sind stärker, wenn (positive) Agglomerationseffekte im Modell berücksichtigt werden. An dieser Modellvariante zeigt sich besonders deutlich, dass die Integration der räumlichen Ballung in Form der beiden hier genutzten Variablen ein wichtiges Element der Marktgebietsmodelle darstellt, das sich nicht ersetzen lässt.

Modellvariante 4 beinhaltet alle zur Verfügung stehenden erklärenden Variablen abgesehen vom Preisniveau, da dieses in Anbetracht der berücksichtigten Dummy-Variablen für die zugehörige Kette redundant ist. Im Gegensatz zu Variante 2 werden hier noch die Agglomerationsvariablen für Apotheken und Drogeriemärkte integriert, die jedoch wieder keine statistisch signifikanten Effekte entfalten. Das unkorrigierte Bestimmtheitsmaß ist nur geringfügig höher als in Variante $2\left(R^{2}=0,669\right)$, während sich der um die Anzahl der aufgenommenen Variablen korrigierte Indikator nicht verändert (Korr. $R^{2}=0,655$ ); die Aufnahme weiterer Erklärungsgrößen leistet also offensichtlich keinen nennenswerten Beitrag zur Varianzaufklärung. Dass die Berücksichtigung aller Variablen den Erklärungsgehalt des Modells nicht verbessert, zeigt außerdem die Kollinearitätsdiagnose: Die VIF-Werte sind durchgängig höher als in den anderen Modellen, wobei der kritische Wert von VIF = 5 in zwei Fällen überschritten wird; Verzerrungen aufgrund von Multikollinearität sind also nicht unwahrscheinlich. An dieser Modellvariante zeigt sich, dass die Qualität bzw. Aussagekraft solcher Modelle nicht notwendigerweise mit ihrer Komplexität bzw. mit der Zahl berücksichtigter Erklärungsgrößen steigt.

Insgesamt offenbaren die hier durchgeführten Modellvergleiche, in denen verschiedene alternative Spezifikationen gegenübergestellt wurden, dass die Aussagekraft der hier gebildeten Modelle durch die Berücksichtigung weiterer Informationen verbessert werden kann. Insbesondere die Integration der Anbieterzugehörigkeit zu Unternehmen bzw. Vertriebslinien erhöht die Varianzaufklärung des MCl-Modells für die Marktgebiete der Lebensmittelmärkte deutlich; allerdings sind mit steigendem Umfang der Modelle zumindest mit den hier verfügbaren Erklärungsgrößen - keine reellen Verbesserungen mehr zu erreichen. Viel wichtiger ist jedoch die Feststellung, dass in keinem Fall die Einbindung zusätzlicher Erklärungsgrößen die Aussage der Agglomerationsvariablen reduziert oder gar negiert; es zeigt sich deutlich, dass die bereits festgestellten Effekte der räumlichen Ballung 
auf die Marktgebiete auch unter Berücksichtigung weiterer Informationen bestehen bleiben und sich keine Modellvariante finden lässt, in der ohne die Agglomerationsvariablen ein aussagekräftigeres Modell gebildet werden könnte. Als vorteilhaft stellt sich insbesondere Modellvariante 2 heraus, in der sowohl Agglomerationseffekte als auch die Vertriebslinien (Dummy-Variablen) berücksichtigt werden.

\subsubsection{Marktsimulation am Beispiel der Lebensmittelmärkte}

\subsubsection{Das Simulationsmodell}

In diesem Schritt wird eines der empirisch parametrisierten Marktgebietsmodelle in zwei Simulationsrechnungen verwendet; die Anwendung entspricht der Nutzung eines (bezüglich der Modellfunktion deterministischen) HufF-Modells (siehe Kap. 7.2.2), wird hier jedoch zum Zweck der Prognose unter der Annahme zukünftig veränderter Voraussetzungen im betrachteten räumlichen Markt genutzt. Hierbei werden einzelne nachfrage- und/oder angebotsseitige Rahmenbedingungen modifiziert und mit Hilfe der Modelle aufgezeigt, wie sich daraufhin die Kundenströme bzw. Marktgebiete der Einzelhandelsbetriebe unter ansonsten gleich bleibenden Konditionen verändern. Diese Anwendung entspricht prinzipiell der in Gutachten zur Beurteilung der Ansiedlungsverträglichkeit von Einzelhandelsbetrieben, wie sie im Kontext der raumordnerischen und städtebaulichen Beurteilung solcher Vorhaben in bestimmten Fällen durchgeführt werden muss; in diesen Fällen wird ex ante geprüft, welche Kaufkraftumlenkungen durch den Markteintritt des neuen Anbieters induziert werden (WOLF 2012, S. 117ff.). Jedoch sind auch andere Modifikationen der Rahmenbedingungen möglich, die auf die Nachfrageseite (z.B. Fahrtzeiten aufgrund neuer Straßen) oder die Angebotsseite (z.B. Standortkonfiguration der bestehenden Anbieter) abzielen.

In der Untersuchung von VROEGRIJK et al. (2013) werden die Auswirkungen von DiscounterNeuansiedlungen bei veränderten (kontrafaktischen) Standortbedingungen geprüft. FITTKAU (2004) nutzt ein durch empirische Daten kalibriertes HuFF-Modell zur Abschätzung der Veränderung von Marktgebieten unter neuen Verkehrsbedingungen (veränderte Fahrtzeiten aufgrund des Ausbaus einer Autobahn). In jedem Fall zielt eine solche Modellprognose darauf ab, vorher empirisch festgestellte Zusammenhänge, die in ein mathematisches Modell gefasst wurden, auf eine neue Ausgangssituation zu übertragen. Im vorliegenden Fall zielt die Modellprognose auf Veränderungen der Angebotsseite im Lebensmitteleinzelhandel des Untersuchungsgebietes, nämlich den Markteintritt von zwei neuen Anbietern (Szenario 1) und die räumliche Verlagerung zweier bereits bestehender Anbieter (Szenario 2).

Hierzu wird diejenige empirisch parametrisierte Modellfunktion genutzt, deren Aussagekraft (d.h. Varianzaufklärung) in der Modellerweiterung (Kap. 7.2.3) am größten und zugleich die statistische Absicherung am höchsten war. Aufgrund eines Bestimmtheitsmaßes von $R^{2}=$ 0,666 (bzw. 0,655 in korrigierter Form) bei gleichzeitig durchgängig unproblematischen VIFWerten kann die Wahl demnach nur auf die zweite Modellvariante fallen. Dieses Modell beinhaltet neben den schon vorher mehrfach geprüften metrischen Größen (Verkaufsfläche, Fahrtzeit, Konzentrationsvariablen $K_{A j}$ und $K_{K j}$ ) auch Dummy-Variablen für die Vertriebslinien, weshalb eine andere Umwandlung in ein HuFF-Modell als im Fall der Modellvergleiche (Kap. 7.2.2) notwendig ist. Da Dummy-Variablen die Werte 1 (trifft zu) und 0 (trifft nicht zu) annehmen, werden im letzten Fall zwangsweise einzelne Variablenausprägungen der Gleichung gleich null sein (z.B. bei allen Märkten, die nicht zu Aldi gehören: 0,163 * $0=0$ ); in 
einer multiplikativen (Nutzen-)Funktion würde dies dazu führen, dass der gesamte Nutzenterm gleich null wäre $\left(a{ }^{*} b^{*} c^{*} 0=0\right)$, was die Logik der gesamten Berechnung unterminiert. Daher ist es hier notwendig, die zweite von NAKANISHI/COOPER (1982) bzw. HUfF/MCCALLUM (2008) vorgeschlagene Transformation zu nutzen, bei der das linearisierte Regressionsmodell (ohne Störterm) direkt weitergenutzt und als Exponent in eine natürliche Exponentialfunktion eingesetzt wird (siehe Kap. 3.3.1.1). Die Marktanteile berechnen sich dann aus einer transformierten Nutzenfunktion (siehe Formel 43), die alle statistisch signifikant wirkenden Erklärungsgrößen mit ihren Koeffizienten enthält (siehe Formel 44).

$$
\hat{p}_{i j}=\frac{e^{\hat{y}_{i j}}}{\sum_{j=1}^{n} e^{\hat{y}_{i j}}}
$$

$\hat{p}_{\mathrm{ij}}=$ Geschätzte(r) Interaktionswahrscheinlichkeiten/Marktanteil der Alternative j für den Entscheidungsträger i

$\mathrm{e}=$ Eulersche Zahl

$\hat{y_{i j}}=$ Transformierte Nutzenfunktion

$$
\begin{aligned}
& \hat{y}_{i j}=0,732 \log \left(\frac{A_{j}}{\tilde{A}_{j}}\right)-1,780 \log \left(\frac{d_{i j}}{\tilde{d}_{i}}\right)+0,046 \log \left(\frac{K_{K_{j}}}{\widetilde{K}_{K_{j}}}\right)-0,115 \log \left(\frac{K_{A_{j}}}{\widetilde{K}_{A_{j}}}\right) \\
& +0,163 \text { ALDI }-0,093 R E W E+0,059 E D E K A-0,276 N P-0,220 N E T T O
\end{aligned}
$$

$\mathrm{dij}_{\mathrm{j}}=$ Fahrtzeit von Nachfrageort i zu Anbieter $\mathrm{j}$

$A_{j}=$ Verkaufsfläche des Anbieters $j$

$\mathrm{K}_{\mathrm{Aj}}=$ Konzentrationsvariable für den Anbieter $\mathrm{j}$ für die Nähe zu anderen Einzelhandelsanbietern

$\mathrm{K}_{\mathrm{Kj}}=$ Konzentrationsvariable für den Anbieter $\mathrm{j}$ für die Nähe zu gleichartigen Einzelhandelsanbietern

$\tilde{p}_{i}=$ Geometrischer Mittelwert von allen $p_{i}$

$\tilde{\mathrm{d}}_{\mathrm{i}}=$ Geometrischer Mittelwert von allen $\mathrm{d}_{\mathrm{ij}}$

$\tilde{A}_{i}=$ Geometrischer Mittelwert von allen $A_{j}$

$\mathrm{K}_{\mathrm{Aj}}=$ Geometrischer Mittelwert von allen $\mathrm{K}_{\mathrm{Aj}}$

$\mathrm{K}_{\mathrm{Kj}}=$ Geometrischer Mittelwert von allen $\mathrm{K}_{\mathrm{K}_{\mathrm{j}}}$

ALDI, REWE, EDEKA, NP, NETTO = Dummy-Variablen für die jeweilige Kette (Ausprägungen: 1 bzw. 0)

Dieses Modell wird, entsprechend dem Vorgehen beim Modellvergleich (Kap. 7.2.2), im hier untersuchten Gebiet angewandt. Hierbei wird die Funktion zunächst zur modellhaften Abbildung der Ist-Situation und im nächsten Schritt zur Prognose der Kundenströme bzw. Marktgebiete unter veränderten Ausgangsbedingungen genutzt; danach werden die modellierten Kundenzuflüsse auf der Anbieterebene miteinander verglichen. Als lokales Nachfragepotenzial werden auch hier die empirisch ermittelten Einkäufe auf der Ebene der 19 Teilgebiete eingesetzt (insgesamt 1.098 registrierte Einkäufe bei Lebensmittelmärkten), wobei die Prüfung der Auswirkungen durch die Veränderung der Marktbedingungen darin liegt, zu modellieren, wie sich die tatsächlichen bisherigen Einkäufe neu verteilen; es wird also implizit davon ausgegangen, dass die neuen bzw. verlagerten Anbieter kein neues Kundenpotenzial (von inner- oder außerhalb des Untersuchungsgebietes) generieren, sondern dass sich deren Kundenströme ausschließlich aus Umverteilungen der bestehenden Betriebe ergeben. Die anbieterspezifischen Gesamteinkäufe vor und nach der Modifikation werden jeweils grafisch gegenübergestellt. 


\subsubsection{Szenario 1: Ansiedlung Kaufland (Höxter) und Rewe (Holzminden)}

Im ersten Szenario wird geprüft, welche Auswirkungen die Ansiedlung zweier neuer Märkte im Untersuchungsgebiet haben. Hierbei handelt es sich um einen Kaufland-Markt in der Kernstadt Höxters mit einer Verkaufsfläche von 4.135 qm und einen Rewe-Markt in der Kernstadt Holzmindens mit einer Verkaufsfläche von 1.450 qm$^{50}$ (siehe Karte 13); beide Märkte befanden sich zum Zeitpunkt der Untersuchung bereits in Planung, wurden jedoch erst mehrere Monate nach Abschluss der Erhebungs- und Analysephase eröffnet (Herbst 2012 bzw. Frühling 2013). Beide Ansiedlungen - insbesondere der Markt in Höxter - waren von mitunter intensiven kommunalpolitischen Diskussionen bis hin zu gerichtlichen Klagen gegen die Vorhaben begleitet (siehe Kap. 6.1.1.2).

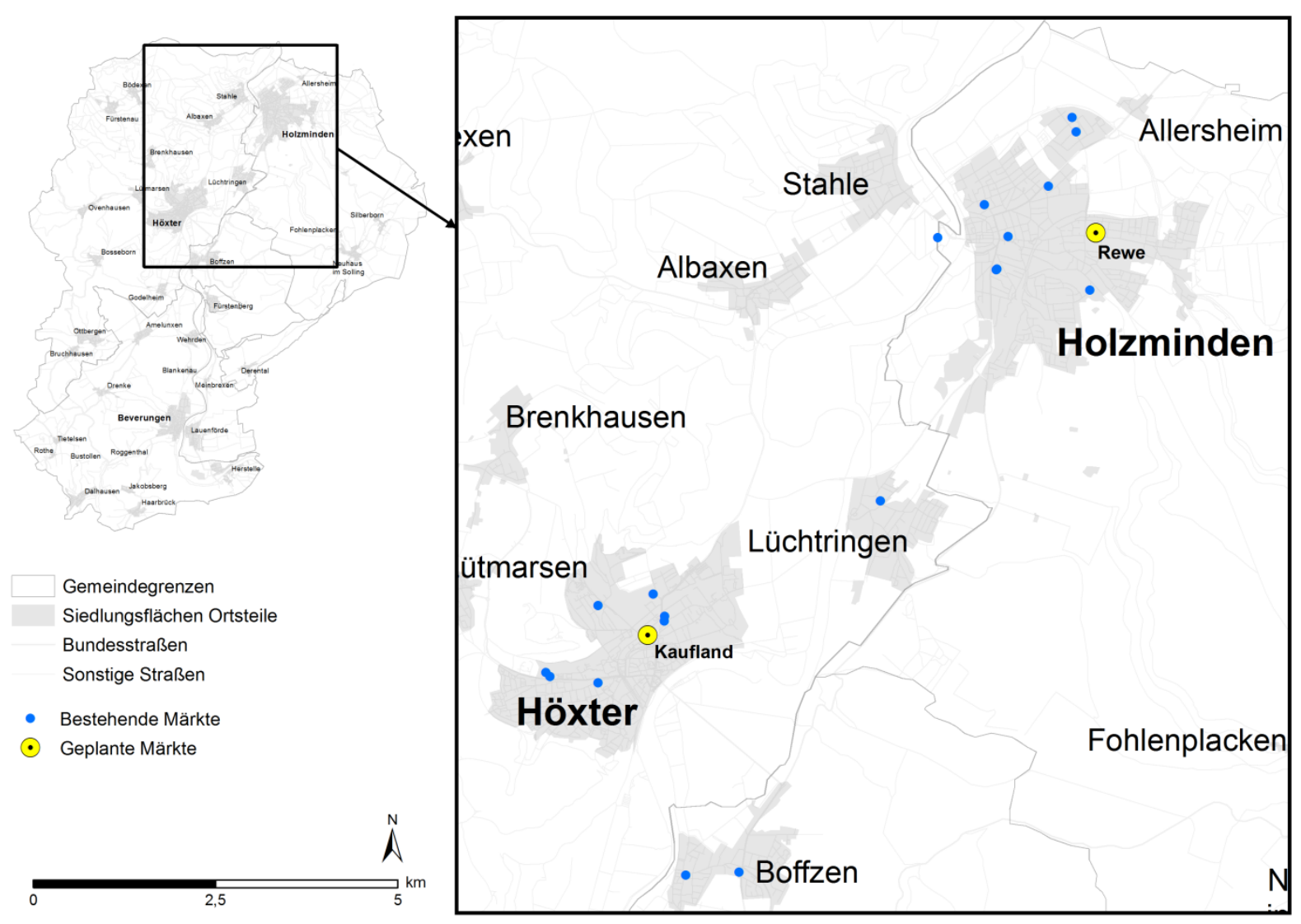

Karte 13: Marktsimulation Lebensmittelmärkte - Szenario 1

Quelle: Eigene Darstellung

Die Standorte der neuen Lebensmittelmärkte sind zwar unterschiedlich charakterisiert, sich aber sehr ähnlich hinsichtlich möglicher positiver Agglomerationseffekte: Der vorgesehene (und später realisierte) Standort des Rewe-Marktes ist eine Ausfallstraße im Nordosten des Stadtgebietes mit nur wenigen kleinen Einzelhandelsbetrieben (z.B. Bäckerei, Tankstelle) im näheren Umfeld; der nächstgelegene Lebensmittelmarkt (Gewerbegebiet Bülte) ist mehrere Kilometer entfernt (CIMA 2010, S. 6f. u. 10f.). Der Standort des neuen Kaufland-Marktes befindet sich in der Nähe zur Höxteraner Innenstadt (nördlich, ca. $250 \mathrm{~m}$ ), ist jedoch nicht unmittelbar in diese oder eine andere Agglomeration eingebettet; auch in der Nähe dieses

\footnotetext{
${ }^{50}$ Die Verkaufsflächengrößen wurden den jeweiligen Verträglichkeitsgutachten entnommen, die im Zuge des baurechtlichen Genehmigungsprozesses erstellt wurden (BULWIENGESA AG 2010, CIMA 2010).
} 
neuen Marktes befinden sich keine anderen Anbieter derselben Branche, da in der Innenstadt keine Lebensmittelmärkte lokalisiert sind (BULWIENGESA AG 2010, S. 15ff.). In beiden Fällen handelt es sich also nicht um Verkaufsstellen, die über ein ausgedehntes Potenzial für Kopplungs- und Vergleichskäufe verfügen; branchengleiche Anbieter - d.h. andere Lebensmittelmärkte - sind kilometerweit entfernt.

Für die beiden neuen Lebensmittelmärkte wurden die Konzentrationsvariablen sowie die Fahrtzeiten von den 19 Nachfrageorten berechnet und die vorliegende Interaktionsmatrix dahingehend erweitert; zudem musste auch für die bereits bestehenden Märkte die Konzentrationsvariable für die räumliche Nähe zu Mitbewerbern $\left(K_{K_{j}}\right)$ neu berechnet werden, da sich durch das Hinzukommen branchengleicher Anbieter auch deren „relativer Standort“ geringfügig ändert. Der Vergleich der Modellergebnisse - die Summe der modellierten Einkäufe aller Anbieter vor den Neuansiedlungen (dunkelblau) und nach den Ansiedlungen (hellblau) - wird in Abbildung 19 dargestellt.

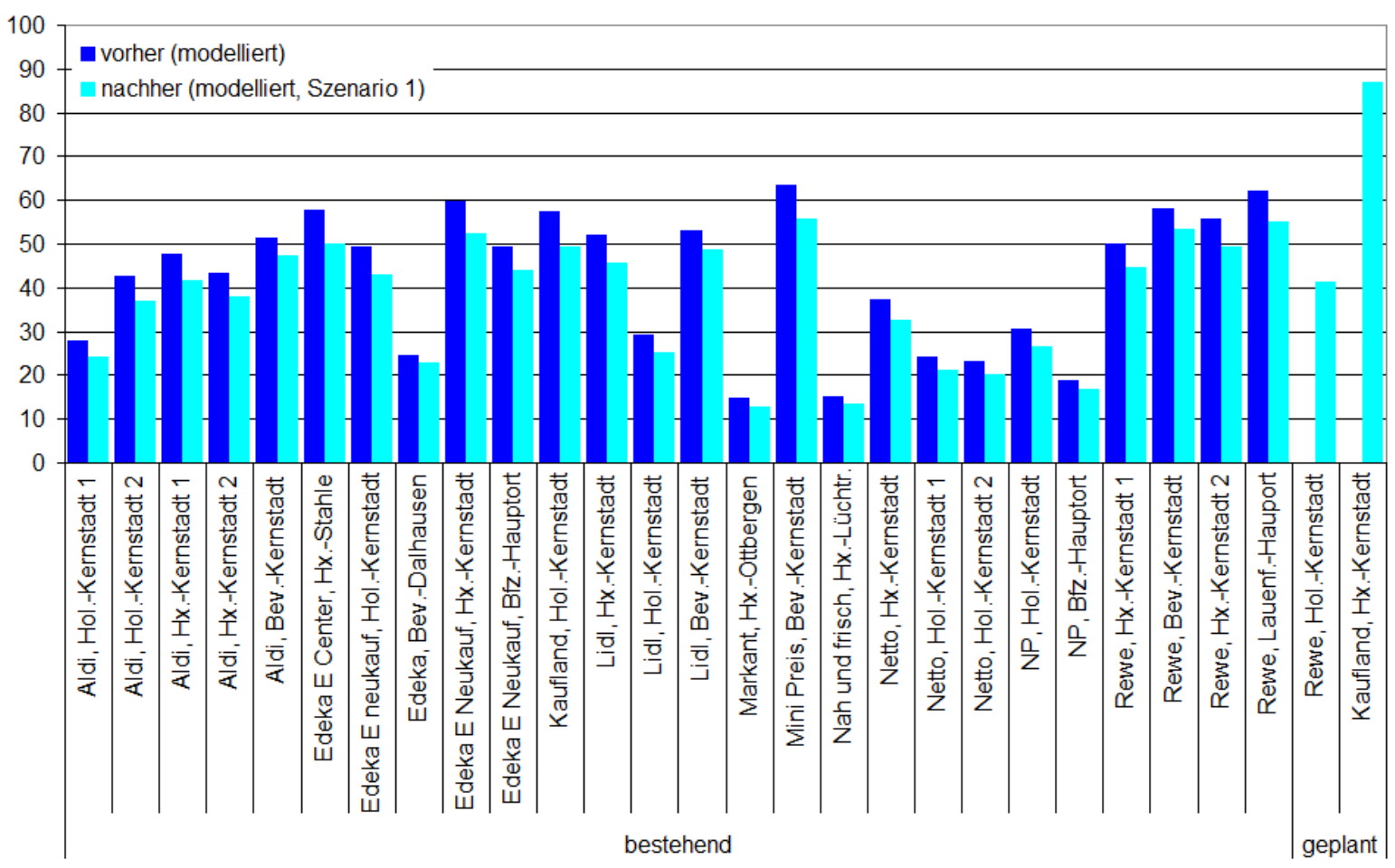

\section{Abbildung 19: Marktsimulation Lebensmittelmärkte - Szenario 1 (Ergebnisse)}

Quelle: Eigene Darstellung

Das Ergebnis der Modellprognose zeigt, dass der neue Verbrauchermarkt in Höxter nach seiner Ansiedlung ca. 87 der 1.098 Einkäufe auf sich ziehen wird, was einem prozentualen Anteil von ca. 7,9 \% von allen Einkäufen entspricht. Der neue Rewe-Markt generiert einen Kundenzufluss von 41 Einkäufen aus dem bestehenden Nachfragepotenzial (ca. 3,8 \% aller Einkäufe). Erwartungsgemäß verzeichnen alle anderen konkurrierenden Märkte Kundenabflüsse, die jedoch in begrenztem Maße unterschiedlich hoch ausfallen: Die größten Abnahmen sind bei jenen Anbietern $z u$ verzeichnen, die sich in denselben Standortgemeinden befinden; so sinkt die Zahl der Einkäufe beispielsweise bei den Aldi- und Edeka-Märkten in den Kernstadtgebieten Höxters und Holzmindens zwischen 12 und 14 \%. 
Vergleichsweise geringe Abflüsse ergeben sich hingegen für die Lebensmittelmärkte in den Teilgebieten von Beverungen sowie im südlichen Teil Höxters (zwischen 7 und $9 \%$ ).

Diese modellierte Neuverteilung der Kundenströme ist vorrangig auf die über-lineare negative Wirkung der Fahrtzeit, d.h. die Distanzsensibilität der Kunden, zurückzuführen: Die Einkaufsorientierung im südlichen Teil des Untersuchungsgebietes verändert sich am wenigsten, da die neuen Anbieter aufgrund ihrer relativ weiten Entfernung für die dortigen Haushalte nur in geringem Maße in Frage kommen; daraus ergeben sich für die dort lokalisierten Lebensmittelmärkte die geringsten Kundenverluste. Am stärksten betroffen sind die Mitbewerber an den Angebotsstandorten im Norden des Untersuchungsgebietes, die mit den neuen Märkten vollständig um dieselben Kunden konkurrieren. Insgesamt zeigt sich also eine noch relativ gleichmäßige Umverteilung der Kundenflüsse zu Gunsten der beiden neuen Märkte, die primär Wettbewerbseffekten geschuldet und durch die Nähe zum Kunden geprägt ist. In diesem Szenario werden keine neuen Standortkooperationen oder Erweiterungen bestehender Agglomerationen vorgenommen, weshalb sich die Konzentrationsgrade der bisherigen Märkte hinsichtlich branchengleicher Anbieter (Variable $\left.K_{K j}\right)$ kaum verändern; daher kann keiner der bestehenden Anbieter von einer Kompensation der Abflüsse oder gar von Zuflüssen aufgrund von Agglomerationseffekten profitieren.

\subsubsection{Szenario 2: Verlagerung Rewe und Aldi (Beverungen)}

Das zweite Szenario unterscheidet sich gegenüber dem ersten in mehrerlei Hinsicht: Es wird geprüft, welche Auswirkungen die gemeindeinterne Verlagerung zweier Lebensmittelmärkte in Beverungen (Verbrauchermarkt Rewe, LM-Discounter Aldi) an einen gemeinsamen Angebotsstandort (Standortkooperation, siehe Karte 14) induzieren. Einerseits erfolgt hier also kein Markteintritt neuer Anbieter, sondern eine Veränderung der Standortkonfiguration der bestehenden Märkte. Andererseits ändert sich der Grad räumlicher Ballung dieser beiden Verkaufsstellen sehr deutlich, da sie bewusst eine Standortkooperation bilden und sich direkt nebeneinander lokalisieren. Die Verlagerungen waren ursprünglich von beiden Unternehmen geplant, wurden jedoch im letzten kommunalen Einzelhandelskonzept der Stadt Beverungen als nicht empfehlenswert angesehen, da hierdurch die Abdeckung der Nahversorgung nicht verbessert bzw. sogar verschlechtert worden wäre (STADT+HANDEL 2011, S. 100ff.). Das Vorhaben wurde daher entgegen des Wunsches der beteiligten Einzelhandelsunternehmen nicht realisiert.

Entsprechend dem Vorgehen im ersten Szenario wurden auch hier neue Fahrtzeiten sowie Konzentrationsvariablen für die Nähe zu Mitbewerbern (Variable $K_{K j}$ ) neu kalkuliert und eine HuFF-Modellrechnung auf Grundlage der erweiterten Formel durchgeführt. Alle anderen Bedingungen - inklusive der Verkaufsflächengrößen der beiden betroffenen Märkte wurden konstant gelassen; eine Sortimentsausweitung der beiden Anbieter, die eine Standortkooperation bilden wollten, wird also nicht angenommen. 


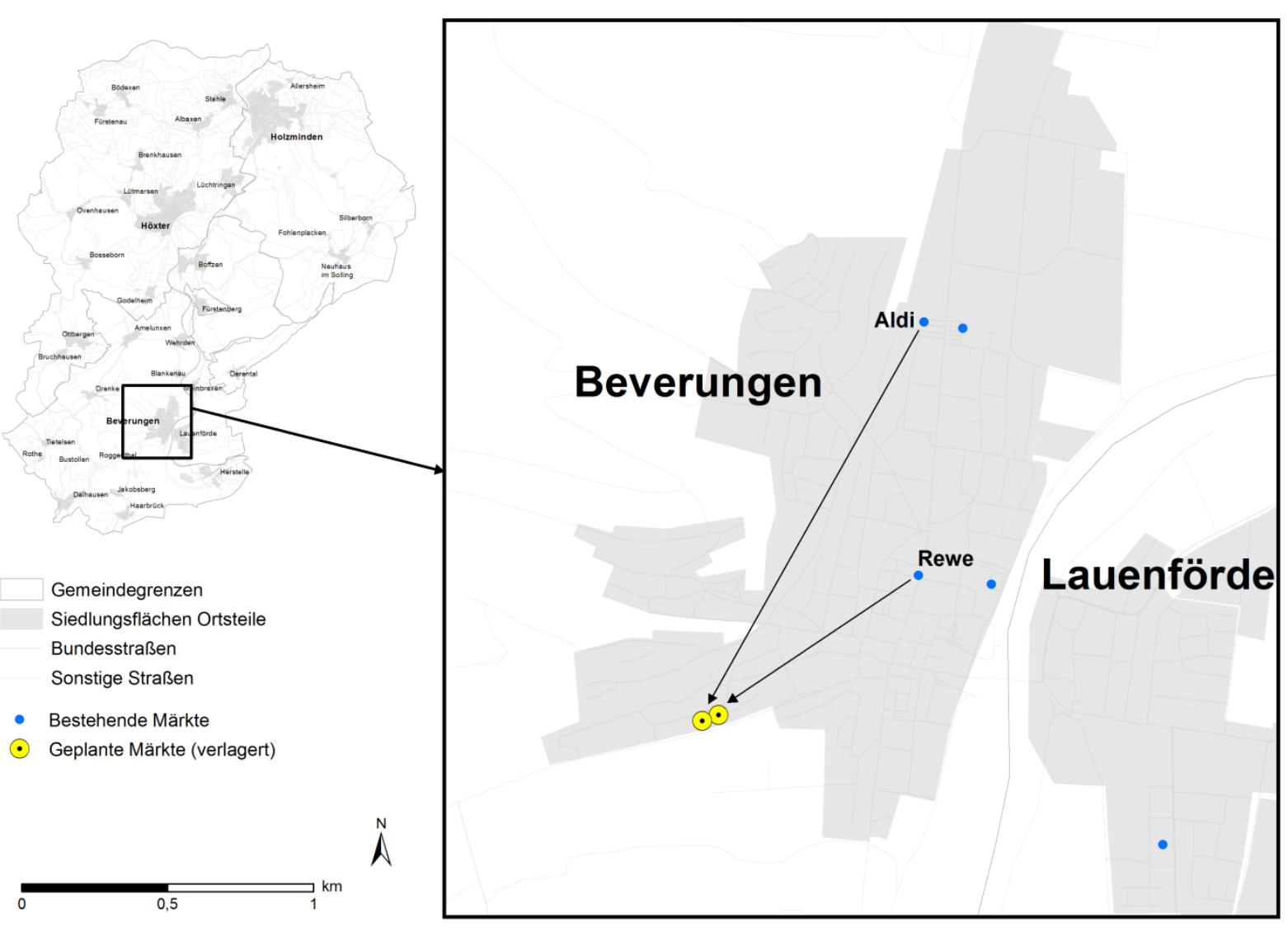

Karte 14: Marktsimulation Lebensmittelmärkte - Szenario 2

Quelle: Eigene Darstellung

Abbildung 20 zeigt den Vergleich der Modellergebnisse vor und nach der Verlagerung der beiden Märkte in eine Standortkooperation. Im Gegensatz zu den relativ gleichmäßigen Kundenverlusten durch die Neuansiedlungen im ersten Szenario verteilen sich die Einkäufe bei den Lebensmittelmärkten sehr ausdifferenziert. Die beiden in eine Standortkooperation verlagerten Märkte (Aldi und Rewe in Beverungen-Kernstadt) können in dieser Position die bei ihnen getätigten Einkäufe steigern: Die Einkäufe beim Aldi-Markt erhöhen sich von ca. 51 auf 55, was einer Zunahme von ca. 7,6 \% entspricht. Der Rewe-Markt verzeichnet nach der Verlagerung ca. 62 gegenüber vorher ca. 58 Einkäufen, womit sich die dort getätigten Einkäufe um ca. 6,1\% erhöhen. Betroffen von Kundenabflüssen sind vorrangig andere Anbieter in den Teilgebieten Beverungens und Lauenfördes, deren Kundenverluste sich zwischen 1,7 \% (Edeka, Beverungen-Dalhausen) und 6,8 \% (Minipreis, BeverungenKernstadt) bewegen. Alle anderen Anbieter verzeichnen nur geringe Veränderungen unterhalb von $1 \%$, wobei in manchen Fällen leichte Abflüsse (z.B. Edeka, Boffzen), in anderen Fällen minimale Zuflüsse (z.B. Lidl, Höxter-Kernstadt) auftreten.

Da die Eigenattraktivität der verlagerten Märkte genauso wie alle anderen Marktbedingungen konstant gehalten wurde, zeigt sich deutlich, dass diese aufgrund der Bildung einer Standortkooperation Kundengewinne realisieren können; Rewe und Aldi würden demnach von einer Verlagerung an einen gemeinsamen Angebotsstandort merkbar profitieren. Die Kombination dieser komplementären Mitbewerber hätte demnach Kundenabflüsse für andere Märkte zur Folge, ohne dass sich an den sonstigen Rahmenbedingungen etwas geändert hätte; somit erscheint der - in diesem Fall durch die Stadtverwaltung nicht 
zugelassene - Wunsch nach der Bildung einer Standortkooperation von Verbrauchermarkt und LM-Discounter als betriebswirtschaftlich nachvollziehbar. Dass von Kundenabflüssen vorrangig Märkte in Beverungen und Lauenförde betroffen sind, ist wiederum dadurch zu erklären, dass die kundenseitigen Transportkosten eine ausschlaggebende Rolle bei den Einkaufsentscheidungen spielen und jene Märkte sich daher verstärkt im Wettbewerb mit den verlagerten Märkten befinden. In anderen Fällen werden nur geringe Veränderungen modelliert, da ihre Marktanteile aus den genannten Teilgebieten bisher schon äußerst gering waren und sie für die dortigen Haushalte keine ernstzunehmende Rolle spielen. Die mitunter auftretenden unerheblichen Veränderungen in den Kundenzuflüssen weiter entfernter Märkte liegt darin begründet, dass sich ihre Konzentrationsgrade durch die Verlagerung geringfügig verändern und die Erreichbarkeit der verlagerten Anbieter durch ihre Standorte am Stadtrand im Verhältnis ungünstiger wird.

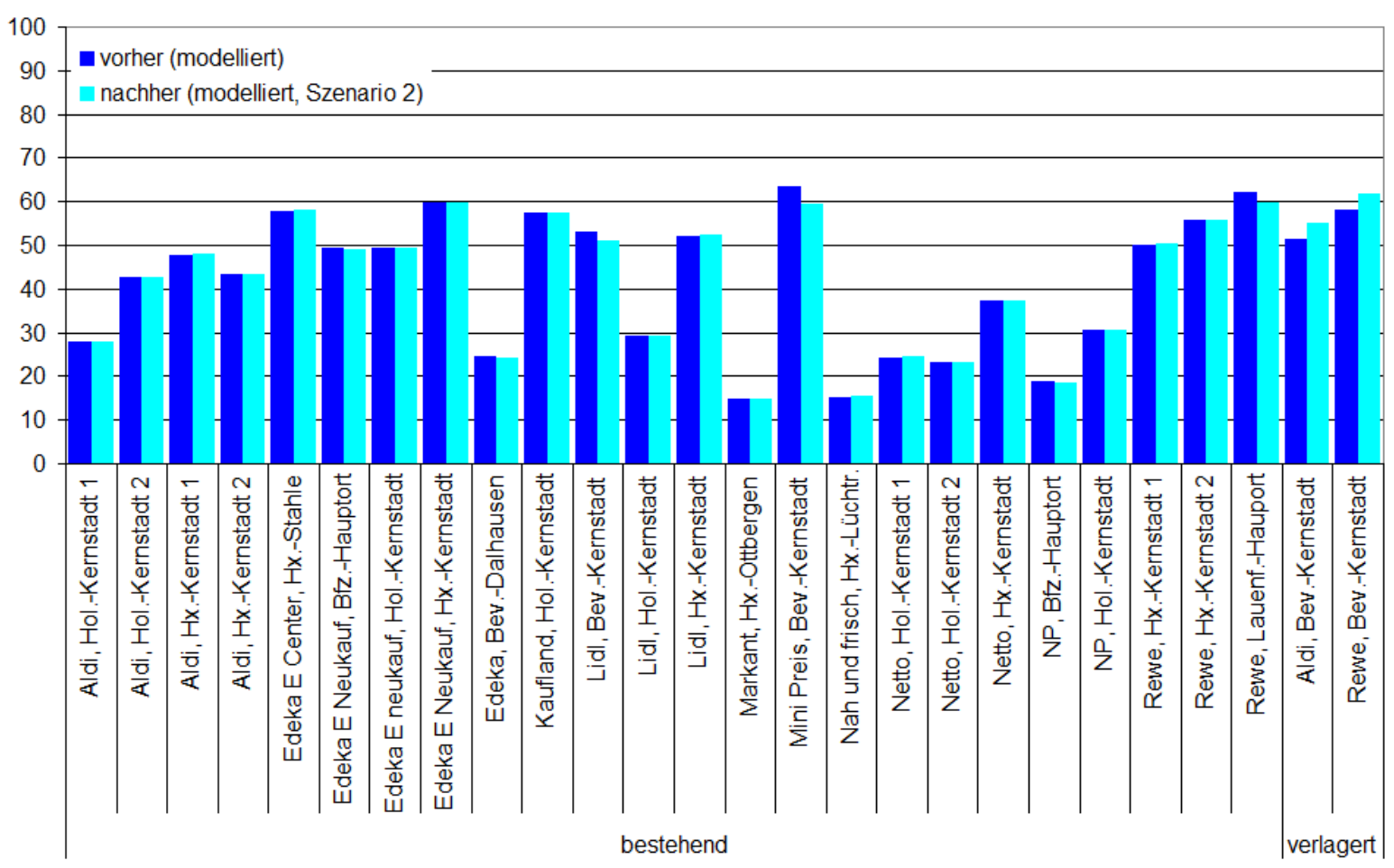

Abbildung 20: Marktsimulation Lebensmittelmärkte - Szenario 2 (Ergebnisse)

Quelle: Eigene Darstellung

\subsection{Implikationen der Ergebnisse für die Praxis}

\subsubsection{Sachrelevante Fragestellungen im Spiegel der Ergebnisse}

\subsubsection{Nahversorgung contra Einzelhandelsagglomerationen?}

Die empirischen Ergebnisse der Modelle sowie ihre Überprüfungen und Erweiterungen zeigen die Bedeutung von (positiven) Agglomerationseffekten bei Einzelhandelsstandorten auf. Insbesondere wurde nachgewiesen, dass die Nähe zu (komplementären) Mitbewerbern im Lebensmitteleinzelhandel die Kundenströme aus dem Marktgebiet erhöht (siehe Kap. 7.1.2.1), was die ebenso empirisch festgestellte Tatsache der räumlichen Ballung dieser 
Anbieter plausibel erklärt. Das zweite Modellszenario (siehe Kap. 7.2.4.3) prognostiziert Kundenzuflüsse für zwei Märkte, wenn diese unter ansonsten gleich bleibenden Bedingungen eine Standortkooperation bilden. Tatsächlich zeigt sich im Hinblick auf die Standortpolitik der Handelsunternehmen ein Trend hin zu Kombinationsstandorten von Verbrauchermärkten und LM-Discountern (siehe z.B. JÜRGENS 2012a u. 2013, STEGNER et al. 2010). Es stellt sich nun die Frage, welche Effekte diese Standortpolitik bzw. das damit verknüpfte Kundenverhalten auf die in der Raumordnung und Stadtplanung häufig als Nahversorgung bezeichnete Zielvorstellung einer wohnortnahen Grundversorgung haben.

Nahversorgung wird häufig zweifach definiert: Ihr quantitativer Aspekt besteht hierbei in einer räumlichen Erreichbarkeit von Angebot innerhalb bestimmter definierter Distanzgrenzen (z.B. 500 Meter fußläufige Entfernung). Ein qualitativ ausreichendes Nahversorgungsangebot besteht in dieser Terminologie hingegen in einem vielfältigen Angebot, wobei insbesondere die Kombination aus mehreren Betriebsformen des Lebensmitteleinzelhandels (z.B. Verbrauchermarkt und LM-Discounter) den Kern des qualitativen Nahversorgungsaspektes ausmacht (Betriebsformenmix) (siehe Kap. 1.4.2.1). Diese beiden Aspekte finden sich als angestrebte Ziele in vielen kommunalen und regionalen Einzelhandelskonzepten, z.B. im auf Nahversorgung fokussierten Zentrenkonzept der Stadt München (LH MüNCHEN 2010) ${ }^{51}$.

Standortkooperationen (z.B. LM-Vollsortimenter und Discounter sowie ergänzende Angebote des Lebensmittelhandwerks und/oder ein Drogeriemarkt) repräsentieren den qualitativen Aspekt der Nahversorgung nahezu vorbildlich, da ihre Angebotsvielfalt vor allem im geballten Auftreten komplementärer Betriebsformen des Lebensmitteleinzelhandels besteht; daher ermöglichen sie Kopplungskäufe und vor allem (präferenz- und erfahrungsgesteuerte bzw. angebotsgesteuerte) Vergleichskäufe und schaffen den Rahmen für einen fruchtbaren Kundenaustausch bzw. ein gemeinsames (größeres) Marktgebiet der Einzelhandelsanbieter. Die betriebswirtschaftlich motivierte räumliche Ballung von Angebot findet ihre Kehrseite im Abbau von nahversorgungsrelevantem Angebot in kleinen ländlichen Ortschaften und städtischen Streulagen bzw. verschärft zumindest diesen Trend, der ursprünglich aus den Flächenansprüchen der Einzelhandelsunternehmen und der wachsenden PKW-Mobilität der privaten Haushalte herrührte; die Problematik einer wohnortnahen Erreichbarkeit der Lebensmittelmärkte (quantitativer bzw. räumlicher Nahversorgungsaspekt) wird hierdurch also weiter verschärft. Ein gutes Beispiel aus dem Untersuchungsgebiet dieser Arbeit ist die angestrebte, jedoch nicht genehmigte, Verlagerung zweier LM-Märkte aus innerstädtischen Lagen an den Stadtrand, um dort eine Standortkooperation zu bilden (siehe Kap. 7.2.4.3).

Hinzu kommt ein weiterer Aspekt: Dass jene beschriebenen Agglomerationsvorteile wirken, bedeutet jedoch keinesfalls, dass hiermit die Standortanforderungen der einzelnen Betriebe (siehe Anhang, Tab. A 1) gedämpft werden; vielmehr muss der Standort für den einzelnen Markt immer noch so günstig sein, dass sein Mindestmarktgebiet bzw. -umsatz (in der Terminologie von CHRISTALLER 1933: „Untere Grenze der Reichweite“) erreicht wird, um

\footnotetext{
${ }^{51}$ Das Münchner Zentrenkonzept definiert, ähnlich wie im Zentrale-Orte-System der Landesraumordnung, eine Zentrenhierarchie von Angebotsstandorten im Stadtgebiet (u.a. Stadtteilzentren, Quartierszentren, Nahbereichszentren), die nach ihrem Angebotsbestand klassifiziert werden (LH MüNCHEN 2010, S. 13ff.). Als konkrete Operationalisierung ausreichender Nahversorgung wird einerseits die Erreichbarkeit mindestens eines Lebensmittelmarktes in einer Luftliniendistanz von $600 \mathrm{~m}$ und andererseits ein Betriebsformenmix (, [...] vielfältiges Angebot [...] in unterschiedlichen Betriebsformen, vom Kleinflächenanbieter bis zum Vollsortimenter und Discounter") angegeben (ebd., S. 22).
} 
betriebswirtschaftlich tragfähig zu sein. Da die LEH-Betriebsformen untereinander immer noch konkurrieren, da sie auf die Abschöpfung derselben Kaufkraft für Güter des täglichen Bedarfs abzielen, muss inr gemeinsames Marktgebiet zugleich so groß sein, dass alle in der Standortkooperation lokalisierten Anbieter hiervon existieren können. Im Ergebnis bedeutet dies, dass sich für Standortkooperationen die betriebswirtschaftlichen Anforderungen der Einzelhandelsunternehmen mindestens summieren; dies spricht in verstärktem Maße gegen die Wahl von Standorten in kleinen ländlichen Ortschaften oder städtischen Nebenzentren, wo kein ausreichendes Marktgebiet generiert werden kann. Die Standortkooperationen, die dem qualitativen Nahversorgungsaspekt Vorschub leisten, sind also auch aus Gründen der ökonomischen Tragfähigkeit ein Problem für eine gleichmäßige Marktabdeckung bzw. die wohnortnahe Erreichbarkeit von Anbietern in fußläufiger Entfernung; diese würde nämlich am ehesten unter der Bedingung einer Konkurrenzmeidung erreicht werden, da sich dann die Anbieter mit dem maximalen Abstand zueinander lokalisieren.

Offensichtlich besteht hier also ein Zielkonflikt zwischen dem qualitativen und dem quantitativen Begriff von Nahversorgung, wobei die zunehmend häufiger auftretenden Standortkooperationen der Vorstellung einer qualitativen Nahversorgung vorbildlich gerecht werden; aufgrund der Ballung des Angebots an jenen Angebotsstandorten nehmen jedoch räumliche Disparitäten der Angebotsausstattung (bzw. der Versorgung) zu, womit die Zielvorstellung einer kleinräumlichen Erreichbarkeit (quantitativer Aspekt) konterkariert wird. Eine wohnortnahe Versorgung ist demnach in vielen Gemeinden oder Stadtteilen, die kein ausreichendes Marktpotenzial bilden, nur noch schwer vorstellbar; der Themenkomplex der Nahversorgung ist ein eindringliches Beispiel dafür, wenn „[...] der beste Standort für die Erzeuger [...] nicht notwendig auch für die Verbraucher am besten [ist]" (LÖscH 1944, S. 67). Abhilfe schaffen können hier subventionierte Angebotsformen (z.B. vereinsgeführter oder genossenschaftlicher Dorfladen), die nicht betriebswirtschaftlich rentabel sein müssen (DORFLADEN-NETZWERK 2014). Andererseits stellt sich vor dem Hintergrund der planerischen Einzelhandelssteuerung auch die Frage nach einer expliziten Berücksichtigung von Agglomerationseffekten in Verträglichkeitsgutachten (siehe Kap. 7.3.2).

\subsubsection{Auswirkungen geplanter innerstädtischer Einkaufszentren}

Die Ansiedlung von geplanten Einkaufszentren in innerstädtischen Zentrenlagen bzw. an deren Rändern ist seit den 2000er Jahren ein sehr umstrittenes Thema (siehe z.B. BECKMANN et al. 2012). Die bisherigen Analysen zu den Auswirkungen innerstädtischer Einkaufszentren auf das sonstige Angebot zeigen mitunter gegensätzliche Ergebnisse (siehe Kap. 4.1.4). Zuletzt belegte LADEMANN (2011) anhand von Mietpreisentwicklungen und Expertenbefragungen, dass solche Ansiedlungen tendenziell keine negativen Effekte induzieren, sondern im Gegenteil viel mehr dafür spricht, dass sie den Angebotsstandort aufwerten, da Agglomerations- gegenüber Wettbewerbseffekten überwiegen. In der vorliegenden Untersuchung sind geplante Einkaufszentren nicht ausdrücklich behandelt worden, da im Untersuchungsgebiet - mit einer Ausnahme (Minipreis Center, Beverungen) keine Angebotsformen existieren, die als solches bezeichnet werden können; jedoch sind die Ergebnisse des Nachweises positiver Agglomerationseffekte bei Einkaufentscheidungen bzw. Marktgebieten im Einzelhandel auf diesen Sachverhalt übertragbar. Diese Resultate stützen eher die Analyse bzw. die Position von LADEMANN (2011) als die gegenüber innerstädtischen Einkaufszentren pauschal kritischen Standpunkte. 
Da sich Agglomerationsvorteile im Einzelhandel empirisch nachweisen lassen, muss die Beurteilung von innerstädtischen Einkaufszentren daher vor dem Hintergrund des Wechselspiels von Wettbewerbs- und Agglomerationseffekten erfolgen; eine pauschale Position für oder gegen jene Ansiedlungen ist daher nicht möglich. Vielmehr muss eine Reihe von Fragestellungen bearbeitet werden, um die möglichen (positiven und/oder negativen) Auswirkungen der Ansiedlung einzelner innerstädtischer EKZ zu beurteilen:

- Nähe bzw. Einbettung des EKZ am Angebotsstandort Innenstadt

- Wie weit ist das EKZ vom zentralen Geschäftsbereich der Innenstadt entfernt? Liegt es innerhalb einer - hier nicht näher bestimmbaren Reichweite, innerhalb der noch ein Kundenaustausch stattfindet?

○ Ist es möglich, die sonstige Innenstadt einfach zu umgehen bzw. zu umfahren?

- Setzt der Besuch des EKZ einen fußläufigen Weg durch die Innenstadt voraus?

$>$ Erhöht das EKZ also die Passantenfrequenzen der sonstigen Innenstadt? Wirkt es als Magnet bzw. profitiert die Innenstadt von „Shared business“?

- Anbieter- und Sortimentsstruktur im EKZ und der sonstigen Innenstadt

- Sind die Anbieter unterschiedlicher Branchen im EKZ und der sonstigen Innenstadt zueinander komplementär? Werden also horizontale und/oder vertikale Kopplungskäufe ermöglicht (z.B. beim Einkauf von Nahrungsmitteln und Drogerieprodukten)?

- Wie substituierbar bzw. ähnlich sind sich die Anbieter und Sortimente der gleichen Branche im EKZ und der sonstigen Innenstadt? Besteht also die Möglichkeit für Vergleichskäufe unterschiedlichen Typs (z.B. beim Einkauf von Bekleidung, Schuhen, Möbeln oder Elektronikartikeln)?

- Gibt es betriebsformenspezifische Komplementaritäten zwischen eigentlich kompetitiven Anbietern im EKZ und der Innenstadt (z.B. bei LM-Märkten)?

$>$ Können also positive Agglomerationseffekte aufgrund von Kopplungs- und Vergleichskäufen überhaupt wirksam werden? Oder besteht zwischen EKZ und dem restlichen Angebotsstandort ein reines Wettbewerbsverhältnis?

- Ausgangssituation des Angebotsstandortes Innenstadt

- Verfügt die Innenstadt über einen gemeinsamen Marktauftritt bzw. ein zentrales Agglomerationsmanagement (z.B. im Rahmen von Citymarketing/ Citymanagement)?

○ Verfügt die sonstige Innenstadt über eigene Magnetbetriebe? Sind diese so lokalisiert, dass sie als Gegenpol im Sinne eines zweiten Kundenankers fungieren können?

- Planen ggf. bisherige Magnetanbieter eine Verlagerung in das neue EKZ?

$>$ Ist die Innenstadt also für sich genommen als Angebotsstandort wettbewerbsfähig? 
Prinzipiell zeugt der empirische Nachweis von konsumentenseitigen Agglomerationsvorteilen im Einzelhandel jedenfalls davon, dass innerstädtische Einkaufszentren in der Tat eine Aufwertung des gesamten Angebotsstandortes mit sich bringen können; eine pauschale Wertung als „Angriff auf die City“ ist demnach nicht belastbar. Weiterhin stellt sich die Frage, wie jene Agglomerationseffekte ggf. im Rahmen vorhergehender Verträglichkeitsprüfungen einbezogen werden können (siehe Kap. 7.3.2), die auch im Fall der Ansiedlung von innerstädtischen Einkaufszentren vorgenommen werden müssten.

\subsubsection{Zentrenhierarchie in der Landes-, Regional- und Stadtplanung}

Auf verschiedenen Ebenen werden - maßgeblich zum Zweck der Einzelhandelssteuerung Hierarchien von Zentren unterschiedlicher Ausstattungsniveaus definiert; insbesondere die Zuweisung des zentralen Rangs einer Gemeinde durch die Landesraumordnung (Ober- und Mittelzentren) bzw. die Regionalplanung (Grund- bzw. Unterzentren) spielt eine essentielle Rolle bei der Zulassung großflächiger Einzelhandelsbetriebe (siehe Kap. 1.3.2). Das planerische Zentrale-Orte-Konzept nimmt eine Hierarchisierung nach Güterkategorien und deren Bedarfsstufen (siehe Kap. 1.3.2) vor, wobei der Angebotsbestand in den Gemeinden ihrem Rang entsprechend ausgebaut werden soll bzw. darf (am Beispiel des Landes Niedersachsen siehe Tabelle 34). Ähnlich wird auch auf kommunaler Ebene verfahren (z.B. Stadt München, siehe Kap. 7.3.1.1).

\begin{tabular}{ccc}
\hline Zentrenrang & Zentrale Versorgungsaufgaben & Zuweisung des Zentrenrangs \\
\hline Oberzentrum & $\begin{array}{c}\text { "spezialisierter höherer Bedarf“ } \\
+ \text { "gehobener Bedarf“ } \\
+ \text {,allgemeiner täglicher Grundbedarf“ }\end{array}$ & LROP \\
\hline Mittelzentrum & "gehobener Bedarf“ & LROP \\
\hline Grundzentrum & „allgemeiner täglicher Grundbedarf“ & RROP \\
\hline Außerhalb des Zentralen Orte & „allgemeiner täglicher Grundbedarf“ & "wohnortbezogene Nahversorgung“ \\
\hline
\end{tabular}

Tabelle 34: Zentrenhierarchie im Zentrale-Orte-System von Niedersachsen

Quelle: Eigene Darstellung, Datengrundlage: LROP Niedersachsen 2012, Lesefassung, S. 11 f.

Die grundsätzliche Annahme im Zentrale-Orte-Konzept, das auf Teilen der Theorie von CHRISTALLER (1933) fußt, ist, dass Einkaufsentscheidungen vor allem distanzabhängig sind und zentrale Orte je nach Besorgungstyp angesteuert werden; Einwohner eines Grundzentrums würden demnach ihren „allgemeinen täglichen Grundbedarf“ vor Ort einkaufen, für den "gehobenen Bedarf“ ein Mittelzentrum und für den „spezialisierten höheren Bedarf" ein Oberzentrum aufsuchen (Die Formulierungen der Güterklassifikation entstammen dem LROP Niedersachsen). Die Besuchshäufigkeit entspricht hierbei den Bedarfsstufen, d.h. der Grundbedarf (Grundzentrum) wird häufig eingekauft, der gehobene Bedarf (Mittelzentrum) deutlich seltener und der Spezialbedarf (Oberzentrum) nur gelegentlich. Es stellt sich vor diesem Hintergrund die Frage, inwiefern die bereits von CHRISTALLER in Teilen erörterten Agglomerationseffekte (siehe Kap. 2.3.1.4) in diesen Zentrenhierarchien Berücksichtigung finden, deren politisch formuliertes Ziel es ist, eine möglichst gleichmäßige räumliche Angebotsausstattung zu erhalten bzw. zu schaffen und räumlichen Versorgungsdisparitäten entgegenzuwirken. 
Hierbei muss zunächst festgehalten werden, dass die impliziten Vorstellungen zum Konsumentenverhalten im Zentrale-Orte-System nicht im Widerspruch zu Kopplungen des Einkaufs von Gütern derselben Bedarfsstufe (horizontale Kopplungskäufe) stehen: Die Versorgung mit dem „allgemeinen täglichen Grundbedarf“ kann beispielsweise durch die Verbindung von Anbietern dieser Bedarfsstufe (z.B. großflächige Lebensmittelmärkte und Drogeriemärkte) gewährleistet werden, die allesamt in einem Grundzentrum angesiedelt sein können bzw. dürfen; somit ist das ZO-Konzept kompatibel mit der Einkaufsstrategie horizontaler Kopplungen.

Die Verbindung des Erwerbs von Gütern unterschiedlicher Bedarfsstufen (vertikale Kopplungskäufe) wird hingegen nicht berücksichtigt bzw. ist nicht kompatibel mit den Annahmen der planerischen Zentrenhierarchie: Werden beispielsweise Grundbedarfsgüter (z.B. Nahrungsmittel) mit dem Erwerb von mittel- und/oder langfristigen Gütern (z.B. Baumarktartikel, Einrichtungsgegenstände, Elektronikartikel) gekoppelt, so sind letztere im Grundzentrum nicht verfügbar; die logische Konsequenz für die Konsumenten daraus wäre, das niederrangige Zentrum zu umgehen und stattdessen alle Einkäufe im Mittel- oder Oberzentrum durchzuführen ${ }^{52}$. Dies führt zu Kundenverlusten der niederrangigen Zentren und in letzter Konsequenz möglicherweise zu deren Bedeutungsverlust, wie es insbesondere von LANGE (1973) ausführlich thematisiert wird (siehe Kap. 2.3.3). Unabhängig davon, wie groß die empirische Relevanz von vertikalen Kopplungskäufen tatsächlich ist, muss also festgestellt werden, dass die ZO-Zentrenhierarchie dieses Kundenverhalten nicht greifen kann bzw. implizit davon ausgeht, dass es nicht stattfindet.

In ähnlicher Weise werden auch Agglomerationseffekte in Bezug auf kompetitive Anbieter nicht berücksichtigt: Beispielsweise kann beim Lebensmitteleinkauf auch ein höherrangiges Zentrum angesteuert werden, da dort eine größere Betriebsformenvielfalt vorherrscht und somit die Möglichkeit von (präferenz-/erfahrungsgesteuerten und/oder angebotsgesteuerten) Vergleichskäufen besser gegeben ist. In ähnlicher Weise ist diese Einkaufsorientierung dann plausibel, wenn typische „shopping goods“ (z.B. Bekleidung, Schuhe) in höherrangigen Zentren erworben werden, da dort eine größere Auswahl aufgefunden wird (suchgesteuerte Vergleichskäufe).

Abgesehen von der grundsätzlichen Kritik, dass die Zentrenzuweisung im Regelfall auf ganze Gemeinden abzielt (was CHRISTALLER ausdrücklich nicht vorsah, siehe Kap. 2.3.1.1), ist festzustellen, dass das ZO-System (nicht aber die zu Grunde liegende Theorie) implizit davon ausgeht, dass Agglomerationseffekte im Einzelhandel nicht existieren; einzig horizontale Kopplungskäufe widersprechen den modellhaften Vorstellungen zumindest nicht. Daher erscheint es für die Steuerung der räumlichen Einzelhandelsentwicklung sinnvoll, das raumordnungspolitische Konzept, dessen Ziel die Vorbeugung von räumlichen Disparitäten ist, für den wichtigen Teilaspekt der Agglomerationseffekte zu öffnen, deren Kehrseite eben jene räumlichen Disparitäten sind, die in der zu Grunde gelegten Theorie ja beschrieben werden. Wie dies zu gewährleisten ist, kann nicht im Rahmen dieser Untersuchung beantwortet werden; erste Ansätze hierzu bestehen aber bereits in Form der Berücksichtigung von Einzelhandelsagglomerationen in raumordnerischen Vorschriften bzw. Genehmigungsverfahren (siehe Kap. 7.3.2).

\footnotetext{
52 DeITERS (2006, S. 299ff.) gibt diesbezüglich ein einfaches schematisches Beispiel zur Verteilung der Einkäufe von Haushalten unter Berücksichtigung der unterschiedlichen Einkaufshäufigkeit für bestimmte Güter.
} 


\subsubsection{Durchführung von Standortanalysen und Verträglichkeitsbeurteilungen}

Die Ergebnisse der vorliegenden Untersuchung bestehen einerseits in der theoriegeleiteten empirischen Analyse von Marktgebieten im Einzelhandel unter Berücksichtigung von Agglomerationseffekten und andererseits in einer konkreten Operationalisierung dieser Zusammenhänge in einem Marktgebietsmodell; beides konnte im Rahmen der Untersuchung gewährleistet werden und kann daher prinzipiell in die Praxis umgesetzt werden. Hiervon betroffen sind einerseits betriebliche Standortanalysen, die von Einzelhandelsunternehmen im Rahmen ihrer Expansionsplanung vorgenommen werden, und andererseits Auswirkungsanalysen im Zusammenhang von Verträglichkeitsgutachten, die im Zuge von raumordnerischen und städtebaulichen Genehmigungsverfahren von Ansiedlungs- und Erweiterungsvorhaben erstellt werden. Die Ziele beider Untersuchungen sind gegenläufig (betriebswirtschaftliche Gewinnorientierung bzw. planerische Regulierung zum Schutz bestimmter Angebotsstandorte), jedoch ist die verwendete Methodik ähnlich; in beiden Fällen kommen auch mathematische Marktgebietsmodelle (insb. HuFF-Modell) zum Einsatz (zur Standortanalyse im Einzelhandel siehe z.B. MüLLER-HAGEDORN/NATTER 2011, S. 174ff.; zum Vorgehen bei Verträglichkeitsgutachten siehe z.B. WOLF 2012, S. 118ff.).

Die unternehmerische Standortanalyse zum Zweck der Expansionsplanung kann gezielt im Hinblick auf mögliche Agglomerationseffekte erfolgen bzw. diese zumindest integrieren. Hierfür sind Untersuchungen mit Hilfe von Regressionsanalysen denkbar, die im Kontext der Standortanalyse genutzt werden und auf die ökonometrische Erklärung des Geschäftserfolgs abzielen; als abhängige Variable fungiert hierbei häufig der Umsatz der Verkaufsstellen, während verschiedene Standortfaktoren (z.B. Kaufkraft, Passantenfrequenzen, Anzahl der Konkurrenten im Marktgebiet) die erklärenden Variablen bilden (MüLLER-HAGEDORN/NATTER 2011, S. 193ff.). Als Prädiktoren können hierbei neben diesen Erklärungsgrößen auch Agglomerationsvariablen genutzt werden, wobei sich die in dieser Untersuchung kalkulierten Konzentrationsvariablen aufgrund ihrer distanzgewichteten Berücksichtigung aller relevanten Anbieter durchaus anbieten. Hierbei muss die Zahl der betrachteten Konzentrationsgrade nicht auf zwei beschränkt sein; vielmehr ist eine differenzierte Betrachtung im Hinblick auf verschiedene Agglomerationsformen möglich (Beispiel siehe Formel 45). Die relevanten Informationen liegen den Unternehmen vor (z.B. Umsatz der Verkaufsstellen), können bei Marktforschungsinstituten erworben oder notfalls selbst erhoben werden.

$T_{j s}=a+b_{1} A_{j}+b_{2} P_{s}+b_{3} F_{s}+\ldots+b_{5} K_{j m}+b_{6} K_{j n}+\ldots+\varepsilon_{j s}$

$\mathrm{T}_{\mathrm{js}}=$ Umsatz der Verkaufsstelle $\mathrm{j}$ am Angebotsstandort s

$A_{j}=$ Verkaufsfläche der Verkaufsstelle $j$

$P_{s}=$ Kaufkraft im Marktgebiet des Angebotsstandortes $s$

$\mathrm{F}_{\mathrm{s}}=$ Passantenfrequenz am Angebotsstandort s

$\mathrm{K}_{\mathrm{jm}}=$ Konzentrationsvariable für die Verkaufsstelle j für die Nähe zu allen $m$ Anbietern (z.B. Mitbewerber)

$K_{j n}=$ Konzentrationsvariable für die Verkaufsstelle j für die Nähe zu allen $n$ Anbietern (z.B. Betriebe anderer Branchen)

$\mathrm{a}=$ Konstante (Achsenabschnitt)

$b_{1}, b_{2}, b_{3}, b_{5}, b_{6}=$ Regressionskoeffizienten (Steigungen)

$\varepsilon_{j \mathrm{~s}}=$ Residuum

Die Ergebnisse der Modelle können beispielsweise zur zielgerichteten Identifikation nützlicher bzw. schädlicher Angebotsformen im Umfeld identifiziert werden, was in groben Zügen dem Gedanken der Angebotskompatibilität von NELSON (1958) entspricht (hierzu z.B. 
auch WOTRUBA 2014); diese Informationen könnten im Zuge der Filialexpansion berücksichtigt werden (z.B. zur Umsatzprognose und/oder in Checklisten). Generell sind regressionsanalytische Verfahren zur Untersuchung der Relevanz von Standortfaktoren aber nur für jene Unternehmen sinnvoll durchführbar, die bereits über eine aussagekräftige Menge von Verkaufsstellen verfügen. Ergänzend oder unabhängig davon sind Anwendungen der Konzentrationsvariablen in Marktgebietsmodellen denkbar, die ebenso zum Methodenportfolio betrieblicher Standortanalysen zählen und Gegenstand der vorliegenden Untersuchung waren. Die Tatsache, dass im Lebensmitteleinzelhandel bereits gezielt Standortkooperationen gesucht werden, lässt allerdings darauf schließen, dass zumindest einige Einzelhandelsunternehmen bereits derartige Analysen vorgenommen haben und die Berücksichtigung möglicher Agglomerationseffekte in der Standortpolitik in diesen Fällen keine Neuerung darstellt.

Die Relevanz der ketten-/betriebsformenspezifischen Standortfaktoren und insbesondere die realen Umsätze von Verkaufsstellen sind bei der Erstellung von Verträglichkeitsgutachten demgegenüber meist nicht bekannt. In diesen Fällen, in denen zumeist die durch das Einzelhandelsvorhaben induzierten räumlichen Kaufkraftumlenkungen prognostiziert werden müssen, ist die Anwendung von theoretisch-deduktiven Marktgebietsmodellen (insb. des HufF-Modells) besonders häufig (WOLF 2012, S. 123f.). Hierbei besteht die Möglichkeit der Nutzung eines um Konzentrationsgrößen erweiterten Modells zur Modellierung der Kunden-/ Kaufkraftströme, wobei sich allerdings die Frage nach einer adäquaten Gewichtung insbesondere dieser Variablen stellt. Alternativ könnten auch andere Methoden zur Modellanpassung genutzt werden, z.B. iterative Verfahren zur Schätzung der Parameter (z.B. MARINOV/CZAMANSKI 2012) oder zur empirisch gestützten Anpassung der Indikatoren selbst (z.B. GÜSSEFELDT 2002). Natürlich sind im Vorfeld auch MCl-Modellanalysen auf der Basis von Haushalts- oder POS- Befragungen möglich, die jedoch den Untersuchungsaufwand enorm steigern. Zumindest in Einzelhandelskonzepten werden die hierfür notwendigen Erhebungen (Kartierung des Einzelhandelsbestandes, Befragungen zur Einkaufsorientierung) in den meisten Fällen durchgeführt, wie die Beispiele aus dem eigenen Untersuchungsgebiet zeigen (z.B. JUNKER UND KRUSE 2009, STADT+HANDEL 2011).

Eine weitere Methode der Verträglichkeitsbeurteilung bildet die Ermittlung der durch das Einzelhandelsvorhaben hervorgerufenen Kaufkraftabschöpfungsquoten, wie es z.B. das LEP Bayern vorschreibt. Die raumordnerische Verträglichkeitsprüfung besteht in der Berechnung der voraussichtlichen sortimentsspezifischen Marktanteile des Einzelhandelsgroßprojektes in seinem Marktgebiet bzw. der Standortgemeinde; ab einer in den LROP definierten Grenze der Kaufkraftabschöpfung gilt das Vorhaben als nicht mehr verträglich (JAEHRLING 2012, S. 106f.). Im LEP Bayern werden mittlerweile auch Agglomerationen nicht großflächiger Einzelhandelsbetriebe, die innerhalb einer bestimmten Entfernung zueinander $\operatorname{stehen}^{53}$, als „Einzelhandelsgroßprojekt“ aufgefasst; im Rahmen der Verträglichkeitsprüfungen werden deren Marktanteile summiert und somit eine gemeinsame Kaufkraftabschöpfung zu Grunde gelegt. Dieses Vorgehen beinhaltet allerdings mehrere Probleme: Einerseits wird eine Agglomeration exakt durch eine Meter-Entfernung abgegrenzt, wobei unterstellt wird, dass unterhalb dieser Grenze die Betriebe als Einheit zu betrachten sind und oberhalb keine Kopplungs- und Vergleichskäufe mehr stattfinden. Zudem bedeutet die Summierung der

\footnotetext{
${ }^{53}$ Als Entfernungsgrenze wird zumeist eine Luftliniendistanz von 150 Metern angesetzt (VALLÉE 2012, S. 54).
} 
einzelnen Betriebe eine implizite Zusammenfassung zu einem Großbetrieb und berücksichtigt somit nicht die (positiven) Agglomerationseffekte im eigentlichen Sinne, die aus der Kombination verschiedener Betriebe herrühren (z.B. durch Vergleichskäufe); die gemeinsame Anziehungskraft ist nach dem Konzept der Agglomerationsvorteile größer als die Summe der Attraktivitäten der einzelnen Anbieter.

Grundsätzlich existieren also viele Möglichkeiten, Agglomerationseffekte durch die Nähe zu branchenungleichen oder konkurrierenden Einzelhandelsanbietern in Standortanalysen und Verträglichkeitsbeurteilungen zu berücksichtigen. Wie auch die vorliegende Untersuchung zeigt, besteht ein wesentliches Problem der praktischen Durchführung in der Erhebung von Primärdaten bzw. der Beschaffung von Sekundärdaten. Dem empirischen Vorgehen werden daher durch die Begrenztheit zeitlicher und finanzieller Ressourcen - sowohl in der universitären Forschung als auch im privatwirtschaftlichen Sektor - enge Grenzen gesetzt.

\subsection{Einschränkungen und Fehlerquellen der Untersuchung}

\subsubsection{Allgemeine Probleme und Einschränkungen}

\subsubsection{Zur Erhebung und Recherche der notwendigen Daten}

Um die (möglichen) Probleme bzw. Fehlerquellen und Einschränkungen der vorliegenden Untersuchung sachgerecht aufzuarbeiten, ist es notwendig, zwischen den Problematiken zu trennen, die allgemein für derartige Studien (MCl-Marktgebietsanalysen) zutreffen, und denen, die explizit das Vorgehen in dieser Untersuchung anbelangen. Zunächst werden die erstgenannten Schwierigkeiten besprochen. Eine Herausforderung dieser und artverwandter Studien stellt der vergleichsweise hohe Aufwand der Datenerhebung dar.

Für Marktgebietsanalysen ist es notwendig, alle sachrelevanten Einzelhandelsanbieter zu kartieren und hierbei ggf. noch weitere notwendige Eigenschaften dieser Betriebe (z.B. Verkaufsfläche, Sortimente, Öffnungszeiten, Alter etc.) zu erfassen. Der damit verbundene Aufwand variiert natürlich mit der Anzahl der betrachteten Angebotsformen und kann daher auch vergleichsweise gering sein; zumindest ist eine solche Bestandserhebung elementarer Teil von Einzelhandelskonzepten und Verträglichkeitsgutachten. Zudem besteht auch die Möglichkeit, Anbieterdaten von externen Marktforschungs- bzw. Consulting-Unternehmen zu beschaffen, sofern hierfür finanzielle Ressourcen vorliegen. JÜRGENS (2012a u. 2013) nutzt beispielsweise das "Wer-zu-wem-Firmenverzeichnis“ sowie Daten des zur Nielsen Company gehörenden Anbieters TradeDimensions. Auch VROEGRIJK et al. (2013) greifen auf extern eingekaufte Daten zurück (Anbieter: Reed Business Information). In vielen Fällen ist es zudem möglich, Daten (z.B. Größen der Verkaufsflächen) auch aus bereits existierenden Gutachten zu beziehen, wie es in der vorliegenden Untersuchung gemacht wurde. Die Erfassung der untersuchungsrelevanten Einzelhandelsbetriebe stellt also nicht die größte Schwierigkeit dar.

Sofern, wie im vorliegenden Fall, alle Anbieter eines Untersuchungsgebietes berücksichtigt werden müssen (notwendig zur Kalkulation der allgemeinen Konzentrationsvariablen), ist die Angebotserfassung deutlich aufwendiger. In den o.g. Datensätzen kommerzieller Anbieter sind zwar bestimmte Anbieter (z.B. alle Lebensmittelmärkte ab einer definierten Größe) erfasst, nicht jedoch alle; eine eigene Erhebung dieser Betriebe ist daher nahezu 
unumgänglich. Dass (mitunter vollständige) Anbieterlisten vorliegen und diese zur Verfügung gestellt werden, wie es in zwei Untersuchungsgemeinden der Fall war, stellt eine erfreuliche, aber eher seltene (und zufällige) Ausnahme dar. In anderen Ländern liegen mitunter sogar amtliche Daten hierzu vor, wie etwa die in Schweden durchgeführten Untersuchungen (z.B. ÖNER/LARSSON 2013, SCHENK 2008) zeigen, was die Angebotserfassung deutlich erleichtert. Die letzte vollständige amtliche Einzelhandelserfassung in Deutschland erfolgte jedoch in der Handels- und Gaststättenzählung (HGZ) 1993, womit sich die Frage erübrigt, ob diese Daten - außer für historische Zeitvergleiche - heutzutage noch sinnvoll nutzbar sind.

Als ebenso aufwendig stellt sich die Befragung zur räumlichen Einkaufsorientierung heraus; im vorliegenden Fall wurde hierzu eine telefonische Haushaltsbefragung durchgeführt, was abseits vom Erhebungsaufwand auch andere Problemquellen beinhaltet (siehe Kap. 7.4.2.1). Auch hier ist es in bestimmten Fällen möglich, Daten extern einzukaufen (z.B. VROEGRIJK et al. 2013) ${ }^{54}$. Wenn derartige Daten aber nicht zur Verfügung stehen bzw. nicht beschafft werden können, ist eine eigene Primärerhebung notwendig. Der Durchführung solcher Befragungen sind aber unausweichlich enge (vorrangig finanzielle) Grenzen gesetzt, wobei eine telefonische Haushaltsbefragung im Vergleich zu postalischen oder persönlichen Befragungen mittlerweile eine relativ günstige Alternative darstellt. In jedem Fall ist aber ein Pool von Adressen bzw. Telefonnummern notwendig, der extern und kostenpflichtig beschafft werden muss (z.B. Deutsche Post, Telefonbuch-DVD).

Wesentlich einfacher und preiswerter sind vor diesem Hintergrund Passanten- bzw. POSBefragungen oder andere Erhebungen am Angebotsstandort (z.B. „Licence plate analysis“ bei KUBIS/HARTMANN 2007); diese sind jedoch mit den bekannten Problemen einer verzerrten Erfassung bzw. mangelnder Repräsentativität belastet, da nur tatsächliche Besucher erfasst werden und eben nicht jene Haushalte/Einwohner, die die untersuchten Angebotsstandorte gar nicht erst frequentieren (siehe Kap. 5.1.4). Hinzu kommt ein weiteres praktisches Durchführungsproblem: Während POS-Befragungen im öffentlichen Raum (z.B. Fußgängerzone) im Regelfall problemlos durchgeführt werden können, muss für derartige Aktivitäten auf Privatgrundstücken (z.B. im Eingangsbereich oder auf dem Parkplatz eines Lebensmittelmarktes oder im Mall-Bereich eines Einkaufszentrums) eine Erlaubnis der Geschäftsführung eingeholt werden; ob diese in jedem Fall erteilt wird, ist zumindest fraglich.

Schließlich kann auch die Erfassung weiterer, für die Untersuchung indirekt benötigter, Sekundärdaten ein Problem darstellen. Stark abhängig vom jeweiligen Untersuchungsgebiet kann der Fall auftreten, dass bestimmte sozio-demographische Daten in kleinräumiger Auflösung nicht öffentlich verfügbar sind oder gar überhaupt nicht existieren; diese bevölkerungsstatistischen Angaben können beispielsweise für die Kalkulation der anvisierten Stichprobengröße oder einen nachträglichen Abgleich der Eigenschaften von Stichprobe und Grundgesamtheit nützlich sein. Sind in größeren Städten häufig detaillierte Daten zu Bevölkerungszahlen und Haushaltsstrukturen frei verfügbar (z.B. Stadt Göttingen, GÖSIS 2014), ist dies in kleineren Städten und Gemeinden bzw. deren Ortsteilen häufig nicht der Fall. In der vorliegenden Untersuchung lagen beispielsweise für die einzelnen Ortsteile nur

\footnotetext{
${ }^{54}$ Die kommerziell vertriebenen GfK-Marktforschungsdaten und insbesondere das GfK-Haushaltspanel bieten eine breite Informationslage zur konsumentenseitigen Einkaufsorientierung, Ausgaben im Einzelhandel und Produktpräferenzen (Überblick: WILDNER/SCHERÜBL 2006). Sie sind - finanzielle Ressourcen vorausgesetzt - für Untersuchungen wie die vorliegende äußerst brauchbar.
} 
Einwohnerzahlen vor, nicht jedoch Angaben zur Haushaltsstruktur oder Altersverteilung; eine kleinräumige Berücksichtigung differenzierter demographischer Strukturen war daher im vorliegenden Fall nicht möglich.

\subsubsection{Aussagekraft und Beschränkungen des MCI-Modells}

Das MCl-Modell von NAKANISHI/COOPER (1974) besticht durch einen guten empirischen Zugang mit Hilfe der ausgiebig fundierten, vergleichsweise einfach handhabbaren und häufig angewandten Methode der linearen Regressionsanalyse. Zudem eignet es sich für die Analyse von Marktgebieten im Einzelhandel sehr gut, da es auf dem HuFF-Modell aufbaut und sich auf dieser Grundlage inhaltlich interpretieren lässt. Abgesehen von der trivialen Erkenntnis, dass ökonometrische (und auch ganz allgemein mathematische) Modelle niemals in der Lage sind, menschliches Handeln vollständig zu erfassen (und dies auch niemals zur Aufgabe hatten), gibt es jedoch noch weitere Einschränkungen, die solche Modelle im Allgemeinen und auch das MCl-Modell im Speziellen betreffen.

Hierzu zählen zunächst die Annahmen zu den statistischen Ausgangsbedingungen linearer Regressionsmodelle bzw. die Konsequenzen der Verletzung dieser Annahmen, die im vorliegenden Fall besprochen und die Modelle dahingehend überprüft wurden (siehe Kap. 5.3.2.2). Die MCl-Modelle in dieser Untersuchung haben diesen Prüfungen standgehalten, d.h. ihre statistische Belastbarkeit ist nachgewiesen bzw. mögliche Fehlerquellen sind kompensiert worden (siehe Kap. 6.3). Streng genommen sind jene Modellüberprüfungen notwendig, um die Aussagekraft der Ergebnisse zu untermauern, faktisch unterbleiben sie aber in vielen Fällen. Die Modellerweiterungen bzw. alternativen Spezifikationen (Kap. 7.2.3, Tab. 33) zeigen auf, dass über die Hinzunahme zusätzlicher Variablen ein verbesserter Erklärungsgehalt erreicht werden kann (Modellvariante 2), jedoch auch ein erhöhtes Risiko von verzerrenden Multikollinearitätseffekten besteht (Modellvariante 4). Das „beste“ Modell ist also keinesfalls das komplexeste (d.h. mit den meisten Erklärungsgrößen); der Erhöhung der Aussagekraft sind enge Grenzen gesetzt, wobei Erweiterungen immer mit einer Prüfung der Annahmenverletzungen (insb. Multikollinearität) einhergehen sollten.

Abseits von diesen bekannten Problemen, die alle ökonometrischen und insbesondere lineare Regressionsmodelle betreffen, verfügt das $\mathrm{MCl}-$ Modell noch über weitere spezifische Barrieren, die sich vorrangig auf die Vor- und Nachbereitung der erhobenen Daten beziehen; diese liegen in den Voraussetzungen der $\mathrm{MCl}$-Modellanalyse begründet und wurden im Rahmen dieser Arbeit mehrfach aufgeworfen:

- Das Untersuchungsgebiet muss vor der Untersuchung räumlich abgegrenzt werden. Die Abgrenzung muss so erfolgen, dass der Großteil der Einkaufsinteraktionen innerhalb dessen stattfindet, also weder die darin lokalisierten Anbieter Kunden in relevantem Umfang von außerhalb auf sich ziehen noch Kunden von innerhalb des Untersuchungsgebietes in ernstzunehmendem Maße außerhalb einkaufen

- Um aussagekräftige Ergebnisse zu erzielen, müssen möglichst alle relevanten Anbieter berücksichtigt werden, d.h. theoretisch auch jene, die nur sehr geringe oder gar keine Marktanteile vorweisen

- Aufgrund der mathematischen Eigenschaften der notwendigen Modelltransformation (Geometrische Mittelwerte, Logarithmieren) dürfen keine Ausprägungen der Variablen auftreten, die gleich null oder negativ sind bzw. die Interaktionsmatrix darf 
keine leeren Zellen enthalten; d.h. auch lokale Marktanteile von null - die in der Realität vorkommen - können im Modell nicht abgebildet werden

Diese zunächst plausiblen Anforderungen der MCl-Modellanalyse sind in der Praxis jedoch schwer umzusetzen bzw. stehen im Widerspruch zueinander: Das vorher abgegrenzte Untersuchungsgebiet bildet gewissermaßen die Summe bzw. Überschneidung der Marktgebiete aller betrachteten Anbieter. In diesem modellhaft abgebildeten räumlichen Markt werden alle relevanten Anbieter berücksichtigt (z.B. alle Lebensmittelmärkte), da die Einflussfaktoren des Einkaufsverhaltens nicht adäquat analysiert werden können, wenn ein wesentlicher Teil der in Frage kommenden Betriebe unbeachtet bleibt. Dies hat automatisch zur Folge, dass sehr heterogene Anbieter mit unterschiedlicher Eigenattraktivität und ungleichen Standortbedingungen (z.B. Dorfzentrum, Gewerbegebiet, Einkaufszentrum, Innenstadt) aufgenommen werden; daraus folgt aber zugleich, dass diese berücksichtigten Anbieter (z.B. Supermärkte, LM-Discounter, SB-Warenhäuser) über unterschiedlich große Marktgebiete verfügen, da diese ein Spiegelbild ihrer Anziehungskraft und ihres Standortes sind. Eine Teilgruppe der Anbieter (z.B. SB-Warenhäuser) generiert also aufgrund der großen Eigenanziehungskraft auch Kundenströme von außerhalb des vordefinierten Untersuchungsgebietes, während eine andere Teilgruppe (z.B. Supermärkte) nur über kleine Marktgebiete verfügt, die sich nicht über das gesamte Untersuchungsgebiet erstrecken.

In diesem Fall bestehen mehrere Möglichkeiten: Entweder wird das Untersuchungsgebiet verkleinert, was die Marktgebiete der "großen“ Anbieter verfälschen würde, oder vergrößert, womit die Anzahl leerer Zellen aufgrund nicht stattfindender Interaktionen mit den „kleinen“ Anbietern steigt. Weiterhin ist es noch möglich, die Nachfrageorte so weit zu aggregieren, dass keine leeren Zellen mehr vorkommen (wie z.B. bei COLOMÉ PERALES 2002, TIHI/ORUC 2012), was aber die räumliche Auflösung des Modells beeinträchtigt. Eine weitere Alternative bestünde darin, nur sehr homogene Anbieter in der Modellanalyse zu berücksichtigen, mit denen Interaktionen aus allen Teilgebieten des Untersuchungsgebietes bestehen (z.B. nur Verbrauchermärkte ab einer bestimmten Größe, die in dezentralen, PKW-orientierten Lagen angesiedelt sind), und kleine, weniger frequentierte Anbieter vollständig auszuschließen; dies würde aber wiederum eine gewaltige Informationsreduktion bedeuten und der Vorgabe, alle relevanten Anbieter zu berücksichtigen, nicht gerecht werden. In vielen Fällen wird es sich aber nicht vermeiden lassen, zumindest einzelne Anbieter aus der Analyse auszuschließen, wenn diese kaum oder gar nicht als Einkaufsziel erfasst wurden (z.B. kleine Märkte in Solitärlagen); auch hierbei gehen Informationen verloren.

Offensichtlich ist es daher kaum möglich, alle relevanten Anbieter zu berücksichtigen und Anbieter-Nachfrager-Interaktionen außerhalb des Untersuchungsgebietes zu vermeiden und hierbei noch alle Zellen der Interaktionsmatrix (bzw. die lokalen Marktanteile) gänzlich zu füllen (ohne die Daten dementsprechend nachzubearbeiten wie z.B. HARTMANN 2005 bzw. KUBIS/HARTMANN 2007); die vollständige Erfüllung aller drei o.g. Voraussetzungen ist also unrealistisch. Generell betrachtet existieren für die aufgezeigten Problematiken keine Ideal-, sondern lediglich mehrere Möglichkeiten von pragmatischen Kompromisslösungen; dies stellt die wesentliche Schwäche der Anwendung des ansonsten sehr ausgereiften $\mathrm{MCl}$ Modells in räumlichen Märkten (v.a. Einzelhandel) dar. Hinzu kommt, dass in vielen Veröffentlichungen von Untersuchungen mit MCI-Modellen (z.B. GHOSH 1984, GoNZÁLEZBENITO et al. 2000, SUÁREZ-VEGA et al. 2011) und auch in der Anwendungsbeschreibung von Huff/McCAllum (2008) keine Hinweise darauf zu finden sind, ob die skizzierten 
Probleme aufgetreten sind und ob bzw. wie sie gelöst wurden oder zu lösen sind (Angaben hierzu machen Colomé Perales 2002, HARTMANN 2005 und TIHI/ORUC 2012, s.o.); dies erschwert eine Begegnung der aufgezeigten Schwierigkeiten zusätzlich.

Weiterhin kommt hinzu, dass die in empirisch fundierten Marktgebietsmodellen analysierten Aspekte bzw. ganz konkret die ermittelten Parameter stets nur einen beschränkten räumlichzeitlichen Gültigkeitsbereich haben. Zwar sind die grundsätzlichen Zusammenhänge als „allgemeingültig“ zu betrachten, jedoch nicht notwendigerweise ihre konkrete Ausgestaltung bzw. die Intensität der Wirkung einzelner Größen (LADEMANN 2007, S. 148; LÖFFLER 1999, S. 52). Eine exakte Übertragung eines geschätzten Modells auf andere Untersuchungsräume ist daher nicht möglich bzw. nicht empfehlenswert.

\subsubsection{Untersuchungsspezifische Einschränkungen und potenzielle Fehlerquellen}

\subsubsection{Abgrenzung des Untersuchungsgebietes und Nachbearbeitung der Interaktionsmatrix}

Hinsichtlich der Vorabgrenzung des Untersuchungsgebietes und der Kalkulation von lokalen Marktanteilen bzw. der Vollendung der Interaktionsmatrix werden in $\mathrm{MCl}$-Anwendungen notwendigerweise Kompromisse geschlossen, um die Modellanalyse überhaupt durchführen zu können (siehe Kap. 7.4.1.2). Auch in der vorliegenden Untersuchung waren hierfür mehrere Anpassungsschritte notwendig:

- Die Abgrenzung des Untersuchungsgebietes wurde anhand sekundärempirischer Daten aus verschiedenen Einzelhandelsgutachten vorgenommen; das Ergebnis bestand in einem Gebiet, in dem nachgewiesenermaßen Einkaufsinteraktionen zwischen nahezu allen Gemeinden bzw. Ortsteilen stattfinden (siehe Kap. 5.2.1)

- Um der geringen Bevölkerungszahl und somit der voraussichtlich (zu) geringen Teilstichprobengröße in einigen der 34 Ortsteile Rechnung zu tragen, wurde das Untersuchungsgebiet in 19 Teilgebiete aufgeteilt (siehe Kap. 5.3.1.1)

- Nach dem Vorbild von HaRTMAnN (2005) bzw. Kubis/HARTMAnN (2007) wurde die Interaktionsmatrix durch den Ausschluss von lokalen Marktanteilen $\left(p_{i j}\right)$ gleich null nachbearbeitet, indem zu allen lokal registrierten Einkäufen eins addiert und auf dieser Basis die lokalen Marktanteile kalkuliert wurden (siehe Kap. 5.3.1.2)

- Für die Lebensmittelmärkte wurde zudem eine betriebsformenspezifische Korrektur der berücksichtigten empirischen Marktgebiete vorgenommen (siehe Kap. 5.3.1.5)

So konnte gewährleistet werden, dass recht heterogene kompetitive Anbieter im Modell berücksichtigt werden, dennoch die Interaktionsmatrix keine leeren Zellen aufweist und das Untersuchungsgebiet nicht wesentlich zu groß oder zu klein abgegrenzt ist. Es handelt sich hierbei also um eine Kompromisslösung, die - in der vorliegenden wie auch in anderen Untersuchungen - zwingend notwendig gewesen ist, jedoch unausweichlich mit Informationsverlusten einhergeht. Insbesondere die Tatsache, dass lokale Marktanteile von null nicht bearbeitet werden können bzw. korrigiert werden müssen, beeinträchtigt in gewisser Hinsicht die Aussagekraft des Modells:

- Für Teile des Untersuchungsgebietes nicht als Einkaufsziel in Frage kommende Anbieter (z.B. entlegene Lebensmittelmärkte mit reiner Nahversorgungsfunktion) werden dennoch mit einer "Mindest-Interaktion“ von einem Einkauf als solche 
registriert; zwar wird diese Erhöhung symmetrisch bei allen Anbietern in jedem Teilgebiet vorgenommen, dennoch wirkt sich dies wie eine „Aufwertung“ dieser eigentlich nicht angesteuerten Anbieter aus. Die tatsächlichen Effekte der Teilnutzen (z.B. Angebotsgröße, Fahrtzeit) müssten demnach stärker sein als es die Modellergebnisse dokumentieren. Diese Einschränkung betrifft fast ausschließlich die Modelle für die Marktgebiete der Lebensmittelmärkte, da in den beiden anderen Fällen (Elektronik- und Baumärkte) nahezu immer das gesamte Untersuchungsgebiet abgedeckt wird; hiermit ist möglicherweise auch die vergleichsweise geringe Varianzaufklärung der Modelle für die LM-Märkte (siehe Kap. 6.3.1) erklärbar

- Es ist davon auszugehen, dass einige Anbieter mit hoher Eigenattraktivität über ein Marktgebiet verfügen, das teilweise über das Untersuchungsgebiet hinausgeht. Bestimmte potenzielle Nachfrageorte konnten aber nicht im Untersuchungsgebiet berücksichtigt werden (z.B. Ortschaften der Samtgemeinde Bevern östlich der Kernstadt Holzmindens, Bad Karlshafen südöstlich von Beverungen), da sie laut der vorliegenden Gutachten nur zum Marktgebiet einzelner Untersuchungsstädte gehören (z.B. nur Holzminden oder nur Beverungen). Eine Berücksichtigung dieser Nachfrageorte hätte ggf. die Marktgebiete einzelner Anbieter komplettiert, umgekehrt jedoch eine wesentlich größere Menge leerer Zellen in der Interaktionsmatrix zurückgelassen, da von dort aus andere Anbieter nicht angesteuert werden (z.B. keine Einkaufsinteraktionen zwischen Holzminden und Bad Karlshafen)

Diese Einschränkungen sind eine notwendige Begleiterscheinung der Voraussetzungen für eine MCl-Modellanalyse, insbesondere wenn, wie im vorliegenden Fall, ein flächenmäßig recht großes und heterogenes Untersuchungsgebiet vorliegt. Die hierdurch auftretenden Verzerrungen sind aber als recht gering einzuschätzen; hierfür sprechen einerseits die theoretische Plausibilität der Ergebnisse und andererseits die Feststellung, dass jene Modellresultate, die bereits Gegenstand anderer Untersuchungen waren (z.B. hinsichtlich Verkaufsfläche und Fahrtzeit), mit diesen inhaltlich konsistent sind.

\subsubsection{Datenerhebung mittels telefonischer Haushaltsbefragung}

Die Erfassung der räumlichen Einkaufsorientierung erfolgte mittels einer telefonischen Haushaltsbefragung, wobei die Datengrundlage der zu kontaktierenden Personen, aus der die Stichprobe gezogen wurde, von einer Telefonbuch-DVD stammt (siehe Kap. 5.2.3.3). Dieses besonders in Deutschland durchaus übliche Vorgehen offenbart einen wesentlichen Nachteil: Zwar sind in dieser Kartei sowohl Festnetz- als auch Mobilfunknummern jeweils verschiedener Anbieter verzeichnet, jedoch können über ein solches Verzeichnis niemals alle Haushalte des jeweiligen Untersuchungsgebietes erreicht und befragt werden:

- Nach wie vor verfügen nicht alle Haushalte über einen Festnetzanschluss oder ein Mobiltelefon, wenngleich der Anteil telefonisch erreichbarer Haushalte mittlerweile mit über $99 \%$ angegeben wird (FUCHS 2012, S. 53)

- Ein weitaus größeres Problem stellen Haushalte dar, die zwar über Festnetzund/oder Mobiltelefonie erreichbar sind, jedoch nicht in gedruckten oder digitalen Telefonbüchern eingetragen sind. Zwar wird die im vorliegenden Fall genutzte Nummernkartei (TVG VERLAG 2011) damit beworben, dass Telefonbucheinträge 
durch eigene Recherchen angereichert werden, jedoch ist davon auszugehen, dass sie nicht alle tatsächlich existierenden Telefonnummern beinhaltet

- Bestimmte Personengruppen sind telefonisch schwieriger erreichbar als andere (z.B. Berufstätige mit vielen dienstlichen Reisen, Personen mit mehreren Wohnsitzen); die Wahrscheinlichkeit, dass diese befragt werden, ist somit auch geringer

- Diese drei genannten Einschränkungen telefonischer Befragungen werden noch dadurch verstärkt, dass mögliche Unzulänglichkeiten der Telefonkartei nicht ermittelbar sind: Es existieren keine (öffentlich zugänglichen) Daten über z.B. den Anteil von Geheimnummern oder Haushalten ohne Telefonanschluss; in keinem Fall sind solche Daten aber auf kleinräumiger Ebene (Ortsteile o.ä.) vorhanden. Ob und, wenn ja, welche Haushalte nicht erfasst sind und somit auch nicht in die Befragung einfließen konnten, kann also nicht ausgemacht werden

Zur Erfassung von Geheimnummern wird in der telefonischen Marktforschung gelegentlich das in den USA häufig genutzte Verfahren des Random Digit Dialing (RDD) als Möglichkeit diskutiert. Hierbei werden zufällige Rufnummern generiert, mit realen Vorwahlen verknüpft und über ein computergestütztes Telefonie-System angerufen. Dieses Verfahren ist jedoch, abgesehen vom damit verbundenen technischen und zeitlichen Aufwand, aufgrund der nichtstandardisierten Struktur deutscher Telefonnummern (unterschiedliche Anzahl Ziffern) nicht sinnvoll übertragbar (SCHNELL et al. 2011, S. 282ff.). Hinzu kommt, dass zufällig generierte Nummern bei der Berücksichtigung von Mobilfunkanschlüssen, die über nicht ortsgebundene Vorwahlen verfügen, Befragungen in einem lokal eng begrenzten Untersuchungsgebiet ad absurdum führen würden. Zumindest im vorliegenden Fall ist zusätzlich zu bedenken, dass die Vorwahlen nicht die Siedlungsstruktur des Untersuchungsgebietes repräsentieren; sie decken häufig, aber längst nicht immer, das jeweilige Gebiet der gesamten Gemeinde ab, differenzieren jedoch nicht nach einzelnen Ortsteilen. Eine durch Vorwahlen gestützte Stichprobenziehung hätte dann erfordert, die befragten Personen nach ihrer exakten Adresse (Straße und Hausnummer) zu fragen, um sie den Ortsteilen bzw. Teilgebieten zuordnen zu können; hierbei ist - insbesondere bei unpersönlichen Telefongesprächen aus Gründen der Privatsphäre eine hohe Verweigerungsquote zu erwarten.

Die im vorliegenden Fall gewählte Vorgehensweise war daher die beste Variante der Datenerhebung (und zugleich die in finanzieller Hinsicht einzig gangbare), obgleich Verzerrungen aufgrund nicht vollständig erfassbarer Stichprobenelemente möglich bzw. wahrscheinlich sind. Das eigentliche Problem hierbei ist jedoch, dass die Existenz jener Verzerrungen weder bewiesen noch widerlegt und damit auch nicht korrigiert werden kann. Die hypothetische Ideallösung dürfte in Anbetracht des vorliegenden Forschungsinteresses eine mündliche Haushaltsbefragung sein, die auf der Grundlage von Adressdaten der Einwohnermeldeämter durchgeführt wird; ein solches Vorgehen ist möglich, wenn hierfür eine Unbedenklichkeitsbescheinigung sowie vor allem finanzielle Mittel für den Erwerb dieser Adressdaten vorliegen (ADM 2011).

\subsubsection{Inhaltliche Einschränkungen allgemeiner Art}

Der Fokus des empirischen Teils dieser Untersuchung lag auf dem Nachweis des Einflusses räumlicher Ballung (Potenzial für Kopplungs- und Vergleichskäufe) auf die Marktgebiete von Einzelhandelsanbietern und die Operationalisierung dieser Zusammenhänge in einem 
Marktgebietsmodell. Diese Ziele konnten erreicht werden, jedoch geschah dies auf Kosten anderer Belange, die im vorliegenden Fall unberücksichtigt geblieben sind, obwohl sie wertvolle Informationsgewinne darstellen (können):

- In vielen Untersuchungen, die vorrangig aus der Marketing-Forschung stammen (z.B. DobBelstein 2004, GaURI et al. 2008, POPKOWSKI LeSzCZYC et al. 2004, VROEGRIJK et al. 2013), steht die Differenzierung von Kundentypen im Vordergrund, was im vorliegenden Fall unterblieben ist; die Analysen und ihre Ergebnisse beziehen sich auf alle Konsumenten. Die Berücksichtigung von Nachfragegruppen mit ähnlichen Präferenzen kann aber eine nützliche Konkretisierung bzw. Differenzierung der hier festgestellten Zusammenhänge darstellen, da bei unterschiedlichen Kundentypen (z.B. bezüglich Neigung zur Mehrfachorientierung, Preissensibilität, Mobilitätsbereitschaft und/oder sozio-ökonomischer Merkmale) auch durchaus unterschiedliche Einkaufsmuster zu erwarten sind

- Ebenso unberücksichtigt geblieben sind Unterschiede zwischen Einkaufszwecken (z.B. Haupt- und Ergänzungseinkäufe), wobei auch diese gewiss das räumliche Einkaufsverhalten beeinflussen (z.B. REUTTERER/TELLER 2009)

- In einigen ähnlich gelagerten Untersuchungen werden auch Erklärungsgrößen berücksichtigt, die auf die subjektive Wahrnehmung von Anbietern abzielen (z.B. Image) und nur bzw. auch anhand dessen die Einkaufsstättenwahl erklären (z.B. CLIQUET 1995). Eine Berücksichtigung dieser „subjektiven“ und/oder „qualitativen“ Elemente ist in der vorliegenden Untersuchung nicht vorgesehen gewesen, wurde aber - am Beispiel der Lebensmittelmärkte - in der späteren Modellerweiterung vorgenommen. Hierbei hat sich gezeigt, dass die "Marke“ eines Anbieters einen signifikanten Erklärungsgehalt für seine Kundenzuflüsse besitzt (siehe Kap. 7.2.3). Eine Berücksichtigung dieser Elemente ist also durchaus sinnstiftend

- Die hier durchgeführte empirisch-ökonometrische Modellanalyse bezieht sich notwendigerweise auf das Untersuchungsgebiet, da die in derartigen Modellen ermittelten Einflussgrößen bzw. deren Gewichtung nur innerhalb eines bestimmten räumlich-zeitlichen Bereichs „gültig“ sind (siehe Kap. 7.4.1.2). Im vorliegenden Fall besteht das Untersuchungsgebiet aus mehreren Klein- und Mittelstädten im ländlichen Raum; eine Übertragung auf andere Raumtypen (z.B. Großstädte und/oder deren suburbanes Umland) steht demgegenüber noch aus

- Auch wenn der Online-Einzelhandel nicht in allen Branchen eine nennenswerte Relevanz besitzt und bisher nichts dafür spricht, dass er den stationären Handel in absehbarer Zeit vollständig ablösen wird, so spielt er doch insbesondere im Elektronikeinzelhandel schon eine gewichtige Rolle. In dieser Untersuchung wurden Einkäufe bei Online-Anbietern nicht berücksichtigt bzw. nachträglich herausgerechnet; hierbei bleibt unausweichlich ein (geringer) Teil der erhobenen Informationen ungenutzt. Auch wenn diese Anbieter kein Marktgebiet im hier verstandenen Sinne besitzen, muss eine Möglichkeit gefunden werden, sie in (räumlichen) Entscheidungs- und Marktanteilsmodellen zu berücksichtigen

Diese aufgezeigten Einschränkungen lassen sich mit Hilfe eines dafür ausgelegten Untersuchungsdesigns kompensieren, wie die genannten artverwandten Arbeiten zeigen; z.B. sind die Berücksichtigung subjektiver Anbietermerkmale oder die Segmentierung nach 
Kundengruppen mit dem hier verfolgten Ansatz absolut kompatibel. Auch eine Integration von Online-Anbietern in solche Modelle ist prinzipiell möglich ${ }^{55}$. Diese Erweiterungen bzw. Verfeinerungen der Modelle sind späteren Untersuchungen vorbehalten und sollen in der weiteren Betrachtung keine Rolle mehr spielen.

\subsubsection{Inhaltliche Einschränkungen im Hinblick auf die Fragestellung}

Abgesehen von den Einschränkungen allgemeiner Art bestehen aber auch Beschränkungen im Hinblick auf die im Fokus der Untersuchung stehenden Inhalte:

- In der modellendogenen Abbildung der räumlichen Ballung von Betrieben wurde zwischen branchengleichen bzw. konkurrierenden Anbietern (Vergleichskäufe, Lokalisierungsvorteile) und branchenungleichen Anbietern (Kopplungskäufe, Urbanisierungsvorteile) differenziert. Im letztgenannten Fall konnte so aber nicht genauer identifiziert werden, welche Angebotsformen kopplungsaffin bzw. komplementär, irrelevant oder ggf. eher schädlich sind. In den Grundmodellen wurde nicht zwischen verschiedenen Bedarfsstufen des Angebots getrennt, so dass die Potenziale für horizontale und vertikale Kopplungskäufe nicht separat betrachtet und analysiert werden konnten. In der Modellerweiterung (Kap. 7.2.3) wurden eigene Konzentrationsvariablen für zwei Möglichkeiten horizontaler Kopplungen (Drogeriemärkte, Apotheken) ins Modell aufgenommen, wobei jedoch keine Einflüsse festgestellt wurden; langfristig ist hier jedoch eine tiefergehende Betrachtung notwendig (z.B. durch eine Auftrennung des Kopplungspotenzials nach Bedarfsstufen)

- In den Modellen zu den Marktgebieten der Lebensmittelmärkte wurde zusätzlich eine betriebsformenspezifische Unterscheidung vorgenommen, wobei allerdings nur zweifach unterschieden wurde (Vollsortimenter, Discounter). Diese zwar sachlich korrekte Abgrenzung deckt die wesentlichen Unterschiede zwischen den Anbietern ab (insb. Sortimentstiefe, Preisniveau und Service), ist hierbei jedoch recht grob, zumal die Übergänge zwischen Betriebsformen mitunter fließend sind (z.B. Kaufland) und sich die Discounter-Konzepte untereinander unterscheiden (z.B. Hard-Discounter wie Aldi und Soft- bzw. Marken-Discounter wie Netto)

- In mehreren angebotsorientierten Untersuchungen (z.B. ESTEBAN-BRAvo et al. 2012) wurde ein U-förmiger Zusammenhang zwischen betriebswirtschaftlichem Erfolg und räumlicher Nähe zu kompetitiven Anbietern festgestellt; dieser ist so zu erklären, dass im nahen Umfeld Lokalisierungsvorteile wirksam werden, ab einer bestimmten Entfernung die Wettbewerbseffekte dominieren und sich wiederum

\footnotetext{
${ }^{55}$ Eine Möglichkeit hierzu zeigt HSIAO (2009) in einer Studie zur Wahl des Vertriebskanals beim Bücherkauf auf, in der anhand eines Stated-Choice-Befragungsexperiments und eines binären Logit-Modells die Konsumentenentscheidung für einen stationären bzw. Online-Kauf analysiert wird. Der Grundgedanke hierbei ist, dass beim Online-Kauf bestimmte einkaufsbezogene Transaktionskosten nicht anfallen (Transportkosten durch Einkaufsweg und -zeit), dafür jedoch andere auftreten (Wartezeit bis zur Auslieferung der bestellten Ware). Die Nutzenfunktion enthält somit mehrere Formen von Transaktionskosten bzw. die Abwägung zwischen ihnen. Diese Untersuchung zeigt auf, wie der Online-Vertriebsweg in ein Entscheidungs-/Marktanteilsmodell integriert werden kann, ohne hierbei auf die räumlichen Elemente des Einkaufsweges im stationären Einzelhandel verzichten zu müssen. Abgesehen davon, dass in einer MCl-Anwendung noch einige technische Details (Umgang mit Ausprägungen von null) geklärt werden müssten, zeigt sich das hier verwendete Untersuchungsdesign also auch als grundsätzlich offen gegenüber der Berücksichtigung des nicht-stationären Einzelhandels.
} 
sehr stark isolierte Anbieter (Konkurrenzmeidung) in einer monopolartigen Stellung befinden. Dieser Zusammenhang ist in den Modellen nicht berücksichtigt bzw. überprüft worden, da - entsprechend der mathematischen Verknüpfung im HUFFbzw. MCl-Modell - stets von einem degressiven (positiven) Funktionsverlauf ausgegangen wurde

- Faktisch bestehen auch zwischen branchenungleichen Einzelhandelsanbietern Sortimentsüberschneidungen (z.B. Lampen und Leuchten in Elektronik-, Bau- und Möbelmärkten) und somit theoretisch auch kompetitive Beziehungen; ob hierbei Wettbewerbs- und/oder Agglomerationseffekte wirken, konnte nicht festgestellt werden, da jene Anbieter jeweils in die allgemeinen Konzentrationsvariablen (Kopplungskäufe) einbezogen wurden

- Die Konzentrationsvariablen stellen ein Potenzial in Form der Summe vieler einzelner Nutzenfunktionen dar; diese sind aber selbst nicht empirisch parametrisiert

- Die sowohl zwischen branchengleichen/konkurrierenden als auch andersartigen Betrieben mögliche Komplementarität ist nicht als solche operationalisiert worden; ein sehr konkreter Ansatz hierzu wurde von VROEGRIJK et al. (2013) aufgestellt

Diese genannten Inhalte, die im vorliegenden Fall weitgehend unberücksichtigt geblieben sind, können in späteren Untersuchungen durchaus mit den hier gegebenen Modellen verbunden werden. Von besonderem Interesse ist hierbei insbesondere eine genauere und differenziertere Abbildung der räumlichen Konzentration in den Modellen, die im vorliegenden Fall aufgrund der faktisch bestehenden Angebotskonfiguration und auch der begrenzten Stichprobengröße in der Haushaltsbefragung nicht geleistet werden konnte. Nicht alle Angebotsformen sind über Kopplungen miteinander kombinierbar, was schon NELSON (1958) aufgezeigt hat (hierzu z.B. auch WOTRUBA 2014). Ebenso schwierig ist die Differenzierung dessen, was einen „Konkurrenten“ darstellt, da Sortimentsüberschneidungen und Komplementaritäten zwischen den Ketten jeweils sehr unterschiedlich ausfallen. Allerdings sind hier weitere theoretische Überlegungen und empirisch ermittelte Informationen (z.B. POS-Erhebungen) notwendig, um in diesen Punkten tiefere Differenzierungen vorzunehmen und in ein Modell zu integrieren; schließlich sollten Modellinhalte plausibel begründet und nicht das Produkt einer ziellosen Berechnung möglichst vieler Variablen sein. Einige Ansätze zur diesbezüglichen Erweiterung der hier durchgeführten Modellanalysen werden in Kap. 7.4.3 besprochen.

Weiterhin ergeben sich inhaltliche Einschränkungen bzw. offene Fragen, die jedoch außerhalb des Fokus dieser Untersuchung liegen:

- Kopplungsbeziehungen bestehen nicht nur zwischen Einzelhandelsanbietern, sondern betreffen auch andere (einzelhandelsnahe) Dienstleistungen, die häufig an denselben Angebotsstandorten lokalisiert sind; sie werden mit Einkäufen verbunden bzw. können prinzipiell mit diesen verbunden werden (z.B. Friseur, Arzt, Reinigung, Tankstelle, freizeitorientierte Dienstleistungen, Gastronomie etc.) und spielen daher für die Gesamtattraktivität von Angebotsstandorten ebenso eine Rolle. Diese Dienstleistungen, die z.B. von NELSON (1958) in seinen Kompatibilitätstabellen berücksichtigt werden, wurden in dieser Untersuchung gänzlich ausgespart 
- Die hier untersuchten Anbieter-Nachfrager-Interaktionen haben rein statischen Charakter; die Empirie basiert auf dem - zum Erhebungszeitpunkt aktuellen - IstZustand. Demgegenüber behandelt die wohl komplexeste der zu Grunde gelegten Theorien (LANGE 1973) ausdrücklich die dynamischen Aspekte des räumlichen Einkaufsverhaltens und postuliert eine im Zeitverlauf steigende Relevanz räumlich und/oder sachlich multifinaler Einkäufe sowie die Zunahme räumlicher Disparitäten zwischen Angebotsstandorten. Derartige Entwicklungen sind aber nur über Langzeitstudien bzw. unter Rückgriff auf frühere Erhebungen nachweisbar

- Die theoretischen Erklärungsansätze, die in dieser Arbeit besprochen wurden (Kap. 3), fokussieren i.d.R. die Angebots- und Nachfrageseite, d.h. das räumliche Einkaufsverhalten und die unternehmerische Standortpolitik. Im empirischen Teil dieser Untersuchung ist der Fokus auf die Nachfrageseite gelegt worden, wobei genauso auch die Standort-, Sortiments- und Preisstrategien der Einzelhandelsunternehmen im Kontext von Einzelhandelsagglomerationen einer wissenschaftlichen Aufarbeitung bedürfen

\subsubsection{Weiterer Forschungsbedarf}

\subsubsection{Differenziertere Modellabbildung räumlicher Konzentration}

Aus den Einschränkungen der eigenen Untersuchung sowie die der anderen sachrelevanten Arbeiten lässt sich in mehrerlei Hinsicht ein weiterer Forschungsbedarf ableiten. An dieser Stelle soll der Frage nachgegangen werden, wie Marktgebiete im Einzelhandel im Kontext von Agglomerationseffekten noch differenzierter modellhaft abgebildet und empirisch überprüft werden können. Das Ziel ist die grobe Skizzierung eines komplexeren Modells, dessen empirische Anwendung in zukünttigen Untersuchungen vorgenommen werden kann; ob dies mit Hilfe eines MCl-Modells oder ggf. einer anderen, ähnlich angewandten Variante (z.B. diskretes Entscheidungsmodell) geschieht, ist vor diesem Hintergrund nachrangig.

Die Schlüsselrolle kommt hierbei der Operationalisierung der räumlichen Konzentration (bzw. des Potenzials für Kopplungs- und Vergleichskäufe) zu, die im vorliegenden Fall nach dem Vorbild der Konzentrationsvariablen von FOTHERINGHAM (1985) vorgenommen wurde; der entscheidende Vorteil hierbei liegt in der Erfassung von „Agglomeration“ als Kontinuum (anstatt einer starren Abgrenzung durch Gebietsgrenzen, z.B. Zahl der Anbieter im 1-kmRadius, Verfügbarkeit eines anderen Anbieters: ja/nein) bei gleichzeitig hoher Gewichtung naher Anbieter (siehe Kap. 5.3.1.4). Es fehlt allerdings eine Differenzierung der betrachteten Angebotsformen, da die Betriebe nur mit ihrer gesamten (entfernungsgewichteten) Eigenattraktivität (Verkaufsfläche) eingehen.

Zunächst stellt sich die Frage, wie die räumliche Konzentration mit kompetitiven Anbietern $\left(K_{K j}\right)$ besser abgebildet werden kann. Um hier Abhilfe zu schaffen, kann auf das Maß zur Quantifizierung von Komplementarität zwischen Anbietern von VROEGRIJK et al. (2013) zurückgegriffen werden, das im Wesentlichen auf der „Unähnlichkeit“ hinsichtlich der angebotenen Produktkategorien basiert; es quantifiziert die Komplementarität zwischen zwei branchengleichen Anbietern (je höher das Maß, desto komplementärer bzw. desto besser), beinhaltet jedoch wiederum keine räumliche Komponente (z.B. Entfernung zwischen den Anbietern) bzw. bildet keine Agglomeration ab. Es ist daher naheliegend, dieses Maß mit den Konzentrationsvariablen zu verbinden bzw. in sie einfließen zu lassen (siehe Formel 46). 
Wird diese Abbildungsform gewählt, ist keine Differenzierung der Betriebsformen mehr notwendig, da diese automatisch über den Komplementaritätswert abgedeckt wird. Für die Berechnung der Komplementarität ist jedoch ein nicht zu unterschätzender Aufwand notwendig, da hierfür die genaue Sortimentsstruktur aller berücksichtigten Anbieter bekannt sein muss (zur genauen Berechnung des Indikators siehe VROEGRIJK et al. 2013, S. 613f.).

$$
K_{K_{j}}=\sum_{\substack{k \\ k \neq j}} \frac{A_{k} \text { Komp }_{j k}}{d_{j k}^{\lambda}}
$$

$\mathrm{K}_{\mathrm{kj}}=$ Konzentrationsvariable für die Ballung des Anbieters $\mathrm{j}$ mit allen $\mathrm{k}$ Anbietern

$A_{k}=$ Verkaufsfläche des Anbieters $k$

Kompjk $=$ Komplementarität zwischen Anbieter j und Anbieter k

$\mathrm{djk}_{\mathrm{k}}=$ Entfernung $(\mathrm{km})$ von Anbieter $\mathrm{j}$ zu Anbieter $\mathrm{k}$

Prinzipiell kann dieser Komplementaritäts-Ansatz, der für branchengleiche Anbieter gedacht ist, auch auf Anbieter anderer Branchen übertragen werden, um das Kopplungspotenzial genauer darzustellen. Hierfür wäre es allerdings notwendig, diejenigen Sortimentsbereiche bzw. Produkte bzw. Artikel zu identifizieren, deren Erwerb bevorzugt miteinander verbunden wird; denkbar wäre hier z.B. eine Differenzierung der Sortimentsbereiche nach ihren Bedarfsstufen. Eine andere, einfachere Möglichkeit besteht darin, die allgemeine Konzentrationsgröße $\left(K_{A j}\right)$ entsprechend aufzuteilen bzw. separat mehrerer dieser Variablen zu integrieren. In dieser Untersuchung wurden exemplarisch einzelne Variablen für die Ballung mit Apotheken und Drogerien gebildet; natürlich kann dies auch bezüglich anderer Angebotsformen angewendet werden, jedoch sind der Modellerweiterung aufgrund von möglichen Multikollinearitätseffekten gewisse Grenzen gesetzt (siehe Kap. 7.2.3). Daher bestünde hier eine gangbare Möglichkeit in einer Aufteilung der allgemeinen $K$-Variable anhand des horizontalen und des vertikalen Kopplungspotenzials (siehe Formel 47 bzw. 48). Falls z.B. Lebensmittelmärkte betrachtet werden, würde $K_{H j}$ die räumliche Konzentration mit den Anbietern derselben Bedarfsstufe (z.B. Drogeriemärkte, Schreibwarengeschäfte), d.h. das horizontale Kopplungspotenzial, abbilden; analog würde $K_{V j}$ die Anbieter von Gütern anderer Bedarfsstufen (z.B. Baumärkte), d.h. das vertikale Kopplungspotenzial, beinhalten.

$$
K_{H_{j}}=\sum_{\substack{h \\ h \neq j}} \frac{A_{h}}{d_{j h}^{\lambda}}
$$

$\mathrm{K}_{\mathrm{Hj}}=$ Konzentrationsvariable für die Ballung des Anbieters $\mathrm{j}$ mit allen $\mathrm{h}$ Anbietern von Gütern derselben Bedarfsstufe

$A_{h}=$ Verkaufsfläche des Anbieters $h$

$\mathrm{d}_{\mathrm{j} h}=$ Entfernung $(\mathrm{km})$ von Anbieter $\mathrm{j} z \mathrm{zu}$ Anbieter $\mathrm{h}$

$$
K_{V_{j}}=\sum_{\substack{v \\ v \neq j}} \frac{A_{v}}{d_{j v}^{\lambda}}
$$

$\mathrm{K}_{\mathrm{v} j}=$ Konzentrationsvariable für die Ballung des Anbieters $\mathrm{j}$ mit allen $\mathrm{h}$ Anbietern von Gütern anderer Bedarfsstufen

$A_{v}=$ Verkaufsfläche des Anbieters $v$

$\mathrm{d}_{\mathrm{j} v}=$ Entfernung $(\mathrm{km})$ von Anbieter j zu Anbieter v 


\subsubsection{Empirische Fundierung der Konzentrationsvariablen}

Wenn nun, wie im letzten Kapitel ansatzweise dargestellt, die räumliche Konzentration zu branchengleichen und andersartigen Betrieben differenzierter abgebildet werden kann, besteht weiterhin das Problem, das die implizit zu Grunde liegende Nutzenfunktion (Summe der Nutzen des Besuchs aller anderen berücksichtigten Betriebe) nicht empirisch parametrisiert ist. Es stellt sich hierbei beispielsweise die Frage, wie stark der Effekt der Distanz zwischen den Anbietern ist; nach den Überlegungen einiger Autoren (z.B. ESTEBANBRAVO et al. 2012, LI/LIU 2012) wirken (positive) Agglomerationseffekte im Einzelhandel nur bis zu einer bestimmten Reichweite, die jedoch faktisch unbekannt ist.

Daher ist es sinnvoll, die tatsächliche Distanzwirkung empirisch zu untersuchen und auf dieser Grundlage in den Indikator zu integrieren; selbiges gilt für die anderen Erklärungsgrößen (Attraktivität, ggf. Komplementarität). Eine aufwendige, aber zweckmäßige Hilfe kann hier die tatsächliche Erhebung des Kundenaustauschs zwischen Anbietern durch POS-Befragungen darstellen; auf dieser Grundlage leitet NELSON (1958) eine Formel zum Kundenaustausch bzw. Kompatibilitätstabellen (siehe Kap. 2.4.3). Bei Kundenbefragungen am Angebotsstandort kann ermittelt werden, welche Anbieter im Verbund aufgesucht werden bzw. wie hoch der Grad des Kundenaustauschs $\left(l_{j k}\right)$ zwischen innen ist; in Anlehnung an die Formel von NELSON kann dieser als Funktion der erklärenden Größen aus den o.g. Konzentrationsvariablen aufgefasst werden (siehe Formel 49 am Beispiel der Interaktionen mit branchengleichen bzw. kompetitiven Anbietern).

$$
I_{j k}=f\left(A_{k}, K_{o m p}, d_{j k}\right)
$$

$\mathrm{l}_{\mathrm{jk}}=$ Kundenaustausch zwischen den Anbietern $\mathrm{j}$ und $\mathrm{k}$

$A_{k}=$ Verkaufsfläche des Anbieters $k$

Kompjk $=$ Komplementarität zwischen Anbieter j und Anbieter $\mathrm{k}$

$\mathrm{d} j \mathrm{k}_{\mathrm{k}}=$ Entfernung $(\mathrm{km})$ von Anbieter $\mathrm{j}$ zu Anbieter $\mathrm{k}$

Die ermittelten Echtwerte des Kundenaustauschs können in ein Regressionsmodell als abhängige Variable eingesetzt und den erklärenden Größen gegenübergestellt werden; hierbei ist, ähnlich den anderen Nutzenfunktionen, eine eigentlich nicht-lineare Form anzunehmen, so dass dieses Modell linearisiert werden muss (siehe Formel 50). Auf diese Weise wird also der Kundenaustausch zwischen den Anbietern $j$ und $k$ anhand ihrer Eigenattraktivität, ihrer Komplementarität zueinander und der Distanz zwischen innen empirisch-ökonometrisch erklärt. Die auf diesem Wege ermittelten Parameter können als Gewichtungsexponenten in die Konzentrationsvariablen eingesetzt werden.

$$
\begin{aligned}
& \log \left(I_{j k}\right)=\log (a)+b_{1} \log \left(A_{k}\right)+b_{2} \log \left(K o m p_{j k}\right)+\lambda \log \left(d_{j k}\right)+\varepsilon \\
& b_{1}, b_{2}, \lambda=\text { Regressionskoeffizienten } \\
& a=\text { Konstante } \\
& \varepsilon=\text { Residuen }
\end{aligned}
$$

Analog könnte der Kundenaustausch mit branchenungleichen Anbietern (horizontales bzw. vertikales Kopplungspotenzial) modelliert werden (Beispiel siehe Formel 51 für horizontale Kopplungen zwischen Anbietern). 


$$
\begin{aligned}
& \log \left(I_{j h}\right)=\log (a)+b_{1} \log \left(A_{h}\right)+\lambda \log \left(d_{j h}\right)+\varepsilon \\
& \mathrm{l}_{\mathrm{jh}}=\text { Kundenaustausch zwischen den Anbietern j und h (Anbieter von Gütern derselben Bedarfsstufe) } \\
& \mathrm{A}_{\mathrm{h}}=\text { Verkaufsfläche des Anbieters } \mathrm{h} \\
& \mathrm{d}_{\mathrm{jh}}=\text { Entfernung }(\mathrm{km}) \text { von Anbieter j zu Anbieter } \mathrm{h}
\end{aligned}
$$

Das hier beschriebene Vorgehen ist in der Praxis sicherlich sehr aufwendig und zudem noch nicht vollständig ausgereift. Ein Kernproblem besteht in der Durchführung der empirischen Erhebungen (POS-Befragungen), da hier eine sehr große Stichprobe an möglichst vielen Angebotsstandorten notwendig ist; schließlich sollte im Idealfall der Kundenaustausch zwischen allen Anbieterkombinationen erfasst werden. Prinzipiell zeigt das skizzierte Vorgehen aber eine Option auf, die räumliche Konzentration von Einzelhandelsanbietern wesentlich differenzierter modellintern abzubilden und die Konzentrationsvariablen mit einer empirisch fundierten Gewichtung zu versehen.

\subsubsection{3 Übertragung auf andere Branchen und räumliche Kontexte}

Eine der entscheidenden Neuerungen der vorliegenden Arbeit besteht darin, den Einfluss von Agglomerationseffekten am Beispiel von Branchen außerhalb des Lebensmittelhandels zu untersuchen; in diesem Fall wurden Elektronik- und Baumärkte berücksichtigt. Allerdings bildet auch dieses Vorgehen selbstverständlich kein rundum vollständiges Bild von Agglomerationseffekten im Einzelhandel; hierzu ist es notwendig, vergleichbare Analysen in Bezug auf andere Branchen durchzuführen. Im Bereich zumeist großflächiger Fachmärkte sind hier zunächst Möbelhäuser zu nennen, die in dieser Untersuchung eigentlich behandelt werden sollten, jedoch aufgrund methodischer Schwierigkeiten unberücksichtigt geblieben sind (siehe Kap. 6.2.2.4). Weiterhin empfiehlt sich eine Berücksichtigung von Anbietern typischer „shopping goods“ (z.B. Bekleidungs- und Schuheinzelhandel); hier ist noch von weit höheren positiven Agglomerationseffekten bzw. „shared business“ auszugehen. Im Nahversorgungskontext sind zudem diesbezügliche Zusammenhänge bei Drogeriemärkten zu prüfen - ein Sektor, der bisher in Marktgebietsanalysen vollständig umgangen wurde.

Das Untersuchungsgebiet der vorliegenden Untersuchung befindet sich im ländlichen Raum Ostwestfalens/Südniedersachsens und besteht aus sieben Gemeinden, darunter drei Kleinbzw. Mittelstädte. Die hier ermittelten Zusammenhänge sind in dieser „exakten“ Weise auch nur auf diesen Untersuchungsraum anwendbar, da die Parameter in Marktgebietsmodellen eng an das betreffende Gebiet bzw. an den jeweiligen Untersuchungszeitraum gekoppelt sind (siehe Kap. 7.4.1.2). Da konsumentenseitige Ausgangsbedingungen (u.a. soziodemographische und Einkommensstruktur, Kundenpräferenzen), Angebotsstrukturen (u.a. Verfügbarkeit von bestimmten Ketten, Standortkonfigurationen der Anbieter) und auch die den Einkaufsverkehr betreffende Verkehrserschließung (u.a. Autobahnanbindung, ÖPNVDichte) räumlich und zeitlich variieren, ist in anderen räumlichen Kontexten durchaus davon auszugehen, dass sich die Wirkungsintensität einzelner Komponenten des räumlichen Einkaufsverhaltens anders darstellen.

Die im vorliegenden Fall in einem ländlich geprägten Gebiet durchgeführte Untersuchung sollte mit ähnlicher bzw. gleicher methodischer Herangehensweise auch auf andere Raumtypen übertragen werden. Insbesondere sollten Großstädte bzw. deren suburbanes Umland auf die Ausprägungen der Einkaufsstättenwahl unter Berücksichtigung von Agglomerationseffekten untersucht werden; Unterschiede in der Ausgangssituation ergeben 
sich hier u.a. im Hinblick auf die Mobilität der einkaufenden Bevölkerung (tendenziell geringere PKW-Nutzung, ausgebauter ÖPNV z.B. durch dicht getaktete S- und U-Bahnen, Fußgängerverkehr), die Verfügbarkeit verschiedener Anbieter bzw. Betriebsformen (Stichworte: Auswahl, Mehrfachorientierung) und abweichende demographische Strukturen (z.B. tendenziell mehr Single-Haushalte, jüngere Bevölkerung). Es ist hierbei plausibel anzunehmen, dass sich z.B. der Distanz-/Fahrtzeiteffekt aufgrund einer tendenziell nahen Verfügbarkeit vieler Anbieter anders darstellen wird als im ländlichen Raum; ob selbiges auch für das Potenzial für Kopplungs- und Vergleichskäufe zutrifft, gilt es zu überprüfen.

\subsubsection{Untersuchung der Anbieterstrategien}

In der hier durchgeführten Untersuchung wurden angebotsseitige Aspekte nur am Rand behandelt. In einigen Fällen konnten anhand eigener Aufarbeitungen (z.B. siehe Anhang, Tab. A 1) und früherer Studien Aussagen zur Standortpolitik von Einzelhandelsunternehmen getroffen werden; insgesamt zeigt sich dieser Bereich aber als vergleichsweise wenig bearbeitet. Zwar existieren viele Untersuchungen zur quantitativen Analyse von Standortmustern und Branchenkonzentrationen (siehe Kap. 4.1.1 u. 4.1.2), jedoch sind tiefer gehende empirische Studien zur dahinter stehenden Unternehmenspolitik recht selten. Eine interessante Ausnahme bildet z.B. JÜRGENS (2012a u. 2013), der, zumindest exemplarisch, die Bildung von strategischen Standortkooperationen nachweist. REN et al. (2011) zeigen auf, dass Agglomerationen nicht nur ein typischer Aspekt der Standortpolitik sind, sondern auch die Sortimentspolitik betreffen (Anpassung des Sortiments in Abhängigkeit von der Nähe zu Mitbewerbern). Allerdings findet sich insgesamt nur wenig über die anbieterseitigen Strategien der Standort-, Sortiments- oder Preispolitik im Spiegel der Agglomerationsbildung.

Ein möglicher empirischer Zugang zur Füllung dieser Lücken bilden differenziertere Analysen räumlicher Konzentrationen, in denen ein Vorgehen wie z.B. bei KRIDER/PUTLER (2013) mit der Berücksichtigung einzelner Sortimentskategorien (z.B. REN et al. 2011, VROEGRIJK et al. 2013) kombiniert wird. Allerdings zielt dieses Vorgehen wiederum nur auf eine indirekte Bestimmung der zugehörigen Unternehmenspolitik ab und ist in Anbetracht der notwendigen Berücksichtigung der Sortimente auch recht aufwendig.

Ein gänzlich anderer Ansatz besteht hier in der direkten Adressierung der relevanten Einzelhandelsunternehmen selbst. Denkbar wäre einerseits eine gegenüberstellende Betrachtung der von den Unternehmen nach außen kommunizierten Standortfaktoren, wie es in dieser Arbeit exemplarisch für eine Reihe in Deutschland aktiver Unternehmen des Lebensmitteleinzelhandels vorgenommen wurde (siehe Anhang, Tab. A 1); diese nichtstandardisierten Aussagen könnten mit inhaltsanalytischen Methoden systematisiert und ausgewertet werden. Zudem besteht die Möglichkeit von quantitativen bzw. standardisierten Unternehmensbefragungen, deren Items nicht nur „typische“ Standortfaktoren (Flächen von Grundstücken, Mieten, PKW-Anbindung etc.) abfragen, sondern differenziert die Nähe zu branchengleichen und anderen Anbietern behandeln. Zum genannten Zweck sind aber auch qualitative Untersuchungsansätze denkbar, wie sie etwa JÜRGENS (2012a u. 2013) in Einzelfällen angewandt hat (Experteninterviews). Möglicherweise eignen sich diese in einem Bereich, der im Gegensatz zum räumlichen Einkaufsverhalten weit weniger theoretisch erschlossen ist, sogar besser zur Gewinnung sachrelevanter Erkenntnisse; eine breite Validierung kann später in Form von quantitativen Studien erfolgen. 


\section{$8 \quad$ Fazit}

Die vorliegende Untersuchung hat sich mit der Existenz und den möglichen Ausprägungen von Agglomerationseffekten im Einzelhandel - genauer gesagt: mit dem räumlichen Einkaufsverhalten im Kontext von Angebotsballungen und dessen Auswirkungen auf die Marktgebiete von Einzelhandelsanbietern - beschäftigt. Der dahinter stehende Ausgangsgedanke leitet sich aus der Feststellung ab, dass offensichtlich eine Tendenz zur räumlichen Konzentration von Einzelhandelsangebot an bestimmten (größeren) Angebotsstandorten besteht, während andere (kleinere) Angebotsstandorte an Bedeutung verlieren; hierzu zählen Solitärlagen in Wohngebieten, aber auch kleinere Agglomerationen wie bestimmte Innenstadtbereiche oder Nahversorgungszentren. Die Ausprägungsformen dieser Agglomerationstendenzen sind vielfältig; sie reichen von altbekannten Erscheinungen wie der Ballung von Fachmärkten und dem Aufbau von geplanten Einkaufszentren „auf der Grünen Wiese“ über deren mittlerweile anzutreffende Orientierung in Richtung der Innenstädte bis hin zum jungen Phänomen geplanter Standortkooperationen eigentlich konkurrierender Anbieter (z.B. verschiedene Betriebsformen des Lebensmitteleinzelhandels). Die Relevanz der Agglomerationstendenzen spiegelt sich in den aktuellen Diskussionen zur Gewährleistung der Nahversorgung (insbesondere im Hinblick auf Lebensmittelmärkte) und zu den Auswirkungen innerstädtischer bzw. innenstadtnaher Einkaufszentren wider. Auch im Zusammenhang der Einzelhandelssteuerung in der räumlichen Planung auf verschiedenen Ebenen gewinnen Einzelhandelsagglomerationen seit Ende der 2000er Jahre an Bedeutung.

Die Standortpolitik zählt zu den zentralen Handlungsparametern der Einzelhandelsbetriebe; ihre räumliche Ballung müsste demnach die Folge betriebswirtschaftlicher Standortstrategien sein, deren Ursprung u.a. im räumlichen Einkaufsverhalten der Verbraucher zu suchen ist. Die Einkaufsstrategien, welche die Wahl von agglomerierten Anbietern als vorteilhaft erscheinen lassen, sind Kopplungs- und Vergleichskäufe bei gleichzeitiger Minimierung des damit verbundenen Aufwands; sofern die Möglichkeit solcher räumlich und/oder sachlich multifinaler Einkäufe ein Attraktivitätsmerkmal bei der Einkaufsstättenwahl darstellt, müsste sich die Kundenfrequentierung eines Einzelhandelsanbieters (auch) über sein Potenzial für Kopplungs- und Vergleichskäufe erklären lassen. Die zentralen Fragestellungen der Arbeit bestanden daher darin, dass 1. geprüft werden sollte, ob und, wenn ja, welchen Effekt die räumliche Ballung von Einzelhandelsbetrieben auf ihren Kundenzufluss aus dem Marktgebiet hat (Inhaltliches Ziel) und 2. eine Methode entwickelt werden sollte, wie etwaig festgestellte Effekte in Marktgebietsmodellen zur Modellierung von Kunden-/Kaufkraftströmen abzubilden sind (Methodologisches Ziel).

Im ersten Schritt wurden hierzu die theoretischen Grundlagen aufgearbeitet, wobei sehr heterogene Konzepte aus der Mikroökonomie (v.a. CHAMBERLIN 1933 und Nachfolger), der „traditionellen“ Wirtschaftsgeographie bzw. Raumwirtschaftstheorie (u.a. CHRISTALLER 1933) und ihren Weiterführungen (LANGE 1973), der empirisch-induktiven Standortforschung (NELSON 1958) und des betriebswirtschaftlichen Marketings Berücksichtigung fanden. Vor diesem Hintergrund stellte sich heraus, dass das fokussierte Thema theoretisch sehr breit aufgearbeitet ist, aber aus sehr unterschiedlichen Perspektiven, die mitunter völlig eigenständig sind. Das erste Teilergebnis dieser Arbeit besteht daher darin, diese heterogenen Ansätze entlang der Forschungsfrage zusammenzuführen. 
Im Kern besteht der kundenseitige Reiz an Einzelhandelsagglomerationen darin, dass sie die notwendigerweise hinzunehmenden Transportkosten (Einkaufsweg) sowie weitere mit dem Einkauf verbundene Transaktionskosten reduzieren und zudem eine bessere Erfüllung konsumentenseitiger Präferenzen und Ansprüche ermöglichen. Dies ist auf fünf ggf. miteinander verbundene Einkaufsstrategien zurückzuführen: Aus Gründen der Zeitersparnis und anderer Formen der Minimierung mit dem Einkauf verbundener Transaktionskosten führen Konsumenten bei ihren Besorgungen Kopplungskäufe durch, sowohl hinsichtlich von Gütern derselben Bedarfsstufe (horizontale Kopplung) als auch verschiedener Bedarfsstufen (vertikale Kopplung). Weiterhin besteht das klassische "Shopping“ in Form von suchgesteuerten Vergleichskäufen zwischen kompetitiven Anbietern (Typisches Beispiel: Schuhkauf). Dieses bei Suchgütern typische Einkaufsverhalten greift jedoch nicht bei Erfahrungsgütern, zu denen die Güter des täglichen Bedarfs (insb. Lebensmittel) gehören: Hier ist die Verkettung des Besuchs mehrerer Anbieter einerseits durch eine konsequente Preisorientierung (Wahrnehmung der Sonderangebote mehrerer Anbieter) zu erklären (Angebotsgesteuerte Vergleichskäufe) und andererseits durch das gezielte Aufsuchen von mehreren (Lebensmittel-)Märkten aufgrund von Präferenzen für jeweils spezifische Produktund Anbietervarianten (Präferenz- und erfahrungsgesteuerte Vergleichskäufe); demnach existiert nicht nur zwischen kopplungsaffinen Branchen, sondern auch zwischen im Wettbewerb stehenden Anbietern eine Form von Komplementarität. Die beiden letztgenannten Einkaufsstrategien sind den klassischen (Standort-)Theorien fremd, werden jedoch in neueren Marketing-Ansätzen aufgearbeitet (z.B. POPKOWSKI LESZCZYC et al. 2004, VROEGRIJK et al. 2013); sie erklären v.a. die räumliche Ballung von kompetitiven Lebensmittelmärkten, die ein recht neues Phänomen darstellen.

Unter ansonsten gleichen Bedingungen bevorzugen die Konsumenten daher Anbieter, die aufgrund ihrer räumlichen Nähe zu komplementären und/oder kompetitiven Betrieben die Möglichkeit von Kopplungs- und/oder Vergleichskäufen bieten. Sie akzeptieren zu deren Wahrnehmung auch weitere Einkaufswege als zu ggf. näher gelegenen Anbietern ohne Potenzial für Kopplungs- und Vergleichskäufe. Anbieter in Agglomerationen können daher größere Kundenzuflüsse aus ihrem Marktgebiet generieren als ihre Mitbewerber an isolierten bzw. weniger agglomerierten Angebotsstandorten. In der Standortpolitik besteht demnach ein ökonomischer Anreiz zur räumlichen Ballung aufgrund von positiven Agglomerationseffekten (Lokalisierungsvorteile durch die Ballung mit branchengleichen bzw. konkurrierenden Anbietern, Urbanisierungsvorteile durch die Nähe zu andersartigen Betrieben); der Abbau von anderweitig lokalisiertem Angebot ist die notwendige Kehrseite hiervon, was die räumlich ungleiche Angebotsausstattung bzw. Versorgung fördert bzw. weiter verstärkt.

Es stellte sich weiterhin die Frage, wie Marktgebiete im Einzelhandel unter Berücksichtigung von Agglomerationseffekten empirisch angegangen werden können; daher erfolgte eine Auseinandersetzung mit den mathematischen bzw. ökonometrischen Modellen des räumlichen Einkaufsverhaltens, wie sie u.a. in der Markt- und Standortforschung eingesetzt werden. Hierbei wurde mit dem Multiplicative Competitive Interaction (MCl) Model von NAKANISHI/COOPER (1974) ein Weg gefunden, beide Forschungsfragen dieser Arbeit zu kombinieren. Dieses ökonometrische Modell, dessen Zielgröße empirische Marktgebiete bzw. lokale Marktanteile von Anbietern sind, basiert auf dem bekannten HUFF-Modell (HUFF 1962, 1963, 1964), das seit Jahrzehnten erfolgreich in Einzelhandelsgutachten und der 
betrieblichen Standortanalyse eingesetzt wird, und besteht im Wesentlichen darin, diesen nicht-linearen Modellansatz in ein lineares Regressionsmodell zu transferieren und es somit empirisch-ökonometrischen Verfahren (lineare Regressionsanalyse) zugänglich zu machen. Das HuFF-Modell besitzt eigene theoretische Inhalte zum Einkaufsverhalten, die auch in das theoretische Konzept dieser Arbeit eingeflossen sind und sich mit dem MCl-Modell empirisch überprüfen lassen; das HUFF-Modell bietet also einen theoretischen Rahmen für das $\mathrm{MCl}$ Modell und umgekehrt ist das MCl-Modell ein empirisch-ökonometrischer Zugang des HuFFModells. Zudem hat FOTHERINGHAM (1985) bereits einen theoretischen Ansatz entwickelt, wie Agglomerationseffekte in die Nutzenfunktionen von Marktgebietsmodellen insbesondere dem HUFF-Modell - integriert werden können. Es war also naheliegend, beide Ideen zu verbinden und in der eigenen Untersuchung einzusetzen.

Zwar existieren schon einige Arbeiten aus den Jahren 2003 bis 2013, in denen grundsätzlich ähnliche Fragen behandelt wurden, jedoch weisen diese entscheidende Beschränkungen auf: So existierte bisher kein empirisch-ökonometrischer Modellansatz, in dem die genannten Formen von Urbanisierungseffekten und Lokalisierungseffekten gemeinsam integriert wurden und erst recht keiner, in dem dabei noch Agglomerationen im engeren geographischen Sinne abgebildet wurden. Die Integration bzw. simultane Prüfung beider Effekte unter gleichzeitiger Nutzung eines adäquaten Maßes für räumliche Konzentration wurden somit zu den zentralen Zielen des empirischen Teils der vorliegenden Arbeit. Weiterhin wurde erstmals geprüft, welche betriebsformenspezifischen Agglomerationseffekte im Lebensmitteleinzelhandel wirksam werden, was v.a. vor dem Hintergrund der steigenden Zahl an Standortkooperationen von Anbietern verschiedener Betriebsformen (z.B. Verbrauchermarkt und LM-Discounter) eine interessante Frage darstellt; hierzu wurde eine separate Untersuchung zur räumlichen Ballung mit kompetitiven Anbietern der gleichen sowie anderer Betriebsformen durchgeführt bzw. deren Effekte abgesondert. Zudem wurde mit dem vorliegenden Vorgehen ein weiteres Defizit ausgeglichen, nämlich durch die Berücksichtigung weiterer Branchen außerhalb des Lebensmitteleinzelhandels; bisherige Arbeiten waren fast ausnahmslos auf das räumliche Einkaufsverhalten beim Einkauf von Lebensmitteln bzw. die Marktgebiete von Lebensmittelmärkten beschränkt. Das zweite Teilergebnis dieser Arbeit besteht daher im Entwurf eines Marktgebietsmodells, das gleichzeitig Lokalisierungs- und Urbanisierungseffekte unter Nutzung eines adäquaten Maßes für die räumliche Konzentration abbilden kann.

Um die MCI-Modellanalysen durchführen zu können, wurde im Untersuchungsgebiet (sieben angrenzende Gemeinden im ländlich geprägten Raum des Grenzgebietes von Ostwestfalen und Südniedersachen) zunächst eine Vollerhebung bzw. Kartierung des Einzelhandels durchgeführt; diese ist notwendig gewesen, um einerseits die untersuchungsrelevanten Einzelhandelsbetriebe (Lebensmittelmärkte, Elektronikmärkte, Bau- und Heimwerkermärkte, Möbelmärkte) zu identifizieren und andererseits allgemeine Konzentrationsvariablen für diese zu bilden, die das Kopplungspotenzial des jeweiligen Anbieters ausdrücken. Weiterhin wurden Konzentrationsvariablen zur Abbildung der räumlichen Konzentration in Bezug auf kompetitive Anbieter erstellt. In die MCl-Modelle wurden die Kernerklärungsgrößen des HUFF-Modells (Eigenattraktivität der Anbieter bzw. Verkaufsfläche, Transportkosten bzw. PKW-Fahrtzeit vom Nachfrage- zum Angebotsstandort) als Kontrollvariablen integriert. Im Untersuchungsgebiet ist die räumliche Einkaufsorientierung der Haushalte über eine repräsentative telefonische Haushaltsbefragung erfasst worden; die auf dieser Grundlage 
errechneten lokalen Marktanteile der Einzelhandelsbetriebe bildeten die erklärenden Variablen in den $\mathrm{MCl}-$ Modellen.

In der Modellanalyse wurden einerseits die Hypothesen zu den Wirkungen der erklärenden Größen im ursprünglichen HuFF-Modell (Angebotsgröße, Transportkosten) getestet. Der eigentliche Fokus lag jedoch auf dem Zusammenhang zwischen der Ballung einzelner Anbieter und dem räumlichen Einkaufsverhalten der Konsumenten. Hierbei wurden die Hypothesen formuliert, dass in allen betrachteten Branchen sowohl die räumliche Ballung mit andersartigen Betrieben (Kopplungspotenzial) als auch mit konkurrierenden (Potenzial für Vergleichskäufe) einen positiven Einfluss auf den Kundenzufluss aus den Marktgebieten haben. Da weit über die Hälfte der Möbeleinkäufe außerhalb des Untersuchungsgebietes stattfanden, wurden sie aus der Modellanalyse ausgeschlossen. Für die Lebensmittelmärkte wurde zusätzlich eine betriebsformenspezifische Analyse durchgeführt; hierbei wurden separate Modelle jeweils für LM-Vollsortimenter und LM-Discounter gebildet und mit eigenen Konzentrationsvariablen für die jeweils eigene und die andere Betriebsform versehen. Um den hohen Ansprüchen ökonometrischer Modellbildung gerecht zu werden, wurden alle $\mathrm{MCl}$ Modelle im Hinblick auf etwaige Annahmenverletzungen linearer Regressionsmodelle getestet und zudem mehrfach parametrisiert; hierbei kamen u.a. heteroskedastizitätsrobuste Inferenzstatistiken sowie separate schrittweise Regressionsanalysen zum Einsatz. Zudem wurden durch die Nutzung der Methode der geographisch gewichteten Regression (GWR) erstmalig Marktgebietsmodelle mit räumlich nicht-stationären Parametern geschätzt.

Die Ergebnisse der Modellanalysen bestätigen den Großteil der Hypothesen. Abgesehen davon, dass abermals die erklärenden Größen des HuFF-Modells in ihrer Wirkungsrichtung und -größe empirisch verifiziert werden konnten, sind auch weitgehend positive Einflüsse der räumlichen Ballung auf die konsumentenseitige Einkaufsorientierung nachgewiesen worden. Im Lebensmitteleinzelhandel beeinflusst die räumliche Nähe zu konkurrierenden Anbietern die eigenen Kundenströme aus dem Marktgebiet positiv; dieser Effekt wird differenzierter in der betriebsformenspezifischen Betrachtung: Für Vollsortimenter ist die Nähe zu Discountern positiv und umgekehrt, wohingegen die Nähe zur jeweils gleichen Betriebsform die eigenen Kundenzuflüsse schmälert. Dieses erstmalig nachgewiesene Ergebnis bestätigt klar die Vorstellungen einer Komplementarität zwischen diesen nur bedingt substituierbaren Angebotsformen: Kunden haben die Möglichkeit, entsprechend ihren Präferenzen für bestimmte Produkt-Anbieter-Kombinationen, ihren persönlichen Warenkorb durch die Besuche mehrerer Märkte zu optimieren; sofern diese Märkte geballt auftreten, ist zusätzlich noch eine Minimierung des Einkaufsaufwandes hiermit verbunden. Kopplungspotenzial entfaltet in den vorliegenden Modellen keinen positiven Effekt auf die Kundenzuflüsse, was insbesondere für die LM-Discounter gilt; dies ist ein Hinweis darauf, dass beim Lebensmitteleinkauf viele theoretisch mögliche Kopplungen praktisch nicht relevant sind und Agglomerationseffekte in dieser Branche vorrangig durch die Nähe zu komplementärkompetitiven Anbietern von Gütern derselben Bedarfsstufe auftreten.

Im Fall der Anbieter von mittel- und langfristigen Gütern (Elektronikmärkte, Baumärkte) wurde erstmals empirisch nachgewiesen, dass ihre Kundenzuflüsse durch das jeweilige externe Kopplungspotenzial unter ansonsten gleichen Bedingungen gesteigert werden; hierbei ist anzunehmen, dass vorrangig das Angebot anderer Fachmärkte relevant ist. Positive Einflüsse aufgrund der räumlichen Nähe zu konkurrierenden Anbietern sind im Fall der Elektronikmärkte gefunden worden; auch dieser Zusammenhang ist erstmalig empirisch 
ermittelt worden. Der Grund hierfür ist maßgeblich in den „klassischen“ suchgesteuerten Vergleichskäufen zu finden, bei denen mehrere Anbieter aufgesucht werden, um Aspekte der angebotenen Produkte miteinander zu vergleichen. Beim Kauf dieser Produkte (z.B. Waschmaschine oder Kaffeevollautomat) ist aufgrund der Tragweite der Anschaffung (nicht zuletzt finanzieller Art) eine breite Marktübersicht notwendig, die - abseits der möglichen Informationsbeschaffung über das Internet - auch vor Ort erfolgt. Bei Baumärkten ist hingegen ein negativer Effekt der Konkurrenznähe zu verzeichnen; dies ist allerdings möglicherweise mit der Standortkonfiguration im Untersuchungsgebiet erklärbar: Effektiv existieren dort keine Ballungen von Baumärkten; dies kann einerseits die Folge einer bewussten Konkurrenzmeidung sein, andererseits jedoch der Grund dafür, dass sich Agglomerationseffekte durch Vergleichskäufe aufgrund der großen Entfernung zwischen den Anbietern gar nicht ausbilden können, obwohl sie prinzipiell auftreten könnten.

In allen Fällen ist also nachgewiesen worden, dass die räumliche Ballung von Anbietern des Einzelhandels einen Einfluss auf ihre Marktgebiete hat; dieser Einfluss ist zumeist positiv, wenngleich er in seiner Intensität deutlich hinter anderen Faktoren (Eigenattraktivität und Erreichbarkeit) zurücksteht. Dies ist dadurch erklärbar, dass es sich bei den untersuchten Anbietern i.d.R. selbst um "Magnetbetriebe" mit einem hohen Anteil an "Generative business" handelt. Das dritte und wichtigste Teilergebnis der vorliegenden Forschungsarbeit besteht also darin, dass Agglomerationseffekte als erklärende Größen des räumlichen Einkaufsverhaltens empirisch identifiziert werden konnten.

Die Modelle sind mehrfach im Hinblick auf ihre Aussagekraft überprüft worden; sie erklären die tatsächlichen Marktgebiete der Anbieter stets besser als Modelle ohne Berücksichtigung von Agglomerationseffekten. Auch sind Modellerweiterungen vorgenommen worden, durch die am Beispiel der Lebensmittelmärkte aufgezeigt wurde, dass es zwar Möglichkeiten gibt, die Aussagekraft der Modelle noch deutlich zu verbessern, der Einfluss durch Agglomerationseffekte jedoch hierdurch nicht geschmälert wird. Zwei durchgeführte Modellsimulationen anhand realer Beispiele aus dem Untersuchungsgebiet transferieren die Ergebnisse der Arbeit auf eine Prognoseebene: In einem der beiden Simulationsrechnungen wurde überprüft, wie sich die (tatsächlich geplante, jedoch nicht erlaubte) Bildung einer Standortkooperation auf die Marktgebiete der Lebensmittelmärkte auswirkt; hier zeigt sich, dass die beiden Märkte, für die eine Verlagerung vorgesehen war, von dieser profitieren würden.

Die Untersuchung hat also ihr erstes Ziel (Inhaltliches Ziel) dahingehend erreicht, dass kundenseitige positive Agglomerationseffekte als Determinanten des räumlichen Einkaufsverhaltens bzw. von Marktgebieten im Einzelhandel empirisch nachgewiesen werden konnten. Dieser Einfluss ist zumeist positiv, d.h. räumlich geballtes Angebot ist aufgrund der Möglichkeit von verschiedenen Formen von Kopplungs- und Vergleichskäufen attraktiver als solches abseits von Agglomerationen. Abgesehen von branchen- und standortspezifischen Detailfragen steht dieses Ergebnis im Einklang mit den sehr heterogenen Theorien zum Einkaufsverhalten bzw. zur Standortpolitik im Einzelhandel.

Die untersuchten Zusammenhänge sind relevant für verschiedene damit indirekt verbundene Fragestellungen der Handelsforschung. Hierzu gehört die angestrebte wohnortnahe Grundversorgung mit Gütern des täglichen Bedarfs (Nahversorgung); offensichtlich besteht hier ein Zielkonflikt zwischen der quantitativen und der qualitativen Dimension von Nahversorgung, da Standortkooperationen zwar die Vorstellung von Angebots- bzw. 
Betriebsformenvielfalt (Qualitative Dimension) mustergültig abbilden, die räumliche Ballung an einzelnen Angebotsstandorten aber ein gleichmäßiges Verkaufsstellennetz und damit eine fußläufige Erreichbarkeit von überall aus (Quantitative Dimension) in Frage stellen. Die Frage nach den Auswirkungen der umstrittenen innerstädtischen Einkaufszentren stellt sich im Lichte nachgewiesener positiver Agglomerationseffekte sehr differenziert dar: Innenstädte können, wie auch angebotsseitige Untersuchungen bestätigen, durchaus von EKZ in unmittelbarer Nähe profitieren; entscheidend ist, wie nah diese EKZ sind und ob das dort offerierte Angebot komplementär zu dem am sonstigen Angebotsstandort ist. Weiterhin sind die Ergebnisse für die räumliche Planung auf verschiedenen Ebenen interessant, da in diesem Rahmen die Berücksichtigung von Agglomerationen in der Einzelhandelssteuerung seit einigen Jahren diskutiert wird; die gewonnenen Erkenntnisse zeigen, dass dies sinnvoll bzw. notwendig ist.

Wie eine Berücksichtigung von Agglomerationseffekten im Rahmen von Standortanalysen und Verträglichkeitsbeurteilungen gewährleistet werden kann, war das zweite Ziel dieser vorliegenden Arbeit; auch dieses Ziel (Methodologisches Ziel) konnte erreicht werden. Genau genommen wurden beide Ziele simultan dadurch erreicht, dass ein aus dem HuFF-Modell heraus entwickeltes ökonometrisches Modell genutzt wurde; es ist wiederum möglich, diese Zusammenhänge in Marktgebietsmodelle (insb. HuFF-Modell) zu integrieren. Zudem wurde durch die GWR-Modellierung aufgezeigt, wie sich räumliche Variationen in Marktgebietsmodelle integrieren lassen; diese Vorgehensweise ersetzt jedoch die konventionellen Modellanalysen nicht, sondern stellt - bestenfalls - eine kleinräumige Konkretisierung bereits ermittelter Zusammenhänge dar.

Zusammengefasst bestehen die Stärken der vorliegenden Untersuchung einerseits in einer Zusammenführung der sehr heterogenen theoretischen Erklärungsansätze des räumlichen Einkaufsverhaltens im Kontext von Agglomerationen in einem konsistenten theoretischen Konzept. Andererseits bildet die Aufstellung eines Marktgebietsmodells, das zur Abbildung beider Formen von Agglomerationseffekten imstande ist und hierbei ein adäquates Konzentrationsmaß verwendet, eine entscheidende Neuerung. Die wichtigste Stärke der vorliegenden Arbeit besteht darin, dass Agglomerationseffekte als Determinante des räumlichen Einkaufsverhaltens empirisch nachgewiesen werden konnten. Die Untersuchung beinhaltet auch einige Schwachstellen, die u.a. in der Erhebungsmethode (Telefonbefragung) sowie der Abbildung von Agglomerationen in den $\mathrm{MCl}-$ Modellen liegen; zu diesbezüglichen Erweiterungen und einer Möglichkeit zur empirischen Fundierung der verwendeten Konzentrationsvariablen wurden Vorschläge unterbreitet, die späteren Untersuchungen überlassen bleiben. Ebenso ist es geboten, das vorliegende oder ein ähnliches Untersuchungsdesign auf andere Einzelhandelsbranchen und vor allem andere räumliche Kontexte zu übertragen. Zudem ist auch das $\mathrm{MCl}-$ Modell aufgrund seiner mathematischen Eigenschaften (Transformation der Funktion in ein lineares Modell) nicht unproblematisch bzw. besitzt einzelne mögliche Fehlerquellen.

Insgesamt zeigt die Untersuchung auf, dass das bearbeitete Themenfeld eine sehr große Relevanz für die heutige Einzelhandelsentwicklung besitzt und mit vielen Fragestellungen dieser Fachdisziplin direkt oder indirekt verbunden ist. Interessant ist vor diesem Hintergrund auch die hohe empirische bzw. Praxisrelevanz vieler „alter“ Raumwirtschaftstheorien, die innen heutzutage gerne abgesprochen wird; dies betrifft insbesondere die viel getadelten 
Theorien von CHRISTALLER (1933) und LÖSCH (1944), denen oftmals unterstellt wird, dass sie gar keine Agglomerationseffekte berücksichtigen - was in der vorliegenden Arbeit recht eindeutig widerlegt werden kann. Auch wenn die Möglichkeit von multifinalen Einkäufen nicht das Gewicht besitzt wie es LANGE (1973) in seiner Theorie annimmt, so hat dieses komplexe Werk eine hohe empirische Relevanz, da die entsprechenden Entwicklungen auf der Angebotsseite nachweislich stattfinden. Kaum berücksichtigt werden in Standortfragen die Arbeiten aus der Denkschule der monopolistischen Konkurrenz (CHAMBERLIN 1933 und Nachfolger), obwohl sie eine wichtige Basis der Raumwirtschaftstheorien darstellen und selbst konkrete Aussagen zur räumlichen Einzelhandelsentwicklung machen. Die empirischinduktive Standortforschung von NELSON (1958) ergänzt die genannten Theorien sinnvoll. Es zeigt sich sehr eindrucksvoll, dass diese „alten“ Theorien wesentlich mehr inhaltliche Aussagekraft - und vor allem Aktualität - besitzen, als innen oftmals zugesprochen wird.

Keine inhaltlichen Neuerungen bieten hingegen die Ansätze der „neuen“ Raumwirtschaftsbzw. Standorttheorie - der New Economic Geography (z.B. FUJITA/THISSE 2002); deren Arbeiten bestechen durch die Integration bekannter Inhalte in formalisierte Modelle, nicht jedoch - zumindest in Bezug auf die vorliegende Fragestellung - durch das Hervorbringen neuer. Wahrhaft weiterführende Erkenntnisse konnten stattdessen aus neueren MarketingAnsätzen (z.B. POPKOWSKI LESZCZYC et al. 2004, VROEGRIJK et al. 2013) gewonnen werden, die die „alten“ Theorien sinnvoll ergänzen. Die vorliegende Arbeit zeigt, wie diese mitunter voneinander völlig unabhängigen Ansätze berücksichtigt und zusammengeführt werden können; in Anbetracht der Relevanz des Themas ist dies auch notwendig und für zukünftige wissenschaftliche Untersuchungen wünschenswert. 


\section{Literatur- und Quellenverzeichnis}

ADKINS, L. C. (2013): Using gretl for Principles of Econometrics, 4th Edition, Version 1.041. URL: http://www.learneconometrics.com/gretl/using_gretl_for_POE4.pdf (Letzter Zugriff am 20.07.2013).

ADM [= ARBEITSKREIS DEUTSCHER MARKT- UND SOZIALFORSCHUNGSINSTITUTE E.V.] (2008): Richtlinie für telefonische Befragungen. Frankfurt/M. : ADM.

ADM [= ARBEITSKREIS DEUTSCHER MARKT- UND SOZIALFORSCHUNGSINSTITUTE E.V.] (2011): Richtlinie zum Umgang mit Adressen in der Markt- und Sozialforschung. Frankfurt/M. : ADM

Agergard, E./Olsen, P. A./Allpass, J. (1968): The interaction between retailing and the urban centre structure: A theory of spiral movement. Lyngby : Inst. for CenterPlanlægning.

AGO, T. (2008): Central agglomeration of monopolistically competitive firms. In: Journal of Economic Geography, Bd. 8, Nr. 6, S. 811-823.

AK GEOGRAPHISCHE HANDELSFORSCHUNG (2013): Geplante Betriebstypenagglomerationen (= Berichte des Arbeitskreises Geographische Handelsforschung, Bd. 33). Berlin.

ALDI NORD (o.J.): Grundstücke und Immobilien [Expansions-Website]. URL: http://www.aldinord.de/grundstuecke_und_immobilien.html (Letzter Zugriff am 29.07.2014).

ALDI SÜD (o.J.): Wir suchen Grundstücke und Immobilien [Expansions-Website]. URL: https://unternehmen.aldi-sued.de/de/immobilien/wir-kaufen-und-mieten/ (Letzter Zugriff am 29.07.2014).

Allen, P. M./Sanglier, M. (1979): A Dynamic Model of Growth in a Central Place System. In: Geographical Analysis, Bd. 11, Nr. 3, S. 256-272.

Allen, P. M./Sanglier, M. (1981): A Dynamic Model of a Central Place System II. In: Geographical Analysis, Bd. 13, Nr. 2, S. 149-164.

Ansiedlung von Einzelhandelsbetrieben; Bauleitplanung und Genehmigung von Vorhaben (Einzelhandelserlass NRW), Gem. RdErl. d. Ministeriums für Bauen und Verkehr V.4 / VI A 1 - 16.21 - u. d. Ministeriums für Wirtschaft, Mittelstand und Energie322/323-30.28.17 v. 22.09.2008.

Arentze, T. A./Oppewal, H./Timmermans, H. J. P. (2005): A Multipurpose Shopping Trip Model to Assess Retail Agglomeration Effects. In: Journal of Marketing Research, Bd. 42, Nr. 1, S. 109-115.

ASSENMACHER, W. (2002): Einführung in die Ökonometrie. 6. Aufl. München [u.a.] : Oldenbourg.

BAASER, U./ZEHNER, K. (2014): Nahversorgung im Wandel - die Auswirkungen des Strukturwandels im Lebensmitteleinzelhandel auf die Versorgungsqualität benachteiligter Stadtbewohner. Das Beispiel Köln. In: JÜRGENS, U. (2014): Entwicklungen und Perspektiven von Nahversorgung im Lebensmitteleinzelhandel (= Kieler Arbeitspapiere zur Landeskunde und Raumordnung, Bd. 54). S. 35-45. 
BACKhaus, K./ERICHSON, B./PlinkE, W.MEIBER, R. (2000): Multivariate Analysemethoden: Eine anwendungsorientierte Einführung. 9., überarbeitete und erweiterte Auflage. Berlin [u.a.] : Springer.

BAKER, R. G. V. (1996): Multipurpose shopping behaviour at planned suburban shopping centres: a space-time analysis. In: Environment and Planning A, Bd. 28, Nr. 4, S. 611-630.

BALDERJAHN, I./SCHOLDERER, J. (2007): Konsumentenverhalten und Marketing: Grundlagen für Strategien und Maßnahmen. Stuttgart : Schäffer-Poeschel.

Baltas, G./Argouslidis, P. C./SkARMEAS, D. (2010): The Role of Customer Factors in Multiple Store Patronage: A Cost-Benefit Approach. In: Journal of Retailing, Bd. 86, Nr. 1, S. 37-50.

BAthelt, H./GLÜCKLER, J. (2012): Wirtschaftsgeographie: Ökonomische Beziehungen in räumlicher Perspektive. 3., vollständig überarbeitete und erweiterte Auflage. Stuttgart : Ulmer.

Baugesetzbuch (BauGB) in der Fassung der Bekanntmachung vom 23. September 2004 (BGBI. I S. 2414), das durch Artikel 1 des Gesetzes vom 15. Juli 2014 (BGBI. I S. 954) geändert worden ist.

BAUMGARTEN, M./ZEHNER, K. (2007): Standortverlagerungen des Lebensmitteleinzelhandels und ihre Folgen für die Nahversorgung. In: Raumforschung und Raumordnung, Bd. 65, Nr. 3, S. 225-230.

BAUMOL, W. J./IDE, E. A. (1956): Variety in Retailing. In: Management Science, Bd. 3. Nr. 1, S. 93-101.

Baunutzungsverordnung (BauNVO) in der Fassung der Bekanntmachung vom 23. Januar 1990 (BGBI. I S. 132), die zuletzt durch Artikel 2 des Gesetzes vom 11. Juni 2013 (BGBI. I S. 1548) geändert worden ist.

BBE HANDELSBERATUNG (2007): Verträglichkeitsbeurteilung für die Errichtung eines Elektrofachmarktes in Holzminden [Gutachten]. München : BBE Handelsberatung.

BBE HANDElsberatung (2011): Auswirkungsanalyse für die Ansiedlung eines MöbelFachmarktes sowie weiterer Fachmärkte im Gewerbegebiet Bülte in Holzminden [Gutachten]. München : BBE Handelsberatung.

BBE HANDELSBERATUNG (2011): Struktur- und Marktdaten im Einzelhandel 2010. München : BBE Handelsberatung.

BBSR [= BUNDESINSTITUT FÜR BAU-, STADT- UND RAUMFORSCHUNG] (2013a): Städtischer und Ländlicher Raum 2011 [Karte]. URL: http://www.bbsr.bund.de/BBSR/DE/ Raumbeobachtung/Raumabgrenzungen/Kreistypen2/Download_Karte2012_PDF.pdf (Letzter Zugriff am 22.03.2014).

BBSR [ = BUNDESINSTITUT FÜR BAU-, STADT- UND RAUMFORSCHUNG] (2013b): Laufende Raumbeobachtung - Raumabgrenzungen: Siedlungsstrukturelle Kreistypen. URL: http://www.bbsr.bund.de/BBSR/DE/Raumbeobachtung/Raumabgrenzungen/Kreistype n4/kreistypen.html?nn=443270 (Letzter Zugriff am 22.03.2014).

BBSR [= BUNDESINSTITUT FÜR BAU-, STADT- UND RAUMFORSCHUNG] (2013c): Wachsende und schrumpfende Gemeinden in Deutschland URL: http://www.bbsr.bund.de/BBSR/ 
DE/Raumbeobachtung/Raumabgrenzungen/Wachs_Schrumpf_gem/Wachs_Schrum pf_Gemeinden_node.html (Letzter Zugriff am 22.03.2014).

BBSR [= BUNDESINSTITUT FÜR BAU-, STADT- UND RAUMFORSCHUNG] (2013d): Erreichbarkeitsmodell des BBSR. URL: http://www.bbsr.bund.de/BBSR/DE/ Raumbeobachtung/UeberRaumbeobachtung/Komponenten/Erreichbarkeitsmodell/err eichbarkeitsmodell_node.html (Letzter Zugriff am 29.03.2014).

BECK, A. (2004): Die Einkaufsstättenwahl von Konsumenten unter transaktionskostentheoretischen Gesichtspunkten - Theoretische Grundlegung und empirische Überprüfung mittels der Adaptiven Conjoint-Analyse. InauguralDissertation an der Universität Passau.

BeCKMANN, R. M./HutTENLOHER, C./LINNHOFF, C. (2012): Wirkung von Einkaufszentren in der Innenstadt. Synoptische Aufbereitung vorliegender Studien (Kurzfassung DSSWStudie). Berlin : DSSW.

BEGUIN, H. (1992): Christaller's central place postulates. A commentary. In: The Annals of Regional Science, Bd. 26, Nr. 3, S. 209-229.

BelL, D. E./KeEnEY, R. L./LITTLE, J. D. C. (1975): A Market Share Theorem. In: Journal of Marketing Research, Bd. 12, Nr. 2, S. 136-141.

Berekoven, L./ECKert, W./Ellenrieder, P. (2009): Marktforschung. Methodische Grundlagen und praktische Anwendung. 12., überarbeitete und erweiterte Auflage. Wiesbaden : Gabler.

Berman, B./Evans, J. R. (2013): Retail management: a strategic approach. 12. Auflage. Boston [u.a.] : Pearson.

BHB [= Handelsverband Heimwerken, Bauen Und GaRTEN E.V.] (2013): (Gewichtete) Verkaufsfläche in der Bau- und Heimwerkermarktbranche und Branchendefinition: Bau- und Heimwerkermarkt URL: http://www.bhb.org/fileadmin/website/ Markt_Statistik/Definitionen/BHB-Def_VKF-gew_2013-v1.pdf (Letzter Zugriff am 20.03.2014).

BIRKIN, M./HePPENSTALL, A. (2011): Extending Spatial Interaction Models with Agents for Understanding Relationships in a Dynamic Retail Market. In: Urban Studies Research, Bd. 2011, Article ID 403969.

BITKOM [= BUNDESVERBAND INFORMATIONSWIRTSCHAFT, TELEKOMMUNIKATION UND NEUE Medien E. V.] (2012): Die Zukunft der Consumer Electronics - 2012. Berlin : BITKOM.

Blotevogel, H. H. (1996): Zentrale Orte: Zur Karriere und Krise eines Konzeptes in Geographie und Raumplanung. In: Erdkunde, Bd. 50, Nr. 1, S. 9-25.

BMVBS [= BUNDESMINISTERIUM FÜR VERKEHR, BAU UND STADTENTWICKLUNG] (2011): Ohne Auto einkaufen. Nahversorgung und Nahmobilität in der Praxis (= Werkstatt: Praxis, Bd. 76). Berlin: BMVBS.

BMVBS [= BUNDESMINISTERIUM FÜR VERKEHR, BAU UND STADTENTWICKLUNG] (2013): Nahversorgung in ländlichen Räumen (=BMVBS-Online-Publikation, Bd. 02/2013). Berlin: BMVBS.

BÖKEMANN, D. (1967): Das innerstädtische Zentralitätsgefüge - dargestellt am Beispiel der Stadt Karlsruhe. Dissertation an der Technischen Hochschule Karlsruhe. Karlsruhe. 
Bootz, P. (1968): Die Bestimmung der Einflussbereiche städtischer Absatzzentren im Konsumgütersektor der Wirtschaft. In: Zur Methodik der Regionalplanung (= Veröffentlichungen der Akademie für Raumforschung und Landesplanung, Forschungs- und Sitzungsberichte, Bd. 41). Hannover : Jänecke.

BORCHARD, K. (2012): Strukturveränderungen im Einzelhandel - Zum Wandel der Standortfaktoren. In: KONZE, H./WOLF, M. (Hrsg.): Einzelhandel in NordrheinWestfalen planvoll steuern! (= Arbeitsberichte der ARL [Akademie für Raumforschung und Landesplanung], Bd. 2). Hannover : ARL. S. 15-21.

BORGERS, A./Vosters, C. (2011): Assessing preferences for mega shopping centres: A conjoint measurement approach. In: Journal of Retailing and Consumer Services, Bd. 18, Nr. 4, S. 322-332.

BORTZ, J./SCHUSTER, C. (2010): Statistik für Human- und Sozialwissenschaftler. 7., vollständig überarbeitete und erweiterte Auflage. Berlin [u.a.] : Springer.

BR-Drucksache 474/12 B vom 21.09.2012: Stellungnahme des Bundesrates - Entwurf eines Gesetzes zur Stärkung der Innenentwicklung in den Städten und Gemeinden und weiteren Fortentwicklung des Städtebaurechts.

BRÖCKER, J./FRITSCH, M. (2012): Ökonomische Geographie. München : Vahlen.

Brooks, C. M./KaufMANN, P. J./LICHTENSTEIN D. R. (2004): Travel Configuration on Consumer Trip-Chained Store Choice. In: Journal of Consumer Research, Bd. 31, Nr. 2, S. 241-248.

BRoOKS, C. M./KAUfMANN, P. J./LICHTENSTEIN D. R. (2008): Trip chaining behavior in multidestination shopping trips: A field experiment and laboratory replication. In: Journal of Retailing, Bd. 84, Nr. 1, S. 29-38.

BRown, S. (1987): A perceptual approach to retail agglomeration. In: Area, Bd. 19, Nr. 2, S. 131-140.

BRown, S. (1989a): Retail Location Theory: The Legacy of Harold Hotelling. In: Journal of Retailing, Bd. 65, Nr. 4, S. 450-470.

BRown, S. (1989b): Harold Hotelling and the principle of minimum differentiation. In: Progress in Human Geography, Bd. 13, Nr. 4, S. 471-493.

BRoWN, S. (1989c): Retailing and the Importance of Micro-Locational Linkages. In: Management Decision, Bd. 27, Nr. 5, S. 4-11.

BRown, S. (1993): Retail location theory: evolution and evaluation. In: The International Review of Retail, Distribution and Consumer Research, Bd. 3, Nr. 2, S. 185-229.

BRown, S. (1994): Retail Location at the Micro-Scale: Inventory and Prospect. In: The Service Industries Journal, Bd. 14, Nr. 4, S. 542-551.

Brune, W./Junker, R./Pump-UhlmanN, H. (2006): Angriff auf die City: kritische Texte zur Konzeption, Planung und Wirkung von integrierten und nicht integrierten ShoppingCentern in zentralen Lagen. Düsseldorf : Droste.

BUCKLIN, L. P. (1971a): Trade Area Boundaries: Some Issues in Theory and Methodology. In: Journal of Marketing Research, Bd. 8, Nr. 2, S. 30-37. 
BUCKLIN, L. P. (1971b): Retail Gravity Models and Consumer Choice: A Theoretical and Empirical Critique. In: Economic Geography, Bd. 47, Nr. 4, S. 489-497.

BüHL, A. (2010): PASW [SPSS] 18: Einführung in die moderne Datenanalyse. 12., aktualisierte Auflage. München [u.a.] : Pearson.

BuLWIENGESA AG (2010): Markt-, Standort- und Wirkungsanalyse Neuansiedlung Verbrauchermarkt Brenkhäuser/Albaxer Straße, Höxter [Gutachten]. Hamburg : BulwienGesa AG.

BÜNTING-GRUPPE (o.J.): Wir entwickeln Vielfalt [Expansions-Website]. URL: http://www. buenting.de/index.php?id=59 (Letzter Zugriff am 29.07.2014).

BVerwG, Urteil vom 10.11.2011 - 4 CN 9.10.

BVerwG, Urteil vom 24.11.2005 - 4 C 8.05.

BVerwG, Urteil vom 27.04.1990 - 4 C 16.87.

CADWALLADER, M. (1975): A behavorial model of consumer spatial decision making. In: Economic Geography, Bd. 51, Nr. 4, S. 339-349.

CALLIES, C. (2004): Kommunale Einzelhandelszentrenkonzepte und ihre Anwendung als Steuerungsinstrument der städtischen Einzelhandelsentwicklung - Ziele, Ansätze, Wirkungsweise und Erfahrungen aus der Praxis. Dissertation an der Universität Dortmund. Dortmund.

Camminatiello, I./Lucadamo, A. (2010): Estimating Multinomial Logit Model with Multicollinear Data. In: Asian Journal of Mathematics and Statistics, Bd. 3, Nr. 2, S. 93-101.

Chamberlin, E. (1933): The Theory of Monopolistic Competition. Cambridge : Harvard University Press.

ChARLTON, M./FOthERINGHAM, S./BRUNSDON, C. (2006): Geographically Weighted Regression (= ESRC National Centre for Research Methods, NCRM Methods Review Paper, Bd. 006).

ChristalleR, W. (1933): Die zentralen Orte in Süddeutschland (Nachdruck von 1968). Darmstadt : Wiss. Buchges.

CIMA (2004): Einzelhandelsentwicklungskonzept für die Stadt Holzminden [Gutachten]. Lübeck : CIMA.

CIMA (2010): Verträglichkeitsuntersuchung zur Ansiedlung eines Verbrauchermarktes in der Sollingstraße in Holzminden [Gutachten]. Lübeck : CIMA.

CLIQUET, G. (1995): Implementing a subjective MCI model: an application to the furniture market. In: European Journal of Operational Research, Bd. 84, Nr. 2, S. 279-291.

CLIQUET, G. (2006): Retail Location Models. In: CLIQUET, G. (Hrsg.): Geomarketing. Models and Strategies in Spatial Marketing [E-Book-Ausgabe]. London : ISTE. S. 137-163.

Colomé Perales, R. (2002): Consumer Choice in Competitive Location Models. Dissertation and der Universitat Pompeu Fabra. Barcelona.

CONVERSE, P. D. (1949): New Laws of Retail Gravitation. In: Journal of Marketing, Bd. 14, Nr. 3, S. 379-384. 
COOPER, L. G./NAKANISHI, M. (2010): Market-Share Analysis: Evaluating competitive marketing effectiveness. Boston [u.a.] : Kluwer (1. Auflage 1988; Auflage 2010: EBook-Version, URL: http://www.anderson.ucla.edu/faculty/lee.cooper/MCl_Book/ BOOKI2010.pdf, letzter Zugriff am 25.06.2013).

Craig, C. S./Ghosh, A./McLafferty, S. (1984): Models of the Retail Location Process: A Review. In: Journal of Retailing, Bd. 60, Nr. 1, S. 5-36.

DAMIAN, D. S./DIAS CURTO, J./CASTRO PINTO, J. (2011): The impact of anchor stores on the performance of shopping centres: the case of Sonae Sierra. In: International Journal of Retail \& Distribution Management, Bd. 39, Nr. 6, S. 456-475.

De Beule, M./Van den Poel, D./Van de Weghe, N. (2014): An extended Huff-model for robustly benchmarking and predicting retail network performance. In: Applied Geography, Bd. 46, Nr. 1, S. 80-89.

DE LANGE, N. (2013): Geoinformatik in Theorie und Praxis. 3. Auflage. Berlin [u.a.] : Springer.

DEITERS, J. (1978): Zur empirischen Überprüfbarkeit der Theorie zentraler Orte : Fallstudie Westerwald mit 26 Tabellen und einem Anhang (= Arbeiten zur rheinischen Landeskunde, Bd. 44). Bonn : Dümmler.

DEITERS, J. (2006): Von der Zentralitätsforschung zur geographischen Handelsforschung Neuorientierung oder Paradigmenwechsel in der Wirtschafts- und Sozialgeographie? In: Die Erde, Bd. 137, Nr. 4, S. 293-317.

Dellaert, B. G. C./Arentze, T. A./Bierlaire, M./Borgers, A. W. J./Timmermans, H. J. P. (1998): Investigating Consumers' Tendency to Combine Multiple Shopping Purposes and Destinations. In: Journal of Marketing Research, Bd. 35, Nr. 2, S. 177-188.

DeR HANDEL (2012): Media Markt verspricht Multichannel-Erlebnis (Artikel vom 13.01.2012). URL: $\quad$ http://www.derhandel.de/news/technik/pages/E-Commerce-Media-Marktverspricht-Multichannel-Erlebnis-8150.html (Letzter Zugriff am 28.11.2013).

DER HANDEL (2013): Otto und Zalando - ungleiche Rivalen im Online-Modehandel (Artikel vom 02.01.2013). URL: http://www.derhandel.de/news/technik/pages/E-CommerceOtto-und-Zalando---ungleiche-Rivalen-im-Online-Modehandel-9329.html (Letzter Zugriff am 28.11.2013).

Des Rosiers, F./ThÉRIAUlt, M./LAVOIE, C. (2009): Retail Concentration and Shopping Center Rents - A Comparison of Two Cities. In: Journal of Real Estate Research, Bd. 31, Nr. 2, S. 165-207.

Des Rosiers, F./ThÉRIAUlt, M./MÉnÉtRIER, L. (2005): Spatial Versus Non-Spatial Determinants of Shopping Center Rents: Modeling Location and NeighborhoodRelated Factors. In: Journal of Real Estate Research, Bd. 27, Nr. 3, S. 293-319.

DesmeUles, R. (2002): The Impact of Variety on Consumer Happiness: Marketing and the Tyranny of Freedom. In: Academy of Marketing Science Review, Nr. 12, S. 1-18.

DEUTSCHE HYPO (2013): Perspektiven der Einzelhandels-Immobilienmärkte in Deutschland. Hannover : Deutsche Hypo.

Dicken, P./LLOYD, P. (1999): Standort und Raum. Theoretische Perspektiven in der Wirtschaftsgeographie. Stuttgart : Ulmer. 
Die WeLt (2012): So drücken Sie die Preise bei Media Markt und Saturn (Artikel vom 06.01.2012). URL: http://www.welt.de/13802075 (Letzter Zugriff am 16.06.2014).

DIE WELT (2013): Zwölf neue Einkaufszentren in Deutschland (Artikel vom 10.10.2013). URL: http://www.welt.de/120774314 (Letzter Zugriff am 29.11.2013).

DiekmanN, A. (2008): Empirische Sozialforschung: Grundlagen, Methoden, Anwendungen. Reinbek : Rowohlt.

DION, D./CliqueT, G. (2006): Consumer Spatial Behavior. In: CliQUeT, G. (Hrsg.): Geomarketing. Models and Strategies in Spatial Marketing [E-Book-Ausgabe]. London : ISTE. S. 29-56.

DISQ [= DEUTSCHES INSTITUT FÜR SERVICEQUALITÄT] (2012): Studie Lebensmittelmärkte (10.05.2012). URL: http://www.disq.de/mai2-2012.php (Letzter Zugriff am 13.06.2012).

DobBELSTEIN, T. (2004): Die Nutzung probabilistischer Potenzialmodelle zur verkaufsstellenspezifischen Marktpotenzialprognose - dargestellt am Beispiel von Presseartikeln. In: Marketing ZFP, Bd. 26, Nr. 2, S. 121-140.

DORFLADEN-NETZWERK (2014): Dorfläden in Deutschland. URL: http://dorfladen-netzwerk.de/ dorflaeden-in-deutschland/ (Letzter Zugriff am 02.07.2014).

Dramowicz, E. (2005): Retail Trade Area Analysis Using the Huff Model. In: Directions Magazine 02.07.2005. URL: http://www.directionsmag.com/articles/retail-trade-areaanalysis-using-the-huff-model/123411 (Letzter Zugriff am 21.12.2011).

DREZNER, T. (2006): Derived attractiveness of shopping malls. In: IMA Journal of Management Mathematics, Bd. 17, Nr. 4, S. 349-358.

EATON, B. C./LIPSEY, R. G. (1975): The Principle of Minimum Differentiation Reconsidered: Some New Developments in the Theory of Spatial Competition. In: The Review of Economic Studies, Bd. 42, Nr. 1, S. 27-49.

EATON, B. C./LIPSEY, R. G. (1979): Comparison Shopping and the Clustering of Homogeneous Firms. In: Journal of Regional Science, Bd. 19, Nr. 4, S. 421-435.

EATON, B. C./LIPSEY, R. G. (1982): An Economic Theory of Central Places. In. The Economic Journal, Bd. 92, Nr. 365, S. 56-72.

EAton, B. C./TWEedLe, J. (2012): A Hotelling style model of spatial competition for a convenience good. In: The Annals of Regional Science, Bd. 40, Nr. 2, S. 447-469.

ECKERT, A./HE, Z.MEST, D. S. (2013): An empirical examination of clustering and dispersion within Canadian shopping centers. In: Journal of Retailing and Consumer Services, Bd. 20, Nr. 6, S. 625-633.

ECKeY, H.-F./Kosfeld, R./Dreger, C. (2011): Ökonometrie. Grundlagen - Methoden Beispiele. 4. Auflage. Wiesbaden : Gabler.

ECKEY, H.-F./KOSFELD, R./TÜRCK, M. (2005): Regional Convergence in Germany. A Geographically Weighted Regression Approach (= Volkswirtschaftliche Diskussionsbeiträge, Bd. 76/05). Kassel : Universität Kassel.

EdekA GRuppe (o.J. a): Menschen. Märkte. Perspektiven. [Expansionsbroschüre]. URL: https://www.edeka-verbund.de/Unternehmen/media/edeka_gruppe/gruppe/ 
gruppenprofil/weitere_leistungsfelder_1/edeka_expansion_immobilien/downloads_2/p df_expo_2012/expansionsbroschuere.pdf (Letzter Zugriff am 29.07.2014).

EDEKA GRUPPE (o.J. b): Qualifizierte Nahversorgung mit EDEKA [Argumentationsbroschüre]. URL: $\quad$ http://www.edeka-verbund.de/Unternehmen/media/edeka_gruppe/gruppe/ gruppenprofil/weitere_leistungsfelder_1/edeka_expansion_immobilien/downloads_2/p df_2/EDEKA_Argumentationsbroschuere.pdf (Letzter Zugriff am 29.07.2014).

EHI RETAIL INSTITUTE (1999): Handel aktuell 1999. Köln.

EHI ReTAIL INSTITUTE (2006): Handel aktuell. Struktur, Kennzahlen und Profile des deutschen und internationalen Handels. Ausgabe 2006/2007. Köln.

ENGEL, E. (1857): Die vorherrschenden Gewerbszweige in den Gerichtsämtern mit Beziehung auf die Productions- und Consumtionsverhältnisse des Königreichs Sachsen. II. Das Gesetz der Dichtigkeit. In: Zeitschrift des Statistischen Bureaus des Königlich Sächsischen Ministeriums des Inneren, Bd. 3, Nr. 8/9, S. 153-182.

ENGELKAMP, P./SELL, F. L. (2013): Einführung in die Volkswirtschaftslehre. 6., überarbeitete und erweiterte Auflage. Berlin [u.a.] : Springer.

EPPLE, M./PETER, K. (2010): Innerstädtische Shopping Center - besser als ihr Ruf! Die Wirkungen von Shopping Centern in Innenstädten unter die Lupe genommen. In: Berichte des Arbeitskreises Geographische Handelsforschung, Bd. 28, S. 5-13.

Eppli, M. J./Benjamin, J. D. (1994): The Evolution of Shopping Center Research: A Review and Analysis. In: Journal of Real Estate Research, Bd. 9, Nr. 1, S. 5-32.

EPPLI, M. J./SHILLING, J. D. (1996): How Critical Is a Good Location to a Regional Shopping Center? In: The Journal of Real Estate Research, Bd. 12, Nr. 3, S. 459-468.

ERNSTE, H. (2011): Angewandte Statistik in Geografie und Umweltwissenschaften. Stuttgart : UTB.

ESRI (1998): ESRI Shapefile Technical Description (= ESRI White Paper, Juli 1998).

ESRI (2013a): Erstellen eines Netzwerk-Datasets [Funktionsbeschreibung]. URL: http:// help.arcgis.com/de/arcgisdesktop/10.0/help/index.html\#//00470000000w000000 (Letzter Zugriff am 29.03.2014).

ESRI (2013b): Von der Erweiterung "ArcGIS Network Analyst" verwendete Algorithmen [Funktionsbeschreibung]. URL: http://resources.arcgis.com/de/help/main/10.1/index. html\#//004700000053000000 (Letzter Zugriff am 29.03.2014).

ESRI (2013c): Geographisch gewichtete Regression (GWR) [Funktionsbeschreibung]. URL: http://help.arcgis.com/de/arcgisdesktop/10.0/help/index.html\#//005p00000021000000 (Letzter Zugriff am 11.01.2012).

ESRI (2013d): Interpretieren von GWR-Ergebnissen [Funktionsbeschreibung]. URL: http:// help.arcgis.com/de/help/main/10.1/index.html\#//005p00000032000000 (Letzter Zugriff am 11.01.2012).

Esteban-Bravo, M./Múgica, J. M./VIDAl-Sanz, J. M. (2012): Do Business Density And Variety Determine Retail Performance? In: Open Journal of Economic Research, Bd . 2, Nr. 1, S. 27-37. 
FAMILA NORDOST (o.J.): Daten und Fakten. URL: http://www.famila-nordost.de/ unternehmen/geschichte/ (Letzter Zugriff am 29.07.2014).

FAZ [= FRANKFURTER AlLGEMEINE ZEITUNG] (2013): Rangliste: Die größten Unternehmen 2013 (Stand: 03.07.2013). URL: http://www.faz.net/aktuell/wirtschaft/unternehmen/ rangliste-die-groessten-unternehmen-2013-12267817.html (Letzter Zugriff am 24.07.2014).

FEIX, C. (2007): Bedeutung von "Geo Business intelligence" und Geomarketing zur Entscheidungsunterstützung unternehmerischer Planungsprozesse im Kontext wirtschaftlicher Liberalisierung : Konzeption, Entwicklung und Anwendung komplexer räumlicher Algorithmen für den Aufbau eines GIS-gestützten Geomarketing-Systems am Beispiel Deutsche Post World Net. Dissertation an der Freien Universität Berlin. Berlin.

FISCHER, M. M. (2006): Spatial Interaction Models and the Role of Geographic Information Systems. In: FISCHER, M. M. (Hrsg.): Spatial Analysis and GeoComputation. Berlin [u.a.] : Springer. S. 29-42.

FITTKAU, D. (2004): Beeinflussung regionaler Kaufkraftströme durch den Autobahnlückenschluss der A49 Kassel-Gießen. Zur empirischen Relevanz der „New Economic Geography“ in wirtschaftsgeographischen Fragestellungen. Dissertation an der Georg-August-Universität Göttingen. Göttingen.

Forster, J. J. H./BRUMmeLL, A. C. (1984): Multi-purpose trips and central place theory. In: Australian Geographer, Bd. 16, Nr. 2, S. 120-127.

FORTUNE (2014): Global 500 2014. URL: http://fortune.com/global500 (Letzter Zugriff am 24.07.2014).

FOTHERINGHAM, A. S. (1985): Spatial competition and agglomeration in urban modelling. In: Environment and Planning A, Bd. 17, Nr. 2, S. 213-230.

Fox, E. J./HocH, S. J. (2005): Cherry-Picking. In: Journal of Marketing, Bd. 69, Nr. 1, S. 4662.

FROHWERK, S. (2011): Asymmetrien in der Neuen Ökonomischen Geographie. Modelle, Simulationsmethoden und wirtschaftspolitische Diskussion (= Potsdamer Schriften zur Raumwirtschaft, Bd. 3). Potsdam : Universitätsverlag Potsdam.

FuCHS, M. (2012): Der Einsatz von Mobiltelefonen in der Umfrageforschung. Methoden zur Verbesserung der Datenqualität. In: FAULBAUM, F./STAHL, M./WIEGAND, E. (Hrsg.): Qualitätssicherung in der Umfrageforschung: Neue Herausforderungen für die Marktund Sozialforschung. Wiesbaden : Springer. S. 51-73.

FuJITA, M./KRugman, P./MORI, T. (1999): On the evolution of hierarchical urban systems. In: European Economic Review, Bd. 43, Nr. 2, S. 209-251.

Fujita, M./Krugman, P./Venables, A. J. (2001): The Spatial Economy. Cities, Regions and International Trade. Cambridge : M.I.T. Press.

FuJITA, M./MORI, T. (2005): Frontiers of the New Economic Geography. In: Papers in Regional Science, Bd. 84, Nr. 3, S. 377-405. 
FuJITA, M./OGAWA, H./THISSE, J.-F. (1988): A spatial competition approach to central place theory: some basic principles. In: Journal of Regional Science, Bd. 28, Nr. 4, S. 477494.

FUJITA, M./THISSE, J.-F. (2000): The Formation of Economic Agglomerations: Old Problems and New Perspectives. In: HURLOT, J.-M./THISSE, J.-F. (Hrsg.): Economics of Cities Theoretical Perspectives. Cambridge : Cambridge University Press. S. 3-73.

FUJITA, M./THISSE, J.-F. (2002): Economics of Agglomeration: Cities, Industrial Location, and Regional Growth. Cambridge [u.a.] : Cambridge University Press.

Garate, G./Pennington-Cross, A. (2013): Measuring the Impact of Agglomeration on Productivity: Evidence from Chilean Retailers. In: Urban Studies [im Erscheinen].

GatZlafF, D. H./SiRmans, G. S./Diskin, B. A. (1994): The Effect of Anchor Tenant Loss on Shopping Center Rents. In: Journal of Real Estate Research, Bd. 9, Nr. 1, S. 99-110.

GAURI, D. K./SUDHIR, K./TALUKDAR, D. (2008): The Temporal and Spatial Dimensions of Price Search: Insights from Matching Household Survey and Purchase Data. In: Journal of Marketing Research, Bd. 45, Nr. 2, S. 226-240.

GAUTSCHI, D. (1981): Specification of Patronage Models for Retail Center Choice. In: Journal of Marketing Research, Bd. 18, Nr. 2, S. 162-174.

GermelmanN, C. C./Neder, P. (2012): Shopping-Center. In: ZenTES, J./SwOBOdA, B./MORSchetT, D./SChramm-KleIN, H. (Hrsg.): Handbuch Handel. Strategien Perspektiven - Internationaler Wettbewerb. 2., vollständig überarbeitete Auflage. Wiesbaden : Springer. S. 329-350.

GFK (2012): Einkaufen in Zeiten knapper Zeit (= Consumer Index, Total Grocery 08/2012). URL: $\quad$ http://www.gfkps.com/imperia/md/content/ps_de/consumerindex/ci_082012_od.pdf (Letzter Zugriff am 24.07.2014).

GFK (2014): Nachhaltig oder regional? - Am besten beides (= Consumer Index, Total Grocery 03/2014). URL: http://www.gfk.com/de/documents/news\%20deutschland/ ci_03_2014.pdf (Letzter Zugriff am 24.07.2014).

GFK GeOMARKETING GMBH (2009): Großstädte punkten als Einkaufsziele für Bekleidung. Pressemitteilung vom 27. Juli 2009. URL: http://www.gfk-geomarketing.de/fileadmin/ newsletter/pressemitteilung/pos_umsaetze_textil_2009.html (Letzter Zugriff am 30.11.2009).

GFK GeOMARKETING GmBH (2012): Deutsche Flächenumsätze im Aufwärtstrend. Pressemitteilung vom 29. November 2012. URL: http://archiv.gfk-geomarketing.de/ presse/20121129_PM_Verkaufsflaechen_fin.pdf (Letzter Zugriff am 03.04.2013).

GFK GeOMARKETING GMBH (2013): Sortimentskaufkraft 2013 Deutschland [Erläuterungen]. Bruchsal.

GFK SE (2012): Top-Standorte wachsen auf Kosten strukturschwacher Regionen. Pressemitteilung vom 14. Februar 2012. URL: http://www.gfk.com/de/Documents/ Pressemitteilungen/2012/20120214_gfk_einzelhandelsums_tze_2012_dfin.pdf (Letzter Zugriff am 08.07.2014).

Ghosh, A. (1984): Parameter Nonstationarity in Retail Choice Models. In: Journal of Business Research, Bd. 12, Nr. 4, S. 425-436. 
GHOSH, A. (1986): The Value of a Mall and Other Insights from a Revised Central Place Model. In: Journal of Retailing, Bd. 62, Nr. 1, S. 79-97.

GIF [= Gesellschaft FÜR IMMOBILIENWIRTSCHAFTLICHE FORSCHUNG E.V.] (2000): Ausgesuchte Begriffs- und Lagedefinitionen der Einzelhandels-Analytik. Grundlagen für die Beurteilung von Einzelhandelsprojekten. Wiesbaden.

GIJSBRECHTS, E./CAMPO, K./NISOL, P. (2008): Beyond promotion-based store switching: Antecedents and patterns of systematic multiple-store shopping. In: International Journal of Research in Marketing, Bd. 25, Nr. 1, S. 5-21.

GMA [= GESELLSCHAFT FÜR MARKT- UND ABSATZFORSCHUNG] (1999): Die Stadt Beverungen als Einzelhandelsstandort [Gutachten]. Ludwigsburg [u.a.] : GMA.

GONZÁLEZ-BENITO, O. (2005): Spatial competitive interaction of retail store formats: modeling proposal and empirical results. In: Journal of Business Research, Bd. 58, Nr. 4, S. 457-466.

GonzÁlez-Benito, Ó./Greatorex, M./Muños-Gallego, P. A. (2000): Assessment of potential retail segmentation variables - An approach based on a subjective $\mathrm{MCl}$ resource allocation model. In: Journal of Retailing and Consumer Services, Bd. 7, Nr. 3, S. 171-179.

GonzÁlez-Benito, O./Muñoz-Gallego, P. A./Kopalle, P. K. (2005): Asymmetric competition in retail store formats: Evaluating inter- and intra-format spatial effects. In: Journal of Retailing, Bd. 81, Nr. 1, S. 59-73.

GÖSIS [= Göttinger Statistisches Informationssystem] (2014): Göttingen kleinräumig. URL: http://www.goesis.goettingen.de/kleinraeumig/intro.php?navld=04 (Letzter Zugriff am 17.07.2014).

GRIFFITH, D. (1982): A Generalized Huff Model. In: Geographical Analysis, Bd. 14, Nr. 2, S. 135-144.

Gujarati, D. N./Porter, D. C. (2009): Basic Econometrics. 5. Auflage. Boston [u.a.] : McGraw-Hill//rwin.

GüSSEFELDT, J. (1999): Regionalanalyse : Methodenhandbuch und Programmsystem GraphGeo. 2. Auflage. München [u.a.] : Oldenbourg.

GüSSEFELDT, J. (2002): Zur Modellierung von räumlichen Kaufkraftströmen in unvollkommenen Märkten. In: Erdkunde, Bd. 56, Nr. 4, S. 351-370.

GüSSEFELDT, J. (2003): Empirische Aspekte einiger Modelle der „New Economic Geography“ im Kontext jüngerer Entwicklungen des Einzelhandels. In: Die Erde, Bd. 134, Nr. 1, S. 81-110.

GüSSEFELDT, J. (2005): Die Raumwirtschaftstheorien von Christaller und Lösch aus der Sicht von Wirtschaftsgeographie und "New Economic Geography“ (= Göttinger geographische Abhandlungen, Bd. 114). Göttingen : Goltze.

GuY, C./BENnISON, D./CLARKE, R. (2005): Scale economies and superstore retailing: new evidence from the UK. In: Journal of Retailing and Consumer Services, Bd. 12, Nr. 2 , S. 73-81.

HÄDER, M. (2010): Empirische Sozialforschung. Wiesbaden : VS Verlag für Sozialwissenschaften. 
HANDBuRY, J./Weinstein, D. E. (2011): Is the New Economic Geography right? Evidence from price data (= NBER Working Paper, Bd. 17067). Cambridge : NBER.

HANGEBRUCH, N. (2012): Entwicklungstendenzen im Einzelhandel und ihre Konsequenzen für die Nachnutzung ehemaliger Kauf- und Warenhausstandorte. In: KONZE, H./WOLF, M. (Hrsg.): Einzelhandel in Nordrhein-Westfalen planvoll steuern! (= Arbeitsberichte der ARL [Akademie für Raumforschung und Landesplanung], Bd. 2). Hannover : ARL. S. 22-29.

HANSEN, W. G. (1959): How Accessibility Shapes Land Use. In: Journal of the American Institute of Planners, Bd. 25, Nr. 2, S. 73-76.

HaRdin III., W. G.Molverton, M. (2000): Micro-Market Determinants of Neighborhood Center Rental Rates. In: Journal of Real Estate Research, Bd. 20, Nr. 3, S. 299-322.

Hardin III., W. G./Wolverton, M./CARR, J. (2002): An Empirical Analysis of Community Center Rents. In: Journal of Real Estate Research, Bd. 23, Nr. 1/2, S. 163-178.

HARDMEIER, S./FONTANA, M.-C. (2006): Overreporting: ein vernachlässigtes Problem und die Schwierigkeit von Gegenmaßnahmen. In: ZUMA Nachrichten, Bd. 30, Nr. 58, S. 5080.

HARTMANN, I. C. (2013): Agglomeration von Einzelhandelsbetrieben und Raumordnung. In: SPANNOWSKY, W./HOFMEISTER, A. (Hrsg.): Einzelhandelsentwicklung in den Gemeinden - aktuelle Fach- und Rechtsfragen. Berlin : Lexxion. S. 45-58.

HARTMANN, M. (2005): Gravitationsmodelle als Verfahren der Standortanalyse im Einzelhandel (= Statistik Regional Electronic Papers, Bd. 02/2005). Halle.

HAYES, A. F./CAI, L. (2007): Using heteroskedasticity-consistent standard error estimators in OLS regression: An introduction and software implementation. In: Behavior Research Methods, Bd. 39, Nr. 4, S. 709-722.

HDE [= HANDELSVERBAND DEUTSCHLAND] (2012): Zahlenspiegel 2012. Berlin : HDE.

HDE [= HANDELSVERBAND DEUTSCHLAND] (2013): Einzelhandel verliert Anteil am privatem Konsum (Stand: März 2013). URL: http://www.einzelhandel.de/index.php/presse/ zahlenfaktengrafiken/verbraucherstatistik/item/110193-

einzelhandelverliertanteilamprivatemkonsum (Letzter Zugriff am 24.07.2014).

HeineberG, H. (2006): Stadtgeographie. 3. Aufl. Paderborn : Schöningh.

HeinemanN, G. (2008): Multi-Channel-Handel. Erfolgsfaktoren und Best Practices. 2. Auflage. Wiesbaden : Gabler.

HEINRITZ, G. (1979a): Zentralität und zentrale Orte. Stuttgart : Teubner.

HEINRITZ, G. (1979b): Die aktionsräumliche Relevanz der Verhaltensdimension „Besucherfrequenz“. In: Geographische Zeitschrift, Bd. 67, Nr. 4, S. 314-323.

HeINRITZ, G. (1999): Methodische Probleme von Einzugsbereichsmessungen. In: HeINRITZ, G. (Hrsg.): Die Analyse von Standorten und Einzugsbereichen : methodische Grundfragen der Geographischen Handelsforschung (= Geographische Handelsforschung, Bd. 2). Passau : L.I.S. S. 33-44.

HeINRITZ, G./KLEIN, K. E./POPP, M. (2003): Geographische Handelsforschung. Stuttgart : Borntraeger. 
HeINRITZ, G./POPP, M. (2011): Geographische Handelsforschung. In: GEBHARDT, H./GLASER, R./RADTKE, U./REuber, P. (Hrsg.): Geographie. Physische Geographie und Humangeographie. 2. Auflage. Heidelberg : Spektrum Akademischer Verlag. S. 10021012.

HeINRITZ, G./TheIS, C. (1997): The Relevance of Coupling Potential in Retailing. In: Die Erde, Bd. 128, Nr. 3, S. 219-234.

HELBICH, M./GÖRGL, P. J. (2010): Räumliche Regressionsmodelle als leistungsfähige Methoden zur Erklärung der Driving Forces von Zuzügen in der Stadtregion Wien? In: Raumforschung und Raumordnung, Bd. 68, Nr. 2, S. 103-113.

HeUSS, E. (1965): Allgemeine Markttheorie. Tübingen : Mohr.

HINLOOPEN, J./MARTIN, S. (2013): Costly Location in Hotelling Duopoly (= Tinbergen Institute Discussion Paper, Bd. 13-101/VII). Amsterdam : Tinbergen Institute.

HOETKER, G. (2007): The use of logit and probit models in strategic management research: Critical issues. In: Strategic Management Journal, Bd. 28, Nr. 4, S. 331-343.

HoldREN, B. R. (1965): Competition in Food Retailing. In: Journal of Farm Economics, Bd. 47, Nr. 5, S. 1323-1331.

HOPFINGER, H./SCHMIDT, A. (2010): Innerstädtische Standorte für Einkaufszentren Bedrohung oder Bereicherung? Das Beispiel der „Erlangen Arcaden“. In: Standort, Bd. 34, Nr. 1, S. 20-26.

Hotelling, H. (1929): Stability in Competition. In: The Economic Journal, Bd. 39, Nr. 153, S. 41-57.

HSIAO, M.-H. (2009): Shopping mode choice: Physical store shopping versus e-shopping. In: Transportation Research Part E: Logistics and Transportation Review, Bd. 45, Nr. 1, S. 86-95.

HuFF, D. L. (1962): Determination of Intra-Urban Retail Trade Areas. Los Angeles : University of California.

HuFF, D. L. (1963): A Probabilistic Analysis of Shopping Center Trade Areas. In: Land Economics, Bd. 39, Nr. 1, S. 81-90.

HUFF, D. L. (1964): Defining and Estimating a Trading Area. In: Journal of Marketing, Bd. 28, Nr. 4, S. 34-38.

HufF, D. L. (1981): Retail Location Theory. In: StAMPfL, R. W./HIRSCHMAN, E. C. (Hrsg.): Theory in Retailing: Traditional and Nontraditional Sources. Chicago : American Marketing Association. S. 108-121.

HufF, D. L./BATSELL, R. R. (1975): Conceptual and Operational Problems with Market Share Models of Consumer Spatial Behavior. In: Advances in Consumer Research, Bd. 2, S. $165-172$.

HUFF, D. L./LUTZ, J. M. (1995): Change and Continuity in the Irish Urban System, 1966-81. In: Urban Studies, Bd. 32, Nr. 1, S. 155-173.

HufF, D. L./McCALLUM, B. M. (2008): Calibrating the Huff Model Using ArcGIS Business Analyst (= ESRI White Paper, September 2008). URL: http://www.esri.com/library/ whitepapers/pdfs/calibrating-huff-model.pdf (Letzter Zugriff am 19.10.2011). 
Hunt, L. M./Boots, B./Kanaroglou, P. S. (2004): Spatial choice modelling: new opportunities to incorporate space into substitution patterns. In: Progress in Human Geography, Bd. 28, Nr. 6, S. 746-766.

IÖW [= INSTITUT FÜR ÖKOLOGISCHE WIRTSCHAFTSFORSCHUNG GGMBH] (2005): Versorgung mit Waren des täglichen Bedarfs im ländlichen Raum. Studie für den Verbraucherzentrale Bundesverband e.V. (Zusammenfassung und Fazit). Berlin : IÖW.

ISARD, W. (1960): Methods of Regional Analysis: an Introduction to Regional Science. Cambridge : M.I.T. Press.

JAEHRLING, H. (2012): Schwellenwerte in der landesplanerischen Steuerung des großflächigen Einzelhandels und ihre Begründung - Ein Blick in andere Bundesländer. In: KONZE, H.MOLF, M. (Hrsg.): Einzelhandel in Nordrhein-Westfalen planvoll steuern! (= Arbeitsberichte der ARL [Akademie für Raumforschung und Landesplanung], Bd. 2). Hannover : ARL. S. 101-113.

JANNING, H. (2012): Eckpunkte einer möglichen landesplanerischen Steuerung. In: KONZE, H.MOLF, M. (Hrsg.): Einzelhandel in Nordrhein-Westfalen planvoll steuern! (= Arbeitsberichte der ARL [Akademie für Raumforschung und Landesplanung], Bd. 2). Hannover : ARL. S. 72-100.

JENKIS, H. (1996): Raumordnung und Raumordnungspolitik. München [u.a.] : Oldenbourg.

JenNE, A. (2006): Der Einzelhandel in Grund- und Mittelzentren. Rahmenbedingungen, Trends und neue Herausforderungen. In: HeInEBERG, H./JENNE, A. (Hrsg.): Angebotsund Akzeptanzanalysen des Einzelhandels in Grund- und Mittelzentren. Fallstudien Attendorn, Dorsten, Hilden, Hörstel und Nordhorn. Münster : Aschendorff. S. 19-56.

Jensen-ButleR, C. (1972): Gravity Models as Planning Tools: A Review of Theoretical and Operational Problems. In: Geografiska Annaler, Series B, Human Geography, Bd. 54, Nr. 1, S. 68-78.

JONES LANG LASALLE (2011): Retail City Scout Deutschland 2011. Hamburg [u.a.] : Jones Lang LaSalle.

JUNKER UND KRUSE (2005): Fortschreibung der Einzelhandelsuntersuchung für die Stadt Höxter [Gutachten]. Dortmund : Junker und Kruse.

JUNKER UND KRUSE (2009): Einzelhandels- und Zentrenkonzept für Stadt Höxter. Endversion Oktober 2009 [Gutachten]. Dortmund : Junker und Kruse.

JUNKER, R./KÜHN, G. (2009): Einkaufscenter und Innenstädte - Trends, Auswirkungen, Handlungsempfehlungen. In: Neues Archiv für Niedersachsen, Bd. 60, Nr. 2, S. $52-$ 71.

JÜRGENS, U. (2012a): Standortmuster von Lebensmitteldiscountern - eine systematische Betrachtung am Beispiel Schleswig-Holstein. In: Berichte des Arbeitskreises Geographische Handelsforschung, Bd. 31, S. 35-41.

JÜRGENS, U. (2012b): Discounter versus Supermarkt? Untersuchungen in SchleswigHolstein. In: Standort, Bd. 36, Nr. 1, S. 11-16.

JÜRGENS, U. (2013): Nahversorgung durch Aldi, Lidl und Co? In: Geographische Rundschau, Bd. 65 , Nr. 3, S. 50-57. 
JÜRGENS, U. (2014): Forschungsfragen zur Nahversorgung. In: JÜRGENS, U. (2014): Entwicklungen und Perspektiven von Nahversorgung im Lebensmitteleinzelhandel (= Kieler Arbeitspapiere zur Landeskunde und Raumordnung, Bd. 54). S. 1-6.

KAISER'S TENGELMANN (o.J.): Nachhaltig - Innovativ - Erfolgreich. Wir expandieren weiter! [Expansionsbroschüre] URL: http://tna4.tna.cust.incoweb.de/fileadmin/corporate/ content/pdf/complete.pdf (Letzter Zugriff am 29.07.2014).

KANHÄUSSER, C. (2007): Modellierung und Prognose von Marktgebieten am Beispiel des Möbeleinzelhandels. In: KLEIN, R./RAUH, J. (Hrsg.): Analysemethodik und Modellierung in der geographischen Handelsforschung (= Geographische Handelsforschung, Bd. 13). Passau : L.I.S. S. 75-110.

KAUFLAND (O.J.): Expansion Deutschland [Expansions-Website]. URL: https://www.kaufland.de/Home/05_Unternehmen/009_Immobilien/001_Expansion/00 2_Deutschland/index.jsp? (Letzter Zugriff am 29.07.2014).

KIM, P.-J./KIM, W./ChUNG, W.-K./YounN, M.-K. (2011): Using new Huff model for predicting potential retail market in South Korea. In: Africa Journal of Business Management, Bd. 5, Nr. 5, S. 1543-1550.

KLEIN, K. (2014): Der Beitrag von LM-Discountern zu einer "qualifizierten“ LMNahversorgung. In: JÜRGENS, U. (2014): Entwicklungen und Perspektiven von Nahversorgung im Lebensmitteleinzelhandel $(=$ Kieler Arbeitspapiere zur Landeskunde und Raumordnung, Bd. 54). S. 81-122.

KLEIN, K. E. (1997): Wandel der Betriebsformen im Einzelhandel. In: Geographische Rundschau, Bd. 49, Nr. 9, S. 499-504.

KLEIN, R. (1992): Dezentrale Grundversorgung im ländlichen Raum. Interaktionsmodelle zur Abschätzung von Nachfragepotentialen im Einzelhandel (= Osnabrücker Studien zur Geographie, Bd. 12). Osnabrück : Selbstverlag des Fachgebietes Osnabrück im Fachbereich Kultur- und Geowissenschaften der Universität Osnabrück.

KLEIN, R. (2005): Ökonomische und theoretische Grundlagen der Wirtschaftsgeographie. In: SCHENK, W./SCHLIEPHAKE, K. (Hrsg.): Allgemeine Anthropogeographie. Gotha [u.a.] : Klett-Perthes. S. 335-352.

KLEIN, R. (2007): Der probabilistische Ansatz zur Modellierung des räumlichen Einkaufsverhaltens. In: KLEIN, R./RAUH, J. (Hrsg.): Analysemethodik und Modellierung in der geographischen Handelsforschung (= Geographische Handelsforschung, Bd. 13). Passau : L.I.S. S. 55-74.

KLEIN, R./LÖFFLER, G. (1988): Kalibrierung und praxisorientierte Erweiterung raumrelevanter Standortmodelle. Ein Beitrag zur Versorgungssicherung der Bevölkerung ländlich/peripherer Räume mit Gütern des kurzfristigen Bedarfs (= Forschungsbericht. Informationszentrum Raum und Bau, Fraunhofer-Gesellschaft. T, Bd. 2047). Stuttgart : IRB Verlag.

KNOBLICH, H./NIEMEYER, H.-W./LIPPOLD, D. (1976): Die Erforschung konsumwirtschaftlicher Einflussbereiche zentraler Orte mit Hilfe gravitationstheoretischer Modellansätze. In: Neues Archiv für Niedersachsen, Bd. 25, Nr. 2, S. 95-104. 
KOCH, H.-J. (2010): Erhaltung und Entwicklung „Zentraler Versorgungsbereiche“ in der jüngeren Rechtsprechung des Bundesverwaltungsgerichtes. In: Die Verwaltung, Bd. 45, Nr. 2, S. 233-249.

KÖHLER, H. (2012): Kopplungen am Arbeitsort. Ein synchronischer Vergleich der Aktivitätenkopplungen Erwerbstätiger an ihrem Arbeitsort. Dissertation an der Humboldt-Universität zu Berlin. Berlin.

KOHSAKA, H. (1984): An Optimization of the Central Place System in Terms of the Multipurpose Shopping Trip. In: Geographical Analysis, Bd. 16, Nr. 3, S. 250-269.

KoschNY, R. P./LISCHKA, H. (2009): Bedeutung der Wettbewerbssituation unter markt- und standortanalytischen Gesichtspunkten beim Rating von Einzelhandelsimmobilien. In: EVERLING, O./JAHN, O./KAMMERMEIER, E. (Hrsg.): Rating von Einzelhandelsimmobilien : Qualität, Potenziale und Risiken sicher bewerten. Wiesbaden : Gabler. S. 405-421.

KOTLER, P. (1971): Marketing Decision Making. A Model Building Approach. New York [u.a.] : Holt, Rinehart and Winston.

KRIDER, R. E./PUTLER, D. S. (2013): Which Birds of a Feather Flock Together? Clustering and Avoidance Patterns of Similar Retail Outlets. In: Geographical Analysis, Bd. 45, Nr. 2, S. 123-149.

KROL, B. (2010): Standortfaktoren und Standorterfolg im Electronic Retailing. Konzeptualisierung, Operationalisierung und Erfolgswirkungen von virtuellen Standorten elektronischer Einzelhandelsunternehmen. Wiesbaden : Gabler.

KRÜGER, T./Anders, S./WAlther, M./KLEIN, K./Segerer, M. (2013): Qualifizierte Nahversorgung im Lebensmitteleinzelhandel - Kurzfassung des Endberichts (aktualisierte Fassung). Hamburg/Regensburg : HCU/IRE|BS.

KRÜGER, T.MALTHER, M. (2007): Auswirkungen Innerstädtischer Shopping Center. In: WeHRHEIM, J. (Hrsg.): Shopping Malls (= Stadt, Raum und Gesellschaft, Bd. 24). Wiesbaden : VS Verlag für Sozialwissenschaften. S. 191-208.

KRugman, P. (1991a): Increasing Returns and Economic Geography. In: Journal of Political Economy, Bd. 99, Nr. 3, S. 483-499.

Krugman, P. (1991b): Geography and Trade. Cambridge [u.a.] : M.I.T. Press.

KRUGman, P. (1998): What's new about the New Economic Geography? In: Oxford Review of Economic Policy, Bd. 14, Nr. 2, S. 7-17.

Krugman, P. (2011): The New Economic Geography, Now Middle-aged. In: Regional Studies, Bd. 45, Nr. 1, S. 1-7.

KUBIS, A./HARTMANN, M. (2007): Analysis of Location of Large-area Shopping Centres. A Probabilistic Gravity Model for the Halle-Leipzig Area. In: Jahrbuch für Regionalwissenschaft, Bd. 27, Nr. 1, S. 43-57.

KÜHN, G. (2011): Einzelhandel in den Kommunen und Nahversorgung in Mittel- sowie Großstädten (= Difu-Papers, Oktober 2011). Berlin : Difu.

KULKE, E. (2005): Räumliche Konsumentenverhaltensweisen. In: KULKE, E. (Hrsg.): Dem Konsumenten auf der Spur. Neue Angebotsstrategien und Nachfragemuster (= Geographische Handelsforschung, Bd. 11). Passau : L.I.S. S. 9-26. 
KULKE, E. (2009): Wirtschaftsgeographie. 4. Auflage. Paderborn [u.a.] : Schöningh.

KULKE, E. (2010): Strukturwandel im Einzelhandel. In: KULKE, E. (Hrsg.): Wirtschaftsgeographie Deutschlands. 2., völlig neu bearbeitete Auflage. Heidelberg : Spektrum Akademischer Verlag. S. 217-231.

LADEMANN, R. (2007): Zum Einfluss von Verkaufsfläche und Standort auf die Einkaufswahrscheinlichkeit. In: SCHUCKEL, M./TOPOROWSKI, W. (Hrsg.): Theoretische Fundierung und praktische Relevanz der Handelsforschung. Wiesbaden : Gabler.

LADEMANN, R. (2011): Innerstädtische Einkaufszentren - Eine absatzwirtschaftliche Wirkungsanalyse (= Göttinger Handelswissenschaftliche Schriften, Bd. 77). Göttingen : GHS.

LADEMANN, R. P. (2013): Wettbewerbsökonomische Grundlagen des Betriebsformenwettbewerbs im Lebensmitteleinzelhandel. In: RIEKHOF, H.-C. (Hrsg.): Retail Business in Deutschland. Perspektiven, Strategien, Erfolgsmuster. Mit Fallstudien und Praxisbeispielen von Aldi, Budnikowsky, Dell, Görtz, Hugo Boss, Keen on fashion, Kiel's, Lush, Otto Group, Sport Scheck, Takko. 3., überarbeitete und erweiterte Auflage. Wiesbaden : Springer. S. 3-30.

LAL, R./RAO, R. (1997): Supermarket Competition: The Case of Every Day Low Pricing. In: Marketing Science, Bd. 16, Nr. 1, S. 60-80.

LAMMERS, K./STILLER, S. (2000): Regionalpolitische Implikationen der Neuen Ökonomischen Geographie (= HWWA Discussion Paper, Bd. 85). Hamburg : HWWA.

Landesentwicklungsprogramm Bayern (LEP), 1. September 2013.

Landes-Raumordnungsprogramm Niedersachsen (LROP) i. d. Fassung vom 8. Mai 2008 (nicht amtliche Textfassung).

Landes-Raumordnungsprogramm Niedersachsen (LROP). Nicht-amtliche Lesefassung September 2012.

LANGE, S. (1973): Wachstumstheorie zentralörtlicher Systeme (= Beiträge zum Siedlungsund Wohnungswesen und zur Raumplanung, Bd. 5). Münster : Institut für Siedlungsund Wohnungswesen der Universität Münster.

LeE, M.-L./PACE, R. K. (2005): Spatial Distribution of Retail Sales. In: The Journal of Real Estate Finance and Economics, Bd. 31, Nr. 1, S. 53-69.

LeVY, M./WeITZ, B. A. (2012): Retailing management. 8. Auflage. New York : McGraw-Hill Irwin.

LH MÜNCHEN [ = LANDESHAUPTSTADT MÜNCHEN, REFERAT FÜR StADTPLANUNG UND BAUORDNUNG] (2010): Zentrenkonzept München. Fortschreibung mit Schwerpunkt Nahversorgung - Kurzfassung. URL: http://www.muenchen.de/rathaus/dms/ Home/Stadtverwaltung/Referat-fuer-Stadtplanung-und-Bauordnung/stadtentwicklung/ flaechennutzungsplanung/pdf/zentrenkonzept_muenchen_2010.pdf (Letzter Zugriff am 26.03.2014). München : LH München.

LI, Y./LIU, L. (2012): Assessing the impact of retail location on store performance: A comparison of Wal-Mart and Kmart stores in Cincinnati. In: Applied Geography, Bd. 32, Nr. 2, S. 591-600. 
LIDL (o.J.): Total flexibel [Expansions-Website]. URL: http://www.lidl-immobilien.de/ cps/rde/xchg/lidl_ii/hs.xsl/5186.htm (Letzter Zugriff am 29.07.2014).

LIEFNER, I./SCHÄTZL, L. (2012): Theorien der Wirtschaftsgeographie. 10. Auflage. Paderborn.

LÖFFLER, G. (1998): Market areas - a methodological reflection on their boundaries. In: GeoJournal, Bd. 45, Nr. 4, S. 265-272.

LÖFFLER, G. (1999): Marktgebiet und Einzugsbereich - mathematisch-statistische Modellansätze zu ihrer Abgrenzung. In: HEINRITZ, G. (Hrsg.): Die Analyse von Standorten und Einzugsbereichen : methodische Grundfragen der Geographischen Handelsforschung (= Geographische Handelsforschung, Nr. 2). Passau : L.I.S. S. 4563.

Lösch, A. (1940): Die räumliche Ordnung der Wirtschaft. 1. Auflage. Jena : Fischer.

Lösch, A. (1944): Die räumliche Ordnung der Wirtschaft. 2. Auflage. Jena : Fischer.

LUCE, R. D. (1959): Individual choice behavior: a theoretical analysis. New York : Wiley.

MaieR, G./TÖDTLING, F. (2006): Regional- und Stadtökonomik 1. Standorttheorie und Raumstruktur. 4. aktualisierte und erweiterte Auflage. Wien : Springer.

MANKIW, N. G. (2004): Grundzüge der Volkswirtschaftslehre. 3. überarbeitete Auflage. Stuttgart : Schäffer-Poeschel.

MARINOV, M./CZAMANSKI, D. (2012): Normative issues in the organization of modern retailers in Israel. In: GeoJournal, Bd. 77, Nr. 3, S. 383-398.

MARKANT (o.J.): Neue Standorte [Expansions-Website]. URL: http://www.markant-online.de/ neue-standorte/ (Letzter Zugriff am 29.07.2014)

MARSCHAK, J. (1960): Binary-Choice Constraints and Random Utility Indicators. In: ARROW, K. J./KARLIN, S./SUPPES, P. (Hrsg.): Mathematical methods in Social Sciences. Stanford : Stanford University Press. S. 312-329.

MARSTALLER, J. (2011): Standortagglomerationen im Möbeleinzelhandel. In: Berichte des Arbeitskreises Geographische Handelsforschung, Bd. 30, S. 39-41.

MCFADDEN, D. (1974): Conditional logit analysis of qualitative choice behavior. In: ZAREMBKA, P. (Hrsg.): Frontiers in econometrics. New York [u.a.] : Academic Press. S. 105-142.

METRO AG (2012): METRO-Handelslexikon 2012/2013. Düsseldorf.

MICHALLIK, F. (2010): Instrumentarien zur Steuerung von Einzelhandel in Deutschland und Spanien (= Schriften der Deutsch-Spanischen Juristenvereinigung, Bd. 38). Zugl. Dissertation an der Humboldt-Universität Berlin. Frankfurt/Main : Lang.

MONHEIM, R. (2007): Isolation oder Kopplung? Empirische Befunde zur Versachlichung anhaltender Kontroversen um innerstädtische Shopping Center. In: Berichte des Arbeitskreises Geographische Handelsforschung, Bd. 22, S. 24-29.

MoOsmüLLER, G. (2004): Methoden der Empirischen Wirtschaftsforschung. München [u.a.] : Pearson.

Mossig, I./DORENKAMP, A. (2008): Belebt eine Shopping-Mall das innerstädtische Geschäftszentrum? Das Beispiel der „Galerie Neustädter Tor“ in Gießen. In: Spiegel der Forschung, Bd. 25, Nr. 1, S. 80-87. 
MÜLLER, S. (2012): Identifying spatial nonstationarity in German regional firm start-up data. In: Jahrbuch für Regionalwissenschaft, Bd. 32, Nr. 2, S. 113-132.

MülLER-HAGEDORN, L. (2009): Bau-, Miet- und Verkaufsflächen im Einzelhandel - Zur Diskussion um die Abgrenzung der Verkaufsfläche. In: SCHRÖDER, H./OLBRICH, R./ KenNING, P./EVANSCHITZKY, H. (Hrsg.): Distribution und Handel in Theorie und Praxis. Festschrift für Prof. Dr. Dieter Ahlert. Wiesbaden : Gabler. S.351-378.

MüLleR-HAGEDORN, L./NATtER, M. (2011): Handelsmarketing. 5. aktualisierte und überarbeitete Auflage. Stuttgart : Kohlhammer.

MülleR-HAGEdoRN, L./SCHUCKEL, M. (1995a): Die Prognose des Umsatzes neuer Einkaufszentren mit Hilfe des Modells von Huff - Theorie und Fallbeispiel (I). In: Das Wirtschaftsstudium, Bd. 24, Nr. 6, S. 514-518.

MülleR-HAGEdORN, L./SCHUCKEL, M. (1995b): Die Prognose des Umsatzes neuer Einkaufszentren mit Hilfe des Modells von Huff - Theorie und Fallbeispiel (II). In: Das Wirtschaftsstudium, Bd. 24, Nr. 7, S. 597-604.

MüLLER-HAGEDORN, L./SCHUCKEL, M. (2001): Möglichkeiten der Ermittlung und Prognose von Marktgebieten, dargestellt am Beispiel CentrO Oberhausen. In: SCHUCKEL, M. (Hrsg.): Stadt- und Standortmarketing (= Sonderhefte der Mitteilung des Instituts für Handelsforschung an der Universität Köln, Bd. 44). Köln : Institut für Handelsforschung. S. 89-143.

MÜLleR-HAGedoRn, L./TOPOROWSKI, W./ZIELKE, S. (2012): Der Handel. Grundlagen Management - Strategien. 2., vollständig überarbeitete Auflage. Stuttgart : Kohlhammer.

MuLligAN, G. F. (1984): Agglomeration and Central Place Theory: A Review of the Literature. In: International Regional Science Review, Bd. 9, Nr. 1, S. 1-42.

Mulligan, G. F./PARTRidge, M. D./CARRUthers, J. I. (2012): Central place theory and its reemergence in Regional Science. In: The Annals of Regional Science, Bd. 48, Nr. 2, S. 405-431.

MundeLL, M. L. (2013): Shopping Centre Choice: A Behavioural Perspective. Dissertation an der University of Durham.

NAKANISHI, M. (1976): Attitudinal Influence on Retail Patronage Behavior. In: Advances in Consumer Research, Bd. 3, Nr. 1, S. 24-29.

NAKANISHI, M./COOPER, L. G. (1974): Parameter Estimation for a Multiplicative Competitive Interaction Model - Least Squares Approach. In: Journal of Marketing Research, Bd. 11, Nr. 3, S. 303-311.

NAKANISHI, M./COOPER, L. G. (1982): Simplified estimation procedures for MCI models. In: Marketing Science, Bd. 1, Nr. 3, S. 314-322.

NeIS, P./Zielstra, D./ZIPF, A. (2012): The Street Network Evolution of Crowdsourced Maps: OpenStreetMap in Germany 2007-2011. In: Future Internet, Bd. 4, Nr. 1, S. 1-21.

Nelson, P. (1970): Information and Consumer Behavior. In: Journal of Political Economy, Bd. 78, Nr. 2, S. 311-329.

NeLsON, R. L. (1958): The selection of retail locations. New York : Dodge. 
Räumliches Einkaufsverhalten und Standortpolitik im Einzelhandel unter Berücksichtigung von Agglomerationseffekten

NetTo (o.J.): Discount und qualifizierte Nahversorgung unter einem Dach [Expansionsbroschüre]. URL: https://www.netto-online.de/media/handzettel/ onlinemagazin/9999-99-20e3ec247e7ddd361f8fb8e611fee848/expansion/ broschuere_expansion_05_2013.pdf (Letzter Zugriff am 29.07.2014).

Nevin, J. R./Houston, M. J. (1980): Image as a Component of Attraction to Intraurban Shopping Areas. In: Journal of Retailing, Bd. 56, Nr. 1, S. 77-93.

NeWmaRK, G. L./PLAUT, P. O. (2005): Shopping Trip-Chaining Behavior at Malls in a Transitional Economy. In: Transportation Research Record: Journal of the Transportation Research Board, Nr. 1939. S. 174-183.

Nielsen [=The Nielsen Company (Germany) GmbH] (2012): Handel - Verbraucher Werbung, Deutschland 2012. Frankfurt a.M.

NiESSEN, J./HAMM, U. (2007): Verknüpfung von Daten des tatsächlichen Kaufverhaltens mit Befragungsergebnissen über das bekundete Kaufverhalten und Einstellungen von Verbrauchern. In: KUHLMANN, F./SCHMITZ, P.M. (Hrsg.): Good Governance in der Agrar- und Ernährungswirtschaft (= Schriften der Gesellschaft für Wirtschafts- und Sozialwissenschaften des Landbaus e.V., Bd. 42). Landwirtschaftsverlag : Münster. S. 417-426.

NORD/LB (2002): Standortentwicklungskonzept für die Stadt Holzminden [Gutachten]. Hannover : NORD/LB.

NP (o.J.): Standortsuche [Expansions-Website]. URL: http://www.np.de/unternehmen/ standortsuche/ (Letzter Zugriff am 29.07.2014).

O'KELLY, M. E. (1999): Trade-area models and choice-based samples. In: Environment and Planning A, Bd. 31, Nr. 4, S. 613-627.

OKoruwa, A. A./NourSE, H. O./TerzA, J. V. (1994): Estimating Sales for Retail Centers: An Application of the Poisson Gravity Model. In: Journal of Real Estate Research, Bd. 9, Nr. 1, S. 85-97.

ÖNER, Ö./LARSSON, J. P. (2013): Location and Co-location in Retail - A Probabilistic Approach Using Geo-coded Data for Swedish Metropolitan Retail Markets (= HUI Working Papers, Bd. 80). Stockholm : HUl.

OPENSHAW, S./VENERIS, Y. (2003): Numerical experiments with central place theory and spatial interaction modelling. In: Environment and Planning A, Bd. 35, Nr. 8, S. 13891403.

OPPEWAL, H./HOLYOAKE, B. (2004): Bundling and retail agglomeration effects on shopping behavior. In: Journal of Retailing and Consumer Services, Bd. 11, Nr. 2, S. 61-74.

ORPANA, T./LAMPINEN, J. (2003): Building spatial choice models from aggregate data. In: Journal of Regional Science, Bd. 43, Nr. 2, S. 319-347.

OsteRHAGE, F. (2009): Zentrenkonzepte statt Zentrale-Orte-Konzept? Zukunftsweisende Ansätze zur räumlichen Lenkung der Einzelhandelsentwicklung. In: Berichte des Arbeitskreises Geographische Handelsforschung, Bd. 26, S. 41-46.

OTTAVIANO, G. I. P. (2011): 'New' new economic geography: firm heterogeneity and agglomeration economies. In: Journal of Economic Geography, Bd. 11, Nr. 2, S. 231 240. 
OVERFELD, K./JAHN, O. (2009): Standortfaktoren für das Rating von Einzelhandelsimmobilien. In: EVERLING, O./JAHN, O./KAMMERMEIER, E. (Hrsg.): Rating von Einzelhandelsimmobilien: Qualität, Potenziale und Risiken sicher bewerten. Wiesbaden : Gabler. S. 423-438.

PAN, H./LI, Y./DANG, A. (2013): Application of network Huff model for commercial network planning at suburban - Taking Wujin district, Changzhou as a case. In: Annals of GIS, Bd. 19, Nr. 3, S. 131-141.

PANCRAS, J./SRIRAM, S./KUMAR, V. (2012): Empirical Investigation of Retail Expansion and Cannibalization in a Dynamic Environment. In: Management Science, Bd. 58, Nr. 11, S. 2001-2018.

PARR, J. B. (2002a): Agglomeration economies: ambiguities and confusions. In: Environment and Planning A, Bd. 34, Nr. 4, S. 717-731.

PARR, J. B. (2002b): Missing Elements in the Analysis of Agglomeration Economies. In: International Regional Science Review, Bd. 25, Nr. 2, S. 151-168.

PARR, J. B. (2002c): The location of economic activity: central place theory and the wider urban system. In: MCCANN, P. (Hrsg.): Industrial Location Economics. Northampton : Elgar. S. 32-82.

PEnNy (o.J.): Erstmal zu Penny. Wenn Sie mit uns wachsen wollen [Expansionsbroschüre]. URL: http://www.penny.de/fileadmin/files/content/unternehmen/markteroeffnungen/ files/140131_PENNY_Broschuere_Expansion.zip (Letzter Zugriff am 29.07.2014)

Picone, G. A./Ridley, D. B./Zandbergen, P. A. (2009): Distance decreases with differentiation: Strategic agglomeration by retailers. In: International Journal of Industrial Organization, Bd. 27, Nr. 3, S. 463-473.

PItTroff, R. (2009): Shopping-Center in Deutschland: Themen und Perspektiven. In: EVERLING, O./JAHN, O./KAMmERMEIER, E. (Hrsg.): Rating von Einzelhandelsimmobilien : Qualität, Potenziale und Risiken sicher bewerten. Wiesbaden : Gabler. S. 15-33.

Poddig, T./DichtL, H./PetersmeIeR, K. (2008): Statistik, Ökonometrie, Optimierung. Methoden und inre praktischen Anwendungen in Finanzanalyse und Portfoliomanagement. 4., vollständig überarbeitete Auflage. Bad Soden/Ts. : Uhlenbruch.

POPIEN, R. (1989): Die Bedeutung von Kopplungsmöglichkeiten für den Einzelhandel. In: HEINRITZ, G. (Hrsg.): Geographische Untersuchungen zum Strukturwandel im Einzelhandel (= Münchener Geographische Hefte, Bd. 63). Regensburg : Laßleben.

Popkowski LeszczYc, P. T. L./SINHA, A./SAHGAL, A. (2004): The effect of multi-purpose shopping on pricing and location strategy for grocery stores. In: Journal of Retailing, Bd. 80, Nr. 2, S. 85-99.

Popp, H. (1979): Zur Bedeutung des Kopplungsverhaltens bei Einkäufen in Verbrauchermärkten - Aktionsräumliche Aspekte. In: Geographische Zeitschrift, Bd. 77, Nr. 4, S. 301-313.

POPP. M. (1998): Das Einkaufsverhalten im Lebensmittelbereich und seine Relevanz für die Standortplanung. In: Handelsforschung, Bd. 13, S. 163-182. 
Räumliches Einkaufsverhalten und Standortpolitik im Einzelhandel unter Berücksichtigung von

PREISSNER, M./KNOB, A. (2006): Standortplanung im Einzelhandel vor dem Hintergrund des demografischen Wandels. In: Handel im Fokus, Bd. 58, Nr. 2, S. 101-112.

PuRPER, G. (2007): Die Betriebsformen des Einzelhandels aus Konsumentenperspektive. Wiesbaden : DUV.

RAO, R. C. (2012): Models of retail competition. In: SHANKAR, V./CARPENTER, G. S. (Hrsg.): Handbook Of Marketing Strategy. Cheltenham [u.a.] : Elgar. S. 78-106.

RASOULI, S./TIMmERMANS, H. (2013): Assessment of model uncertainty in destinations and travel forecasts of models of complex spatial shopping behaviour. In: Journal of Retailing and Consumer Services, Bd. 20, Nr. 2, S. 139-146.

RATERS, E. (1976): Die Entwicklung des raumbezogenen Versorgungsverhaltens und des zentralörtlichen Versorgungsgefüges unter besonderer Berücksichtigung von Veränderungen des Einkommens und des Raumwiderstandes : ein Beitrag zur Dynamisierung der Theorie der zentralen Orte. Berlin : Duncker \& Humblot.

RAuH, J./SchenK, T./FeHLER, M./KLÜGL, F./PuPPE, F. (2007): Der simulierte Konsument. In: KLEIN, R./RAUH, J. (Hrsg.): Analysemethodik und Modellierung in der geographischen Handelsforschung (= Geographische Handelsforschung, Bd. 13). Passau : L.I.S. S. 127-152.

RAUH, R./SCHENK, T. A./SCHRÖDL, D. (2012): The simulated consumer - an agent-based approach to shopping behaviour. In: Erdkunde, Bd. 66, Nr. 1, S. 13-25.

Raumordnungsgesetz (ROG) vom 22. Dezember 2008 (BGBI. I S. 2986), das zuletzt durch Artikel 9 des Gesetzes vom 31. Juli 2009 (BGBI. I S. 2585) geändert worden ist.

REAL (o.J.): Großflächige SB-Warenhäuser mit vielseitigen Eigenmarken [Selbstdarstellung]. URL: http://www.real.info/de/unternehmen/profil.html (Letzter Zugriff am 29.07.2014).

REDding, S. J. (2010): The Empirics of New Economic Geography. In: Journal of Regional Science, Bd. 50, Nr. 1, S. 297-311.

REILLY, W. J. (1929): Methods for the Study of Retail Relationships (= Studies in Marketing, Bd. 4). Austin : Bureau of Business Research, The University of Texas.

REILLY, W. J. (1931): The Law of Retail Gravitation. New York : Selbstverlag W. J. Reilly.

Ren, C. R./Hu, Y./Yu, J./Hausman, J. (2011): Managing Product Variety and Collocation in a Competitive Environment: An Empirical Investigation of Consumer Electronics Retailing. In: Management Science, Bd. 57, Nr. 6, S. 1009-1024.

Reutterer, T./TelleR, C. (2009): Store format choice and shopping trip types. In: International Journal of Retail \& Distribution Management, Bd. 37, Nr. 8, S. 695-710.

REWE (o.J. a): Für jeden Standort das richtige Konzept [Expansionsbroschüre]. URL: https://immobilien.rewe.de/dam/immobilien/downloads/rewe_expansionsbroschuere_ 2013.pdf (Letzter Zugriff am 29.07.2014).

REWE (o.J. b): REWE Supermarkt - Vollsortiment an jedem Standort [Expansions-Website]. URL: https://immobilien.rewe.de/expansion/rewe-supermarkt.html (Letzter Zugriff am 29.07.2014).

REWE (o.J. c): Der frischeorientierte Markt um die Ecke [Expansions-Website]. URL: https://immobilien.rewe.de/expansion/rewe-city.html (Letzter Zugriff am 29.07.2014). 
REWE (o.J. d): Wochenmarkt-Charme mit Riesenauswahl [Expansions-Website]. URL: https://immobilien.rewe.de/expansion/rewe-center.html (Letzter Zugriff am 29.07.2014).

RIEMENSCHNEIDER, M. (2006): Der Wert von Produktvielfalt: Wirkung großer Sortimente auf das Verhalten von Konsumenten. Wiesbaden : DUV (zugl. Dissertation an der Universität St. Gallen).

RogalL, H. (2013): Volkswirtschaftslehre für Sozialwissenschaftler. Einführung in eine zukunftsfähige Wirtschaftslehre. 2. Auflage. Wiesbaden : Springer.

ROHRLACK, C. (2007): Logistische und Ordinale Regression. In: ALBERS, S./KLAPPER, D./KONRADT, U.MALTER, A.MOLF, J. (Hrsg.): Methodik der empirischen Forschung. 2. überarbeitete und erweiterte Auflage. Wiesbaden : Gabler. S. 199-214.

Rosser, J. B. (2011): The New Economic Geography Approach and Other Views. In: Rosser, J. B. (Hrsg.): Complex Evolutionary Dynamics in Urban-Regional and Ecologic-Economic Systems. From Catastrophe to Chaos and Beyond. New York [u.a.] : Springer. S. 23-42.

ROTHSCHILD, K. W. (1981): Einführung in die Ungleichgewichtstheorie. Berlin [u.a.] : Springer.

ROY, J. R./THILL, J.-C. (2004): Spatial interaction modelling. In: Papers in Regional Science, Bd. 92, Nr. 1, S. 339-361.

SADAHIRO, Y. (2001): A PDF-based analysis of the spatial structure of retailing. In: GeoJournal, Bd. 52, Nr. 3, S. 237-252.

SCHENK, H.-O. (1979): Die "Gesetze“ des Handels. In: ScHANZ, G. (Hrsg.): Betriebswirtschaftliche Gesetze, Effekte und Prinzipien. München : Vahlen. S. 28-37.

SCHENK, T. (2008): Multiagentensysteme zur Simulation von Konsumentenentscheidungen (= Würzburger Geographische Arbeiten, Bd. 101). Würzburg : Selbstverlag des Instituts für Geographie der Julius-Maximilians-Universität Würzburg.

SCHENK, W./SCHLIEPHAKE, K. (2005): Allgemeine Anthropogeographie. Gotha [u.a.] : KlettPerthes.

SCHENKHOFF, H. J./POHLE, H. (2010): Der Discounter als Nahversorger: Das Beispiel ALDI in Thüringen. In: RosenfELD, M. T. W.MEIB, D. (Hrsg.): Gleichwertigkeit der Lebensverhältnisse zwischen Politik und Marktmechanismus: Empirische Befunde aus den Ländern Sachsen, Sachsen-Anhalt und Thüringen. Hannover : ARL. S. 109119.

SCHNEDLITZ, P./RYCHLY, N./LIENBACHER, E. (2012): Dynamik im Handel: Vom Fachgeschäft zum Fachmarkt. In: ZenTES, J./SWOBODA, B./MORSCHETT, D./SCHRAMM-KLEIN, H. (Hrsg.): Handbuch Handel. Strategien - Perspektiven - Internationaler Wettbewerb. 2., vollständig überarbeitete Auflage. Wiesbaden : Springer. S. 259-276.

SCHNedlitZ, P./TELleR, C. (2008): Das Einkaufszentrum als Agglomerationsklasse: Begriffliche Diskussion und empirische Evaluierung von Agglomerationseffekten. In: GRUBER, M. (Hrsg.): Agglomerationseffekte und Bestandsverhältnisse in Einkaufszentren. Wien : Manz. S. 1-52.

SCHNELL, R./HILL, P. B./ESSER, E. (2011): Methoden der empirischen Sozialforschung. München : Oldenbourg. 
SCHÖLER, K. (1981): Das Marktgebiet im Einzelhandel. Determinanten, Erklärungsmodelle und Gestaltungsmöglichkeiten des räumlichen Absatzes (= Betriebswirtschaftliche Studien, Bd. 108). Berlin.

SCHÖLER, K. (2005): Raumwirtschaftstheorie. München : Vahlen.

SCHRAMm-KLEIN, H. (2012): Standortpolitik im Handel. In: ZeNTES, J./SWOBODA, B./MorschetT, D./SChramM-KlEIN, H. (Hrsg.): Handbuch Handel. Strategien Perspektiven - Internationaler Wettbewerb. 2., vollständig überarbeitete Auflage. Wiesbaden : Springer. S. 487-506.

SCHRÖDER, H. (2012): Handelsmarketing. Strategien und Instrumente für den stationären Einzelhandel und für Online-Shops. Mit Praxisbeispielen. 2. Aufl. Wiesbaden : Springer.

SCHULTE, T. (2007): Zentrenkonzepte und Zentrale Versorgungsbereiche - Handlungsbedarf, Grundlagen und Anforderungen am Beispiel Nordrhein-Westfalens. In: RaumPlanung, Bd. 132/133, S. 135-138.

SCHÜRMANN, C. (1999): Schöne heile Einkaufswelt. Eine Methode zur Abschätzung der wohnstandörtlichen Versorgungsqualität. (=IRPUD Arbeitspapier, Bd. 167). Dortmund.

SöLLNER, F. (2012): Die Geschichte des ökonomischen Denkens. 3. Auflage. Berlin [u.a.] : Springer.

SPENCER, A. H. (1978): Deriving measures of attractiveness for shopping centres. In: Regional Studies, Bd. 12, Nr. 6, S. 713-726.

SPERLE, T. (2012): Was kommt nach dem Handel? Umnutzung von Einzelhandelsflächen und deren Beitrag zur Stadtentwicklung. Dissertation an der Universität Stuttgart. Stuttgart.

StAdeRmAnN, A./Stolz, M. (2012): Integration und Auswirkungen innerstädtischer ShoppingCenter in Mittelstädten am Beispiel der Stadtgalerie in Witten. In: Berichte des Arbeitskreises Geographische Handelsforschung, Bd. 32, S. 26-34.

STADT+HANDEL (2011): Einzelhandelskonzept für die Stadt Beverungen [Gutachten]. Karlsruhe : Stadt+Handel.

Stanley, T. J./SeWALL, M. A. (1976): Image Inputs to a Probabilistic Model: Predicting Retail Potential. In: Journal of Marketing, Bd. 40, Nr. 3, S. 48-53.

STATISTISCHES BUNDESAMT (2012): Mikrozensus 2011 [Qualitätsbericht]. Wiesbaden : Statistisches Bundesamt.

STATISTISCHES BUNDESAMT (2014): Unternehmen, Beschäftigte, Umsatz und weitere betriebs- und volkswirtschaftliche Kennzahlen im Handel - Jahresstatistik im Handel - Wirtschaftszweig WZ08-47. Generiert durch die GENESIS-Online-Datenbank. URL: https://www-genesis.destatis.de/genesis/online (Letzter Zugriff am 24.07.2014).

StegneR, E./TORGE, S./VON DER HeIDE, J. M. (2010): Koppelstandorte im deutschen Lebensmittelhandel: Ein anhaltender Trend mit Gegentrend (GfK Geomarketing White Paper, September 2010). Nürnberg : GfK Geomarketing.

STEINRÖX, M. (2013): Ländlicher Raum bald ohne Nahversorgung? In: Neues Archiv für Niedersachsen, Bd. 64, Nr. 2, S. 108-120. 
StERNBERG, R. (2001): New Economic Geography und Neue regionale Wachstumstheorie aus wirtschaftsgeographischer Sicht. In: Zeitschrift für Wirtschaftsgeographie, Bd. 45, Nr. 3/4, S. 159-180.

STERNBERG, R. (2009): Erster Nobelpreis für einen „economic geographer“ - eine Bewertung aus Sicht eines Wirtschaftsgeographen. In: Zeitschrift für Wirtschaftsgeographie, Bd. 53, Nr. 1/2, S. 106-124.

SuÁrez-Vega, R./Santos-Peñate, D. R./Dorta-GonzÁlez, P./RodríGuez-Díaz, M. (2011): A multi-criteria GIS based procedure to solve a network competitive location problem. In: Applied Geography, Bd. 31, Nr. 1, S. 282-291.

TABUCHI, T./THISSE, J.-F. (2011): A new economic geography model of central places. In: Journal of Urban Economics, Bd. 69, Nr. 2, S. 240-252.

TAKAHASHI, T. (2013): Agglomeration in a city with choosy consumers under imperfect information. In: Journal of Urban Economics, Bd. 76, S. 28-42.

TALUKDAR, D./GAURI, D. K./GREWAL, D. (2010): An Empirical Analysis of the Extreme Cherry Picking Behavior of Consumers in the Frequently Purchased Goods Market. In: Journal of Retailing, Bd. 86, Nr. 4, S. 336-354.

TEGUT (o.J.): tegut... Standortplanung [Expansions-Website]. URL: http://www.tegut.com/ aktuell/einzelartikel/expansion.html (Letzter Zugriff am 29.07.2014).

TELLER, C. (2008): Shopping streets versus shopping malls - determinants of agglomeration format attractiveness from the consumers' point of view. In: The International Review of Retail, Distribution and Consumer Research, Bd. 18, Nr. 4, S. 381-403.

TELLER, C./ELMS, J. (2010): Managing the attractiveness of evolved and created retail agglomerations formats. In: Marketing Intelligence \& Planning, Bd. 28, Nr. 1, S. 2545.

TElLER, C./ELMS, J. (2012): Urban Place Marketing and Retail Agglomeration Customers. In: Journal of Marketing Management, Bd. 28, Nr. 5/6, S. 546-567.

Teller, C./Elms, J./ThOmson, J. A./PAdDison, A. R. (2010): Place marketing and urban retail agglomerations: An examination of shoppers' place attractiveness perceptions. In: Place Branding and Public Diplomacy, Bd. 6, Nr. 2, S. 124-133.

TELLER, C./REUTTERER, T. (2008): The evolving concept of retail attractiveness: What makes retail agglomerations attractive when customers shop at them? In: Journal of Retailing and Consumer Services, Bd. 15, Nr. 3, S. 127-143.

Teller, C./Reutterer, T./Schneditz, P. (2008): Hedonic and utilitarian shopper types in evolved and created retail agglomerations. In: The International Review of Retail, Distribution and Consumer Research, Bd. 18, Nr. 3, S. 283-309.

TELLER, C./SCHNEDLITZ, P. (2012): Drivers of agglomeration effects in retailing: The shopping mall tenant's perspective. In: Journal of Marketing Management, Bd. 28, Nr. 9/10, S. 1043-1061.

Temme, J. (2007): Discrete-Choice-Modelle. In: Albers, S./KLAPPER, D./KonRAdT, U.MALTER, A.MOLF, J. (Hrsg.): Methodik der empirischen Forschung. 2. überarbeitete und erweiterte Auflage. Wiesbaden : Gabler. S. 327-341. 
Räumliches Einkaufsverhalten und Standortpolitik im Einzelhandel unter Berücksichtigung von Agglomerationseffekten

THILL, J.-C. (1992): Spatial duopolistic competition with multipurpose and multistop shopping. In: The Annals of Regional Science, Bd. 26, Nr. 3, S. 287-304.

ThURSTONE, L. L. (1927): A law of comparative judgment. In: Psychological Review, Bd. 34, Nr. 4, S. 273-286.

TIETZ, B./RothHAAR, P. (1991): City-Studie : Marktbearbeitung und Management für die City ; die Zukunft des Einzelhandels in der Stadt. Landsberg/Lech : Verlag Moderne Industrie.

TIHI, B./Oruc, N. (2012): Competitive Location Assessment - the MCI Approach. In: South East European Journal of Economics and Business, Bd. 7, Nr. 2, S. 35-49.

TIMmERMANS, H. J. P. (1981): Multiattribute shopping models and ridge regression analysis. In: Environment and Planning A, Bd. 13, Nr. 1, S. 43-56.

Timmermans, H. J. P. (1993): Retail Environments and Spatial Shopping Behavior. In: GAERLING, T./GolledGE, R. G. (Hrsg.): Behavior and environment: psychological and geographical approaches. Amsterdam : North-Holland. S. 342-377.

TIMMERMANS, H. J. P. (2012): Retail and spatial consumer behaviour. In: WeLLS, V./FOXALL, G. (Hrsg.): Handbook Of Developments In Consumer Behaviour. Cheltenham [u.a.] : Elgar. S. 121-146.

TraIN, K. E. (2009): Discrete Choice Methods with Simulation. 2. Auflage. Cambridge [u.a.] : Cambridge University Press.

TREBBIN, A./FranZ, M./HASSLER, M. (2013): Großhandelskooperationen für den kleinflächigen Einzelhandel in ländlichen Räumen am Beispiel Mittelhessen. In: Zeitschrift für Wirtschaftsgeographie, Bd. 57, Nr. 3, S. 139-154.

TVG VeRLAG (2011): Das Telefonbuch [DVD]. Frühjahr/Sommer 2011. Frankfurt : TVG Verlag.

UECHTRITZ, M. (2010): Agglomerationsregelungen in der Regionalplanung zur Steuerung des Einzelhandels. In: HAGER, G. (Hrsg.): Regionalplanerische Steuerung des großflächigen Einzelhandels. Kleine Regionalplanertagung Baden-Württemberg 2009 (= ARL-Arbeitsmaterial, Bd. 354). Hannover : ARL. S. 17-33.

URBAN, D./MAYERL, J. (2008): Regressionsanalyse: Theorie, Technik und Anwendung. 3., überarbeitete und erweiterte Auflage. Wiesbaden : VS Verlag für Sozialwissenschaften.

VALLÉE, D. (2012): Analyse der Steuerungswirkungen. In: KONZE, H./WOLF, M. (Hrsg.): Einzelhandel in Nordrhein-Westfalen planvoll steuern! (= Arbeitsberichte der ARL [Akademie für Raumforschung und Landesplanung], Bd. 2). Hannover : ARL. S. 3954.

VANDENBROUCKE, D. A. (1995): Agglomeration and market area division in a simulated two level central place system. In: Regional Science Perspectives, Bd. 25, Nr. 1, S. 74-83.

VARIAN, H. R. (2007): Grundzüge der Mikroökonomik. 7., überarbeitete und erweiterte Auflage. München/Wien : Oldenbourg.

VGH Baden-Württemberg, Urteil vom 21.09.2010 - 3 S 324/08.

VGH Baden-Württemberg, Urteil vom 22.9.2005 - 3 S 1061/04. 
VGH Baden-Württemberg, Urteil vom 27.09.2007 - 3 S 2875/06.

VoGEL, V. (2006): Standortforschung für Einzelhandelsgroßprojekte - Ansätze und Methoden für raumwirksame großflächige Handelsbetriebe und Einkaufszentren. Dissertation an der Otto-Friedrich-Universität Bamberg. Bamberg.

VON AUER, L. (2013): Ökonometrie. Eine Einführung. 6., durchgesehene und aktualisierte Auflage. Heidelberg [u.a.] : Springer.

VON FRIELING, H. D. (2008): Raum und Regionalentwicklung in der neoklassischen Ökonomie - ein kritischer Überblick. In: KRUMBEIN, W./VON FRIELING, H. D./KRÖCHER, U./STRÄTER, D. (Hrsg.): Kritische Regionalwissenschaft - Gesellschaft, Politik, Raum. Theorien und Konzepte im Überblick. Münster : Westfälisches Dampfboot. S. 168190.

VON THÜNEN, J. H. (1826): Der isolirte [isolierte] Staat in Beziehung auf Landwirthschaft und Nationalökonomie : oder Untersuchungen über den Einfluß, den die Getreidepreise, der Reichthum des Bodens und die Abgaben auf den Ackerbau ausüben. Hamburg : Perthes.

VRoegriJK, M./GIJSBRECHTS, E./CAMPo, K. (2013): Close Encounter with the Hard Discounter: A Multiple-Store Shopping Perspective on the Impact of Local HardDiscounter Entry. In: Journal of Marketing Research, Bd. 51, Nr. 3, S. 352-370.

Weber, A. (1909): Über den Standort der Industrien. Erster Teil: Reine Theorie des Standorts. Tübingen : Mohr.

WeERS-HeRmanns, T. F. (2007): Planerische Steuerung des Einzelhandels aus kommunaler und regionaler Sicht (= Planungsrecht, Bd. 12). Göttingen : Vandenhoeck \& Ruprecht.

WHEELER, D. C. (2014): Geographically Weighted Regression. In: FISCHER, M. M./NIJKAMP, P. (Hrsg.): Handbook of Regional Science. Berlin [u.a.] : Springer. S. 1435-1459.

Wied-NebBeling, S./Schott, H. (2005): Grundlagen der Mikroökonomik. 3. Auflage. Berlin [u.a.] : Springer.

WiELAND, T. (2012): Agglomerationsvorteile im Einzelhandel - Empirische Befunde. In: Berichte des Arbeitskreises Geographische Handelsforschung, Bd. 31, S. 5-8.

WIELAND, T. (2013): Einkaufsstättenwahl, Einzelhandelscluster und räumliche Versorgungsdisparitäten - Modellierung von Marktgebieten im Einzelhandel unter Berücksichtigung von Agglomerationseffekten. In: SCHRENK, M./POPOVICH, V./ZEILE, P./ELISEI, P. (Hrsg.): REAL CORP 2013. Planning Times. Proceedings of 18th International Conference on Urban Planning, Regional Development and Information Society. Schwechat : CORP. S. 275-284.

WILDNER, R./SCHERÜBL, B. (2006): Model-assisted analysis, simulation and forecasting with consumer panel data. In: Yearbook of marketing and consumer research, Bd. 4, S. 529.

WINKER, P. (2010): Empirische Wirtschaftsforschung und Ökonometrie. Berlin : Springer.

WIRTSCHAFTSWOCHE (2009): Discounter Lidl: Schlechtes Image - gute Geschäfte (Artikel vom 02.02.2009). URL: http://www.wiwo.de/unternehmen/einzelhandel-discounterlidl-schlechtes-image-gute-geschaefte/5511452.html (Letzter Zugriff am 24.03.2014). 
WITT, U. (1987): Individualistische Grundlagen der evolutorischen Ökonomik (= Die Einheit der Gesellschaftswissenschaften, Bd. 47). Tübingen : Mohr.

WOLF, M. (2012): Anforderungen an Einzelhandelsgutachten. In: KONZE, H.MOLF, M. (Hrsg.): Einzelhandel in Nordrhein-Westfalen planvoll steuern! (= Arbeitsberichte der ARL [Akademie für Raumforschung und Landesplanung], Bd. 2). Hannover : ARL. S. 114134.

WOLINSKY, A. (1983): Retail Trade Concentration due to Consumers' Imperfect Information. In: The Bell Journal of Economics, Bd. 14, Nr. 1, S. 275-282.

WORLD BANK (2009): World Development Report 2009: Reshaping Economic Geography. Washington : The World Bank.

WotruBA, M. (2014): Kopplungseffekte von Einzelhandelsbetrieben. Sind geplante Einkaufsorte bessere Kopien der Innenstadt? In: Standort, Bd. 38, Nr. 2, S. 92-95.

YUE, Y./WANG, H./HU, B./LI, Q./LI, Y./YEH, A. (2012): Exploratory calibration of a spatial interaction model using taxi GPS trajectories. In: Computers, Environment and Urban Systems, Bd. 36, Nr. 2, S. 140-153.

Yuo, T./Crosby, N./LIZIERI, C./McCANN, P. (2004): Tenant Mix Variety in Regional Shopping Centres: Some UK Empirical Analyses (= Real Estate \& Planning Working Paper, Bd. 2004-02). Reading : Henley Business School.

Yuo, T./Lizieri, C./McCanN, P./Crosby, N. (2011): Rental Values in UK Shopping Malls. In: Urban Studies, Bd. 48, Nr. 8, S. 1667-1679.

ZECK, H. (2003): Zentrale Orte als räumliches Konzept für Anpassungsstrategien. In: Informationen zur Raumentwicklung, Bd. 7, Nr. 12, S. 725-736.

ZHU, T./SINGH, V./DUKES, A. (2011): Local competition, entry, and agglomeration. In: Quantitative Marketing and Economics, Bd. 9, Nr. 2, S. 129-154.

ZIMMERMANN, M. (2002): Standortplanung für Dienstleistungsunternehmen : das Beispiel multifunktionaler Sportanlagen. Wiesbaden : DUV. 


\section{Anhang}

Abbildung A 1: Erhebungsbogen der Einzelhandelskartierung (schematisch) 287

Abbildung A 2: Fragebogen der telefonischen Haushaltsbefragung (schematisch).

Tabelle A 1: Standortanforderungen ausgewählter LEH-Filialisten und -Kooperativen .......280

Tabelle A 2: Untersuchungsgebiet nach Ortsteilen und zugeordneten eigenen Gebieten...282

Tabelle A 3: Untersuchungsgebiet nach eigener Segmentierung .283

Tabelle A 4: Erfasste Lokalzeitungsberichte nach Erscheinungsdatum .284

Tabelle A 5: Liste Experteninterviews und sonstige Gespräche. .286

Tabelle A 6: Eigene Branchenkategorien und ihre Entsprechung nach der WZ2008-

Klassfikation

Tabelle A 7: Einzelhandelsangebot nach Leitbranchen und Ortsteilen 291

Tabelle A 8: Empirische Interaktionsmatrix - Beispiel Elektromärkte. 296 Tabelle A 9: Erfasste Elektronikkäufe im Online-Handel - Zahl und Anteil nach Gebieten .299 
Tabelle A 1: Standortanforderungen ausgewählter LEH-Filialisten und -Kooperativen

Quelle: Eigene Darstellung, Datengrundlagen: ALdI NORD (o.J.), ALDI SÜD (o.J.), BÜNTING-GRUPPE (o.J.), EdEKA-GRUPPE (o.J. a,b), FAMILA NoRDOST (o.J.), KAISER's TENGELMANN (o.J.), Kaufland (o.J.), Lidl (o.J.), MARKAnt (o.J.), Netto (o.J.), NP (o.J.), Penny (o.J.), ReAl (o.J.), Rewe (o.J., a,b,c,d), TEgut (o.J.)

\begin{tabular}{|c|c|c|c|c|c|c|c|c|}
\hline \multicolumn{2}{|c|}{$\begin{array}{l}\text { Unternehmen bzw. } \\
\text { Vertriebslinie }\end{array}$} & \multirow{2}{*}{$\begin{array}{l}\text { Grundstück } \\
\text { bei Neubau } \\
\text { [qm] }\end{array}$} & \multirow{2}{*}{$\begin{array}{l}\text { Verkaufs- } \\
\text { fläche [qm] }\end{array}$} & \multirow{2}{*}{$\begin{array}{l}\text { Zusatz- } \\
\text { fläche } \\
\text { [qm] }\end{array}$} & \multirow{2}{*}{$\begin{array}{l}\text { Standort- } \\
\text { kommune } \\
\text { [min. EW] }\end{array}$} & \multirow{2}{*}{$\begin{array}{l}\text { Markt- } \\
\text { gebiet } \\
\text { [min. EW] }\end{array}$} & \multirow{2}{*}{ Standorttypen } & \multirow{2}{*}{ Weitere Anforderungen } \\
\hline Name & Betriebsform & & & & & & & \\
\hline Aldi Nord* & $\mathrm{DC}$ & $a b 4.000$ & $\begin{array}{l}\text { k.A. }(1.100 \mathrm{qm} \\
\text { gesamt) }\end{array}$ & k.A. & k.A. & k.A. & k.A. & k.A. \\
\hline Aldi Süd* & $\mathrm{DC}$ & $a b 3.000$ & $\mathrm{ab} 750$ & k.A. & k.A. & 10.000 & k.A. & $\begin{array}{l}\text { k.A. } \\
\end{array}$ \\
\hline Edeka & SM/VM & ab 3.500 & $\begin{array}{l}\text { ab } 1.200 \text { (in } \\
\text { Ausnahmen } \\
\text { weniger) }\end{array}$ & k.A. & k.A. & 5.000 & $\begin{array}{c}\text { Stichworte u.a. „Nahversorgung“, } \\
\text { „Kopplungskäufe“ }\end{array}$ & $\begin{array}{c}\text { min. } 1 \text { Parkplatz pro } 15 \mathrm{qm} \\
\text { Verkaufsfläche (bei gemeinsamer } \\
\text { Parkplatznutzung: } 1 \text { Parkplatz pro } 10 \mathrm{qm} \\
\text { Verkaufsfläche) }\end{array}$ \\
\hline $\begin{array}{l}\text { Edeka } \\
\text { E Center }\end{array}$ & VM/SBW & ab 10.000 & ab 2.500 & k.A. & k.A. & 15.000 & $\begin{array}{c}\text { Stichworte u.a. „Nahversorgung“, } \\
\text { „Kopplungskäufe“ }\end{array}$ & $\begin{array}{c}\text { min. } 1 \text { Parkplatz pro } 15 \mathrm{qm} \\
\text { Verkaufsfläche (bei gemeinsamer } \\
\text { Parkplatznutzung: } 1 \text { Parkplatz pro } 10 \mathrm{gm} \\
\text { Verkaufsfläche) }\end{array}$ \\
\hline $\begin{array}{l}\text { Famila } \\
\text { Nordost }\end{array}$ & VM/SBW & k.A. & $2.500-5.000$ & k.A. & k.A. & k.A. & k.A. & ( \\
\hline $\begin{array}{c}\text { Famila } \\
\text { Nordwest }\end{array}$ & VM/SBW & ab 15.000 & $3.000-10.000$ & k.A. & k.A. & k.A. & k.A. & Mehr als 200 ebenerdige Parkplätze \\
\hline $\begin{array}{l}\text { Kaiser's } \\
\text { Tengelmann }\end{array}$ & SM/VM & ab 4.000 & $1.000-2.000$ & $\begin{array}{l}350-400 \\
\text { qm }\end{array}$ & k.A. & 10.000 & $\begin{array}{l}\text { Solitärstandorte, „Kombistandorte } \\
\text { mit Discountern“, Einkaufszentren } \\
\text { ohne SB-Warenhaus }\end{array}$ & min. 80 eigene Parkplätze \\
\hline Kaufland & VM/SBW & $a b 6.000$ & $a b 2.000$ & k.A. & 10.000 & 25.000 & k.A. & $\begin{array}{l}\text { Baurecht für großflächigen Einzelhandel } \\
\text { (Sonder- oder Kerngebiet) }\end{array}$ \\
\hline Lidl & $\mathrm{DC}$ & ab 4.000 & $\begin{array}{c}700-1.300 \\
\text { (innerstädtisch), } \\
800-1.300 \\
\text { (Ortsrandlage) }\end{array}$ & $\mathrm{ab} 300 \mathrm{qm}$ & 5.000 & 10.000 & $\begin{array}{l}\text { Solitärstandorte, Einkaufszentren, } \\
\text { zentrale Lagen (Partnerschaften mit } \\
\text { ergänzenden Nutzern: EH und } \\
\text { Dienstleistungen); Stichwort: } \\
\text { „Nahversorgung“ }\end{array}$ & $\begin{array}{c}\text { Hohe Frequenz und Sichtbarkeit; } \\
\text { Anlieferungsmöglichkeiten für LKW mit } \\
\text { 40t Gesamtgewicht und einer Länge von } \\
18,5 \mathrm{~m}\end{array}$ \\
\hline $\begin{array}{c}\text { Markant } \\
\text { Nordwest* }\end{array}$ & SM & ab 4.000 & $800-2.500$ & $350-400$ & 3.000 & 10.000 & „Solitär- oder Verbundstandorte“ & 50-120 Parkplätze \\
\hline $\begin{array}{l}\text { Marktkauf } \\
\text { (Edeka) }\end{array}$ & VM/SBW & ab 15.000 & $a b 4.000$ & k.A. & k.A. & 30.000 & k.A. & $\begin{array}{c}\text { min. } 1 \text { Parkplatz pro } 15 \mathrm{qm} \\
\text { Verkaufsfläche (bei gemeinsamer } \\
\text { Parkplatznutzung: } 1 \text { Parkplatz pro } 10 \mathrm{qm} \\
\text { Verkaufsfläche) }\end{array}$ \\
\hline
\end{tabular}




\begin{tabular}{|c|c|c|c|c|c|c|c|c|}
\hline \multicolumn{2}{|c|}{$\begin{array}{l}\text { Unternehmen bzw. } \\
\text { Vertriebslinie }\end{array}$} & \multirow{2}{*}{$\begin{array}{c}\begin{array}{c}\text { Grundstück } \\
\text { bei Neubau }\end{array} \\
\text { ab } 3.500\end{array}$} & \multirow{2}{*}{$\begin{array}{c}\text { Verkaufs- } \\
\text { fläche [qm] } \\
\text { ab } 800 \text { (ideal: } \\
1.000 \text { ) }\end{array}$} & \multirow{2}{*}{$\begin{array}{l}\begin{array}{c}\text { Zusatz- } \\
\text { fläche }\end{array} \\
\text { ab } 250\end{array}$} & \multirow{2}{*}{$\begin{array}{c}\begin{array}{r}\text { Standort- } \\
\text { kommune }\end{array} \\
\text { k.A. }\end{array}$} & \multirow{2}{*}{$\begin{array}{c}\text { Markt- } \\
\text { gebiet } \\
\text { k.A. }\end{array}$} & \multirow{2}{*}{$\begin{array}{c}\text { Standorttypen } \\
\text { Wohngebiete, Citylagen, ländliche } \\
\text { Ortszentren; Stichworte: } \\
\text { „Nahversorgung“, „Kopplungskäufe“ }\end{array}$} & \multirow{2}{*}{$\begin{array}{c}\text { Weitere Anforderungen } \\
\text { Min. } 60 \text { Parkplätze }\end{array}$} \\
\hline Netto & $\mathrm{DC}$ & & & & & & & \\
\hline Norma & $\mathrm{DC}$ & $a b 3.500$ & $500-2.500$ & k.A. & k.A. & k.A. & k.A. & k.A. \\
\hline $\mathrm{NP}^{*}$ & $\mathrm{DC}$ & $3.000-5.000$ & $600-850$ & k.A. & 2.500 & 5.000 & k.A. & k.A. \\
\hline Penny & $\mathrm{DC}$ & ab 4.500 & $\begin{array}{c}\text { ab } 800 \text { (in } \\
\text { Citylagen 500) }\end{array}$ & k.A. & 5.000 & 10.000 & $\begin{array}{l}\text { "Die Nähe zu anderen } \\
\text { Einzelhandelsstandorten ist nicht } \\
\text { zwingend ein Hinderungsgrund“ }\end{array}$ & Min. 60-80 Parkplätze (ideal: 120) \\
\hline Real & SBW & k.A. & $5.000-15.000$ & k.A. & k.A. & k.A. & k.A. & k.A. \\
\hline Rewe & SM/VM & k.A. & $1.000-3.000$ & k.A. & 5.000 & 10.000 & $\begin{array}{l}\text { Nahversorgungs-, Geschäfts-, } \\
\text { Einkaufs- oder Fachmarktzentren } \\
\text { sowie City- und Stadtteillagen }\end{array}$ & $\begin{array}{c}\text { Ausreichend Parkplätze; Lauf- und } \\
\text { Sichtlagen zu Hauptverkehrsachsen mit } \\
\text { guter Anbindung }\end{array}$ \\
\hline $\begin{array}{l}\text { Rewe } \\
\text { Center }\end{array}$ & VM/SBW & k.A. & ab 3.000 & k.A. & k.A. & 25.000 & $\begin{array}{c}\text { Verbrauchernahe und } \\
\text { zentrenbezogene Standortlagen mit } \\
\text { leistungsfähiger Verkehrsanbindung }\end{array}$ & Min. 300 Parkplätze \\
\hline Rewe City & SM & k.A. & $500-1.000$ & k.A. & 100.000 & k.A. & $\begin{array}{c}\text { City-Lagen, Stadtteilzentren oder } \\
\text { hochverdichtete } \\
\text { Nahversorgungsschwerpunkte }\end{array}$ & $\begin{array}{l}\text { Lauf-/Sichtlagen zu } \\
\text { Hauptverkehrsachsen, ÖPNV- } \\
\text { Haltestellen von Vorteil }\end{array}$ \\
\hline Tegut* $^{*}$ & VM & $a b 6.000$ & ab 1.200 & $a b 400$ & k.A. & k.A. & $\begin{array}{c}\text { Stadtteilversorger, } \\
\text { Fachmarktzentrum; „Als } \\
\text { Vollversorger eine Ergänzung zu } \\
\text { den Discount-Mitbewerbern“ }\end{array}$ & $\begin{array}{l}\text { Min. } 130 \text { Parkplätze; Verkehrsgünstige } \\
\text { Anbindung }\end{array}$ \\
\hline Tegut City* & SM & k.A. & $350-650$ & $\begin{array}{l}\text { k.A. } \\
\text { (Gesamtfl } \\
\text { äche min. } \\
500 \text { ) }\end{array}$ & 50.000 & k.A. & $\begin{array}{c}\text { Fußläufige und hoch frequentierte } \\
\text { Lage z. B. Fußgängerzonen, } \\
\text { Einkaufszentren }\end{array}$ & $\begin{array}{l}\text { Anlieferung mind. mit } 7,5 \text { t LKW; ca. } 20 \\
\text { Parkplätze in der Nähe; Nähe zu ÖPNV- } \\
\text { Knotenpunkten }\end{array}$ \\
\hline $\begin{array}{l}\text { Betriebsform } \\
\text { k.A. = keine }\end{array}$ & $=$ Supe & & & & & & & \\
\hline
\end{tabular}


Räumliches Einkaufsverhalten und Standortpolitik im Einzelhandel unter Berücksichtigung von Agglomerationseffekten

Tabelle A 2: Untersuchungsgebiet nach Ortsteilen und zugeordneten eigenen Gebieten

Quelle: Eigene Darstellung, Datengrundlagen: Landkreis Höxter (Stichtag 31.12.2012), Landkreis Holzminden (Stichtag 30.06.2012)

\begin{tabular}{|c|c|c|c|c|c|c|c|}
\hline \multicolumn{3}{|c|}{ Gemeinde } & \multicolumn{3}{|c|}{ Ortsteil } & \multicolumn{2}{|r|}{ Eigenes Gebiet } \\
\hline AGS & PLZ & Name & Name & ID & Einwohner 2012 & ID & Name \\
\hline 05762008 & 37688 & Beverungen & Amelunxen & 19 & 1.099 & 11 & Beverungen-Nordost \\
\hline 05762008 & 37688 & Beverungen & Blankenau & 20 & 279 & 11 & Beverungen-Nordost \\
\hline 05762008 & 37688 & Beverungen & Dalhausen & 21 & 1.717 & 14 & Beverungen-Süd \\
\hline 05762008 & 37688 & Beverungen & Drenke & 22 & 371 & 15 & Beverungen-West \\
\hline 05762008 & 37688 & Beverungen & Haarbrück & 23 & 488 & 14 & Beverungen-Süd \\
\hline 05762008 & 37688 & Beverungen & Herstelle & 24 & 985 & 13 & Beverungen-Südost \\
\hline 05762008 & 37688 & Beverungen & Jakobsberg & 25 & 275 & 14 & Beverungen-Süd \\
\hline 05762008 & 37688 & Beverungen & Kernstadt & 18 & 6.525 & 12 & Beverungen-Kernstadt \\
\hline 05762008 & 37688 & Beverungen & Rothe & 26 & 158 & 15 & Beverungen-West \\
\hline 05762008 & 37688 & Beverungen & Tietelsen & 27 & 232 & 15 & Beverungen-West \\
\hline 05762008 & 37688 & Beverungen & Wehrden & 28 & 828 & 11 & Beverungen-Nordost \\
\hline 05762008 & 37688 & Beverungen & Würgassen & 29 & 854 & 13 & Beverungen-Südost \\
\hline 03255023 & 37603 & Holzminden & Kernstadt & 01 & 20.894 & 01 & Holzminden-Kernstadt \\
\hline 03255023 & 37603 & Holzminden & Mühlenberg & 02 & 107 & 02 & Holzminden-Sollingortschaften \\
\hline 03255023 & 37603 & Holzminden & Neuhaus im Solling & 03 & 1.425 & 02 & Holzminden-Sollingortschaften \\
\hline 03255023 & 37603 & Holzminden & Silberborn & 04 & 778 & 02 & Holzminden-Sollingortschaften \\
\hline 05762020 & 37671 & Höxter & Albaxen & 06 & 1.688 & 04 & Höxter-Albaxen \\
\hline 05762020 & 37671 & Höxter & Bödexen & 07 & 851 & 05 & Höxter-Nord \\
\hline 05762020 & 37671 & Höxter & Bosseborn & 08 & 557 & 09 & Höxter-Südost \\
\hline 05762020 & 37671 & Höxter & Brenkhausen & 09 & 1.350 & 08 & Höxter-West \\
\hline 05762020 & 37671 & Höxter & Bruchhausen & 10 & 692 & 10 & Höxter-Süd \\
\hline 05762020 & 37671 & Höxter & Fürstenau & 11 & 1.203 & 05 & Höxter-Nord \\
\hline 05762020 & 37671 & Höxter & Godelheim & 12 & 916 & 09 & Höxter-Südost \\
\hline 05762020 & 37671 & Höxter & Kernstadt & 05 & 13.510 & 07 & Höxter-Kernstadt \\
\hline 05762020 & 37671 & Höxter & Lüchtringen & 13 & 3.094 & 06 & Höxter-Lüchtringen \\
\hline 05762020 & 37671 & Höxter & Lütmarsen & 14 & 961 & 08 & Höxter-West \\
\hline 05762020 & 37671 & Höxter & Ottbergen & 15 & 1.548 & 10 & Höxter-Süd \\
\hline 05762020 & 37671 & Höxter & Ovenhausen & 16 & 1.107 & 08 & Höxter-West \\
\hline 05762020 & 37671 & Höxter & Stahle & 17 & 2.464 & 03 & Höxter-Stahle \\
\hline 03255004 & 37691 & SG Boffzen & Boffzen & 30 & 2.668 & 16 & Boffzen-Boffzen \\
\hline 03255009 & 37691 & SG Boffzen & Derental & 33 & 660 & 19 & Boffzen-Derental \\
\hline 03255014 & 37699 & SG Boffzen & Fürstenberg & 31 & 1.141 & 17 & Boffzen-Fürstenberg \\
\hline 03255026 & 37697 & SG Boffzen & Lauenförde & 32 & 2.084 & 18 & Boffzen-Lauenförde \\
\hline 03255026 & 37697 & SG Boffzen & Meinbrexen & 34 & 394 & 18 & Boffzen-Lauenförde \\
\hline
\end{tabular}


Tabelle A 3: Untersuchungsgebiet nach eigener Segmentierung

Quelle: Eigene Darstellung, Datengrundlagen: Landkreis Höxter (Stichtag 31.12.2012), Landkreis Holzminden (Stichtag 30.06.2012), Eigene Berechnungen

\begin{tabular}{|c|l|r|}
\hline \multicolumn{2}{|l}{ Eigenes Gebiet } \\
\hline ID & Name & Einwohner 2012 \\
\hline 01 & Holzminden-Kernstadt & 20.894 \\
\hline 02 & Holzminden-Sollingortschaften & 2.310 \\
\hline 03 & Höxter-Stahle & 2.464 \\
\hline 04 & Höxter-Albaxen & 1.688 \\
\hline 05 & Höxter-Nord & 2.054 \\
\hline 06 & Höxter-Lüchtringen & 3.094 \\
\hline 07 & Höxter-Kernstadt & 13.510 \\
\hline 08 & Höxter-West & 3.418 \\
\hline 09 & Höxter-Südost & 1.473 \\
\hline 10 & Höxter-Süd & 2.240 \\
\hline 11 & Beverungen-Nordost & 2.206 \\
\hline 12 & Beverungen-Kernstadt & 6.525 \\
\hline 13 & Beverungen-Südost & 1.839 \\
\hline 14 & Beverungen-Süd & 2.480 \\
\hline 15 & Beverungen-West & 761 \\
\hline 16 & Boffzen & 2.668 \\
\hline 17 & Fürstenberg & 1.141 \\
\hline 18 & Lauenförde & 2.478 \\
\hline 19 & Derental & 660 \\
\hline
\end{tabular}


Räumliches Einkaufsverhalten und Standortpolitik im Einzelhandel unter Berücksichtigung von Agglomerationseffekten

Tabelle A 4: Erfasste Lokalzeitungsberichte nach Erscheinungsdatum Quelle: Eigene Darstellung

\begin{tabular}{|c|c|c|}
\hline Zeitung & Datum & Titel \\
\hline Täglicher Anzeiger Holzminden & 17.03 .2005 & "UWG versagt Markt in der Gartenstraße Zustimmung" \\
\hline Täglicher Anzeiger Holzminden & 23.02 .2006 & „In der Bahnhofstraße beginnen die Bauarbeiten“ \\
\hline Täglicher Anzeiger Holzminden & 17.04.2007 & „Media-Markt unter Dach und Fach“ \\
\hline Täglicher Anzeiger Holzminden & 25.08 .2007 & „Media-Markt an der Bülte - sind wir wirklich so blöd?" [Leserbrief] \\
\hline Täglicher Anzeiger Holzminden & 12.10.2007 & „Rat Holzminden macht den Weg frei für Media Markt“ \\
\hline Täglicher Anzeiger Holzminden & 16.01.2008 & „Was wird aus dem Rewe-Markt in Lauenförde?" \\
\hline Täglicher Anzeiger Holzminden & 18.01.2008 & „Hitzige Wortgefechte bei Diskussion um Standort für Rewe-Markt“ \\
\hline Täglicher Anzeiger Holzminden & 30.01 .2008 & „Heiße Diskussionen um Standort für Rewe-Markt in Lauenförde“ \\
\hline Täglicher Anzeiger Holzminden & 02.02 .2008 & „Höxter klagt gegen Media-Markt-Bau in Holzminden“ \\
\hline Täglicher Anzeiger Holzminden & 15.02.2008 & „Opfer eines kommunalpolitischen Eifersuchtsdramas““ \\
\hline Täglicher Anzeiger Holzminden & 28.02 .2008 & „Höxter wollte Media Markt - auch - auf der ,Grünen Wiese“" \\
\hline Täglicher Anzeiger Holzminden & 02.03 .2008 & „Anwohner schalten sich ein: ,Es gibt gute Alternativen zu Rewe“" \\
\hline Täglicher Anzeiger Holzminden & 14.03.2008 & „Mediamarkt: Stadt Höxter unterliegt vor Gericht“ \\
\hline Täglicher Anzeiger Holzminden & 15.03.2008 & „Die Bürger wollen kein gerichtliches Verfahren““ \\
\hline Täglicher Anzeiger Holzminden & 09.05 .2008 & „Zweite Ausfahrt des Supermarktes wird gestrichen“ \\
\hline Täglicher Anzeiger Holzminden & 05.12 .2008 & „Deutliche Mehrheit im Lauenförder Rat für den Rewe-Neubau“ \\
\hline Neue Westfälische (HX) & 15.04 .2009 & „Wir haben Hoffnung“ \\
\hline Neue Westfälische (HX) & 20.05 .2009 & „Konzept für den Einzelhandel wird vorgestellt" \\
\hline Neue Westfälische (HX) & 21.05 .2009 & „Ein schwarzer Tag für Höxter“ \\
\hline Neue Westfälische $(\mathrm{HX})$ & 28.05 .2009 & "Lex Kaufland stößt auf Widerstand“ \\
\hline Neue Westfälische (HX) & 04.06 .2009 & „FDP lehnt Einzelhandelskonzept ab“ \\
\hline Neue Westfälische (HX) & 06.06 .2009 & „Planungen nehmen kein Ende“ \\
\hline Neue Westfälische $(\mathrm{HX})$ & 10.06.2009 & „Die Umsätze brechen ein“ \\
\hline Neue Westfälische (HX) & 11.06.2009 & „Nichts dramatisieren"“ \\
\hline Neue Westfälische $(\mathrm{HX})$ & 13.06.2009 & „Bringt Runder Tisch die Rettung für Hertie?" \\
\hline Neue Westfälische $(\mathrm{HX})$ & 15.06.2009 & „Protestaktion vor Hertie-Häusern“ \\
\hline Neue Westfälische (HX) & 18.06.2009 & „Bezirksregierung sagt Nein“ \\
\hline Neue Westfälische (HX) & 19.06.2009 & „'Transparenz sieht anders aus'“ \\
\hline Neue Westfälische (HX) & 26.06 .2009 & „Detmold hält Entscheidung auf“ \\
\hline Neue Westfälische (HX) & 27.06 .2009 & „Die Kritik zurückgewiesen“ \\
\hline Neue Westfälische (HX) & 30.06 .2009 & „Drei Fraktionen setzen sich für Kaufland-Standort ein“ \\
\hline Neue Westfälische (HX) & 01.07 .2009 & „Bürger an der Brenkhäuser Straße fürchten mehr Lärm“ \\
\hline Neue Westfälische (HX) & 02.07 .2009 & „Ein letztes Mal zu Hertie“ \\
\hline Neue Westfälische $(\mathrm{HX})$ & 11.07 .2009 & „Stadt begrüßt Erhalt von Woolworth“ \\
\hline Neue Westfälische (HX) & 29.07 .2009 & „'Hertie wird mir fehlen'“ \\
\hline Neue Westfälische (HX) & 19.08 .2009 & „'Höxteraner Lösung' für Hertie-Nachfolge“ \\
\hline Neue Westfälische $(\mathrm{HX})$ & 18.09 .2009 & „'Ein ganzes Stück voran gekommen'“ \\
\hline Neue Westfälische $(\mathrm{HX})$ & 18.09 .2009 & "Neues Leben in Höxters Mitte" \\
\hline Täglicher Anzeiger Holzminden & 12.01 .2010 & „'Kein Bülte-Filialist tut etwas für die Entwicklung der Stadt"“ \\
\hline Täglicher Anzeiger Holzminden & 21.01 .2010 & „Holzminden blutet eigene Innenstadt aus“" (Leserbrief) \\
\hline Täglicher Anzeiger Holzminden & 12.03 .2010 & „Möbel Finke plant ,Preisrebell' in Holzminden“ \\
\hline Täglicher Anzeiger Holzminden & 27.03 .2010 & „Weser Wohnwelt darf sich vergrößern“ \\
\hline Täglicher Anzeiger Holzminden & 14.04 .2010 & „Innenstadt nicht irreparabel schädigen““ \\
\hline Täglicher Anzeiger Holzminden & 19.08 .2010 & „Rewe will an die Sollingstraße“ \\
\hline Täglicher Anzeiger Holzminden & 19.08 .2010 & „Zwei Märkte rund ums Wohnen in der Bülte“ \\
\hline Neue Westfälische (HX) & 01.12 .2010 & „Hertie-Haus wird abgerissen“ \\
\hline
\end{tabular}




\begin{tabular}{|c|c|c|}
\hline Zeitung & Datum & Titel \\
\hline Neue Westfälische (HX) & 18.12 .2010 & „Innenstadt ist ein Problem“ \\
\hline Neue Westfälische (HX) & 28.01 .2011 & „Vorbehalte zurückgewiesen“ \\
\hline Neue Westfälische $(\mathrm{HX})$ & 03.02 .2011 & „'Kaufland-Projekt ist kontraproduktiv“" \\
\hline Neue Westfälische $(\mathrm{HX})$ & 05.02 .2011 & „FDP bewertet Kaufland-Projekt kritisch“ \\
\hline Neue Westfälische (HX) & 18.02 .2011 & „Erst der Abriss, dann die Fragen“ \\
\hline Neue Westfälische $(\mathrm{HX})$ & 28.05 .2011 & „,Grünes Licht für Kaufland“ \\
\hline Täglicher Anzeiger Holzminden & 01.07 .2011 & „Finke kann jetzt seinen ,Preis-Rebell' in der Bülte bauen“ \\
\hline Neue Westfälische (HX) & 16.07 .2011 & „Nahversorgung sichern“ \\
\hline Neue Westfälische $(\mathrm{HX})$ & 16.08 .2011 & „Kaufland-Markt darf gebaut werden“ \\
\hline Täglicher Anzeiger Holzminden & 11.11 .2011 & "E-Neukauf Boffzen nach Umbau neu eröffnet" \\
\hline Täglicher Anzeiger Holzminden & 22.02 .2012 & „Anwohner fürchten um ihre Lebensqualität” \\
\hline Täglicher Anzeiger Holzminden & 13.03 .2012 & „Drei Kreis-Holzmindener Filialen auf Schlecker-Streichliste“ \\
\hline Täglicher Anzeiger Holzminden & 20.03 .2012 & „Wohngebiet bleibt Wohngebiet?" (Leserbrief) \\
\hline Neue Westfälische $(\mathrm{HX})$ & 24.03 .2012 & „Neue Klage gegen Kaufland“ \\
\hline Täglicher Anzeiger Holzminden & 03.04 .2012 & „An der Sollingstraße kann gebaut werden“ \\
\hline Neue Westfälische $(\mathrm{HX})$ & 17.04 .2012 & "Sieben Klagen gegen Kaufland“ \\
\hline Täglicher Anzeiger Holzminden & 19.07.2012 & "Großer Hagebaumarkt soll in die Bülte kommen“ \\
\hline Neue Westfälische (HX) & 21.11 .2012 & „Eröffnung nach ungeheurem Kraftakt" \\
\hline Neue Westfälische (HX) & 21.03 .2013 & „Platz für mehr Möbel" \\
\hline
\end{tabular}


Räumliches Einkaufsverhalten und Standortpolitik im Einzelhandel unter Berücksichtigung von Agglomerationseffekten

Tabelle A 5: Liste Experteninterviews und sonstige Gespräche

Quelle: Eigene Darstellung

\begin{tabular}{|l|c|}
\hline \multicolumn{1}{|c|}{ Expertengespräche im Vorlauf der Arbeit } & 14.05 .2009 \\
\hline $\begin{array}{l}\text { Herr Jens-Martin Wolff } \\
\text { Stadt Holzminden, Dezernat IV - Baudezernat, Leiter }\end{array}$ & 04.06 .2009 \\
\hline $\begin{array}{l}\text { Herr Ludger Ernst } \\
\text { Stadt Beverungen, Abt. IV - Bauabteilung, Leiter/Aufgabenbereich Bauleitplanung }\end{array}$ & 04.06 .2009 \\
\hline $\begin{array}{l}\text { Herr Ralf Schwager } \\
\text { Kaufhaus Schwager GmbH, Geschäftsführer } \\
\text { Stadtmarketing Holzminden GmbH, Geschäftsführer }\end{array}$ & 05.06 .2009 \\
\hline $\begin{array}{l}\text { Herr Thomas Schwingel } \\
\text { Stadt Höxter, Fachbereich 5 - Planen und Bauen, Abt. 51 - Stadtplanung und Umwelt }\end{array}$ & 06.03 .2012 \\
\hline \multicolumn{1}{|c|}{ Sonstige Gespräche während der Bearbeitung } \\
\hline $\begin{array}{l}\text { Herr Ludger Ernst } \\
\text { Stadt Beverungen, Abt. IV - Bauabteilung, Leiter/Aufgabenbereich Bauleitplanung }\end{array}$ & 16.03 .2012 \\
\hline $\begin{array}{l}\text { Frau Martina Schumann } \\
\text { Tourist Information Fürstenberg, Mitarbeiterin }\end{array}$ & 15.05 .2012 \\
\hline $\begin{array}{l}\text { Frau Katharina Postert } \\
\text { Touristik-Information Hochsolling, Mitarbeiterin }\end{array}$ & \\
\hline
\end{tabular}


Erfassungsbogen Einzelhandelsbetriebe und Leerstände

Lfd. $\mathrm{Nr}$.:

\begin{tabular}{|c|c|c|c|c|c|}
\hline \multicolumn{4}{|c|}{ Standortdaten } & & Gebiet-ID: . \\
\hline \multicolumn{6}{|c|}{ Gemeinde/Ortsteil: } \\
\hline \multirow[t]{2}{*}{$\begin{array}{l}\text { Beverungen } \\
\text { O Kernstadt } \\
\text { O Amelunxen } \\
\text { O Blankenau } \\
\text { O Dalhausen } \\
\text { O Drenke } \\
\text { O Haarbrück }\end{array}$} & $\begin{array}{l}\text { O Herstelle } \\
\text { O Jakobsberg } \\
\text { O Rothe } \\
\text { O Tietelsen } \\
\text { O Wehrden } \\
\text { O Würgassen }\end{array}$ & $\begin{array}{l}\text { Höxter } \\
\text { O Kernstadt } \\
\text { O Albaxen } \\
\text { O Bödexen } \\
\text { O Bosseborn } \\
\text { O Brenkhausen } \\
\text { O Bruchhausen }\end{array}$ & $\begin{array}{l}\text { O Godelheim } \\
\text { O Lüchtringen } \\
\text { O Lütmarsen } \\
\text { O Ottbergen } \\
\text { O Ovenhausen } \\
\text { O Stahle }\end{array}$ & $\begin{array}{l}\text { Holzminden } \\
\text { O Kernstadt } \\
\text { O Mühlenberg } \\
\text { O Neuhaus im Solling } \\
\text { O Silberborn }\end{array}$ & $\begin{array}{l}\text { Samtgemeinde Boffzen } \\
\text { O Boffzen } \\
\text { O Derental } \\
\text { O Fürstenberg } \\
\text { O Lauenförde } \\
\text { O Lauenförde-Meinbrexen }\end{array}$ \\
\hline & & & & Koordinaten: $\mathrm{X}$ & $Y$ \\
\hline
\end{tabular}

Anbieterdaten

O Leerstand O Geplanter Standort

Name:

Betriebsform:

O Verbrauchermarkt/ SB-Warenhaus

O Discounter

O Supermarkt

O Kauf-/Warenhaus

O Fachgeschäft
O Fachmarkt
O Convenience Store
O Sonstiges

Sonstiges:

O Filialist/Kooperative überregional

O Filialist/Kooperative regional

O Eingeschränktes Angebot

Geöffnet von

bis
O Untersuchungsrelevanter Anbieter

Verkaufsfläche: qm

\section{Branche (WZ2008-Unterklasse):}

Lebensmittel (Schwerpunkt)

O Nahrungs- und Genussmittel, Getränke, Tabakwaren, ohne ausgeprägten

Schwerpunkt (47111)

O Sonstiger EH mit Waren versch. Art, Hauptrichtung NuG (47112)

O Obst, Gemüse, Kartoffeln (47210)

O Fleisch, Fleischwaren (inkl. Metzger) (47220)

O Fisch, Meeresfrüchte, Fischerzeugnisse (47230)

O Backwaren, Süßwaren (inkl. Bäcker) (47240)

O Getränke (47250)

O Tabakwaren (47260)

O Sonstiger EH mit Nahrungs- und Genussmitteln (47290)

Elektroartikel/Unterhaltungselektronik

O Datenverarbeitungsgeräte, periphere Geräte, Software (47410)

O Telekommunikationsgeräte (47420)

O Geräte der Unterhaltungselektronik (47430)

O Elektrische Haushaltsgeräte (47540)

O Bespielte Ton- und Bildträger (47630)

O Foto- und optische Erzeugnisse (47782)

\section{Bau/Garten}

O Anstrichmittel, Bau- und Heimwerkerbedarf (47523)

O Vorhänge, Teppiche, Fußbodenbeläge, Tapeten (47530)

O Blumen, Pflanzen, Sämereien, Düngemittel (47761)

O Zoologischer Bedarf, Lebende Tiere (47762)

Möbel/Einrichtungsgegenstände

O Wohnmöbel (47591)

O Keramische Erzeugnisse und Glaswaren (47592)

Drogerie

O Kosmetische Erzeugnisse und Körperpflegemittel (47750)

Apotheke

O Apotheken (47730)
Bekleidung

O Bekleidung (47710)

Schuhe, Lederwaren

O Schuhe (47721)

O Lederwaren und Reisegepäck (47722)

Sonstiger Einzelhandel

O Waren versch. Art, ohne Nahrungsmittel (47191)

O Waren versch. Art, Hauptrichtung Nicht-Nahrungsmittel (47192)

O Textilien (47510)

O Metall- und Kunststoffwaren (47521)

O Musikinstrumente und Musikalien (47593)

O Haushaltsgegenstände a.n.g. (47599)

O Bücher (47610)

O Zeitschriften und Zeitungen (47621)

O Schreib- und Papierwaren, Schul- und Büroartikel (47622)

O Fahrräder, Fahrradteile und -zubehör (47641)

O Sport- und Campingartikel (ohne Campingmöbel) (47642)

O Spielwaren $(47650$

O Medizinische/Orthopädische Artikel (47740)

O Uhren Schmuck (47770)

O Augenoptiker (47781)

O Kunstgegenstände, Bilder, Kunstgewerbliche Erzeugnisse,

Briefmarken, Münzen, Geschenkartikel (47783)

O Sonstiges a.n.g. (47789)

O Antiquitäten, antike Teppiche (47791)

O Antiquariate (47792)

O Sonstige Gebrauchtwaren (47799)

Spezielle Angebotsform (HGZ-relevant):

Sonstige Anmerkungen:

O Lebensmittelhandwerk O Dorfladen (nicht-

O Sonst. Handwerk

kommerziell)

O Tankstellenshop

O Florist

Abbildung A 1: Erhebungsbogen der Einzelhandelskartierung (schematisch)

Quelle: Eigene Darstellung 
Räumliches Einkaufsverhalten und Standortpolitik im Einzelhandel unter Berücksichtigung von Agglomerationseffekten

\section{Telefonische Haushaltsbefragung zur räumlichen Einkaufsorientierung}

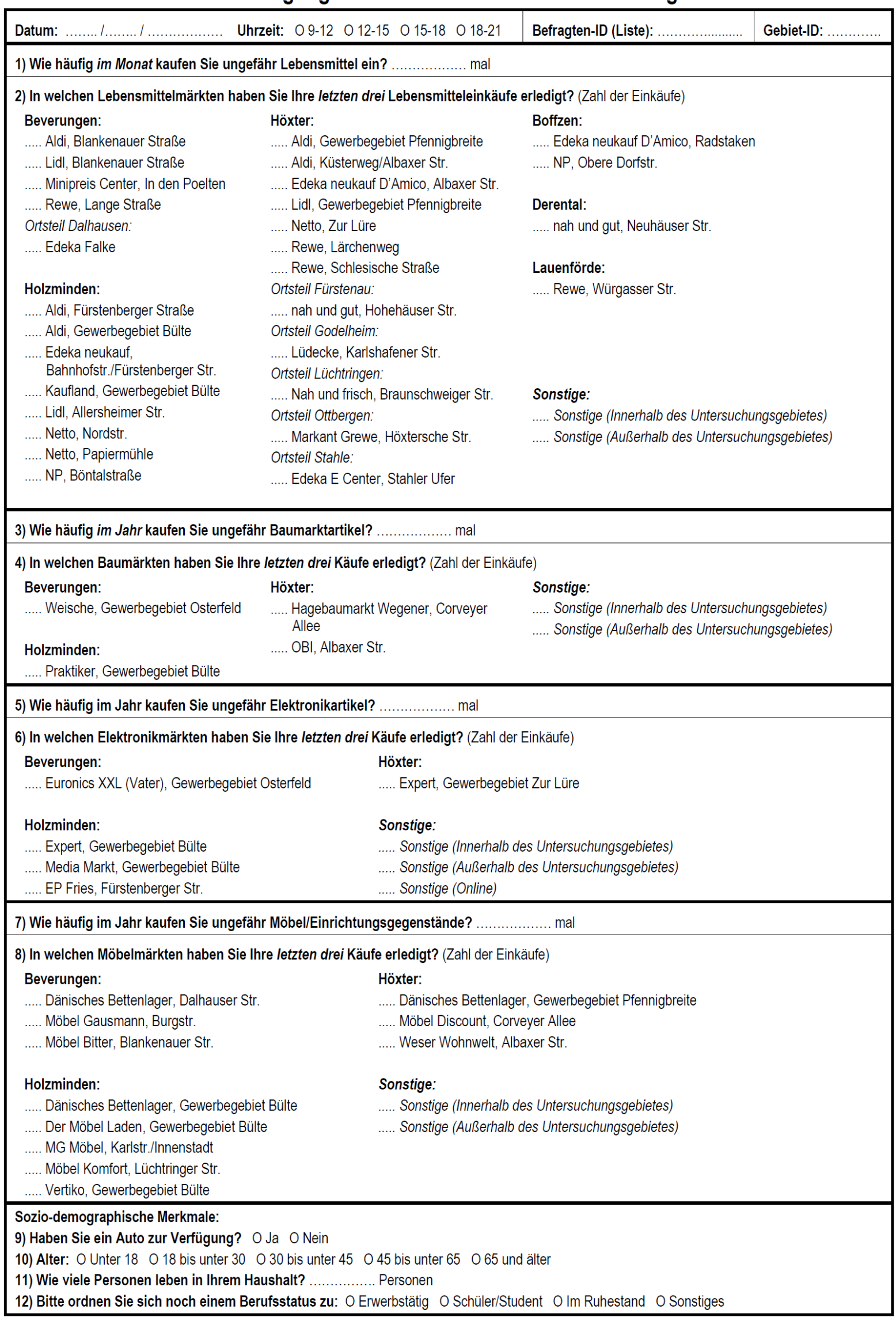

Abbildung A 2: Fragebogen der telefonischen Haushaltsbefragung (schematisch)

Quelle: Eigene Darstellung 
Tabelle A 6: Eigene Branchenkategorien und ihre Entsprechung nach der WZ2008-Klassfikation Quelle: Eigene Darstellung

\section{Einzelhandel mit Lebensmitteln (Schwerpunkt)}

47111 - Einzelhandel mit Nahrungs- und Genussmitteln, Getränken und Tabakwaren, ohne ausgeprägten Schwerpunkt (inkl. Tankstellenshops)

47112 - Sonstiger Einzelhandel mit Waren versch. Art, Hauptrichtung Nahrungs- und Genussmittel, Getränke und Tabakwaren

47120 - Einzelhandel mit Obst, Gemüse und Kartoffeln

47220 - Einzelhandel mit Fleisch und Fleischwaren (inkl. Verkaufsstellen von Metzgereien)

47230 - Einzelhandel mit Fisch, Meeresfrüchten und Fischerzeugnissen

47240 - Einzelhandel mit Back- und Süßwaren (inkl. Verkaufsstellen von Bäckereien)

47250 - Einzelhandel mit Getränken

47260 - Einzelhandel mit Tabakwaren

47290 - Sonstiger Einzelhandel mit Nahrungs- und Genussmitteln

\section{Einzelhandel mit Drogeriewaren}

47750 - Einzelhandel mit kosmetischen Erzeugnissen und Körperpflegemitteln

\section{Einzelhandel mit Apothekenwaren}

47730 - Apotheken

\section{Einzelhandel mit Elektroartikeln/Unterhaltungselektronik}

47410 - Einzelhandel mit Datenverarbeitungsgeräten, peripheren Geräten und Software

47420 - Einzelhandel mit Telekommunikationsgeräten

47430 - Einzelhandel mit Geräten der Unterhaltungselektronik

47540 - Einzelhandel mit elektrischen Haushaltsgeräten

47630 - Einzelhandel mit bespielten Ton- und Bildträgern

47782 - Einzelhandel mit Foto- und optischen Erzeugnissen (ohne Augenoptiker)

\section{Einzelhandel mit Bau-/Gartenartikeln}

47523 - Einzelhandel mit Anstrichmitteln, Bau- und Heimwerkerbedarf

47530 - Einzelhandel mit Vorhängen, Teppichen, Fußbodenbelägen und Tapeten

47761 - Einzelhandel mit Blumen, Pflanzen, Sämereien und Düngemitteln

47762 - Einzelhandel mit zoologischem Bedarf und lebenden Tieren

Einzelhandel mit Möbeln und Einrichtungsgegenständen

47591 - Einzelhandel mit Wohnmöbeln

47592 - Einzelhandel mit keramischen Erzeugnissen und Glaswaren

\section{Einzelhandel mit Bekleidung}

47710 - Einzelhandel mit Bekleidung

Einzelhandel mit Schuhen und Lederwaren

47721 - Einzelhandel mit Schuhen

47722 - Einzelhandel mit Lederwaren und Reisegepäck

\section{Sonstiges}

47191 - Einzelhandel mit Waren verschiedener Art (ohne Nahrungsmittel)

47192 - Einzelhandel mit Waren verschiedener Art, Hauptrichtung Nicht-Nahrungsmittel

47510 - Einzelhandel mit Textilien

47521 - Einzelhandel mit Metall- und Kunststoffwaren a. n. g.

47593 - Einzelhandel mit Musikinstrumenten und Musikalien

47599 - Einzelhandel mit Haushaltsgegenständen a. n. g.

47610 - Einzelhandel mit Büchern 
Räumliches Einkaufsverhalten und Standortpolitik im Einzelhandel unter Berücksichtigung von Agglomerationseffekten

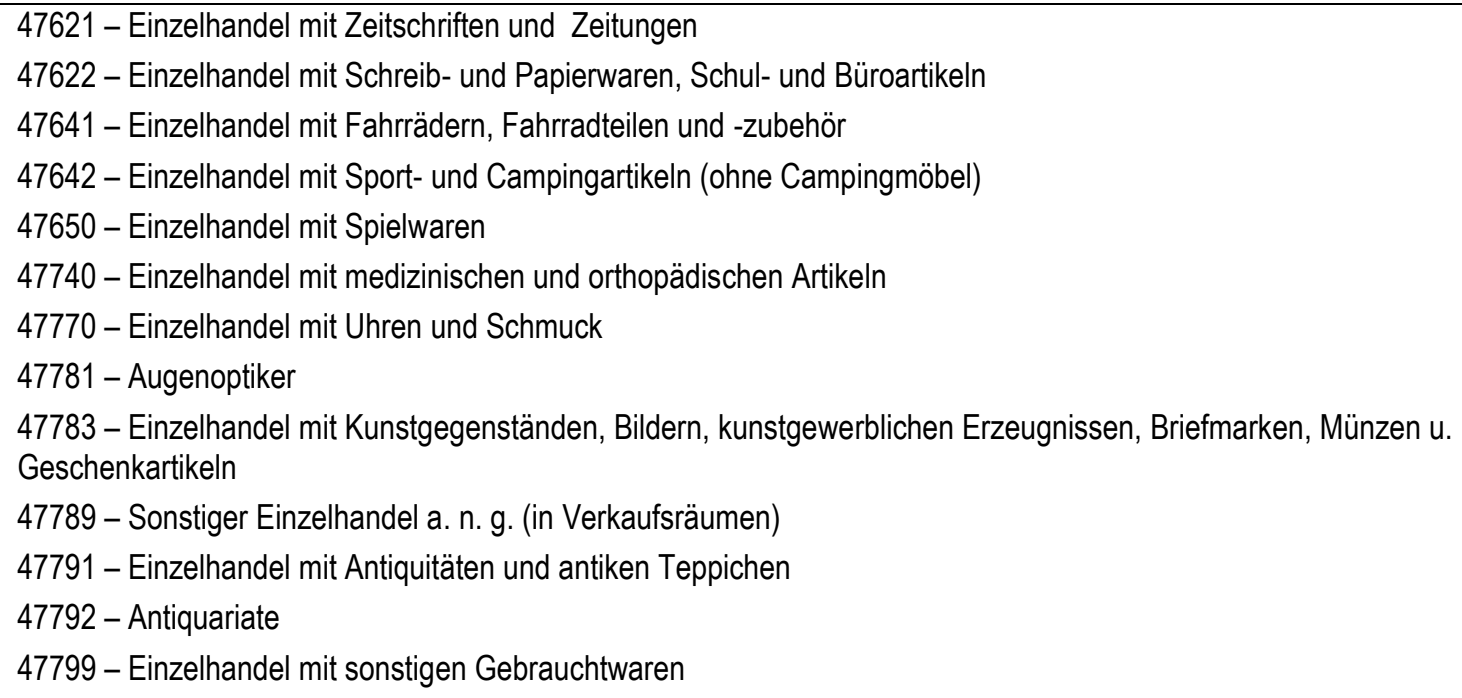


Tabelle A 7: Einzelhandelsangebot nach Leitbranchen und Ortsteilen

Quelle: Eigene Darstellung, Datengrundlage: Eigene Erhebungen (Stand: März 2012) und Berechnungen, Landkreis Höxter (Stichtag 31.12.2012), Landkreis Holzminden (Stichtag 30.06.2012)

\begin{tabular}{|c|c|c|c|c|c|c|c|c|c|c|c|c|}
\hline \multicolumn{3}{|c|}{ Gemeinde } & \multicolumn{2}{|c|}{ Ortsteil } & \multicolumn{4}{|c|}{ EH-Angebot Apotheken } & \multicolumn{4}{|c|}{ EH-Angebot Bau/Garten } \\
\hline AGS & PLZ & Name & Name & Einwohner 2012 & Anzahl & pro $1.000 \mathrm{EW}$ & VKF [qm] & pro $1.000 \mathrm{EW}$ & Anzahl & pro $1.000 \mathrm{EW}$ & VKF [qm] & pro $1.000 \mathrm{EW}$ \\
\hline 05762008 & 37688 & Beverungen & Amelunxen & 1.099 & 0 & 0,00 & 0 & 0,00 & 0 & 0,00 & 0 & 0,00 \\
\hline 05762008 & 37688 & Beverungen & Blankenau & 279 & 0 & 0,00 & 0 & 0,00 & 0 & 0,00 & 0 & 0,00 \\
\hline 05762008 & 37688 & Beverungen & Dalhausen & 1.717 & 1 & 0,58 & 60 & 34,94 & 1 & 0,58 & 50 & 29,12 \\
\hline 05762008 & 37688 & Beverungen & Drenke & 371 & 0 & 0,00 & 0 & 0,00 & 0 & 0,00 & 0 & 0,00 \\
\hline 05762008 & 37688 & Beverungen & Haarbrück & 488 & 0 & 0,00 & 0 & 0,00 & 1 & 2,05 & 50 & 102,46 \\
\hline 05762008 & 37688 & Beverungen & Herstelle & 985 & 0 & 0,00 & 0 & 0,00 & 0 & 0,00 & 0 & 0,00 \\
\hline 05762008 & 37688 & Beverungen & Jakobsberg & 275 & 0 & 0,00 & 0 & 0,00 & 0 & 0,00 & 0 & 0,00 \\
\hline 05762008 & 37688 & Beverungen & Kernstadt & 6.525 & 6 & 0,92 & 370 & 56,70 & 11 & 1,69 & 5.756 & 882,15 \\
\hline 05762008 & 37688 & Beverungen & Rothe & 158 & 0 & 0,00 & 0 & 0,00 & 0 & 0,00 & 0 & 0,00 \\
\hline 05762008 & 37688 & Beverungen & Tietelsen & 232 & 0 & 0,00 & 0 & 0,00 & 0 & 0,00 & 0 & 0,00 \\
\hline 05762008 & 37688 & Beverungen & Wehrden & 828 & 0 & 0,00 & 0 & 0,00 & 0 & 0,00 & 0 & 0,00 \\
\hline 05762008 & 37688 & Beverungen & Würgassen & 854 & 0 & 0,00 & 0 & 0,00 & 0 & 0,00 & 0 & 0,00 \\
\hline 03255004 & \begin{tabular}{|l|}
37691 \\
\end{tabular} & SG Boffzen & Boffzen & 2.668 & 1 & 0,37 & 60 & 22,49 & 1 & 0,37 & 100 & 37,48 \\
\hline 03255009 & 37691 & SG Boffzen & Derental & 660 & 0 & 0,00 & 0 & 0,00 & 0 & 0,00 & 0 & 0,00 \\
\hline 03255014 & 37699 & SG Boffzen & Fürstenberg & 1.141 & 0 & 0,00 & 0 & 0,00 & 1 & 0,88 & 200 & 175,28 \\
\hline 03255023 & 37603 & Holzminden & Kernstadt & 20.894 & 7 & 0,34 & 375 & 17,95 & 13 & 0,62 & 7.304 & 349,57 \\
\hline 03255023 & 37603 & Holzminden & Mühlenberg & 107 & 0 & 0,00 & 0 & 0,00 & 0 & 0,00 & 0 & 0,00 \\
\hline 03255023 & 37603 & Holzminden & Neuhaus im Solling & 1.425 & 1 & 0,70 & 30 & 21,05 & 0 & 0,00 & 0 & 0,00 \\
\hline 03255023 & 37603 & Holzminden & Silberborn & 778 & 0 & 0,00 & 0 & 0,00 & 0 & 0,00 & 0 & 0,00 \\
\hline 05762020 & 37671 & Höxter & Albaxen & 1.688 & 0 & 0,00 & 0 & 0,00 & 0 & 0,00 & 0 & 0,00 \\
\hline 05762020 & 37671 & Höxter & Bödexen & 851 & 0 & 0,00 & 0 & 0,00 & 1 & 1,18 & 147 & 172,74 \\
\hline 05762020 & 37671 & Höxter & Bosseborn & 557 & 0 & 0,00 & 0 & 0,00 & 0 & 0,00 & 0 & 0,00 \\
\hline 05762020 & 37671 & Höxter & Brenkhausen & 1.350 & 0 & 0,00 & 0 & 0,00 & 2 & 1,48 & 446 & 330,37 \\
\hline 05762020 & 37671 & Höxter & Bruchhausen & 692 & 0 & 0,00 & 0 & 0,00 & 0 & 0,00 & 0 & 0,00 \\
\hline 05762020 & 37671 & Höxter & Fürstenau & 1.203 & 0 & 0,00 & 0 & 0,00 & 1 & 0,83 & 24 & 19,95 \\
\hline 05762020 & 37671 & Höxter & Godelheim & 916 & 0 & 0,00 & 0 & 0,00 & 0 & 0,00 & 0 & 0,00 \\
\hline 05762020 & 37671 & Höxter & Kernstadt & 13.510 & 6 & 0,44 & 202 & 14,95 & 13 & 0,96 & 20.482 & $1.516,06$ \\
\hline 05762020 & 37671 & Höxter & Lüchtringen & 3.094 & 1 & 0,32 & 35 & 11,31 & 1 & 0,32 & 65 & 21,01 \\
\hline 05762020 & 37671 & Höxter & Lütmarsen & 961 & 0 & 0,00 & 0 & 0,00 & 0 & 0,00 & 0 & 0,00 \\
\hline 05762020 & 37671 & Höxter & Ottbergen & 1.548 & 1 & 0,65 & 24 & 15,50 & 0 & 0,00 & 0 & 0,00 \\
\hline 05762020 & 37671 & Höxter & Ovenhausen & 1.107 & 0 & 0,00 & 0 & 0,00 & 1 & 0,90 & 16 & 14,45 \\
\hline 05762020 & 37671 & Höxter & Stahle & 2.464 & 0 & 0,00 & 0 & 0,00 & 2 & 0,81 & 40 & 16,23 \\
\hline 03255026 & 37697 & SG Boffzen & Lauenförde & 2.084 & 1 & 0,48 & 40 & 19,19 & 0 & 0,00 & 0 & 0,00 \\
\hline 03255026 & 37697 & SG Boffzen & Meinbrexen & 394 & 0 & 0,00 & 0 & 0,00 & 0 & 0,00 & 0 & 0,00 \\
\hline Summe & & & & 73.903 & 25 & & 1.196 & & 49 & & 34.680 & \\
\hline Mittelwert & & & & & & 0,14 & & 6,30 & & 0,37 & & 107,85 \\
\hline VK & & & & & & 1,80 & & 1,99 & & 1,51 & & 2,75 \\
\hline
\end{tabular}




\begin{tabular}{|c|c|c|c|c|c|c|c|c|c|c|c|c|}
\hline \multicolumn{3}{|c|}{ Gemeinde } & \multicolumn{2}{|c|}{ Ortsteil } & \multicolumn{4}{|c|}{ EH-Angebot Bekleidung } & \multicolumn{4}{|c|}{ EH-Angebot Drogeriewaren } \\
\hline AGS & PLZ & Name & Name & Einwohner 2012 & Anzahl & pro $1.000 \mathrm{EW}$ & VKF [qm] & pro $1.000 \mathrm{EW}$ & Anzahl & pro $1.000 \mathrm{EW}$ & VKF [qm] & pro $1.000 \mathrm{EW}$ \\
\hline 05762008 & 37688 & Beverungen & Amelunxen & 1.099 & 0 & 0,00 & 0 & 0,00 & 0 & 0,00 & 0 & 0,00 \\
\hline 05762008 & 37688 & Beverungen & Blankenau & 279 & 0 & 0,00 & 0 & 0,00 & 0 & 0,00 & 0 & 0,00 \\
\hline 05762008 & 37688 & Beverungen & Dalhausen & 1.717 & 2 & 1,16 & 160 & 93,19 & 0 & 0,00 & 0 & 0,00 \\
\hline 05762008 & 37688 & Beverungen & Drenke & 371 & 0 & 0,00 & 0 & 0,00 & 0 & 0,00 & 0 & 0,00 \\
\hline 05762008 & 37688 & Beverungen & Haarbrück & 488 & 0 & 0,00 & 0 & 0,00 & 0 & 0,00 & 0 & 0,00 \\
\hline 05762008 & 37688 & Beverungen & Herstelle & 985 & 0 & 0,00 & 0 & 0,00 & 0 & 0,00 & 0 & 0,00 \\
\hline 05762008 & 37688 & Beverungen & Jakobsberg & 275 & 0 & 0,00 & 0 & 0,00 & 0 & 0,00 & 0 & 0,00 \\
\hline 05762008 & 37688 & Beverungen & Kernstadt & 6.525 & 15 & 2,30 & 4.416 & 676,78 & 4 & 0,61 & 1.652 & 253,18 \\
\hline 05762008 & 37688 & Beverungen & Rothe & 158 & 0 & 0,00 & 0 & 0,00 & 0 & 0,00 & 0 & 0,00 \\
\hline 05762008 & 37688 & Beverungen & Tietelsen & 232 & 0 & 0,00 & 0 & 0,00 & 0 & 0,00 & 0 & 0,00 \\
\hline 05762008 & 37688 & Beverungen & Wehrden & 828 & 0 & 0,00 & 0 & 0,00 & 0 & 0,00 & 0 & 0,00 \\
\hline 05762008 & 37688 & Beverungen & Würgassen & 854 & 0 & 0,00 & 0 & 0,00 & 0 & 0,00 & 0 & 0,00 \\
\hline 03255004 & 37691 & SG Boffzen & Boffzen & 2.668 & 1 & 0,37 & 550 & 206,15 & 0 & 0,00 & 0 & 0,00 \\
\hline 03255009 & 37691 & SG Boffzen & Derental & 660 & 0 & 0,00 & 0 & 0,00 & 0 & 0,00 & 0 & 0,00 \\
\hline 03255014 & 37699 & SG Boffzen & Fürstenberg & 1.141 & 0 & 0,00 & 0 & 0,00 & 0 & 0,00 & 0 & 0,00 \\
\hline 03255023 & 37603 & Holzminden & Kernstadt & 20.894 & 20 & 0,96 & 4.641 & 222,12 & 5 & 0,24 & 1.670 & 79,93 \\
\hline 03255023 & 37603 & Holzminden & Mühlenberg & 107 & 0 & 0,00 & 0 & 0,00 & 0 & 0,00 & 0 & 0,00 \\
\hline 03255023 & 37603 & Holzminden & Neuhaus im Solling & 1.425 & 1 & 0,70 & 50 & 35,09 & 1 & 0,70 & 150 & 105,26 \\
\hline 03255023 & 37603 & Holzminden & Silberborn & 778 & 0 & 0,00 & 0 & 0,00 & 0 & 0,00 & 0 & 0,00 \\
\hline 05762020 & 37671 & Höxter & Albaxen & 1.688 & 0 & 0,00 & 0 & 0,00 & 0 & 0,00 & 0 & 0,00 \\
\hline 05762020 & 37671 & Höxter & Bödexen & 851 & 0 & 0,00 & 0 & 0,00 & 0 & 0,00 & 0 & 0,00 \\
\hline 05762020 & 37671 & Höxter & Bosseborn & 557 & 0 & 0,00 & 0 & 0,00 & 0 & 0,00 & 0 & 0,00 \\
\hline 05762020 & 37671 & Höxter & Brenkhausen & 1.350 & 1 & 0,74 & 160 & 118,52 & 0 & 0,00 & 0 & 0,00 \\
\hline 05762020 & 37671 & Höxter & Bruchhausen & 692 & 0 & 0,00 & 0 & 0,00 & 0 & 0,00 & 0 & 0,00 \\
\hline 05762020 & 37671 & Höxter & Fürstenau & 1.203 & 0 & 0,00 & 0 & 0,00 & 0 & 0,00 & 0 & 0,00 \\
\hline 05762020 & 37671 & Höxter & Godelheim & 916 & 0 & 0,00 & 0 & 0,00 & 0 & 0,00 & 0 & 0,00 \\
\hline 05762020 & 37671 & Höxter & Kernstadt & 13.510 & 24 & 1,78 & 12.058 & 892,52 & 7 & 0,52 & 1.442 & 106,74 \\
\hline 05762020 & 37671 & Höxter & Lüchtringen & 3.094 & 0 & 0,00 & 0 & 0,00 & 1 & 0,32 & 130 & 42,02 \\
\hline 05762020 & 37671 & Höxter & Lütmarsen & 961 & 0 & 0,00 & 0 & 0,00 & 0 & 0,00 & 0 & 0,00 \\
\hline 05762020 & 37671 & Höxter & Ottbergen & 1.548 & 0 & 0,00 & 0 & 0,00 & 1 & 0,65 & 170 & 109,82 \\
\hline 05762020 & 37671 & Höxter & Ovenhausen & 1.107 & 0 & 0,00 & 0 & 0,00 & 0 & 0,00 & 0 & 0,00 \\
\hline 05762020 & 37671 & Höxter & Stahle & 2.464 & 0 & 0,00 & 0 & 0,00 & 0 & 0,00 & 0 & 0,00 \\
\hline 03255026 & 37697 & SG Boffzen & Lauenförde & 2.084 & 0 & 0,00 & 0 & 0,00 & 0 & 0,00 & 0 & 0,00 \\
\hline 03255026 & 37697 & SG Boffzen & Meinbrexen & 394 & 0 & 0,00 & 0 & 0,00 & 0 & 0,00 & 0 & 0,00 \\
\hline \multicolumn{4}{|l|}{ Summe } & 73.903 & 64 & & 22.035 & & 19 & & 5.214 & \\
\hline \multicolumn{4}{|l|}{ Mittelwert } & & & 0,24 & & 66,01 & & 0,09 & & 20,50 \\
\hline \multicolumn{5}{|l|}{ VK } & & 2,30 & & 2,87 & & 2,30 & & 2,54 \\
\hline
\end{tabular}




\begin{tabular}{|c|c|c|c|c|c|c|c|c|c|c|c|c|}
\hline \multicolumn{3}{|c|}{ Gemeinde } & \multicolumn{2}{|c|}{ Ortsteil } & \multicolumn{4}{|c|}{ EH-Angebot Elektrogeräte/Unterhaltungselektronik } & \multicolumn{4}{|c|}{ EH-Angebot Lebensmittel (Schwerpunkt) } \\
\hline AGS & PLZ & Name & Name & Einwohner 2012 & Anzahl & pro $1.000 \mathrm{EW}$ & VKF [qm] & pro $1.000 \mathrm{EW}$ & Anzahl & pro $1.000 \mathrm{EW}$ & VKF [qm] & pro $1.000 \mathrm{EW}$ \\
\hline 05762008 & 37688 & Beverungen & Amelunxen & 1.099 & 1 & 0,91 & 40 & 36,40 & 2 & 1,82 & 150 & 136,49 \\
\hline 05762008 & 37688 & Beverungen & Blankenau & 279 & 0 & 0,00 & 0 & 0,00 & 0 & 0,00 & 0 & 0,00 \\
\hline 05762008 & 37688 & Beverungen & Dalhausen & 1.717 & 0 & 0,00 & 0 & 0,00 & 5 & 2,91 & 450 & 262,09 \\
\hline 05762008 & 37688 & Beverungen & Drenke & 371 & 0 & 0,00 & 0 & 0,00 & 2 & 5,39 & 100 & 269,54 \\
\hline 05762008 & 37688 & Beverungen & Haarbrück & 488 & 0 & 0,00 & 0 & 0,00 & 2 & 4,10 & 65 & 133,20 \\
\hline 05762008 & 37688 & Beverungen & Herstelle & 985 & 0 & 0,00 & 0 & 0,00 & 5 & 5,08 & 375 & 380,71 \\
\hline 05762008 & 37688 & Beverungen & Jakobsberg & 275 & 0 & 0,00 & 0 & 0,00 & 0 & 0,00 & 0 & 0,00 \\
\hline 05762008 & 37688 & Beverungen & Kernstadt & 6.525 & 7 & 1,07 & 1.554 & 238,16 & 22 & 3,37 & 6.819 & $1.045,06$ \\
\hline 05762008 & 37688 & Beverungen & Rothe & 158 & 0 & 0,00 & 0 & 0,00 & 0 & 0,00 & 0 & 0,00 \\
\hline 05762008 & 37688 & Beverungen & Tietelsen & 232 & 0 & 0,00 & 0 & 0,00 & 1 & 4,31 & 70 & 301,72 \\
\hline 05762008 & 37688 & Beverungen & Wehrden & 828 & 0 & 0,00 & 0 & 0,00 & 2 & 2,42 & 60 & 72,46 \\
\hline 05762008 & 37688 & Beverungen & Würgassen & 854 & 0 & 0,00 & 0 & 0,00 & 0 & 0,00 & 0 & 0,00 \\
\hline 03255004 & 37691 & SG Boffzen & Boffzen & 2.668 & 3 & 1,12 & 260 & 97,45 & 8 & 3,00 & 1.975 & 740,25 \\
\hline 03255009 & 37691 & SG Boffzen & Derental & 660 & 0 & 0,00 & 0 & 0,00 & 2 & 3,03 & 180 & 272,73 \\
\hline 03255014 & 37699 & SG Boffzen & Fürstenberg & 1.141 & 0 & 0,00 & 0 & 0,00 & 3 & 2,63 & 135 & 118,32 \\
\hline 03255023 & 37603 & Holzminden & Kernstadt & 20.894 & 21 & 1,01 & 6.377 & 305,21 & 59 & 2,82 & 15.744 & 753,52 \\
\hline 03255023 & 37603 & Holzminden & Mühlenberg & 107 & 0 & 0,00 & 0 & 0,00 & 0 & 0,00 & 0 & 0,00 \\
\hline 03255023 & 37603 & Holzminden & Neuhaus im Solling & 1.425 & 0 & 0,00 & 0 & 0,00 & 3 & 2,11 & 330 & 231,58 \\
\hline 03255023 & 37603 & Holzminden & Silberborn & 778 & 0 & 0,00 & 0 & 0,00 & 1 & 1,29 & 30 & 38,56 \\
\hline 05762020 & 37671 & Höxter & Albaxen & 1.688 & 0 & 0,00 & 0 & 0,00 & 2 & 1,18 & 68 & 40,28 \\
\hline 05762020 & 37671 & Höxter & Bödexen & 851 & 0 & 0,00 & 0 & 0,00 & 3 & 3,53 & 124 & 145,71 \\
\hline 05762020 & 37671 & Höxter & Bosseborn & 557 & 0 & 0,00 & 0 & 0,00 & 1 & 1,80 & 10 & 17,95 \\
\hline 05762020 & 37671 & Höxter & Brenkhausen & 1.350 & 0 & 0,00 & 0 & 0,00 & 4 & 2,96 & 171 & 126,67 \\
\hline 05762020 & 37671 & Höxter & Bruchhausen & 692 & 0 & 0,00 & 0 & 0,00 & 1 & 1,45 & 59 & 85,26 \\
\hline 05762020 & 37671 & Höxter & Fürstenau & 1.203 & 0 & 0,00 & 0 & 0,00 & 6 & 4,99 & 355 & 295,10 \\
\hline 05762020 & 37671 & Höxter & Godelheim & 916 & 0 & 0,00 & 0 & 0,00 & 2 & 2,18 & 175 & 191,05 \\
\hline 05762020 & 37671 & Höxter & Kernstadt & 13.510 & 10 & 0,74 & 2.207 & 163,36 & 45 & 3,33 & 9.208 & 681,57 \\
\hline 05762020 & 37671 & Höxter & Lüchtringen & 3.094 & 0 & 0,00 & 0 & 0,00 & 6 & 1,94 & 740 & 239,17 \\
\hline 05762020 & 37671 & Höxter & Lütmarsen & 961 & 0 & 0,00 & 0 & 0,00 & 1 & 1,04 & 100 & 104,06 \\
\hline 05762020 & 37671 & Höxter & Ottbergen & 1.548 & 0 & 0,00 & 0 & 0,00 & 6 & 3,88 & 797 & 514,86 \\
\hline 05762020 & 37671 & Höxter & Ovenhausen & 1.107 & 0 & 0,00 & 0 & 0,00 & 3 & 2,71 & 211 & 190,61 \\
\hline 05762020 & 37671 & Höxter & Stahle & 2.464 & 0 & 0,00 & 0 & 0,00 & 9 & 3,65 & 2.805 & $1.138,39$ \\
\hline 03255026 & 37697 & SG Boffzen & Lauenförde & 2.084 & 0 & 0,00 & 0 & 0,00 & 6 & 2,88 & 2.005 & 962,09 \\
\hline 03255026 & 37697 & SG Boffzen & Meinbrexen & 394 & 0 & 0,00 & 0 & 0,00 & 1 & 2,54 & 30 & 76,14 \\
\hline \multicolumn{4}{|l|}{ Summe } & 73.903 & 42 & & 10.438 & & 213 & & 43.341 & \\
\hline \multicolumn{4}{|l|}{ Mittelwert } & & & 0,14 & & 24,72 & & 2,48 & & 281,33 \\
\hline \multicolumn{5}{|l|}{ VK } & & 2,44 & & 2,83 & & 0,59 & & 1,11 \\
\hline
\end{tabular}




\begin{tabular}{|c|c|c|c|c|c|c|c|c|c|c|c|c|}
\hline \multicolumn{3}{|c|}{ Gemeinde } & \multicolumn{2}{|c|}{ Ortsteil } & \multicolumn{4}{|c|}{ EH-Angebot Möbel/Einrichtung } & \multicolumn{4}{|c|}{ EH-Angebot Schuhe/Lederwaren } \\
\hline AGS & PLZ & Name & Name & Einwohner 2012 & Anzahl & pro $1.000 \mathrm{EW}$ & VKF [qm] & pro $1.000 \mathrm{EW}$ & Anzahl & pro $1.000 \mathrm{EW}$ & VKF [qm] & pro $1.000 \mathrm{EW}$ \\
\hline 05762008 & 37688 & Beverungen & Amelunxen & 1.099 & 1 & 0,91 & 50 & 45,50 & 0 & 0,00 & 0 & 0,00 \\
\hline 05762008 & 37688 & Beverungen & Blankenau & 279 & 0 & 0,00 & 0 & 0,00 & 0 & 0,00 & 0 & 0,00 \\
\hline 05762008 & 37688 & Beverungen & Dalhausen & 1.717 & 1 & 0,58 & 40 & 23,30 & 0 & 0,00 & 0 & 0,00 \\
\hline 05762008 & \begin{tabular}{|l|l|}
37688 \\
\end{tabular} & Beverungen & Drenke & 371 & 0 & 0,00 & 0 & 0,00 & 0 & 0,00 & 0 & 0,00 \\
\hline 05762008 & 37688 & Beverungen & Haarbrück & 488 & 0 & 0,00 & 0 & 0,00 & 0 & 0,00 & 0 & 0,00 \\
\hline 05762008 & \begin{tabular}{|l|}
37688 \\
\end{tabular} & Beverungen & Herstelle & 985 & 1 & 1,02 & 100 & 101,52 & 0 & 0,00 & 0 & 0,00 \\
\hline 05762008 & 37688 & Beverungen & Jakobsberg & 275 & 0 & 0,00 & 0 & 0,00 & 0 & 0,00 & 0 & 0,00 \\
\hline 05762008 & \begin{tabular}{|l|}
37688 \\
\end{tabular} & Beverungen & Kernstadt & 6.525 & 7 & 1,07 & 3.370 & 516,48 & 3 & 0,46 & 560 & 85,82 \\
\hline 05762008 & \begin{tabular}{|l|}
37688 \\
\end{tabular} & Beverungen & Rothe & 158 & 0 & 0,00 & 0 & 0,00 & 0 & 0,00 & 0 & 0,00 \\
\hline 05762008 & 37688 & Beverungen & Tietelsen & 232 & 0 & 0,00 & 0 & 0,00 & 0 & 0,00 & 0 & 0,00 \\
\hline 05762008 & \begin{tabular}{|l|}
37688 \\
\end{tabular} & Beverungen & Wehrden & 828 & 0 & 0,00 & 0 & 0,00 & 0 & 0,00 & 0 & 0,00 \\
\hline 05762008 & \begin{tabular}{|l|}
37688 \\
\end{tabular} & Beverungen & Würgassen & 854 & 0 & 0,00 & 0 & 0,00 & 0 & 0,00 & 0 & 0,00 \\
\hline 03255004 & 37691 & SG Boffzen & Boffzen & 2.668 & 1 & 0,37 & 120 & 44,98 & 0 & 0,00 & 0 & 0,00 \\
\hline 03255009 & 37691 & SG Boffzen & Derental & 660 & 0 & 0,00 & 0 & 0,00 & 0 & 0,00 & 0 & 0,00 \\
\hline 03255014 & 37699 & SG Boffzen & Fürstenberg & 1.141 & 0 & 0,00 & 0 & 0,00 & 1 & 0,88 & 100 & 87,64 \\
\hline 03255023 & 37603 & Holzminden & Kernstadt & 20.894 & 6 & 0,29 & 4.910 & 235,00 & 8 & 0,38 & 2.110 & 100,99 \\
\hline 03255023 & 37603 & Holzminden & Mühlenberg & 107 & 0 & 0,00 & 0 & 0,00 & 0 & 0,00 & 0 & 0,00 \\
\hline 03255023 & \begin{tabular}{|l|}
37603 \\
\end{tabular} & Holzminden & Neuhaus im Solling & 1.425 & 0 & 0,00 & 0 & 0,00 & 0 & 0,00 & 0 & 0,00 \\
\hline 03255023 & 37603 & Holzminden & Silberborn & 778 & 0 & 0,00 & 0 & 0,00 & 0 & 0,00 & 0 & 0,00 \\
\hline 05762020 & 37671 & Höxter & Albaxen & 1.688 & 0 & 0,00 & 0 & 0,00 & 0 & 0,00 & 0 & 0,00 \\
\hline 05762020 & 37671 & Höxter & Bödexen & 851 & 0 & 0,00 & 0 & 0,00 & 0 & 0,00 & 0 & 0,00 \\
\hline 05762020 & 37671 & Höxter & Bosseborn & 557 & 0 & 0,00 & 0 & 0,00 & 0 & 0,00 & 0 & 0,00 \\
\hline 05762020 & 37671 & Höxter & Brenkhausen & 1.350 & 1 & 0,74 & 400 & 296,30 & 0 & 0,00 & 0 & 0,00 \\
\hline 05762020 & 37671 & Höxter & Bruchhausen & 692 & 0 & 0,00 & 0 & 0,00 & 0 & 0,00 & 0 & 0,00 \\
\hline 05762020 & 37671 & Höxter & Fürstenau & 1.203 & 1 & 0,83 & 250 & 207,81 & 0 & 0,00 & 0 & 0,00 \\
\hline 05762020 & 37671 & Höxter & Godelheim & 916 & 0 & 0,00 & 0 & 0,00 & 0 & 0,00 & 0 & 0,00 \\
\hline 05762020 & 37671 & Höxter & Kernstadt & 13.510 & 10 & 0,74 & 11.726 & 867,95 & 9 & 0,67 & 1.871 & 138,49 \\
\hline 05762020 & 37671 & Höxter & Lüchtringen & 3.094 & 0 & 0,00 & 0 & 0,00 & 0 & 0,00 & 0 & 0,00 \\
\hline 05762020 & 37671 & Höxter & Lütmarsen & 961 & 0 & 0,00 & 0 & 0,00 & 0 & 0,00 & 0 & 0,00 \\
\hline 05762020 & 37671 & Höxter & Ottbergen & 1.548 & 0 & 0,00 & 0 & 0,00 & 0 & 0,00 & 0 & 0,00 \\
\hline 05762020 & 37671 & Höxter & Ovenhausen & 1.107 & 1 & 0,90 & 30 & 27,10 & 0 & 0,00 & 0 & 0,00 \\
\hline 05762020 & 37671 & Höxter & Stahle & 2.464 & 0 & 0,00 & 0 & 0,00 & 0 & 0,00 & 0 & 0,00 \\
\hline 03255026 & 37697 & SG Boffzen & Lauenförde & 2.084 & 0 & 0,00 & 0 & 0,00 & 0 & 0,00 & 0 & 0,00 \\
\hline 03255026 & 37697 & SG Boffzen & Meinbrexen & 394 & 0 & 0,00 & 0 & 0,00 & 0 & 0,00 & 0 & 0,00 \\
\hline \multicolumn{4}{|l|}{ Summe } & 73.903 & 30 & & 20.996 & & 21 & & 4.641 & \\
\hline \multicolumn{4}{|l|}{ Mittelwert } & & & 0,22 & & 69,59 & & 0,07 & & 12,15 \\
\hline \multicolumn{5}{|l|}{ VK } & & 1,67 & & 2,53 & & 2,90 & & 2,80 \\
\hline
\end{tabular}




\begin{tabular}{|c|c|c|c|c|c|c|c|c|c|c|c|c|}
\hline \multicolumn{3}{|c|}{ Gemeinde } & \multicolumn{2}{|c|}{ Ortsteil } & \multicolumn{4}{|c|}{ Sonstiges EH-Angebot } & \multicolumn{4}{|c|}{ EH-Angebot insgesamt } \\
\hline AGS & PLZ & Name & Name & Einwohner 2012 & Anzahl & pro $1.000 \mathrm{EW}$ & VKF [qm] & pro $1.000 \mathrm{EW}$ & Anzahl & pro $1.000 \mathrm{EW}$ & VKF [qm] & pro $1.000 \mathrm{EW}$ \\
\hline 05762008 & 37688 & Beverungen & Amelunxen & 1.099 & 0 & 0,00 & 0 & 0,00 & 4 & 3,64 & 240 & 218,38 \\
\hline 05762008 & 37688 & Beverungen & Blankenau & 279 & 1 & 3,58 & 100 & 358,42 & 1 & 3,58 & 100 & 358,42 \\
\hline 05762008 & 37688 & Beverungen & Dalhausen & 1.717 & 2 & 1,16 & 90 & 52,42 & 12 & 6,99 & 850 & 495,05 \\
\hline 05762008 & 37688 & Beverungen & Drenke & 371 & 0 & 0,00 & 0 & 0,00 & 2 & 5,39 & 100 & 269,54 \\
\hline 05762008 & 37688 & Beverungen & Haarbrück & 488 & 0 & 0,00 & 0 & 0,00 & 3 & 6,15 & 115 & 235,66 \\
\hline 05762008 & 37688 & Beverungen & Herstelle & 985 & 0 & 0,00 & 0 & 0,00 & 6 & 6,09 & 475 & 482,23 \\
\hline 05762008 & 37688 & Beverungen & Jakobsberg & 275 & 0 & 0,00 & 0 & 0,00 & 0 & 0,00 & 0 & 0,00 \\
\hline 05762008 & 37688 & Beverungen & Kernstadt & 6.525 & 21 & 3,22 & 6.532 & $1.001,07$ & 96 & 14,71 & 31.029 & $4.755,40$ \\
\hline 05762008 & 37688 & Beverungen & Rothe & 158 & 0 & 0,00 & 0 & 0,00 & 0 & 0,00 & 0 & 0,00 \\
\hline 05762008 & 37688 & Beverungen & Tietelsen & 232 & 0 & 0,00 & 0 & 0,00 & 1 & 4,31 & 70 & 301,72 \\
\hline 05762008 & 37688 & Beverungen & Wehrden & 828 & 0 & 0,00 & 0 & 0,00 & 2 & 2,42 & 60 & 72,46 \\
\hline 05762008 & 37688 & Beverungen & Würgassen & 854 & 0 & 0,00 & 0 & 0,00 & 0 & 0,00 & 0 & 0,00 \\
\hline 03255004 & 37691 & SG Boffzen & Boffzen & 2.668 & 2 & 0,75 & 90 & 33,73 & 17 & 6,37 & 3.155 & $1.182,53$ \\
\hline 03255009 & 37691 & SG Boffzen & Derental & 660 & 0 & 0,00 & 0 & 0,00 & 2 & 3,03 & 180 & 272,73 \\
\hline 03255014 & 37699 & SG Boffzen & Fürstenberg & 1.141 & 1 & 0,88 & 150 & 131,46 & 6 & 5,26 & 585 & 512,71 \\
\hline 03255023 & 37603 & Holzminden & Kernstadt & 20.894 & 46 & 2,20 & 14.559 & 696,80 & 185 & 8,85 & 57.690 & $2.761,08$ \\
\hline 03255023 & 37603 & Holzminden & Mühlenberg & 107 & 0 & 0,00 & 0 & 0,00 & 0 & 0,00 & 0 & 0,00 \\
\hline 03255023 & 37603 & Holzminden & Neuhaus im Solling & 1.425 & 2 & 1,40 & 160 & 112,28 & 8 & 5,61 & 720 & 505,26 \\
\hline 03255023 & 37603 & Holzminden & Silberborn & 778 & 2 & 2,57 & 130 & 167,10 & 3 & 3,86 & 160 & 205,66 \\
\hline 05762020 & 37671 & Höxter & Albaxen & 1.688 & 1 & 0,59 & 99 & 58,65 & 3 & 1,78 & 167 & 98,93 \\
\hline 05762020 & 37671 & Höxter & Bödexen & 851 & 0 & 0,00 & 0 & 0,00 & 4 & 4,70 & 271 & 318,45 \\
\hline 05762020 & 37671 & Höxter & Bosseborn & 557 & 0 & 0,00 & 0 & 0,00 & 1 & 1,80 & 10 & 17,95 \\
\hline 05762020 & 37671 & Höxter & Brenkhausen & 1.350 & 0 & 0,00 & 0 & 0,00 & 8 & 5,93 & 1.177 & 871,85 \\
\hline 05762020 & 37671 & Höxter & Bruchhausen & 692 & 1 & 1,45 & 14 & 20,23 & 2 & 2,89 & 73 & 105,49 \\
\hline 05762020 & 37671 & Höxter & Fürstenau & 1.203 & 0 & 0,00 & 0 & 0,00 & 8 & 6,65 & 629 & 522,86 \\
\hline 05762020 & 37671 & Höxter & Godelheim & 916 & 0 & 0,00 & 0 & 0,00 & 2 & 2,18 & 175 & 191,05 \\
\hline 05762020 & 37671 & Höxter & Kernstadt & 13.510 & 37 & 2,74 & 6.562 & 485,71 & 161 & 11,92 & 65.758 & $4.867,36$ \\
\hline 05762020 & 37671 & Höxter & Lüchtringen & 3.094 & 1 & 0,32 & 26 & 8,40 & 10 & 3,23 & 996 & 321,91 \\
\hline 05762020 & 37671 & Höxter & Lütmarsen & 961 & 0 & 0,00 & 0 & 0,00 & 1 & 1,04 & 100 & 104,06 \\
\hline 05762020 & 37671 & Höxter & Ottbergen & 1.548 & 2 & 1,29 & 98 & 63,31 & 10 & 6,46 & 1.089 & 703,49 \\
\hline 05762020 & 37671 & Höxter & Ovenhausen & 1.107 & 0 & 0,00 & 0 & 0,00 & 5 & 4,52 & 257 & 232,16 \\
\hline 05762020 & 37671 & Höxter & Stahle & 2.464 & 0 & 0,00 & 0 & 0,00 & 11 & 4,46 & 2.845 & $1.154,63$ \\
\hline 03255026 & 37697 & SG Boffzen & Lauenförde & 2.084 & 2 & 0,96 & 70 & 33,59 & 9 & 4,32 & 2.115 & $1.014,88$ \\
\hline 03255026 & 37697 & SG Boffzen & Meinbrexen & 394 & 0 & 0,00 & 0 & 0,00 & 1 & 2,54 & 30 & 76,14 \\
\hline Summe & & & & 73.903 & 121 & & 28.680 & & 584 & & 171.221 & \\
\hline Mittelwert & & & & & & 0,68 & & 94,80 & & 4,43 & & 683,24 \\
\hline VK & & & & & & 1,52 & & 2,30 & & 0,71 & & 1,69 \\
\hline
\end{tabular}


Räumliches Einkaufsverhalten und Standortpolitik im Einzelhandel unter Berücksichtigung von Agglomerationseffekten

Tabelle A 8: Empirische Interaktionsmatrix - Beispiel Elektromärkte Quelle: Eigene Erhebungen und Berechnungen

\begin{tabular}{|c|c|c|c|c|c|c|c|c|}
\hline $\mathrm{i}$ & $\varnothing \mathrm{E}_{\mathrm{i}}$ & $\Sigma \mathrm{E}_{\mathrm{i}}$ & & $\mathrm{dij}_{\mathrm{i}}$ & $E_{i j}$ & $p_{i j}$ \\
\hline 01 & 3,06 & 159 & E01 & Media Markt & Holzminden-Kernstadt & 5,19 & 33 & 0,208 \\
\hline 01 & 3,06 & 159 & E02 & Expert & Höxter-Kernstadt & 9,42 & 0 & 0,000 \\
\hline 01 & 3,06 & 159 & E03 & Expert & Holzminden-Kernstadt & 4,85 & 104 & 0,654 \\
\hline 01 & 3,06 & 159 & E04 & Euronics XXL Medien Markt & Beverungen-Kernstadt & 20,10 & 0 & 0,000 \\
\hline 01 & 3,06 & 159 & E07 & EP Fries & Holzminden-Kernstadt & 2,42 & 3 & 0,019 \\
\hline 01 & 3,06 & 159 & \multicolumn{3}{|c|}{ Sonstige (außerhalb des Untersuchungsgebietes) } & -- & 2 & 0,013 \\
\hline 01 & 3,06 & 159 & \multicolumn{3}{|c|}{ Sonstige (innerhalb des Untersuchungsgebietes) } & -- & 17 & 0,107 \\
\hline 02 & 2,78 & 35 & E01 & Media Markt & Holzminden-Kernstadt & 13,22 & 9 & 0,257 \\
\hline 02 & 2,78 & 35 & E02 & Expert & Höxter-Kernstadt & 18,38 & 2 & 0,057 \\
\hline 02 & 2,78 & 35 & E03 & Expert & Holzminden-Kernstadt & 12,88 & 22 & 0,629 \\
\hline 02 & 2,78 & 35 & E04 & Euronics XXL Medien Markt & Beverungen-Kernstadt & 26,11 & 0 & 0,000 \\
\hline 02 & 2,78 & 35 & E07 & EP Fries & Holzminden-Kernstadt & 12,19 & 0 & 0,000 \\
\hline 02 & 2,78 & 35 & \multicolumn{3}{|c|}{ Sonstige (außerhalb des Untersuchungsgebietes) } & -- & 1 & 0,029 \\
\hline 02 & 2,78 & 35 & \multicolumn{3}{|c|}{ Sonstige (innerhalb des Untersuchungsgebietes) } & -- & 1 & 0,029 \\
\hline 03 & 1,88 & 30 & E01 & Media Markt & Holzminden-Kernstadt & 8,74 & 6 & 0,200 \\
\hline 03 & 1,88 & 30 & E02 & Expert & Höxter-Kernstadt & 9,30 & 6 & 0,200 \\
\hline 03 & 1,88 & 30 & E03 & Expert & Holzminden-Kernstadt & 8,39 & 17 & 0,567 \\
\hline 03 & 1,88 & 30 & E04 & Euronics XXL Medien Markt & Beverungen-Kernstadt & 19,99 & 0 & 0,000 \\
\hline 03 & 1,88 & 30 & E07 & EP Fries & Holzminden-Kernstadt & 5,64 & 0 & 0,000 \\
\hline 03 & 1,88 & 30 & \multicolumn{3}{|c|}{ Sonstige (außerhalb des Untersuchungsgebietes) } & -- & 0 & 0,000 \\
\hline 03 & 1,88 & 30 & \multicolumn{3}{|c|}{ Sonstige (innerhalb des Untersuchungsgebietes) } & -- & 1 & 0,033 \\
\hline 04 & 3,75 & 29 & E01 & Media Markt & Holzminden-Kernstadt & 9,63 & 8 & 0,276 \\
\hline 04 & 3,75 & 29 & E02 & Expert & Höxter-Kernstadt & 10,19 & 7 & 0,241 \\
\hline 04 & 3,75 & 29 & E03 & Expert & Holzminden-Kernstadt & 9,28 & 10 & 0,345 \\
\hline 04 & 3,75 & 29 & E04 & Euronics XXL Medien Markt & Beverungen-Kernstadt & 20,87 & 0 & 0,000 \\
\hline 04 & 3,75 & 29 & E07 & EP Fries & Holzminden-Kernstadt & 6,53 & 1 & 0,034 \\
\hline 04 & 3,75 & 29 & \multicolumn{3}{|c|}{ Sonstige (außerhalb des Untersuchungsgebietes) } & -- & 0 & 0,000 \\
\hline 04 & 3,75 & 29 & \multicolumn{3}{|c|}{ Sonstige (innerhalb des Untersuchungsgebietes) } & -- & 3 & 0,103 \\
\hline 05 & 2,05 & 30 & E01 & Media Markt & Holzminden-Kernstadt & 17,85 & 3 & 0,100 \\
\hline 05 & 2,05 & 30 & E02 & Expert & Höxter-Kernstadt & 12,58 & 20 & 0,667 \\
\hline 05 & 2,05 & 30 & E03 & Expert & Holzminden-Kernstadt & 17,50 & 2 & 0,067 \\
\hline 05 & 2,05 & 30 & E04 & Euronics XXL Medien Markt & Beverungen-Kernstadt & 21,35 & 0 & 0,000 \\
\hline 05 & 2,05 & 30 & E07 & EP Fries & Holzminden-Kernstadt & 14,75 & 0 & 0,000 \\
\hline 05 & 2,05 & 30 & \multirow{2}{*}{\multicolumn{3}{|c|}{ Sonstige (außerhalb des Untersuchungsgebietes) }} & -- & 0 & 0,000 \\
\hline 05 & 2,05 & 30 & \multicolumn{2}{|c|}{ Sonstige (innerhalb des Untersuchungsgebietes) } & & -- & 5 & 0,167 \\
\hline 06 & 2,07 & 34 & E01 & Media Markt & Holzminden-Kernstadt & 11,07 & 2 & 0,059 \\
\hline 06 & 2,07 & 34 & E02 & Expert & Höxter-Kernstadt & 7,15 & 23 & 0,676 \\
\hline 06 & 2,07 & 34 & E03 & Expert & Holzminden-Kernstadt & 10,73 & 8 & 0,235 \\
\hline 06 & 2,07 & 34 & E04 & Euronics XXL Medien Markt & Beverungen-Kernstadt & 17,83 & 0 & 0,000 \\
\hline 06 & 2,07 & 34 & E07 & EP Fries & Holzminden-Kernstadt & 7,47 & 0 & 0,000 \\
\hline 06 & 2,07 & 34 & \multicolumn{3}{|c|}{ Sonstige (außerhalb des Untersuchungsgebietes) } & -- & 1 & 0,029 \\
\hline 06 & 2,07 & 34 & \multicolumn{3}{|c|}{ Sonstige (innerhalb des Untersuchungsgebietes) } & -- & 0 & 0,000 \\
\hline 07 & 2,98 & 145 & E01 & Media Markt & Holzminden-Kernstadt & 13,93 & 23 & 0,159 \\
\hline 07 & 2,98 & 145 & E02 & Expert & Höxter-Kernstadt & 3,66 & 66 & 0,455 \\
\hline 07 & 2,98 & 145 & E03 & Expert & Holzminden-Kernstadt & 13,58 & 10 & 0,069 \\
\hline 07 & 2,98 & 145 & E04 & Euronics XXL Medien Markt & Beverungen-Kernstadt & 11,36 & 1 & 0,007 \\
\hline 07 & 2,98 & 145 & E07 & EP Fries & Holzminden-Kernstadt & 10,32 & 0 & 0,000 \\
\hline 07 & 2,98 & 145 & \multicolumn{3}{|c|}{ Sonstige (außerhalb des Untersuchungsgebietes) } & -- & 7 & 0,048 \\
\hline 07 & 2,98 & 145 & \multicolumn{3}{|c|}{ Sonstige (innerhalb des Untersuchungsgebietes) } & -- & 38 & 0,262 \\
\hline 08 & 3,93 & 46 & E01 & Media Markt & Holzminden-Kernstadt & 18,58 & 7 & 0,152 \\
\hline 08 & 3,93 & 46 & E02 & Expert & Höxter-Kernstadt & 8,32 & 26 & 0,565 \\
\hline 08 & 3,93 & 46 & E03 & Expert & Holzminden-Kernstadt & 18,24 & 3 & 0,065 \\
\hline 08 & 3,93 & 46 & E04 & Euronics XXL Medien Markt & Beverungen-Kernstadt & 17,08 & 0 & 0,000 \\
\hline 08 & 3,93 & 46 & E07 & EP Fries & Holzminden-Kernstadt & 14,98 & 0 & 0,000 \\
\hline
\end{tabular}




\begin{tabular}{|c|c|c|c|c|c|c|c|c|}
\hline $\mathrm{i}$ & $\varnothing \mathrm{E}_{\mathrm{i}}$ & $\sum \mathrm{E}_{\mathrm{i}}$ & \multicolumn{3}{|c|}{ j } & $d_{i j}$ & $E_{i j}$ & $\mathrm{p}_{\mathrm{ij}}$ \\
\hline 08 & 3,93 & 46 & \multicolumn{3}{|c|}{ Sonstige (außerhalb des Untersuchungsgebietes) } & -- & 5 & 0,109 \\
\hline 08 & 3,93 & 46 & \multicolumn{3}{|c|}{ Sonstige (innerhalb des Untersuchungsgebietes) } & -- & 5 & 0,109 \\
\hline 09 & 2,14 & 33 & E01 & Media Markt & Holzminden-Kernstadt & 18,14 & 7 & 0,212 \\
\hline 09 & 2,14 & 33 & E02 & Expert & Höxter-Kernstadt & 7,87 & 13 & 0,394 \\
\hline 09 & 2,14 & 33 & E03 & Expert & Holzminden-Kernstadt & 17,80 & 6 & 0,182 \\
\hline 09 & 2,14 & 33 & E04 & Euronics XXL Medien Markt & Beverungen-Kernstadt & 8,45 & 2 & 0,061 \\
\hline 09 & 2,14 & 33 & E07 & EP Fries & Holzminden-Kernstadt & 14,53 & 0 & 0,000 \\
\hline 09 & 2,14 & 33 & \multicolumn{3}{|c|}{ Sonstige (außerhalb des Untersuchungsgebietes) } & -- & 2 & 0,061 \\
\hline 09 & 2,14 & 33 & \multicolumn{3}{|c|}{ Sonstige (innerhalb des Untersuchungsgebietes) } & -- & 3 & 0,091 \\
\hline 10 & 2,08 & 30 & E01 & Media Markt & Holzminden-Kernstadt & 21,61 & 1 & 0,033 \\
\hline 10 & 2,08 & 30 & E02 & Expert & Höxter-Kernstadt & 11,34 & 12 & 0,400 \\
\hline 10 & 2,08 & 30 & E03 & Expert & Holzminden-Kernstadt & 21,26 & 0 & 0,000 \\
\hline 10 & 2,08 & 30 & E04 & Euronics XXL Medien Markt & Beverungen-Kernstadt & 10,56 & 1 & 0,033 \\
\hline 10 & 2,08 & 30 & E07 & EP Fries & Holzminden-Kernstadt & 18,00 & 0 & 0,000 \\
\hline 10 & 2,08 & 30 & \multicolumn{3}{|c|}{ Sonstige (außerhalb des Untersuchungsgebietes) } & -- & 5 & 0,167 \\
\hline 10 & 2,08 & 30 & \multicolumn{3}{|c|}{ Sonstige (innerhalb des Untersuchungsgebietes) } & -- & 11 & 0,367 \\
\hline 11 & 4,64 & 28 & E01 & Media Markt & Holzminden-Kernstadt & 20,08 & 1 & 0,036 \\
\hline 11 & 4,64 & 28 & E02 & Expert & Höxter-Kernstadt & 9,81 & 10 & 0,357 \\
\hline 11 & 4,64 & 28 & E03 & Expert & Holzminden-Kernstadt & 19,73 & 0 & 0,000 \\
\hline 11 & 4,64 & 28 & E04 & Euronics XXL Medien Markt & Beverungen-Kernstadt & 7,45 & 10 & 0,357 \\
\hline 11 & 4,64 & 28 & E07 & EP Fries & Holzminden-Kernstadt & 16,47 & 0 & 0,000 \\
\hline 11 & 4,64 & 28 & \multicolumn{3}{|c|}{ Sonstige (außerhalb des Untersuchungsgebietes) } & -- & 6 & 0,214 \\
\hline 11 & 4,64 & 28 & \multicolumn{3}{|c|}{ Sonstige (innerhalb des Untersuchungsgebietes) } & -- & 1 & 0,036 \\
\hline 12 & 3,10 & 90 & E01 & Media Markt & Holzminden-Kernstadt & 24,02 & 9 & 0,100 \\
\hline 12 & 3,10 & 90 & E02 & Expert & Höxter-Kernstadt & 13,75 & 21 & 0,233 \\
\hline 12 & 3,10 & 90 & E03 & Expert & Holzminden-Kernstadt & 23,67 & 8 & 0,089 \\
\hline 12 & 3,10 & 90 & E04 & Euronics XXL Medien Markt & Beverungen-Kernstadt & 3,28 & 43 & 0,478 \\
\hline 12 & 3,10 & 90 & E07 & EP Fries & Holzminden-Kernstadt & 20,41 & 0 & 0,000 \\
\hline 12 & 3,10 & 90 & \multirow{2}{*}{\multicolumn{3}{|c|}{ Sonstige (außerhalb des Untersuchungsgebietes) }} & -- & 4 & 0,044 \\
\hline 12 & 3,10 & 90 & \multicolumn{2}{|c|}{ Sonstige (innerhalb des Untersuchungsgebietes) } & & -- & 5 & 0,056 \\
\hline 13 & 2,63 & 36 & E01 & Media Markt & Holzminden-Kernstadt & 28,71 & 2 & 0,056 \\
\hline 13 & 2,63 & 36 & E02 & Expert & Höxter-Kernstadt & 18,44 & 8 & 0,222 \\
\hline 13 & 2,63 & 36 & E03 & Expert & Holzminden-Kernstadt & 28,36 & 3 & 0,083 \\
\hline 13 & 2,63 & 36 & E04 & Euronics XXL Medien Markt & Beverungen-Kernstadt & 7,97 & 19 & 0,528 \\
\hline 13 & 2,63 & 36 & E07 & EP Fries & Holzminden-Kernstadt & 25,10 & 0 & 0,000 \\
\hline 13 & 2,63 & 36 & \multicolumn{3}{|c|}{ Sonstige (außerhalb des Untersuchungsgebietes) } & -- & 2 & 0,056 \\
\hline 13 & 2,63 & 36 & \multicolumn{3}{|c|}{ Sonstige (innerhalb des Untersuchungsgebietes) } & -- & 2 & 0,056 \\
\hline 14 & 2,17 & 59 & E01 & Media Markt & Holzminden-Kernstadt & 30,49 & 8 & 0,136 \\
\hline 14 & 2,17 & 59 & E02 & Expert & Höxter-Kernstadt & 20,23 & 11 & 0,186 \\
\hline 14 & 2,17 & 59 & E03 & Expert & Holzminden-Kernstadt & 30,15 & 1 & 0,017 \\
\hline 14 & 2,17 & 59 & E04 & Euronics XXL Medien Markt & Beverungen-Kernstadt & 9,78 & 19 & 0,322 \\
\hline 14 & 2,17 & 59 & E07 & EP Fries & Holzminden-Kernstadt & 26,89 & 0 & 0,000 \\
\hline 14 & 2,17 & 59 & \multicolumn{3}{|c|}{ Sonstige (außerhalb des Untersuchungsgebietes) } & -- & 4 & 0,068 \\
\hline 14 & 2,17 & 59 & \multicolumn{3}{|c|}{ Sonstige (innerhalb des Untersuchungsgebietes) } & -- & 16 & 0,271 \\
\hline 15 & 1,00 & 14 & E01 & Media Markt & Holzminden-Kernstadt & 23,28 & 4 & 0,286 \\
\hline 15 & 1,00 & 14 & E02 & Expert & Höxter-Kernstadt & 13,01 & 2 & 0,143 \\
\hline 15 & 1,00 & 14 & E03 & Expert & Holzminden-Kernstadt & 22,94 & 4 & 0,286 \\
\hline 15 & 1,00 & 14 & E04 & Euronics XXL Medien Markt & Beverungen-Kernstadt & 6,61 & 3 & 0,214 \\
\hline 15 & 1,00 & 14 & E07 & EP Fries & Holzminden-Kernstadt & 19,67 & 0 & 0,000 \\
\hline 15 & 1,00 & 14 & \multicolumn{3}{|c|}{ Sonstige (außerhalb des Untersuchungsgebietes) } & -- & 1 & 0,071 \\
\hline 15 & 1,00 & 14 & Sonst & ge (innerhalb des Untersuchun & sgebietes) & -- & 0 & 0,000 \\
\hline 16 & 3,20 & 57 & E01 & Media Markt & Holzminden-Kernstadt & 16,39 & 10 & 0,175 \\
\hline 16 & 3,20 & 57 & E02 & Expert & Höxter-Kernstadt & 14,70 & 20 & 0,351 \\
\hline 16 & 3,20 & 57 & E03 & Expert & Holzminden-Kernstadt & 16,04 & 10 & 0,175 \\
\hline 16 & 3,20 & 57 & E04 & Euronics XXL Medien Markt & Beverungen-Kernstadt & 16,47 & 2 & 0,035 \\
\hline 16 & 3,20 & 57 & E07 & EP Fries & Holzminden-Kernstadt & 12,78 & 0 & 0,000 \\
\hline 16 & 3,20 & 57 & Sonst & ge (außerhalb des Untersuchu & gsgebietes) & -- & 2 & 0,035 \\
\hline
\end{tabular}


Räumliches Einkaufsverhalten und Standortpolitik im Einzelhandel unter Berücksichtigung von Agglomerationseffekten

\begin{tabular}{|c|c|c|c|c|c|c|c|c|}
\hline$i$ & $\varnothing \mathrm{E}_{\mathrm{i}}$ & $\Sigma \mathrm{E}_{\mathrm{i}}$ & & $\mathrm{j}$ & & $d_{i j}$ & $E_{i j}$ & $p_{i j}$ \\
\hline 16 & 3,20 & 57 & \multicolumn{3}{|c|}{ Sonstige (innerhalb des Untersuchungsgebietes) } & -- & 13 & 0,228 \\
\hline 17 & 1,98 & 34 & E01 & Media Markt & Holzminden-Kernstadt & 19,59 & 9 & 0,265 \\
\hline 17 & 1,98 & 34 & E02 & Expert & Höxter-Kernstadt & 17,90 & 15 & 0,441 \\
\hline 17 & 1,98 & 34 & E03 & Expert & Holzminden-Kernstadt & 19,24 & 1 & 0,029 \\
\hline 17 & 1,98 & 34 & E04 & Euronics XXL Medien Markt & Beverungen-Kernstadt & 14,78 & 2 & 0,059 \\
\hline 17 & 1,98 & 34 & E07 & EP Fries & Holzminden-Kernstadt & 15,98 & 0 & 0,000 \\
\hline 17 & 1,98 & 34 & \multicolumn{3}{|c|}{ Sonstige (außerhalb des Untersuchungsgebietes) } & -- & 1 & 0,029 \\
\hline 17 & 1,98 & 34 & \multicolumn{3}{|c|}{ Sonstige (innerhalb des Untersuchungsgebietes) } & -- & 6 & 0,176 \\
\hline 18 & 2,62 & 64 & E01 & "Media Markt & Holzminden-Kernstadt & 25,25 & 9 & 0,141 \\
\hline 18 & 2,62 & 64 & E02 & Expert & Höxter-Kernstadt & 14,99 & 15 & 0,234 \\
\hline 18 & 2,62 & 64 & E03 & Expert & Holzminden-Kernstadt & 24,91 & 5 & 0,078 \\
\hline 18 & 2,62 & 64 & E04 & Euronics XXL Medien Markt & Beverungen-Kernstadt & 4,51 & 32 & 0,500 \\
\hline 18 & 2,62 & 64 & E07 & EP Fries & Holzminden-Kernstadt & 21,65 & 0 & 0,000 \\
\hline 18 & 2,62 & 64 & \multicolumn{3}{|c|}{ Sonstige (außerhalb des Untersuchungsgebietes) } & -- & 0 & 0,000 \\
\hline 18 & 2,62 & 64 & \multicolumn{3}{|c|}{ Sonstige (innerhalb des Untersuchungsgebietes) } & -- & 3 & 0,047 \\
\hline 19 & 1,58 & 34 & E01 & Media Markt & Holzminden-Kernstadt & 23,99 & 7 & 0,206 \\
\hline 19 & 1,58 & 34 & E02 & Expert & Höxter-Kernstadt & 22,30 & 12 & 0,353 \\
\hline 19 & 1,58 & 34 & E03 & Expert & Holzminden-Kernstadt & 23,64 & 6 & 0,176 \\
\hline 19 & 1,58 & 34 & E04 & Euronics XXL Medien Markt & Beverungen-Kernstadt & 12,60 & 7 & 0,206 \\
\hline 19 & 1,58 & 34 & E07 & EP Fries & Holzminden-Kernstadt & 20,38 & 1 & 0,029 \\
\hline 19 & 1,58 & 34 & \multirow{2}{*}{\multicolumn{3}{|c|}{$\begin{array}{l}\text { Sonstige (außerhalb des Untersuchungsgebietes) } \\
\text { Sonstige (innerhalb des Untersuchungsgebietes) }\end{array}$}} & -- & 0 & 0,000 \\
\hline 19 & 1,58 & 34 & & & & -- & 1 & 0,029 \\
\hline
\end{tabular}

$\mathrm{i}=$ Konsumentenwohnort (Ortsteil bzw. aus mehreren kleinen Ortsteilen aggregiertes Gebiet)

$\mathrm{j}$ = Anbieter bzw. Angebotsstandort (Elektromarkt)

$\varnothing \mathrm{E}_{\mathrm{i}}=$ Durchschnittliche Zahl von Einkäufen von Elektroartikeln in Gebiet $\mathrm{i}$

$\Sigma \mathrm{E}_{\mathrm{i}}=$ Summe aller erfassten Einkäufe von Elektroartikeln in Gebiet $\mathrm{i}$ (nur stationärer Einzelhandel)

$\mathrm{d}_{\mathrm{ij}}=$ Distanz (Fahrtzeit) zwischen Konsumentenwohnort $\mathrm{i}$ und Angebotsstandort $\mathrm{j}$

$E_{i j}=$ Erfasste Einkäufe aus dem Konsumentenwohnort $\mathrm{i}$ bei Anbieter $\mathrm{j}$

$\mathrm{p}_{\mathrm{ij}}=$ Anteil der erfassten Einkäufe bei Anbieter $\mathrm{j}$ an allen erfassten Einkäufen aus dem Konsumentenwohnort $\mathrm{i}$ (=Marktanteil) 
Tabelle A 9: Erfasste Elektronikkäufe im Online-Handel - Zahl und Anteil nach Gebieten Quelle: Eigene Erhebungen und Berechnungen

\begin{tabular}{|c|c|c|c|c|}
\hline $\mathbf{i}$ & $\boldsymbol{\Sigma} \mathbf{E}_{\mathbf{i}}$ & $\boldsymbol{\Sigma} \mathbf{E}_{\mathbf{i} \text { online }}$ & $\boldsymbol{\Sigma E}_{\mathbf{i}}+\mathbf{\Sigma} \mathbf{E}_{\text {i online }}$ & $\boldsymbol{p}_{\mathbf{i j} \text { online }}$ \\
\hline 01 & 159 & 11 & 170 & 0,065 \\
\hline 02 & 35 & 0 & 35 & 0,000 \\
\hline 03 & 30 & 0 & 30 & 0,000 \\
\hline 04 & 29 & 1 & 30 & 0,033 \\
\hline 05 & 30 & 3 & 33 & 0,091 \\
\hline 06 & 34 & 3 & 37 & 0,081 \\
\hline 07 & 145 & 15 & 160 & 0,094 \\
\hline 08 & 46 & 4 & 50 & 0,080 \\
\hline 09 & 33 & 9 & 42 & 0,214 \\
\hline 10 & 30 & 5 & 35 & 0,143 \\
\hline 11 & 28 & 3 & 31 & 0,097 \\
\hline 12 & 90 & 4 & 94 & 0,043 \\
\hline 13 & 36 & 0 & 36 & 0,000 \\
\hline 14 & 59 & 3 & 62 & 0,048 \\
\hline 15 & 14 & 0 & 14 & 0,000 \\
\hline 16 & 57 & 1 & 58 & 0,017 \\
\hline 17 & 34 & 3 & 37 & 0,081 \\
\hline 18 & 64 & 5 & 69 & 0,072 \\
\hline 19 & 34 & 2 & 36 & 0,056 \\
\hline
\end{tabular}

$\mathrm{i}=$ Konsumentenwohnort (Ortsteil bzw. aus mehreren kleinen Ortsteilen aggregiertes Gebiet) $\mathrm{j}=$ Anbieter bzw. Angebotsstandort (Elektromarkt)

$\Sigma \mathrm{E}_{\mathrm{i}}=$ Summe aller erfassten Einkäufe von Elektroartikeln in Gebiet $\mathrm{i}$ (nur stationärer Einzelhandel)

$\sum \mathrm{E}_{\mathrm{i} \text { Online }}=$ Summe aller erfassten Einkäufe von Elektroartikeln im Online-Handel in Gebiet $\mathrm{i}$

$p_{i j}$ Online $=$ Anteil der erfassten Einkäufe im Online-Handel an allen erfassten Einkäufen (inkl. Online-Handel) aus dem Konsumentenwohnort i 


\section{Lebenslauf}

\section{Persönliche Angaben}

Geb. 07. Januar 1982 in Holzminden

Familienstand: ledig

Staatsangehörigkeit: deutsch

\section{Schulausbildung}

$\begin{array}{ll}08 / 1994-06 / 2001 & \begin{array}{l}\text { Campe Gymnasium Holzminden } \\ \text { Schulabschluss: Allgemeine Hochschulreife (Abitur) }\end{array} \\ 08 / 1992-07 / 1994 & \text { Orientierungsstufe Astrid-Lindgren-Schule, Holzminden } \\ 08 / 1988-07 / 1992 & \text { Grundschule An den Teichen, Holzminden }\end{array}$

\section{Zivildienst}

07/2001 - 05/2002 Deutsches Jugendherbergswerk, Jugendherberge Holzminden

\section{Wissenschaftlicher Werdegang}

\begin{tabular}{ll}
\hline Seit 04/2009 & Promotion im Fach Geographie, Georg-August-Universität Göttingen \\
& Dissertationsthema: „Räumliches Einkaufsverhalten und Standortpolitik im \\
& Einzelhandel unter Berücksichtigung von Agglomerationseffekten - \\
& Theoretische Erklärungsansätze, modellanalytische Zugänge und eine \\
& empirisch-ökonometrische Marktgebietsanalyse anhand eines Fallbeispiels \\
& aus dem ländlichen Raum Ostwestfalens/Südniedersachsens“ \\
10/2002-08/2008 & Studium der Geographie an der Georg-August-Universität Göttingen \\
& Nebenfächer: Medien- und Kommunikationswissenschaft, Politikwissenschaft \\
& Diplomarbeit: „Kaufkraftstromprognose für einen großflächigen \\
& Elektrofachmarkt - Eine standortanalytische Untersuchung mittels HUFF- \\
& Modell am Beispiel des geplanten Media-Markt-Standortes in Holzminden“ \\
& Abschluss: Diplom-Geograph
\end{tabular}

\section{Berufstätigkeit}

\begin{tabular}{ll}
\hline Seit 02/2012 & $\begin{array}{l}\text { isr - Institut für Stadt- und Regionalmanagement, München/Göttingen } \\
\text { Projektleitung und -mitarbeit } \\
\text { 08/2010-11/2012 }\end{array}$ \\
& $\begin{array}{l}\text { Landesinstitut für Statistik der Autonomen Provinz Bozen-Südtirol (ASTAT), } \\
\text { Bozterner Mitarbeiter }\end{array}$ \\
Seit 04/2010 & $\begin{array}{l}\text { Geographisches Institut der Georg-August-Universität Göttingen } \\
\text { Lehrbeauftragter } \\
\text { 10/2008-05/2013 }\end{array}$ \\
& $\begin{array}{l}\text { Geographisches Institut der Georg-August-Universität Göttingen } \\
\text { Wissenschaftliche Hilfskraft }\end{array}$
\end{tabular}

